\title{
Religiosity and the Definition, Frequency, and Justification of Lying \\ by Congressional Staff
}

\author{
Scott Andrew Giles \\ Shelburne, Vermont
}

Bachelor of Arts, Saint Lawrence University, 1982

Master of Arts, University of Virginia, 1995

A Dissertation presented to the Graduate Faculty of the University of Virginia in Candidacy

for the Degree of

Doctor of Philosophy

Department of Religious Studies University of Virginia

May 2014 


\section{TABLE OF CONTENTS}

Chapter I-Introduction -----------------------------------------------------Page 1

Chapter II-Theory: Definition and Justification for Lying----------Page 5

Chapter III-Methodology---------------------------------------------------Page 25

Chapter IV-Descriptives----------------------------------------------------Page 80

Chapter V-Religiosity Indicators------------------------------------------Page 87

Chapter VI-Lying and Being Lied to------------------------------------Page 176

Chapter VII-Definition of a Lie-------------------------------------------Page 205

Chapter VIII—Justification for Telling a Lie----------------------------Page 251

Chapter IX-The Cases------------------------------------------------------Page 311

Chapter X-Discussion and Findings-------------------------------------Page 448

Bibliography---------------------------------------------------------------------'Page 480

Appendix A-Web Survey--------------------------------------------------Page 484

Appendix B-Web Site-------------------------------------------------------Page 506 
If untruth presupposes cleverness and skill, we get artful lying and repute; courtiers and politicians, for example, have to achieve their aims by lying, and everyone should flee any position in which untruth is indispensable to him.

Immanuel Kant

Lectures on Ethics

\section{Chapter I. Introduction}

Nearly every campaign for political office begins and ends with claims and counterclaims about the honesty and integrity of the candidate and his or her opponent. These claims are crafted to address the high expectations we hold of elected officials and the deepseated mistrust we have for politicians as a class. ${ }^{1}$ They also contribute to and reflect one of the striking paradoxes of American politics. American voters typically hold their own representatives in high esteem while holding politicians as a class in very low regard.

While character and its attributes have always been important factors in evaluating political figures, they have assumed a progressively more important role over the past 40 years. Electoral reforms stemming from protests at the 1968 Democratic National Convention, the rise in importance of television, ${ }^{2}$ and the advent of new communications

\footnotetext{
${ }^{1} 55 \%$ of Americans hold the honesty and ethical standards of members of Congress to be very low. Senators are held in slightly higher regard with $49 \%$ of Americans holding Senators' honesty and ethical standards to be very low. Gallup, "Honesty and Ethics Poll Finds Congress' Image Tarnished: For First Time, Majority of Americans Say Its Members Have Low Ethics," http://www.gallup.com/poll/124625/Honesty-Ethics-Poll-Finds-Congress-Image-Tarnished.aspx. ${ }^{2}$ Steven R. Goldzwig and Patricia A. Sullivan, "Electronic Democracy, Virtual Politics, and Local Communities," in Political Communication Ethics: An Oxymoron?, ed. Jr. Robert E. Denton (London: Praeger, 2000).
} 
technologies converged to emphasize the perceived qualities of the candidates over their detailed policy positions. ${ }^{3}$

Religious affiliations, beliefs, and levels of commitment have long been an integral part of this public assessment of political character. Today, they assume particular prominence. Every political candidate for major office is expected to discuss and demonstrate a strong commitment to his or her religious beliefs. A recent poll by the Pew Forum on Religious Life revealed that although many people believed that "religion" was losing its influence on government leaders, more than 61 percent stated that they wanted their leaders in Congress to have "strong religious beliefs."4

The poll did not provide additional information regarding why the public wants elected officials with "strong religious beliefs" or what it expects from these officials as a result of those beliefs. It can be argued, however, that the public expects that religious beliefs will be expressed through individual character traits (i.e., honesty) and moral principles and practices, as well as a commitment to particular conservative, liberal or progressive social agendas.

These expectations need not be in conflict. As they are currently expressed in the nation's capital, however, they appear to be in tension. Concomitant with these public expectations, we have witnessed a rise of partisanship, increased polarization, and a

\footnotetext{
${ }^{3}$ Gary W. Selnow, "Internet Ethics," in Political Communications Ethics: An Oxymoron?, ed. Jr. Robert E. Denton (London: Praeger, 2000).

${ }^{4}$ Andrew Kohut et al., "Religion, Politics and the President: Growing Number of Americans Say Obama Is a Muslim," in 2010 Annual Religion and Public Life Survey ( Pew Forum on Religion \& Public Life, 2010). 
breakdown of comity and trust between and among members of the House and Senate. Perhaps nothing captured this more clearly than the 2006 incident in which the bipartisan effort to replace the retiring House Chaplain unexpectedly devolved into a partisan political fight replete with accusations of dishonesty, sectarianism and anti-Catholic bias. ${ }^{5}$

Congressional Quarterly, in cooperation with the Pew Center for Religion and Public Life, conducted a survey in 2010 to determine the religious affiliation of members of Congress. Several denominations and faiths are overrepresented in Congress (in view of their numbers among the general population) but virtually no member of Congress describes him or herself as unaffiliated and only six (1\%) failed or declined to answer the question. $^{6}$ By contrast, $16 \%$ of the general population describes itself as being unaffiliated (atheist, agnostic or nothing in particular).

No similar work has been done to explore the religious affiliation and commitments of the 15,000 congressional staff who both represent and guide the elected officials for whom they work. This dissertation examines the religious affiliation and religiosity of congressional staff and attempts to determine whether or not this affects the definition, prevalence, and justification of lying.

Most staff members believe themselves to be honest representatives of their employers as well as ardent advocates for their party, their ideology, their constituents, and, in some

\footnotetext{
${ }^{5}$ Juliet Eilperin, Fight Club Politics: How Partisanship Is Poisoning the House of Representatives (Lanham, MD: Rowman \& Littlefield Publishers, 2006).

6 "Faith on the Hill: The Religious Composition of the 112th Congress," Pew Forum on Religion and Public Life, http://pewforum.org/Government/Faith-on-the-Hill--The-Religious-Composition-of-the-112thCongress.aspx.
} 
cases, their faith. The public places value in the religious commitments of elected officials and, by extension, their staff. These religious commitments are associated with and believed to contribute to higher standards of conduct as well as adherence to particular policy positions.

This research explores the practice and justification of lying in the political and legislative communities of Congress. The empirical focus was on congressional staff but the applications extend to elected members of the House and Senate. Cases were drawn from constituent relationships, legislative relationships, and political and campaign activities and attempted to determine whether increased religiosity affects the definition and practice of lying. 


\section{Chapter II. Theory: Definition of and Justification for Lying}

In 1978, when Sissela Bok's seminal book Lying was published, Bok noted that despite its import for ethics and law, little formal philosophical work had been done on the subject. ${ }^{7}$ Since that time, a body of work attempting to refine the definition of lying has emerged. ${ }^{8}$ There is convergence and overlap in these efforts but significant definitional differences remain. These differences are not trivial. They can rule an action "in or out" of consideration as a lie and, therefore, as a matter that stands in need of justification. Bok separated the "moral domain" of intended truthfulness or deception from the "vaster domain of truth and falsity." This approach attempted to avoid epistemological questions about our ability to know truth and focused upon the intention of the liar to deceive. To this end, Bok defined lying as "any intentionally deceptive message which is stated." For Bok, there is an "imbalance" between truth-telling and lying. Lying always stands in need of justification, while telling the truth does not.

Much of the literature on lying that has followed Bok's work draws upon linguistic analysis and increasingly complex cases to form a definition that is intended to capture our considered intuitions about lying. The test of a good definition, it is argued, is that it includes all of the cases we commonly believe to be cases of lying while excluding all of the cases we commonly believe to be not lying.

\footnotetext{
${ }^{7}$ Sissela Bok, Lying: Moral Choice in Public and Private Life (New York: Vintage Books, 1989).

${ }^{8}$ Thomas L. Carson, "The Definition of Lying," NOÜS 4(2006); Lying and Deception: Theory and Practice (New York: Oxford University Press, 2010); Alan Strudler, "Deception Unraveled," Journal of Philosophy 102, no. 9 (2005); "The Distinctive Wrong in Lying," Ethical Theory and Moral Practice 13 (2)(2010).

${ }^{9}$ Bok, Lying: Moral Choice in Public and Private Life., p 6.
} 
This analysis frequently begs the question as to whether or not the "considered" intuitions of the authors provide an adequate foundation for analysis or how divergent intuitions are to be understood or evaluated. Some authors (e.g. Thomas L. Carson and Don Fallis) have suggested that these questions may be tested through experimental philosophy. Recent studies raise significant questions, however, about the promise of this approach. ${ }^{10}$ Nonetheless, to the extent that there are common intuitions, these definitions serve as a useful starting point for survey research.

Review of the literature suggests that the current conversation about the definition of lying can be organized around a matrix of definitional questions. ${ }^{11}$ The answers to these questions (or the non-consideration of these questions) can be used to compare and contrast competing definitions of lying. Several of these questions are closely related (e.g., context and trust), and answers to one often implicate answers to another. The line between definitional considerations and normative considerations is sometimes quite thin. Nonetheless, the questions have utility because they reflect a constellation of issues or choices that proposed definitions are being tested against in the contemporary literature. Put another way, a definition may be counted as more or less adequate by some commentators to the extent that it accounts satisfactorily for these questions in the face of ever more complex cases. These questions include:

1. Does a lie require a statement?

2. Does a lie require untruthfulness?

\footnotetext{
${ }^{10}$ Stacey Swain; Joshua Alexander; Jonathan M. Weinberg, "The Instability of Philosophical Intuitions: Running Hot and Cold on Truetemp," Philosophy and Phenomenological Research 76, no. 1 (2008).

${ }^{11}$ The idea for this matrix was inspired by James Edwin Mahon's three necessary conditions as outlined in the Stanford Encyclopedia of Philosophy. See James Edwin Mahon, "The Definition of Lying and Deception," in Stanford Encyclopedia of Philosophy, ed. Edward N. Zalta (Stanford: Stanford Metaphysics Research Lab, 2008).
} 
3. Does a lie require a false proposition?

4. Does a lie require deception (success)?

5. Does a lie require a specific addressee/dupe?

6. Does a lie require intent to deceive?

7. What if any role does context play in the definition of lying (e.g., games, negotiations, or a play)?

8. Does lying include withholding information?

9. What role does consent form in the definition of lying?

10. What role does trust form in the definition of lying?

11. Are there different types of lies based on subject or intent?

12. Do people have a right to the truth that can be overridden by the use they intend to put the knowledge to?

A brief look at a common definition of lying can be used to illustrate the analytic utility of these questions and the limits of a seemingly clear and simple definition. The Oxford English Dictionary (OED) defines lying "as to make a false statement with the intention to deceive." 12

The OED definition excludes forms of deception that are not signaled (disguises, for example, are not lies). The definition neglects the question of truthfulness and focuses on the truth or falsity of the proposition in question. Statements made by would be liars that he or she believes to be false (untruthful) and that are made with the intent to deceive would not count as lies if, accidentally and unbeknownst to the liar, the statements were actually true. Some commentators have rejected the idea that luck could play a larger role than intent or untruthfulness in determining whether a statement counted as a lie. ${ }^{13}$ Similarly, the OED definition does not specify to whom the false statement must be made or if it must be made to anyone in particular. As a result, a literal read would seem to

\footnotetext{
12 "Lie," in The Compact Edition of the Oxford English Dictionary (Oxford: Oxford University Press, 1971)

${ }^{13}$ James Edwin Mahon, "A Definition of Deceiving," International Journal of Applied Philosophy 21, no. 2 (2007).
} 
include disputed cases about false statements made to co-conspirators (who you do not intend to deceive) for the benefit of eavesdroppers (who you do intend to deceive but to whom the statement is not addressed in any strict sense). In this instance, to whom was the lie told--the individual to whom the false statement was directed or the individual the speaker intended to deceive?

In addition, there is ambiguity (and, indeed, disagreement) about the role and import of intention to deceive. An individual may offer a false statement with the intent to deceive the addressee about the truth of the specific proposition, about the individual's belief about the truth of the proposition, or implicitly about another proposition, or all three. One can imagine a situation in which I tell you that the world is flat. I do not intend that you believe that the world is flat, but I do intend that you believe that I believe the world is flat. A variation on this is the oft-cited and disputed case of Athanasius. Disguised and fleeing persecution, he is approached by soldiers who do not recognize him and ask him if he has seen Athanasius. He responds that "he is not far from you" and they depart in the belief that he is not Athanasius and that he is nearby.

Carson complicates this picture further by arguing that not all lies require intent to deceive. To make this case, he asks you to imagine yourself as a witness to a brutal murder. Fearing for your life, you perjure yourself in court by stating that you did not see the murderer commit the murder, hoping that the jury does not believe you and convicts the murderer. ${ }^{14}$

${ }^{14}$ Carson, "The Definition of Lying."

8| P a g e 
The OED definition is also silent about the role of context. There are circumstances in which false statements are common and perhaps even expected. Magicians, card players, storytellers, and spies routinely make false statements with intent to deceive their audiences. In some of these situations, there may be restricted expectation of truth-telling and even the possibility that the participants have implicitly or explicitly consented to the making of false statements in advance. The OED definition would consider all of these to be lies. Other definitions exclude statements made in contexts in which the truth of a proposition is not being "warranted," 15 in which norms of truthfulness are not in effect, ${ }^{16}$ which do not involve a breach of trust, ${ }^{17}$ or that are directed toward individuals who do not have a "right" to the truth. ${ }^{18}$

Simpler definitions like that offered by Bok and the OED have given way, at least in the philosophical literature, to more complex definitions seeking to answer some of the questions previously raised against the OED definition. James Edwin Mahon has put forward a definition that in one of its forms is representative, broadly speaking, of a group of definitions that pivot around untruthfulness and the intention to deceive. Mahon defines lying as follows:

To lie $($ to another person $)={ }_{\mathrm{df}}$ to make a believed-false statement (to another person), either with the intention that that statement be believed to be true (by the other person), or with the intention that it be believed (by the other person) that that statement is believed to be true (by the person making the statement), or with both intentions. ${ }^{19}$

\footnotetext{
15 Ibid.

${ }^{16}$ Don Fallis, "What Is Lying?," The Journal of Philosophy 106, no. 1 (2009).

17 Strudler, "The Distinctive Wrong in Lying."

${ }^{18}$ Hugo Grotius, The Law of War and Peace, trans. F.W. Kelsey (Indianapolis: Bobbs-Merrill., 1925).

${ }^{19}$ James Edwin Mahon, "Two Definitions of Lying," International Journal of Applied Philosophy 22, no. 2 (2008).
} 
This definition restricts lying to statements that are untruthful and which are made in order to deceive the addressee/dupe that the statement is true or that the liar believes it to be true. The truth or falsity of the statement is not relevant to the definition and the statement must be made to a specific person. A truthful statement made to deceive someone would not count as a lie nor would the statement in the case of the eavesdropper. Withholding information would not count as a lie and it is unclear how Mahon would handle the case of the "bald-faced" lie, in which all parties know that the speaker is making a statement that he or she does not believe.

Thomas L. Carson offers a competing definition of lying that pivots around the context in which the statement is delivered and the cultural understandings or communication norms in effect when the statement is made. Noting that there is some support for and against the requirement that a lie include a false statement, Carson offers two variations of his definition of lying.

L7. A person S tells a lie to another person S1 iff: 1 . S makes a false statement $\mathrm{X}$ to $\mathrm{S} 2$. S believes that $\mathrm{X}$ is false or probably false (or, alternatively, $S$ does not believe that $X$ is true), 3.S states $X$ in a context in which $S$ thereby warrants the truth of $X$ to $S 1$, and 4 . S does not take herself to be not warranting the truth of what she says to S1.

\section{Or}

L7'. A person S tells a lie to another person S1 iff: 1. S. makes a statement $\mathrm{X}$ to $\mathrm{S} 1,2$. S believes that $\mathrm{X}$ is false or probably false (or, alternatively, $\mathrm{S}$ does not believe that $\mathrm{X}$ is true), and 3. $\mathrm{S}$ intends to warrant the truth of $\mathrm{X}$ to $\mathrm{S} 1 .^{20}$

Definitions L7 and L7' differ from each other principally in that L7 requires that the statement be false while L7' does not. Carson does not require strict untruthfulness (in

${ }^{20}$ Carson, Lying and Deception: Theory and Practice. 
the sense that Mahon does) and includes statements that the liar believes are untrue. As a result, a statement made with false certainty may count as a lie.

Carson's most significant break with Mahon and the "intentionalists" comes in his rejection of the centrality of the intent to deceive. His definition turns instead on the notion of warranting. He argues that in every culture there are certain "contextual understandings" about whether and when a statement should be taken to be "warranted to be true" and that a warranty of truth "is a kind of guarantee or promise that what one says is true."21 Questions arise about the role of intent in Carson's notion of warranting but it has the effect of excluding statements made in contexts (games, plays, magic shows) in which it is not a norm that one warrants the truth of what one says. Fallis makes a similar argument drawing upon Grice's norms of conversation. ${ }^{22}$ Both Fallis and Carson believe that this also reflects their intuition that lying constitutes a violation of trust.

The Mahon and Carson definitions are exemplars of two widely discussed types of definitions of a lie. The Mahon definition is simpler and may have the benefit of being closer to common everyday usage. The Carson definition is more complex but may more adequately address some of the more complicated cases. Plain language versions of the Carson definition will be presented to staff within the survey.

${ }^{21}$ Ibid. p25.

${ }^{22}$ Fallis, "What Is Lying?." 


\section{Definitions Used in Social Psychology Research.}

There have been numerous studies examining the willingness of physicians and other professionals to lie or use deception in professional contexts. ${ }^{23}$ There have been few major studies attempting to understand the nature and frequency of lying in the general public. Two of these studies are of particular relevance to my research.

Bella DePaulo and her colleagues asked 77 college students and 70 community members to keep a diary of all of their social interactions for a week. A social interaction was any exchange with another person that lasted 10 minutes or more. The only exception to the 10-minute rule was an interaction that included a lie. The instructions defined lying as "intentionally trying to mislead someone." A lie occurred in every interaction that included "both the intent to deceive and the actual deception." Lies were interpreted by the respondents to be both verbal and non-verbal. One can infer from the discussion of the findings that "actual deception" referred to an actual attempt to lie rather than a requirement that the lie be successful.

During review of the diaries, the types of lies were sorted into a rough typology that organized lies in terms of their content (e.g., feelings or achievements), their "reason" (e.g., self-centered or other-oriented), and their type (e.g., outright, exaggeration, or subtle). ${ }^{24}$ DePaulo argued, in contrast with Bok, that "the whole truth is neither possible,

\footnotetext{
${ }^{23}$ Dennis H. Novack et al., "Physician's Attitudes toward Using Deception to Resolve Difficult Ethical Problems," Journal of the American Medical Association 261, no. 20 (1989).

${ }^{24}$ B DePaulo et al., "Lying in Everyday Life," Journal of Personality and Social Psychology Vol. 70(1996).
} 
nor desirable." ${ }^{25}$ Consistent with this, respondents were told to exclude instances in which they replied "fine" to an inquiry about how they felt or were doing that day. DePaulo estimated that undergraduates reported an average of two lies per day while the community members reported an average of one lie a day.

The DePaulo study offers insight into the type of lies, broadly defined, that college students and members of a university community tell during the course of a week. It provides data about frequency, but the samples are neither large enough nor representative of the general population and the results have limited value for understanding the frequency of lying in the public-at-large.

Kim Serota and her colleagues built upon the DePaulo study by conducting a broad population survey of U.S. adults. The goal of this survey was to ascertain the selfreported frequency of lying by U.S. adults, the types of individuals to whom the lies were directed, and whether lying occurred more frequently on the phone or through email than in person. Respondents were asked to think about their interactions over the previous 24 hours. In the instructions to their survey, they stated:

"Most people think a lie occurs any time you intentionally try to mislead someone. Some lies are big while others are small; some are completely false statements and others are truths with a few essential details made up or left out. Some lies are obvious, and some are subtle. Some lies are told for a good reason. Some lies are selfish; other lies protect others. We are interested in all types of lies." 26

\footnotetext{
${ }^{25}$ Bella DePaulo, "The Hows and Whys of Lies," in The Social Psychology of Good and Evil, ed. A.G. Miller (New York: Guilford Press, 2004).

${ }^{26}$ Kim B. Serota, Timothy R. Levine, and Franklin J. Boster, "The Prevalence of Lying in America: Three Studies of Self-Reported Lies," Human Communication Research 36(2010).
} 
These instructions have the advantage of being inclusive but conflate deception and lying and permit inclusion of interactions that may not uncontrovertibly be thought to be lies. The instructions also do not tell respondents to exclude untruthful responses to questions such as "how are you doing" or "how do you feel." The report suggested that the average rate of lying is around 1.65 lies per day. Importantly, however, focus on the average hid the fact that the majority of lies were told by a relatively small portion of the surveyed population. In fact, $60 \%$ of the respondents indicated that they had not lied during the

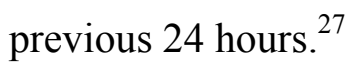

These studies, and the definitions they used, despite their limitations, provide an opportunity to compare congressional staff with the subjects evaluated in these studies. I expected that congressional staff would acknowledge lying at rates that were equal to or lower than the general public while demonstrating a willingness to lie when considering specific cases. As will be seen, staff and fellows reported being lied to at rates significantly higher than that found by Serota. Staff also reported telling more lies, but the difference was not statistically significant.

\section{When, if ever, is a lie justified?}

The case most frequently drawn to test the adequacy of various approaches to the permissibility of lying is that of a lie to a would-be murderer. Imagine that an innocent friend hides in your house fearing that he will be murdered. The would-be murderer comes to your house and asks you whether your friend is hiding in your house. You cannot avoid an answer. Should you answer truthfully?

${ }^{27}$ Ibid. 
The answer to this question, and indeed to the question of whether, to what extent, and under what circumstances a lie is morally permissible (or even required) has yielded as many different answers as has the definition of what constitutes a lie. Each answer is derived from and with different theoretical and epistemological assumptions and commitments. I am interested in six ways of answering this question. Staff will be asked which, if any, of these approaches inform their reasoning about lying.

\section{a. Absolute Prohibition}

Augustine of Hippo and Immanuel Kant each argued for absolute prohibitions on telling a lie. Their answer is viewed as counterintuitive by many philosophers and theologians and they serve as prototypical antagonists for their arguments.

Augustine of Hippo's prohibition on lying is rooted in his belief that speech and language are divine gifts and that humanity is created in God's triune image. The mind reflects the image of God, and the process of putting thoughts into words is an "allegory" of the triune being of God. A lie - understood as saying what you do not think — is a misappropriation of the divine gift of speech for oneself and is a sin that moves one further away from participation in God. Paul Griffiths states that for Augustine:

"Duplicitous speech - the lie-divides speech from thought. It relates speech and thought inappropriately, improperly, sinfully, and in doing so ruptures God's image in us."28

${ }^{28}$,Paul J. Griffiths, Lying: An Augustinian Theology of Duplicity (Eugene, Oregon: Wipf and Stock, 2004). p.73. 
Augustine's prohibition should be viewed through the lens of his understanding of harm. To the consequentialist, he argues that there are sinful harms (lying, adultery) and nonsinful harms (suffering or death). The stakes are high: movement toward or away from participation in God in the temporal world and finally and completely in the eternal world. No temporal good or harm can justify commission of a sin or one of its paradigm forms, the telling of a lie. ${ }^{29}$ Lies, like any sin, may cause lesser or greater harm, but this harm does not reach to the permissibility of the act itself.

Immanuel Kant's absolute prohibition on lying is among the best known and most criticized elements of his writing. Kant presents three types of lies: a lie in the ethical sense, in the juridical sense, and in the sense of right. Common to all three is the idea that a lie is an untruthful statement made with the intention that it be believed to be true. ${ }^{30}$ There are complications with this definition that I won't explore other than to note several things that are excluded under this definition. Omissions and concealments are excluded as are statements in which the intent is to deceive about something other than the proposition itself (this does not mean that they are permitted, but rather that they must be analyzed as something other than a lie). The lie in the juridical sense adds intent to harm the individual to whom the lie is told. In addition, there is the controversial notion of the "necessary" lie — a lie in which one's answer is coerced. ${ }^{31}$

\footnotetext{
29 Ibid.

${ }^{30}$ James Edwin Mahon, "The Truth About Kant on Lies," in The Philosophy of Deception, ed. Clancy Martin (Oxford: Oxford University Press, 2009).

${ }^{31}$ Kant's definition of lying appears to have evolved over time and it is not clear that the "necessary" lie would meet earlier requirements for what it means to make a statement. See Carson, Lying and Deception: Theory and Practice.
} 
Kant makes several arguments in support of his position. The first argument draws upon the notion of the categorical imperative (either as universal law or as requirement to treat people as ends and not merely as means). The second, as Carson has noted, appears to contain consequentialist elements taken up by other philosophers who reject much of what Kant argues. He suggests that lying undercuts trust in contracts and to some extent the trust that is necessary for the very possibility of communication. These constitute harms to humanity inherent in any lie without regard to the immediate harm or good that may result. ${ }^{32}$ Whether the absolute prohibition on lying is required by the categorical imperative is a matter of dispute. Nonetheless, Kant himself concluded that "to be truthful in all declarations is, therefore, a sacred and unconditionally commanding law of reason which admits of no expediency whatever."

b. Permissibility of Lying to Someone Who Does Not Have A Right To The Truth

Hugo Grotius is the most well-known proponent of lying as a violation of a natural right to truthfulness that can, under certain circumstances, be overridden. Grotius argued that language, the ability to communicate externally what is within the mind, is a "gift of nature" that distinguishes humans from the rest of creation. Words, glyphs, or any conventional sign, when used to convey meaning, "imply an obligation in all the persons concerned, to receive and employ them in their common acceptation." Lies violate the "existing and permanent" rights of the individual to whom they are directed. More specifically, they violate a right of "liberty of judgment" that is part of the mutual

${ }^{32}$ Immanuel Kant, Grounding of Metaphysics of Morals trans. James Ellington, 3 ed. (Hackett Publishing Company, 1993). 
obligation implied through the creation and sustenance of the communal enterprise that is language. ${ }^{33}$

A lie is defined as a statement made to a person, using conventional signs that are used in such a way that the person to whom they are addressed believes that they are being used according to the convention, which is believed false by the liar, with the intention to deceive the person to whom it is addressed. This definition excludes eavesdroppers and equivocation - use of words that have more than one meaning — from lying. ${ }^{34}$ As we shall see, it may be necessary to modify his definition further to state that the individual to whom the lie is directed must have or retain the right to truthfulness.

Grotius ascribes several inferences to this framework. Children and the mentally ill do not possess the power (and therefore the liberty) of judging, and as a result lies do not impair the exercise of their rights. Grotius suggests that this does not "incur the guilt of willful falsehood." His conclusions about the beneficial lie provide another perspective on the role of this right; if there is certainty of intent, and the deception is discovered or disclosed, it does not fall within the "strict denomination of a lie or falsehood." Grotius presumes that one would consent to this benefit, and that if there is tremendous certainty about the benefit, this presumption may be treated as express consent.

Grotius's reasoning about these cases may derive from his thinking about contracts. Drawing upon the analogy of debt, a right may become obsolete by virtue of payment,

\footnotetext{
${ }^{33}$ Hugo Grotius, The Rights of War and Peace, trans. A.C. Campbell, (Ithaca: Cornell University Library, 2009).

${ }^{34}$ Ibid.
} 
release, or non-performance of one's obligations. The right to truthfulness may be relinquished by consent, by non-performance of a related obligation, or by a superseding right. Responding to the case of the lie to the murderer, Grotius concludes that one may lie when it might be the only means of saving the life of an "innocent person, of obtaining some object of equal importance, or of diverting another from the perpetration of some horrid design. ${ }^{, 35}$ Grotius's analysis of the case of the murderer pivots around whether and to what extent the murderer retains the right to the liberty of judgment. The cases in the survey were designed to reveal whether staff believe that some individuals are more (or less) entitled to truthfulness.

\section{c. Prima Facie Prohibition on Lying}

Some authors argue that the absolutist positions of Augustine and Kant, and to a lesser extent the rights approach of Grotius, fail to adequately capture the complexity of our moral intuitions and experience. ${ }^{36}$ They suggest that the absolute prohibition on lying is counter to our intuitions and seems to elevate this rule above any and all other moral or non-moral obligations. ${ }^{37}$ Following W.D. Ross, Richard Brandt, Brad Hooker and others, they propose ethical systems or theories containing multiple prima facie moral rules. These rules are more than rules of thumb, are not absolutely binding, and always have moral force but may be infringed or overridden by another prima facie rule or duty

\footnotetext{
35 Ibid.

${ }^{36}$ One might argue that Grotius has imported consequentialist elements into his reasoning about cases that raises questions about the strength of the right to liberty of judgment.

${ }^{37}$ Carson, Lying and Deception: Theory and Practice.
} 
of equal or higher importance. ${ }^{38}$ Analysis of the case of the murderer would turn upon the definition of a lie; the rules that are considered relevant; the framework used for weighing the applicability, weight and bindingness of the rules in the situation; and the particular facts of the case. Staff will be presented with cases to which competing rules might be applied.

\section{d. Act Utilitarianism}

Utilitarianism, broadly speaking, is the monistic moral theory that there is a single moral principle (utility) and that one should always act (or refrain from acting) in such a way that will produce the most value (or least negative value). There are competing views of value as well as different ways to calculate value. Act utilitarianism holds that a particular act (located in a specific place and time) is preferred based solely on the consequences that are/will be produced by that specific act. Rules are replaced with "rules of thumb" that guide but do not bind the agent. Every situation and circumstance involves its own calculation of utility. The decision to be truthful or to lie to the murderer would pivot around the comparison of the increase or loss of value resulting from the act and its various alternatives.

38 Tom L. Beauchamp and James F. Childress, Principles of Biomedical Ethics, 3 ed. (New York: Oxford University Press, 1989). 
e. Trust

The violation of trust is invoked at some point in nearly every consideration of lying and deception. For some authors, it operates in the background as one of the conditions necessary for the possibility of language; for other authors, it plays a more prominent role in the evaluation of the permissibility of a particular lie or deception. Carson argues that the wrongness of lie must in part be evaluated in terms of the strength of the warrant of truthfulness that the liar presents and the corresponding level of trust that is breached.

Negotiations, however, often take place in messy contexts in which there is limited trust. ${ }^{39}$ Peter C. Cramton and J. Gregory Dees observed professional negotiators and posited the Mutual Trust Principle in order to explain why individuals frequently condone lies about settlement preferences during negotiations while condemning lies in other contexts. This descriptive principle holds that it is:

"unfair to require an individual to take a significant risk or incur a significant cost out of respect for the moral rights of others, if that individual has no reasonable grounds for trusting that the relevant others will (or would) take the same risk or make the same sacrifice." 40

Their goal was to begin with the state of "actual practice" and conquer the state of nature "inch by inch." I will not discuss the merits of their project but it does capture two useful elements.

\footnotetext{
${ }^{39}$ J.G. Dees and P.C. Cramton, "Shrewd Bargaining on the Moral Frontier: Toward a Theory of Morality in Practice," Business Ethics Quarterly 1(1991).

${ }^{40}$ Ibid.
} 
Trust plays a significant if not central role in negotiations (either because it exists or because of its absence). It is part of what people find objectionable about being lied to and it is also offered as a justification for lying to others. Cramton and Dees theorize that lying and deception are more likely to occur and be justified (by practitioners) in situations involving low levels of trust. ${ }^{41}$ The staff survey provided an opportunity for a limited test of this hypothesis.

Respondents were presented with three cases involving negotiations. The first case dealt with a bill negotiation in which there was an opportunity to lie about a mistake made by the legislative counsel. The second case dealt with a situation in which the respondent was invited to lie or not lie about the strength of leadership support for her position. The third case established a situation in which the respondent could be construed to "warrant" the truth of his intentions in the form of a promise to bring about a result he knew he could not achieve.

The cases provided an interesting, though perhaps prosaic, insight. The role that expectations of deception play in influencing behavior is not consistent across all of the respondent groups. Individuals who indicated that they would lie in a particular situation overwhelmingly expect that the other party would lie if their circumstances were reversed. It is unclear whether this reflects a rationalization for lying, the assumption that others behave as they do, or an example of the Mutual Trust Principle at work.

${ }^{41}$ It is a little unclear whether the deception is possible or probable and to what extent this distinction affects the authors' assessment of the permissibility of offering the first deception. 
Following Cramton and Dees, one might expect that individuals indicating that they would not lie also do not expect the other party to lie. However, this does not appear to be the case. For example, in the Conference Committee Case 53\% of staff who indicated they would not lie nevertheless expected that the other staff would lie if their circumstances were reversed. For these staff, expectations of deceptive behavior are not sufficient to justify lying on their part.

\section{f. Self-Defense}

Expanding upon the intuition that lying involves a breach of trust, Alan Strudler argues that lying may be understood as a defensive act operating under the rules governing selfdefense. ${ }^{42}$ Carson draws upon the analogy with violence to state that lying about one's negotiating position (usually limited to reservation price) is permissible if all of the following conditions are met:

1. One's negotiating partner is lying and the lies will result in harm to you

2. You can't mitigate the harm through means other than lying

3. The harm you cause by lying does not exceed the harm that you will suffer if you do not lie. ${ }^{43}$

This framework focuses less on trust (or its absence) and more on defending interests and positions from other parties who use deception to advance their own interests and/or positions. Proponents draw equally upon the analogy to protecting one's property against theft or defending oneself from an attacker. If someone enters a store and steals

\footnotetext{
${ }^{42}$ Strudler, "Deception Unraveled."

${ }^{43}$ Carson, Lying and Deception: Theory and Practice. There are additional rules from the ethics of selfdefense that might be useful for these discussions. These would include least possible infringement of prohibition against lying, probability of success, and requirement to minimize the impact of the infringement. See for example, Beauchamp and Childress, Principles of Biomedical Ethics.
} 
an item, they would argue, you are entitled to use force to reclaim or protect your property. These same actions would not be permitted outside the context of self-defense or defense of property. Similarly, a lie may be permitted to the extent that it protects one's reservation price or other critical information and if there is evidence that you are being lied to by your negotiation partner about some element critical to the negotiations. 


\section{Chapter III. Methodology}

\section{A. Prior Research on Congressional Staff}

There is little published academic research involving broad-based surveys of congressional staff. With few exceptions, the work that has been done has focused on small samples of "elites" - individuals selected by the researchers because they were influential within specific policy areas (e.g., foreign policy). ${ }^{44}$ During the past several years, there have been three efforts to survey staff, each with different goals and with differing approaches to obtaining data.

\section{Congressional Management Foundation}

The Congressional Management Foundation (CMF), which provides management support services to House and Senate staff, conducts periodic survey research involving congressional staff. In 2010, it released "Communicating with Congress-Perceptions of Citizen Advocacy on Capitol Hill."45 The foundation enlisted House leadership staff to stimulate participation in the project and emailed a web based survey to House chiefs of staff, House legislative directors, Senate administrative assistants and staff affinity groups (e.g., House Chiefs of Staff Association). The survey was in the field for one month. After direct appeals by House leadership staff, the survey generated 260 responses. Seventy-two percent of the respondents were from House staff, resulting in the overrepresentation of House staff in the results. Information on response rates is not available.

\footnotetext{
${ }^{44}$ See for example, Jonathan Monten Joshua W. Busby, Jordan Tama, and Willian Inboden, "Congress Is Already Post-Partisan: Agreement across the Aisle on U.S. Foreign Policy," Foreign Affairs (2013).

${ }^{45}$ Kathy Goldschmidt, "Communicating with Congress--Perceptions of Citizen Advocacy on Capitol Hill," (Washington, DC: Congressional Management Foundation, 2011).
} 


\section{National Journal-the Hill People}

Every four years National Journal conducts a project entitled “The Hill People." The National Journal staff identify 300 leadership and committee staff and deploy journalists to interview each of them. National Journal uses these interviews to profile each staff member as well as to provide limited demographic and opinion data gathered through the interview process. ${ }^{46}$ A number of staff decline to participate. The group includes topranking committee and leadership staff and excludes staff working in House or Senate personal offices.

\section{George Washington University Graduate School of Political Management (GWU)}

The most recent and largest-scale project was conducted as part of a commercial venture involving the Graduate School of Political Management at George Washington University, Lobbying.Info, and The Original U.S. Congress Handbook. The survey was conducted by the market research firm ORI located in Herndon, VA. The purpose of the survey was to understand the sources staff use to gain information about policy issues and to identify the preferred and most effective ways for advocates to communicate with them. $^{47}$

The GWU study sourced staff names and email addresses from "The Original U.S. Congress Handbook." The investigators sent the survey to the entire survey frame of 13,530 staff. The survey yielded a $5.3 \%$ response rate, with 1,158 staff starting the

\footnotetext{
46 "Hill People Project," http://www.nationaljournal.com/hill-people-who-are-they-and-where-did-theycome-from-20110616.

${ }^{47}$ David K. Rehr to The BLOG, 2013, http://www.huffingtonpost.com/david-k-rehr/experience-and-agemismat_b_1747274.html.
} 
survey and 716 staff completing the survey. Using the entire population rather than a random sample appears to have been done to acquire a high number of responses. The investigators report a margin of error of $\pm 3.6 \%$ and have not indicated whether or how they have considered the impact, if any, of non-response bias. Fifty-five percent of their respondents were male and self-described party affiliation between democrat and republicans was evenly split (46\% republican and $45 \%$ democrat). ${ }^{48}$ Results have not been released separately for House and Senate staff.

\section{B. Challenges to Surveying Congressional Staff}

There are numerous challenges to surveying congressional staff. Political candidates routinely receive political policy questionnaires that they choose to complete or ignore based on political considerations. The instruments are often used by advocacy organizations (along with vote scorecards) as part of the endorsement process, and are commonly drawn upon by opponents as part of opposition research designed to embarrass or discredit candidates. Interviews with current and former senior staff confirmed that many experienced staff members believe that surveys simply create unnecessary opportunities for misrepresentation and political embarrassment.

Candidates have become reluctant to complete these surveys, and some congressional offices have established policies that do not permit staff to respond to survey requests. These policies are not universally adhered to within individual offices. Twenty-seven House staff who were part of the sample for this research responded that they were

\footnotetext{
${ }^{48}$ David Rehr, "The Congressional Communications Report: 2012," (Washington, DC: George Washington University Graduate School of Political Management, 2012).
} 
prohibited by office policy from responding to the survey; 19 Senate staff responded the same way. There were several instances, however, in which one staff member from an office participated in the survey while another from the same office indicated that he or she was were prohibited by office policy. One House staff member, recalling the Congressional Management Foundation survey in which House leadership staff intervened to increase participation (see above), indicated via email that she believed there was a House-wide prohibition on participating in surveys. ${ }^{49}$

\section{Creation of a Web Site}

In order to establish the legitimacy of the project, as well as to provide additional information about the project, I acquired the domain "religionandcongress.org." Using Web Site Builder 6.1 .2 by Go Daddy, I constructed a simple six-page website. The site contained a welcome message, a description of the project, my biography, and the names of a bipartisan group of current and former staff who had agreed to serve as an advisory group. The website also contained an email form (designed to be hidden from web crawlers). All content was preapproved by the Institutional Review Board. After securing permission to display the Department of Religious Studies logo, I worked with the design staff at UVA Printing Services to develop a logo that could be used in both online and print applications.

${ }^{49}$ Personal correspondence with House and Senate staff. 


\section{Research on Religion and the Professional Practice of Congressional Staff}

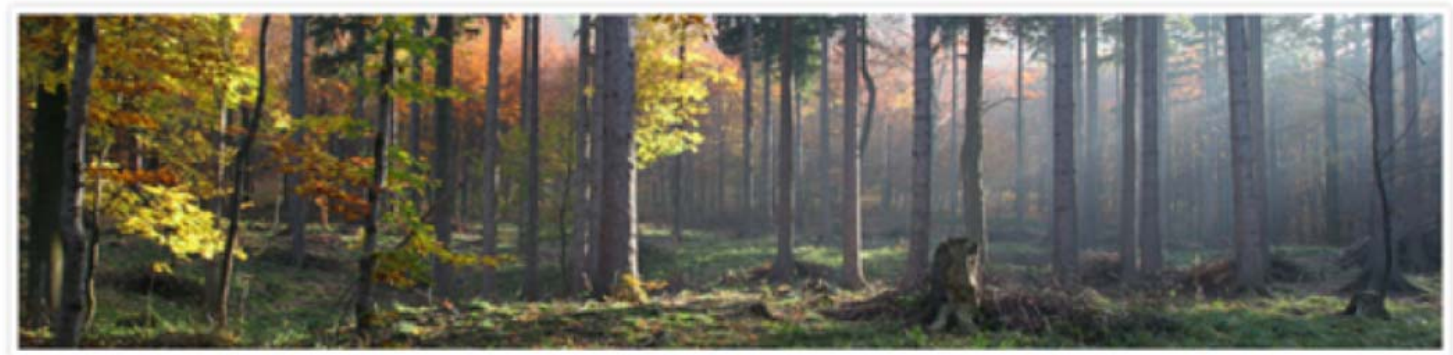

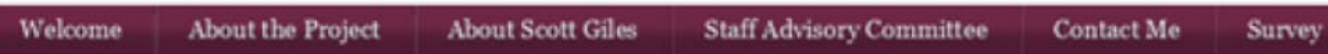

Welcome

This web site provides additional information about my research project on religious affliation and the professional practice of Congressional staff. As a former Congressional staffer, I am very grateful for all of the support and advice that staff from both sides of the aisle have provided to make this project sucoeed. I would also like to thank the Stennis Center for Public Service Leadership for its interest in and participation in this project.

If you are here because you recently received an email inviting you to participate in the survey. let me take this opportunity to thank you for taking the time to learn more about the study. I hope you will join your colleagues by taking the time to fill out the survey that you received. I think you will find it both interesting and thought provoking.

Feel free to check back over the next couple of months for more information about the study and how it is progressing.

\section{UNIVRBRTY \\ VIRGINLA}

\section{Content copyright 2013. RELIGIONANDCONGRESS. ORG. All riatis reserved.}

\section{AWEBsite}

\section{Survey Delivery Methodology}

Members of the House and Senate and their staffs receive tens of thousands of pieces of mail each year. Mail items are sorted upon receipt by interns or legislative correspondents and mail, even that addressed directly to a staff member, frequently enters the mail system designed to ensure that constituent communications are promptly responded to. This frequently delays the delivery of mail and makes it more difficult to ensure that mail goes to the individuals for whom it is intended. As will be noted later, mail now also goes through offsite irradiation prior to being delivered to the office. The 
irradiation process delays delivery by an additional two to three weeks and discolors and physically degrades the items.

Congressional staff have universal access to the internet, rely heavily upon and prefer email for their communications. ${ }^{50}$ This universal access eliminates the sampling issues associated with access to the internet that must be accounted for when surveying other populations (e.g., underrepresentation of low-income and/or elderly populations).

I decided to deliver the survey via email using secure web-based technology provided by Qualtrics. This reduced the overall cost of the project and mitigated some of the response burden by allowing easy access to the survey anywhere the subject accessed email. Each member of the sample was provided an individualized link to prevent a single individual from responding more than once. The link also allowed demographic information (gender, political party of employer, zip code, etc.) to be appended to the response file. Individual identifiers were removed upon completion of the surveys.

\section{Snowden Affair}

Initiation of this survey coincided with the revelations by Edward Snowden that the National Security Agency (NSA) was engaged in broad-based collection of domestic data from internet providers. ${ }^{51}$ Staff from the sample contacted me expressing grave doubts about whether their responses could be confidential given the NSA activities. As a result, some indicated that they would not participate. Others asked for a link on a web

${ }^{50} \mathrm{Rehr}$, "The Congressional Communications Report: 2012."

${ }^{51}$ Mirren Gidda, "Edward Snowden and the Nsa Files--Timeline," The Guardian, http://www.theguardian.com/world/2013/jun/23/edward-snowden-nsa-files-timeline. 
page that would allow them to participate without using the individualized link that had been emailed to them.

\section{Creation of Web Link}

Using the Qualtrics survey tool, I created a "Take Survey" link that could be appended to the project web site (www.religionandcongress.org). Responses obtained through the web link did not contain any of the embedded demographic information available through responses obtained through the individualized links. One additional question was added to this web version of the survey — "do you work for the House or Senate" in order to allow responses to be analyzed by House or Senate chamber.

To minimize the possibility that the survey would be taken by staff not included in the random sample, the site was not optimized for search. Staff could find the site only if I sent them the link or if they received it from one of their peers who were part of the sample. In addition, in order to prevent an individual from taking the survey more than once, I activated the anti-ballot stuffing features of Qualtrics. This feature places a cookie in the browser of an individual who takes the survey. If the individual attempts to retake the survey, the software recognizes the cookie and prevents access. The features can be circumvented by a motivated and knowledgeable respondent by clearing the browser cache or by using a different browser. Staff appeared more concerned about preserving their anonymity than influencing the outcome of the study. Reflecting concerns about confidentiality, five of the 38 staff who completed the web link version of the survey answered every question but the single demographic question asking whether they worked for the House or Senate. 
I also built and launched a smartphone-optimized version of the website, and the Qualtrics survey tool allowed me to optimize the survey for smartphones. Most questions on the survey presented appropriately on smartphones, but several of the questions $(13,14,15$, and 47$)$ may not have always displayed correctly on all phones because of the length of the text. In addition, senior congressional staff are generally issued Blackberry's rather than IPhones. ${ }^{52}$ The Blackberry has limited browser capability, and questions 14,15 , and 47 could not be properly displayed on this platform. All of the survey questions met web accessibility standards (visually impaired, etc.) except question 48 (position/title).

Congressional staff utilize work-issued computers for most of their email. As noted earlier, they also utilize smartphones (Blackberry) when away from their desks. The prevalence of smartphones poses a technological challenge that needs to be mitigated through creation of "scraped" or smartphone-optimized sites and surveys. Future survey efforts should take into account the growing reliance upon Blackberries when designing and executing surveys of congressional staff. Blackberry-optimized surveys would minimize use of graphics and use simple question structures and formats that are easy to read on a small screen. In addition, attempting to take a survey on a smartphone may significantly increase the response burden. This suggests that smartphone-optimized surveys need to be shorter than those delivered via paper, to a computer, or by telephone.

${ }^{52}$ Rehr, "The Congressional Communications Report: 2012." 


\section{E. Tailored Design Method}

The survey and all communications with the sample were created drawing upon the Tailored Design Method developed by Don A. Dillman, Jolene Smythe and Leah Melani Christian. ${ }^{53}$ This method utilizes social exchange theory that emphasizes techniques designed to: a) increase the perceived benefits of responding; b) minimize the perceived costs of responding; and, c) establish trust so that the benefits of responding are perceived as being greater than the costs. The authors believe that it is possible to achieve $80 \%$ or higher response rates from mail and telephone surveys of the general population. ${ }^{54} \mathrm{~A}$ non-exhaustive list of the guidelines that Dillman et al., advocate include:

- Use of adult-to-adult communication style (many surveyors use adult-to-child)

0 request help or advice

o Avoid use of subordinating language

o Show positive regard

o Say thank you

- Support group values where possible

- Minimize use of "forcing" features that require a respondent to answer every question before moving to the next

- Provide tangible rewards (e.g., tokens)

- Make the questionnaire interesting or entertaining

- Provide social validation

- Inform respondents that opportunities to respond are limited

- Make it convenient to respond

- Make questionnaires short and easy to complete

- Minimize requests to obtain personal or sensitive information

- Emphasize similarity to other requests or tasks to which a person has already responded

- Establish trust

o Obtain sponsorship of legitimate authority

o Provide an advance token of appreciation

- Ensure confidentiality and security

\footnotetext{
${ }^{53}$ Don A. Dillman, Jolene D. Smyth, and Leah Melani Christian, Internet, Mail, and Mixed-Mode Surveys: The Tailored Design Method, 3rd ed. (Hoboken, New Jersey: John Wiley \& Sons, 2009).

${ }^{54}$ Priscilla Salant and Don A. Dillman, How to Conduct Your Own Survey (New York: John Wilely \& Sons, 1994).
} 
- Use appealing survey features

- Make multiple contacts with a different look or feel

In addition to the guidelines regarding questions and communications style, the Tailored Survey Method offers guidelines regarding question structure and survey format. For example, the question stem should state both the positive and the negative stem ("do you favor or oppose" in lieu of "do you favor") to avoid acquiescence. Similarly, close attention must be paid to the size, length, and spacing of answer boxes to avoid prompting. ${ }^{55}$ Questions were developed using the recommended structure wherever possible and appropriate. The Qualtrics survey tool employed research-based question formatting that met or exceeded all of the requirements of the Tailored Survey Method. In addition, answer choices that were not part of Likert scales were presented to respondents in random order to mitigate presentation effects.

Two elements of the Tailored Survey Method were not employed as part of this study. Dillman is a strong advocate of the use of prepaid financial incentives and believes that it is one of the "largest contributors to improved response rates." House and Senate gift rules place significant limitations on the ability of staff to accept gifts and likely would have raised serious questions in the mind of potential respondents about the legitimacy of the project. While this barrier might have been overcome, I did not have the resources to provide the recommended $\$ 2$ bill to each member of the sample. Research on surveys of general populations suggests that this token could increase the response rate by $15-20 \% .^{56}$

${ }^{55}$ Dillman, Smyth, and Christian, Internet, Mail, and Mixed-Mode Surveys: The Tailored Design Method. p. 120.

${ }^{56}$ Ibid. 
In addition, Dillman encourages the use of mixed-mode survey techniques that employ phone interviews as one of the follow-up modes. Resources did not permit the use of phone survey follow-up, and it is not at all clear that staff would have been comfortable answering the survey questions without the anonymity provided by the electronic mode. Finally, as discussed earlier, I added a mode by creating a website to allow additional communications with members of the sample and to reinforce the academic (as opposed to political) nature of the project. I did not capture web statistics regarding the number of visits to the site. Eighty-nine staff chose to access the survey through this method. The survey tool captured the institutional IP address of the respondent (House or Senate but not office), allowing the responses to be sorted by chamber even when respondents failed to answer the final question regarding whether they worked for the House or Senate.

\section{Contact Strategy}

The Tailored Survey Method involves sending a letter to each member of the sample that introduces the study, provides a token (if one is being provided), and indicates that the survey will arrive via email in the next week. The survey is followed-up immediately afterward by a postcard reminding respondents to complete the questionnaire. This in turn is followed by a reminder using another mode of contact and a different message. Assuming everything is well-timed, members of the sample receive a reminder message every five to 10 business days. The messages, to the extent resources are available, should be mixed in mode (e.g., mail, email, phone, etc.) and different in message, tone, and look and feel. Messages that are repeated verbatim have the verbal effect of nagging and may discourage participation. The tone of each successive message should 
be progressively more assertive but not so strong that it provokes a negative reaction. ${ }^{57}$ One advantage of the Qualtrics survey system was that it allowed me to avoid sending reminders to individuals who had already completed the survey. One of the features not available in Qualtrics, commonly used in electronic social marketing, was the ability to segregate those who opened the email but had not completed the survey. This feature of other email marketing platforms allows the sender to fine-tune email subject headings to maximize the chance that the emails are actually read. Qualtrics is exploring adding this feature to its product as a result of this project.

I secured permission from the Department of Religious Studies to utilize the department logo on the envelope, the postcard, the survey, a website and my email correspondence. I worked with UVA Printing Services and the university's Public Affairs Office on the development of a Department of Religious Studies Logo that could be used to print envelopes and postcards and that would be optimized for web, email and other electronic platforms.

Email inquiries from members of the samples were sent to my UVA email account and forwarded to my work account. This allowed me to respond immediately to staff inquiries about the project and to respondent requests to be removed from the research panel. Importantly, only a handle of staff chose to use the unsubscribe feature built into Qualtrics. Most contacted me directly to request that they be removed or to explain that they were not permitted to participate. Consistent with the strategy of taking advantage of the possible perceived institutional legitimacy of the University of Virginia and the

${ }^{57}$ Ibid. 
Department of Religious Studies, my email responses were all delivered from my UVA account.

\section{Contact Schedule/Timeline}

This project surveyed three distinct but related sample frames: The Stennis Center for Public Service Leadership Senior Fellows; current House staff; and current Senate staff. Twenty-five members of the Stennis sample frame were contained in the House and Senate staff sample frames. More detail about each of these sample frames is provided elsewhere in the discussion of the samples and how they were obtained.

Each sample received a choreographed succession of physical mail and electronic mail contacts. In addition to these scheduled contacts, each individual who emailed me to ask questions about the survey or to inform me that he or she was unwilling or unable (office policy) to participate in received a personal response within three hours. They were thanked for contacting me; had their questions answered or were told that their names would be removed from future emails; they were reminded that responses would be anonymous; they were reminded that this was academic rather than advocacy research; they were informed that I would keep the link to the survey they had received open for a few weeks; and they were told that, should they change their minds at any point over the next several weeks, they could also take the survey by going to the "Take Survey" link on www.religionandcongress.org. Although there is no way to determine whether this resulted in any conversions, these emails coincided with an increase in the numbers of surveys completed through the website. 
House and Senate offices have official hours from 9:00 a.m. to 6:00 p.m. except on Fridays and during recesses, when many offices close at 5:00 p.m. With the exception of one reminder that was accidentally sent during the evening, all electronic survey invites and reminders were scheduled to be sent at 8:45 a.m. to coincide with the time that most staff arrive at their desks and would be able to respond to the survey on their office computers.

\section{A. Stennis Center for Public Service Leadership}

On June 4, 2013, Rex Buffington, president of the Stennis Center for Public Service Leadership, sent an email to 260 Stennis Fellows informing them of the research project, offering his support for the project, and encouraging them to participate.

On June 10, 2013, I sent a letter to each of the fellows to introduce the project, provide a link to the website (which at this point did not offer a way to take the survey), and indicate that fellows would receive an email containing a link to the survey within a few days of receiving the letter. Letters were personalized and hand-signed consistent with social exchange theory.

Post-9/11 provisions for scanning and sterilizing all mail going to Congress added a complication to the timing. All mail is sent to a U.S. postal facility in Ohio or New Jersey to be irradiated. ${ }^{58}$ This adds anywhere from two to four weeks to the normal

\footnotetext{
${ }^{58}$ Environmental Protection Agency, "Mail Irradiation," Environmental Protection Agency, http://www.epa.gov/radiation/sources/mail_irrad.html.
} 
delivery time. As a result, the communications stream for fellows on the Hill had to be separated from the stream for those no longer working on the Hill. In addition, irradiation substantially discolored some of the postcards and may have reduced their visual appeal and value.

Tuesday, June 18, 2013, I distributed the survey by email to each of the "non-federal" fellows (those who no longer worked for the government).

Thursday, June 20, 2013, I mailed out the reminder postcards to each of the fellows (both "non-federal" and "federal").

Tuesday, June 25, 2013, I distributed the survey by email to each of the federal fellows (those currently employed by Congress or another Federal agency).

Tuesday, July 2, 2013, I sent a reminder email to any non-federal fellows who had not completed the survey.

Monday, July 8, 2013, I sent a reminder email to all federal fellows who had not completed the survey.

Monday, July 29, 2013, I sent a reminder email to all non-federal fellows who had not completed the survey. 
Tuesday, July 30,2013 , I sent a reminder email to all federal fellows who had not yet completed the survey.

Monday, August 12, 2013, I sent a final reminder email to all non-federal fellows who had not yet completed the survey.

Tuesday, August 13,2013, I sent a final reminder to all federal fellows who had not yet completed the survey.

Monday, August 26, 2013, the survey was formally closed and no new responses could be logged.

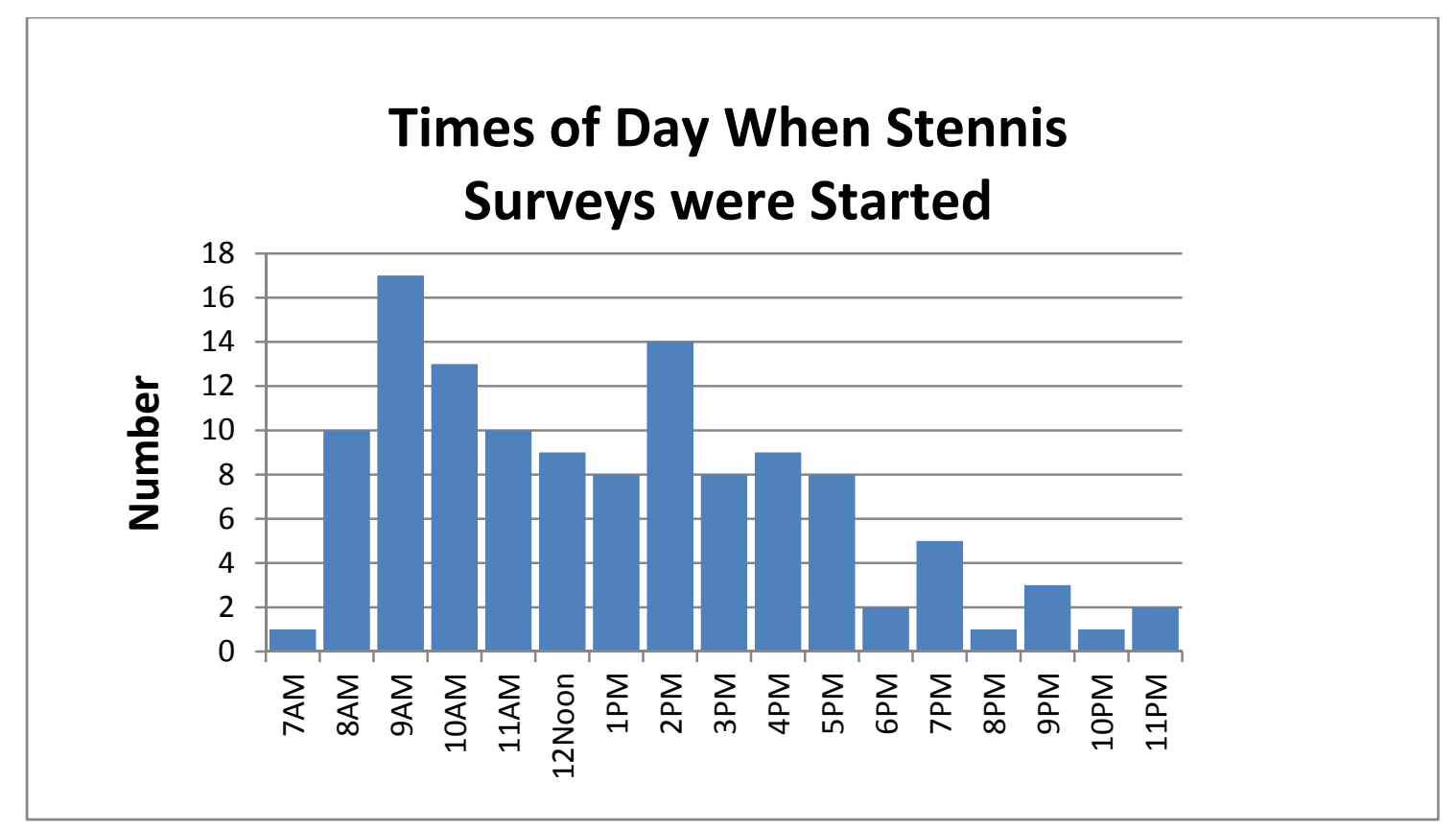




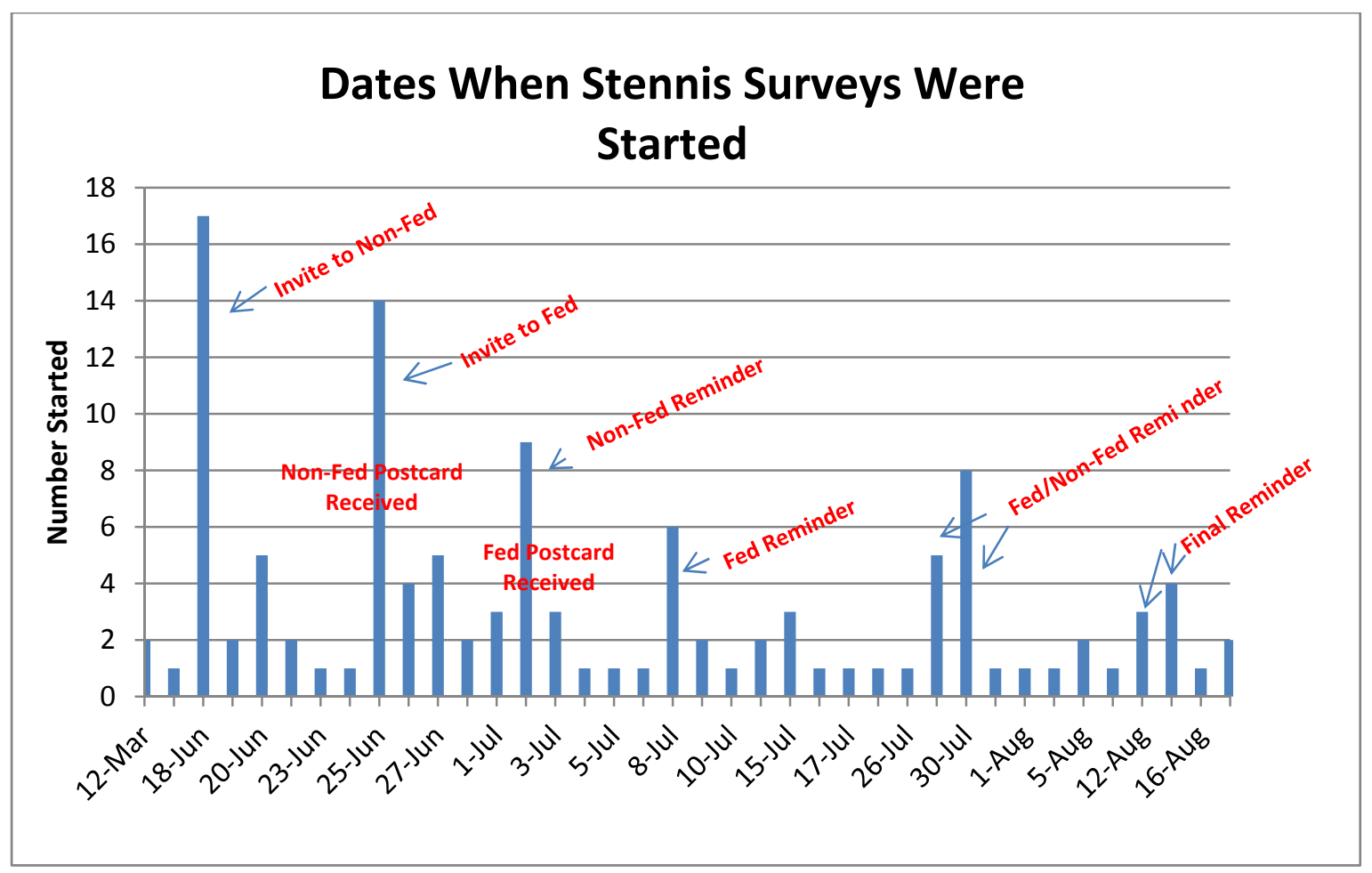

\section{B. House and Senate Samples}

Wednesday, June 19,2013, I sent a letter to each staff member in the sample to introduce the project, provide a link to the website (which at this point did not offer a way to take the survey) and indicate that staff would receive an email containing a link to the survey within a few days of receiving the letter. All 4,000 letters were personalized and handsigned.

Monday, June 24, 2013, I sent new letters out to the House and Senate staff whose original letters had been returned because of Post Office errors or changes in address.

Monday, July 1, 2013, I distributed the survey by email to each of the House and Senate staff in the sample. 
Tuesday, July 2, 2013, I created a "Take Survey" tab on the project website, www.religionandcongress.org, at the request of House staff who wanted the additional anonymity of responding to the survey through a generic link. The survey link was created through the Qualtrics “web link” survey distribution tool.

Tuesday, July 16, 2013, I sent a reminder email to each of the Senate staff who had not submitted a completed survey.

Monday, July 22, 2013, I sent a reminder to each of the House staff who had not submitted a completed survey.

Monday, August 5, 2013, I sent a new reminder email to each of the House and Senate staff who had not submitted a completed survey.

Monday, August 19, 2013, I sent a final reminder email to each of the Senate staff who had not yet submitted a completed survey.

Monday, August 26, 2013, I sent a final reminder email to each House staff member who had not yet submitted a completed survey. 

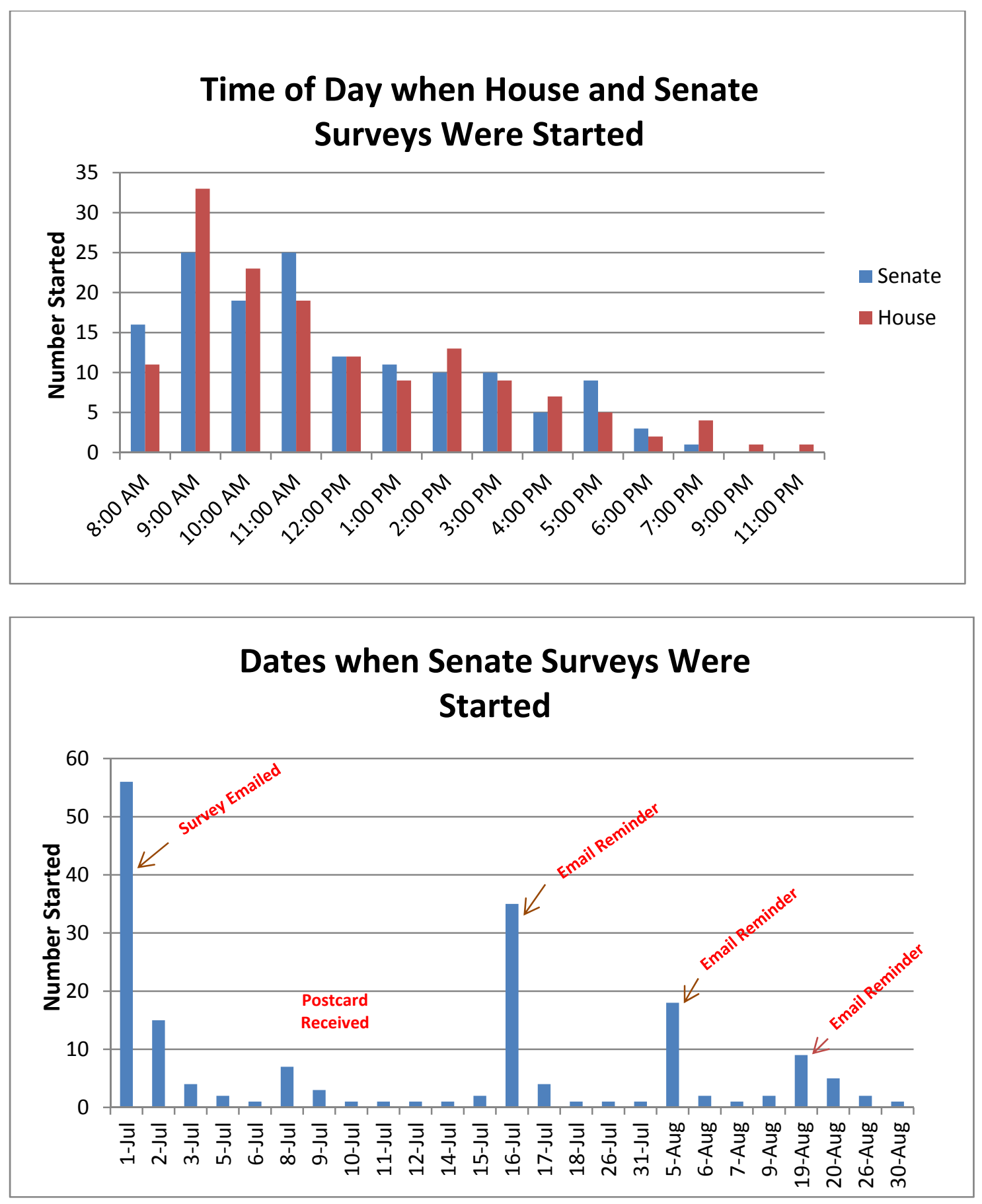


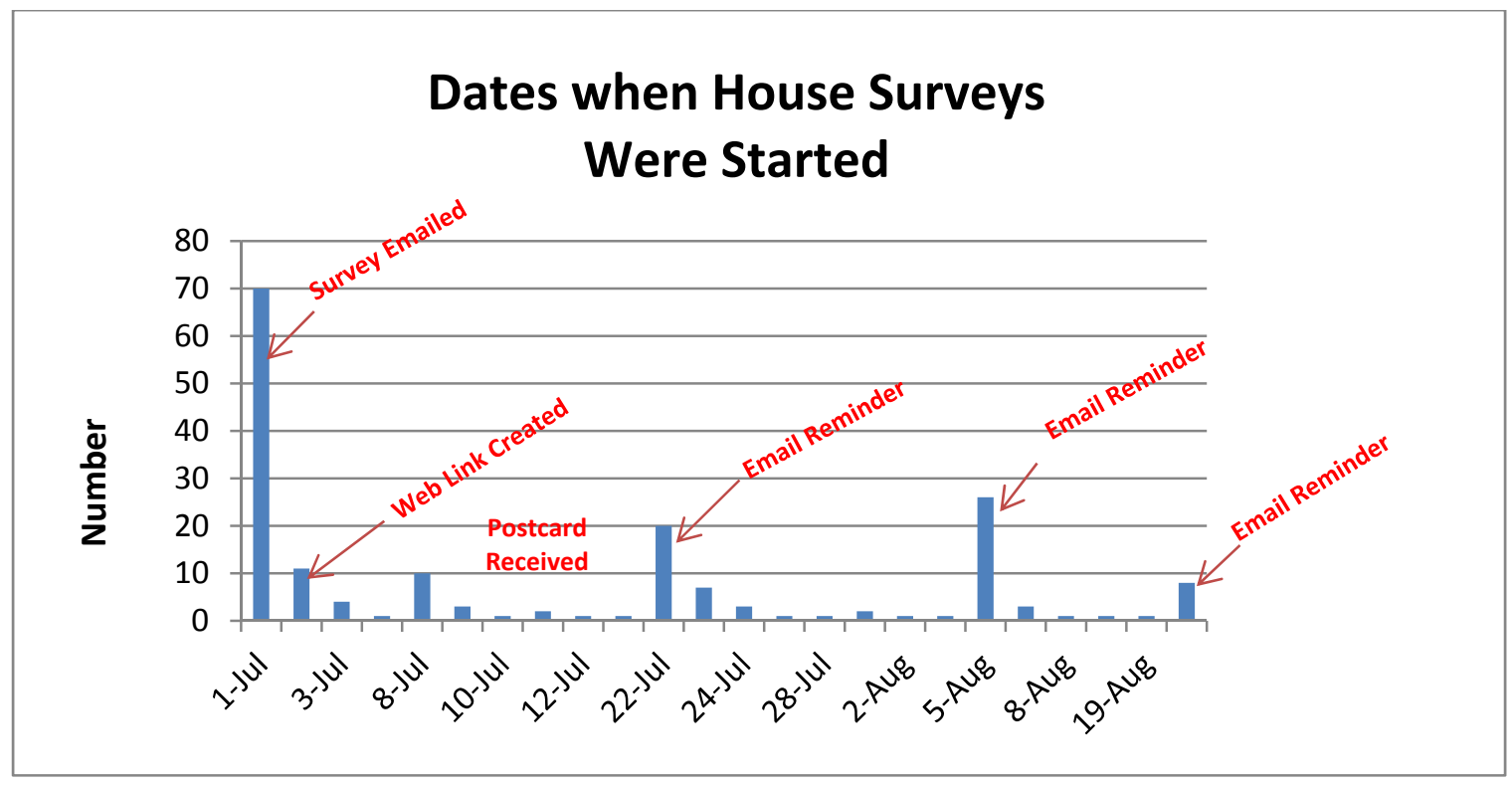

\section{Sample Selection for House and Senate Staff}

The U.S. House of Representatives and Senate do not publish comprehensive data on congressional staff. Two official data sources can be used to estimate the total number and names of staff, one is payroll information (office, name, and salary) released quarterly by the Clerk of the House and Secretary of the Senate, and the other is the House and Senate Directories that are issued twice a year. The Congressional Research Service (CRS) estimated that there were 14,709 staff working in House and Senate member offices, leadership offices, officer offices, committees and for offices of officials in 2010 .

Both the payroll data and the directory data have limitations. Both data sets reflect snapshots in time that purport to be accurate at the time the information is filed. Since staff are frequently paid by multiple sources (personal office and committee), payroll data 
overstate the total number of staff. Unfortunately, there is no simple way to remove duplicated records from this file set.

Conversely, although the directories will likely include all senior staff (e.g., administrative assistants, chiefs of staff, and legislative directors), there are no guarantees that they include all junior staff or district staff. This may lead to underestimates of the total sample size and to oversampling senior staff and leadership positions. In addition, there is no certainty that the people listed in the directory are actually employed by the member, senator, or office. The directory includes federal employees temporarily detailed from executive offices, fellows sponsored by associations, and individuals temporarily working for Congress under the Intergovernmental Personnel Act. This leads to overestimates of the total population. Finally, as with the payroll data, it is also common for members of committees, particularly subcommittee chairs, to have staff assigned to both the committee and personal offices.

\section{Congressional Research Service (CRS) Estimate of House Staff}

CRS relied upon the directories (head count as opposed to FTE) for the purposes of making an estimate of the number of House staff. Rather than counting all of the staff in all member offices (because of a lack of resources), CRS selected a random sample of 45 offices. Telephone directory data was obtained for those offices to compute average office staff counts. Individuals were assumed to be working in Washington, D.C. if the directory listed them as working in the Rayburn, Longworth, or Cannon House office buildings. From these averages, CRS estimated the total staff count and estimated the ratio of member district staff to member Washington staff, multiplying the averages 
derived from their samples by the total number of member offices. ${ }^{59}$ CRS estimated that 7,360 staff worked in member offices in 2009. These counts include part-time staff, interns, law clerks, detailees, and other non-permanent staff engaged when the directories were presented.

Republicans recaptured the House in 2010 and froze representation and committee budgets in FY2012 and FY2013. Leadership budgets were reduced and effective March 1, 2013 sequestration was implemented, resulting in a 5.3\% cut to all personal, committee, and leadership representational budgets. ${ }^{60}$ These budget choices may have resulted in the reduction in the total number of staff in 2011-2013. ${ }^{61}$ CRS planned to do annual re-estimates of the number of staff, but has not done so.

CRS actually counted the number of House committee staff $(1,362)$, House leadership staff (219), and House officers' and officials' staffs (828). ${ }^{62}$ These counts include parttime staff, interns, law clerks, detailees, and other non-permanent staff provided to the House clerk at the time the directories went to print.

\footnotetext{
${ }^{59}$ R. Eric Peterson, Parker H. Reynolds, and Amber Hope Wilhelm, "House of Representatives and Senate Staff Levels in Member, Committee, Leadership, and Other Offices, 1977-2010," (Washington, DC: Library of Congress Congressional Research Service, 2010).

60

http://cha.house.gov/sites/republicans.cha.house.gov/files/documents/Revised\%20Sequester\%20FAQs\%20 2013.pdf

${ }^{61}$ Chip Slawson, "Congressional Staff Salaries Plummet to 2008 Levels " LegiStorm, http://www.legistorm.com/blog/congressional-staff-salaries-plummet-to-2008-levels.html.

${ }^{62}$ Peterson, Reynolds, and Wilhelm, "House of Representatives and Senate Staff Levels in Member, Committee, Leadership, and Other Offices, 1977-2010."
} 


\section{CRS Estimate of Senate Staff}

In contrast with the estimates for House staffing, CRS provided a full count of all telephone directory listings for Senate offices $(4,346)$, committees $(1,246)$, leadership (176), and officers and officials (331). These counts include part-time staff, interns, law clerks, detailees, and other non-permanent staff engaged when the directories were sent to print.

\section{George Washington University Graduate School of Political Management}

As described earlier, the GWU study sourced staff names and email addresses from one of its partner organizations, "The Original U.S. Congress Handbook." The investigators reported that they obtained a list of 13,530 House and Senate staff.

\section{$\underline{\text { LegiStorm }}$}

LegiStorm is a for-profit company, located on Capitol Hill, that was created in 2006. It became widely known as being the only online source for staff salaries, financial disclosures, trips, gifts, and earmarks. LegiStorm has expanded its offerings to include biographical information, consisting of educational backgrounds, employment histories, social media links, hometowns, hobbies and activities, and family connections. The company is non-partisan and receives revenue through paid subscriptions, advertising, licensing, and data sales. House and Senate offices receive free access.

Data are obtained directly from the House and Senate offices and from a wide variety of publicly available sources (payroll, directories, social media) and verified with the offices. The data are updated daily to capture new hires and departures. 
I contracted with LegiStorm to provide me with a random sample of 2,000 U.S. House of

Representatives staff and a separate random sample of 2,000 U.S. Senate staff. The

LegiStorm database is updated throughout the day as changes are discovered and

reviewed. As a result, this sample is drawn from the data as they existed on May 15,

2013.

The sample included full-time staff (to the extent that part-time staff could be identified) employed in:

- The offices (D.C. and district) of Members of Congress and U.S. Senators

- House and Senate committees

- Senate leadership offices

o Democratic Senatorial Campaign Committee

o National Republican Senatorial Committee

o Office of the President Pro Tempore of the Senate

o Office of the Secretary for the Majority

o Office of the Secretary for the Minority

o Office of the Senate Majority Leader

o Office of the Senate Majority Whip/Assistant Majority Leader

o Office of the Senate Minority Leader

o Office of the Senate Minority Whip

o Office of the Senate Republican Conference

o Senate Democratic Conference

o Senate Democratic Policy Committee

o Senate Democratic Steering and Outreach Committee

o Senate Republican Policy Committee

- Staff from the Office of the President of the Senate (Vice President of the United States)

- House of Representatives leadership offices

o Democratic Congressional Campaign Committee

o House Democratic Caucus

o House Democratic Steering and Policy Committee

o House Republican Conference

o House Republican Policy Committee

o House Republican Steering Committee

o National Republican Congressional Committee

o Office of the House Assistant Minority Leader

o Office of the House Majority Leader

o Office of the House Majority Whip 
o Office of the House Minority Leader

o Office of the House Minority Whip

o Office of the Speaker of the House of Representatives

The sample excluded:

- Part-time staff (to the extent they could be identified)

- Interns

- Detailees from federal agencies

- Fellows paid by other organizations

- Staff from congressional support agencies

o Architect of the Capitol

o Congressional Budget Office

o Library of Congress

o General Accountability Office

o Government Printing Office

o Medicare Payment Advisory Commission

o Office of Compliance

o U.S. Capitol Police

- Staff from the Office of the Chaplain of the Senate

- Staff from the Office of the Secretary of the Senate

- Staff from the Office of the Senate Legal Counsel

- Staff from the Office of the Senate Legislative Counsel

- Staff from the Office of the Senate Sergeant at Arms

- Staff from the House Press Galleries

- Staff from the Office of the Chaplain of the U.S. House of Representatives

- Staff from the Office of the Chief Administrative Officer of the House of Representatives

- Staff from the Office of the Clerk of the House of Representatives

- Staff from the Office of the House General Counsel

- Staff from the Office of the Inspector General of the House of Representatives

- Staff from the Office of the Law Revision Counsel

- Staff from the Office of the House Legislative Counsel

- Staff from the Office of the Parliamentarian of the House of Representatives

- Staff from the Office of the Sergeant at Arms of the House of Representatives

\section{Comparison with CRS Population Estimates}

The CRS report estimated that in 2010 there were 8,941 House staff in member personal offices, committee offices, and leadership offices (including part-time staff, interns, law clerks, detailees, and other non-permanent staff engaged when the directories went to 
print). LegiStorm's data base contained 7,977 unduplicated staff meeting the criteria I had established on May 15, 2013 when my sample was selected.

The CRS report estimated that in 2010 there were 5,768 Senate staff in personal, committee and leadership offices (including part-time staff, interns, law clerks, detailees, and other non-permanent staff engaged when the directories went to print). LegiStorm's database contained 5,097 unduplicated staff meeting the criteria on May 15, 2013 when my sample was selected.

In the case of both the House and Senate sample frames, the May 15, 2013 LegiStorm database contained $12 \%$ fewer staff than the 2010 CRS methodologies. Some of this difference can be attributed to the absence of part-time staff, interns, detailees, fellows and other non-policy or member staff in the LegiStorm sample. It is also possible that the budget pressures between 2010 and 2013 resulted in reductions in the number of staff. ${ }^{63}$ CRS anticipated that it would update the report but have not done so. Inquiries by Congressman Peter Welch (D-VT) on my behalf indicate that CRS currently does not plan to update the analysis.

\section{Sample Selection}

In order to ensure adequate participation by Senate staff, I decided to oversample the Senate by drawing separate random 2,000 person samples of House staff and Senate staff.

${ }^{63}$ Slawson, "Congressional Staff Salaries Plummet to 2008 Levels ". 


\section{House Staff}

LegiStorm put all 7,977 of the members of the House of Representatives staff contained within its database that met the research criteria (above) into an array. The array was then shuffled using the PHP: Hypertext Preprocessor (PHP) shuffle command. The first 2,000 names were selected from this randomized list of House staff for the survey sample. The process was repeated for the list of the 5,097 potential members of the U.S. Senate staff contained within the LegiStorm database. I received two separate files from LegiStorm, one containing the House list and one containing the Senate list.

The lists were reviewed for completeness of the records and to determine whether the samples contained records from excluded groups (e.g., interns). The House data set contained two Senate staff members, seven individuals whose employers had been defeated the prior fall, and two individuals who, based on a review of social media, had moved to other employment. The data set also included 19 staff records which were missing physical or email addresses. Addresses for these individuals were located through the Congressional Yellow Book, the National Journal database, or social media. If these sources did not have the information, the addresses were obtained by calling the offices directly. Four of these staff could not be located, leaving the final sample with 1,985 records. The sample constituted $24.9 \%$ of the eligible LegiStorm population. Review of the sample revealed the following demographic traits:

- $1,016(51.2 \%)$ were female

- $969(48.8 \%)$ were male

- $833(42 \%)$ worked for Democratic members 
- $1,110(55.9 \%)$ worked for Republican members ${ }^{64}$

- $42(2.1 \%)$ worked for non-partisan offices or independents

- $263(13.2 \%)$ worked for House committees

- $34(1.7 \%)$ worked for members of the House leadership

- $4(0.2 \%)$ worked for a coalition or caucus

- $1,684(84.8 \%)$ worked for a personal office

- $786(39.6 \%)$ worked in a member's district office

- $1,199(60.4 \%)$ worked in Washington, D.C.

\section{Senate Staff}

The Senate list prepared by LegiStorm contained eight temporary staff (interns, law clerks, and finance associates) and 16 records with missing physical or email addresses. As with the House file, the missing addresses were located through the Congressional Yellow Book, the National Journal database, or social media. If these sources did not have the information, addresses were obtained by calling the offices directly. When the two Senate staff from the House file were included, the sample size was reduced to 1,994. The sample constituted $39.1 \%$ of the eligible LegiStorm population. Review of the final sample revealed the following demographic characteristics:

- $1,061(53.2 \%)$ were female

- $933(46.8 \%)$ were male

- $1,087(54.5 \%)$ worked for Democratic members

- $797(40.0 \%)$ worked for Republican members

- $110(5.5 \%)$ worked for non-partisan offices or independents

- $340(17.1 \%)$ worked for a Senate committee

- $71(3.6 \%)$ worked for a member of the Senate leadership

- $1,582(79.3 \%)$ worked for a senator's personal office

- $1(0.1 \%)$ worked for a coalition or caucus

- $678(34.0 \%)$ worked in a senator's district office

- $1,316(66.0 \%)$ worked in Washington, DC

\footnotetext{
${ }^{64}$ House and Senate rules divide leadership and committee budgets based on majority status. In general the majority party receives two-thirds of committee funding as well as funding for additional leadership positions. An exception was made in the Senate when there was a 50/50 split and Senator Jeffords became an independent aligned with the Democrats. See Standing Rules of the Senate.
} 


\section{The Stennis Sample}

The Stennis Center for Public Service Leadership was established by Congress in honor of the late Senator John Stennis of Mississippi. The center is governed by a board of trustees appointed by the Democratic and Republican leadership of the House and Senate and has a small staff that administers several leadership programs, including the Stennis Congressional Staff Fellows Program.

Each year, the center invites a bipartisan "class" of 20 to 24 senior congressional staff (i.e., staff directors, administrative assistants, legislative directors) to participate in a one year staff leadership development program. Participants are nominated by past participants and reviewed and selected by a selection committee. The center strives for balance in party, institution, and role (member's office, committee, or leadership office). This group is not representative of congressional staff at large. It is, however, arguably representative of staff holding leadership positions on Capitol Hill. In addition, former fellows (including those no longer working on the Hill) are designated as senior fellows and serve as mentors to more junior staff. They afford a unique opportunity to survey key influencers within congressional staff.

After a year of negotiation with the center, I was able to obtain the center's support for this research project. The Stennis Center provided me with the names and addresses - to the extent they were known — of 272 fellows. Not all of the records were complete. Many did not have phone numbers, and 30 did not have a physical address. I used Legistorm, social media (LinkedIn, Facebook, Pinterest), and skip-tracing tools used in the financial services industry to locate the missing physical and email addresses. These tools allowed me to locate 15 of the missing addresses as well as assign genders to each 
of the fellows. I converted the file from Word to Excel and used the random number generator function in Excel to create a record number for each fellow.

The sample contained 257 current and former senior staff. Ninety members of the sample had physical addresses in the House or the Senate; 17 were employed by another federal agency, 36 had no current employment record, 16 worked for foundations or educational institutions, and 83 were employed by lobbying firms or advocacy groups such as AARP. The remainder were employed in various state and local government positions.

\section{E. The Survey Instrument (Appendix A)}

Survey Section I--Religious affiliation and religiosity

Historically, there have been two ways to measure the role of religion in public and professional life: public opinion surveys and religiosity scales developed by social psychologists. The public opinion surveys are among the most well-known and include the General Social Survey (GSS) conducted by the National Opinion Research Center and the U.S. Religious Landscape Survey (Landscape Survey) conducted by the Pew Forum on Religion and Public Life. The GSS has been administered since 1972 and provides snapshots of changes that have occurred over the past 40 years. The Landscape Survey, conducted in 2007, provides a broader look at religious affiliation and its correlation with "culture war" social and political issues. ${ }^{65}$ In addition, Gallup has done

${ }^{65}$ Luis Lugo et al., "U.S.Religious Landscape Survey: Religious Beliefs and Practices; Diverse and Politically Relevant," (Washington, DC: Pew Forum On Religion and Public Life, 2008). 
general population polling since 1948 to collect data on religious affiliation and religiosity. ${ }^{66}$

In contrast to the relatively small universe of public opinion surveys and polls, there are at least 177 different religiosity scales currently being used by the research community. ${ }^{67}$ Each of these scales reflects different conceptual and definitional commitments. Some pay greater attention to the "interior" aspects of religious experience while others give greater weight to the "external" aspects of ritual and practice. ${ }^{68}$

Most of these instruments have been designed for use in specific contexts (such as pastoral counseling), within specific traditions or denominations, and for specific purposes, including, but not limited to, research. Many have been tested on relatively small populations and with few exceptions have been used with relatively homogenous groups. Several efforts are underway to design a short form survey for research purposes, but these are still in development or of unproven reliability and validity. ${ }^{69}$

In 1998, and again in 2010, the GSS included the Brief Multidimensional Measure of Religion/Spirituality. This permitted later researchers to compare their samples against an

\footnotetext{
${ }^{66}$ Gallup, "Honesty and Ethics Poll Finds Congress' Image Tarnished: For First Time, Majority of Americans Say Its Members Have Low Ethics".

${ }^{67}$ Peter C. Hill and Ralph W. Hood Jr, eds., Measures of Religiosity (Birmingham: Religious Education Press, 1999).

${ }^{68}$ Marsha Cutting and Michelle Walsh, "Religiosity Scales: What Are We Measuring in Whom?," Archive for the Psychology of Religion 30, no. 1-2 (2008).

${ }^{69}$ Jr.; Nathaniel G. Wade; Terry L. Hight; Michael E. McCullough; James T. Berry; Jennifer S. Ripley; Jack W. Berry; Michelle M. Schmitt; Kevin H. Bursley Everett L. Worthington, "The Religious Commitment Inventory--10: Development, Refinement, and Validation of a Brief Scale for Research and Counseling," Journal of Counseling Psychology 50, no. No.1 (2003).
} 
unstratified probability sample of all U.S. households. ${ }^{70}$ The survey used in this research included some elements from the prior GSS surveys as well as elements derived from the Hoge Intrinsic Religious Motivation Scale and the Duke University Religious Index Scale.

The Hoge Intrinsic Religious Motivation Scale (1972) was designed to improve upon Allport and Ross's Religious Orientation Scale. As its name suggests, the Hoge scale focuses primarily on the intrinsic aspect of religious motivations, behaviors and beliefs.

Respondents are asked whether they "strongly disagree," "moderately disagree,"

"moderately agree" or "strongly agree" with the following statements:

1. My faith involves all of my life. (Intrinsic)

2. One should seek God's guidance when making every important decision. (Intrinsic)

3. In my life I experience the presence of the Divine. (Intrinsic)

4. My faith sometimes restricts my actions. (Intrinsic)

5. Nothing is as important to me as serving God as best I know how. (Intrinsic)

6. I try hard to carry my religion over into all my other dealings in life. (Intrinsic)

7. My religious beliefs are what really lie behind my whole approach to life. (Intrinsic)

8. It doesn't matter so much what I believe as long as I lead a moral life. (Extrinsic)

9. Although I am a religious person, I refuse to let religious considerations influence my everyday affairs. (Extrinsic)

10. Although I believe in my religion, I feel there are many more important things in life. (Extrinsic)

The reliability of this index has been confirmed through research and questions drawn from the index have been used in the General Social Survey, in the U.S. Religious

${ }^{70}$ MD Farr A. Curlin et al., "Religious Characteristics of U.S. Physicians," J GEN INTERN MED 20(2005). 
Landscape Survey, as well as in contemporary research in medical ethics. ${ }^{71}$ The scale has the additional advantage that it is non-sectarian and seemingly does not include language or questions that would be deemed offensive to individuals of non-Christian faiths. ${ }^{72}$

The Duke Religious Index Scale is a five-question scale designed to measure multiple dimensions of religious experience: organizational, non-organizational, and intrinsic religiosity. ${ }^{73}$ The intrinsic religiosity questions are drawn from the Hoge scale but the Likert response items are modified. The extrinsic religiosity questions include frequency of participation in public (religious meetings) and private (prayer, meditation) activities. Respondents are asked:

1. How often do you attend church or other religious meetings? (Organizational)

2. How often do you spend time in private religious activities, such as prayer, meditation, or Bible study? (Non-organizational)

3. In my life, I experience the presence of the Divine (i.e., God). (Intrinsic Religiosity)

4. My religious beliefs are what really lie behind my whole approach to life. (Intrinsic Religiosity)

5. I try hard to carry my religion over into all other dealings in life. (Intrinsic Religiosity $)^{74}$

\footnotetext{
${ }^{71}$ Farr A. Curlin et al., "Religion, Conscience, and Controversial Clinical Practices," New England Journal of Medicine 356, no. 6 (2007); ibid.

${ }^{72}$ Hill and Hood Jr, Measures of Religiosity.

${ }^{73}$ These three dimensions of religious involvement were recommended at a National Institute on Aging and the Fetzer Institute conference (16-17 March 1995) on Methodological Approaches to the Study of Religion, Aging, and Health.

${ }^{74}$ Hill and Hood Jr, Measures of Religiosity.
} 
The GSS contained 35 items measuring various dimensions of religiosity and other aspects of religious attitudes or practice. These measures included variations on three items from the religiosity scales. Respondents were asked (codebook variable name precedes question):

1. Relig - What is your religious preference? Is it Protestant, Catholic, Jewish, some other religion, or no religion?

2. Reliten - Would you call yourself a strong RELIGIOUS PREFERENCE or a not very strong RELIGIOUS PREFERENCE?

3. Pray-About how often do you pray? (drawn from the Duke index)

4. Fund-Fundamentalism/liberalism of respondent's religion

5. Attend - How often do you attend religious services? (Duke index)

6. Postlife-Do you believe there is a life after death?

7. Sprel_-What is your husband/wife's religions preference?

8. Relig16 - In what religion were you raised?

9. Fund16-Fundamentalism/liberalism of religion respondent raised in.

20. Spfund_Fundamentalism/liberalism of religion.

21. Prayer-US Supreme Court has ruled that no state or local government may require the reading of the Lord's Prayer.

22. Bible - Which of these statements comes closest to describing your feelings about the Bible?

23. God-Which statement comes closest to expressing what you believe about God?

24. Reborn - Would you say you have been "born again" or have had a "born again" experience?

25. Savesoul - Have you ever tried to encourage someone to believe in Jesus Christ or to accept Jesus Christ as his or her savior?

26. Punsin-- Those who violate God's rules must be punished. 
27. Rellife - I try hard to carry my religious beliefs into all my other dealings in life. (Drawn from Hoge index)

28. Relpersn-To what extent do you consider yourself a religious person?

29. Sprtprsn - To what extent do you consider yourself a spiritual person?

30. Relexp-Did you ever have a religious or spiritual experience that changed your life?

31. Relexper--Has there ever been a turning point in your life when you made a new and personal commitment to religion?

32. relid1 - (IF R is Protestant) When it comes to your religious identity, would you say you are Pentecostal, fundamentalist, evangelical, mainline, or liberal Protestant, or do none of these describe you?

33. Cathid - (If R is Catholic) When it comes to your religious identity, would you say you are traditional, moderate, or liberal Catholic, or do none of these describe you?

34. Godview - Which of the following views comes closest to your own view of God?

35. Relactiv-How often do you take part in the activities and organizations of a church or place of worship other than attending services?

Section I of the survey instrument developed for this research contained four questions on religious preference (e.g., Buddhist, Catholic, Protestant) taken directly from the 2010 GSS in order to permit comparisons with the GSS sample frame. The survey included skip logic permitting delivery of additional specification questions to respondents who selected Protestant (e.g., Baptist, Episcopal, Methodist) or Jewish (Conservative, Orthodox, Reformed).

Section II of the survey instrument contained eight questions taken from the Hoge scale, one question from the Duke scale (also contained in the GSS), and six questions taken solely from the 1998 and 2010 General Social Survey. The questions from the Hoge and 
Duke scales permit evaluation of each of the respondents along dimensions of intrinsic and extrinsic religiosity as well as the ability to test the internal consistency of these scales when used with a new population. The questions from the GSS permit comparison of congressional staff with the GSS adult population along the three dimensions of religiosity scales recommended by the National Institute of Aging. GSS questions were excluded if they did not measure a dimension of religiosity, were political in nature, or would not easily apply to non-Christian faiths. The following questions were retained:

1. Which of the following statements comes closest to expressing what you believe about God? (GSS God)

2. How often do you attend church, synagogue or other religious services? (Duke, GSS Attend)

3. About how often do you pray or meditate? (Duke, GSS Pray)

4. Has there been a turning point in your life when you had a new and personal commitment to religion? (GSS Relexper)

5. To what extent do you consider yourself a religious person? (GSS Relpersn)

6. To what extent do you consider yourself a spiritual person? (GSS Sprtprsn)

7. How often do you take part in the activities and organizations of a church or place of worship other than attending service? (GSS Relactiv)

8. I try hard to carry my religious beliefs over into all my other dealings in life. (Hoge, GSS Rellife)

9. My faith involves all my life. (Hoge)

10. One should seek God's guidance when making every important decision. (Hoge)

11. My faith sometimes restricts my actions. (Hoge)

12. Nothing is as important to me as serving God as best I know how. (Hoge)

13. It doesn't matter so much what I believe as long as I lead a moral life. (Hoge)

14. Although I am a religious person, I refuse to let religious considerations influence my everyday affairs. (Hoge)

15. Although I believe in my religion, I feel there are many more important things in life. (Hoge) 


\section{Section III-Frequency of Being Lied To and Lying}

Section III of the Survey examined the experience of congressional staff with lying and being lied to. As discussed earlier, there have been numerous studies examining the willingness of physicians and other professionals to lie or use deception in professional contexts. $^{75}$ There have been few major studies attempting to understand the nature and frequency of lying in the general public. Two of these studies are of particular relevance to my research.

Bella DePaulo and her colleagues asked 77 college students and 70 community members to keep a diary of all of their social interactions for a week. A social interaction was any exchange with another person that lasted 10 minutes or more. The only exception to the 10-minute rule was an interaction that included a lie. The instructions defined lying as "intentionally trying to mislead someone." A lie occurred in every interaction that included "both the intent to deceive and the actual deception." Lies were interpreted by the respondents to be both verbal and non-verbal. One can infer from the discussion of the findings that "actual deception" referred to an actual attempt to lie rather than a requirement that the lie be successful. Students reported an average of two lies per day while community members reported an average of one lie per day.

Kim Serota and her colleagues built upon the DePaulo study by conducting a broad population survey of U.S. adults. The goal of this survey was to ascertain the selfreported frequency of lying by U.S. adults, the types of individuals to whom the lies were directed, and whether lying occurred more frequently on the phone or through email than

${ }^{75}$ Novack et al., "Physician's Attitudes toward Using Deception to Resolve Difficult Ethical Problems." 61 | P a g e 
in person. Respondents were asked to think about their interactions over the previous 24

hours. In the instructions to their survey, they stated:

"Most people think a lie occurs any time you intentionally try to mislead someone. Some lies are big while others are small; some are completely false statements and others are truths with a few essential details made up or left out. Some lies are obvious, and some are subtle. Some lies are told for a good reason. Some lies are selfish; other lies protect others. We are interested in all types of lies." $" 76$

The instructions were designed to be worded "permissibly" in order to reduce social desirability bias and improve accuracy. ${ }^{77}$ They have the advantage of being inclusive but conflate deception and lying and permit inclusion of interactions that may not uncontrovertibly be thought to be lies. Unlike the DePaulo study, the instructions do not tell respondents to exclude untruthful responses to questions such as "how are you doing" or "how do you feel."

The respondents were presented with five types of people and two modes of communications as a memory prompt and to support additional analysis. The report suggested that the average rate of lying is around 1.65 lies per day. ${ }^{78}$

\section{Surveys and Sensitive Questions}

There is a rich literature about the willingness and ability of respondents to answer sensitive survey questions accurately and honestly. ${ }^{79}$ Sensitive questions have a number

\footnotetext{
${ }^{76}$ Serota, Levine, and Boster, "The Prevalence of Lying in America: Three Studies of Self-Reported Lies."

${ }^{77}$ Ibid.

${ }^{78}$ Ibid.

${ }^{79}$ RM Groves et al., Survey Methodology (Hoboken, NJ: John Wiley \& Sons, Inc., 2004).
} 
of characteristics: They may be viewed as being too personal or intrusive; they may raise concerns about the personal repercussions should the respondents' answers be disclosed to the public; or they may ask the respondent to acknowledge believing something or behaving in a way that violates one or more social norms. ${ }^{80}$ The presence of social desirability factors is believed to reduce the number of respondents who participate in a survey, increase item non-response rates, and impair the quality or accuracy of the responses that are provided. This appears to be particularly true of questions that attempt to capture the prevalence of socially undesirable behaviors. ${ }^{81}$

Researchers in the social sciences have attempted to quantify and correct for the impact of social desirability bias. Early research and efforts to develop social desirability bias scales treated response bias as a personality trait rather than an individual response to a specific question in a specific context. Research by Tourangeau ${ }^{82}$ and by Fisher and $\mathrm{Katz}^{83}$ suggests that social desirability bias is better understood as the result of the sensitivity of specific questions to specific individuals in specific contexts.

Researchers have divided social desirability bias into two factors: self-deception and impression management. Self-deception describes responses that reflect honest but overly positive presentations of oneself. Impression management describes responses that are biased by a desire to depict oneself in a way that is believed by the respondent to

\footnotetext{
${ }^{80}$ Roger Tourangeau and Ting Yan, "Sensitive Questions in Surveys," Psychological Bulleting 133, no. 5 (2007).

${ }^{81}$ R. Tourangeau, L.J. Rips, and K. Rasinksii, The Psychology of Survey Response (Cambridge, England: Cambridge University Press, 2000).

${ }^{82}$ Ibid.

${ }^{83}$ Robert J. Fisher and James E. Katz, "Social-Desirability Bias and the Validity of Self-Reported Values," Psychology and Marketing 17(2), no. February (2000).
} 
be socially conventional or acceptable. ${ }^{84}$ Impression management is particularly at issue during surveys involving human interviewers.

One way to ascertain the strength of the social desirability bias for respondents answering specific questions is by comparing their self-reports of the prevalence of a behavior with their estimates of the prevalence of the same behavior in others. ${ }^{85}$ This section and three of the cases in the final section of this survey contain a role reversal question in which respondents are asked to identify or predict the behavior of the individual or individuals with whom they are conversing if their situations are or were reversed.

While it is useful to know the strength of the social desirability bias, it is even more important to try to reduce its impact on survey results. There is a great deal of literature on strategies for reducing the impact of social desirability bias on population survey results. Following the guidance of Tourangeau and Yan, this survey employed the following strategies:

1. Respondents were ensured confidentiality,

2. The survey was self-administered,

3. Respondents could use a private setting (computer, smartphone, or tablet of one's choice),

4. The survey used forgiving, neutral, and nonjudgmental wording of questions,

5. All communication emphasized the shared professional experiences of the researcher and respondents. ${ }^{86}$

\footnotetext{
${ }^{84}$ Ibid.

${ }^{85}$ Serota, Levine, and Boster, "The Prevalence of Lying in America: Three Studies of Self-Reported Lies."

${ }^{86}$ Tourangeau and Yan also recommend use of indirect questions and bogus pipeline, neither of which were used in this study.
} 
Consistent with these strategies, and to measure the strength of the social desirability bias, this section of the survey instrument diverged from Serota's survey by asking respondents to think about the previous 24 hours and indicate the number of times they believe they were lied to either face-to-face or by phone. The list of individuals who might have lied to them was expanded for mnemonic reasons to reflect the professional context of congressional staff. Respondents were asked how many times they believed they were lied to by the following groups:

1. Family members (Serota)

2. Friends (Serota)

3. Lobbyists

4. Congressional staff

5. Journalists

6. Executive branch personnel

7. People you do not know but might see occasionally (Serota)

8. Total strangers (Serota)

The question was divided into four matrices, each of which were presented to respondents on their own page. To reduce response burden, each option contained a drop-down box allowing respondents to skip the question or choose a number between 0 and 10. As will be reviewed in the discussion section, although this response format did not create any anomalies during field testing, it may have contributed to the generation of outlier responses that pose analysis challenges. 


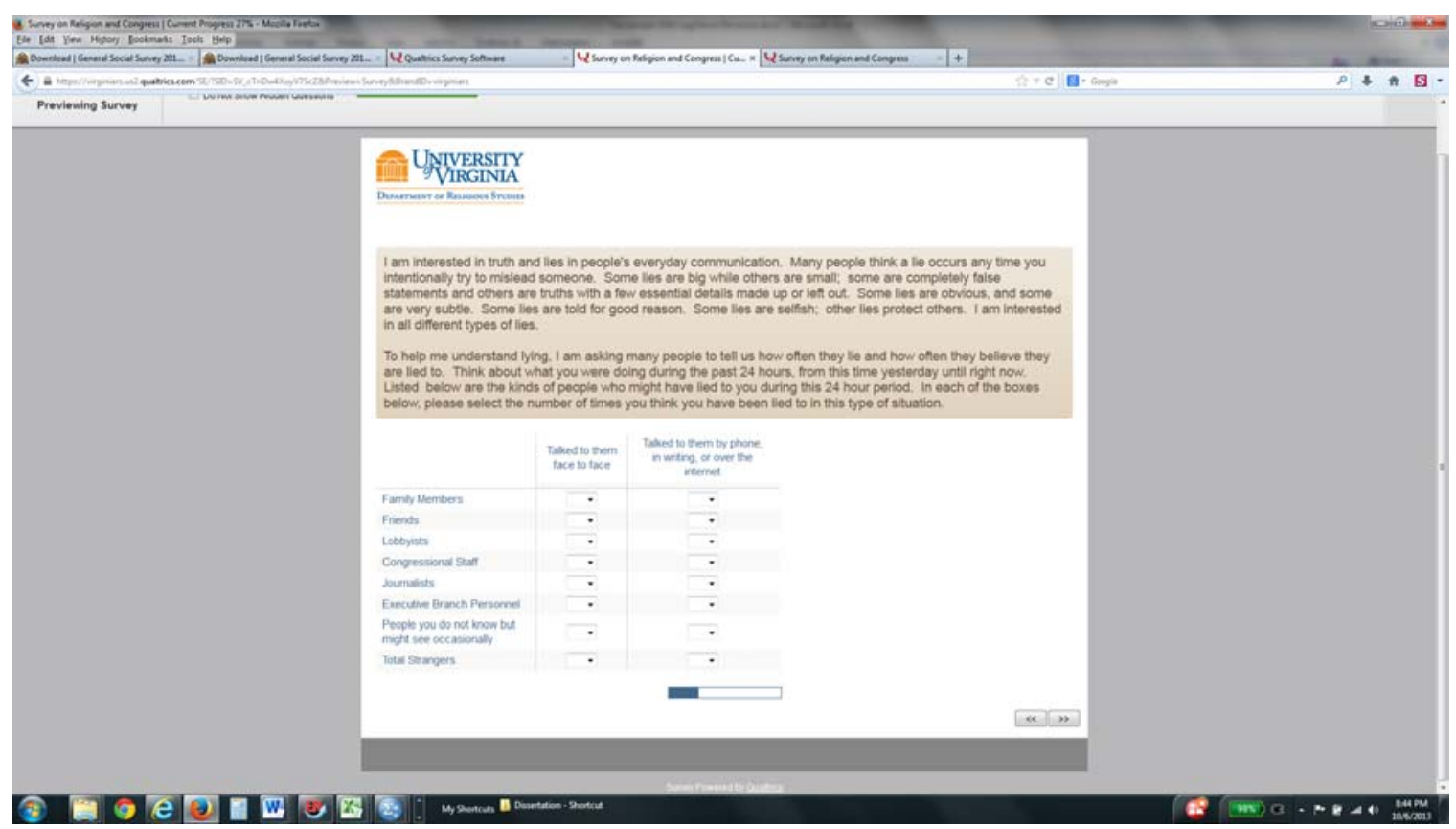

The second question of this section of the survey followed Serota nearly verbatim and asked respondents to report the frequency with which they told lies within the prior 24 hours. The response options were modified to include the same additional categories provided in the previous question. As noted previously, the question was framed very permissively and the definition of lying was very broad. This section precedes more specific questions about the definition of lying in order to avoid unintended priming effects. Respondents did not have the ability to go back to this question once they had completed it. As with the prior question, this question was presented as a matrix that asked respondents to identify the number of times they had lied to different groups of people "face-to-face" or by "phone, in writing, or over the internet." To minimize the response burden, respondents were provided with drop-down boxes that allowed responses from zero to 10 . 


\section{Section IV-Definitions and Justifications}

Section IV was designed to assess how congressional staff define lying and measure whether and under what conditions they believe that a lie is morally permissible. The first question asked staff to select a definition that most closely comported with their personal definition of a lie. The second question reversed the question and invited them to look at a series of statements and identify any which they did not believe comported with their personal definition of a lie. The third question provided a series of views about whether and under what circumstances lying is morally permissible. Respondents were asked to select each statement that comported with their personal beliefs about lying.

\section{Definitions}

The first question provided respondents with three definitions of lying as well as the option to select "other" and provide their own definition. The first definition_- "any intentionally deceptive statement"- was drawn from Bok and aligns with the definition used by DePaulo and Serota in their research. ${ }^{87}$ The second definition- "a false statement that is intended to deceive someone"-was taken from the Oxford English Dictionary. The third definition - "a false statement that the author asserts/claims is true whether he or she expects to succeed in deceiving someone or not"- was derived from the definition provided by Carson (liar warrants as true) but includes the concept of intent to deceive that is central to Mahon. The wording of this last definition was modified from the verbatim presentation of the Carson definition in response to respondent

\footnotetext{
${ }^{87}$ Bok argues that a lie requires a statement. This is not explicitly part of the DePaulo and Serota definition.
} 
feedback during field testing. Presentation of these options was randomized to mitigate order-related response bias.

The second question was designed to tease out the features of the definition of a lie contained in the philosophical literature that resonated with the respondents. This question provided respondents with six definitions of a lie and asked them to indicate whether they believed the described statement was a "lie" or "not a lie." Unlike the previous question, the structure of the question was designed to permit respondents to select as many or as few statements as they believed comported with their own definition of a lie. One benefit of this structure is that it may more clearly capture the messier, at times conflicting, and usually unsystematic views that people commonly have about complex issues such as lying. Presentation of the options included a forcing feature that encouraged each of the definitions to be evaluated before the respondent could move to the next question. ${ }^{88}$

The first definition was "a statement that is partly true but which omits relevant facts or opinions that would lead reasonable people to different conclusions than the author wants them to reach." This question was designed to capture "partial truths" as well as the limits (if any) on "spinning."

\footnotetext{
${ }^{88}$ Following the Tailored Design Method, this was one of a few questions that contained modified forcing. A respondent who tried to move to the next question without evaluating each of the definitions received a reminder "pop-up box" which indicated that one or more of the questions had not been answered and asked whether he or she wanted to go back and answer the question or proceed without answering.
} 
The second definition — " a statement that is untrue but is issued in a situation where people may not expect fully truthful statements"- was intended to capture views on bluffing and campaigns that would be examined later in the survey when respondents were provided with cases about negotiation and political campaigns.

The third definition - "a statement that is untrue but that is made in order to avoid hurting someone's feelings"- was intended to capture views on what are conversationally referred to as "white lies."

The fourth definition_- "a statement that you assert/claim is true when you are actually uncertain about the truth of falsehood of your statement"- - was designed to capture views on "bullshitting" as well as on Carson's modified definition of a lie in which the "liar" does not believe that the statement is true but cannot be said to believe that the statement is false or probably false.

The fifth definition of a lie- " a statement that is untrue but which is not expected to succeed in deceiving anyone" — was designed to capture views on the role of intention that plays such a central role in the philosophical literature.

The final definition - "a statement that is untrue but is made to someone who does not have a right to the information" - was intended to capture views on the definition of a lie put forward by Grotius as well as to refine evaluation of responses to the subsequent case dealing with classified information. 


\section{Justifications}

This question presented respondents with 10 statements about when it was permissible to tell a lie, and asked them to indicate whether the statement did or did not reflect their views about lying. This question, like the definition question, included a reminder that would pop up if the respondent tried to move to the next question without evaluating each of the statements. Presentation of the statements was randomized to mitigate order related response bias. I will refer to the statements in numerical order solely for convenience purposes.

The first statement— “it is never OK to tell a lie" — reflects the absolute prohibition on telling a lie reflected in the work by Augustine of Hippo and Immanuel Kant.

The second statement_ - "it is only OK to tell a lie if it will benefit the person to whom the lie is told" - was designed to capture both utilitarian considerations and the role of the white lie. It also cross-walks with the subsequent case about the cancer patient (see page 72 for a description of the hypothetical cases used in the survey).

The third statement— “it is OK to tell a lie if it will help more people than it will harm"was designed to capture the extent to which utilitarian considerations are at play in the thinking of congressional staff. This question cross walks with the cases about the legislative negotiations.

The fourth statement — "it is OK to lie in situations where others are lying to you"-was designed to capture the extent to which considerations about "defensive lying" play a role in staff practice. As noted earlier, the survey also captured contextual information about 
how frequently the respondent believed he was lied to in the previous 24 hours and provided cases in which the respondent was asked how she believed another staff member would handle the situation if their roles were reversed.

The fifth statement—“' “It is OK to lie to someone you don't believe has a right to the information they seek"- is designed to capture the extent to which staff believe there are situations (following Grotius) in which individuals do not have the right to the truth. The respondent is also provided a case (the classification case) later in the survey that asks him or her how he or she would respond to a constituent who is not cleared for but wants access to classified information.

The sixth statement_ - "it is OK to lie to someone who intends to use the information in an unethical or illegal way"-provides a way to test the consistency of the responses offered by respondents who indicated that they believed in an absolute prohibition on lying.

The seventh statement - "it is OK to lie to advance a good or important legislative, political, or social cause"- captures respondents views about choices with which staff are frequently confronted. This statement also cross-walks with several of the legislative cases provided at the end of the survey.

The eighth statement - “it is OK to lie to protect a friend, family member, or someone important to you"-provides respondents with one of the standard objections to the absolute prohibition on lying (case of the murderer) while introducing the idea of relationship. This statement can be cross-walked with the case involving the cancer 
patient and the case involving the friend who is viewing pornographic material on office computers.

The ninth statement_- "it is OK to lie to strengthen you negotiating position during legislative or regulatory negotiations"- can be cross-walked with the idea that there are situations in which the truth is not expected as well as the cases involving legislative negotiations. This also allows respondents to indicate whether they agree with Strudler or Carson that there are situations in which "defensive" lies may be justified.

The tenth statement- "it is OK to lie during political or legislative campaigns when the other candidate or advocate is lying about you or your position"— provides an opportunity to assess whether respondents believe that the behavior of other parties affects their view of whether or when a lie is justified. Similar to the ninth statement, this provides an opportunity for respondents to indicate whether they believe that the truth is not expected in political or legislative campaigns or that this is a situation in which "defensive" lies are justified.

\section{Section V. Cases}

Section V consists of eight cases drawn from situations in my own staff experience and field tested with current and former staff. The cases were designed to remove some of the abstraction that existed within the previous sections of the survey. Each case sets up a situation that can be cross walked with earlier questions about the definition of a lie, the frequency with which one lied, and justifications for lying. Each case presents respondents with a simple "yes" or "no" response option while permitting them to choose 
"other" and offer an alternate response. Respondents were then asked the reason that for their response. The options included both definitional (e.g., it was not a lie) and justification options (e.g., you believe your boss has a right to know).

The introduction to this section used permissive language in order to try to mitigate the impact of social desirability bias. In addition, assuming that there would be at least some social desirability bias to avoid reporting lying, the first case was developed to present respondents with a non-threatening situation in which field testing suggested that the social pressure to lie or not lie would be ambiguous.

In addition, the cases were carefully drawn so that at least one case would fall within the experience of each of the respondents. Forty percent of the House staff and $34 \%$ of the Senate staff in the sample worked in district offices. These staff are more likely to have experiences with constituents, the press, campaigns, and grant and contract advocacy. They are much less likely to have direct experience with the legislative process.

The first case, herein referred to as the Cancer Case, presented the respondent with a very sick colleague who appears to the respondent to be getting progressively weaker. She comes to the office to take her mind off of treatment and tells the respondent that she thinks she looks better and asks the respondent if he or she agrees. The case was constructed to cross walk with previous questions about definitions of a lie and with justifications for lying if one was deemed to have been told. 
The second case, herein referred to as the Pornography Case, presented the respondent with a colleague downloading pornographic material onto an office computer. The colleague promises to stop and the respondent promises not to tell. The next day the respondent is asked by his or her member/senator whether the respondent has seen anyone in the office using illicit sites. As with the prior case, this was constructed to permit cross-walk between questions about the definition and justification for telling a lie. In addition, the case was drawn to elicit from respondents the role, if any, of conflicting rules, obligations, or rights in their response to the case as presented.

The third case, herein referred to as the Natural Disaster Case, presented respondents with a contract advocacy scenario that has political overtones. The respondent is portrayed as having tried unsuccessfully to get his or her boss to make a call to an agency on behalf of a constituent business. A contract unexpectedly is awarded and during the press calls, the respondent is asked whether his or her member/senator personally called the administrator to advocate for the grant. The scenario is presented in the context that newspapers have challenged the member/senator's effectiveness and that a local official is considering a challenge. The case was drawn to permit cross walks with the definitions and justifications questions and add the context of a political campaign and the idea that the answer might be used against the member/senator.

The fourth case, herein referred to as the Conference Committee Case, presented respondents with a scenario in which legislative negotiations are deadlocked. The respondent learns that the other side will recede if they believe the respondent's 
leadership will defeat the bill over the provision (which the respondent does not believe to be true).

The case was drawn to elicit respondents' attitudes toward lying in the context of negotiation, whether they believe it justified to lie to strengthen their negotiating position, as well as situations in which they may avail themselves of the uncertainty of their knowledge. After indicating how they would respond, respondents were then asked to reverse roles and predict how the other staff member would respond. This reversal provides context regarding staff expectations of the prevalence of lying in these situations as well as some indication of the strength of the social desirability bias.

The fifth case, herein referred to as the Amendment Case, presented respondents with a scenario in which they were working to secure support for a surprise amendment that would result in the defeat of a bill they believe would result in the loss of millions of lives. The bill sponsor becomes suspicious and asks the respondent whether his or her boss plans to offer an amendment. The case was designed to emphasize the consequences of the scenario in a way that neutrally mirrors attitudes toward the most controversial issues Congress has recently taken up (e.g., abortion, war) and to elicit the role that consequences play in respondents' assessment of the case. This case was also followed by the role reversal question in which respondents were asked what they believed the bill sponsor would say if their roles were reversed.

The sixth case, herein referred to as the Classified Case, presented respondents with a scenario in which they had been read into a classified new research and development 
program that will yield many contract opportunities. A constituent business leader who has not been cleared asks the respondent whether the R\&D program exists and whether he or she has been read in. This case was designed to present the respondents with a potential conflict of obligations as well as a scenario in which respondents might draw upon the constituent's right to the truth.

The seventh case, herein referred to as the Presidential Debate, was derived from Carson's work Lying and Deception. In his discussion of "bullshit," he provides the case of a presidential candidate who is asked whether he/she will make opposition to abortion and Roe v. Wade a requirement for anyone he/she will nominate for the Supreme Court. The case was modified to ask whether the candidate would make "support of your policy" on Roe v. Wade a requirement for anyone he/she will nominate. For Carson, this constitutes an example of "evasion by means of bullshit." 89 The case was designed to test whether Carson's assessment is shared by congressional staff as well as provide an opportunity for the respondent to assess whether someone else's statement comported with the respondent's definition of a lie.

The eighth and final case, herein referred to as the Bill Promise Case, depicts a scenario in which staff member A offers to immediately release and pass a bill in exchange for a promise from the respondent to move a bill that staff member A will be bringing forward in a few months. The respondent was told that his or her leadership opposes the proposed bill and will not allow it to come to the floor. The respondent was then asked whether she would indicate that she will pass the bill in exchange for getting his bill enacted.

${ }^{89}$ Carson, Lying and Deception: Theory and Practice. 
The respondent was also asked how the other staff member would respond if their roles were reversed.

\section{Delimitations and Limitations of the Study}

As discussed in the methodology section, review of the research literature did not reveal any prior examples of research using a random probability sample of congressional staff. Personal experience suggested that staff would be reluctant to participate in research, and numerous steps were taken to establish the non-partisan and academic nature of the research. As a result, it was difficult to predict response rates. In order to maximize response rates, this research used the Tailored Design Method. Tailored Design Method has been known to generate response rates as high as $80 \%$ in the general population. Ideally, the Tailored Design Method uses a mixed mode design that includes letters, emails, postcards, and telephone calls.

Because this research project was self-funded, I limited the size of my sample to 2,000 House and 2,000 Senate staff. Each subject received a letter introducing the project, an email invite with the survey attached, a follow-up postcard, and email reminders. Cost prevented the inclusion of a telephone component. Every senior Stennis Fellow for whom contact information could be obtained was invited to participate in the research and received the same communication stream with the addition of a letter from the Stennis Center president introducing the project and encouraging Fellows to participate. One hundred seventeen (45.5\%) members of the Stennis sample consented to participate in the survey and 92 (35.8\%) completed all of the questions. One hundred sixty-eight $(8.5 \%)$ members of the House sample consented to participate in the survey and 110 
$(5.5 \%)$ completed all of the questions. Similarly, $166(8.3 \%)$ of the Senate sample consented to participate in the survey and 108 (5.4\%) completed all of the questions. This response rate was comparable to the $5.3 \%$ response rate generated by the ORI Study conducted on behalf of George Washington University, which was published after this survey had been launched.

Although these response rates appear equal to, and to some extent higher than, those experienced by other surveys, several factors depressed the response rate:

1. Snowden revelations. As mentioned earlier, some staff would not participate due to the revelation by Edward Snowden that National Security Agency's collection of domestic internet data was more expansive than previously understood.

2. Government Mail Screening. As part of the post 9/11 security changes, all physical mail going to the House or Senate is screened offsite and irradiated. This screening process can take several days or weeks, and there was no clearly consistent pattern mail delivery. Introductory letters were mailed in large batches, and letters within the same batch varied in delivery date by days and in at least one case two to three weeks. The same was true with the postcards. This made it difficult to choreograph the timing of the communications. In addition, the irradiation process discolored the postcards and envelopes in a way that diminished their visual appeal. 
3. Office policies. Some offices established policies that did not permit staff to participate in surveys. As noted earlier, these policies were honored by some staff and not by others.

4. Response rates. We now know that response rates for surveys of congressional staff will have an upper boundary of around $5.3 \%$. This suggests that to obtain an independent margin of error of $5 \%$ with a $95 \%$ confidence interval for each body of Congress, one would need to plan to use a sample of 6,796 House staff. The theoretically required sample size for the Senate would be larger than the frame from which the sample was being drawn. Unless response rates can be increased, it will be difficult to gain a clear picture of the Senate using standard statistical techniques.

Institutional Review Board

The project and methodology were reviewed and approved by the University of Virginia Institutional Review Board for the Social Sciences and the Humanities. 


\section{Chapter IV. Descriptives}

As indicated in the previous section, response rates for the surveys varied by population and by question. It is common within polling reports to report a "margin of error" for the entire survey. The margin of error is a function of sample size, the response distribution (50\% responded "yes"), and the confidence level the researcher is willing to accept $(90 \%$, $95 \%$, or $99 \%$ ). As a result, individual variables will generally have individual margins of error that differ from the reported level for the entire survey. I will report separately for each variable.

\section{Design Weights}

All variables in this section were calculated and reported three ways. I report separate responses for House and Senate staff. In addition, in some instances, I report weighted and unweighted combined responses for all staff. This permits analysis using a larger number of responses and allows for greater confidence levels in some statistical analysis. Because Senate staff were oversampled (by design) to obtain sufficient responses, the responses for House and Senate staff were weighted when analyzing at the "all staff level." Weighting has the effect, however, of artificially inflating the total number of cases. This, in turn, negatively affects analysis of the relationship between variables and increases the likelihood that a statistic will be inappropriately deemed significant. One method for addressing this is to "normalize" the weights so that the total number of weighted cases equals the total number of actual cases. 
The responses for "all staff" have been weighted to account for the oversampling of the Senate and then normalized to restore the $\mathrm{N}$ to the actual number of respondents. The following method was used:

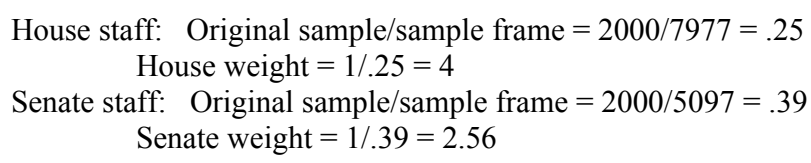

The weights were then normalized by calculating the mean of all of the weights (3.294) and dividing each individual weight by the mean of all weights.

House: $4 / 3.294=1.21$

Senate: $2.6 / 3.294=.79$

The General Social Survey is a household survey. As a result, not all adults have an equal probability of being surveyed. Adults in households with few adults are more likely to be surveyed than adults in households with many adults. The sample was weighted using the variable "adults." Each weight was then divided by the mean (1.943) of all weights. The actual (unweighted) number of respondents was 4901. Applying the weight increased the number of respondents to 9523. Normalizing reduced the number of weighted respondents to 4901. Normalized data is identified as all staff-weighted.

\section{Response Weights}

It is common to weight survey responses to compensate for differences in response rates among various segments of the survey population. For example, when conducting a general population survey, gender and age are often correlated with different response 
rates. ${ }^{90}$ In instances when the researcher has accurate information about the gender and age of the sample, the respondents, and the sample frame, it is possible to calculate weights that equalize the proportion of these segments in the responses and in the sample frame. The decision to use these weights has theoretical implications that must be carefully thought through, analyzed and defended. For example, different weight schemes make different assumptions about the impact of segment characteristics on responses.

This survey did not ask respondents for their gender or party affiliation. These questions were excluded from the survey to stimulate higher response rates. Early feedback during the field testing suggested that some staff might be reluctant to participate on the grounds that certain combinations of gender, party, and chamber would permit identification of specific individuals, or out of fear that the research would be used for partisan purposes. The House and Senate staff lists procured from LegiStorm, however, included gender and party. This data was linked to the unique survey link that was provided to each member of the sample. As a result, gender and party data were available for each respondent who completed the survey using the unique survey link he or she was provided. This data was not available for the Stennis Center participants.

The Snowden incident required the creation of an additional survey portal that did not capture either gender or party. Sixteen percent (58) of the House and Senate survey respondents used this portal. While it is instructive to look at the gender and party of the

${ }^{90}$ Nojin Kwak and Barry Radler, "A Comparison between Mail and Web Surveys: Response Pattern, Respondent Profile, and Data Quality," Journal of Official Statistics 18, no. 2 (2002).

82 I P a g e 
respondents for whom data are available, it is not possible to determine whether the respondents vary meaningfully from either the sample or the sample frame by party or gender. As a result, I did not weight the data by any of the respondent characteristics.

\section{Respondent Characteristics}

Demographic data was available for $84.9 \%$ of the House respondents and $83.1 \%$ of the Senate respondents. Analysis of the respondent demographics indicates that they mirror the sample closely, with three exceptions. One, committee staff and leadership staff are slightly overrepresented in the sample. This is likely due to the fact that a number of the Stennis Fellows were also in the House and Senate samples. Two, response rates for Stennis Fellows was higher than for the House or Senate samples. The third exception was the proportion of staff working in DC offices versus staff working in state or district offices. This may represent the impact of the web respondents for whom there is no demographic information. While there is no way to definitively identify the location of web respondents, correspondence I had with respondents regarding the web survey link and subsequent IP address mapping strongly suggests that many, if not most, of the web respondents were based out of D.C. This was particularly true of the House sample. 

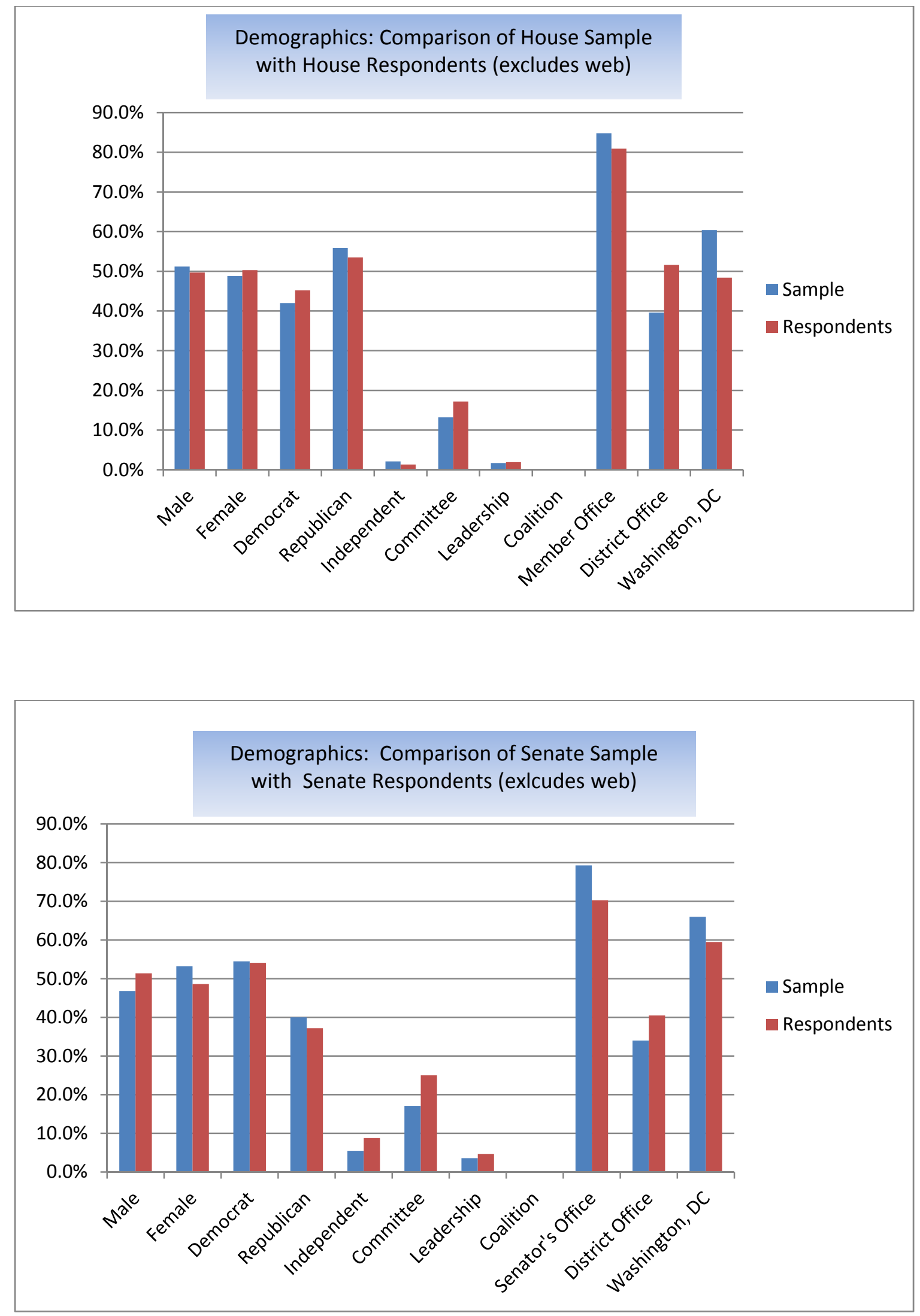
Table

Demographics: Comparison of Sample with Known Respondent Characteristics (excludes web respondents)

\begin{tabular}{lcccc}
\hline \hline House & $\begin{array}{c}\text { Sample } \\
\text { Frequency }\end{array}$ & $\begin{array}{c}\text { Sample } \\
\text { Percent }\end{array}$ & $\begin{array}{c}\text { Respondent } \\
\text { Frequency }\end{array}$ & $\begin{array}{c}\text { Respondent } \\
\text { Percent }\end{array}$ \\
\hline Male & 969 & $51.2 \%$ & 78 & $49.7 \%$ \\
Female & 1016 & $48.8 \%$ & 79 & $50.3 \%$ \\
Democrat & 833 & $42.0 \%$ & 71 & $45.2 \%$ \\
Republican & 1110 & $55.9 \%$ & 84 & $53.5 \%$ \\
Independent & 42 & $2.1 \%$ & 2 & $1.3 \%$ \\
Committee & 263 & $13.2 \%$ & 27 & $17.2 \%$ \\
Leadership & 34 & $1.7 \%$ & 3 & $1.9 \%$ \\
Coalition & 4 & $0.2 \%$ & 0 & $0.0 \%$ \\
Member Office & 1684 & $84.8 \%$ & 127 & $80.9 \%$ \\
District Office & 786 & $39.6 \%$ & 81 & $51.6 \%$ \\
Washington, DC & 1199 & $60.4 \%$ & 76 & $48.4 \%$ \\
\hline \hline & & & & \\
\hline \hline Senate & & & & \\
\hline Male & Sample & Sample & Respondent & Respondent \\
Female & 933 & $46.8 \%$ & 76 & $51.4 \%$ \\
Democrat & 1061 & $53.2 \%$ & 72 & $48.6 \%$ \\
Republican & 1087 & $54.5 \%$ & 80 & $54.1 \%$ \\
Independent & 797 & $40.0 \%$ & 55 & $37.2 \%$ \\
Committee & 110 & $5.5 \%$ & 13 & $8.8 \%$ \\
Leadership & 340 & $17.1 \%$ & 37 & $25.0 \%$ \\
Coalition & 71 & $3.6 \%$ & 7 & $4.7 \%$ \\
Senator's Office & 1582 & $0.1 \%$ & 0 & $0.0 \%$ \\
District Office & $79.3 \%$ & 104 & $70.3 \%$ \\
Washington, DC & 1316 & $66.0 \%$ & 88 & $40.5 \%$ \\
\hline \hline
\end{tabular}

Demographics: Gender of Respondents Including Web

\begin{tabular}{llcccc}
\hline \hline \multirow{2}{*}{ Chamber } & & & & & Cumulative \\
\hline House & Web & 28 & 15.1 & 15.1 & Percent \\
& Female & 79 & 42.7 & 42.7 & 15.1 \\
& Male & 78 & 42.2 & 42.2 & 57.8 \\
& Total & 185 & 100.0 & 100.0 & 100.0 \\
\hline \multirow{2}{*}{ Senate } & Web & 30 & 16.9 & 16.9 & 16.9 \\
& Female & 72 & 40.4 & 40.4 & 57.3 \\
& Male & 76 & 42.7 & 42.7 & 100.0
\end{tabular}




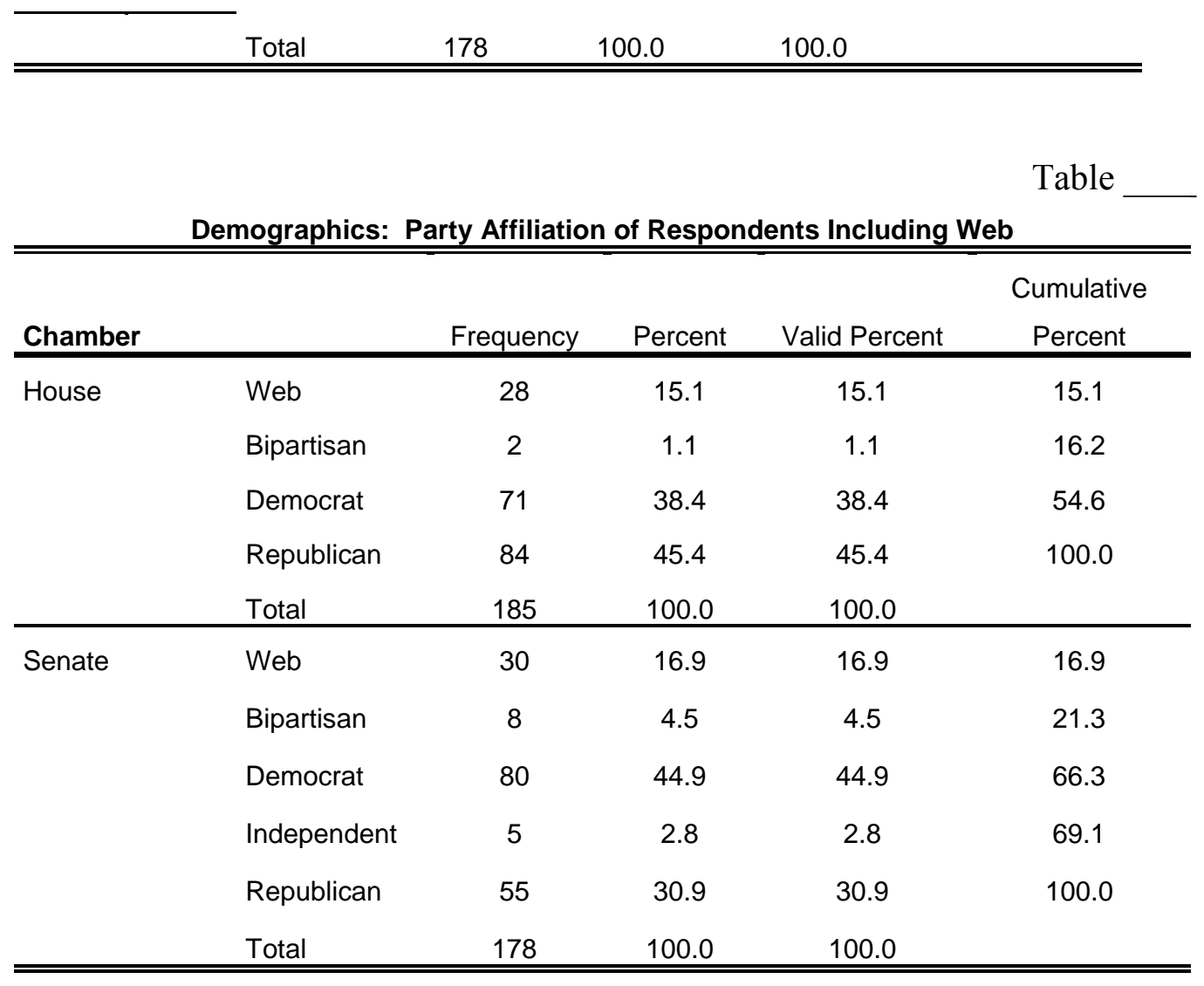

Table

Demographics: Office Including Web

\begin{tabular}{llcccc}
\hline \hline \multirow{2}{*}{ Chamber } & & & & & \multicolumn{2}{c}{$\begin{array}{c}\text { Cumulative } \\
\text { Pouse }\end{array}$} & Frequency & Percent & Valid Percent & Percent \\
& Committee & 28 & 15.1 & 15.1 & 15.1 \\
& Leadership & 3 & 14.6 & 14.6 & 29.7 \\
& Member & 127 & 1.6 & 1.6 & 31.4 \\
& Total & 185 & 100.0 & 100.0 & 100.0 \\
\hline \multirow{2}{*}{ Senate } & Web & 30 & 16.9 & 16.9 & 16.9 \\
& Committee & 37 & 20.8 & 20.8 & 37.6 \\
& Leadership & 7 & 3.9 & 3.9 & 41.6 \\
& Senator & 104 & 58.4 & 58.4 & 100.0 \\
& Total & 178 & 100.0 & 100.0 & \\
\hline \hline
\end{tabular}




\section{Chapter V. Religiosity Indicators}

Respondents were asked two questions about their religious preference or affiliation using wording adopted from the 2010 GSS and 15 questions taken from religiosity scales. 169 House staff and 168 Senate staff answered the question. Descriptive statistics will be provided in separate sections of this chapter for House staff, Senate staff, all staffweighted as well as total religiosity scores for party and gender.

As will be explored in greater detail in this chapter, two significant trends emerged. House staff reported higher mean and median religiosity scores than did Senate staff. Closer look at these numbers, at least where party was available, revealed that these differences could largely be explained by the differing party makeup of each chamber. Republican staff (the majority of staff in the House) reported substantially higher religiosity scores than Democratic staff (the majority of staff in the Senate). There was a small but not statistically significant interaction between party and chamber with regard to religiosity. 


\section{Estimated Marginal Means of Religiosity Scale Totals}

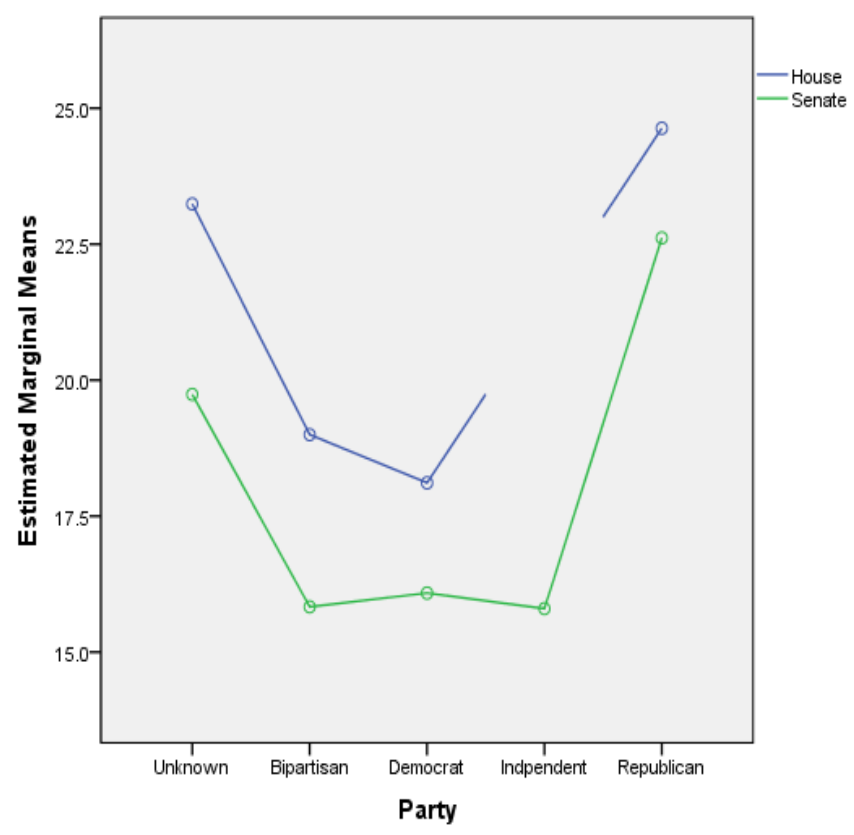

Non-estimable means are not plotted

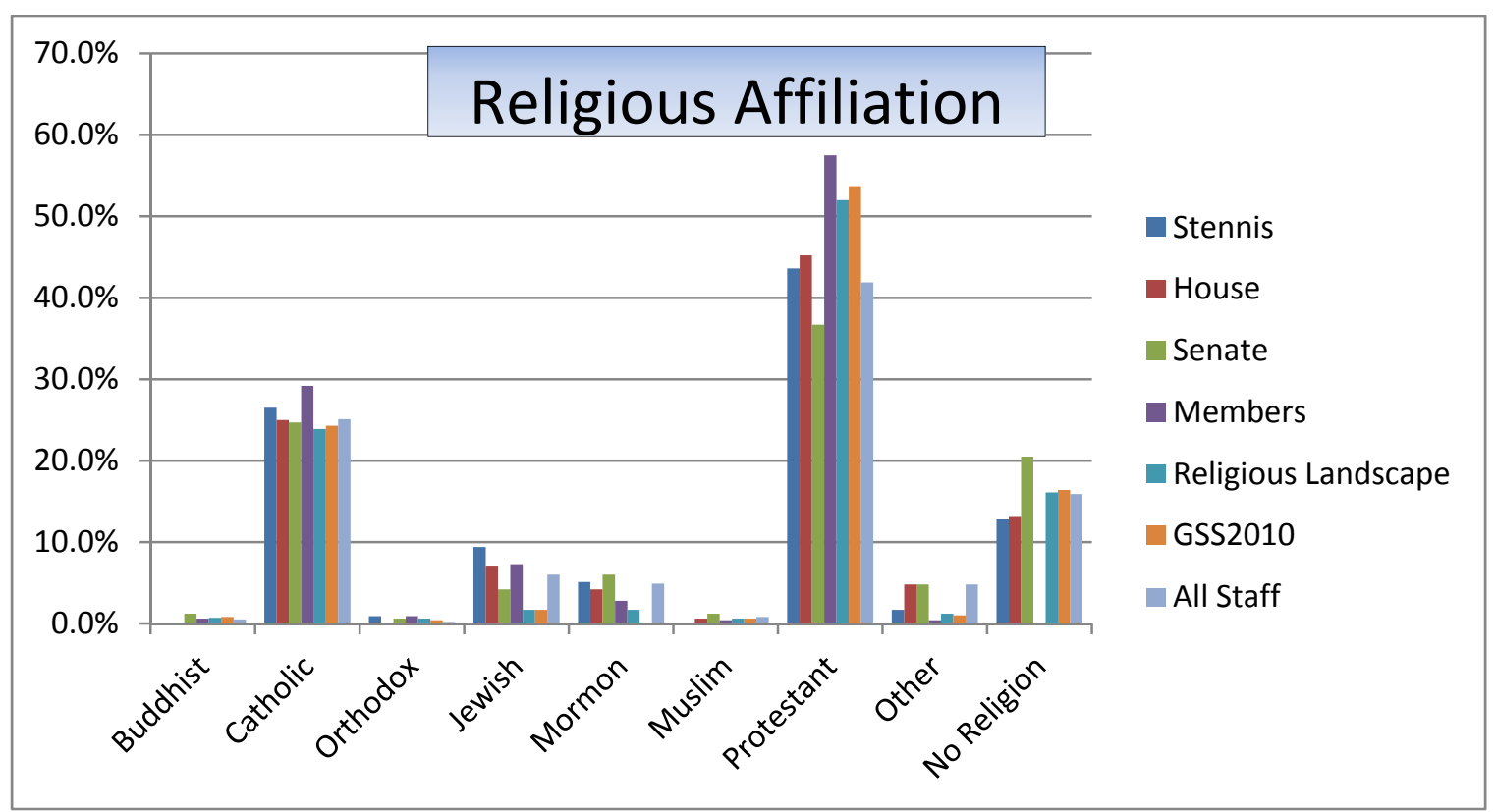

Confidence intervals were calculated for each of the variable categories of the House and Senate samples. ${ }^{91}$ The widest confidence intervals were $\pm 7.5 \%$ for the House sample and

${ }^{91}$ Confidence intervals were calculated using the STATPAC statistics calculator. 
$\pm 7.3 \%$ for the Senate sample. The widest confidence interval for Stennis Fellows was $\pm 6.7 \%$. The widest confidence interval for the all staff-weighted sample was $\pm 5.24 \%$. Religious preference "other" responses in the staff and Stennis surveys were recoded where appropriate to populate the correct category (e.g., Methodist was recoded as Protestant and then Methodist). For comparability, the GSS categories "Christian" and “Inter-/non-denominational” were recoded as Protestant. Combined responses (e.g., both Jewish and Catholic) remained "other."

The GSS code book assigns respondents who identify with the Church of Latter Day Saints as Protestant; however, the GSS2010 survey data did not include any respondents coded as members of the Mormon church or its variants. ${ }^{92}$ In contrast, the Pew Religious Landscape Survey suggests that Mormons constitute $1.7 \%$ of the adult population.

The religious preferences of the staff largely mirror the general adult population and the members for whom they work. The percentages of staff who reported that they were Buddhist, Catholic and Orthodox were consistent with a hypothesis that House and Senate staff reflect the general population.

\section{Catholic}

Members of Congress (29.2\%) identify themselves as being Catholic more frequently than do GSS2010 adults (24.3\%), House staff (25.4\%), Senate staff (24.6\%), or all staffweighted (25.1\%). The two-sample, two-tailed t-statistic was significant at the .05 level for the difference in proportions between members of Congress and the GSS2010 adult

\footnotetext{
${ }^{92}$ See for example, The Association of Religion Data Archives, "General Social Survey Cross-Section and Panel Combined," http://www.thearda.com/Archive/Files/Descriptions/GSS10PAN.asp.
} 
population, $t(5434)=2.49, p=.013$. Catholics have slightly but statistically significantly higher representation among members of Congress than they do in the general population.

The two-sample, two-tailed t-statistic was not significant at the .05 level for the difference in proportions between Members of Congress and Senate staff (the staff/member pairing that enjoyed the widest spread in percentage), $t(700)=1.155$, $p=.248$. The null hypothesis that there is no difference in proportions between the two groups cannot be rejected. Catholics appear to be represented among staff at rates comparable to the general population. The possibility remains, however, that the difference in representation between staff and members of Congress is a result of sampling.

Jewish

Members of Congress (7.3\%) identify as being Jewish at greater rates than the general population (1.7\%). This pattern was repeated by the Stennis Fellows (9.4\%), House staff (7.1\%), all staff (6\%) and Senate staff (4.2\%). The two-sample, two-tailed t-statistics were significant at the .05 level for the difference in proportions between Stennis Fellows and GSS2010 adults, $t(5016)=6.04, p=.000$; for the difference in proportions between House staff and GSS2010 adults, $t(5068)=5.06, p=.000$; for the difference in proportions between all staff and GSS2010 adults, $t(5235)=5.47, p=.000$; and for the difference in proportions between Senate staff and GSS2010 adults, $t(5066)=2.39, p=.016$. 


\section{Mormon}

Stennis Fellows (5.1\%), House staff (4.2\%) Senate staff (6\%), members of Congress $(2.8 \%)$ and all staff-weighted staff (4.9\%) reported their religious preference as Mormon at greater rates than GSS2010 adults (0\%). As mentioned previously, the Pew Religious Landscape Survey reported that $1.7 \%$ of U.S. adults reported their religious preference as Mormon. The absence of access to the raw data in the Pew study prevents testing the statistical significance of the differences between staff and adults in the Pew study. The two-sample, two-tailed t-statistic for the difference in proportions was significant at the .05 level for the differences between Stennis Fellows and GSS2010 adults, $t(5016)=15.78, p=.000$; House staff and GSS2010 adults, $t(5068)=14.11, p=.000$; Senate staff and GSS2010 adults, $t(5066)=17.18, p=.000$; and all staff-weighted, $t(5235)=15.74, p=.000$. One possible explanation for this higher representation of Mormons in Congress and among staff may be the weighted representation of states, particularly in the Senate.

\section{Protestant}

Members of Congress (57.5\%) identify themselves as being Protestant slightly more frequently than do GSS2010 adults (53.7\%). The two-sample, two-tailed t-statistic was not significant at the .05 level for the difference in proportions, $t(5434)=1.68, p=.095$. The null hypothesis that there is no difference in proportions cannot be rejected. In contrast, congressional staff identify themselves as being Protestant less frequently than do members of Congress or the GSS2010 adults. $45 \%$ of House staff, $37.5 \%$ of Senate staff , $41.9 \%$ of all staff-weighted, and $43.6 \%$ of Stennis Fellows identify themselves as being Protestant. The two-sample, two-tailed t-statistic for the difference 
between proportions was significant at the .05 level for the differences between House staff and members of Congress, $t(702)=2.85, p=.005$; Senate staff and members of Congress, $t(700)=4.61, p=.000 ;$ all staff-weighted and members of Congress, $t(869)=4.48, p=.000$; House staff and GSS2010 adults, $t(5068)=2.23, p=.026$; Senate staff and GSS2010 adults, $t(5066)=4.23, p=.000$; and all staff-weighted and GSS2010 adults, $t(5235)=4.19, p=.000$.

\section{No Religion}

The frequency with which staff reported "no religion" was reflective of adults in the GSS2010 survey but posed their greatest divergence with Members of Congress. 16.1\% and $16.4 \%$ of adults responded "no religion" in the Pew Religious Landscape Survey and the 2010 GSS. Similarly, $12.8 \%$ of Stennis respondents indicated "no religion," $13.1 \%$ of House staff indicated "no religion," and $20.5 \%$ of Senate staff respondents reported no religion. A two-sample, two-tailed t-test between proportions was conducted to determine if there was a significant difference between the House and Senate or between the Senate and the GSS adult population. The t-statistic was not significant at the .05 level for either pairing, $t(334)=1.82, p=.07$ and $t(5066)=1.37, p=.17$. The null hypothesis that there was no difference in proportions between House and Senate staff and between Senate staff and the GSS adults cannot be rejected.

In contrast, the Pew Research Religion \& Public Life Project reported that no congressman or senator indicated that he or she did not have a religious preference. ${ }^{93}$ The two-sample, two-tailed t-statistic was significant at the .05 level for the difference

93 "Faith on the Hill: The Religious Composition of the 112th Congress". 
between senate staff and members of Congress, $t(700)=10.7, p=.000$, for the difference between Stennis fellows and members of Congress, $t(650)=8.37, p=.000$; for the difference between House staff and members of Congress, $t(702)=8.47, p=.000$; and for the difference between all staff and members of Congress, $t(869)=9.56, p=.000$. The two-sample, two-tailed t-statistic was also significant at the .05 level for the difference between members of Congress and GSS2010 adults, $t(5434)=10.14, p=.000$.

This data suggests that members of Congress are more likely to affiliate with a religion or religious group than either the general population or their staff. There are at least three possible explanations that could be explored through future research.

In some communities, religious groups form important social communities from which community and political leaders emerge. Active membership in these religious groups is sometimes a prerequisite to building the social and political connections within the broader community that are necessary to attain elected office.

It is also possible that the political process itself, reflecting the perceived expectations of voters, strongly incents Members of Congress to identify with a religious community as a demonstration of their faith without regard to the strength of the affiliation. An example of this might be found in the 2004 presidential candidacy of Howard Dean. Governor Dean initially declined to discuss his religious affiliation or beliefs in public. Pressure 
from the media and from campaign supporters in "Bible belt states" influenced the extent to which he was willing to discuss his religious affiliation and beliefs. ${ }^{94} 95$

Thirdly, and perhaps less charitably, the difference could simply reflect differences in methodologies between this study and the Pew study. Participants in the staff and general population surveys were provided confidentiality and the confidence that their responses would not have consequences. Members of the House and Senate knew that their responses would be made public. It is possible that an anonymous survey of members of Congress would yield results similar to those generated by this study or by the GSS and Pew adult studies.

What is your religious preference? Is it:

\begin{tabular}{|c|c|c|c|c|c|}
\hline \multicolumn{2}{|l|}{ Chamber } & \multirow{2}{*}{ Frequency } & \multirow{2}{*}{ Percent } & \multirow{2}{*}{$\frac{\text { Valid Percent }}{25.4}$} & \multirow{2}{*}{$\begin{array}{c}\text { Cumulative } \\
\text { Percent } \\
25.4\end{array}$} \\
\hline \multirow[t]{8}{*}{ House } & Catholic & & & & \\
\hline & Jewish & 12 & 6.5 & 7.1 & 32.5 \\
\hline & Latter Day Saints & 7 & 3.8 & 4.1 & 36.7 \\
\hline & Muslim & 1 & .5 & .6 & 37.3 \\
\hline & Protestant & 76 & 41.1 & 45.0 & 82.2 \\
\hline & Other & 8 & 4.3 & 4.7 & 87.0 \\
\hline & No religion & 22 & 11.9 & 13.0 & 100.0 \\
\hline & Total & 169 & 91.4 & 100.0 & \\
\hline Missing & System & 16 & 8.6 & & \\
\hline \multicolumn{2}{|l|}{ Total } & 185 & 100.0 & & \\
\hline \multirow[t]{2}{*}{ Senate } & Buddhist & 2 & 1.1 & 1.2 & 1.2 \\
\hline & Catholic & 41 & 23.0 & 24.6 & 25.7 \\
\hline \multicolumn{6}{|c|}{$\begin{array}{l}95 \text { Dean's description of his departure from the Episcopal Church surprised both members of the church and } \\
\text { leaders of the diocese who did not universally recollect events as described in the interview. Conversation } \\
\text { with Tom Little, Chancellor of the Diocese of Vermont, } 2004 \text {. }\end{array}$} \\
\hline
\end{tabular}




\begin{tabular}{|c|c|c|c|c|c|}
\hline & Eastern Orthodox & 1 & .6 & .6 & 26.3 \\
\hline & Jewish & 7 & 3.9 & 4.2 & 30.5 \\
\hline & Latter Day Saints & 10 & 5.6 & 6.0 & 36.5 \\
\hline & Muslim & 2 & 1.1 & 1.2 & 37.7 \\
\hline & Protestant & 62 & 34.8 & 37.1 & 74.9 \\
\hline & Other & 8 & 4.5 & 4.8 & 79.6 \\
\hline & No religion & 34 & 19.1 & 20.4 & 100.0 \\
\hline & Total & 167 & 93.8 & 100.0 & \\
\hline Missing & System & 11 & 6.2 & & \\
\hline Total & & 178 & 100.0 & & \\
\hline
\end{tabular}

What is your religious preference? Is it:

\begin{tabular}{llcccc}
\hline \hline \multirow{2}{*}{ Stennis Fellows } & & & & Cumulative \\
\hline \multirow{2}{*}{ Valid } & Catholic & Frequency & Percent & Valid Percent & Percent \\
& Eastern Orthodox & 1 & 25.4 & 26.5 & 26.5 \\
& Jewish & 11 & .8 & .9 & 27.4 \\
& Latter Day Saints & 6 & 9.0 & 9.4 & 36.8 \\
& Protestant & 51 & 4.9 & 5.1 & 41.9 \\
& Other & 2 & 1.8 & 43.6 & 85.5 \\
& No religion & 15 & 12.3 & 1.7 & 87.2 \\
& Total & 117 & 95.9 & 100.0 \\
Missing & System & 5 & 4.1 & & \\
\hline \hline
\end{tabular}

What is your religious preference?

\begin{tabular}{lcccc}
\hline \hline General Social Survey2010 & & & & Cumulative \\
& Frequency & Percent & Valid Percent & Percent \\
\hline Protestant & 2426 & 49.5 & 49.5 & 49.5 \\
Catholic & 1190 & 24.3 & 24.3 & 73.8 \\
Jewish & 84 & 1.7 & 1.7 & 75.5 \\
None & 805 & 16.4 & 16.4 & 91.9 \\
Other (specify) & 50 & 1.0 & 1.0 & 93.0 \\
Buddhism & 40 & .8 & .8 & 93.8 \\
Hinduism & 16 & .3 & .3 & 94.1
\end{tabular}




\begin{tabular}{lcccc}
\hline Other Eastern religion & 4 & .1 & .1 & 94.2 \\
Muslim/lslam & 28 & .6 & .6 & 94.7 \\
Orthodox Christian & 21 & .4 & .4 & 95.2 \\
Christian & 182 & 3.7 & 3.7 & 98.9 \\
Native American & 2 & .0 & .0 & 98.9 \\
Inter-/non-denominational & 23 & .5 & .5 & 99.4 \\
Don't know & 5 & .1 & .1 & 99.5 \\
No answer & 25 & .5 & .5 & 100.0 \\
Total & 4901 & 100.0 & 100.0 & \\
\hline \hline
\end{tabular}

What is your religious preference? Is it:

\begin{tabular}{llcccc}
\hline \hline \multirow{2}{*}{ All Staff-weighted } & & & & Cumulative \\
Valid & Buddhist & 2 & .4 & .5 & .5 \\
& Catholic & 84 & 23.2 & 25.1 & 25.6 \\
& Eastern Orthodox & 1 & .2 & .2 & 25.8 \\
& Jewish & 20 & 5.5 & 6.0 & 31.8 \\
& Latter Day Saints & 16 & 4.5 & 4.9 & 36.6 \\
& Muslim & 3 & .8 & .8 & 37.5 \\
& Protestant & 141 & 38.7 & 41.9 & 79.3 \\
& Other & 16 & 4.4 & 4.8 & 84.1 \\
& No religion & 53 & 14.7 & 15.9 & 100.0 \\
& Total & 336 & 92.3 & 100.0 & \\
Missing & System & 28 & 7.7 & & \\
\hline \hline & & 364 & 100.0 & & \\
\hline
\end{tabular}




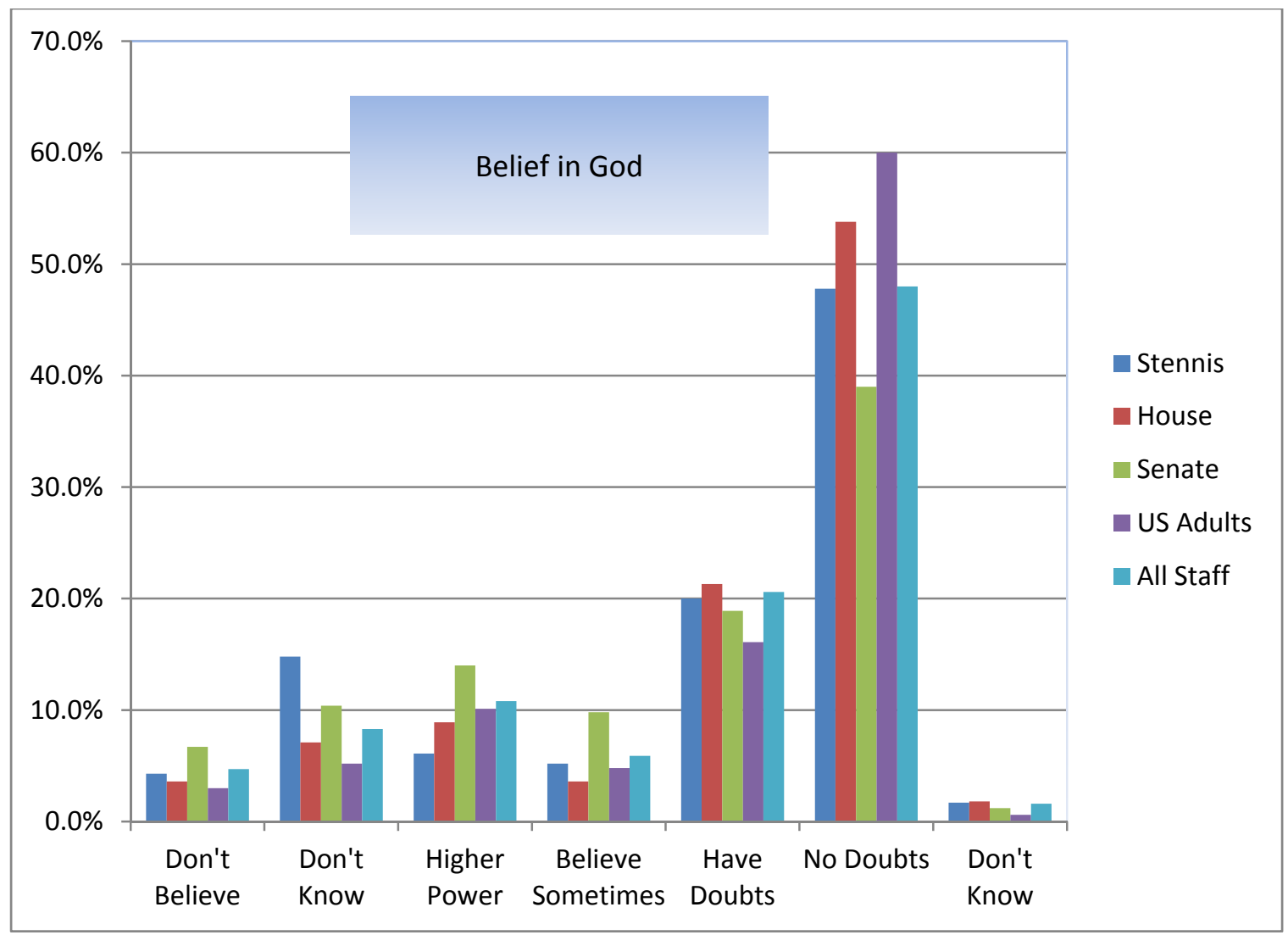

Respondents were asked "which of the following statements comes closest to expressing what you believe about God?" and were presented with seven response options: 1) I don't believe in God; 2) I don't know whether there is a God and I don't believe there is any way to find out; 3) I don't believe in a personal God but do believe in a higher power of some kind; 4) I find myself believing in God some of the time, but not others; 5) While I have doubts, I feel that I do believe in God; 6) I know God really exists and I have no doubts about it; 7) and other. ${ }^{96}$

Confidence intervals were calculated for each of the variable categories of the House and Senate samples. The widest confidence intervals were $\pm 7.5 \%$ for the House sample and

${ }^{96}$ The question appeared on the 2010 General Social Services Survey (GSS God). 
$\pm 7.5 \%$ for the Senate sample. The widest confidence interval for Stennis Fellows was $\pm 6.9 \%$. The widest confidence interval for the all staff-weighted sample was $\pm 5.3 \%$.

\section{Don't Believe}

Senate staff (6.7\%) were more likely than Stennis Fellows (4.3\%) or GSS2010 adults $(3 \%)$ to say that they didn't believe in God. The two-sample, two-tailed t-statistic was significant at the .05 level for the difference between Senate staff and GSS2010 adults, $\mathrm{t}(5064)=2.68, \mathrm{p}=.007$. The difference in proportions between House and Senate staff, $\mathrm{t}(333)=1.33, \mathrm{p}=.18$, and between all staff-weighted and GSS2010 adults, $\mathrm{t}(5235)=1.73$, $\mathrm{p}=.084$, were not significant at the .05 level. The difference between Senate staff and U.S. adults was statistically significant but the null hypothesis that there was no difference in proportions between House and Senate staff and between all staff-weighted and U.S. adults could not be rejected.

\section{Don't Know}

The Stennis Fellows (14.8\%) were more likely than House $(7.1 \%)$ or Senate $(10.3 \%)$ staff or GSS2010 adult (5.2\%) respondents to indicate that they did not know whether God exists. The difference between Stennis Fellows and House respondents was significant at the .05 level, $t(283)=2.1, p=.036$, as was the difference in proportions between Stennis Fellows and GSS2010 adults, $\mathrm{t}(5014)=4.51, \mathrm{p}=.000$. The difference in proportions between Stennis Fellows and Senate staff was not significant at the .05 level, $\mathrm{t}(278)=1.13, \mathrm{p}=.26$. 
The two-sample, two-tailed t-statistic for the difference in proportions with regard to whether they indicated that they did not know whether God exists was not significant at the .05 level between House and Senate staff, $t(333)=1.04, p=.299$, or for the difference between House staff and GSS2010 adults, $\mathrm{t}(5069=1.09, \mathrm{p}=.27$. The null hypothesis that there was no difference in proportions cannot be rejected. The two-sample, two-tailed tstatistic was significant at the .05 level for the difference between Senate staff and GSS2010 adults, $\mathrm{t}(5064)=2.87, \mathrm{p}=.004$, and for the difference between all staff-weighted and GSS2010 adults, $\mathrm{t}(5235)=2.44, \mathrm{p}=.015$. There is a small but statistically significant difference between Senate staff and U.S. adults and between all staff-weighted and U.S. adults. Stennis Fellows, Senate staff and all staff-weighted were more likely to respond that they did not know whether God exists than GSS2010 adults.

\section{Believe Sometimes}

Senate staff (9.7\%) were more likely than House staff (3.5\%), Stennis Fellows (5.2\%) or GSS2010 adults (4.8\%) to indicate that they believed in God sometimes. The twosample, two-tailed t-statistic was significant at the .05 level for the difference in proportions between House and Senate staff, $\mathrm{t}(333)=2.293, \mathrm{p}=.022$, and for the difference between Senate staff and GSS2010 adults, $\mathrm{t}(5064)=2.85, \mathrm{p}=.004$. The $\mathrm{t}$-statistic was not significant at the .05 level for the difference between Stennis Fellows and Senate staff, $\mathrm{t}(278)=1.38, \mathrm{p}=.17$. The null hypothesis that there is no difference in proportions cannot be rejected. 


\section{Have Doubts But Believe}

House staff (21.8\%) were more likely than Stennis Fellows (20\%), Senate staff (18.8\%) or GSS2010 adults (16.1\%) to indicate that they have doubts but feel they do believe in God. The two-sample, two-tailed t-statistic for the difference in proportions between House staff and GSS2010 adults (the pair with the widest spread) was significant at the .05 level, $\mathrm{t}(5069)=1.978, \mathrm{p}=.0481$. The $\mathrm{t}$-statistic was not significant at the .05 level for any of the other pairings. The null hypothesis that there was no difference in proportions between Stennis Fellows and GSS2010 adults, between Senate staff and GSS2010 adults, and between all staff-weighted and GSS2010 adults could not be rejected.

\section{No Doubts}

Senate staff (39.4\%) respondents were less likely than either House (53.5\%) or GSS2010 $(60 \%)$ respondents to indicate that they had no doubts about the existence of God. A two-sample, two-tailed t-test between proportions was conducted to determine if there was a significant difference between the House and Senate and the Senate and the GSS adult population. The t-statistic for the House and Senate comparison was significant at the .05 level, $t(333)=2.59, p=.01$. The difference between the Senate sample and the GSS2010 adult sample was significant at the .05 level, $t(5064)=5.3, p=.000001$. The difference in proportions between the House sample and the GSS2010 adult sample was not significant at the .05 level, $t(5069)=1.7, p=.09$. Senate staff were less likely than House staff or U.S. adults to indicate that they have no doubts about the existence of God. 


\section{Chamber}

I don't believe in God

I don't know whether there is a God and I don't believe there is any way to find out

I don't believe in a personal God, but do believe in a Higher Power of some kind

I find myself believing in God some of the time, but not at others

While I have doubts, I feel that I do believe in God

I know God really exists and I have no doubts about it

Don't know

Total

Missing

Total

Senate

I don't believe in God
Frequency

6

12

15

6

37

91

3

170

15

185

I don't know whether there is a God and I don't believe there is any way to find out

I don't believe in a personal God, but do believe in a Higher Power of some kind

I find myself believing in God some of the time, but not at others

While I have doubts, I feel that I do believe in God

I know God really exists and I have no doubts about it

Don't know

Total

Missing

6

2

5

3

11

17

23

16

31

65

2

165
Percent

3.2

Valid Percent

3.5

3.5

6.5

7.1

10.6

8.1

8.8

19.4

22.9

3.2

3.5

21.8

44.7

20.0

49.2

53.5

98.2

1.6

1.8

100.0

91.9

100.0

8.1

100.0

6.2

6.7

6.7

9.6

10.3

17.0

12.9

13.9

30.9

9.0

9.7

40.6

17.4

18.8

59.4

36.5

39.4

98.8

1.1

1.2

100.0

92.7

100.0

13

\section{3}




\begin{tabular}{|c|c|c|c|c|c|}
\hline Chamber & & Frequency & Percent & Valid Percent & Percent \\
\hline \multirow[t]{9}{*}{ House } & I don't believe in God & 6 & 3.2 & 3.5 & 3.5 \\
\hline & $\begin{array}{l}\text { I don't know whether there is } \\
\text { a God and I don't believe } \\
\text { there is any way to find out }\end{array}$ & 12 & 6.5 & 7.1 & 10.6 \\
\hline & $\begin{array}{l}\text { I don't believe in a personal } \\
\text { God, but do believe in a } \\
\text { Higher Power of some kind }\end{array}$ & 15 & 8.1 & 8.8 & 19.4 \\
\hline & $\begin{array}{l}\text { I find myself believing in God } \\
\text { some of the time, but not at } \\
\text { others }\end{array}$ & 6 & 3.2 & 3.5 & 22.9 \\
\hline & $\begin{array}{l}\text { While I have doubts, I feel } \\
\text { that I do believe in God }\end{array}$ & 37 & 20.0 & 21.8 & 44.7 \\
\hline & $\begin{array}{l}\text { I know God really exists and } \\
\text { I have no doubts about it }\end{array}$ & 91 & 49.2 & 53.5 & 98.2 \\
\hline & Don't know & 3 & 1.6 & 1.8 & 100.0 \\
\hline & Total & 170 & 91.9 & 100.0 & \\
\hline & Missing & 15 & 8.1 & & \\
\hline Total & & 185 & 100.0 & & \\
\hline \multirow[t]{9}{*}{ Senate } & I don't believe in God & 11 & 6.2 & 6.7 & 6.7 \\
\hline & $\begin{array}{l}\text { I don't know whether there is } \\
\text { a God and I don't believe } \\
\text { there is any way to find out }\end{array}$ & 17 & 9.6 & 10.3 & 17.0 \\
\hline & $\begin{array}{l}\text { I don't believe in a personal } \\
\text { God, but do believe in a } \\
\text { Higher Power of some kind }\end{array}$ & 23 & 12.9 & 13.9 & 30.9 \\
\hline & $\begin{array}{l}\text { I find myself believing in God } \\
\text { some of the time, but not at } \\
\text { others }\end{array}$ & 16 & 9.0 & 9.7 & 40.6 \\
\hline & $\begin{array}{l}\text { While I have doubts, I feel } \\
\text { that I do believe in God }\end{array}$ & 31 & 17.4 & 18.8 & 59.4 \\
\hline & $\begin{array}{l}\text { I know God really exists and } \\
\text { I have no doubts about it }\end{array}$ & 65 & 36.5 & 39.4 & 98.8 \\
\hline & Don't know & 2 & 1.1 & 1.2 & 100.0 \\
\hline & Total & 165 & 92.7 & 100.0 & \\
\hline & Missing & 13 & 7.3 & & \\
\hline Total & & 178 & 100.0 & & \\
\hline
\end{tabular}


Which of the following statements comes closest to expressing what you believe about God?

\begin{tabular}{|c|c|c|c|c|}
\hline Stennis Fellows & \multirow{2}{*}{$\frac{\text { Frequency }}{5}$} & \multirow{2}{*}{$\frac{\text { Percent }}{4.1}$} & \multirow{2}{*}{$\frac{\text { Valid Percent }}{4.3}$} & \multirow{2}{*}{$\begin{array}{c}\begin{array}{c}\text { Cumulative } \\
\text { Percent }\end{array} \\
4.3\end{array}$} \\
\hline I don't believe in God & & & & \\
\hline $\begin{array}{l}\text { I don't know whether there is } \\
\text { a God and I don't believe } \\
\text { there is any way to find out }\end{array}$ & 17 & 13.9 & 14.8 & 19.1 \\
\hline $\begin{array}{l}\text { I don't believe in a personal } \\
\text { God, but do believe in a } \\
\text { Higher Power of some kind }\end{array}$ & 7 & 5.7 & 6.1 & 25.2 \\
\hline $\begin{array}{l}\text { I find myself believing in God } \\
\text { some of the time, but not at } \\
\text { others }\end{array}$ & 6 & 4.9 & 5.2 & 30.4 \\
\hline $\begin{array}{l}\text { While I have doubts, I feel } \\
\text { that I do believe in God }\end{array}$ & 23 & 18.9 & 20.0 & 50.4 \\
\hline $\begin{array}{l}\text { I know God really exists and } \\
\text { I have no doubts about it }\end{array}$ & 55 & 45.1 & 47.8 & 98.3 \\
\hline Don't know & 2 & 1.6 & 1.7 & 100.0 \\
\hline Total & 115 & 94.3 & 100.0 & \\
\hline Missing & 7 & 5.7 & & \\
\hline Total & 122 & 100.0 & & \\
\hline
\end{tabular}

Which statement comes closest to expressing what you believe about God?

\begin{tabular}{|c|c|c|c|c|}
\hline General Social Survey & Frequency & Percent & Valid Percent & $\begin{array}{c}\text { Cumulative } \\
\text { Percent }\end{array}$ \\
\hline I don't believe in God. & 148 & 3.0 & 3.0 & 3.0 \\
\hline $\begin{array}{l}\text { I don't know whether there is } \\
\text { a God, and I don't believe } \\
\text { there is any way to find out. }\end{array}$ & 253 & 5.2 & 5.2 & 8.2 \\
\hline $\begin{array}{l}\text { I don't believe in a personal } \\
\text { God, but do believe in a } \\
\text { Higher Power of some kind. }\end{array}$ & 494 & 10.1 & 10.1 & 18.3 \\
\hline $\begin{array}{l}\text { I find myself believing in God } \\
\text { some of the time, but not at } \\
\text { others. }\end{array}$ & 235 & 4.8 & 4.8 & 23.1 \\
\hline $\begin{array}{l}\text { While I have doubts, I feel } \\
\text { that I do believe in God. }\end{array}$ & 790 & 16.1 & 16.1 & 39.2 \\
\hline
\end{tabular}




\begin{tabular}{lcccc}
\hline I know God really exists and & 2943 & 60.0 & 60.0 & 99.2 \\
I have no doubts about it. & & & & 99.7 \\
Don't know & 26 & .5 & .5 & 100.0 \\
No answer & 12 & .3 & .3 & \\
Total & 4901 & 100.0 & 100.0 & \\
\hline \hline
\end{tabular}

Which of the following statements comes closest to expressing what you believe about God?

\begin{tabular}{|c|c|c|c|c|c|}
\hline \multirow{2}{*}{ All Staff } & & \multirow{3}{*}{$\frac{\text { Frequency }}{16}$} & \multirow{3}{*}{$\frac{\text { Percent }}{4.4}$} & \multirow{3}{*}{$\frac{\text { Valid Percent }}{4.7}$} & \multirow{3}{*}{$\begin{array}{c}\begin{array}{c}\text { Cumulative } \\
\text { Percent }\end{array} \\
4.7\end{array}$} \\
\hline & & & & & \\
\hline & I don't believe in God & & & & \\
\hline & $\begin{array}{l}\text { I don't know whether there is } \\
\text { a God and I don't believe } \\
\text { there is any way to find out }\end{array}$ & 28 & 7.7 & 8.3 & 13.1 \\
\hline & $\begin{array}{l}\text { I don't believe in a personal } \\
\text { God, but do believe in a } \\
\text { Higher Power of some kind }\end{array}$ & 36 & 10.0 & 10.8 & 23.9 \\
\hline & $\begin{array}{l}\text { I find myself believing in God } \\
\text { some of the time, but not at } \\
\text { others }\end{array}$ & 20 & 5.5 & 5.9 & 29.8 \\
\hline & $\begin{array}{l}\text { While I have doubts, I feel } \\
\text { that I do believe in God }\end{array}$ & 69 & 19.0 & 20.6 & 50.4 \\
\hline & $\begin{array}{l}\text { I know God really exists and } \\
\text { I have no doubts about it }\end{array}$ & 161 & 44.3 & 48.0 & 98.4 \\
\hline & Don't know & 5 & 1.4 & 1.6 & 100.0 \\
\hline & Total & 336 & 92.2 & 100.0 & \\
\hline & Missing & 28 & 7.8 & & \\
\hline Total & & 364 & 100.0 & & \\
\hline
\end{tabular}




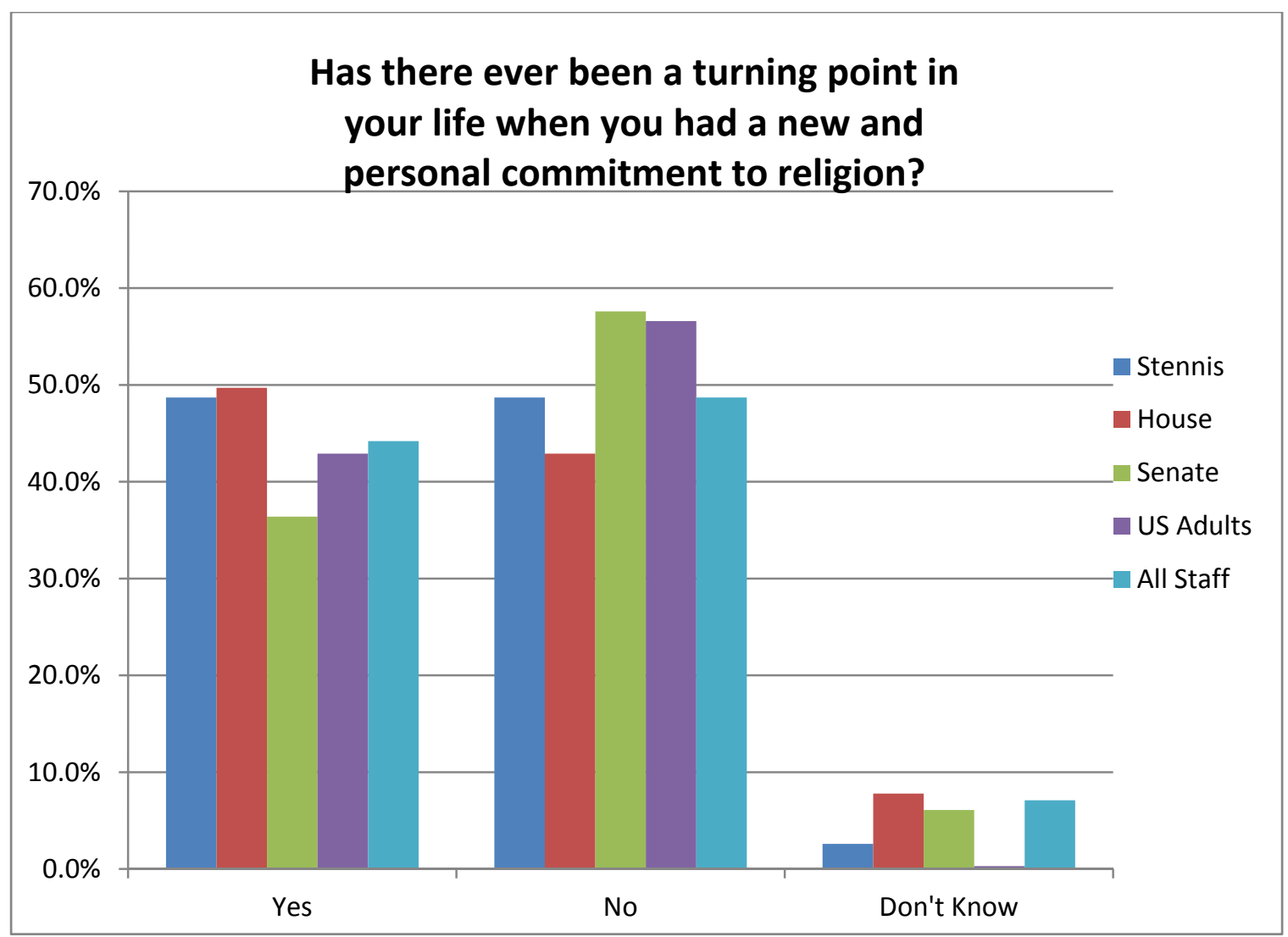

Respondents were asked whether there "has ever been a turning point in your life where you had a new and personal commitment to religion. Respondents were provided with three response options; 1) yes, 2) no, 3) don't know. ${ }^{97}$

Confidence intervals were calculated for each of the variable categories of the House and Senate samples. The widest confidence intervals were $\pm 7.6 \%$ for the House sample and $\pm 7.5 \%$ for the Senate sample. The widest confidence interval for Stennis Fellows was $\pm 6.9 \%$. The widest confidence interval for the all staff-weighted sample was $\pm 5.3 \%$.

${ }^{97}$ This question appeared on the 2010 General Social Survey (GSS RELEXPER). 
Yes

House and Senate staff differed significantly in the percentage who indicated that there had been a turning point in their life when they made a new and personal commitment to religion, with $49.7 \%$ of House staff indicating "yes" compared with $36.4 \%$ of Senate staff. A two-sample, two-tailed t-test between proportions was conducted to determine if there was a significant difference between the House and Senate. The t-statistic was significant at the .05 level, $t(332)=2.46, p=.01$.

House staff (49.4\%) respondents were more likely than U.S. adults (42.9\%) to indicate that there had been a turning point in their life. The two-sample, two-tailed t-test between proportions was not significant at the .05 level, $t(5067)=1.67, p=.095$. The null hypothesis that there was no difference in the proportions of the populations could not be rejected.

No

Conversely, the House sample reported "no" less frequently $(42.9 \%)$ than the general adult population $(56.6 \%)$ in part because $7.7 \%$ of House staff reported "don't Know" compared with $.3 \%$ of the GSS sample. A two-tailed, t-test between proportions determined that the difference in proportions of those saying "no" was statistically significant at the .05 level, $t(5067)=3.52, p=.0004$.

\section{Don't Know}

In addition, and intriguingly, a greater proportion of Stennis (2.6\%), House (7.8\%), Senate $(6.1 \%)$, and all staff $(7.1 \%)$ respondents reported "don't know" than did the GSS 
respondents $(.3 \%)$. The t-statistic was significant at the .05 level for all four

comparisons, $t(5014)=4.2, p=.0004, t(5067)=12.96, p=.000001, t(5065)=10.52$, $p=.000001$, and $t(5233)=13.96, p=.000001$. It is not clear why staff would be less clear about this element of their religious experience than adults in the GSS2010 survey. A chi-square test for independence confirmed a low to medium association between agreement with the statement and House or Senate chamber, $X^{2}(2, n=334)=7.5, p=.023$, Cramer's V=.150.

Has there been a turning point in your life when you had a new and personal commitment to religion?

\begin{tabular}{|c|c|c|c|c|c|c|}
\hline \multicolumn{3}{|c|}{ Chamber } & \multirow{2}{*}{$\begin{array}{r}\text { Frequency } \\
83\end{array}$} & \multirow{2}{*}{$\frac{\text { Percent }}{44.9}$} & \multirow{2}{*}{$\frac{\text { Valid Percent }}{49.4}$} & \multirow{2}{*}{$\begin{array}{r}\begin{array}{c}\text { Cumulative } \\
\text { Percent }\end{array} \\
49.4\end{array}$} \\
\hline House & & Yes & & & & \\
\hline & & No & 72 & 38.9 & 42.9 & 92.3 \\
\hline & & Don't know & 13 & 7.0 & 7.7 & 100.0 \\
\hline & & Total & 168 & 90.8 & 100.0 & \\
\hline & Missing & System & 17 & 9.2 & & \\
\hline & Total & & 185 & 100.0 & & \\
\hline \multirow[t]{6}{*}{ Senate } & & Yes & 60 & 33.7 & 36.1 & 36.1 \\
\hline & & No & 96 & 53.9 & 57.8 & 94.0 \\
\hline & & Don't know & 10 & 5.6 & 6.0 & 100.0 \\
\hline & & Total & 166 & 93.3 & 100.0 & \\
\hline & Missing & System & 12 & 6.7 & & \\
\hline & Total & & 178 & 100.0 & & \\
\hline
\end{tabular}

Has there been a turning point in your life when you had a new and personal commitment to religion?

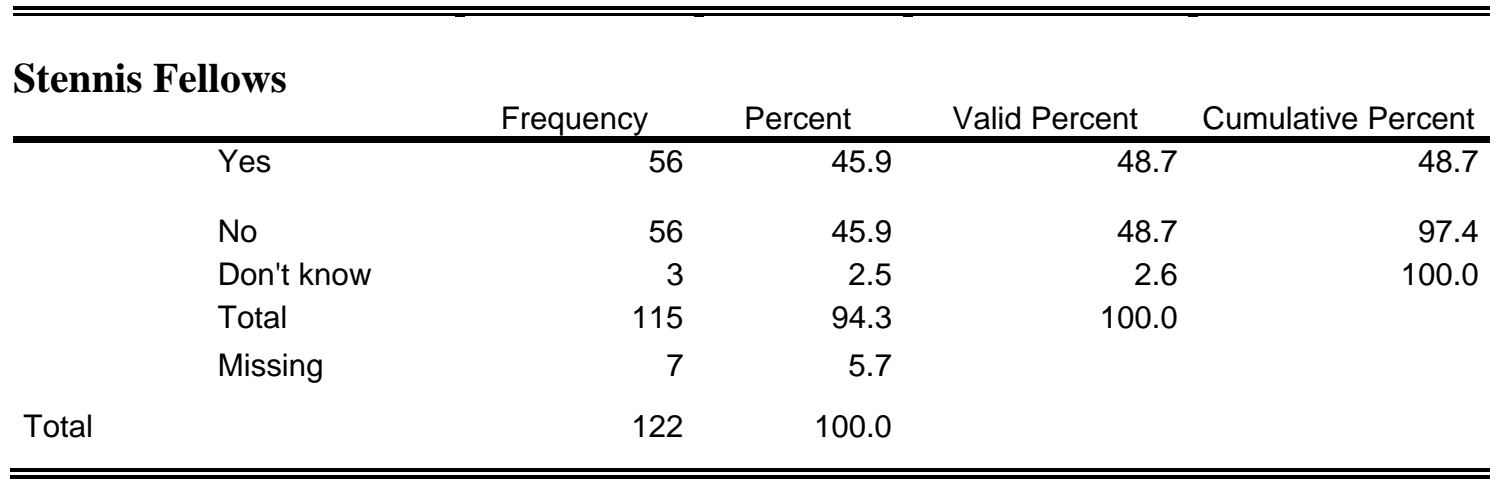


Has there ever been a turning point in your life when you made a new and personal commitment to religion?

\begin{tabular}{lrrrr}
\hline \hline General Social Survey & & & & \\
& Frequency & \multicolumn{1}{c}{ Percent } & \multicolumn{1}{c}{ Valid Percent } & Cumulative Percent \\
\hline Yes & 2102 & 42.9 & 42.9 & 42.9 \\
No & 2773 & 56.6 & 56.6 & 99.5 \\
Don't know & 14 & .3 & .3 & 99.8 \\
No answer & 11 & .2 & .2 & 100.0 \\
Total & 4901 & 100.0 & 100.0 & \\
\hline \hline
\end{tabular}

Has there been a turning point in your life when you had a new and personal commitment to religion?

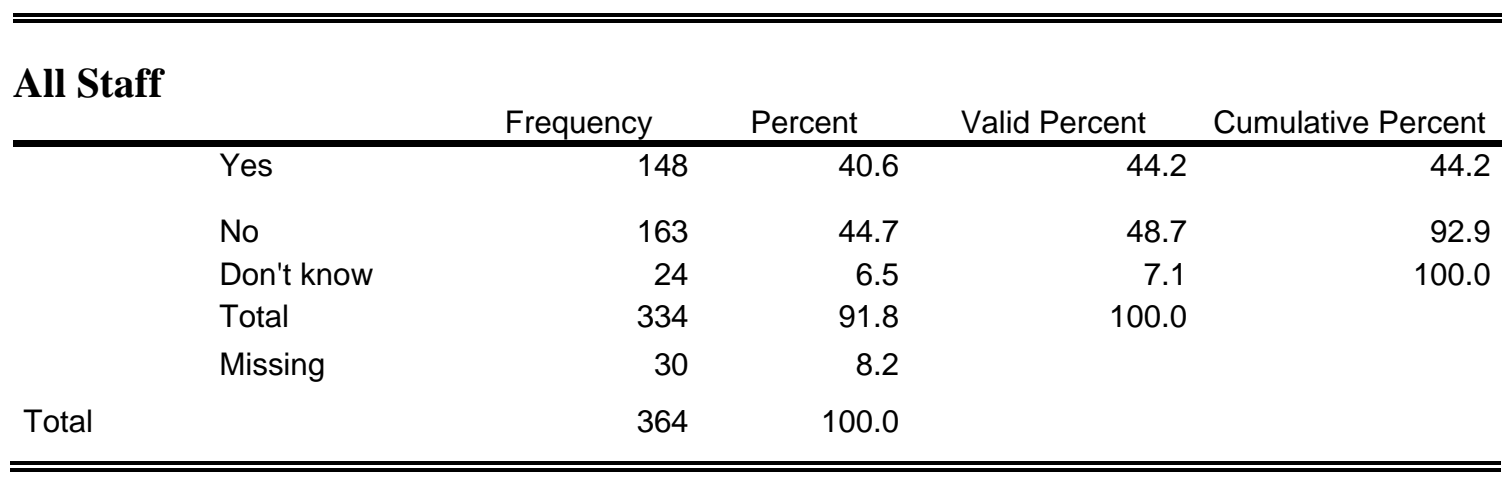




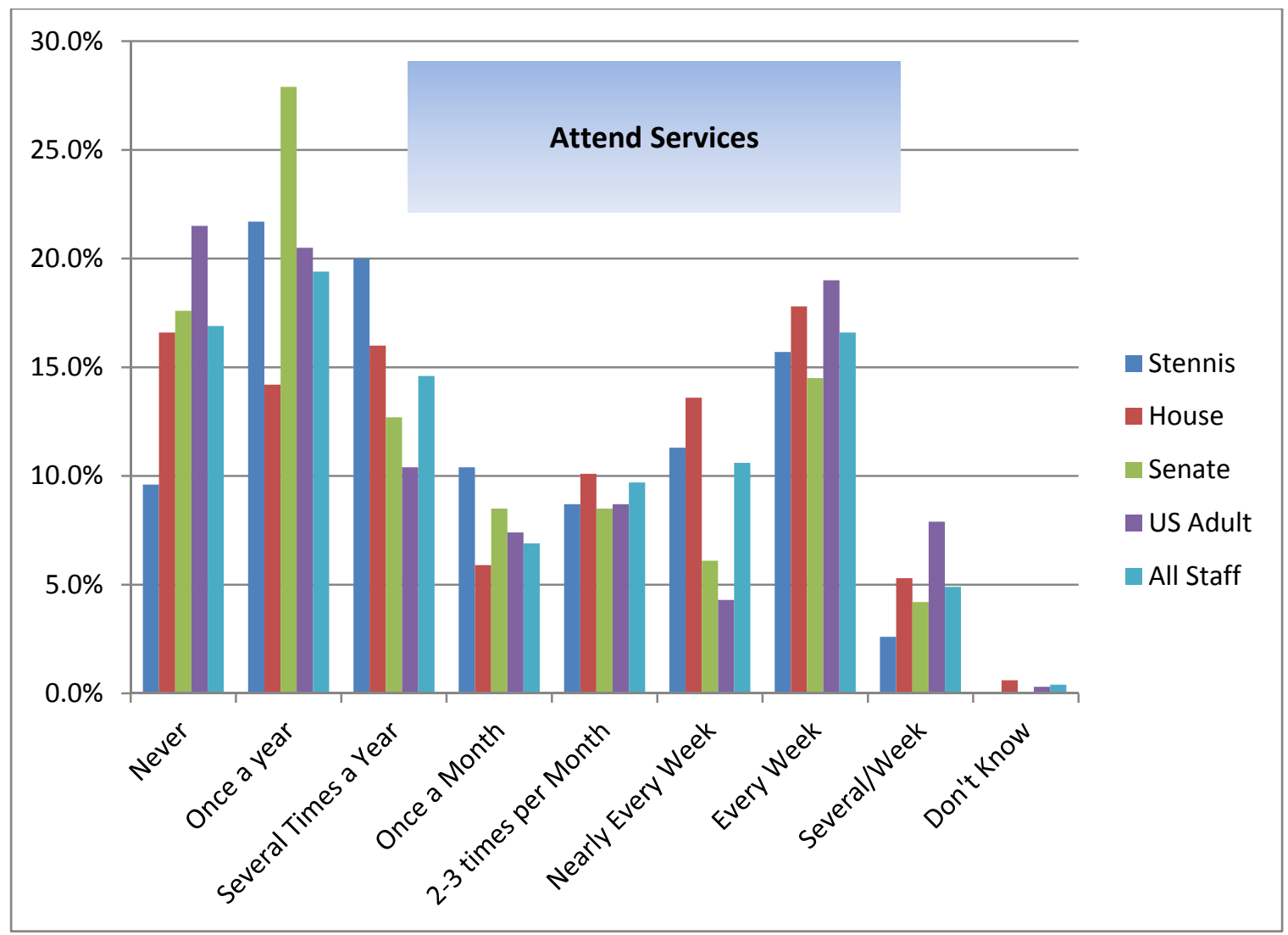

Respondents were asked "how often do you attend church, synagogue or other religious services" and provided the following response items: 1) never; 2) once a year; 3) several times a year; 4) once a month; 5) two to three times per month; 6) nearly every week, 7) every week; 8) several times a week; or 9) don't know. ${ }^{98}$

Confidence intervals were calculated for each of the variable categories of the House and Senate samples. The widest confidence intervals were $\pm 5.7 \%$ for the House sample and $\pm 6.8 \%$ for the Senate sample. The widest confidence interval for Stennis Fellows was $\pm 5.7 \%$. The widest confidence interval for all staff-weighted was $\pm 4.2 \%$.

${ }^{98}$ Question adopted from Duke Religion Index and the 2010 General Social Survey (GSS ATTEND). 


\section{Never Attend}

Stennis Fellows respondents $(9.6 \%)$ were less likely than House staff $(16.5 \%)$, Senate staff $(17.5 \%)$, or U.S. adults $(21.5 \%)$ to indicate that they never attended church services. Two-sample, two-tailed t-test of proportions were conducted to determine if the differences were statistically significant. The t-statistic was significant at the .05 level, $t(5014)=3.08, p=.002$ for the difference between Stennis Fellows and U.S. adults. The differences were not statistically significant at the .05 level for the differences between Stennis Fellows and House staff, $t(283)=1.66, p=.097$, Stennis Fellows and Senate staff, $t(279)=1.86, p=.06$. In these instances the null hypothesis that there is no difference in the proportions within the populations cannot be rejected.

\section{Once A Year}

Senate respondents $(27.7 \%)$ were more likely than Stennis Fellows $(21.7 \%)$, House staff (14.1\%) or U.S. adults $(20.5 \%)$ to indicate that they attended services once a year. The GSS survey gave respondents the option of responding less than once a year and once a year rather than simply once a year. For comparison purposes, these GSS categories were collapsed into the single category "once a year." Two-sample, two-tailed t-tests of the differences between proportions were conducted to determine if the differences were significant. The differences between the Stennis Fellows and the House staff, $t(283)=1.67, p=.96$ and the Stennis Fellows and the Senate staff, $t(280)=1.14, p=.266$ were not significant at the .05 level. The null hypothesis that there is no difference in the proportions within the populations cannot be rejected. 


\section{Several Times A Year}

The two-sample, two-tailed t-statistics for the difference in proportions of respondents indicating they attended services several times a year were, however, significant at the .05 level for the difference between House staff and Senate staff, $t(334)=3.07, p=.002$, House staff and U.S. adults, $t(5069)=2.04, p=.004$; and Senate staff and U.S. adults, $t(5065)=2.22, p=.027$. Senate staff were more likely than House staff or GSS2010 adults to report that they attended services once a year. In contrast, House staff were less likely than either Senate staff or GSS2010 adults to report that they attended service once a year.

\section{Once A Month}

Stennis Fellows (10.4\%) were more likely than House staff (5.9\%), Senate staff $(8.4 \%)$ or GSS2010 adults (7.4\%) to report that they attended service once a month. The twosample, two-tailed t-statistic for the difference in proportions between Stennis Fellows and House staff, $t(283)=1.4, p=.16$, was not significant at the .05 level. Two-sample, two-tailed t-statistics were not significant at the .05 level for any of the other pairings. The null hypothesis that there was no difference in proportions cannot be rejected.

Nearly Every Week

Stennis Fellows (11.3\%), House staff (13.5\%), and all staff (10.6\%) were more likely than Senate staff $(6 \%)$ or U.S. adults $(4.3 \%)$ to indicate that they attended services nearly every week. The two-sample, two-tailed t-statistic was significant at the .05 level for the difference between House and Senate staff, $t(334)=2.3, p=.022$; House staff and U.S. adults $t(5069)=5.61, p=.000001$; and all staff-weighted and U.S. adults, $t(5236)=5.27$, 
$p=.000001$. Stennis Fellows, House staff, and all staff-weighted all report attending services nearly every week in greater numbers than Senate staff or GSS2010 adults.

\section{Every Week}

GSS2010 adults (19\%) were more likely to report attending services every week than Stennis Fellows (15.7\%), House staff (17.6\%), Senate staff (15.1\%) or all staff-weighted (16.6\%). The two-sample, two-tailed t-statistic was not significant at the .05 level for the difference between GSS2010 adults and Senate staff, $t(5065)=1.26, p=.207$, or any of the pairings. The null hypothesis that there is no difference in the proportions in the populations cannot be rejected.

A chi-square test for independence confirmed a small to medium association between attending church, synagogue or other religious services and House or Senate chamber, $X^{2}(8, n=336)=15.629, p=.048$, Cramer's V=.216.

How often do you attend church, synagogue or other religious services?

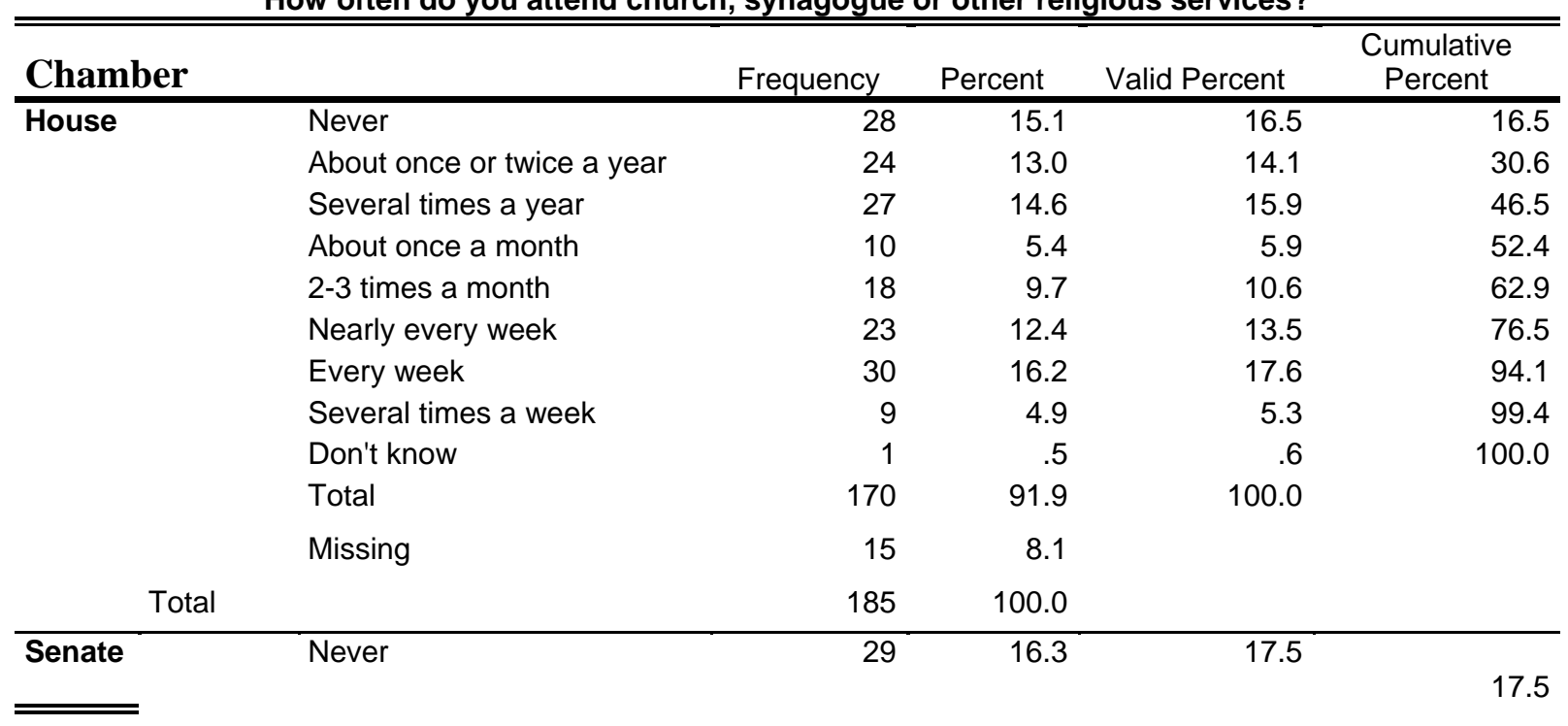




\begin{tabular}{llrrrr}
\hline & About once or twice a year & 46 & 25.8 & 27.7 & 45.2 \\
Several times a year & 21 & 11.8 & 12.7 & 57.8 \\
& About once a month & 14 & 7.9 & 8.4 & 66.3 \\
2-3 times a month & 14 & 7.9 & 8.4 & 74.7 \\
Nearly every week & 10 & 5.6 & 6.0 & 80.7 \\
& Every week & 25 & 14.0 & 15.1 & 9.2 \\
Several times a week & 7 & 3.9 & 100.0 & 100.0 \\
& Total & 166 & 93.3 & & \\
& Missing & 12 & 6.7 & & \\
\hline
\end{tabular}

How often do you attend church, synagogue or other religious services?

\begin{tabular}{lrrrr}
\hline \hline Stennis Fellows & & & & \multicolumn{2}{c}{$\begin{array}{c}\text { Cumulative } \\
\text { Percent }\end{array}$} \\
\hline Never & Frequency & Percent & Valid Percent & 9.6 \\
About once or twice a year & 11 & 9.0 & 21.7 & 31.3 \\
Several times a year & 25 & 20.5 & 20.0 & 51.3 \\
About once a month & 23 & 18.9 & 10.4 & 61.7 \\
2-3 times a month & 12 & 9.8 & 8.7 & 70.4 \\
Nearly every week & 10 & 8.2 & 11.3 & 81.7 \\
Every week & 13 & 10.7 & 15.7 & 97.4 \\
Several times a week & 18 & 14.8 & 2.6 & 100.0 \\
Total & 3 & 2.5 & 100.0 & \\
Total & 115 & 94.3 & & \\
\hline \hline
\end{tabular}

How often do you attend religious services?

\begin{tabular}{lrrrr}
\hline \hline General Social Survey & & & & \multicolumn{2}{c}{$\begin{array}{c}\text { Cumulative } \\
\text { Percent }\end{array}$} \\
\hline Never & Frequency & Percent & Valid Percent & 21.5 \\
Less than once a year & 1055 & 21.5 & 6.9 & 21.5 \\
Once a year & 339 & 6.9 & 13.6 & 28.4 \\
Several times a year & 665 & 13.6 & 10.4 & 42.0 \\
Once a month & 511 & 10.4 & 7.4 & 52.4 \\
Two to three times a month & 362 & 7.4 & 8.7 & 59.8 \\
Nearly every week & 425 & 8.7 & 4.3 & 68.5 \\
Every week & 212 & 4.3 & 19.0 & 72.8 \\
More than once a week & 931 & 19.0 & 7.9 & 91.8 \\
Don't know, no answer & 387 & 7.9 & .3 & 99.7 \\
Total & 14 & .3 & 100.0 & 100.0 \\
\hline \hline
\end{tabular}

How often do you attend church, synagogue or other religious services?

\begin{tabular}{crrrr}
\hline \hline \multirow{2}{*}{ All Staff } & & & & \multicolumn{2}{c}{ Cumulative } \\
Percent
\end{tabular}




\begin{tabular}{lrrrr}
\hline About once a month & 23 & 6.4 & 6.9 & 57.8 \\
2-3 times a month & 33 & 9.0 & 9.7 & 67.5 \\
Nearly every week & 36 & 9.8 & 10.6 & 78.1 \\
Every week & 56 & 15.4 & 16.6 & 94.8 \\
Several times a week & 16 & 4.5 & 4.9 & 99.6 \\
Don't know & 1 & .3 & .4 & 100.0 \\
Total & 337 & 92.4 & 100.0 & \\
Missing & 28 & 7.6 & & \\
Total & 364 & 100.0 & & \\
\hline \hline
\end{tabular}

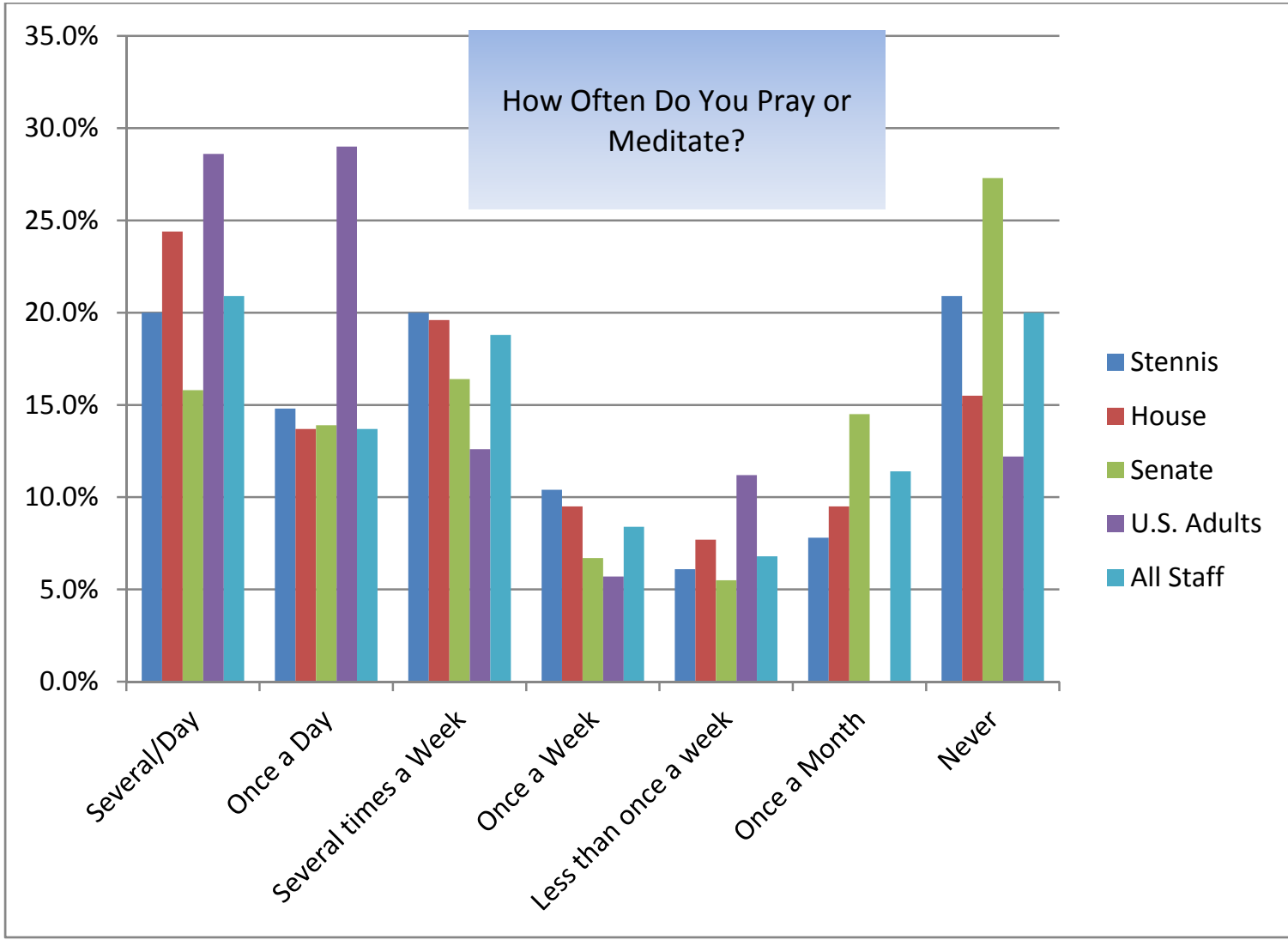

Respondents were asked "about how often do you pray or meditate" and provided the following response items: 1) several times a day; 2) once a day; 3) several times a week; 4) once a week; 5) less than once a week; 6) once a month; or 7) never. ${ }^{99}$

Confidence intervals were calculated for each of the variable categories of the House and Senate samples. The widest confidence intervals were $\pm 6.5 \%$ for the House sample and

\footnotetext{
${ }^{99}$ Question adopted from Duke Religion Index and appeared in the 2010 General Social Survey (GSS
} PRAY) 
$\pm 5.7 \%$ for the Senate sample. The widest confidence interval for Stennis Fellows was $\pm 5.6 \%$. The widest confidence interval for the all staff-weighted sample was $\pm 4.3 \%$.

Several Times A Day

U.S. adults (28.6\%) were more likely than Stennis Fellows (20.\%), House staff (24.3\%), Senate staff $(15.7 \%)$ or all staff-weighted $(20.9 \%)$ to indicate that they prayed or meditated several times a day. The t-statistic was significant at the .05 level for the differences between the Stennis respondents and U.S. adults, $t(5014)=2.02, p=.043$; for the differences between U.S. adults and all staff, $t(5235)=3.04, p=.002$; and for the differences between Senate staff and U.S. adults, $t(5065)=-3.63, p=.0003$. The twosample, two-tailed t-statistic was not significant at the .05 level for the difference between House staff and U.S. adults, $t(5068)=1.22, p=.222$, or for the differences between House and Senate staff, $t(333)=1.97, p=.0501$. The null hypothesis that there was no difference in proportions cannot be rejected.

\section{Once A Day}

U.S. adults (29\%) were also far more likely to indicate that they prayed once a day than the Stennis Fellows (14.8\%), House staff (13.6\%), Senate staff (13.9\%) or all staff (13.7\%). The t-statistic was significant at the .05 level for the difference between Stennis Fellows and U.S. adults, $t(5014)=3.33, p=.0009$; House staff and U.S. adults, $t(5068)=4.36, p=.00001$; Senate staff and U.S. adults, $t(5065)=3.73, p=.0002$; and all staff and U.S. adults, $t(5235)=6.04, p=.000001$. 
Several Times $A$ Week

GS2010 adults respond that they pray or meditate more frequently than congressional staff. Stennis Fellows (20\%), House staff (20.1\%), Senate staff (16.9\%) and all staff $(18.8 \%)$ were more likely than U.S. adults $(12.6 \%)$ to indicate that they prayed several times a week. The two-sample, two-tailed t-statistic was significant at the .05 level for the difference between Stennis Fellows and U.S. adults, $t(5014)=2.35, p=.02$; House staff and U.S. adults, $t(5068)=2,72, p=.005$; and all staff and U.S. adults, $t(5235)=3.26$, $p=.001$. The t-statistic was not significant at the .05 level for the difference between Senate staff and U.S. adults, $t(5065)=1.63, p=.1$. The null hypothesis that there was no difference in proportions between Senate staff and U.S. adults cannot be rejected.

\section{Once A Month}

Senate staff (14.5\%) were more likely than Stennis (7.8\%) or House staff $(9.5 \%)$ to report that they prayed once a month. GSS2010 respondents were not given once a month as a response option. The t-statistic was not significant at the .05 level for the differences between the Senate staff and the House staff, $t(333)=1.4, p=.16$; or the Senate staff and the Stennis Fellows, $t(279)=1.72 p=.09$. The null hypotheses that there were no differences in proportions between House and Senate staff and between Senate staff and Stennis Fellows cannot be rejected.

Never

Continuing a pattern of lower-reported prayer or meditation frequency, Senate staff $(27.1 \%)$ were more likely to indicate that they never prayed than Stennis Fellows (20.9\%), House staff (15.4\%) or U.S. adults (11.2\%). The two-sample, two-tailed t-test 
was significant at the .05 level for the difference between Stennis Fellows and U.S. adults, $t(5014)=2.8, p=.005$; Senate staff and U.S. adults, $t(5065)=5.67, p=.000001$; and House staff and Senate staff, $t(333)=2.62, p=.009$. In addition, the two-sample, twotailed t-statistic for the difference in proportions between all staff-weighted and U.S. adults was significant at the .05 level, $t(5235)=4.15, p=.00003$. The t-statistics for the difference between House staff and U.S. adults $t(5068)=1.24, p=.22$, and Stennis Fellows and Senate staff, $t(279)=1.19, p=.24$, were not significant at the .05 level.

A chi-square test for independence indicated no significant association between frequency of prayer and meditation with House or Senate chamber, $X^{2}(6, n=335)=$ $12.251, p=.057$, Cramer's V=.191.

About how often do you pray or meditate?

\begin{tabular}{|c|c|c|c|c|c|}
\hline Chamber & & Frequency & Percent & Valid Percent & $\begin{array}{c}\text { Cumulative } \\
\text { Percent }\end{array}$ \\
\hline \multirow[t]{10}{*}{ House } & Several times a day & 41 & 22.2 & 24.3 & 24.3 \\
\hline & Once a day & 23 & 12.4 & 13.6 & 37.9 \\
\hline & Several times a week & 34 & 18.4 & 20.1 & 58.0 \\
\hline & Once a week & 16 & 8.6 & 9.5 & 67.5 \\
\hline & Less than once a week & 13 & 7.0 & 7.7 & 75.1 \\
\hline & Once a month & 16 & 8.6 & 9.5 & 84.6 \\
\hline & Never & 26 & 14.1 & 15.4 & 100.0 \\
\hline & Total & 169 & 91.4 & 100.0 & \\
\hline & Missing & 16 & 8.6 & & \\
\hline & Total & 185 & 100.0 & & \\
\hline \multirow[t]{10}{*}{ Senate } & Several times a day & 26 & 14.6 & 15.7 & 15.7 \\
\hline & Once a day & 23 & 12.9 & 13.9 & 29.5 \\
\hline & Several times a week & 28 & 15.7 & 16.9 & 46.4 \\
\hline & Once a week & 11 & 6.2 & 6.6 & 53.0 \\
\hline & Less than once a week & 9 & 5.1 & 5.4 & 58.4 \\
\hline & Once a month & 24 & 13.5 & 14.5 & 72.9 \\
\hline & Never & 45 & 25.3 & 27.1 & 100.0 \\
\hline & Total & 166 & 93.3 & 100.0 & \\
\hline & Missing & 12 & 6.7 & & \\
\hline & Total & 178 & 100.0 & & \\
\hline
\end{tabular}


About how often do you pray or meditate?

\begin{tabular}{|c|c|c|c|c|}
\hline Stennis Fellows & Frequency & Percent & Valid Percent & $\begin{array}{c}\text { Cumulative } \\
\text { Percent }\end{array}$ \\
\hline Several times a day & 23 & 18.9 & 20.0 & 20.0 \\
\hline Once a day & 17 & 13.9 & 14.8 & 34.8 \\
\hline Several times a week & 23 & 18.9 & 20.0 & 54.8 \\
\hline Once a week & 12 & 9.8 & 10.4 & 65.2 \\
\hline Less than once a week & 7 & 5.7 & 6.1 & 71.3 \\
\hline Once a month & 9 & 7.4 & 7.8 & 79.1 \\
\hline Never & 24 & 19.7 & 20.9 & 100.0 \\
\hline Total & 115 & 94.3 & 100.0 & \\
\hline Missing & 7 & 5.7 & & \\
\hline Total & 122 & 100.0 & & \\
\hline
\end{tabular}

About how often do you pray?

\begin{tabular}{|c|c|c|c|c|}
\hline General Social Survey & Frequency & Percent & Valid Percent & $\begin{array}{c}\text { Cumulative } \\
\text { Percent }\end{array}$ \\
\hline Several times a day & 1404 & 28.6 & 28.6 & 28.6 \\
\hline Once a day & 1419 & 29.0 & 29.0 & 57.6 \\
\hline Several times a week & 620 & 12.6 & 12.6 & 70.3 \\
\hline Once a week & 278 & 5.7 & 5.7 & 75.9 \\
\hline Less than once a week & 547 & 11.2 & 11.2 & 87.1 \\
\hline Never & 599 & 12.2 & 12.2 & 99.3 \\
\hline Don't know & 20 & .4 & .4 & 99.7 \\
\hline No answer & 14 & .3 & .3 & 100.0 \\
\hline Total & 4901 & 100.0 & 100.0 & \\
\hline \multicolumn{5}{|c|}{ About how often do you pray or meditate? } \\
\hline All Staff & Frequency & Percent & Valid Percent & $\begin{array}{c}\text { Cumulative } \\
\text { Percent }\end{array}$ \\
\hline Several times a day & 70 & 19.2 & 20.9 & 20.9 \\
\hline Once a day & 46 & 12.6 & 13.7 & 34.6 \\
\hline Several times a week & 63 & 17.4 & 18.8 & 53.5 \\
\hline Once a week & 28 & 7.7 & 8.4 & 61.8 \\
\hline Less than once a week & 23 & 6.3 & 6.8 & 68.6 \\
\hline Once a month & 38 & 10.5 & 11.4 & 80.0 \\
\hline Never & 67 & 18.4 & 20.0 & 100.0 \\
\hline Total & 336 & 92.1 & 100.0 & \\
\hline Missing & 29 & 7.9 & & \\
\hline Total & 364 & 100.0 & & \\
\hline
\end{tabular}




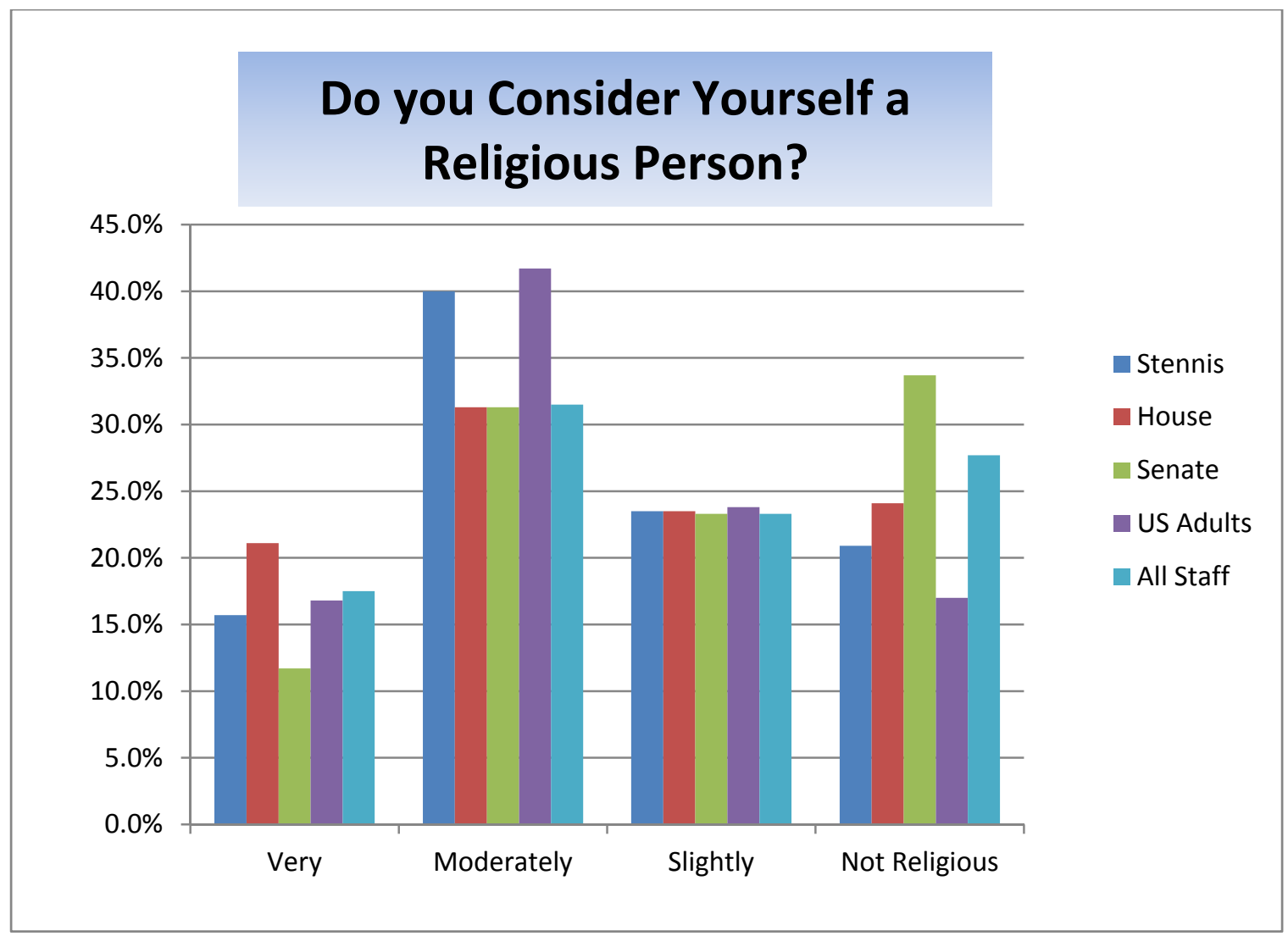

Respondents were presented with the question "to what extent do you consider yourself a religious person" and provided the following response choices: 1) very religious; 2) moderately religious; 3 ) slightly religious; or 4) not religious at all. ${ }^{100}$

Confidence intervals were calculated for each of the variable categories of the House and Senate samples. The widest confidence interval was $\pm 7.1 \%$ for the House sample and $\pm 7.1 \%$ for the Senate sample. The widest confidence interval for Stennis Fellows was $\pm 6.8 \%$. The widest confidence interval for the all staff-weighted sample was $\pm 5.0 \%$.

${ }^{100}$ Question appeared in the 2010 General Social Survey (GSS RELPERSN). 
Very Religious

House staff (21\%) were more likely than Stennis Fellows (15.7\%), Senate staff $(12.2 \%)$ or U.S. adults $(16.8 \%)$ to consider themselves very religious. The two-sample, twotailed t-statistic was significant at the .05 level for the difference in proportions between House and Senate staff, $t(329)=2.15, p=.03$. A greater proportion of House staff than Senate staff consider themselves to be very religious.

The two-sample, two-tailed t-statistic was not significant at the .05 level for the difference between proportions for Stennis Fellows and House staff, $t(280)=1,12, p=.26$, House staff and U.S. adults, $t(5066)=1.42, p=.15$; Senate staff and U.S. adults, $t(5063)=1.56, p=.12$; or all staff and U.S. adults, $t(5231)=.33, p=.74$. The null hypotheses that there were no differences in proportions within the populations could not be rejected.

\section{Moderately Religious}

House (31.7\%) and Senate (31.1\%) staff were less likely than Stennis Fellows (40\%) or U.S. adults $(41.7 \%)$ to consider themselves moderately religious. The t-statistic was significant at the .05 level for the difference in proportions for House staff and U.S. adults, $t(5066)=1.58, p=.009$, and Senate staff and U.S. adults, $t(5063)=2.71, p=.006$. House and Senate staff are less likely to report that they consider themselves moderately religious than U.S. adults in the GSS2010 survey.

The two-sample, two-tailed t-statistic was not significant at the .05 level for the difference in the proportion of respondents who consider themselves moderately religious for House staff and Stennis Fellows, $t(280)=1.44, p=.15$, or for Senate staff and Stennis 
Fellows, $t(277)=1.54, p=.125$. The null hypothesis that there is no difference in the proportions within the populations cannot be rejected.

\section{Slightly Religious}

Stennis Fellows (23.5\%), House staff (23.4\%), Senate staff (23.2\%) and all staffweighted (23.3\%) reported being slightly religious at rates comparable to GSS2010 respondents $(23.8 \%)$.

\section{Not Religious}

Senate staff (33.5\%) were significantly more likely to describe themselves as being not religious than Stennis Fellows (20.9\%), House staff (24\%), or U.S. adults (17\%). In addition all staff-weighted (27.7\%) were more likely than U.S. adults to indicate that they were not religious. The two-sample, two-tailed t-statistic was significant at the .05 level for the difference in proportions between House staff and U.S. adults, $t(5066)=2.36$, $p=.018$; Senate staff and U.S. adults, $t(5063)=5.47, p=.00001$; all staff and U.S. adults, $t(5231)=4.95, p=.000001$; and for the difference between Stennis Fellows and Senate staff, $t(272)=1.98, p=.048$. A higher proportion of congressional staff report being not religious than GSS2010 adults.

The t-statistic was not significant at the .05 level for the difference between Stennis Fellows and U.S. adults, $t(5014)=1.1, p=.23$. The null hypothesis that there is no difference in proportions between the populations of Stennis Fellows and U.S. adults cannot be rejected. 


\section{Moderately or Very Combined}

$52.7 \%$ of House staff describe themselves as being moderately or very religious compared with $52.3 \%$ of Senate staff and $45.7 \%$ of Stennis Fellows. The collapsed categories hide a difference in level of intensity between House and Senate staff. House staff, as noted earlier, describe themselves as being very religious in greater proportion than do Senate staff.

A chi-square test for independence indicated no significant association between selfdescribed religiosity and House or Senate chamber, $X^{2}(3, n=331)=6.48, p=.090$, Cramer's V=0.140.

To what extend do you consider yourself a religious person?

\begin{tabular}{|c|c|c|c|c|c|}
\hline Chamber & & Frequency & Percent & Valid Percent & $\begin{array}{c}\text { Cumulative } \\
\text { Percent }\end{array}$ \\
\hline \multirow[t]{6}{*}{ House } & Very religious & 35 & 18.9 & 21.0 & 21.0 \\
\hline & Moderately religious & 53 & 28.6 & 31.7 & 52.7 \\
\hline & Slightly religious & 39 & 21.1 & 23.4 & 76.0 \\
\hline & Not religious at all & 40 & 21.6 & 24.0 & 100.0 \\
\hline & Total & 167 & 90.3 & 100.0 & \\
\hline & Missing & 18 & 9.7 & & \\
\hline Total & & 185 & 100.0 & & \\
\hline \multirow[t]{6}{*}{ Senate } & Very religious & 20 & 11.2 & 12.2 & 12.2 \\
\hline & Moderately religious & 51 & 28.7 & 31.1 & 43.3 \\
\hline & Slightly religious & 38 & 21.3 & 23.2 & 66.5 \\
\hline & Not religious at all & 55 & 30.9 & 33.5 & 100.0 \\
\hline & Total & 164 & 92.1 & 100.0 & \\
\hline & Missing & 14 & 7.9 & & \\
\hline Total & & 178 & 100.0 & & \\
\hline
\end{tabular}

To what extend do you consider yourself a religious person?

\begin{tabular}{crrrr}
\hline \hline Stennis Fellows & & & & \multicolumn{2}{c}{ Cumulative } \\
Percent
\end{tabular}


Missing

5.7

Total

122

100.0

To what extent do you consider yourself a religious person?

\begin{tabular}{crrrr}
\hline \hline General Social Survey & Frequency & Percent & Valid Percent & $\begin{array}{c}\text { Cumulative } \\
\text { Percent }\end{array}$ \\
\hline Very religious & 824 & 16.8 & 16.8 & 16.8 \\
Moderately religious & 2042 & 41.7 & 41.7 & 58.5 \\
Slightly religious & 1167 & 23.8 & 23.8 & 82.3 \\
Not religious at all & 833 & 17.0 & 17.0 & 99.3 \\
Don't know & 19 & .4 & .4 & 99.7 \\
No answer & 16 & .3 & .3 & 100.0 \\
Total & 4901 & 100.0 & 100.0 & \\
\hline \hline
\end{tabular}

To what extend do you consider yourself a religious person?

\begin{tabular}{llrrrr}
\hline \hline \multirow{2}{*}{ All Staff } & & & & \multicolumn{2}{c}{ Cumulative } \\
& & Frequency & Percent & Valid Percent & Percent \\
\hline & Very religious & 58 & 16.0 & 17.5 & 17.5 \\
& Moderately religious & 104 & 28.6 & 31.5 & 49.0 \\
& Slightly religious & 77 & 21.2 & 23.3 & 72.3 \\
& Not religious at all & 92 & 25.2 & 27.7 & 100.0 \\
& Total & 332 & 91.0 & 100.0 & \\
\cline { 2 - 4 } Total & System & 33 & 9.0 & & \\
\hline \hline
\end{tabular}

Do You Consider Yourself a Spiritual Person?

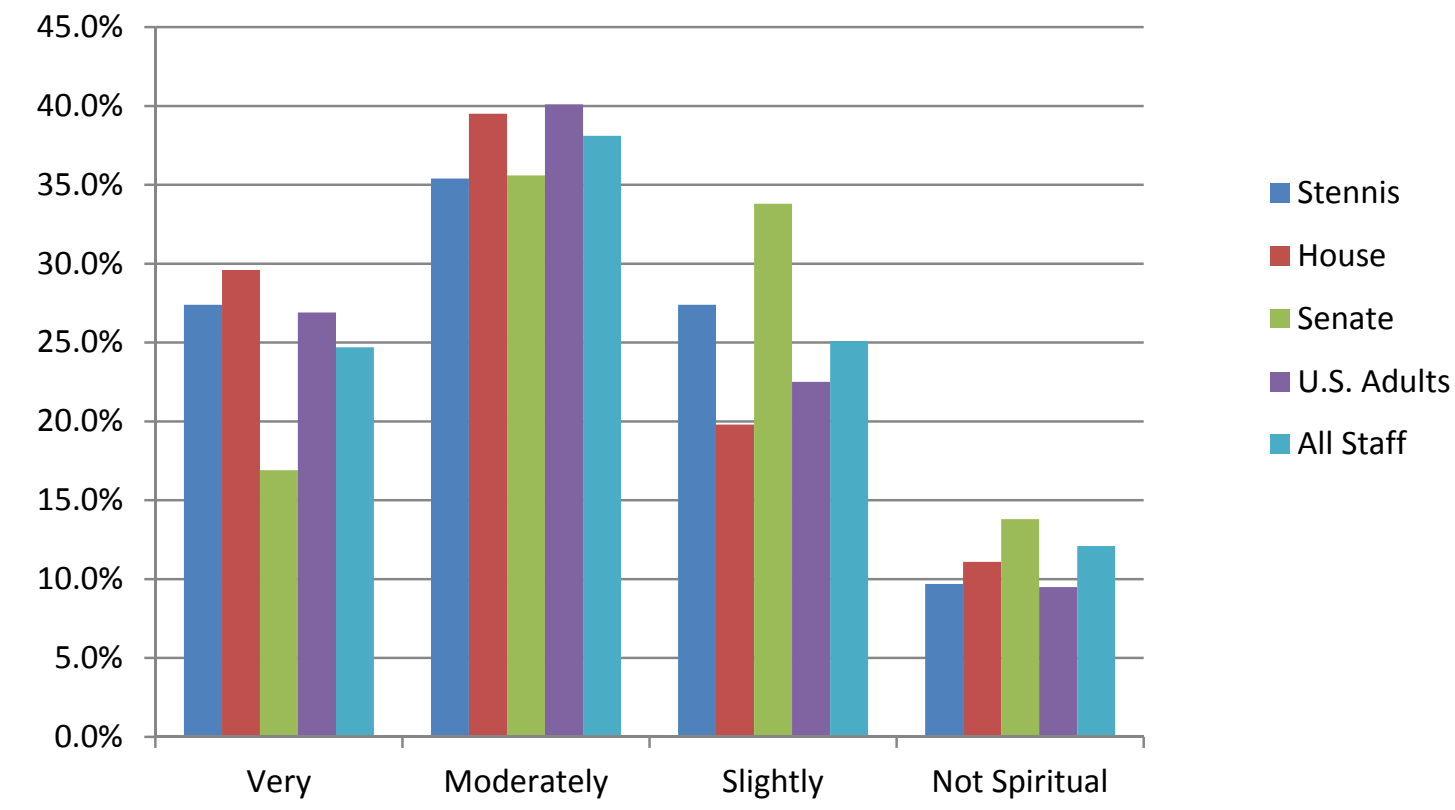


Respondents were presented with the question "to what extent do you consider yourself a spiritual person" and provided the following response choices: 1) very spiritual; 2) moderately spiritual; 3) slightly spiritual; or 4) not spiritual at all. ${ }^{101}$

Confidence intervals were calculated for each of the variable categories of the House and Senate samples. The widest confidence intervals were $\pm 7.5 \%$ for the House sample and $\pm 7.4 \%$ for the Senate sample. The widest confidence interval for Stennis Fellows was $\pm 6.7 \%$. The widest confidence interval for the all staff-weighted sample was $\pm 5.3 \%$.

\section{Very Spiritual}

House staff (29.4\%) were more likely than Stennis Fellows (27.4\%), Senate staff (17.4\%) or U.S. adults $(26.9 \%)$ to indicate that they considered themselves very spiritual. The two-sample, two-tailed t-test statistic was significant at the .05 level for the difference in proportions between the House and Senate staff, $t(322)=2.55, p=.01$; the difference in proportions between the Stennis Fellows and the Senate staff, $t(272)=1.98, p=.048$; and for the difference in proportions between the Senate staff and U.S. adults, $t(5060)=2.69$, $p=.007$.

\section{Slightly Spiritual}

Senate staff (33.5\%) were more likely than Stennis Fellows (27.4\%), House staff $(19.6 \%)$ or U.S. adults $(22.5 \%)$ to indicate that they considered themselves slightly spiritual. The two-sample, two-tailed, t- statistic was significant at the .05 level for the

${ }^{101}$ Question appeared in the 2010 General Social Survey (GSS SPRTPRSN). 
difference in proportions between the House and Senate staff, $t(322)=2.85, p=.005$, and the Senate staff and U.S. adults, $t(5060)=3.27, p=.001$.

The difference in proportions was not significant at the .05 level for the difference in the proportion of respondents describing themselves as slightly spiritual for Stennis Fellows and Senate staff, $t(272)=1.08, p=.28$, or for Stennis Fellows and U.S. adults, $t(5012)=1.23, p=.22$. The null hypothesis that there is no difference in the proportions within the populations cannot be rejected.

\section{Not Spiritual}

Senate staff (13.7\%) were more likely than Stennis Fellows (9.7\%), House staff $(11 \%)$ or GSS2010 adults $(9.5 \%)$ to report that they were not spiritual. The two-sample, twotailed t-statistic was not significant at the .05 level for the difference in proportions between Senate staff and GSS2010 adults, $t(5060)=1.78, p=.07$. The null hypothesis that there is no difference in proportions within the populations cannot be rejected.

\section{Very or Moderately Spiritual Combined}

$69.3 \%$ of House staff describe themselves as very or moderately spiritual compared with $52.8 \%$ of Senate staff, $62.8 \%$ of Stennis Fellows, and 67\% of GSS2010 adults. The twosample, two-tailed t-statistic was significant for the difference in proportions between House and Senate staff, $t(322)=3.046, p=.003$, and for the difference between Senate staff and GSS2010 adults, $t(5060)=3.76, p=.0002$. The t-statistic was not significant at the .05 level for the difference between Senate staff and Stennis Fellows, $t(272)=1.65, p=.1$, or for the difference between All staff-weighted and GSS2010 adults, $t(5223)=1.56, p=.12$. 
The null hypothesis that there is no difference in the population proportions between Stennis Fellows and Senate staff and between All staff-weighted and GSS2010 adults cannot be rejected.

A chi-square test for independence indicated a statistically significant but weak association between the extent to which an individual considered themselves to be spiritual and House or Senate chamber, $X^{2}(3, n=324)=11.804, p=.008$, Cramer's V=.191.

To what extent do you consider yourself a spiritual person?

\begin{tabular}{|c|c|c|c|c|c|}
\hline Chamber & & Frequency & Percent & Valid Percent & $\begin{array}{c}\text { Cumulative } \\
\text { Percent }\end{array}$ \\
\hline \multirow[t]{5}{*}{ House } & Very spiritual & 48 & 25.9 & 29.4 & 29.4 \\
\hline & Moderately spiritual & 65 & 35.1 & 39.9 & 69.3 \\
\hline & Slightly spiritual & 32 & 17.3 & 19.6 & 89.0 \\
\hline & Not spiritual at all & 18 & 9.7 & 11.0 & 100.0 \\
\hline & Total & 163 & 88.1 & 100.0 & \\
\hline Missing & System & 22 & 11.9 & & \\
\hline Total & & 185 & 100.0 & & \\
\hline \multirow[t]{6}{*}{ Senate } & Very spiritual & 28 & 15.7 & 17.4 & 17.4 \\
\hline & Moderately spiritual & 57 & 32.0 & 35.4 & 52.8 \\
\hline & Slightly spiritual & 54 & 30.3 & 33.5 & 86.3 \\
\hline & Not spiritual at all & 22 & 12.4 & 13.7 & 100.0 \\
\hline & Total & 161 & 90.4 & 100.0 & \\
\hline & Missing & 17 & 9.6 & & \\
\hline Total & & 178 & 100.0 & & \\
\hline
\end{tabular}

To what extent do you consider yourself a spiritual person?

\begin{tabular}{crrrr}
\hline \hline Stennis Fellows & & & & \multicolumn{2}{c}{$\begin{array}{c}\text { Cumulative } \\
\text { Percent }\end{array}$} \\
\hline Very spiritual & Frequency & Percent & Valid Percent & 27.4 \\
Moderately spiritual & 31 & 25.4 & 35.4 & 27.4 \\
Slightly spiritual & 40 & 32.8 & 27.4 & 62.8 \\
Not spiritual at all & 31 & 25.4 & 9.7 & 90.3 \\
Total & 11 & 9.0 & 100.0 & 100.0 \\
& 113 & 92.6 & &
\end{tabular}




\begin{tabular}{lrr} 
& 9 & 7.4 \\
Total & 122 & 100.0 \\
\hline \hline
\end{tabular}

To what extent do you consider yourself a spiritual person?

\begin{tabular}{crrrr}
\hline \hline General Social Survey & & & & \multicolumn{2}{c}{$\begin{array}{c}\text { Cumulative } \\
\text { Percent }\end{array}$} \\
\hline Very spiritual & Frequency & Percent & Valid Percent & 26.9 \\
Moderately spiritual & 1318 & 26.9 & 40.1 & 67.0 \\
Slightly spiritual & 1968 & 40.1 & 22.5 & 89.5 \\
Not spiritual & 1103 & 22.5 & 9.5 & 99.0 \\
Don't know & 464 & 9.5 & .7 & 99.7 \\
No answer & 37 & .7 & .3 & 100.0 \\
Total & 13 & .3 & 100.0 & \\
\hline \hline
\end{tabular}

To what extent do you consider yourself a spiritual person?

\begin{tabular}{|c|c|c|c|c|c|}
\hline \multirow[t]{2}{*}{ All Staff } & & \multirow{2}{*}{$\frac{\text { Frequency }}{80}$} & \multirow{2}{*}{$\frac{\text { Percent }}{22.0}$} & \multirow{2}{*}{$\frac{\text { Valid Percent }}{24.7}$} & \multirow{2}{*}{$\frac{\begin{array}{l}\text { Cumulative } \\
\text { Percent }\end{array}}{24.7}$} \\
\hline & Very spiritual & & & & \\
\hline & Moderately spiritual & 124 & 33.9 & 38.1 & 62.8 \\
\hline & Slightly spiritual & 81 & 22.3 & 25.1 & 87.9 \\
\hline & Not spiritual at all & 39 & 10.7 & 12.1 & 100.0 \\
\hline & Total & 324 & 89.0 & 100.0 & \\
\hline & Missing & 40 & 11.0 & & \\
\hline Total & & 364 & 100.0 & & \\
\hline
\end{tabular}




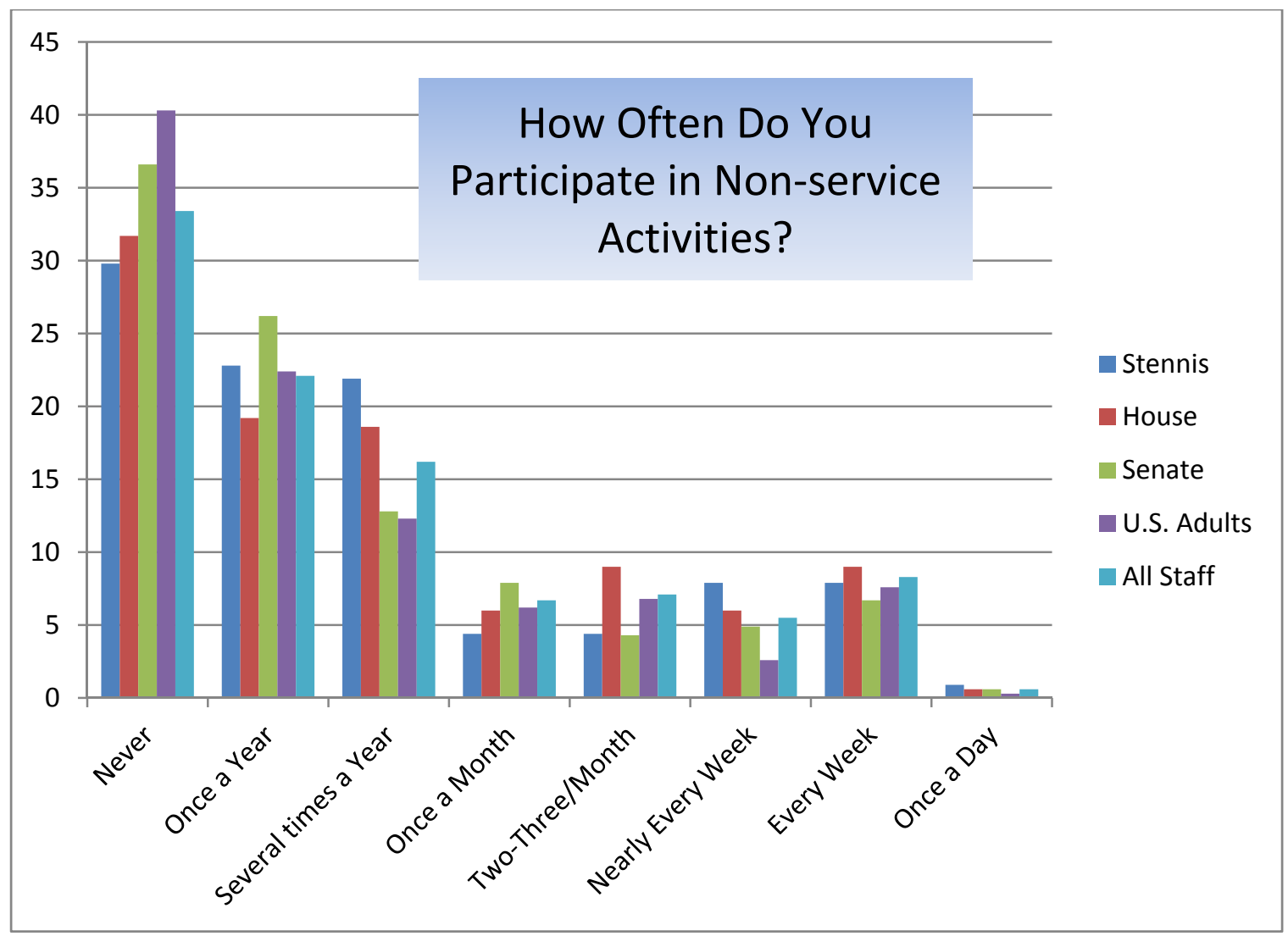

Respondents were asked "how often do you take part in the activities and organizations of a church or place of worship other than attending service" and provided with the following response choices: 1) never; 2) about once or twice a year; 3) several times a year; 4) about once a month; 5) two to three times a month; 6) nearly every week; 7) every week; 8) once a day; or 9) several times a day. ${ }^{102}$

Confidence intervals were calculated for each of the variable categories of the House and Senate samples. The widest confidence intervals were $\pm 7.0 \%$ for the House sample and $\pm 7.3 \%$ for the Senate sample. The widest confidence interval for Stennis Fellows was $\pm 6.4 \%$. The widest confidence interval for the all staff-weighted sample was $\pm 5.0 \%$.

${ }^{102}$ Question appeared on the General Social Survey 2010 (GSS RELACTIV) 
The GSS2010 included an extra response category ("less than once a year") that was not included in the staff surveys. "Less than once a year" and "about once or twice a year" were collapsed into a single category: "once a year" for purposes of making comparisons between the two survey populations.

Never

U.S. adults $(40.3 \%)$ were more likely to indicate that they never took part in activities at their church or place of worship other than worship services than Stennis Fellows $(29.8 \%)$, House staff (31.5\%), Senate staff (36.4\%) or all staff-weighted $(33.4 \%)$. The two-sample, two-tailed t-test statistic was significant at the .05 level for the difference in proportions between Stennis Fellows and U.S. adults, $t(5013)=2.26, p=.024$; House staff and U.S. adults, $t(5067)=2.29, p=.02$; and all staff-weighted and U.S. adults, $t(5233)=2.49, p=.01$.

The t-statistic was not significant at the .05 level for the difference between Senate staff and U.S. adults, $t(5064)=1.01, p=.32$. The null hypothesis that there is no difference in the proportions within the populations between Senate staff and U.S. adults cannot be rejected.

\section{Once A Year}

Senate staff (26.1\%) were more likely to indicate that they participated in activities at their place of worship once a year than Stennis Fellows (22.8\%), House staff (19.6\%), or U.S. adults (22.4\%). Stennis Fellows and all staff-weighted reported "once a year" at levels very similar to U.S. adults. The two-sample, two-tailed t-test statistic was not 
significant at the .05 level for the difference in proportions for Senate staff and U.S. adults, $t(5064)=1.12, p=.27$, or House and Senate staff, $t(331)=1.41, p=.16$. The null hypothesis that there is no difference in proportions between the populations of the Senate staff and U.S. adults or between the populations of House and Senate staff cannot be rejected.

Several Times A Year

Stennis Fellows (21.9\%) were more likely than House staff (18.5\%), Senate staff $(12.7 \%)$ or U.S. adults (12.3\%) to report that they attended activities several times a year. The two-sample, two-tailed t-test statistic was significant at the .05 level for the difference in proportions between Stennis Fellows and Senate staff, $t(277)=2.036, p=.04$; Stennis Fellows and U.S. adults, $t(5013)=3.06, p=.002$; House staff and U.S. adults, $t(5067)=2.39, p=.017$; and all staff-weighted and U.S. adults $t(5233)=2.08, p=.04$.

The two-sample, two-tailed t-statistic was not significant at the .05 level for the difference in proportions between House staff and Senate staff, $t(331)=1.46, p=.15$, or Stennis Fellows and House staff, $t(280)=.703, p=.94$. The null hypothesis that there is no difference in the proportions between House and Senate staff and between Stennis Fellows and House staff cannot be rejected.

\section{Two To Three Times Per Month}

House staff (8.9\%) were more likely than Senate staff $(4.2 \%)$ or U.S. adults $(6.8 \%)$ to report that they attended activities two to three times per month. The two-sample, twotailed t-statistic was not significant at the .05 level for the difference in proportions 
between House staff and Senate staff, $t(331)=1.73, p=.09$; House staff and U.S. adults, $t(5067)=1.05, p=.29$; or Senate staff and U.S. adults, $t(5064)=1.30, p=.19$. The null hypothesis that there is no difference in proportions within the populations cannot be rejected.

\section{Nearly Every Week}

Stennis Fellows (7.9\%) were more likely than House staff (6\%), Senate staff $(4.8 \%)$ or GSS2010 adults $(2.6 \%)$ to report that they participated in non-service activities nearly every week. The two-sample, two-tailed t-statistic for the difference in proportions was significant at the .05 level for the difference between Stennis Fellows and GSS2010 adults, $t(5013)=3.42, p=.0006$, and between House staff and GSS2010 adults, $t(5067)=2.65, p=.008$.

The two-sample, two-tailed t-statistic for the difference in proportions between respondents reporting they participated in non-service activities nearly every week was not significant at the .05 level for the difference between Senate staff and GSS2010 adults, $t(5064)=1.71, p=.008$, or for the difference between Stennis Fellows and House or Senate staff. The null hypothesis that there is no difference in the population proportions cannot be rejected.

Every Week

Stennis Fellows (7.9\%), House staff (8.9\%), Senate staff (7.3\%) and all staff-weighted $(8.3 \%)$ reported participating in non-service activities every week at rates comparable to those reported by GSS2010 adults (7.6\%). 
A chi-square test for independence indicated no association between frequency of attendance at non-service activities and House or Senate chamber, $X^{2}(7, n=333)=7.5$, $p=.379$, Cramer's V=.150.

How often do you take part in the activities and organizations of a church or place of worship other than attending services

\begin{tabular}{|c|c|c|c|c|c|}
\hline \multicolumn{2}{|l|}{ Chamber } & \multirow{2}{*}{$\frac{\text { Frequency }}{53}$} & \multirow{2}{*}{$\frac{\text { Percent }}{28.6}$} & \multirow{2}{*}{$\frac{\text { Valid Percent }}{31.5}$} & \multirow{2}{*}{$\begin{array}{c}\begin{array}{c}\text { Cumulative } \\
\text { Percent }\end{array} \\
31.5\end{array}$} \\
\hline House & Never & & & & \\
\hline & About once or twice a year & 33 & 17.8 & 19.6 & 51.2 \\
\hline & Several times a year & 31 & 16.8 & 18.5 & 69.6 \\
\hline & About once a month & 10 & 5.4 & 6.0 & 75.6 \\
\hline & 2-3 times a month & 15 & 8.1 & 8.9 & 84.5 \\
\hline & Nearly every week & 10 & 5.4 & 6.0 & 90.5 \\
\hline & Every week & 15 & 8.1 & 8.9 & 99.4 \\
\hline & Once a day & 1 & .5 & .6 & 100.0 \\
\hline & Total & 168 & 90.8 & 100.0 & \\
\hline Missing & System & 17 & 9.2 & & \\
\hline Total & & 185 & 100.0 & & \\
\hline \multirow[t]{10}{*}{ Senate } & Never & 60 & 33.7 & 36.4 & 36.4 \\
\hline & About once or twice a year & 43 & 24.2 & 26.1 & 62.4 \\
\hline & Several times a year & 21 & 11.8 & 12.7 & 75.2 \\
\hline & About once a month & 13 & 7.3 & 7.9 & 83.0 \\
\hline & 2-3 times a month & 7 & 3.9 & 4.2 & 87.3 \\
\hline & Nearly every week & 8 & 4.5 & 4.8 & 92.1 \\
\hline & Every week & 12 & 6.7 & 7.3 & 99.4 \\
\hline & Once a day & 1 & 6 & .6 & 100.0 \\
\hline & Total & 165 & 92.7 & 100.0 & \\
\hline & Missing & 13 & 7.3 & & \\
\hline Total & & 178 & 100.0 & & \\
\hline
\end{tabular}

How often do you take part in the activities and organizations of a church or place of worship other than attending services

\begin{tabular}{|c|c|c|c|c|}
\hline Stennis Fellows & Frequency & Percent & Valid Percent & $\begin{array}{c}\text { Cumulative } \\
\text { Percent }\end{array}$ \\
\hline Never & 34 & 27.9 & 29.8 & 29.8 \\
\hline About once or twice a year & 26 & 21.3 & 22.8 & 52.6 \\
\hline Several times a year & 25 & 20.5 & 21.9 & 74.6 \\
\hline About once a month & 5 & 4.1 & 4.4 & 78.9 \\
\hline 2-3 times a month & 5 & 4.1 & 4.4 & 83.3 \\
\hline Nearly every week & 9 & 7.4 & 7.9 & 91.2 \\
\hline Every week & 9 & 7.4 & 7.9 & 99.1 \\
\hline Once a day & 1 & .8 & .9 & 100.0 \\
\hline
\end{tabular}




\begin{tabular}{llccc}
\hline & Total & 114 & 93.4 & 100.0 \\
Missing & System & 8 & 6.6 & \\
Total & & 122 & 100.0 & \\
\hline \hline
\end{tabular}

How often do you take part in the activities and organizations of a church or place of worship other than attending services

\begin{tabular}{|c|c|c|c|c|}
\hline General Social Survey & Frequency & Percent & Valid Percent & $\begin{array}{c}\text { Cumulative } \\
\text { Percent }\end{array}$ \\
\hline Never & 1975 & 40.3 & 40.3 & 40.3 \\
\hline Less than once a year & 384 & 7.8 & 7.8 & 48.1 \\
\hline About once or twice a year & 717 & 14.6 & 14.6 & 62.8 \\
\hline Several times a year & 603 & 12.3 & 12.3 & 75.1 \\
\hline About once a month & 302 & 6.2 & 6.2 & 81.3 \\
\hline Two to three times a month & 336 & 6.8 & 6.8 & 88.1 \\
\hline Nearly every week & 129 & 2.6 & 2.6 & 90.7 \\
\hline Every week & 372 & 7.6 & 7.6 & 98.3 \\
\hline Several times a week & 45 & .9 & .9 & 99.2 \\
\hline Once a day & 16 & .3 & .3 & 99.6 \\
\hline Don't know & 10 & .2 & .2 & 99.8 \\
\hline No answer & 11 & .2 & .2 & 100.0 \\
\hline Total & 4901 & 100.0 & 100.0 & \\
\hline
\end{tabular}

How often do you take part in the activities and organizations of a church or place of worship other than attending services

\begin{tabular}{|c|c|c|c|c|c|}
\hline \multicolumn{2}{|l|}{ All Staff } & \multirow{2}{*}{$\frac{\text { Frequency }}{112}$} & \multirow{2}{*}{$\frac{\text { Percent }}{30.6}$} & \multirow{2}{*}{$\frac{\text { Valid Percent }}{33.4}$} & \multirow{2}{*}{$\begin{array}{c}\begin{array}{c}\text { Cumulative } \\
\text { Percent }\end{array} \\
33.4\end{array}$} \\
\hline & Never & & & & \\
\hline & About once or twice a year & 74 & 20.3 & 22.1 & 55.6 \\
\hline & Several times a year & 54 & 14.8 & 16.2 & 71.8 \\
\hline & About once a month & 22 & 6.1 & 6.7 & 78.5 \\
\hline & 2-3 times a month & 24 & 6.5 & 7.1 & 85.6 \\
\hline & Nearly every week & 18 & 5.1 & 5.5 & 91.1 \\
\hline & Every week & 28 & 7.6 & 8.3 & 99.4 \\
\hline & Once a day & 2 & .5 & 6 & 100.0 \\
\hline & Total & 334 & 91.5 & 100.0 & \\
\hline & Missing & 31 & 8.5 & & \\
\hline Total & & 364 & 100.0 & & \\
\hline
\end{tabular}




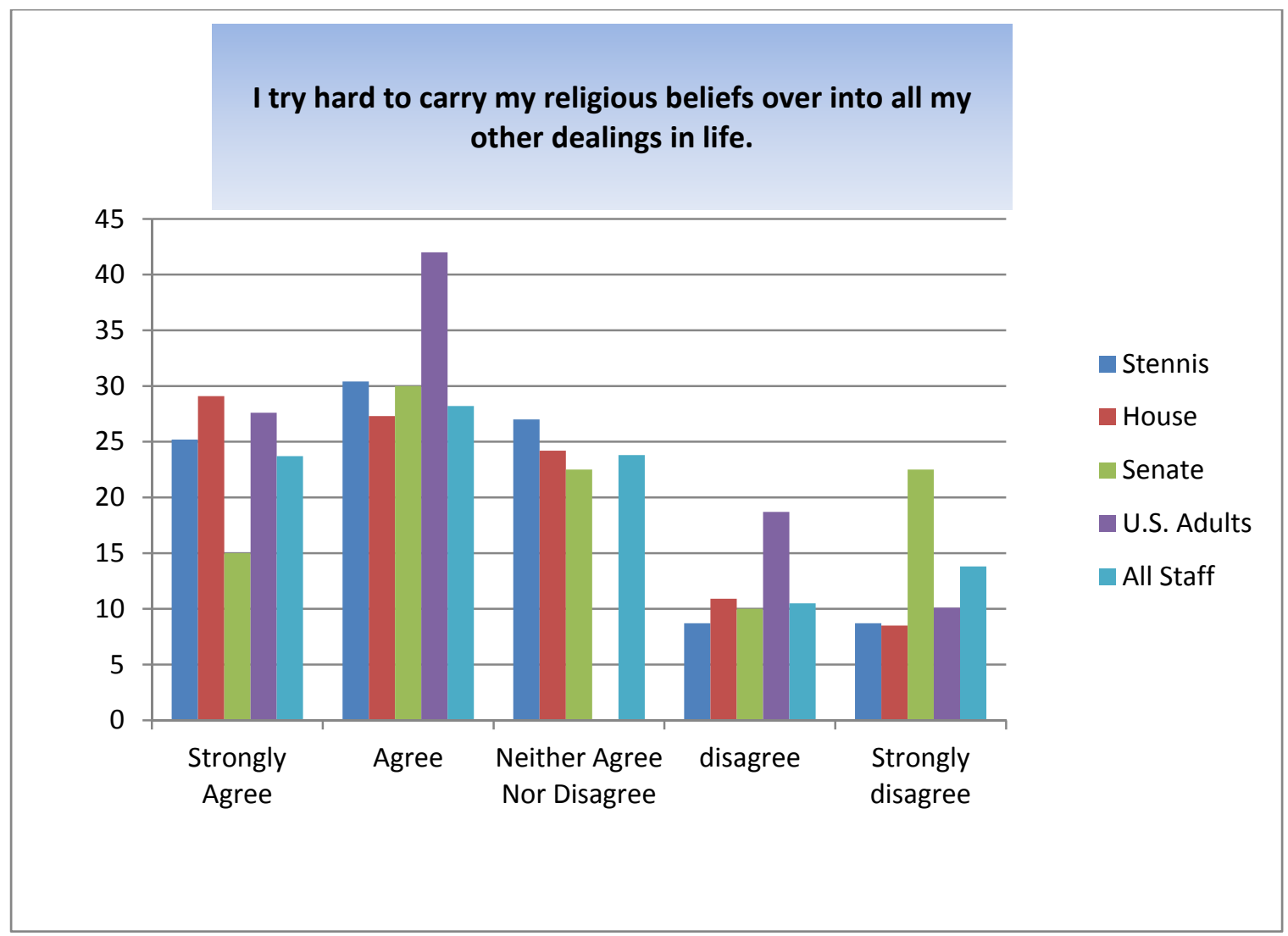

Respondents were asked whether they "strongly agree, agree, disagree, or strongly disagree" with the statement, "I try hard to carry my religious believes over into all my other dealings in life."103

Confidence intervals were calculated for each of the variable categories of the House and Senate samples. The widest confidence intervals were $\pm 6.9 \%$ for the House sample and $\pm 7.03 \%$ for the Senate sample. The widest confidence interval for Stennis Fellows was $\pm 6.4 \%$. The widest confidence interval for the all staff-weighted sample was $\pm 4.8 \%$.

${ }^{103}$ Question was adopted from the Hoge Intrinsic Religious Motivation Scale and appeared on the 2010
General Social Survey (GSS RELLIFE). Designed to measure intrinsic religiosity. 134 | P a g e 
The General Social Survey scale did not include the response category "neither agree nor disagree" that is part of the original Hoge Scale. This may have resulted in higher scores in the "agree" and "disagree" categories among GSS2010 respondents.

\section{Strongly Agree}

House staff (28.9\%) are more likely than Stennis Fellows (25.2\%), Senate staff (15.5\%) or GSS2010 adults (27.6\%) to strongly agree with the statement "I try hard to carry my religious beliefs over into all my other dealings in life."The two-sample, two-tailed tstatistic was significant at the .05 level for the difference in proportions for House and Senate staff, $t(325)=2.91, p=.004$; Stennis Fellows and Senate staff, $t(274)=2.0, p=.046$; and Senate staff and GSS2010 adults, $t(5060)=3.39, p=.0007$.

The two-sample, two-tailed t-statistic was not significant at the .05 level for the difference in proportions for All staff-weighted (23.7\%) and GSS2010 adults, $t(5227)=1.53, p=.125$. The null hypothesis that there is no difference in population proportions between all staff-weighted and GSS2010 adults cannot be rejected.

Agree

GSS2010 adults (42\%) were more likely to agree with the statement than Stennis Fellows (30.4\%), House staff $(27.1 \%)$, Senate staff $(29.8 \%)$ or all staff $(28.2 \%)$. The twosample, two-tailed t-statistic was significant at the .05 level for the difference in proportions between GSS2010 adults and Stennis Fellows, $t(5014)=2.49, p=.013$; GSS2020 adults and House staff, $t(5065)=3.83, p=.0001$; U.S. adults and Senate staff, $t(5060)=3.09, p=.0001$; and GSS2010 adults and all staff, $t(5227)=4.92, p=.000001$. 


\section{Disagree}

U.S. adults (18.7\%) were more likely to disagree with the statement than Stennis Fellows $(8.7 \%)$, House staff $(10.8 \%)$, Senate staff $(9.9 \%)$ or all staff $(10.5 \%)$. The t-statistic was significant at the .05 level for all pairings: U.S. adults and Stennis Fellows, $t(5014)=2.73, p=.006$; U.S. adults and House staff, $t(5065)=2.58, p=.01$; U.S. adults and Senate staff, $t(5060)=2.83, p=.005$; and U.S. adults and all staff, $t(5227)=3.73, p=.0002$.

\section{Strongly Disagree}

Senate staff (22.4\%) were more likely to strongly disagree with the statement than the Stennis Fellows (8.7\%), House staff $(8.4 \%)$, or U.S. adults (10.1\%). The two-sample, two-tailed t-statistic was significant at the .05 level for the difference in proportions between all pairings: Senate staff and Stennis Fellows, $t(274)=3.01, p=.003$; Senate and House staff, $t(325)=3.52, p=.0005$; Senate staff and U.S. adults, $t(5060)=5.02$, $p=.000001 ;$ and all staff and U.S. adults, $t(5227)=2.13, p=.04$.

\section{Agree and Strongly Agree Combined}

$69.6 \%$ of GSS2010 adults agreed or strongly agreed with the statement, compared with $56 \%$ of House staff, $45.3 \%$ of Senate staff, and 55.6\% of Stennis Fellows. The GSS2010 adult results are skewed because respondents were not given the option of "neither agree nor disagree" which was used by 20 to $25 \%$ of the respondents in this survey. The twosample, two-tailed t-statistic for the difference in proportions was not significant at the .05 level for the difference between House and Senate staff, $t(325)=1.94, p=.054$. The null hypothesis that there is no difference in population proportions between House and Senate staff cannot be rejected. 
A chi-square test for independence indicated a statistically significant medium association between level of agreement with the statement and House or Senate chamber, $X^{2}(4, n=327)=17.393, p=.002$, Cramer's V=.231.

I try hard to carry my religious beliefs over into all my other dealings in life.

\begin{tabular}{llcccc}
\hline \hline \multirow{2}{*}{ Chamber } & & & & & Cumulative \\
Percent
\end{tabular}

I try hard to carry my religious beliefs over into all my other dealings in life.

\begin{tabular}{|c|c|c|c|c|c|}
\hline \multicolumn{2}{|c|}{ Stennis Fellows } & \multirow{2}{*}{$\frac{\text { Frequency }}{29}$} & \multirow{2}{*}{$\frac{\text { Percent }}{23.8}$} & \multirow{2}{*}{$\frac{\text { Valid Percent }}{25.2}$} & \multirow{2}{*}{$\begin{array}{c}\text { Cumulative } \\
\text { Percent }\end{array}$} \\
\hline Valid & Strongly agree & & & & \\
\hline & Agree & 35 & 28.7 & 30.4 & 55.7 \\
\hline & Neither Agree nor Disagree & 31 & 25.4 & 27.0 & 82.6 \\
\hline & Disagree & 10 & 8.2 & 8.7 & 91.3 \\
\hline & Strongly Disagree & 10 & 8.2 & 8.7 & 100.0 \\
\hline & Total & 115 & 94.3 & 100.0 & \\
\hline & Missing & 7 & 5.7 & & \\
\hline Total & & 122 & 100.0 & & \\
\hline
\end{tabular}

I try hard to carry my religious beliefs over into all my other dealings in life.

\begin{tabular}{ccccc}
\hline \hline General Social Survey & Frequency & Percent & Valid Percent & $\begin{array}{c}\text { Cumulative } \\
\text { Percent }\end{array}$ \\
\hline Strongly agree & 1355 & 27.6 & 27.6 & 27.6 \\
Agree & 2060 & 42.0 & 42.0 & 69.7
\end{tabular}




\begin{tabular}{lcccc}
\hline Disagree & 918 & 18.7 & 18.7 & 88.4 \\
Strongly disagree & 494 & 10.1 & 10.1 & 98.5 \\
Don't know & 49 & 1.0 & 1.0 & 99.5 \\
No answer & 25 & .5 & .5 & 100.0 \\
Total & 4901 & 100.0 & 100.0 & \\
\hline \hline
\end{tabular}

I try hard to carry my religious beliefs over into all my other dealings in life.

\begin{tabular}{llcccc}
\hline \hline All Staff & & & & Cumulative \\
\hline \multirow{6}{*}{ Total } & Strongly agree & 78 & 21.4 & 23.7 & 23.7 \\
& Agree & 92 & 25.3 & 28.2 & 51.9 \\
& Neither Agree nor Disagree & 78 & 21.4 & 23.8 & 75.7 \\
& Disagree & 34 & 9.4 & 10.5 & 86.2 \\
& Strongly Disagree & 45 & 12.5 & 13.8 & 100.0 \\
& Total & 328 & 90.0 & 100.0 & \\
& Missing & 36 & 10.0 & & \\
\hline \hline
\end{tabular}

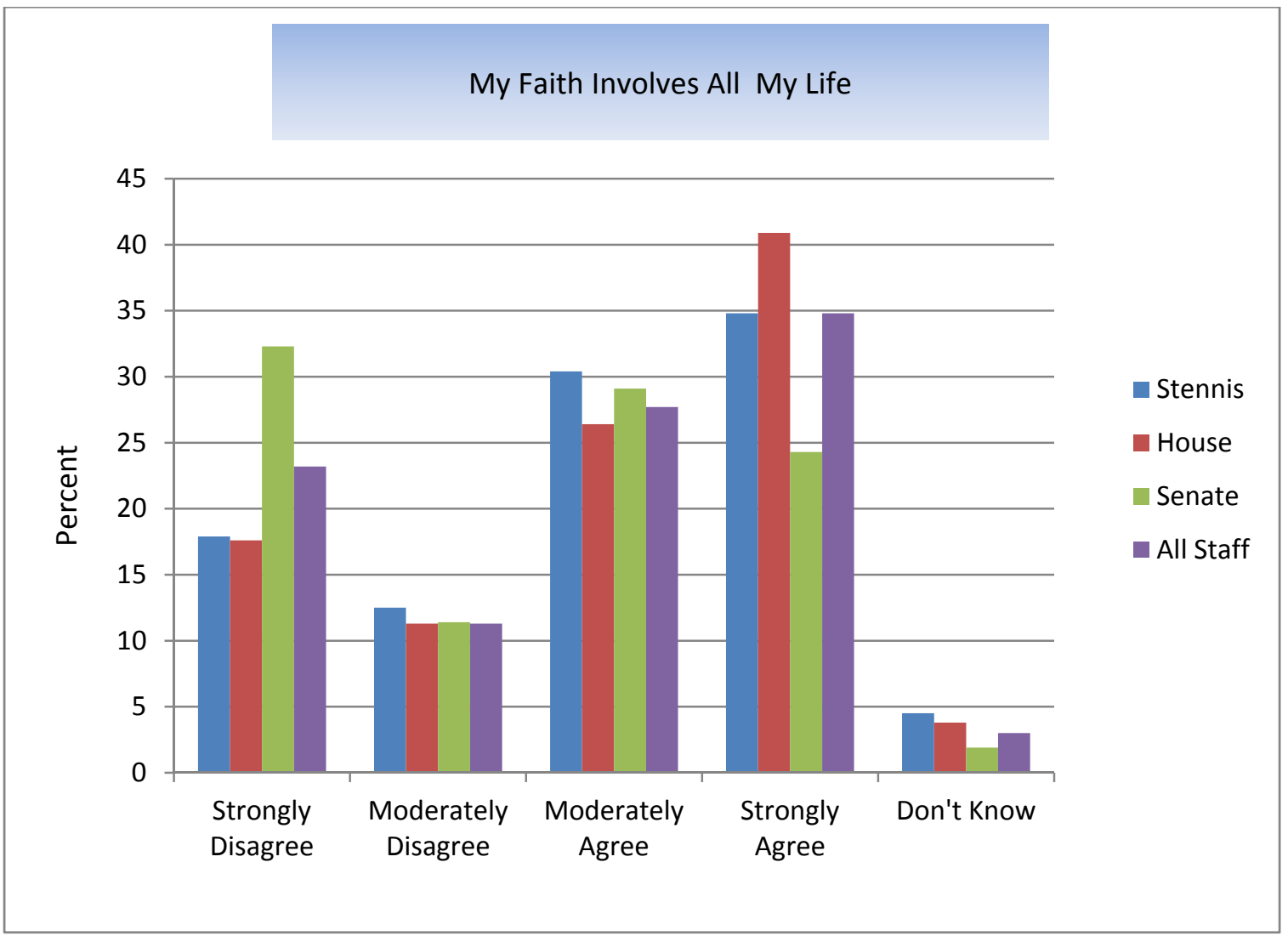


Respondents were asked whether they strongly disagree, moderately disagree, moderately agree, or strongly agree with the statement, "My faith involves all my life."104

Confidence intervals were calculated for each of the variable categories of the House and Senate samples. The widest confidence intervals were $\pm 7.6 \%$ for the House sample and $\pm 7.2 \%$ for the Senate sample. The widest confidence interval for Stennis Fellows was $\pm 6.8 \%$. The widest confidence interval for the All staff-weighted sample was $\pm 5.2 \%$.

\section{Strongly Disagree}

Senate staff (32.1\%)were more likely than Stennis Fellows (17.9\%) or House staff $(17.5 \%)$ to strongly disagree with the statement. The two-sample, two-tailed t-statistic was significant at the .05 level for the difference in proportions for each pairing: Senate staff and House staff, $t(317)=3.02, p=.003$, and Senate staff and Stennis Fellows, $t(269)=2.62, p=.009$.

\section{Strongly Agree}

House staff (40.6\%) were more likely to strongly agree with the statement than Senate staff $(25.8 \%)$ or Stennis Fellows (34.8\%). The two-sample, two-tailed t-statistic was significant at the .05 level for the difference in proportions between the House staff and the Senate staff, $t(317)=2.81, p=.005$. The $\mathrm{t}$-statistic was not significant at the .05 level for the difference in proportions between Senate staff and Stennis Fellows, $t(269)=1.6$, $p=.11$. The null hypothesis that there is no difference in population proportion between Senate staff and Stennis Fellows cannot be rejected.

${ }^{104}$ Adopted from the Hoge Intrinsic Religious Motivation Scale. 


\section{Agree and Strongly Agree Combined}

$67.5 \%$ of House staff agree or strongly agree with the statement, compared with $54.7 \%$ of Senate staff and $65.2 \%$ of Stennis Fellows. The two-sample, two-tailed t-statistic for the difference in proportions was significant at the .05 level for the difference between House and Senate staff, $t(317)=2.35, p=.02$, but not for the difference between Stennis Fellows and Senate staff, $t(269)=1.73, p=.085$. The null hypothesis that there is no difference in population proportions between Stennis Fellows and Senate staff cannot be rejected.

Conversely, $43.4 \%$ of Senate staff disagreed or strongly disagreed with the statement, compared with $30.4 \%$ of Stennis Fellows and $28.8 \%$ of House staff. The two-sample, two-tailed t-statistic was significant at the .05 level for the difference in proportions for House and Senate staff, $t(317)=2.72, p=.007$, and for the difference in proportions for Stennis Fellows and Senate staff, $t(269)=2.17, p=.03$.

A chi-square test for independence indicated a statistically significant medium association between agreement or disagreement with the statement and House or Senate chamber, $X^{2}(4, n=319)=13.228, p=.01$, Cramer's V $=.204$.

My faith involves all of my life.

\begin{tabular}{|c|c|c|c|c|c|}
\hline Chamber & & Frequency & Percent & Valid Percent & $\begin{array}{c}\text { Cumulative } \\
\text { Percent }\end{array}$ \\
\hline \multirow[t]{7}{*}{ House } & Strongly disagree & 28 & 15.1 & 17.5 & 17.5 \\
\hline & Moderately disagree & 18 & 9.7 & 11.3 & 28.7 \\
\hline & Moderately agree & 43 & 23.2 & 26.9 & 55.6 \\
\hline & Strongly agree & 65 & 35.1 & 40.6 & 96.3 \\
\hline & Don't know & 6 & 3.2 & 3.8 & 100.0 \\
\hline & Total & 160 & 86.5 & 100.0 & \\
\hline & Missing & 25 & 13.5 & & \\
\hline Total & & 185 & 100.0 & & \\
\hline
\end{tabular}




\begin{tabular}{llcccc}
\hline Senate & Strongly disagree & 51 & 28.7 & 32.1 & 32.1 \\
& Moderately disagree & 18 & 10.1 & 11.3 & 43.4 \\
& Moderately agree & 46 & 25.8 & 28.9 & 72.3 \\
& Strongly agree & 41 & 23.0 & 25.8 & 98.1 \\
& Don't know & 3 & 1.7 & 1.9 & 100.0 \\
& Total & 159 & 89.3 & 100.0 & \\
& Missing & 19 & 10.7 & & \\
& & 178 & 100.0 & & \\
& & &
\end{tabular}

\begin{tabular}{|c|c|c|c|c|}
\hline Stennis Fellows & Frequency & Percent & Valid Percent & $\begin{array}{c}\text { Cumulative } \\
\text { Percent }\end{array}$ \\
\hline Strongly disagree & 20 & 16.4 & 17.9 & 17.9 \\
\hline Moderately disagree & 14 & 11.5 & 12.5 & 30.4 \\
\hline Moderately agree & 34 & 27.9 & 30.4 & 60.7 \\
\hline Strongly agree & 39 & 32.0 & 34.8 & 95.5 \\
\hline Don't know & 5 & 4.1 & 4.5 & 100.0 \\
\hline Total & 112 & 91.8 & 100.0 & \\
\hline Missing & 10 & 8.2 & & \\
\hline Total & 122 & 100.0 & & \\
\hline
\end{tabular}

My faith involves all of my life.

\begin{tabular}{|c|c|c|c|c|c|}
\hline All Staff & & Frequency & Percent & Valid Percent & $\begin{array}{c}\text { Cumulative } \\
\text { Percent }\end{array}$ \\
\hline & Strongly disagree & 74 & 20.4 & 23.2 & 23.2 \\
\hline & Moderately disagree & 36 & 9.9 & 11.3 & 34.5 \\
\hline & Moderately agree & 88 & 24.2 & 27.7 & 62.2 \\
\hline & Strongly agree & 111 & 30.5 & 34.8 & 97.0 \\
\hline & Don't know & 10 & 2.6 & 3.0 & 100.0 \\
\hline & Total & 319 & 87.6 & 100.0 & \\
\hline & Missing & 45 & 12.4 & & \\
\hline Total & & 364 & 100.0 & & \\
\hline
\end{tabular}




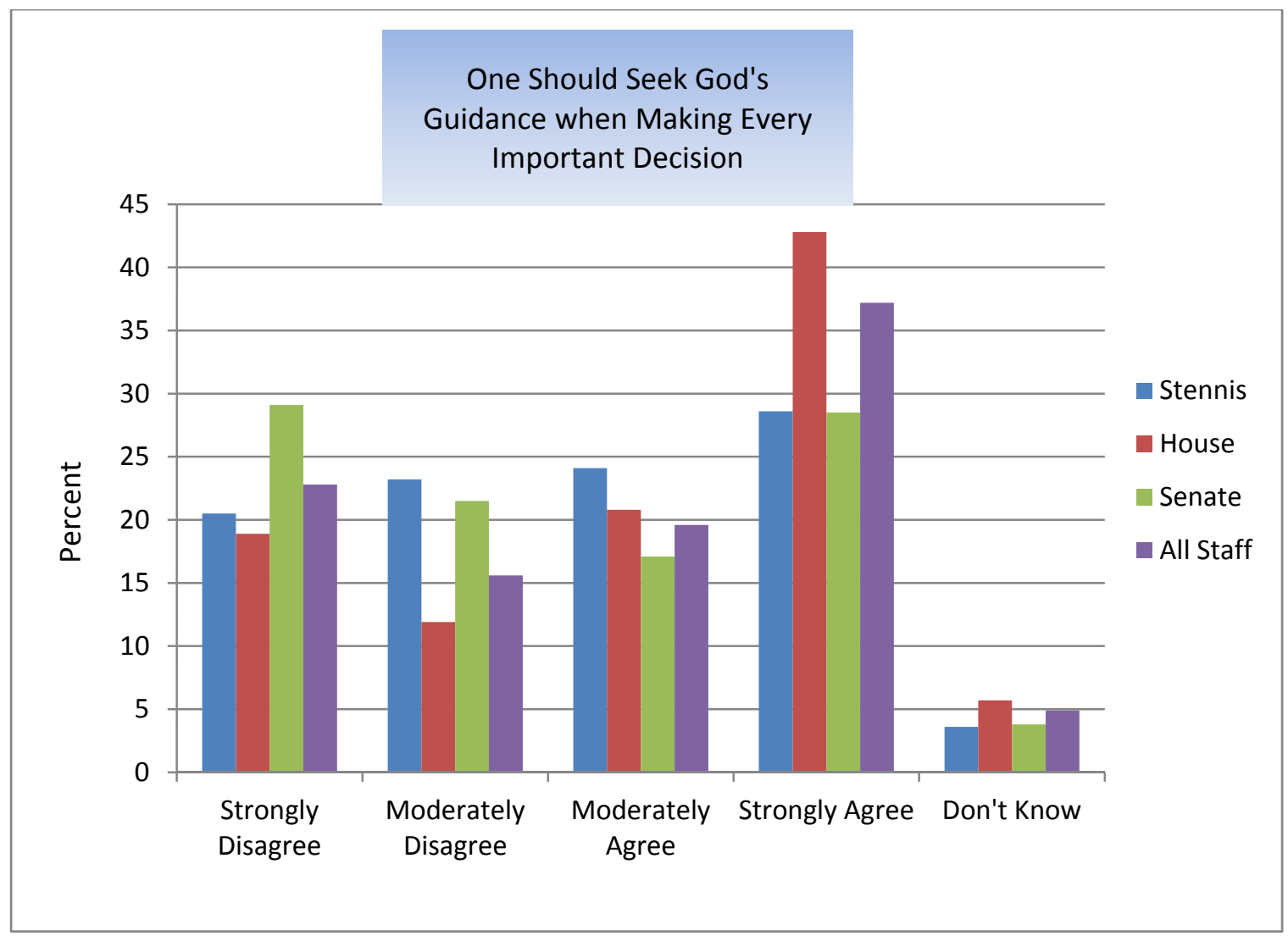

Respondents were asked if they "strongly disagree, moderately disagree, moderately agree, or strongly agree" with the statement, "One should seek God's guidance when making every important decision." 105

Confidence intervals were calculated for each of the variable categories of the House and Senate samples. The widest confidence intervals were $\pm 7.7 \%$ for the House sample and $\pm 7.0 \%$ for the Senate sample. The widest confidence interval for Stennis Fellows was $\pm 6.4 \%$. The widest confidence interval for the all staff-weighted sample was $\pm 5.3 \%$.

\footnotetext{
${ }^{105}$ Adopted from the Hogue Intrinsic Religious Motivation Scale. Designed to measure intrinsic religiosity.
} 


\section{Strongly Disagree}

Senate staff (28.9\%) were more likely than House staff (18.8\%) or Stennis Fellows $(20.5 \%)$ to strongly disagree with the statement. The two-sample, two-tailed t-statistic was significant at the .05 level for the difference in proportions between House and Senate staff, $t(317)=2.12, p=.035$. The two-sample, two-tailed t-statistic was not significant at the .05 level for the difference in proportions between Stennis Fellows and Senate staff, $t(269)=1.56, p=.11$. The null hypothesis that there is no difference in proportions between Stennis Fellows and Senate staff cannot be rejected.

\section{Moderately Disagree}

Stennis Fellows $(23.2 \%)$ were more likely to moderately disagree with the statement than House staff (11.9\%), Senate staff $(21.4 \%)$, or all staff-weighted $(15.6 \%)$. The twosample, two-tailed t-statistic was significant at the .05 level for the difference in proportions between House and Senate staff, $t(317)=2.28, p=.023$, and between Stennis Fellows and House staff, $t(270)=2.47, p=.014$. The t-statistic was not significant at the .05 level for the difference in proportions between Stennis Fellows and Senate staff, $t(269)=.351, p=.72$, or between Stennis Fellows and all staff-weighted, $t(429)=1.816$, $p=.069$. The null hypothesis that there is no difference between the population proportions between Stennis Fellows and Senate staff and between Stennis Fellows and all staff-weighted cannot be rejected.

\section{Moderately Agree}

Stennis Fellows (24.1\%) were more likely to moderately agree with the statement than House staff (21.3\%), Senate staff $(17 \%)$ or all staff-weighted (19.6\%). The two-sample, 
two-tailed t-statistic was not significant at the .05 level for the difference in proportions between Stennis Fellows and Senate staff, $t(269)=1.44, p=.151$. The null hypothesis that there was no difference in population proportions cannot be rejected.

\section{Strongly Agree}

House staff (42.5\%) were more likely to strongly agree with the statement than either Senate staff $(28.9 \%)$ or Stennis Fellows $(28.6 \%)$. The t-statistic was significant at the .05 level for the difference in proportions between House and Senate staff, $t(317)=2.53$, $p=.012$ and between Stennis Fellows and House staff, $t(270)=2.34, p=.02$. The twosample, two-tailed t-statistic was not significant at the .05 level for the difference in proportions between Stennis Fellows and all staff-weighted, $t(429)=1.64, p=.10$. The null hypothesis that there is no difference in the population proportion between Stennis Fellows and all staff cannot be rejected.

\section{Agree and Strongly Agree Combined}

$63.8 \%$ of House staff either agreed or strongly agreed with the statement, compared with $45.9 \%$ of Senate staff and $52.7 \%$ of Stennis Fellows. The two-sample, two-tailed tstatistic was significant at the .05 level for the difference in proportions between House and Senate staff, $t(317)=3.21, p=.001$, but not for the difference in proportions between Stennis Fellows and House staff, $t(270)=1.83, p=.068$. Senate staff were split evenly between those who strongly disagreed $(28.9 \%)$ with the statement and those who strongly agreed $(28.9 \%)$ with the statement. 
A chi-square test for independence confirmed a medium association between agreement with the statement and House or Senate chamber, $X^{2}(4, n=319)=13.260, p=.01$, Cramer's $\mathrm{V}=.204$.

One should seek God's guidance when making every important decision.

\begin{tabular}{|c|c|c|c|c|c|}
\hline Chamber & & Frequency & Percent & Valid Percent & $\begin{array}{c}\text { Cumulative } \\
\text { Percent }\end{array}$ \\
\hline \multirow[t]{7}{*}{ House } & Strongly disagree & 30 & 16.2 & 18.8 & 18.8 \\
\hline & Moderately disagree & 19 & 10.3 & 11.9 & 30.6 \\
\hline & Moderately agree & 34 & 18.4 & 21.3 & 51.9 \\
\hline & Strongly agree & 68 & 36.8 & 42.5 & 94.4 \\
\hline & Don't know & 9 & 4.9 & 5.6 & 100.0 \\
\hline & Total & 160 & 86.5 & 100.0 & \\
\hline & Missing & 25 & 13.5 & & \\
\hline Total & & 185 & 100.0 & & \\
\hline \multirow[t]{7}{*}{ Senate } & Strongly disagree & 46 & 25.8 & 28.9 & 28.9 \\
\hline & Moderately disagree & 34 & 19.1 & 21.4 & 50.3 \\
\hline & Moderately agree & 27 & 15.2 & 17.0 & 67.3 \\
\hline & Strongly agree & 46 & 25.8 & 28.9 & 96.2 \\
\hline & Don't know & 6 & 3.4 & 3.8 & 100.0 \\
\hline & Total & 159 & 89.3 & 100.0 & \\
\hline & Missing & 19 & 10.7 & & \\
\hline Total & & 178 & 100.0 & & \\
\hline
\end{tabular}

One should seek God's guidance when making every important decision.

\begin{tabular}{|c|c|c|c|c|}
\hline Stennis Fellows & Frequency & Percent & Valid Percent & $\begin{array}{c}\text { Cumulative } \\
\text { Percent }\end{array}$ \\
\hline Strongly disagree & 23 & 18.9 & 20.5 & 20.5 \\
\hline Moderately disagree & 26 & 21.3 & 23.2 & 43.8 \\
\hline Moderately agree & 27 & 22.1 & 24.1 & 67.9 \\
\hline Strongly agree & 32 & 26.2 & 28.6 & 96.4 \\
\hline Don't know & 4 & 3.3 & 3.6 & 100.0 \\
\hline Total & 112 & 91.8 & 100.0 & \\
\hline Missing & 10 & 8.2 & & \\
\hline Total & 122 & 100.0 & & \\
\hline
\end{tabular}

One should seek God's guidance when making every important decision.

\begin{tabular}{cccccc}
\hline \hline \multirow{2}{*}{ All Staff } & & & & Cumulative \\
& & Frequency & Percent & Valid Percent & \begin{tabular}{c} 
Percent \\
\hline
\end{tabular} Strongly disagree \\
Moderately disagree & 73 & 19.9 & 22.8 & 22.8 \\
& Moderately agree & 62 & 13.7 & 15.6 & 38.4 \\
& 62 & 17.1 & 19.6 & 57.9
\end{tabular}




\begin{tabular}{|c|c|c|c|c|c|}
\hline & Strongly agree & 119 & 32.5 & 37.2 & 95.1 \\
\hline & Don't know & 16 & 4.3 & 4.9 & 100.0 \\
\hline & Total & 319 & 87.6 & 100.0 & \\
\hline & Missing & 45 & 12.4 & & \\
\hline Total & & 364 & 100.0 & & \\
\hline
\end{tabular}

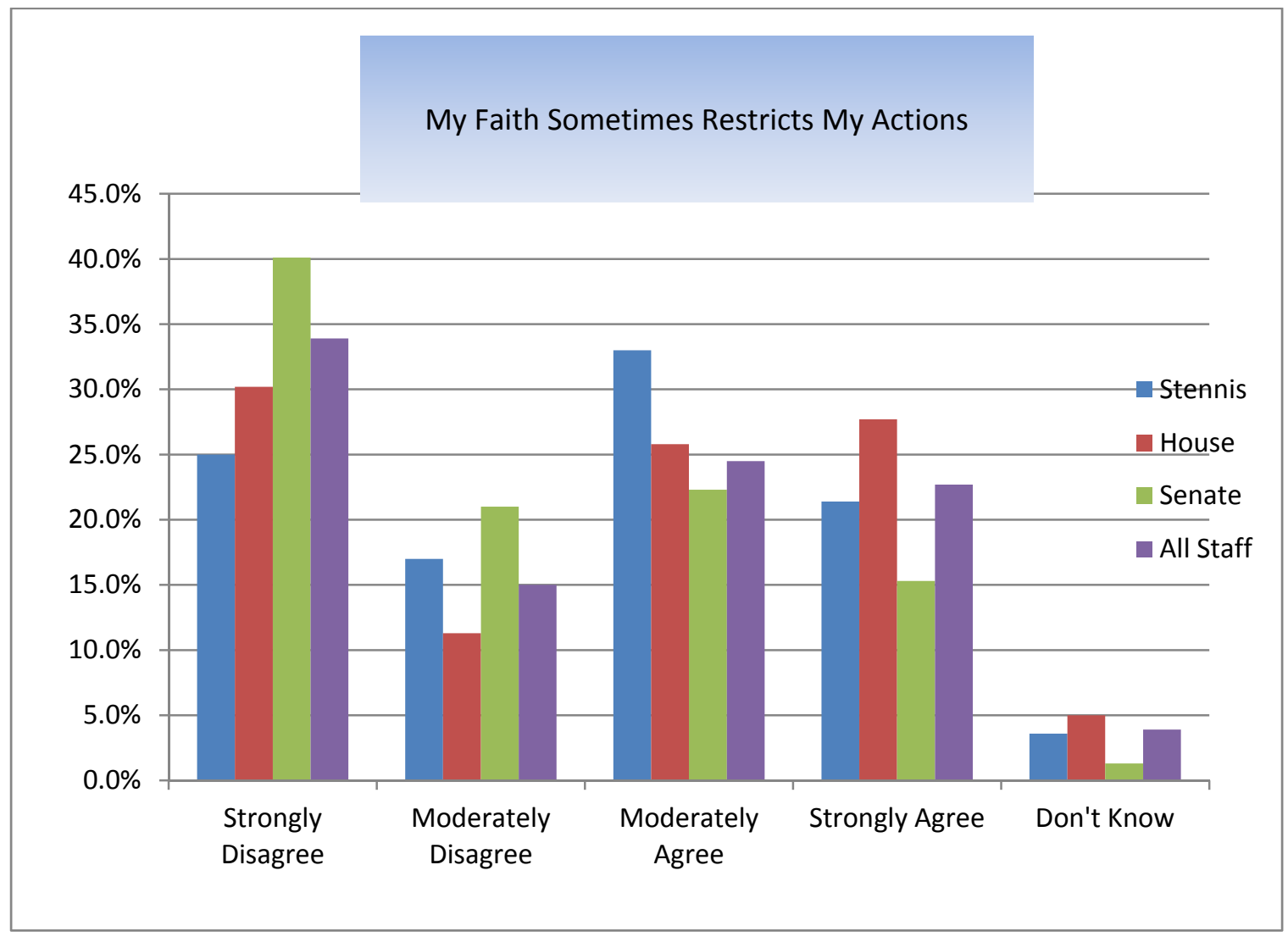

Respondents were asked whether they "strongly disagree, moderately disagree, moderately agree, or strongly agree" with the statement, "My faith sometimes restricts my actions."

Confidence intervals were calculated for each of the variable. The widest confidence intervals were $\pm 7.1 \%$ for the House sample and $\pm 7.6 \%$ for the Senate sample. The

\footnotetext{
${ }^{106}$ Adopted from the Hoge Intrinsic Religious Motivation Scale. Designed to measure intrinsic religiosity.
} 
widest confidence interval for Stennis Fellows was $\pm 6.7 \%$. The widest confidence interval for the all staff-weighted sample was $\pm 5.2 \%$.

\section{Strongly Disagree}

Senate staff (39.9\%) were more likely to strongly disagree with the statement than Stennis Fellows $(25 \%)$ or House staff $(30 \%)$. The two-sample, two-tailed t-statistic for the difference in proportions between Stennis Fellows and Senate staff was significant at the .05 level, $t(268)=2.55, p=.01$. The t-statistic for the difference between House and Senate staff was not significant at the .05 level, $t(316)=1.85, p=.065$. The null hypothesis that there was no difference in proportions between House and Senate staff cannot be rejected.

\section{Moderately Disagree}

Senate staff $(20.9 \%)$ were more likely to moderately disagree with the statement than Stennis Fellows (17\%) or House staff (11.3\%). The two-sample, two-tailed t-statistic for the difference in proportions between House and Senate staff was significant at the .05 level, $t(316)=2.33, p=.02$. The t-statistic was not significant at the .05 level for the difference between Stennis Fellows and Senate staff, $t(268)=.80, p=.42$. The null hypothesis that there was no difference in proportions between Stennis Fellows and Senate staff cannot be rejected.

\section{Moderately Agree}

Stennis Fellows (33\%) were more likely to moderately agree with the statement than House $(25.6 \%)$ or Senate staff $(22.8 \%)$. The two-sample, two-tailed t-statistic for the 
difference between Stennis Fellows and Senate staff was not significant at the .05 level, $t(268)=1.86, p=.064$. The null hypothesis that there was no difference in population proportion between Stennis Fellows and Senate staff cannot be rejected. Similarly, the difference in proportions between House and Senate staff was not significant at the .0 level.

\section{Strongly Agree}

House staff ( $27.5 \%$ ) were more likely to strongly agree with the statement than Stennis Fellows $(21.4 \%)$ or Senate staff (15.2\%). The two-sample, two-tailed t-statistic was significant for the difference between the House and Senate staff at the .05 level, $t(316)=2.67, p=.008$. The t-statistic was not significant at the .05 level for the difference between House staff and Stennis Fellows, $t(270)=1.14, p=.26$. The null hypothesis that there is no difference in population proportion between House staff and Stennis Fellows cannot be rejected.

\section{Moderately and Strongly Disagree Combined}

$60.8 \%$ of Senate staff moderately or strongly disagreed with the statement that "my faith sometimes restricts my actions," compared with $41.3 \%$ of House staff and $42 \%$ of Stennis Fellows. The two-sample, two-tailed t-statistic was significant at the .05 level for the difference in proportions between Senate and House staff, $t(316)=3.48, p=.0006$, and for the difference in proportions between Senate staff and Stennis Fellows, $t(268)=3.05, p=.003$. Conversely, $53.1 \%$ of House staff moderately or strongly agreed with the statement, compared with $38 \%$ of Senate staff and $54 \%$ of Stennis Fellows. 
A chi-square test for independence indicated a statistically significant moderate association between chamber (House or Senate) and agreement or disagreement with the statement "my faith sometimes restricts my actions," $X^{2}(4, n=318)=17.09, p=002$, Cramer's $V=.232$.

My faith sometimes restricts my actions.

\begin{tabular}{|c|c|c|c|c|c|}
\hline \multicolumn{2}{|l|}{ Chamber } & \multirow{2}{*}{$\frac{\text { Frequency }}{48}$} & \multirow{2}{*}{$\frac{\text { Percent }}{25.9}$} & \multirow{2}{*}{$\begin{array}{r}\text { Valid Percent } \\
30.0\end{array}$} & \multirow{2}{*}{$\begin{array}{r}\begin{array}{l}\text { Cumulative } \\
\text { Percent }\end{array} \\
30.0\end{array}$} \\
\hline House & Strongly disagree & & & & \\
\hline & Moderately disagree & 18 & 9.7 & 11.3 & 41.3 \\
\hline & Moderately agree & 41 & 22.2 & 25.6 & 66.9 \\
\hline & Strongly agree & 44 & 23.8 & 27.5 & 94.4 \\
\hline & Don't know & 9 & 4.9 & 5.6 & 100.0 \\
\hline & Total & 160 & 86.5 & 100.0 & \\
\hline Missing & System & 25 & 13.5 & & \\
\hline Total & & 185 & 100.0 & & \\
\hline Senate & Strongly disagree & 63 & 35.4 & 39.9 & 39.9 \\
\hline & Moderately disagree & 33 & 18.5 & 20.9 & 60.8 \\
\hline & Moderately agree & 36 & 20.2 & 22.8 & 83.5 \\
\hline & Strongly agree & 24 & 13.5 & 15.2 & 98.7 \\
\hline & Don't know & 2 & 1.1 & 1.3 & 100.0 \\
\hline & Total & 158 & 88.8 & 100.0 & \\
\hline Missing & System & 20 & 11.2 & & \\
\hline Total & & 178 & 100.0 & & \\
\hline
\end{tabular}

My faith sometimes restricts my actions.

\begin{tabular}{|c|c|c|c|c|}
\hline Stennis Fellows & Frequency & Percent & Valid Percent & $\begin{array}{c}\text { Cumulative } \\
\text { Percent }\end{array}$ \\
\hline Strongly disagree & 28 & 23.0 & 25.0 & 25.0 \\
\hline Moderately disagree & 19 & 15.6 & 17.0 & 42.0 \\
\hline Moderately agree & 37 & 30.3 & 33.0 & 75.0 \\
\hline Strongly agree & 24 & 19.7 & 21.4 & 96.4 \\
\hline Don't know & 4 & 3.3 & 3.6 & 100.0 \\
\hline Total & 112 & 91.8 & 100.0 & \\
\hline Missing & 10 & 8.2 & & \\
\hline Total & 122 & 100.0 & & \\
\hline
\end{tabular}

My faith sometimes restricts my actions.

\begin{tabular}{rrrrrr}
\hline \hline \multirow{2}{*}{ All Staff } & & & & \multicolumn{2}{c}{ Cumulative } \\
& & Frequency & Percent & Valid Percent & Percent \\
\cline { 2 - 6 } & Strongly disagree & 108 & 29.6 & 33.9 & 33.9 \\
& Moderately disagree & 48 & 13.1 & 15.0 & 48.9
\end{tabular}




\begin{tabular}{|c|c|c|c|c|c|}
\hline & Moderately agree & 78 & 21.4 & 24.5 & 73.4 \\
\hline & Strongly agree & 72 & 19.8 & 22.7 & 96.1 \\
\hline & Don't know & 12 & 3.4 & 3.9 & 100.0 \\
\hline & Total & 318 & 87.4 & 100.0 & \\
\hline & Missing & 46 & 12.6 & & \\
\hline Total & & 364 & 100.0 & & \\
\hline
\end{tabular}

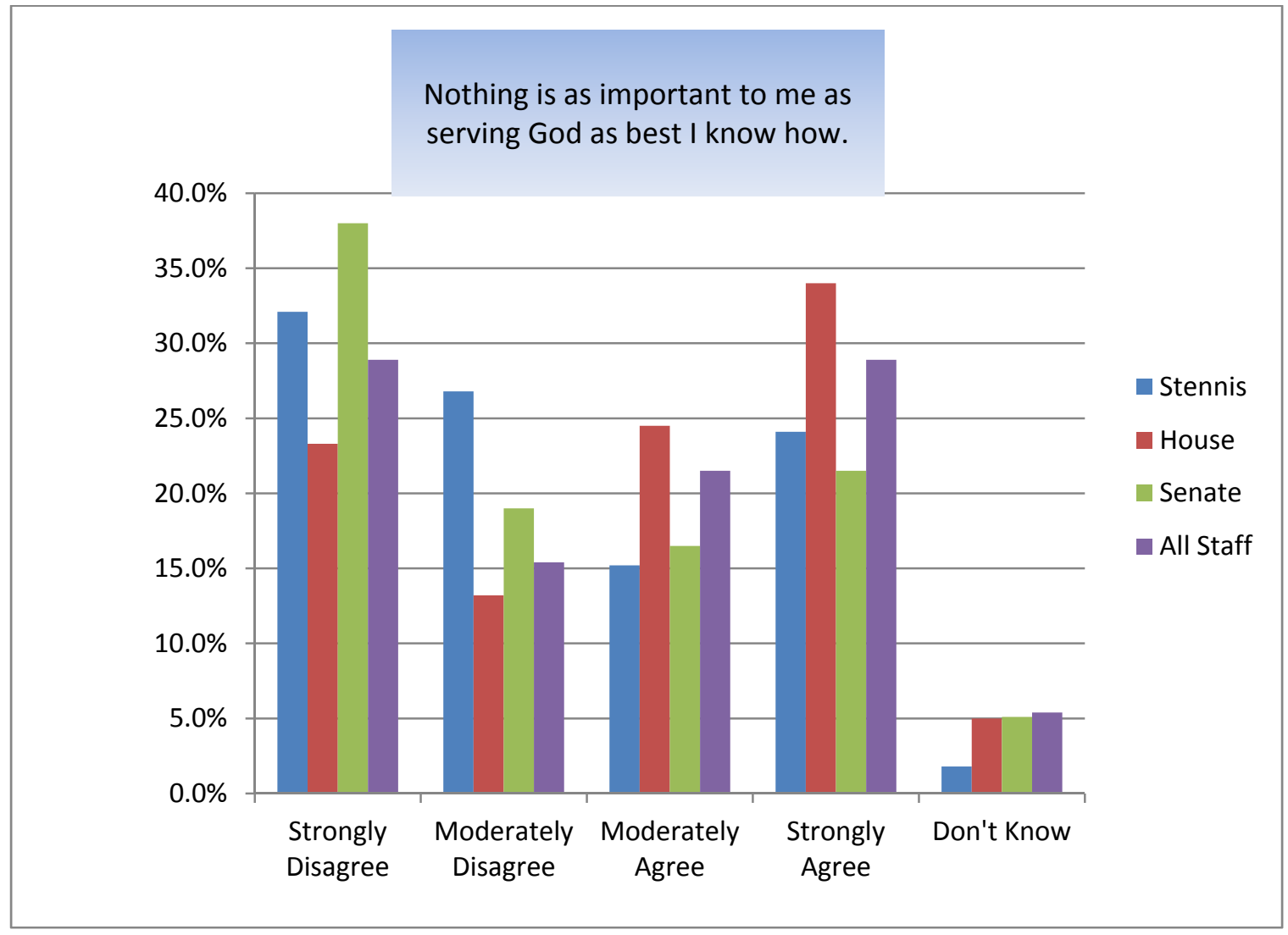

Respondents were asked whether they "strongly disagree, moderately disagree, moderately agree, or strongly agree" with the statement, "Nothing is as important as serving God as best I know how."107

Confidence intervals were calculated for each of the variable categories of the House and Senate samples. The widest confidence intervals were $\pm 7.3 \%$ for the House sample and

\footnotetext{
${ }^{107}$ Question adopted from the Hogue Intrinsic Religious Motivation Scale. Designed to measure intrinsic religiosity.
} 
$\pm 7.5 \%$ for the Senate sample. The widest confidence interval for Stennis Fellows was $\pm 6.6 \%$. The widest confidence interval for the all staff-weighted sample was $\pm 4.9 \%$.

\section{Strongly Disagree}

Senate staff (37.7\%) were more likely to strongly disagree with the statement "nothing is as important to me as serving God as best I know how" than Stennis Fellows (32.1\%) or House staff (23.1\%). The two-sample, two-tailed t-statistic was significant at the .05 level for the difference in proportions between House and Senate staff, $t(317)=2.83$, $p=.005$. The $\mathrm{t}$-statistic was not significant at the .05 level for the difference between Stennis Fellows and House staff, $t(270)=1.65, p=.10$. The null hypothesis that there is no difference in population proportion between Stennis Fellows and House staff cannot be rejected.

\section{Moderately Disagree}

Stennis Fellows (26.8\%) were more likely to moderately disagree with the statement than were House (13.1\%) or Senate (18.9\%) staff. The two-sample, two-tailed t-statistic was significant at the .05 level for the difference in proportions between Stennis Fellows and House staff, $t(270)=2.85, p=.005$. The t-statistic was not significant at the .05 level for the difference between Stennis Fellows and Senate staff, $t(269)=1.54, p=.125$. The null hypothesis that there is no difference in population proportion between Stennis Fellows and Senate staff cannot be rejected. 


\section{Moderately Agree}

House staff (24.4\%) were more likely to moderately agree with the statement than were Senate staff (17\%) or Stennis Fellows (15.2\%). The two-sample, two-tailed t-statistic was not significant at the .05 level for the difference between House staff and Stennis Fellows, $t(270)=1.84, p=.065$. The null hypothesis that there is no difference in population proportion cannot be rejected.

\section{Strongly Agree}

House staff (33.8\%) were more likely to strongly agree with the statement than Stennis Fellows $(24.1 \%)$ or Senate staff $(21.4 \%)$. The t-statistic was significant at the .05 level for the difference in proportions between House and Senate staff, $t(317)=2.48, p=.014$. The two-sample, two-tailed t-statistic was not significant at the .05 level for the difference in proportions between House staff and Stennis Fellows, $t(270)=1.72, p=.086$.

\section{Moderately and Strongly Disagree Combined}

$56.6 \%$ of Senate staff moderately or strongly disagreed with the statement "nothing is as important as serving God as best I know" compared with $36.2 \%$ of House staff and $58.9 \%$ of Stennis Fellows. The two-sample, two-tailed t-statistic was significant at the .05 level for the difference between Senate and House staff, $t(317)=3.65, p=.0003$, and for the difference between Stennis Fellows and House staff, $t(270)=3.7, p=.0003$. Conversely, $58.2 \%$ of House staff moderately or strongly agreed with the statement compared with $38.4 \%$ of Senate staff and $39.3 \%$ of Stennis Fellows. 
A chi-square test for independence indicated a statistically significant moderate association between chamber (House or Senate) and agreement or disagreement with the statement, $X^{2}(4, \mathrm{n}=319)=13.83, \mathrm{p}=008$, Cramer's $V=.208$.

Nothing is as important to me as serving God as best I know how.

\begin{tabular}{llrrrr}
\hline \hline \multirow{2}{*}{ Chamber } & & & & \multicolumn{2}{c}{ Cumulative } \\
Percent
\end{tabular}

Nothing is as important to me as serving God as best I know how.

\begin{tabular}{|c|c|c|c|c|}
\hline Stennis Fellows & Frequency & Percent & Valid Percent & $\begin{array}{c}\text { Cumulative } \\
\text { Percent }\end{array}$ \\
\hline Strongly disagree & 36 & 29.5 & 32.1 & 32.1 \\
\hline Moderately disagree & 30 & 24.6 & 26.8 & 58.9 \\
\hline Moderately agree & 17 & 13.9 & 15.2 & 74.1 \\
\hline Strongly agree & 27 & 22.1 & 24.1 & 98.2 \\
\hline Don't know & 2 & 1.6 & 1.8 & 100.0 \\
\hline Total & 112 & 91.8 & 100.0 & \\
\hline Missing & 10 & 8.2 & & \\
\hline Total & 122 & 100.0 & & \\
\hline
\end{tabular}

Nothing is as important to me as serving God as best I know how.

\begin{tabular}{crrrrr}
\hline \hline \multirow{2}{*}{ All Staff } & & & & \multicolumn{2}{c}{ Cumulative } \\
& & Frequency & Percent & Valid Percent & \multicolumn{2}{c}{ Percent } \\
\hline & Strongly disagree & 92 & 25.3 & 28.9 & 28.9 \\
& Moderately disagree & 49 & 13.5 & 15.4 & 44.3 \\
& Moderately agree & 69 & 18.8 & 21.5 & 65.7 \\
Strongly agree & 92 & 25.3 & 28.9 & 94.6 \\
Don't know & 17 & 4.7 & 5.4 & 100.0
\end{tabular}




\begin{tabular}{llrrr}
\hline & Total & 319 & 87.6 & 100.0 \\
& Missing & 45 & 12.4 & \\
Total & & 364 & 100.0 & \\
\hline \hline
\end{tabular}

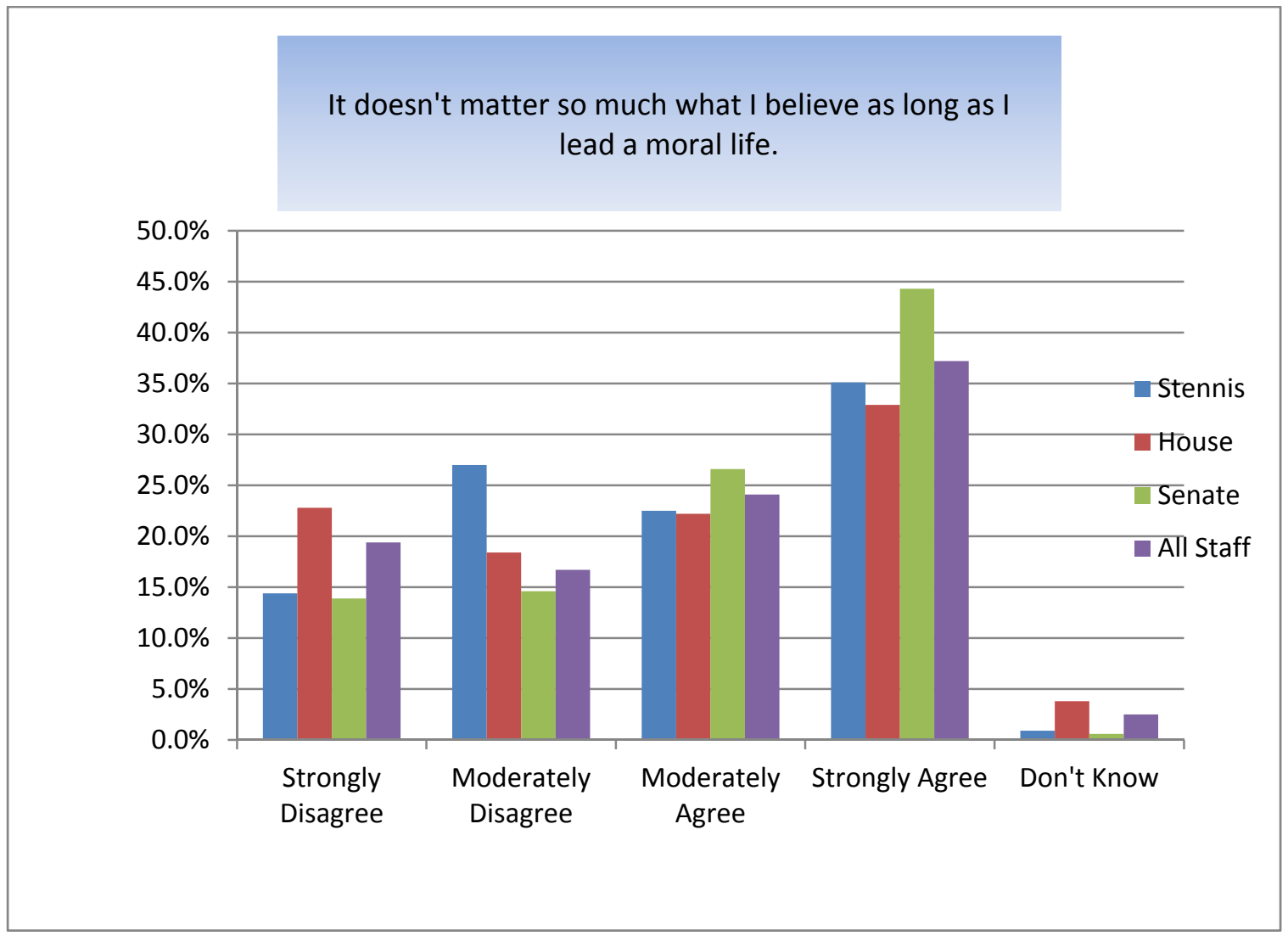

Respondents were asked whether they strongly disagree, moderately disagree, moderately agree, or strongly agree with the statement, “It doesn't matter so much what I believe as long as I lead a moral life." 108

Confidence intervals were calculated for each of the variable categories of the House and Senate samples. The widest confidence intervals were $\pm 7.3 \%$ for the House sample and $\pm 7.7 \%$ for the Senate sample. The widest confidence interval for Stennis Fellows was $\pm 6.8 \%$. The widest confidence interval for the all staff-weighted sample was $\pm 5.3 \%$.

\footnotetext{
${ }^{108}$ Question adopted from the Hoge Intrinsic Religious Motivation Scale. Designed to measure extrinsic religiosity.
} 


\section{Strongly Disagree}

House staff (22.6\%) were more likely to strongly disagree with the statement, "it doesn't matter what I believe as long as I lead a moral life," than Stennis Fellows (14.4\%) or Senate staff $(14.5 \%)$. The two-sample, two-tailed t-statistic for the difference in proportions was not significant at the .05 level for the difference between House and Senate staff, $t(316)=1.86, p=.064$. The null hypothesis that there is no difference in the population proportions cannot be rejected.

\section{Moderately Disagree}

Stennis Fellows (27\%) were more likely to moderately disagree with the statement than House (18.2\%) or Senate staff (14.5\%). The t-statistic for the difference in proportions was significant at the .05 level for the difference in proportions between Stennis Fellows and Senate staff, $t(316)=2.54, p=.01$, but not for the difference between Stennis Fellows and House staff, $t(268)=1.72, p=.09$.

\section{Strongly Agree}

Senate staff (44\%) were more likely than House staff (32.7\%) to strongly agree with the statement. The t-statistic for the difference in proportions between House and Senate staff was significant at the .05 level, $t(316)=2.07, p=.039$, but not for the difference between Senate staff and Stennis Fellows, $t(268)=1.47, p=.14$. The null hypothesis that there is no difference in population proportions between Senate staff and Stennis Fellows cannot be rejected. 
A chi-square test for independence indicated a statistically significant weak association between chamber (House or Senate) and agreement or disagreement with the statement, “it doesn't matter so much what I believe as long as I lead a moral life," $X^{2}(4, n=318)$ $=10.25, \mathrm{p}=036$, Cramer's $V=.179$.

It doesn't matter so much what I believe as long as I lead a moral life.

\begin{tabular}{llrrrr}
\hline \hline \multirow{2}{*}{ Chamber } & & & & \multicolumn{2}{c}{ Cumulative } \\
Percent
\end{tabular}

It doesn't matter so much what I believe as long as I lead a moral life.

\begin{tabular}{|c|c|c|c|c|}
\hline Stennis Fellows & Frequency & Percent & Valid Percent & $\begin{array}{c}\text { Cumulative } \\
\text { Percent }\end{array}$ \\
\hline Strongly disagree & 16 & 13.1 & 14.4 & 14.4 \\
\hline Moderately disagree & 30 & 24.6 & 27.0 & 41.4 \\
\hline Moderately agree & 25 & 20.5 & 22.5 & 64.0 \\
\hline Strongly agree & 39 & 32.0 & 35.1 & 99.1 \\
\hline Don't know & 1 & .8 & .9 & 100.0 \\
\hline Total & 111 & 91.0 & 100.0 & \\
\hline Missing & 11 & 9.0 & & \\
\hline Total & 122 & 100.0 & & \\
\hline
\end{tabular}

It doesn't matter so much what I believe as long as I lead a moral life.

\begin{tabular}{lllll}
\hline \hline All Staff & Frequency & Percent & Valid Percent & $\begin{array}{c}\text { Cumulative } \\
\text { Percent }\end{array}$ \\
\hline
\end{tabular}




\begin{tabular}{|c|c|c|c|c|c|}
\hline & Strongly disagree & 62 & 16.9 & 19.4 & 19.4 \\
\hline & Moderately disagree & 53 & 14.6 & 16.7 & 36.2 \\
\hline & Moderately agree & 77 & 21.1 & 24.1 & 60.3 \\
\hline & Strongly agree & 118 & 32.4 & 37.2 & 97.5 \\
\hline & Don't know & 8 & 2.2 & 2.5 & 100.0 \\
\hline & Total & 318 & 87.2 & 100.0 & \\
\hline & Missing & 46 & 12.8 & & \\
\hline Total & & 364 & 100.0 & & \\
\hline
\end{tabular}

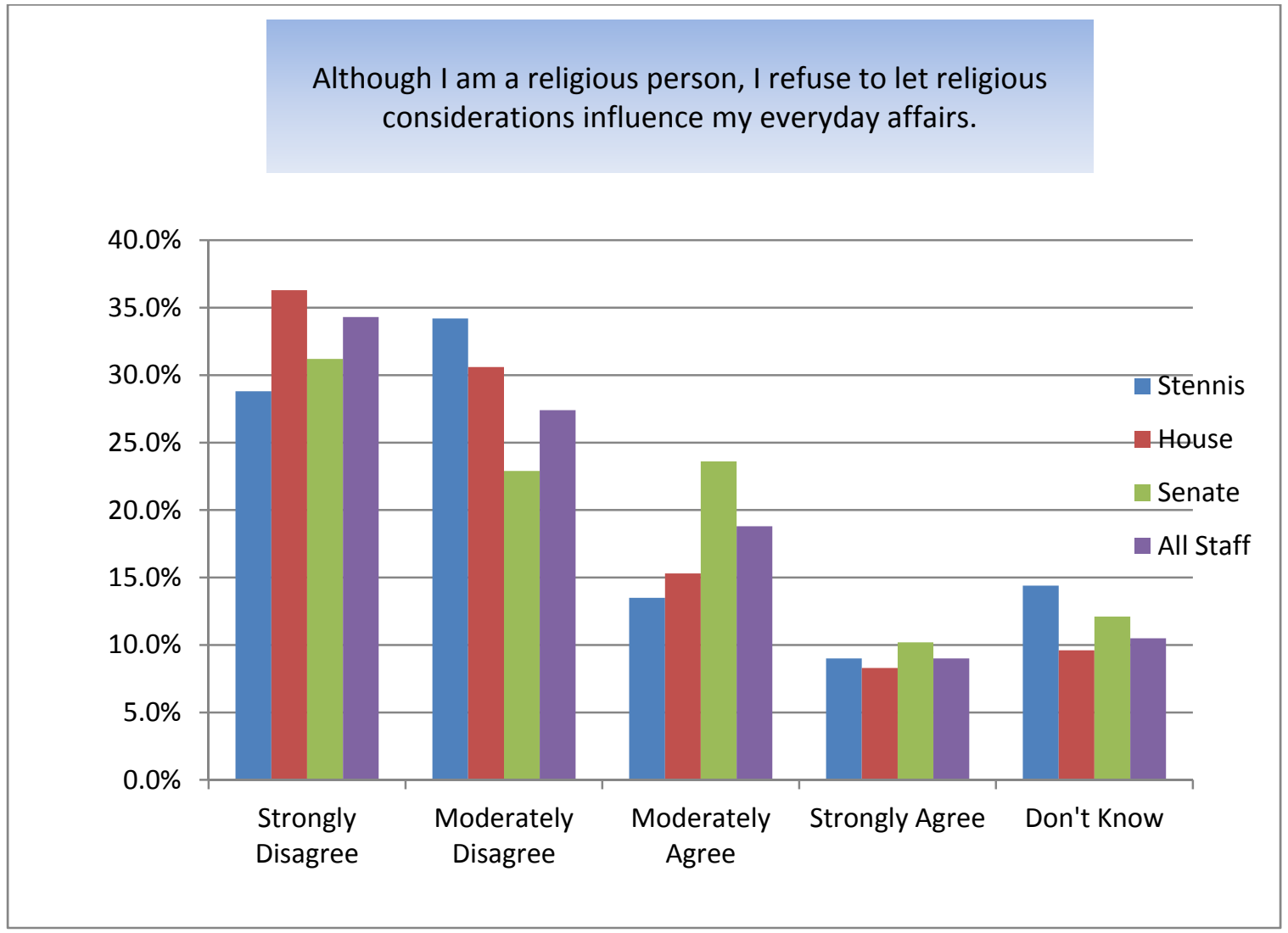

Respondents were asked whether they strongly disagree, moderately disagree, moderately agree, or strongly agree with the statement, "Although I am a religious person, I refuse to let religious considerations influence my everyday affairs."

\footnotetext{
${ }^{109}$ Question adopted from the Hoge Intrinsic Religious Motivation Scale. Designed to measure extrinsic religiosity.
} 
Confidence intervals were calculated for each of the variable categories of the House and Senate samples. The widest confidence intervals were $\pm 7.5 \%$ for the House sample and $\pm 7.2 \%$ for the Senate sample. The widest confidence interval for Stennis Fellows was $\pm 6.8 \%$. The widest confidence interval for the all staff-weighted sample was $\pm 5.2 \%$.

\section{Strongly Disagree}

House staff (36.1\%) were more likely than Senate staff (31.6\%) or Stennis Fellows (28.8\%) to strongly disagree with the statement, "although I am a religious person I refuse to let religious considerations influence my everyday affairs." The two-sample, two-tailed t-statistic was not significant at the .05 level for either House staff and Stennis Fellows, $t(267)=1.26, p=.21$, or for House and Senate staff, $t(314)=.85, p=.399$. The null hypothesis that there is no difference in population proportions cannot be rejected.

\section{Moderately Disagree}

Stennis Fellows (34\%) were more likely to moderately disagree with the statement than either House (30.4\%) or Senate staff (22.8\%). The two-sample, two-tailed t-statistic for the difference in proportions between Stennis Fellows and Senate staff was significant at the .05 level, $t(267)=2.06, p=.04$. The $t$-statistic was not significant for the difference between House and Senate staff, $t(314)=1.52, p=.13$. The null hypothesis that there is no difference in population proportions between House and Senate staff cannot be rejected.

\section{Moderately Agree}

Senate staff $(23.4 \%)$ were more likely to moderately agree with the statement than either House staff (15.8\%) or Stennis Fellows (13.5\%). The two-sample, two-tailed t-statistic 
was significant at the .05 level for the difference between Stennis Fellows and Senate staff, $t(267)=2.02, p=.04$, but not for the difference between House and Senate staff, $t(314)=1.7, p=.09$. The null hypothesis that there is no difference in population proportions between House and Senate staff cannot be rejected.

\section{Strongly Agree}

$33.5 \%$ of Senate staff moderately or strongly agreed with the statement compared with $24 \%$ of House staff and $22.5 \%$ of Stennis Fellows. The two-sample, two-tailed t-statistic was not significant at the .05 level for the difference between Senate staff and House staff, $t(314)=1.9, p=.063$, or for the difference between Senate staff and Stennis Fellows, $t(267)=1.96, p=.051$. The null hypothesis that there is no difference in population proportions between these groups cannot be rejected.

A chi-square test for independence indicated no significant association between House and Senate and agreement or disagreement with the statement, "Although I am a religious person, I refuse to let religious considerations influence my everyday affairs" $X^{2}(4$, $\mathrm{n}=316)=5.28, \mathrm{p}=.260$, Cramer's $V=.129$.

\section{Although I am a religious person, I refuse to let religious considerations influence my everyday} affairs.

\begin{tabular}{llrrrr}
\hline \hline \multirow{2}{*}{ Chamber } & & & & & \multicolumn{2}{c}{ Cumulative } \\
Percent
\end{tabular}




\begin{tabular}{llrrrr}
\hline Senate & Strongly disagree & 50 & 28.1 & 31.6 & 31.6 \\
& Moderately disagree & 36 & 20.2 & 22.8 & 54.4 \\
& Moderately agree & 37 & 20.8 & 23.4 & 77.8 \\
& Strongly agree & 16 & 9.0 & 10.1 & 88.0 \\
& Don't know & 19 & 10.7 & 12.0 & 100.0 \\
& Total & 158 & 88.8 & 100.0 & \\
& Missing & 20 & 11.2 & & \\
& & 178 & 100.0 & & \\
& &
\end{tabular}

Although I am a religious person, I refuse to let religious considerations influence my everyday affairs.

\begin{tabular}{|c|c|c|c|c|}
\hline Stennis Fellows & Frequency & Percent & Valid Percent & $\begin{array}{c}\text { Cumulative } \\
\text { Percent }\end{array}$ \\
\hline Strongly disagree & 32 & 26.2 & 28.8 & 28.8 \\
\hline Moderately disagree & 38 & 31.1 & 34.2 & 63.1 \\
\hline Moderately agree & 15 & 12.3 & 13.5 & 76.6 \\
\hline Strongly agree & 10 & 8.2 & 9.0 & 85.6 \\
\hline Don't know & 16 & 13.1 & 14.4 & 100.0 \\
\hline Total & 111 & 91.0 & 100.0 & \\
\hline Missing & 11 & 9.0 & & \\
\hline Total & 122 & 100.0 & & \\
\hline
\end{tabular}

Although I am a religious person, I refuse to let religious considerations influence my everyday affairs.

\begin{tabular}{lrrrrr}
\hline \hline \multirow{2}{*}{ All Staff } & Frequency & Percent & Valid Percent & $\begin{array}{c}\text { Cumulative } \\
\text { Percent }\end{array}$ \\
\cline { 2 - 6 } & Strongly disagree & 108 & 29.8 & 34.3 & 34.3 \\
& Moderately disagree & 87 & 23.7 & 27.4 & 61.7 \\
& Moderately agree & 59 & 16.3 & 18.8 & 80.5 \\
& Strongly agree & 28 & 7.8 & 9.0 & 89.5 \\
& Don't know & 33 & 9.1 & 10.5 & 100.0 \\
& Total & 316 & 86.7 & 100.0 & \\
& Missing & 48 & 13.3 & & \\
Total & 364 & 100.0 & & \\
\hline \hline
\end{tabular}




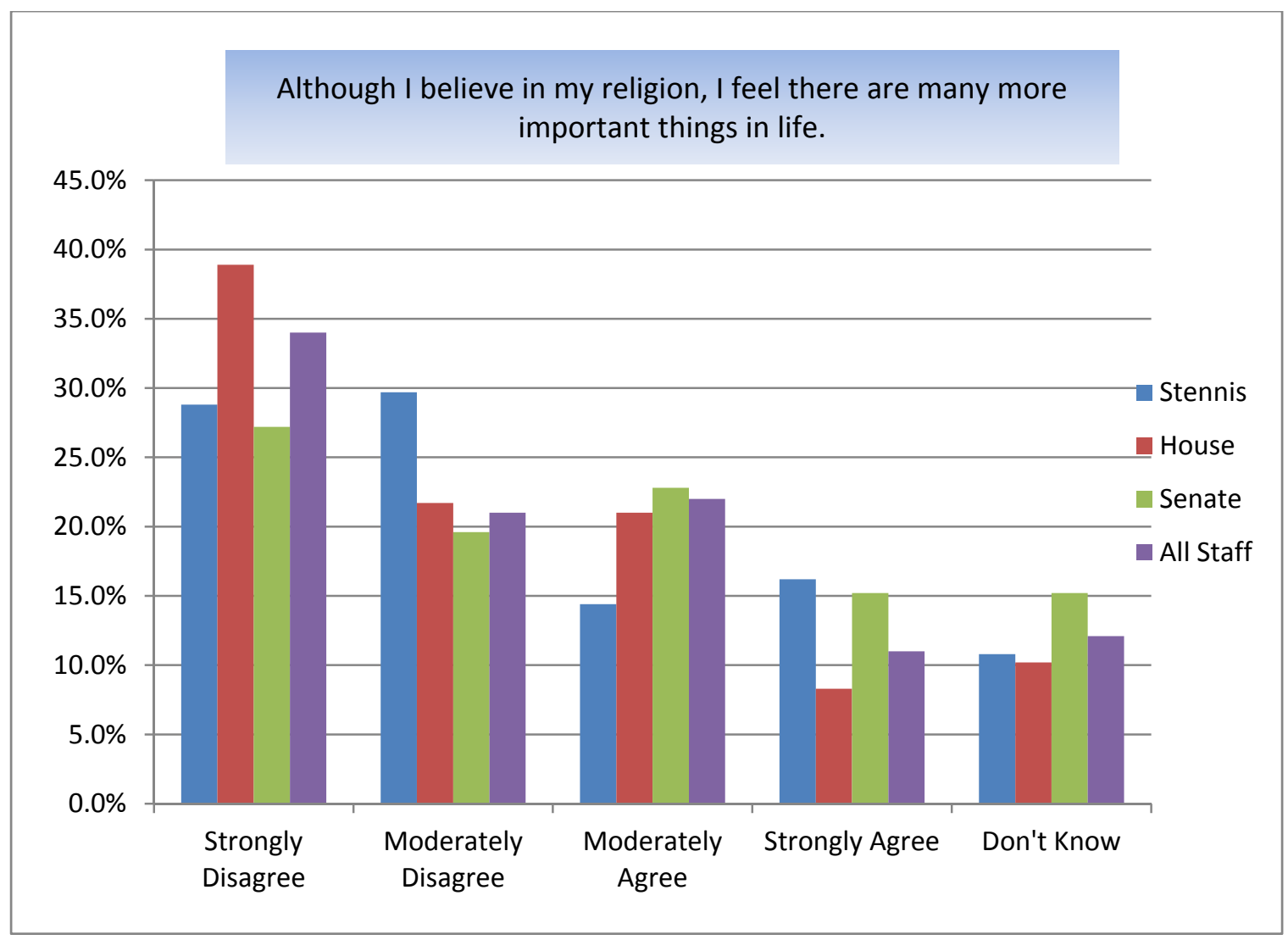

Respondents were asked whether they "strongly disagree, moderately disagree, moderately agree, or strongly agree" with the statement, "Although I believe in my religion, I feel there are many more important things in life." $" 110$

Confidence intervals were calculated for each of the variable categories of the House and Senate samples. The widest confidence intervals were $\pm 7.6 \%$ for the House sample and $\pm 6.9 \%$ for the Senate sample. The widest confidence interval for Stennis Fellows was $\pm 6.5 \%$. The widest confidence interval for the all staff-weighted sample was $\pm 5.2 \%$.

\footnotetext{
${ }^{110}$ Question adopted from Hoge Intrinsic Religious Motivation Scale. Designed to measure extrinsic religiosity.
} 


\section{Strongly Disagree}

House staff (38.6\%) were more likely to strongly disagree with the statement than Stennis Fellows $(28.8 \%)$ or Senate staff $(27 \%)$. The two-sample, two-tailed t-statistic was significant at the .05 level for the difference in proportions between House and Senate staff, $t(315)=2.199, p=.03$, but not for the difference between Stennis Fellows and House staff, $t(267)=1.66, p=.098$. The t-statistic for the difference in proportions between Stennis Fellows and all staff-weighted was also not significant at the .05 level, $t(426)=1.01, p=.32$. The null hypothesis that there was no difference in population proportions between Stennis Fellows and House staff and between Stennis Fellows and all staff cannot be rejected.

\section{Moderately Disagree}

Stennis Fellows (29.7\%) were more likely to moderately disagree than either House $(21.5 \%)$ or Senate staff $(20.1 \%)$. The two-sample, two-tailed t-statistic for the difference between proportions for Stennis Fellows and Senate staff was not significant at the .05 level, $t(268)=1.815, p=.07$. The null hypothesis that there is no difference in population proportions for Stennis Fellows and Senate staff or for Stennis Fellows and House staff cannot be rejected.

\section{Strongly Agree}

Stennis Fellows (16.2\%) were more likely than Senate staff (15.1\%) or House staff $(8.2 \%)$ to strongly agree with the statement. The two-sample, two-tailed t-statistic for the difference in proportions was significant at the .05 level for the difference between 
Stennis Fellows and House staff, $t(267)=2.02, p=.04$, but not between Senate staff and House staff, $t(315)=1.913, p=.06$.

A chi-square test for independence indicated no significant association between House and Senate and agreement or disagreement with the statement, "although I believe in my religion, I feel there are many more important things in life," $X^{2}(4, \mathrm{n}=317)=8.1, \mathrm{p}=.088$, Cramer's $V=.160$.

Although I believe in my religion, I feel there are many more important things in life.

\begin{tabular}{|c|c|c|c|c|c|}
\hline Chamber & & Frequency & Percent & Valid Percent & $\begin{array}{c}\text { Cumulative } \\
\text { Percent }\end{array}$ \\
\hline \multirow[t]{6}{*}{ House } & Strongly disagree & 61 & 33.0 & 38.6 & 38.6 \\
\hline & Moderately disagree & 34 & 18.4 & 21.5 & 60.1 \\
\hline & Moderately agree & 34 & 18.4 & 21.5 & 81.6 \\
\hline & Strongly agree & 13 & 7.0 & 8.2 & 89.9 \\
\hline & Don't know & 16 & 8.6 & 10.1 & 100.0 \\
\hline & Total & 158 & 85.4 & 100.0 & \\
\hline Missing & System & 27 & 14.6 & & \\
\hline Total & & 185 & 100.0 & & \\
\hline \multirow[t]{7}{*}{ Senate } & Strongly disagree & 43 & 24.2 & 27.0 & 27.0 \\
\hline & Moderately disagree & 32 & 18.0 & 20.1 & 47.2 \\
\hline & Moderately agree & 36 & 20.2 & 22.6 & 69.8 \\
\hline & Strongly agree & 24 & 13.5 & 15.1 & 84.9 \\
\hline & Don't know & 24 & 13.5 & 15.1 & 100.0 \\
\hline & Total & 159 & 89.3 & 100.0 & \\
\hline & Missing & 19 & 10.7 & & \\
\hline Total & & 178 & 100.0 & & \\
\hline
\end{tabular}

Although I believe in my religion, I feel there are many more important things in life.

\begin{tabular}{lrrrr}
\hline \hline Stennis Fellows & & & & \multicolumn{2}{c}{ Cumulative } \\
Percent
\end{tabular}


Although I believe in my religion, I feel there are many more important things in life.

\begin{tabular}{|c|c|c|c|c|c|}
\hline All Staff & & Frequency & Percent & Valid Percent & $\begin{array}{c}\text { Cumulative } \\
\text { Percent }\end{array}$ \\
\hline & Strongly disagree & 108 & 29.6 & 34.0 & 34.0 \\
\hline & Moderately disagree & 66 & 18.2 & 21.0 & 55.0 \\
\hline & Moderately agree & 70 & 19.1 & 22.0 & 77.0 \\
\hline & Strongly agree & 35 & 9.5 & 11.0 & 87.9 \\
\hline & Don't know & 38 & 10.5 & 12.1 & 100.0 \\
\hline & Total & 317 & 86.9 & 100.0 & \\
\hline & Missing & 48 & 13.1 & & \\
\hline Total & & 364 & 100.0 & & \\
\hline
\end{tabular}

\section{Religiosity of Congressional Staff}

The survey included eight questions from the Hoge Intrinsic Religious Motivation Scale.

Hoge recommended reverse-scoring the three extrinsic questions and adding the intrinsic and extrinsic variables together. ${ }^{111}$ The original Hoge scale did not include the categories "neither agree or disagree" contained in the GSS2010 or "don't know" as contained in this survey.

In order to calculate a total score for each individual, the questions were rescored as follows:

I try hard to carry my religious beliefs over into all my other dealings in life: strongly agree (5), agree (4), neither agree or disagree (3), disagree (2), and strongly disagree (1).

My faith involves all my life: don't know (0), strongly disagree (1) moderately disagree (2), moderately agree (3), and strongly agree (4).

${ }^{111}$ D.R. Hoge, "A Validated Intrinsic Religious Motivation Scale," Journal for the Scientific Study of Religion 11(1972). 
One should seek God's guidance when making every important decision: don't know (0), strongly disagree (1), moderately disagree (2), moderately agree (3), strongly agree (4).

My faith sometimes restricts my actions: don't know (0), strongly disagree (1), moderately disagree (2), moderately agree (3), and strongly agree (4).

Nothing is as important to me as serving God as best I know how: don't know (0), strongly disagree (1), moderately disagree (2), moderately agree (3), and strongly agree (4).

It doesn't matter so much what I believe as long as I lead a moral life: don't know (0), strongly disagree (4), moderately disagree (3), moderately agree (2), strongly agree (1).

Although I am a religious person, I refuse to let religious considerations influence my everyday affairs: don't know (0), strongly disagree (4), moderately disagree (3), moderately agree (2), and strongly agree (1).

Although I believe in my religion, I feel there are many more important things in life: don't know (0), strongly disagree (4), moderately disagree (3), moderately agree (2), strongly agree (1). 
Cronbach's $\alpha$ coefficient provides an assessment of the internal consistency, reliability and unidimensionality of an instrument or scale with regards to the population to which it is being administered. Alphas can range from 0 to 1 , with 1 representing the highest level of internal consistency. ${ }^{112}$ Scores between .7 and .95 are generally considered acceptable. ${ }^{113}$ Scores that are too low suggest that the scale is measuring multiple dimensions. Scores that are too high suggest that one or more of the questions is redundant and increases response burden without providing corresponding benefit. For this reason, some authors suggest that a maximum Cronbach's $\alpha$ of .9 is appropriate. ${ }^{114}$ Recoded (see above) response scores were totaled in order to generate an individual religiosity score. Respondent scores ranged from 3 to 33 (the maximum possible). Cronbach's $\alpha$ was calculated for all four populations. In each case the Cronbach's $\alpha$ scores were between .884 and .903 , indicating high levels of internal consistency.

\begin{tabular}{|l|l|}
\hline Stennis Fellows & 0.885 \\
\hline House staff & 0.903 \\
\hline Senate staff & 0.884 \\
\hline All staff & 0.899 \\
\hline
\end{tabular}

An inter-item correlation matrix was also generated for the items within the scale to assess the strength of the relationships of the items as applied to House and Senate staff and the Stennis Fellows.

\footnotetext{
${ }^{112}$ Mohsen Tavakol and Reg Dennick, "Making Sense of Cronbach's Alpha," International Journal of Medical Education, no. 2 (2011).

${ }^{113}$ Julie Pallant, Spss Survival Guide, 5th ed. (Berkshire, England: McGraw-Hill Education, 2013).

114 Ibid.
} 


\begin{tabular}{lcccccccc}
\hline \hline & & & & & & & & \\
& & & & & & & \\
& RelAllLifeRev & FathAllRev & SeekGodRev & FaithRestrctRev & ServeGodRev & BeMoralRev & RefRelRev & MorelmptRev \\
\hline RelAllLifev & 1.000 & .716 & .605 & .553 & .600 & .485 & .286 & .386 \\
FathAllRev & .716 & 1.000 & .762 & .631 & .737 & .562 & .299 & .458 \\
SeekGodRev & .605 & .762 & 1.000 & .658 & .787 & .567 & .319 & .485 \\
FaithRestrctRev & .553 & .631 & .658 & 1.000 & .662 & .423 & .311 & .366 \\
ServeGodRev & .600 & .737 & .787 & .662 & 1.000 & .557 & .368 & .473 \\
BeMoralRev & .485 & .562 & .567 & .423 & .557 & 1.000 & .479 & .505 \\
RefRelRev & .286 & .299 & .319 & .311 & .368 & .479 & 1.000 & .666 \\
MorelmptRev & .386 & .458 & .485 & .366 & .473 & .505 & .666 & 1.000 \\
\hline \hline
\end{tabular}

Inter-Item Correlation Matrix for Stennis Fellows

\begin{tabular}{lrrrrrrrr} 
& RelAllLifeRev & FaithAllRev & SeekGodRev & FaithRestrctRev & ServeGodRev & BeMoralRev & RefRelRev & MorelmptRev \\
\hline RelAllifeRev & 1.000 & .672 & .471 & .575 & .569 & .199 & .419 & .340 \\
FaithAllRev & .672 & 1.000 & .746 & .585 & .700 & .416 & .501 & .405 \\
SeekGodRev & .471 & .746 & 1.000 & .501 & .728 & .505 & .414 & .364 \\
FaithRestrctRev & .575 & .585 & .501 & 1.000 & .679 & .353 & .403 & .338 \\
ServeGodRev & .569 & .700 & .728 & .679 & 1.000 & .517 & .521 & .472 \\
BeMoralRev & .199 & .416 & .505 & .353 & .517 & 1.000 & .361 & .337 \\
RefRelRev & .419 & .501 & .414 & .403 & .521 & .361 & 1.000 & .676 \\
MorelmptRev & .340 & .405 & .364 & .338 & .472 & .337 & .676 & 1.000 \\
\hline \hline
\end{tabular}

Questions having inter-item correlations of less than .3 suggest that the question may be measuring something different (i.e., different dimension or attribute) from other items in the scale. The lowest correlations for House and Senate staff and for the Stennis Fellows were for the three items that were designed to measure "extrinsic" religiosity: "It doesn't matter so much what I believe as long as I lead a moral life," "Although I am a religious person, I refuse to let religious considerations influence my everyday affairs," and "although I believe in my religion, I feel there are many more important things in life." 
The mean inter-item correlation for House and Senate staff was .525 with a range from .286 to .787 . The mean inter-item correlation for Stennis Fellows was .492 with a range from .199 to .746 .

Mean scores for the groups indicate higher religiosity scores in the House $(m=21.7$, $S D=7.98)$ than in the Senate $(m=18.8, S D=7.53)$ or for Stennis Fellows $(m=20.873$, $S D=7.3$ ). Two-sample, two-tailed t-statistics were significant at the .05 level for the difference in means between House and Senate staff, $t(310)=2.647, p=.008$, and for the difference between Stennis Fellows and Senate staff, $t(263)=1.99, p=.047$.

Using SPSS, the results of the total religiosity scores were binned into three groups using the "equal percentiles based on the scanned cases" function. The actual groups are not equal in size because the cutoff points fell within a cluster of cases with equal scores (e.g., some cases with a score of 16 would have been assigned to the lower bin and some with a score of 16 would have been assigned to the higher bin).

House staff (39\%) were more likely than Stennis Fellows $(33 \%)$ or Senate staff $(23 \%)$ to report religiosity scores equal to or greater than 26 . The two-sample, two-tailed tstatistic for the difference in proportions between House staff and Senate staff was significant at the .05 level, $t(310)=3.118, p=.0020$. The t-statistic was not significant at the .05 level for the difference between House staff and Stennis Fellows, $t(265)=1.037$, $p=.3008$, or for the difference between Stennis Fellows and Senate staff, $t(263)=1.829$, $p=.0685$. 


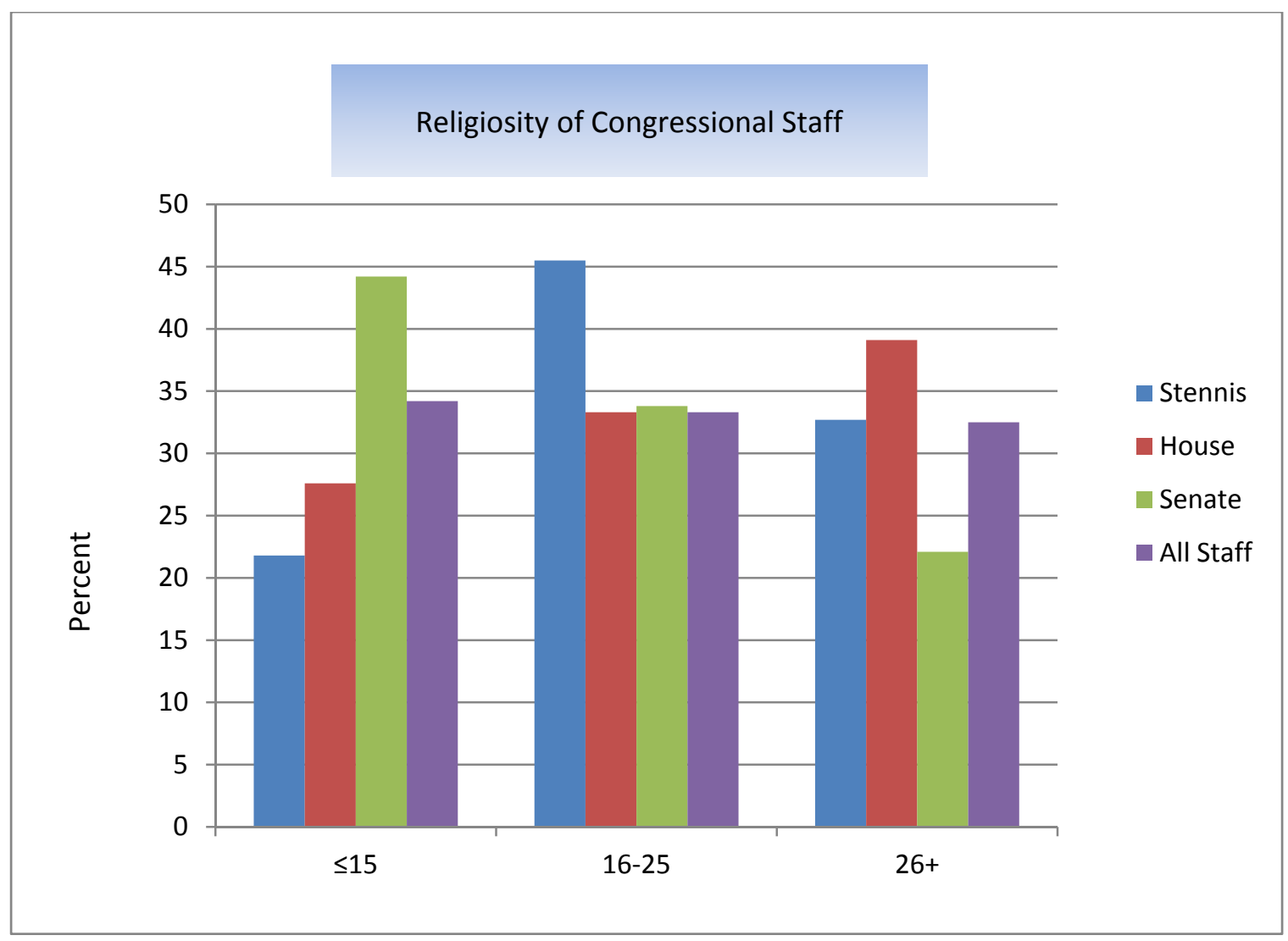

Confidence intervals were calculated for each of the binned variable categories of the House and Senate samples. The widest confidence intervals were $\pm 7.6 \%$ for the House sample and $\pm 7.8 \%$ for the Senate sample. The widest confidence interval for Stennis Fellows was $\pm 7.2 \%$. The widest confidence interval for the all staff-weighted sample was $\pm 5.2 \%$.

Senate staff (43.9\%) were more likely than House staff (28\%) or Stennis Fellows $(21.8 \%)$ to report religiosity scores of 15 or less. The two-sample, two-tailed t-statistic was significant at the .05 level for the difference in proportions for House and Senate staff, $t(310)=2.93, p=.004$, and for the difference between Senate staff and Stennis Fellows, $t(263)=3.72, p=.0002$. 
Stennis Fellows (45.5\%) were more likely than Senate $(33.5 \%)$ or House $(33.1 \%)$ staff to report moderate religiosity scores between 16 and 25. The two-sample, two-tailed tstatistic was significant at the .05 level for the difference in proportions between Stennis Fellows and Senate staff, $t(263)=1.98, p=.049$, and for the difference in proportions between Stennis Fellows and House staff, $t(265)=2.05, p=.041$.

House staff (38.9\%) were more likely than Stennis Fellows (32.7\%) or Senate staff $(22.6 \%)$ to report high religiosity scores of 26 or above. The two-sample, two-tailed tstatistic was significant at the .05 level for the difference between House and Senate staff, $t(310)=3.118, p=.0020$, but not for the difference between House staff and Stennis Fellows, $t(265)=1.037, p=.3008$, or for the difference between Stennis Fellows and Senate staff, $t(263)=1.829, p=.0685$.

A chi-square test for independence indicated that there is a statistically significant moderate association between House and Senate staff and binned Religiosity, $X^{2}$ (2, $n=$ $312)=12.2, \mathrm{p}=.002$, Cramer's $V=.197$.

Hoge Total (Binned in Thirds)

\begin{tabular}{|c|c|c|c|c|c|}
\hline Chamber & & Frequency & Percent & Valid Percent & $\begin{array}{c}\text { Cumulative } \\
\text { Percent }\end{array}$ \\
\hline \multirow[t]{4}{*}{ House } & $<=15.0$ & 44 & 23.8 & 28.0 & 28.0 \\
\hline & $16.0-25.0$ & 52 & 28.1 & 33.1 & 61.1 \\
\hline & $26.0+$ & 61 & 33.0 & 38.9 & 100.0 \\
\hline & Total & 157 & 84.9 & 100.0 & \\
\hline Missing & System & 28 & 15.1 & & \\
\hline Total & & 185 & 100.0 & & \\
\hline \multirow[t]{4}{*}{ Senate } & $<=15.0$ & 68 & 38.2 & 43.9 & 43.9 \\
\hline & $16.0-25.0$ & 52 & 29.2 & 33.5 & 77.4 \\
\hline & $26.0+$ & 35 & 19.7 & 22.6 & 100.0 \\
\hline & Total & 155 & 87.1 & 100.0 & \\
\hline
\end{tabular}




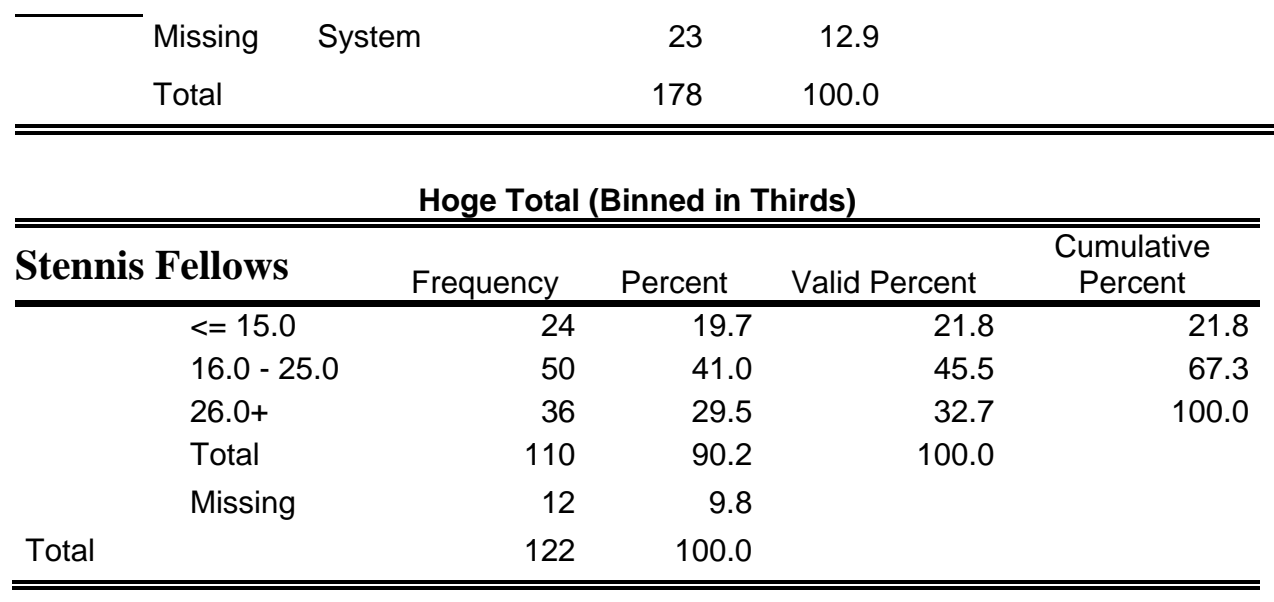

Hoge Total (Binned in Thirds)

\begin{tabular}{|c|c|c|c|c|c|}
\hline All Staff & & Frequency & Percent & Valid Percent & $\begin{array}{c}\text { Cumulative } \\
\text { Percent }\end{array}$ \\
\hline & $<=15.0$ & 107 & 29.3 & 34.2 & 34.2 \\
\hline & $16.0-25.0$ & 104 & 28.5 & 33.3 & 67.5 \\
\hline & $26.0+$ & 101 & 27.8 & 32.5 & 100.0 \\
\hline & Total & 312 & 85.7 & 100.0 & \\
\hline & Missing & 52 & 14.3 & & \\
\hline Total & & 364 & 100.0 & & \\
\hline
\end{tabular}

Hoge Total (Binned) * House or Senate Crosstabulation

\begin{tabular}{|c|c|c|c|c|c|}
\hline & & & \multicolumn{2}{|c|}{ House or Senate } & \multirow[b]{2}{*}{ Total } \\
\hline & & & House & Senate & \\
\hline \multirow[t]{12}{*}{ Hogue Total (Binned) } & $<=15.0$ & Count & $44 a$ & $68_{b}$ & 112 \\
\hline & & $\begin{array}{l}\text { \% within Hoge Total } \\
\text { (Binned) }\end{array}$ & $39.3 \%$ & $60.7 \%$ & $100.0 \%$ \\
\hline & & $\%$ within House or Senate & $28.0 \%$ & $43.9 \%$ & $35.9 \%$ \\
\hline & & $\%$ of Total & $14.1 \%$ & $21.8 \%$ & $35.9 \%$ \\
\hline & $16.0-25.0$ & Count & $52 a$ & $52 a$ & 104 \\
\hline & & $\begin{array}{l}\text { \% within Hoge Total } \\
\text { (Binned) }\end{array}$ & $50.0 \%$ & $50.0 \%$ & $100.0 \%$ \\
\hline & & $\%$ within House or Senate & $33.1 \%$ & $33.5 \%$ & $33.3 \%$ \\
\hline & & $\%$ of Total & $16.7 \%$ & $16.7 \%$ & $33.3 \%$ \\
\hline & $26.0+$ & Count & $61_{\mathrm{a}}$ & $35_{b}$ & 96 \\
\hline & & $\begin{array}{l}\text { \% within Hoge Total } \\
\text { (Binned) }\end{array}$ & $63.5 \%$ & $36.5 \%$ & $100.0 \%$ \\
\hline & & $\%$ within House or Senate & $38.9 \%$ & $22.6 \%$ & $30.8 \%$ \\
\hline & & $\%$ of Total & $19.6 \%$ & $11.2 \%$ & $30.8 \%$ \\
\hline \multirow[t]{4}{*}{ Total } & & Count & 157 & 155 & 312 \\
\hline & & $\begin{array}{l}\% \text { within Hoge Total } \\
\text { (Binned) }\end{array}$ & $50.3 \%$ & $49.7 \%$ & $100.0 \%$ \\
\hline & & $\%$ within House or Senate & $100.0 \%$ & $100.0 \%$ & $100.0 \%$ \\
\hline & & $\%$ of Total & $50.3 \%$ & $49.7 \%$ & $100.0 \%$ \\
\hline
\end{tabular}

Each subscript letter denotes a subset of House or Senate categories whose column proportions do not differ significantly from each other at the .05 level. 


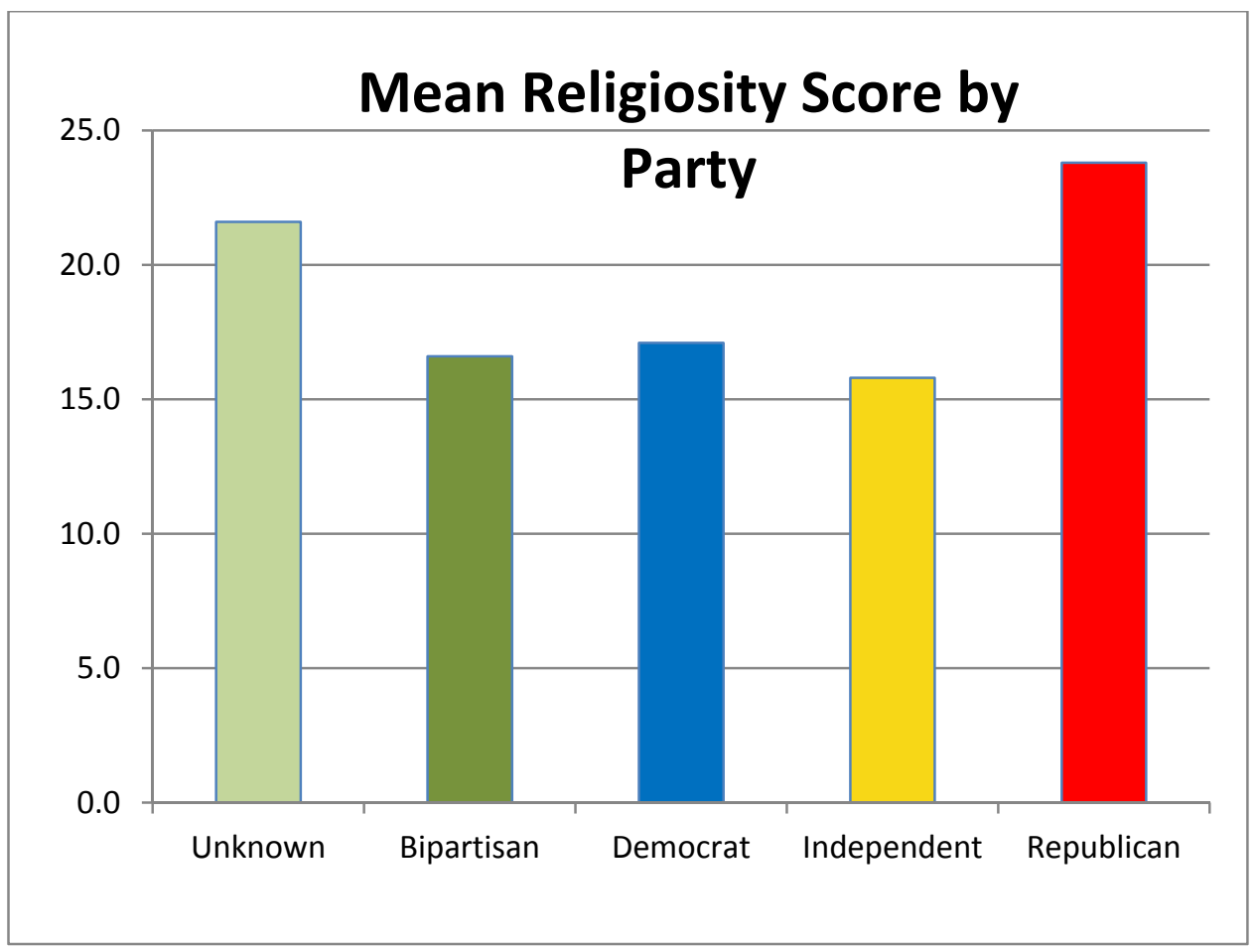

To encourage staff to participate in the study, the survey did not include a question about party identification. This and other demographic information was available, however, for the 264 staff who responded through the individual survey link they were provided.

Party information was not available for respondents who took the survey through the web link. The party of these respondents is referred to in the analysis that follows as "unknown."

Republican staff $(M=23.76, M d n=25, S D=7.3)$ report substantially higher religiosity scores than Democratic staff $(M=17.05, M d n=16, S D=6.9)$, bipartisan staff $(M=16.6$, $M d n=14, S D=6.69)$, or independent $\operatorname{staff}(M=15.8, M d n=15, S D=3.96)$. The number of respondents in the bipartisan and independent groups is too small to draw overly strong conclusions. 
To assess the relationship between political party and religiosity scores, a one-way between-groups analysis of variance was conducted. Respondents were divided into five groups (unknown, bipartisan, Democrat, independent, and Republican). There was a statistically significant difference at the .05 level for political party, $F(4,307)=14.684, p$ $=.000$. The effect size, calculated using eta squared, was .19. Post-hoc comparisons using the Tukey HSD test indicated that the mean score for unknown respondents $(M=21.56, S D=8.33)$ was significantly different from the mean score for Democrats $(M=17.046, S D=6.92)$. The mean score for Democrats was also significantly different than Republicans $(M=23.76, S D=7.33)$

A two-way between-groups analysis of variance was conducted to explore whether there was an interaction between party and chamber on religiosity. Participants were divided into five groups according to their party. The interaction effect between party and chamber was not statistically significant, $F(3,303)=.148, p=.931$. There was a statistically significant main effect for party, $F(4,303)=13.353, p=.000$. The effect size was large (partial eta squared=.150). ${ }^{115}$ Post-hoc comparisons using the Tukey HSD test indicated that the mean score for Democrats $(M=17.046, S D=6.92)$ was significantly different from the mean score for unknown $(M=21.56, S D=8.33)$ and that the mean score for Democrats was significantly different than the mean score for Republicans $(M=23.758) S D=7.32)$.

\footnotetext{
115 Jacob Cohen, Statistical Power Analysis for the Behavioral Sciences, 2nd ed. (Hillsdale, NJ: Lawrence Erlbaum Associates, 1988).
} 
ANOVA

Religiosity Total

\begin{tabular}{lrrrrr}
\hline \hline & Sum of Squares & df & Mean Square & \multicolumn{1}{c}{ F } & Sig. \\
\hline Between Groups & 3108.254 & 4 & 777.063 & 14.684 & .000 \\
Within Groups & 16246.204 & 307 & 52.919 & & \\
Total & 19354.458 & 311 & & & \\
\hline \hline
\end{tabular}

Tests of Between-Subjects Effects

Dependent Variable: Religiosity Total

\begin{tabular}{lcccccc}
\hline \hline Source & $\begin{array}{c}\text { Type III Sum } \\
\text { of Squares }\end{array}$ & df & Square & F & Sig. & $\begin{array}{c}\text { Partial Eta } \\
\text { Squared }\end{array}$ \\
\hline Corrected Model & $3524.026^{\mathrm{a}}$ & 8 & 440.503 & 8.431 & .000 & .182 \\
Intercept & 25224.061 & 1 & 25224.061 & 482.797 & .000 & .614 \\
Party & 2790.585 & 4 & 697.646 & 13.353 & .000 & .150 \\
Chamber & 140.804 & 1 & 140.804 & 2.695 & .102 & .009 \\
Party*House Senate & 23.181 & 3 & 7.727 & .148 & .931 & .001 \\
Error & 15830.433 & 303 & 52.246 & & & \\
Total & 147821.000 & 312 & & & & \\
Corrected Total & 19354.458 & 311 & & & & \\
\hline \hline
\end{tabular}


Tests of Between-Subjects Effects

Dependent Variable: Religiosity Total

\begin{tabular}{lcccccc}
\hline \hline Source & $\begin{array}{c}\text { Type III Sum } \\
\text { of Squares }\end{array}$ & df & $\begin{array}{c}\text { Mean } \\
\text { Square }\end{array}$ & F & Sig. & $\begin{array}{c}\text { Partial Eta } \\
\text { Squared }\end{array}$ \\
\hline Corrected Model & $3524.026^{\mathrm{a}}$ & 8 & 440.503 & 8.431 & .000 & .182 \\
Intercept & 25224.061 & 1 & 25224.061 & 482.797 & .000 & .614 \\
Party & 2790.585 & 4 & 697.646 & 13.353 & .000 & .150 \\
Chamber & 140.804 & 1 & 140.804 & 2.695 & .102 & .009 \\
Party*House Senate & 23.181 & 3 & 7.727 & .148 & .931 & .001 \\
Error & 15830.433 & 303 & 52.246 & & & \\
Total & 147821.000 & 312 & & & & \\
Corrected Total & 19354.458 & 311 & & & & \\
\hline \hline
\end{tabular}

a. R Squared $=.182$ (Adjusted R Squared $=.160$ ) 


\section{Chapter VI. Lying and Being Lied to}

DePaulo and others have argued that lies are ubiquitous-- "a fact of life"-- and that their prevalence is a mark of their social utility for avoiding tension and reducing conflict. ${ }^{116}$ Others, like Bok, trade on the idea that lying is about power and that every lie is in some way exceptional. To wit, lying always stands in need of justification, whereas truth-telling does not. ${ }^{117}$ Observing this debate, Serota has argued that most of the contemporary research on lying has emphasized "experimental studies and hypothesis testing" while paying little attention to important "basic descriptive" work such as prevalence. ${ }^{118}$ The actual prevalence and frequency of lying holds implications for social, linguistic, and ethical theory.

Two models for measuring and describing lying have been developed. The first method involves asking small groups of subjects to keep diaries over the course of seven days. The subjects are asked to track every social interaction that lasts 10 or more minutes and whether they tell a lie (the additional descriptive data vary from study to study). These studies provide data on the percentage of interactions that include lying as well as the ability to calculate the mean number of lies. As will be discussed later, a significant number of subjects report that they do not tell a lie within any given 24-hour period. Expanding the reporting period to seven days captures the lies told by a larger group of subjects; as a result, diary studies are hypothesized to produce higher mean lies per

\footnotetext{
116 DePaulo et al., "Lying in Everyday Life."

${ }^{117}$ Bok, Lying: Moral Choice in Public and Private Life.

${ }^{118}$ Serota, Levine, and Boster, "The Prevalence of Lying in America: Three Studies of Self-Reported Lies."
} 
day. ${ }^{119}$ A shortcoming of the diary study, however, is that the small sample sizes are not representative and the results cannot be generalized to broader populations.

The second method involves using surveys of random samples of adults. These surveys require subjects (who have not been primed) to think back over the previous 24 hours and identify the number of lies they told. There is lag time between the event itself and the recording of the event (although this is also true of diary studies, subjects have been primed to recall these interactions). If lies are ubiquitous, ordinary and non-memorable events, we would expect that respondents would recall fewer lies and as result report fewer lies on surveys. If they are exceptional actions that require justification, we might expect the survey and diary methods to generate comparable results. One benefit of the survey method is that the results can be generalized to larger populations.

DePaulo et al conducted diary studies in 1996 with a small group of college students and another small group of community members. Subjects were asked to keep a diary over the course of seven days that recorded every social interaction which exceeded 10 minutes, and whether they lied. The study reported that students told a mean number of lies per day of $1.96(S D=1.96, n=77)$ and that the community members told a mean number of lies per day of $0.97(S D=0.98, n=70) .{ }^{120}$ One of her findings that was not

\footnotetext{
${ }^{119}$ This point needs further research with larger sample sizes and may be driven by a belief (perhaps justified) that lying is ubiquitous. Broadening the recording period and capturing lies told on days outside the original 24 hour window will clearly increase the mean daily lie calculation for any given individual who reported telling no lies in the original frame. What is not clear, however, is that this will not be counteracted by reductions in mean daily lies told by individuals who lied during the 24 hour window but whose mean is now being reduced by capturing days in which they do not lie.

${ }^{120}$ DePaulo et al., "Lying in Everyday Life."
} 
explored in this research was that lying frequency is correlated with age. Older subjects are reported to tell fewer lies. ${ }^{121}$

Hancock et al. conducted a diary study in 2004 using college students to evaluate the impact of various forms of communication technology (telephone, email, and instant messaging) on lying. The questions and categories of information they requested were derived from the work of DePaulo. Their study suggested that participants lied most frequently on the telephone and least frequently on email. They reported that participants told a mean number of lies per day of $1.58(S D=1.02, n=28) .{ }^{122}$

George and Robb conducted two diary studies in 2008 that were designed to ascertain whether lying is prevalent, whether it varies by communications media, and whether the collection mode (paper, electronic, etc.) affects the reported incidence of lying. They reported that participants told a mean number of lies per day of $0.59(\mathrm{SD}=0.37, \mathrm{n}=24)$ and $0.90(S D=0.54, n=25){ }^{123}$

Serota et al conducted an internet study in 2010 drawing upon a panel of 1000 adults recruited by a market research firm. The sample was stratified using Census CPS data and results were subsequently weighted to mirror the CPS. This study reported that respondents told a mean number of lies per day of $1.65(M d n=0, M o=0, n=998$, Max $=53$ lies, and $S D=4.45$ ). Respondents were asked how many times they lied to five types of

\footnotetext{
${ }^{121}$ Serota, Levine, and Boster, "The Prevalence of Lying in America: Three Studies of Self-Reported Lies."

${ }^{122}$ Jeffrey T. Hancock, Jennifer Thom-Santelli, and Thompson Ritchie, "Deception and Design: The Impact of Communication Technology on Lying Behavior," CHI Letters 6, no. 1 (2004).

${ }^{123}$ Joey F. George and Alastair Robb, "Deception and Computer-Mediated Communication in Daily Life," Communication Reports 21, no. 2 (2008).
} 
individuals in the previous 24 hours either face-to-face or by phone or internet. An important part of her research was that the mean number of lies masked the fact that $60 \%$ of the subjects reported telling no lies and that $5.3 \%$ of the respondents told $50 \%$ of the lies. $^{124}$

Serota et al. conducted a second study with 225 college students, using the same frequency of lies question as in the online survey. The students were asked how many times they believed they had been lied to in the previous 24 hours. This study reported a higher incidence of lying than did the internet study $-M=2.34, S D=2.94, M d n=1, M o=0$, $\mathrm{N}=225, \mathrm{Max}=21$. Most (68\%) of the students told two or fewer lies (24.5\% of all lies), while thirteen students ( $5.8 \%$ of sample) told $22.4 \%$ of the lies. To partially measure the strength of the social desirability bias, students were asked to report on the number of times they believed that others lied to them. The students reported being lied to an average of 2.79 times in the previous 24 hours $(\mathrm{SD}=2.82, \mathrm{~N}=198)$. Seventeen percent reported not being lied to at all. ${ }^{125}$

The survey instrument used in this research employed the same permissive and inclusive wording used by Serota in her survey research. The question was modified in two ways, however. Subjects were first presented with a version of the question that asked them to identify the number of times they believed they had been lied to in the past 24 hours and by whom. Serota asked her internet survey subjects only how many times they had lied (this question was, however, asked of her student panel). This first question was

\footnotetext{
${ }^{124}$ Serota, Levine, and Boster, "The Prevalence of Lying in America: Three Studies of Self-Reported Lies." ${ }^{125}$ Ibid.
} 
designed to prime the subjects thinking, ease them into the question about lying, and provide one measure of the social desirability bias that may affect responses. The second modification involved the response choices. Serota provided her subjects with five categories of individuals to whom one might have lied. These categories serve as a mnemonic device to help respondents recall lies they may have been told or themselves had told. This research provided subjects with eight categories of individuals. The Serota category "business contacts" was replaced with four categories: "lobbyists," "congressional staff," "journalists," and "executive branch personnel."

\section{The number of times Staff and Stennis Fellows believe they were lied to in the past 24 hours.}
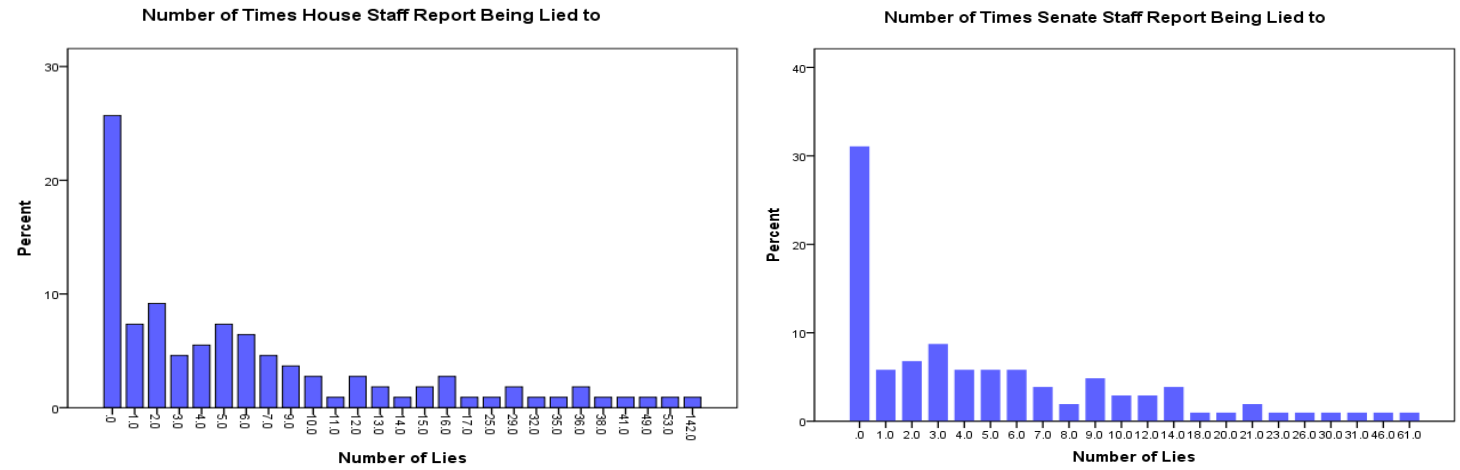

The mean number of lies that House staff believe were told to them was $M=8.96$ $(S D=16.9)$. The median number of lies was $M d n=4.0$ lies per day and the mode was $M o=$ 0. The mean was affected by an individual who reported having been lied to 142 times. Review of the case suggested that the responses were intentional and did not provide clear rationale for elimination. $25.7 \%$ of House staff reported that they were not lied to in the prior 24 hours. $46.8 \%$ of House staff reported being lied to three or fewer times. Ten percent of the staff accounted for $53 \%$ of the reported lies. 
Elimination of the single case reduced the mean number of lies to $M=7.7(S D=11.1)$ and produced a median $M d n=4.0$ and a mode of $M o=0$. This skew suggests that median may be a better measure of central tendency than the mean. Nonetheless, House staff reported being lied to at substantially higher rates than did students from the Serota study. The two-sample, two-tailed t-statistic was significant at the .05 level for the difference in means between House staff and the Serota students, $t(305)=5.02, p=.000$. The t-statistic was still significant at the .05 level when the extreme case was excluded, $t(304)=5.893$, $\mathrm{p}=.0000$.

The mean number of lies that were told to Senate staff was $M=6.3(S D=9.5)$ with a median of $M d n=3$ and a mode of $M o=0$. The responses included two cases that reported significantly more lies (46 and 61). These cases were reviewed, and responses did not seem to be random or unintentional. $31.1 \%$ of Senate staff reported they were not lied to in the prior 24 hours. $52.4 \%$ of Senate staff reported being lied to three or fewer times. $9.7 \%$ of staff accounted for $46 \%$ of the reported lies.

Removal of the two extreme cases reduces the median to $M=5.3(S D=6.8)$ and produces a median of $M d n=3.0$ and mode of $M o=0$. As with the House staff, the median may be a better measure of central tendency. Nonetheless, Senate staff also report being lied to at greater rates than do the students from the Serota study. The two-sample, two-tailed tstatistic was significant at the .05 level for the difference in means between House staff and the Serota students, $t(299)=4.8, p=.000$. The t-statistic for the difference between the House and Senate staff was not significant at the .05 level, $t(210)=1.402, p=.163$. 
Number of Times Staff Were Lied to in Prior 24 Hours

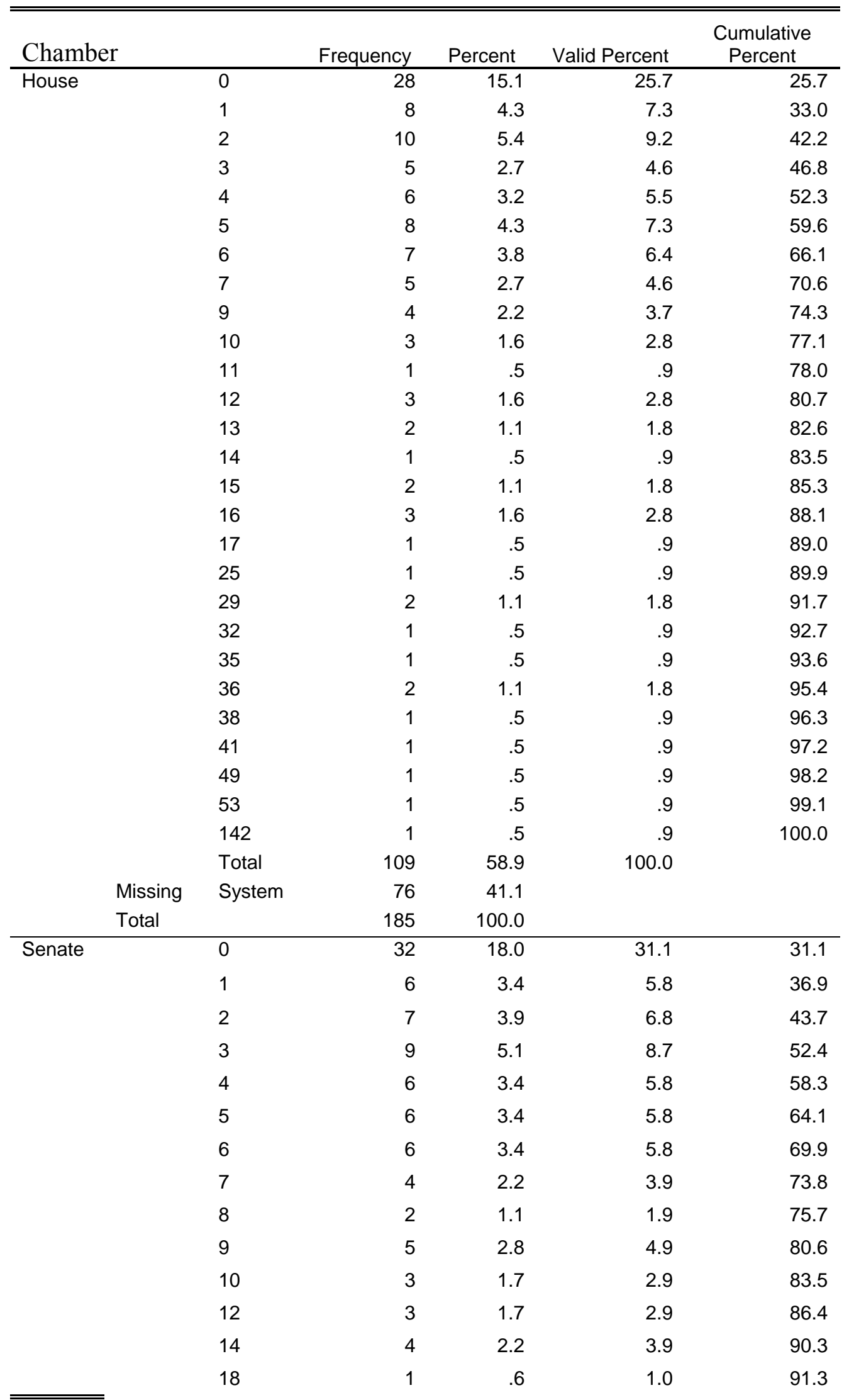




\begin{tabular}{llrrrr} 
& 20 & 1 & .6 & 1.0 & 92.2 \\
& 21 & 2 & 1.1 & 1.9 & 94.2 \\
& 23 & 1 & .6 & 1.0 & 95.1 \\
& 26 & 1 & .6 & 1.0 & 96.1 \\
& 30 & 1 & .6 & 1.0 & 97.1 \\
& 31 & 1 & .6 & 1.0 & 98.1 \\
& 46 & 1 & .6 & 1.0 & 99.0 \\
& 61 & 1 & .6 & 1.0 & 100.0 \\
Missing & Sotal & 103 & 57.9 & 100.0 & \\
Total & System & 75 & 42.1 & & \\
\hline
\end{tabular}

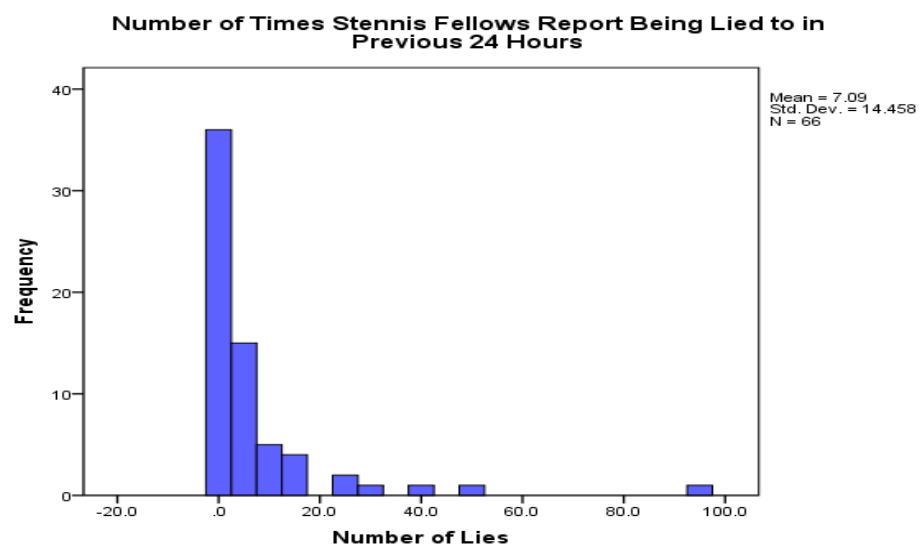

The mean number of lies that were told to Stennis Fellows was $M=7.1(S D=14.5)$ with a median of $M d n=2$ and a mode of $M o=0$. The responses included two cases that reported significantly more lies (52 and 93). These cases were reviewed, and responses did not seem to be random or unintentional. $31.8 \%$ of Stennis Fellows reported that they were not lied to in the previous 24 hours. $10.7 \%$ of Fellows accounted for $76 \%$ of the reported lies.

Removal of these two cases reduces the mean to $M=5.1(S D=7.9)$ and produces a median of $M d n=2.0$, and mode of $M o=0$. Stennis Fellows reported being lied to at higher rates than those reported by students in the Serota study. The two-sample, two-tailed t-statistic 
was significant at the. 05 level for the difference in population means between Stennis

Fellows and Serota students, $t(252)=3.977, p=.0001$. The difference in means was not significant at the .05 level for the difference between Stennis Fellows and House or

Senate staff.

Number of Times Stennis Fellows Believe they were Lied to

\begin{tabular}{|c|c|c|c|c|c|}
\hline & & Frequency & Percent & $\begin{array}{c}\text { Valid } \\
\text { Percent }\end{array}$ & $\begin{array}{c}\text { Cumulative } \\
\text { Percent }\end{array}$ \\
\hline \multirow[t]{22}{*}{ Valid } & 0 & 21 & 17.2 & 31.8 & 31.8 \\
\hline & 1 & 9 & 7.4 & 13.6 & 45.5 \\
\hline & 2 & 6 & 4.9 & 9.1 & 54.5 \\
\hline & 3 & 3 & 2.5 & 4.5 & 59.1 \\
\hline & 4 & 4 & 3.3 & 6.1 & 65.2 \\
\hline & 5 & 3 & 2.5 & 4.5 & 69.7 \\
\hline & 6 & 1 & .8 & 1.5 & 71.2 \\
\hline & 7 & 4 & 3.3 & 6.1 & 77.3 \\
\hline & 8 & 2 & 1.6 & 3.0 & 80.3 \\
\hline & 9 & 2 & 1.6 & 3.0 & 83.3 \\
\hline & 12 & 1 & .8 & 1.5 & 84.8 \\
\hline & 13 & 1 & .8 & 1.5 & 86.4 \\
\hline & 15 & 1 & .8 & 1.5 & 87.9 \\
\hline & 16 & 1 & .8 & 1.5 & 89.4 \\
\hline & 17 & 1 & .8 & 1.5 & 90.9 \\
\hline & 26 & 1 & .8 & 1.5 & 92.4 \\
\hline & 27 & 1 & .8 & 1.5 & 93.9 \\
\hline & 30 & 1 & .8 & 1.5 & 95.5 \\
\hline & 38 & 1 & .8 & 1.5 & 97.0 \\
\hline & 52 & 1 & .8 & 1.5 & 98.5 \\
\hline & 93 & 1 & .8 & 1.5 & 100.0 \\
\hline & Total & 66 & 54.1 & 100.0 & \\
\hline Missing & System & 56 & 45.9 & & \\
\hline Total & & 122 & 100.0 & & \\
\hline
\end{tabular}


The number of times Staff and Stennis Fellows reported that they lied to in the past 24 hours.
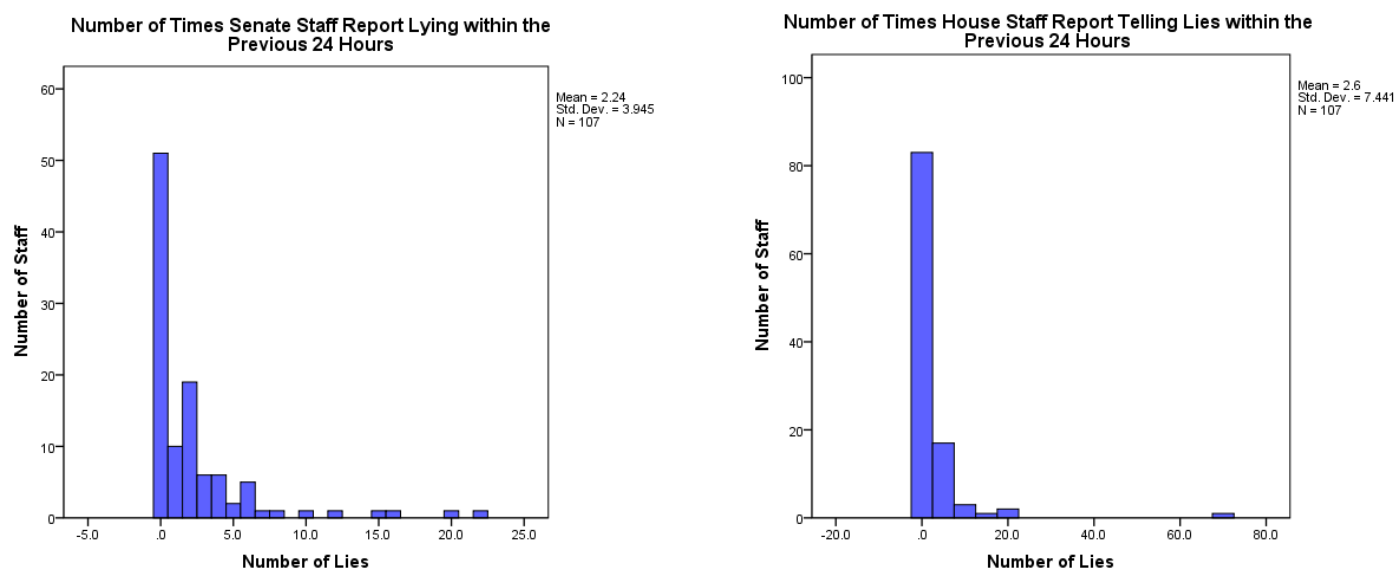

The mean number of lies that House staff reported telling during the previous 24 hours was $M=2.6(S D=7.8)$. The median number of lies was $M d n=1.0$ lies per day and the mode was $M o=0$. The mean was affected by an individual who reported having lied 70 times. Review of the case suggested that the responses were intentional and did not provide clear rationale for elimination. ${ }^{126}$ For illustration purposes, elimination of the single case reduced the mean number of lies to $M=1.96(S D=3.5)$ and produced a median of $M d n=1.0$ and a mode of $M o=0$. The two-sample, two-tailed t-statistic for the difference in means between uncorrected House staff and the Serota population study $(M=1.65, S D=4.45, n=998)$ was not significant at the .05 level, $t(1104)=1.923, p=.0547$. The null hypothesis that there is no difference in median lying between House staff and the Serota adult population cannot be rejected.

\footnotetext{
${ }^{126}$ Serota reports a maximum number of 53 lies within her internet survey panel. It is possible that the use of drop boxes rather than requiring individuals to input individual number may have had an impact. This respondent did, however, successfully use the drop boxes here and elsewhere in the survey to select a mix of numbers in a manner that suggests intent.
} 
$46.7 \%$ of House staff reported telling no lies during the previous 24 hours. $6.5 \%$ of House staff reported telling $43 \%$ of the total lies reported. Sixty percent of Serota's national panel reported telling no lies, and $5 \%$ of respondents reported telling $50 \%$ of all lies. The two-sample, two-tailed t-statistic for the difference in percentages between House staff reporting zero lies and Serota's panel reporting zero lies was significant at the .05 level, $t(1103)=2.635, p=.0085$ suggesting that a higher percentage of House staff reported telling at least one lie than did the adult population in Serota's study.

The mean number of lies that Senate staff reported telling during the previous 24 hours was $M=2.2(S D=7.8)$. The median number of lies was $M d n=1.0$ lies per day and the mode was $M o=0.47 .7 \%$ of Senate staff reported telling no lies (similar to the House). $6.5 \%$ of Senate staff reported telling $43 \%$ of the total lies. The two-sample, two-tailed tstatistic for the difference in proportions between Senate staff and Serota's panel members reporting zero lies was significant at the .05 level, $t(1103)=2.436, p=.0150$, suggesting that a higher percentage of Senate staff reported telling at least one lie than did the adult population in Serota's study. 


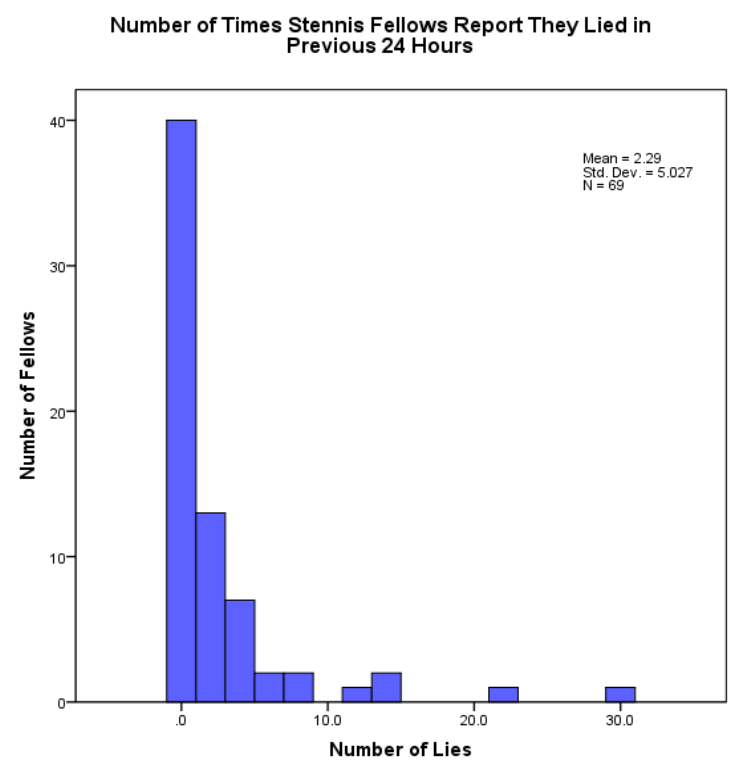

The mean number of lies that Stennis Fellows reported telling during the previous 24 hours was $M=2.3(S D=5)$. The median number of lies was $M d n=0.0$ lies per day and the mode was $M o=0$. The mean was affected by two individuals who reported having lied 22 and 29 times. Review of the case suggested that the responses were intentional and did not provide clear rationale for elimination. For illustration purposes, elimination of the two cases reduced the mean number of lies to $M=1.56(S D=2.97)$ and produced a median of $M d n=0.0$, and a mode of $M o=0$.

Fifty-eight percent of Fellows reported telling no lies. $5.6 \%$ of the Fellows told $49 \%$ of the lies. This is comparable to Serota's national panel, in which $59.9 \%$ of respondents indicated they told no lies and 5.3\% of the respondents told one-half of all of reported lies. $^{127}$

${ }^{127}$ Serota, Levine, and Boster, "The Prevalence of Lying in America: Three Studies of Self-Reported Lies." 


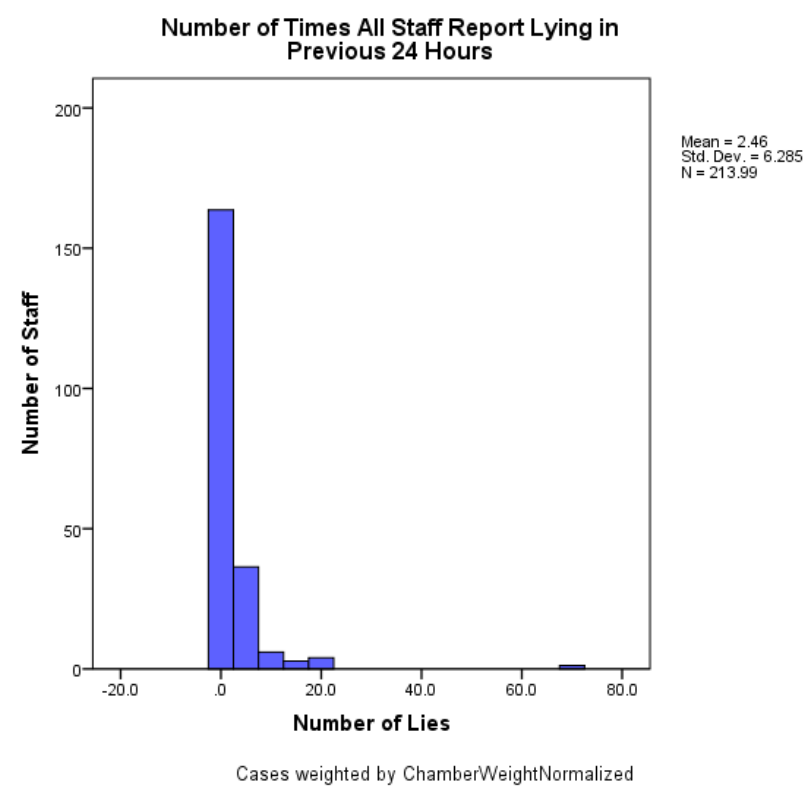

The mean number of lies that all staff-weighted reported telling during the previous 24 hours was $M=2.5(S D=6.3)$. The median number of lies was $M d n=1.0$ per day and the mode was $M o=0$. The mean was affected by an individual who reported having lied 70 times. Review of the case suggested that the responses were intentional and did not provide clear rationale for elimination. Elimination of the single case reduced the mean number of lies to $M=2.1(S D=3.75)$ and produced a median of $M d n=1.0$, and a mode of $M o=0$. The two-sample, two-tailed t-statistic was significant at the .05 level for the difference in mean-reported lying between all staff-weighted (2.5) and Serota adults (1.65), $t(1210)=2.224, p=.0264$.

The t-statistic was not significant at the .05 level if the single prolific liar was excluded, $t(1209)=1.375, p=.169$. As described earlier, the Serota study included a respondent who reported lying 53 times during the prior 24 hours. Review of the prolific House liar's 
responses provided no clear reason for exclusion that would not as easily implicate respondents who indicated zero.

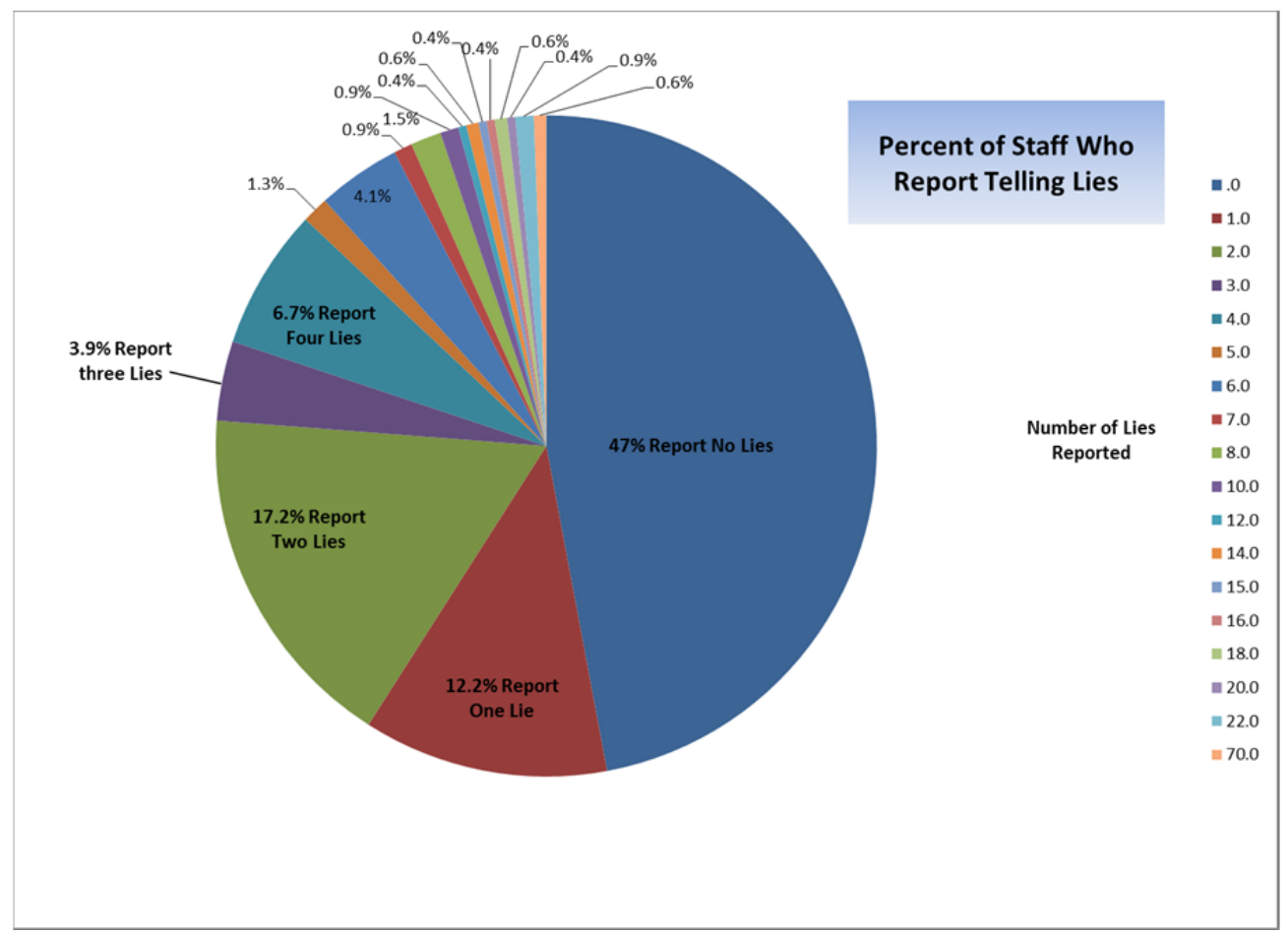

Serota reported that $59.9 \%$ of the adults in her survey reported telling no lies and that $5.3 \%$ of her respondents accounted for $50 \%$ of all lies. Forty-seven percent of all staffweighted respondents reported that they told no lies within the previous 24 hours. $6.5 \%$ of all staff-weighted respondents told $50 \%$ of all reported lies. The two-sample, twotailed t-statistic was significant at the .05 level, $t(1210)=3.465, p=.0006$, for the difference in proportion between congressional staff who report telling no lies and adults in the Serota national panel who did likewise. Although the pattern - many people telling no lies and a handful of prolific liars accounting for most lies - was repeated, fewer staff than Serota adults reported telling no lies within the previous 24 hours. 


\section{$\underline{\text { Power Functions }}$}

One of Serota's major findings, confirmed by this study, was that use of the mean and median numbers for lying obscured the fact that most lies were told by a few individuals. She concluded that the data fit a standard power function. In order to test these findings against the all staff-weighted and Stennis Fellows respondents, the number of lies were graphed and the data were analyzed to determine whether they fit a standard power function. Reported (observed) lying was organized by communication mode (face-to-face or by phone/internet), and graphs of reported lying to the various categories of individuals were overlaid in the charts below. Power functions were calculated for each communication mode and category and these were overlaid as well. ${ }^{128}$

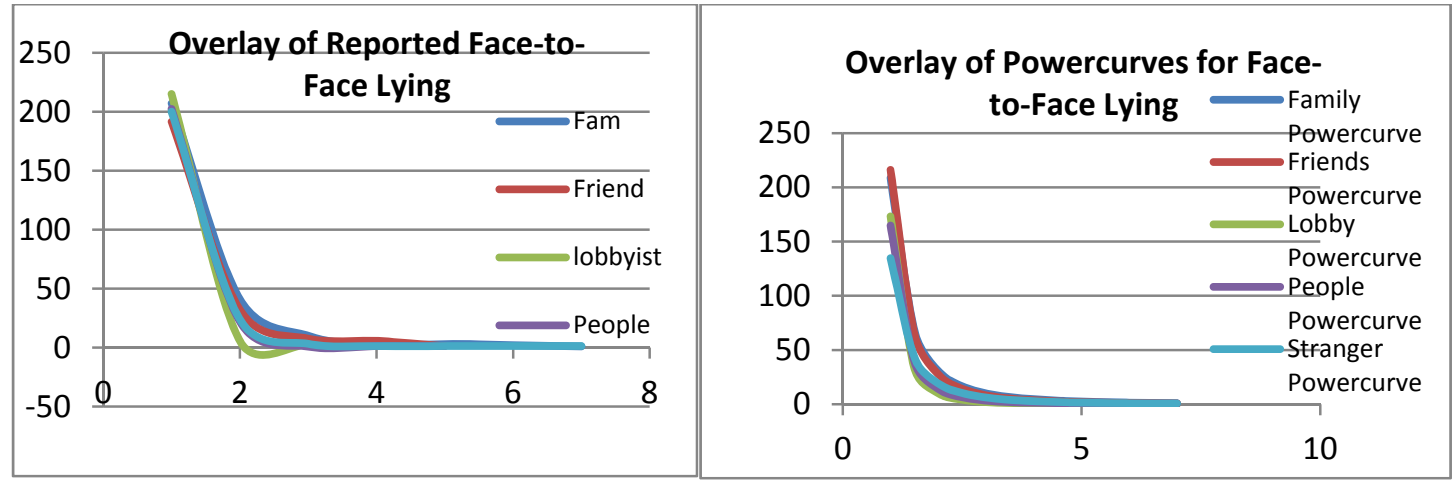

\footnotetext{
${ }^{128}$ Power functions take the form of $\mathrm{y}=\mathrm{bx}^{\wedge}$. In order to calculate the power functions, data were transformed so that zero lies became one lie, one became two, etc. The purpose of this calculation is to demonstrate the consistency of the pattern in which most individuals reported no lies while, ironically, a few prolific liars reported telling many lies.
} 

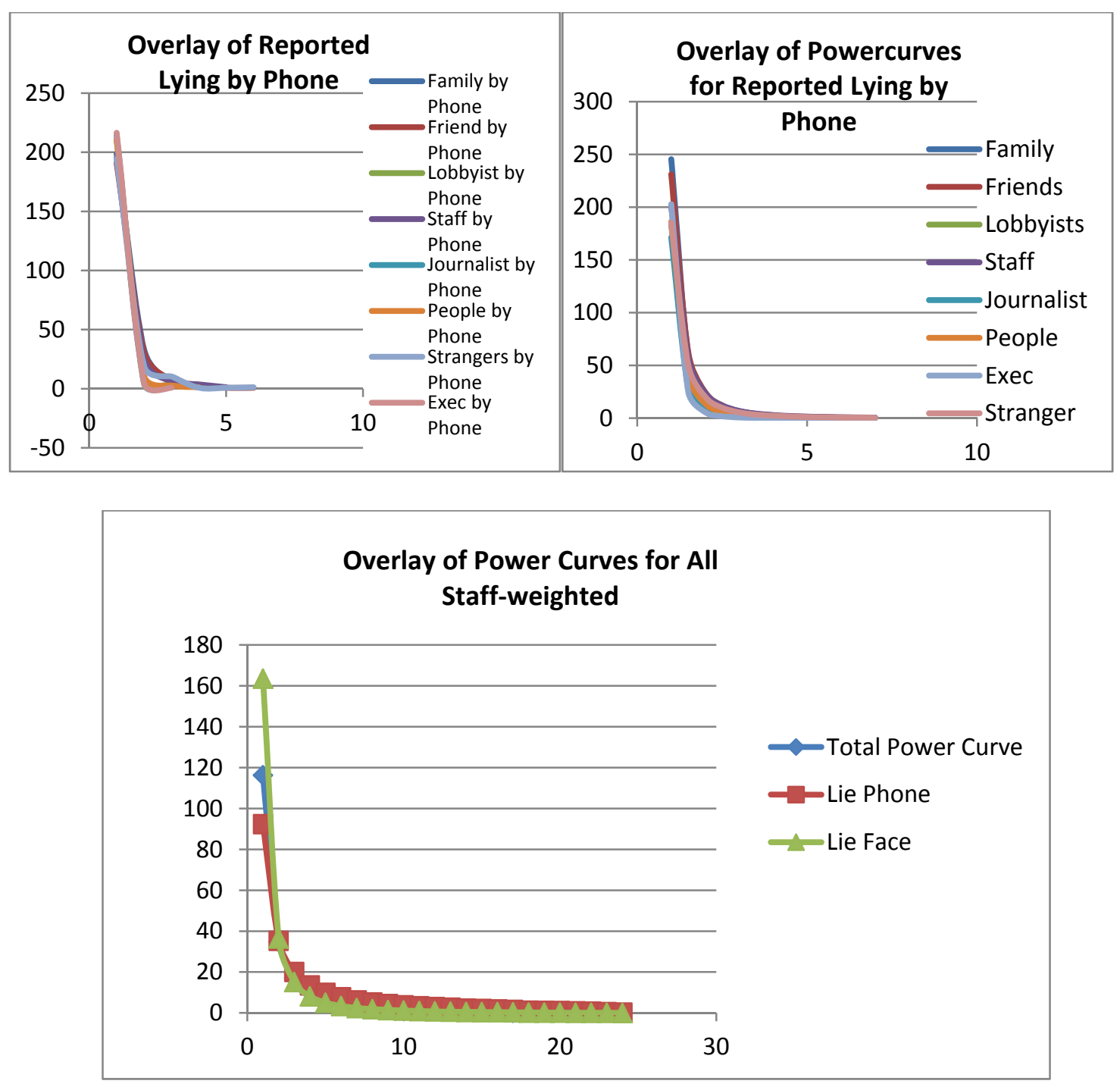

The equations for the power function curves are as follows: 1) total lies $-y=116.19 x^{-1.738}$; 2) phone lies $-y=92.37 x^{-1.388}$; and 3) face-to-face lies $-y=131.76 x^{-1.636}$, where $x$ is the number of lies reported per day and $y$ is the frequency. The large intercept indicates that most respondents reported that they do not lie and that those who did report lying tended to do so infrequently. As was the case with the Serota studies, this pattern appears to be consistently followed without regard to the mode of communication. 
The majority of lies told by all staff-weighted were to friends (143), family (128), other staff (104), and strangers (107). The number of these lies was fairly equally distributed between face-to-face and by phone or internet with no significant differences by mode. Serota also observed in her study that more lies were told to friends and family members than to acquaintances or strangers. ${ }^{129}$ Unlike the DePaulo study, neither my study nor the Serota study captured the number of opportunities or interactions the respondents had with various people during the day. As a result, these data cannot be used to draw conclusions about the relative propensity to lie to various types of individuals. It is just as likely that the higher number of lies told to family and friends reflects greater opportunity rather than greater propensity.
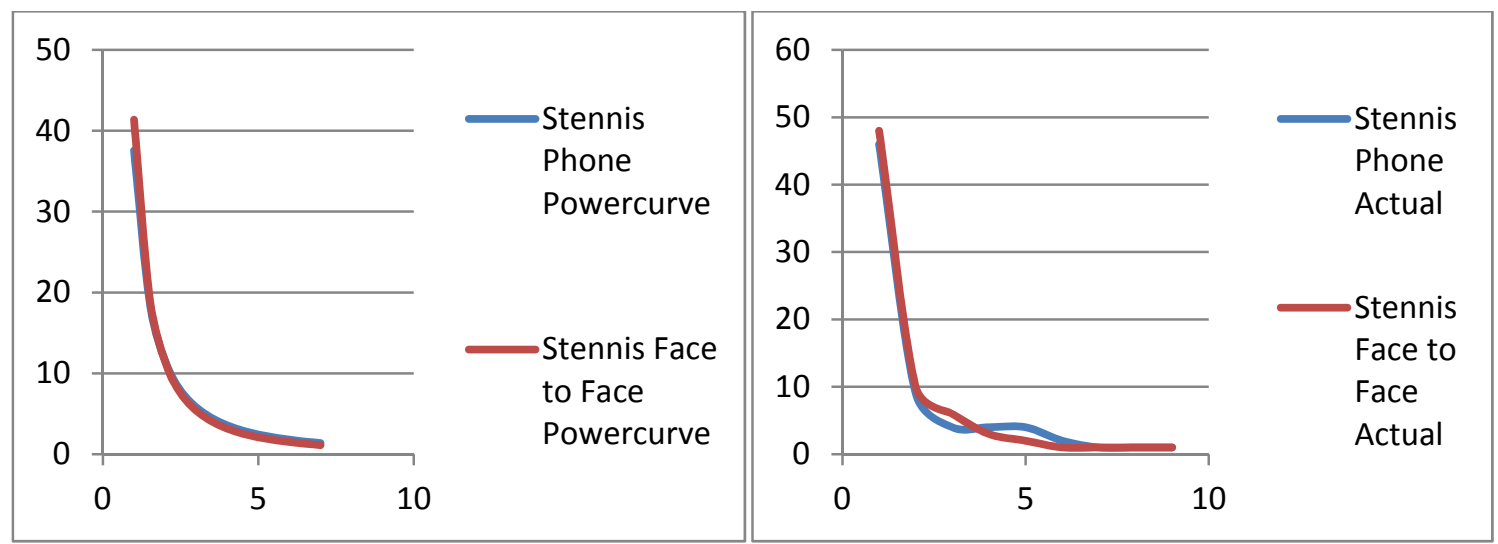

The chart at above right reflects the graphing of actual Stennis data for lies told by phone and lies told face-to-face. The chart at above left, reflects the smoothing of the actual data into a standard power curve.

The figures above indicate that the data fit a standard power function. Fitting a power function curve to the data yields the equations $y=37.543 \mathrm{x}^{-1.699}$ for lies told by phone or

${ }^{129}$ Serota, Levine, and Boster, "The Prevalence of Lying in America: Three Studies of Self-Reported Lies." 
internet and $\mathrm{y}=41.359 \mathrm{x}^{-1.855}$ for lies told face-to-face. Superimposing these curves over each other reveals that they share a common pattern: most Fellows report telling no lies and a few Fellows report telling a substantial percentage of the lies that are reported. As was the case with the Serota studies, this pattern appears to be followed without regard to the mode of communication.

The Number of Times Congressional Staff Reported Lying in the Previous 24 Hours

\begin{tabular}{|c|c|c|c|c|c|c|}
\hline \multicolumn{3}{|c|}{ Chamber } & \multirow{2}{*}{$\frac{\text { Frequency }}{50}$} & \multirow{2}{*}{$\frac{\text { Percent }}{27.0}$} & \multirow{2}{*}{$\begin{array}{c}\text { Valid Percent } \\
46.7\end{array}$} & \multirow{2}{*}{$\begin{array}{c}\begin{array}{c}\text { Cumulative } \\
\text { Percent }\end{array} \\
46.7\end{array}$} \\
\hline House & Valid & .0 & & & & \\
\hline & & 1.0 & 15 & 8.1 & 14.0 & 60.7 \\
\hline & & 2.0 & 18 & 9.7 & 16.8 & 77.6 \\
\hline & & 3.0 & 3 & 1.6 & 2.8 & 80.4 \\
\hline & & 4.0 & 8 & 4.3 & 7.5 & 87.9 \\
\hline & & 5.0 & 1 & .5 & .9 & 88.8 \\
\hline & & 6.0 & 4 & 2.2 & 3.7 & 92.5 \\
\hline & & 7.0 & 1 & .5 & .9 & 93.5 \\
\hline & & 8.0 & 2 & 1.1 & 1.9 & 95.3 \\
\hline & & 10.0 & 1 & .5 & .9 & 96.3 \\
\hline & & 14.0 & 1 & .5 & .9 & 97.2 \\
\hline & & 18.0 & 1 & .5 & .9 & 98.1 \\
\hline & & 22.0 & 1 & .5 & .9 & 99.1 \\
\hline & & 70.0 & 1 & .5 & .9 & 100.0 \\
\hline & & Total & 107 & 57.8 & 100.0 & \\
\hline & Missing & System & 78 & 42.2 & & \\
\hline & & & 185 & 100.0 & & \\
\hline \multirow[t]{16}{*}{ Senate } & Valid & .0 & 51 & 28.7 & 47.7 & 47.7 \\
\hline & & 1.0 & 10 & 5.6 & 9.3 & 57.0 \\
\hline & & 2.0 & 19 & 10.7 & 17.8 & 74.8 \\
\hline & & 3.0 & 6 & 3.4 & 5.6 & 80.4 \\
\hline & & 4.0 & 6 & 3.4 & 5.6 & 86.0 \\
\hline & & 5.0 & 2 & 1.1 & 1.9 & 87.9 \\
\hline & & 6.0 & 5 & 2.8 & 4.7 & 92.5 \\
\hline & & 7.0 & 1 & .6 & .9 & 93.5 \\
\hline & & 8.0 & 1 & .6 & .9 & 94.4 \\
\hline & & 10.0 & 1 & .6 & .9 & 95.3 \\
\hline & & 12.0 & 1 & .6 & .9 & 96.3 \\
\hline & & 15.0 & 1 & .6 & .9 & 97.2 \\
\hline & & 16.0 & 1 & .6 & .9 & 98.1 \\
\hline & & 20.0 & 1 & .6 & .9 & 99.1 \\
\hline & & 22.0 & 1 & .6 & .9 & 100.0 \\
\hline & & Total & 107 & 60.1 & 100.0 & \\
\hline
\end{tabular}




\begin{tabular}{lccc}
\hline Missing & System & 71 & 39.9 \\
Total & & 178 & 100.0 \\
\hline \hline
\end{tabular}

Number of Times Stennis Fellows Reported Lying in the Previous 24

Hours

\begin{tabular}{llrrrr}
\hline \hline & & & & & \\
& & Frequency & Percent & Valid Percent & $\begin{array}{c}\text { Pumulive } \\
\text { Percent }\end{array}$ \\
\hline Valid & .0 & 40 & 32.8 & 58.0 & 58.0 \\
& 1.0 & 8 & 6.6 & 11.6 & 69.6 \\
& 2.0 & 5 & 4.1 & 7.2 & 76.8 \\
& 3.0 & 2 & 1.6 & 2.9 & 79.7 \\
& 4.0 & 5 & 4.1 & 7.2 & 87.0 \\
& 6.0 & 2 & 1.6 & 2.9 & 89.9 \\
& 7.0 & 2 & 1.6 & 2.9 & 92.8 \\
& 11.0 & 1 & .8 & 1.4 & 94.2 \\
& 13.0 & 2 & 1.6 & 2.9 & 97.1 \\
& 22.0 & 1 & .8 & 1.4 & 98.6 \\
& 29.0 & 1 & .8 & 1.4 & 100.0 \\
& Total & 69 & 56.6 & 100.0 & \\
Missing & System & 53 & 43.4 & & \\
Total & & 122 & 100.0 & & \\
\hline \hline
\end{tabular}

Number of Times All Staff-Weighted Reported Telling Lies

\begin{tabular}{|c|c|c|c|c|c|}
\hline & & Frequency & Percent & Valid Percent & $\begin{array}{c}\text { Cumulative } \\
\text { Percent }\end{array}$ \\
\hline \multirow[t]{19}{*}{ Valid } & .0 & 101 & 27.7 & 47.1 & 47.1 \\
\hline & 1.0 & 26 & 7.1 & 12.2 & 59.3 \\
\hline & 2.0 & 37 & 10.1 & 17.2 & 76.5 \\
\hline & 3.0 & 8 & 2.3 & 3.9 & 80.4 \\
\hline & 4.0 & 14 & 4.0 & 6.7 & 87.1 \\
\hline & 5.0 & 3 & .8 & 1.3 & 88.4 \\
\hline & 6.0 & 9 & 2.4 & 4.1 & 92.5 \\
\hline & 7.0 & 2 & .5 & .9 & 93.5 \\
\hline & 8.0 & 3 & .9 & 1.5 & 95.0 \\
\hline & 10.0 & 2 & .5 & .9 & 95.9 \\
\hline & 12.0 & 1 & .2 & .4 & 96.3 \\
\hline & 14.0 & 1 & .3 & .6 & 96.8 \\
\hline & 15.0 & 1 & .2 & .4 & 97.2 \\
\hline & 16.0 & 1 & .2 & .4 & 97.6 \\
\hline & 18.0 & 1 & .3 & .6 & 98.1 \\
\hline & 20.0 & 1 & .2 & .4 & 98.5 \\
\hline & 22.0 & 2 & .5 & .9 & 99.4 \\
\hline & 70.0 & 1 & .3 & .6 & 100.0 \\
\hline & Total & 214 & 58.7 & 100.0 & \\
\hline Missing & System & 150 & 41.3 & & \\
\hline Total & & 364 & 100.0 & & \\
\hline
\end{tabular}


Number of Face-to-Face Lies to Family by All Staff

\begin{tabular}{llrrrr}
\hline \hline & & & & & \multicolumn{2}{c}{$\begin{array}{c}\text { Cumulative } \\
\text { Percent }\end{array}$} \\
\hline Valid & .0 & Frequency & Percent & Valid Percent & 81.0 \\
& 1.0 & 198 & 54.2 & 81.0 & 95.6 \\
& 2.0 & 36 & 9.8 & 14.6 & 99.0 \\
& 5.0 & 8 & 2.3 & 3.5 & 99.5 \\
& 10.0 & 1 & .3 & .5 & 100.0 \\
& Total & 1 & .3 & .5 & \\
Missing & System & 244 & 66.9 & 100.0 & \\
Total & & 121 & 33.1 & & \\
\hline \hline
\end{tabular}

Number of Face-to-Face Lies to Friends by All Staff

\begin{tabular}{llrrrr}
\hline \hline & & & & & \multicolumn{2}{c}{ Cumulative } \\
& & Frequency & Percent & Valid Percent & Percent \\
\hline Valid & .0 & 192 & 52.5 & 80.5 & 80.5 \\
& 1.0 & 32 & 8.8 & 13.4 & 93.9 \\
& 2.0 & 8 & 2.1 & 3.2 & 97.1 \\
& 3.0 & 6 & 1.5 & 2.4 & 99.5 \\
& 5.0 & 1 & .3 & .5 & 100.0 \\
& Total & 238 & 65.3 & 100.0 & \\
Missing & System & 127 & 34.7 & & \\
Total & & 364 & 100.0 & & \\
\hline \hline
\end{tabular}

Number of Face-to-Face Lies to Lobbyists by All Staff

\begin{tabular}{llrrrr}
\hline \hline & & & & \multicolumn{2}{c}{ Cumulative } \\
& & Frequency & Percent & Valid Percent & Percent \\
\hline Valid & .0 & 215 & 59.0 & 96.2 & 96.2 \\
& 1.0 & 6 & 1.5 & 2.5 & 98.8 \\
& 2.0 & 3 & .8 & 1.2 & 100.0 \\
& Total & 224 & 61.3 & 100.0 & \\
Missing & System & 141 & 38.7 & & \\
Total & & 364 & 100.0 & & \\
\hline \hline
\end{tabular}

Number of Face-to-Face Lies to Staff by All Staff

\begin{tabular}{llrrrr}
\hline \hline & & & & \multicolumn{2}{c}{ Cumulative } \\
& & Frequency & Percent & Valid Percent & Percent \\
\hline Valid & .0 & 211 & 57.8 & 90.5 & 90.5 \\
& 15 & 4.2 & 6.5 & 97.1 \\
& 1.0 & 1 & .3 & .5 & 97.6 \\
& 2.0 & 2 & .7 & 1.0 & 98.6 \\
3.0 & 1 & .3 & .5 & 99.1 \\
& 8.0 & 2 & .5 & .9 & 100.0 \\
10.0 & 233 & 63.9 & 100.0 &
\end{tabular}




\begin{tabular}{|c|c|c|}
\hline Missing & System & 132 \\
\hline Total & & 364 \\
\hline
\end{tabular}

Number of Face-to-Face Lies to Journalists by All Staff

\begin{tabular}{llrrrr}
\hline \hline & & & & \multicolumn{2}{c}{ Cumulative } \\
& & Frequency & Percent & Valid Percent & Percent \\
\hline Valid & .0 & 222 & 60.9 & 99.3 & 99.3 \\
& 1.0 & 2 & .4 & .7 & 100.0 \\
& Total & 224 & 61.3 & 100.0 & \\
Missing & System & 141 & 38.7 & & \\
Total & & 364 & 100.0 & & \\
\hline \hline
\end{tabular}

Number of Face-to-Face Lies to Executive Branch by All Staff

\begin{tabular}{llrrrr}
\hline \hline & & & & & Cumulative \\
& & Frequency & Percent & Valid Percent & Percent \\
\hline Valid & .0 & 226 & 62.0 & 100.0 & 100.0 \\
Missing & System & 138 & 38.0 & & \\
Total & & 364 & 100.0 & & \\
\hline \hline
\end{tabular}

Number of Face-to-Face Lies to People You Don't Know But Might See Occasionally by All Staff

\begin{tabular}{llrrrr}
\hline \hline & & & & & \multicolumn{2}{c}{ Cumulative } \\
Valid & .0 & Frequency & Percent & Valid Percent & Percent \\
& 1.0 & 202 & 55.5 & 88.9 & 88.9 \\
& 3.0 & 1 & 6.0 & 9.7 & 98.6 \\
& 5.0 & 1 & .2 & .3 & 98.9 \\
& 10.0 & 1 & .3 & .5 & 99.5 \\
& Total & 228 & 62.4 & .5 & 100.0 \\
Missing & System & 137 & 37.6 & & \\
Total & & 364 & 100.0 & & \\
\hline \hline
\end{tabular}

Number of Face-to-Face Lies to Strangers by All Staff

\begin{tabular}{llrrrr}
\hline \hline & & & & & \multicolumn{2}{c}{ Cumulative } \\
& & Frequency & Percent & Valid Percent & Percent \\
\hline Valid & .0 & 200 & 54.9 & 86.3 & 86.3 \\
& 1.0 & 24 & 6.6 & 10.3 & 96.6 \\
& 2.0 & 3 & .9 & 1.4 & 97.9 \\
& 3.0 & 1 & .3 & .5 & 98.4 \\
& 4.0 & 1 & .3 & .5 & 99.0 \\
& 5.0 & 1 & .3 & .5 & 99.5 \\
& 10.0 & 1 & .3 & .5 & 100.0 \\
& Total & 232 & 63.7 & 100.0 & \\
Missing & System & 132 & 36.3 & & \\
\hline \hline
\end{tabular}


Number of Lies to Family by Phone or Internet by All Staff

\begin{tabular}{llrrrr}
\hline \hline & & & & & \multicolumn{2}{c}{ Cumulative } \\
& & Frequency & Percent & Valid Percent & Percent \\
\hline Valid & .0 & 199 & 54.5 & 83.1 & 83.1 \\
& 1.0 & 33 & 9.1 & 13.9 & 97.0 \\
& 2.0 & 6 & 1.5 & 2.3 & 99.3 \\
& 3.0 & 2 & .4 & .7 & 100.0 \\
& Total & 239 & 65.6 & 100.0 & \\
Missing & System & 125 & 34.4 & & \\
Total & & 364 & 100.0 & & \\
\hline \hline
\end{tabular}

Number of Lies to Friends by Phone or Internet by All Staff

\begin{tabular}{llrrrr}
\hline \hline & & & & & Cumulative \\
& & Frequency & Percent & Valid Percent & Percent \\
\hline Valid & .0 & 191 & 52.4 & 81.4 & 81.4 \\
& 1.0 & 31 & 8.5 & 13.3 & 94.7 \\
& 2.0 & 8 & 2.1 & 3.3 & 98.0 \\
& 3.0 & 3 & .9 & 1.4 & 99.3 \\
& 5.0 & 1 & .2 & .3 & 99.7 \\
& 10.0 & 1 & .2 & .3 & 100.0 \\
& Total & 234 & 64.3 & 100.0 & \\
Missing & System & 130 & 35.7 & & \\
Total & & 364 & 100.0 & & \\
\hline \hline
\end{tabular}

Number of Lies to Lobbyists by Phone or Internet by All Staff

\begin{tabular}{|c|c|c|c|c|c|}
\hline & & Frequency & Percent & Valid Percent & $\begin{array}{c}\text { Cumulative } \\
\text { Percent }\end{array}$ \\
\hline \multirow[t]{4}{*}{ Valid } & .0 & 210 & 57.7 & 94.3 & 94.3 \\
\hline & 1.0 & 9 & 2.5 & 4.1 & 98.4 \\
\hline & 2.0 & 4 & 1.0 & 1.6 & 100.0 \\
\hline & Total & 223 & 61.2 & 100.0 & \\
\hline Missing & System & 141 & 38.8 & & \\
\hline Total & & 364 & 100.0 & & \\
\hline
\end{tabular}

Number of Lies to Staff by Phone or Internet by All Staff

\begin{tabular}{llrrrr}
\multicolumn{5}{c}{ Number of Lies to Staff by Phone or Internet by All Staff } \\
\hline \hline \multirow{6}{*}{ Valid } & \multicolumn{6}{c}{} & & Cumulative \\
& .0 & Frequency & Percent & Valid Percent & Percent \\
\hline & 1.0 & 195 & 53.5 & 84.4 & 84.4 \\
& 2.0 & 25 & 6.8 & 10.7 & 95.1 \\
& 3.0 & 6 & 1.8 & 2.8 & 97.9 \\
& 4.0 & 4 & 1.0 & 1.6 & 99.5 \\
& Total & 1 & .3 & .5 & 100.0 \\
Missing & System & 231 & 63.4 & 100.0 & \\
Total & 133 & 36.6 & & \\
\hline \hline
\end{tabular}


Number of Lies to Journalists by Phone or Internet by All Staff

\begin{tabular}{llrrrr}
\hline \hline & & & & \multicolumn{2}{c}{ Cumulative } \\
& & Frequency & Percent & Valid Percent & Percent \\
\hline Valid & .0 & 214 & 58.8 & 97.1 & 97.1 \\
& 1.0 & 4 & 1.2 & 2.0 & 99.1 \\
& 2.0 & 2 & .5 & .9 & 100.0 \\
& Total & 221 & 60.6 & 100.0 & \\
Missing & System & 144 & 39.4 & & \\
Total & & 364 & 100.0 & & \\
\hline \hline
\end{tabular}

Number of Lies to Executive Branch by Phone or Internet by All Staff

\begin{tabular}{llrrrr}
\hline \hline & & & & & Cumulative \\
& & Frequency & Percent & Valid Percent & Percent \\
\hline Valid & .0 & 216 & 59.4 & 97.5 & 97.5 \\
& 1.0 & 5 & 1.3 & 2.2 & 99.6 \\
& 2.0 & 1 & .2 & .4 & 100.0 \\
& Total & 222 & 60.9 & 100.0 & \\
Missing & System & 142 & 39.1 & & \\
Total & & 364 & 100.0 & & \\
\hline \hline
\end{tabular}

Number of Lies to People You do not Know but might See Occasionally by All Staff

\begin{tabular}{llrrrr}
\hline \hline & & & & & \multicolumn{2}{c}{ Cumulative } \\
& & Frequency & Percent & Valid Percent & Percent \\
\hline Valid & .0 & 210 & 57.7 & 93.3 & 93.3 \\
& 1.0 & 11 & 3.1 & 4.9 & 98.2 \\
& 2.0 & 3 & .8 & 1.2 & 99.5 \\
& 10.0 & 1 & .3 & .5 & 100.0 \\
& Total & 226 & 61.9 & 100.0 & \\
Missing & System & 139 & 38.1 & & \\
Total & & 364 & 100.0 & & \\
\hline \hline
\end{tabular}

Number of Lies to Strangers by Phone or Internet by All Staff

\begin{tabular}{llrrrr}
\hline \hline & & & & & Cumulative \\
& & Frequency & Percent & Valid Percent & Percent \\
\hline Valid & .0 & 194 & 53.3 & 85.7 & 85.7 \\
& 1.0 & 19 & 5.3 & 8.5 & 94.2 \\
& 2.0 & 10 & 2.8 & 4.6 & 98.8 \\
& 3.0 & 1 & .2 & .3 & 99.1 \\
& 5.0 & 1 & .2 & .3 & 99.5 \\
& 10.0 & 1 & .3 & .5 & 100.0 \\
& Total & 227 & 62.2 & 100.0 & \\
Missing & System & 138 & 37.8 & & \\
Total & & 364 & 100.0 & & \\
\hline \hline
\end{tabular}


Power Functions and Being Lied To
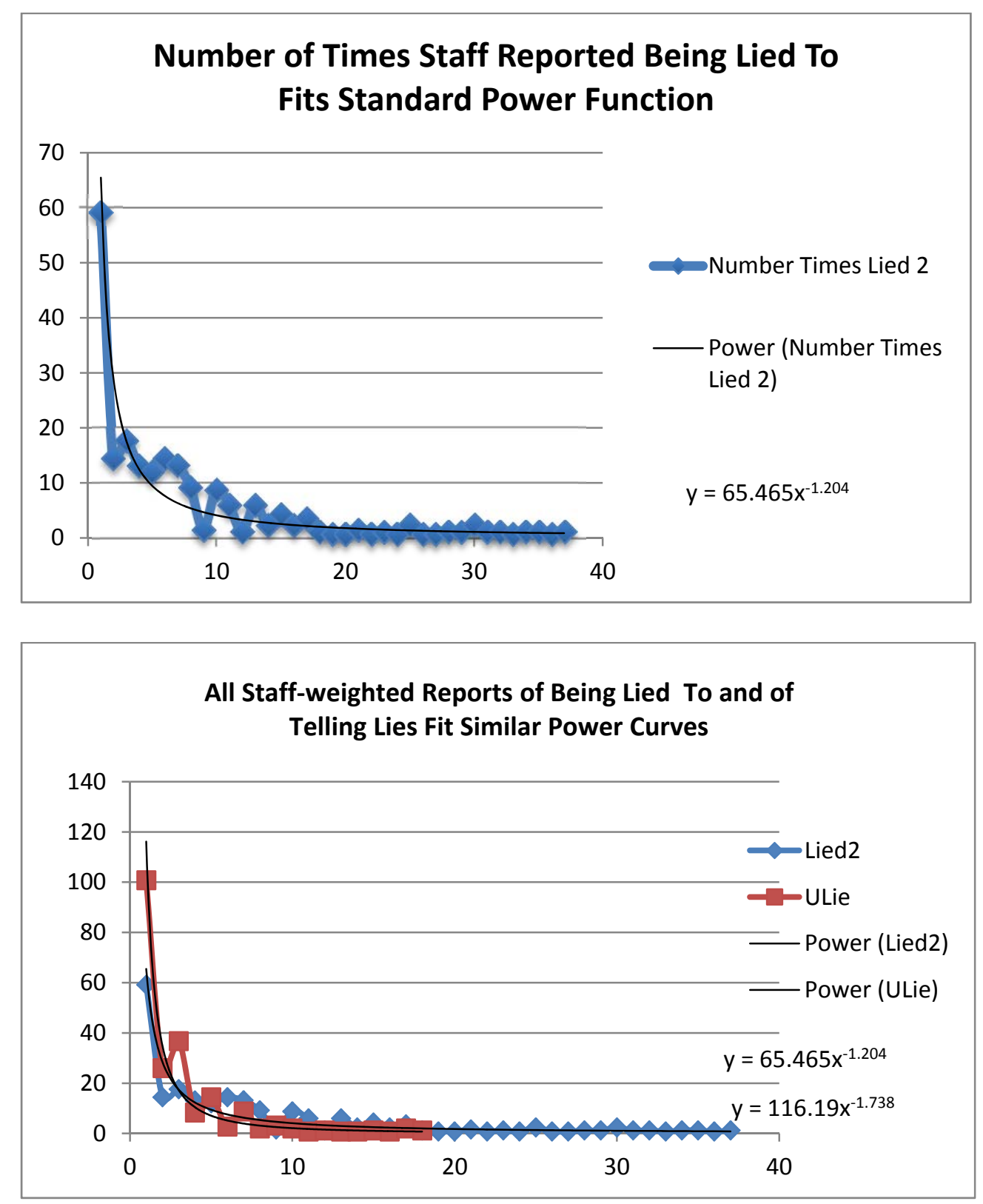

Serota's analysis of reported lying noted that the data fit a standard power function and that mean-reported lies failed to adequately acknowledge the number of individuals who told no lies in the prior 24 hours. She cited the higher level of mean-reported "being lied to" as a paradox that might reflect inherent social desirability bias. 
The charts above reflect the graphing of all staff-weighted data for the number of times staff reported being lied to and the number of times staff reported telling lies. The first chart superimposes a standard power function over the data. The second chart overlays the actual data for number of times that staff reported being lied to and the number of times staff reported lying as well their associated power functions.

The figures above indicate that the data for both reported lying and reported being lied to fit very similar standard power functions. Fitting a power function curve to the data yields the equation $\mathrm{y}=65.465 \mathrm{x}^{-1.204}$ for number of times staff report being lied to and $y=116.19 x^{-1.738}$ for lies told. Superimposing these curves over each other reveals that they share a common pattern: most staff reported being told no lies and most staff reported telling no lies.

\section{Hogue Scores and Frequency of Lying}

The variables "total lies" and "Total Religiosity" were determined to have non-normal distributions using the Shapiro-Wilk's test $(\mathrm{p}<.000)$. The relationship between religiosity as measured by the total religiosity score and the number of lies a respondent reported during the previous 24 hours was explored using both the Pearson Productmoment Correlation Coefficient (parametric) and the Spearman Rank Order Correlation (non-parametric). The correlation between religiosity and reported lies was not statistically significant at the .05 level using the Spearman Rank Order Correlation for all staff-unweighted, $r(210)=-.012, p=.862$; all staff-weighted, $r(210)=-.012, p=.862$; House staff $r(106)=.017, p=.859$; Senate staff $r(107)=-.025, p=.801$; or Stennis Fellows $r(69)=-$ $.157, p=.098$. 
The correlation was also not statistically significant at the .05 level using the Pearson product moment correlation coefficient for all staff-unweighted, $r(210)=-.042, p=.542$; all staff-weighted, $r(210)=-.038, p=.582$; House staff, $r(106)=-.030, p=.761$; Senate staff, $r(104)=-.089, p=.366$; or Stennis Fellows $r(69)=-.189, p=.120$.

The total lies variable had one outlier (described earlier) who reported telling 70 lies. The Spearman Rank Order Correlation and the Pearson Product-moment Correlation Coefficient were recalculated for all staff-unweighted excluding this case. The correlation between religiosity and reported lies was still not statistically significant and the null hypothesis that there is no relationship between the two could not be rejected either including or excluding the single the case of high frequency lying.

\section{Differences between those who report lying and those who don't} report telling any lies.

In order to explore whether there were statistically significant differences between respondents who reported not telling any lies and those who reported lying, the total lies variable was collapsed into two categories: respondents who reported telling no lies and respondents who reported telling at least one lie. Mean religiosity scores were calculated for each group and two-sample, two-tailed t-tests of the differences between means were conducted to determine whether these differences were statistically significant. The tstatistic was not significant at the .05 level for any of the pairings and the null hypothesis - that there is no difference in religiosity between those who reported telling no lies and those who reported lying cannot be rejected. 


\begin{tabular}{|l|c|c|c|c|c|c|c|}
\hline Respondents & No Lies & Lies & No Lies & Lies & T-Statistic & $\begin{array}{c}\text { Degrees of } \\
\text { Freedom }\end{array}$ & Sig \\
& $\begin{array}{c}\text { Mean Religiosity } \\
\text { Score }\end{array}$ & $\begin{array}{c}\text { Mean Religiosity } \\
\text { Score }\end{array}$ & SD & SD & & & \\
All Staff & 20.5 & 21.05 & 8.3 & 7.7 & -0.502 & 208 & 0.616 \\
All Staff (weighted) & 20.7 & 21.3 & 8.3 & 7.8 & -0.543 & 208 & 0.587 \\
House Staff & 21.5 & 22.3 & 8.3 & 8.1 & -0.481 & 104 & 0.631 \\
\hline Senate Staff & 19.5 & 19.8 & 8.2 & 7.1 & -0.196 & 102 & 0.845 \\
Stennis Fellows & 23.6 & 20.5 & 7.1 & 6.8 & 1.806 & 67 & 0.075 \\
\hline
\end{tabular}

To determine whether there was a statistically significant difference between those who reported telling fewer than the mean number of lies and those who reported telling more than the mean number of lies, the total lies variable was collapsed into respondents who reported fewer lies than the mean and those who reported telling more lies than the mean. The t-statistic was not significant at the .05 level for any of the pairings and the null hypothesis - that there is no difference in religiosity between those who reported telling fewer than the mean number of lies and those who reported telling more than the mean number of lies cannot be rejected.

\begin{tabular}{|l|c|c|c|c|c|c|c|}
\hline Respondents & Below Mean Lies & Above Mean Lies & $\begin{array}{c}\text { Below } \\
\text { Mean }\end{array}$ & $\begin{array}{c}\text { Above } \\
\text { Mean }\end{array}$ & T-Statistic & $\begin{array}{c}\text { Degrees of } \\
\text { Freedom }\end{array}$ & Sig \\
\hline All Staff & $\begin{array}{c}\text { Score } \\
\text { Seligiosity }\end{array}$ & $\begin{array}{c}\text { Mean Religiosity } \\
\text { Score }\end{array}$ & SD & SD & & & \\
\hline All Staff (weighted) & 20.9 & 20.6 & 8.1 & 7.6 & 0.198 & 208 & 0.843 \\
House Staff & 21.1 & 20.8 & 8.1 & 7.7 & 0.197 & 208 & 0.844 \\
Senate Staff & 22 & 21.8 & 8.2 & 8.2 & 0.103 & 104 & 0.918 \\
Stennis Fellows & 19.7 & 19.5 & 7.8 & 7.1 & 0.096 & 102 & 0.924 \\
\hline
\end{tabular}

\section{Relationship between Perception of Being Lied to and Reported Lying}

The variables total lies and total lies told to were evaluated using Shapiro-Wilk's test and determined not to be distributed normally. The relationship between lying as measured 
by the total lies and the perception of being lied to as measured by total lies told to was then explored using the Spearman Rank Order Correlation (non-parametric).

\begin{tabular}{|l|c|c|c|}
\hline \multicolumn{1}{|c|}{ Respondents } & Spearman Rho & N & Sig. \\
All Staff & 0.474 & 191 & 0.000 \\
All Staff (weighted) & 0.474 & 191 & 0.000 \\
House Staff & 0.407 & 95 & 0.000 \\
Senate Staff & 0.548 & 96 & 0.000 \\
Stennis Fellows & 0.673 & 62 & 0.000 \\
\hline
\end{tabular}

The correlation between lying and reported lies was statistically significant for each respondent group. In each, case there was a strong positive correlation between the two variables. The difference between the correlations was not statistically significant between the House and the Senate or between Stennis Fellows and all staff. The strength of the correlation was statistically significant $\left(Z_{o b s}=2.4\right)$ for the difference between Stennis Fellows and House staff and for the difference between Stennis Fellows and Senate $\operatorname{staff}\left(\left(Z_{o b s}=2.01\right)\right.$.

To further explore these relationships, the continuous variable total lies was visually binned into a dichotomous ordinal variable containing two values: individuals who reported telling no lies and individuals who reported telling one or more lies. The same was done for the continuous variable total lies told. A chi-square test for independence (with Yates Continuity Correction) indicated that there is a statistically significant and moderate association between reporting that you have or have not been lied to and reporting that you have or have not lied. 


\begin{tabular}{|l|c|c|c|c|c|}
\hline \multicolumn{1}{|c|}{ Respondents } & $X^{2}$ & DF & Sig. & Phi & $N$ \\
\hline All Staff & 33.2 & 1 & 0.000 & 0.417 & 191 \\
\hline All Staff (weighted) & 30.4 & 1 & 0.000 & 0.412 & 190 \\
House Staff & 12.2 & 1 & 0.000 & 0.383 & 95 \\
Senate Staff & 17.3 & 1 & 0.000 & 0.448 & 96 \\
Stennis Fellows & 17.552 & 1 & 0.000 & 0.567 & 62 \\
\hline
\end{tabular}

The continuous variable total lies was also visually binned into a dichotomous ordinal variable containing two values: individuals who reported telling fewer than the average number of lies and individuals who reported more than the average number of lies. The same was done for the continuous variable total lies told. A chi-square test for independence (with Yates Continuity Correction) also indicated that there is a statistically significant and moderate association between reporting that you were lied to above or below the mean and reporting that you lied above or below the average number of times.

\begin{tabular}{|l|c|c|c|c|r|}
\hline \multicolumn{1}{|c|}{ Respondents } & $X^{2}$ & DF & Sig. & Phi & \multicolumn{1}{|c|}{ N } \\
All Staff & 21.8 & 1 & 0.000 & 0.352 & 191 \\
All Staff (weighted) & 20.7 & 1 & 0.000 & 0.343 & 190 \\
House Staff & 5.97 & 1 & 0.015 & 0.279 & 95 \\
Senate Staff & 15.3 & 1 & 0.000 & 0.428 & 96 \\
Stennis Fellows & 21.4 & 1 & 0.000 & 0.634 & 62 \\
\hline
\end{tabular}




\section{Chapter VII. Definition of a Lie}

In the prior question, respondents had been provided the broad and permissive definition of lying that was used in the Serota survey.

I am interested in truth and lies in people's everyday communication. Many people think a lie occurs any time you intentionally try to mislead someone. Some lies are big while others are small; some are completely false statements and others are truths with a few essential details made up or left out. Some lies are obvious, and some are very subtle. Some lies are told for good reason. Some lies are selfish; other lies protect others. I am interested in all different types of lies.

As mentioned earlier, this definition has the advantage of being permissive and was designed to capture a wide range of perspectives not all of which are uncontrovertibly lies. In order to reduce the impact exposure to this definition might have on responses to subsequent questions, the survey was set to prevent respondents from returning to this definition after they had completed the question.

Congressional staff reported being lied to at rates significantly greater than reported in the Serota studies, but reported telling lies at rates that were nominally but not statistically significantly greater than the general adult population. Various tests of the relationship between reported lying and religiosity could find no statistically significant relationship. A significant relationship was discovered, however, between the frequency with which respondents reported being lied to and the frequency with which they reported telling lies.

In order to better understand how staff and fellows define lying, they were presented with two questions about their definition of a lie. Following the guidelines provided by the 
Tailored Design Method, the instructions were permissive, and respondents were first told that people have different definitions of lying. They were then presented with the definitions of a lie put forward by Sisela Bok, the Oxford English Dictionary, and a simplified version of Carson's definition drawing upon the idea of warranting truthfulness. Respondents were also given the opportunity to select "other" and provide their own definition. Very few respondents chose this option.

The definitions were presented in random order to reduce presentation bias, and respondents could select only one option.

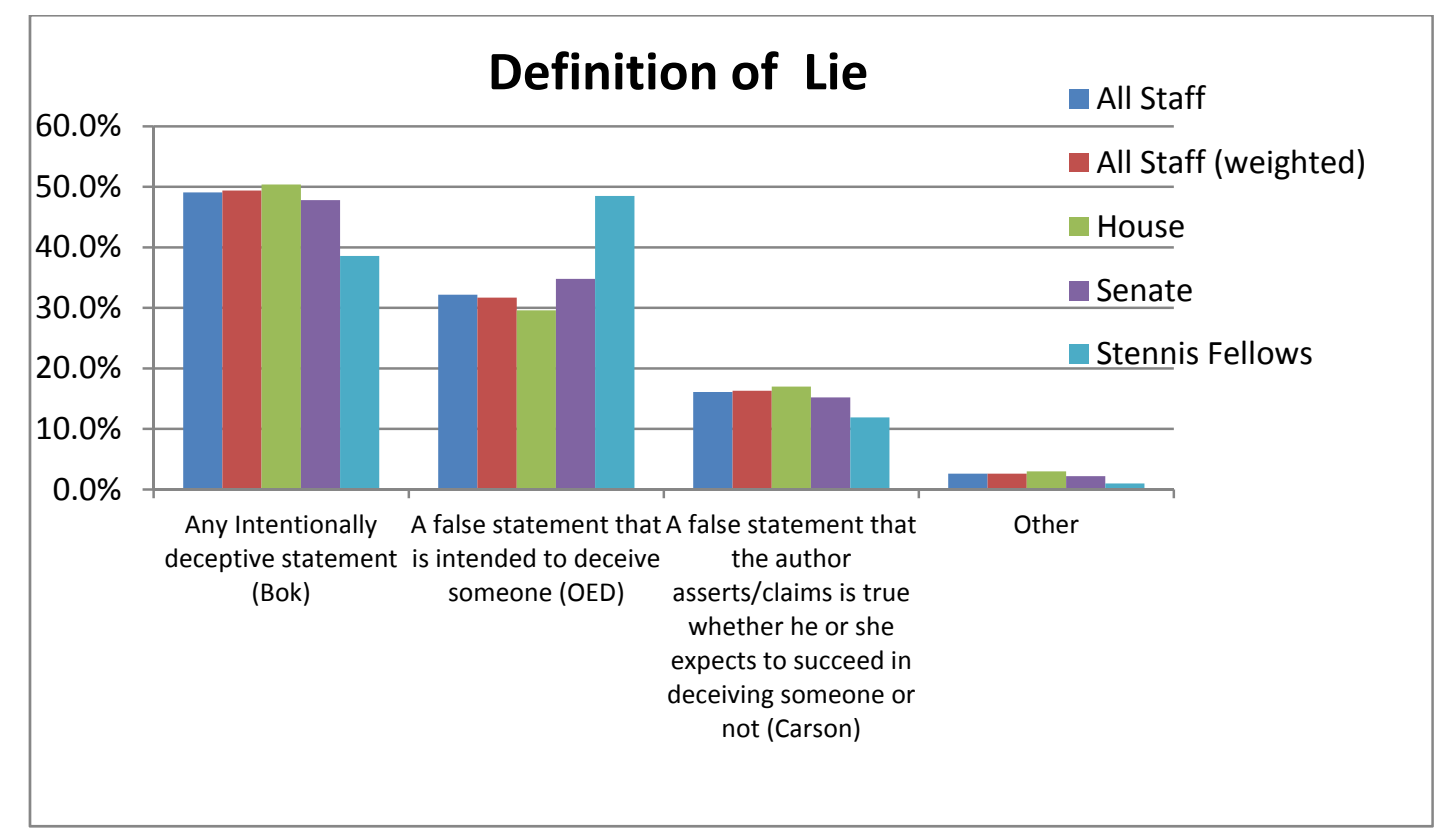

Confidence intervals were calculated for each of the variable categories of the House and Senate samples. The widest confidence intervals were $\pm 8.5 \%$ for the House sample and $\pm 8.3 \%$ for the Senate sample. The widest confidence interval for Stennis Fellows was $\pm 7.8 \%$. The widest confidence interval for the all staff-weighted sample was $\pm 5.9 \%$. 
Among House and Senate staff, the Bok definition proved to be most popular, followed by the definition from the Oxford English Dictionary, and then the Carson definition. Stennis Fellows preferred the OED definition over the Bok definition by a slight margin. The Carson definition was selected by only $12 \%$ of fellows and $16 \%$ of all staffweighted.

Stennis Fellows (38.6\%) were least likely to define a lie as "any intentionally deceptive statement." The t-statistic was not, however, significant at the .05 level for the difference between Stennis Fellows and House staff, $t(234)=-1.8, p=.07$, the group which shared the widest difference in percentages. The null hypotheses that there is no difference between Stennis Fellows and House staff cannot be rejected.

Stennis Fellows (48.5\%) were more likely to define a lie as "a false statement that is intended to deceive someone" than House staff (29.6\%), Senate staff (34.8\%) or all staffweighted (31.7\%). The t-statistic was significant at the .05 level for the difference between Stennis Fellows and House staff, $t(234)=2.96, p=.003$; Stennis Fellows and Senate staff, $t(237)=2.13, p=.034$; and Stennis Fellows and all staff-weighted, $t(371)=3.00, p=.003$. 


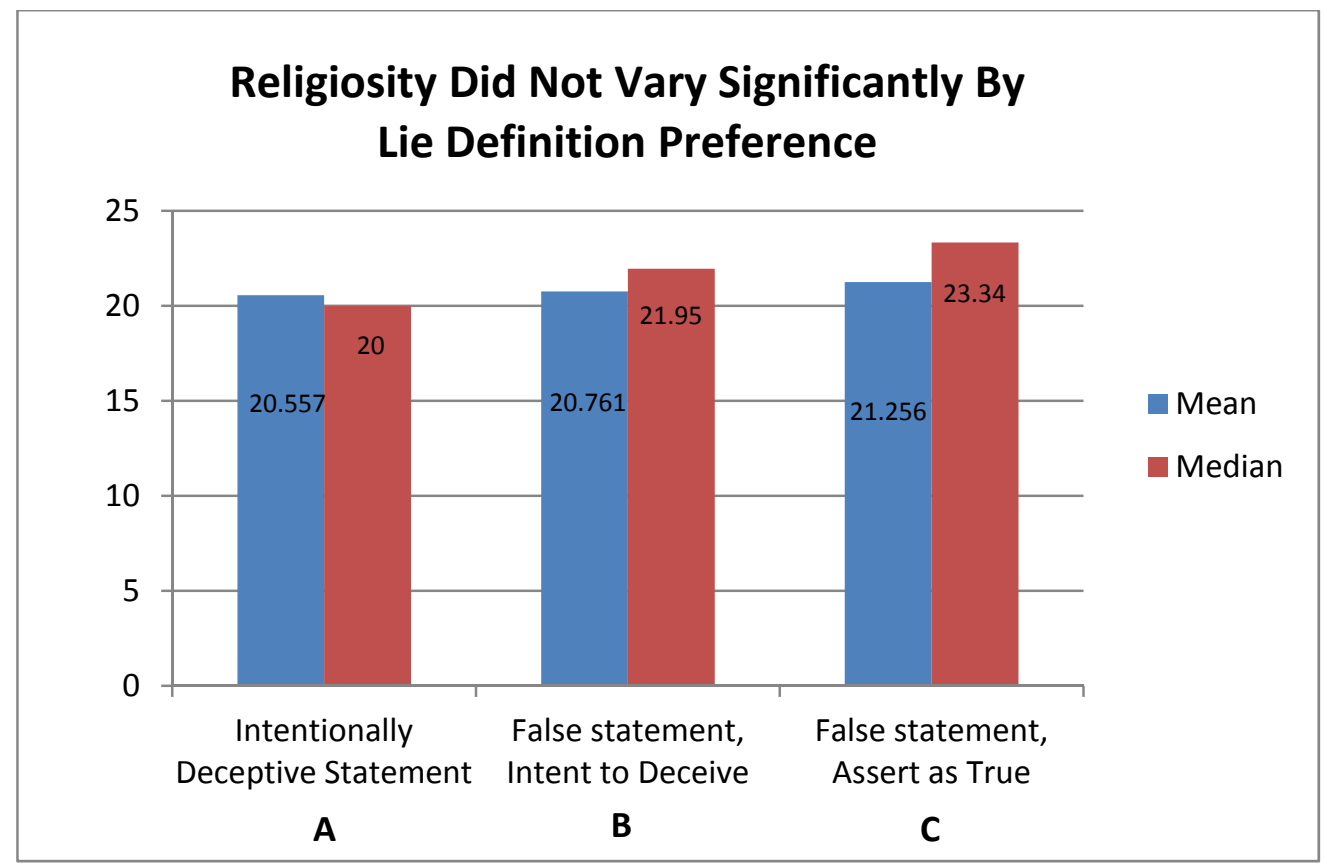

All staff-weighted respondents who preferred the definition that a lie is "any intentionally deceptive statement" (Definition A) had nominally lower mean and median religiosity scores than those who preferred the definition that a lie is a "false statement that is intended to deceive someone" (Definition B) or who preferred the definition that a lie is a "false statement that the author asserts/claims is true whether he or she expects to succeed in deceiving someone or not" (Definition C). The two-sample, two-tailed t-statistic for the difference in means was not significant at the .05 level for the difference between the mean religiosity scores of respondents who selected Definition A and respondents who selected Definition B, $t(214)=0.183, p=.8553$, or between respondents who selected Definition A and respondents who selected Definition C, $t(172)=0.491, p=.6242$. 


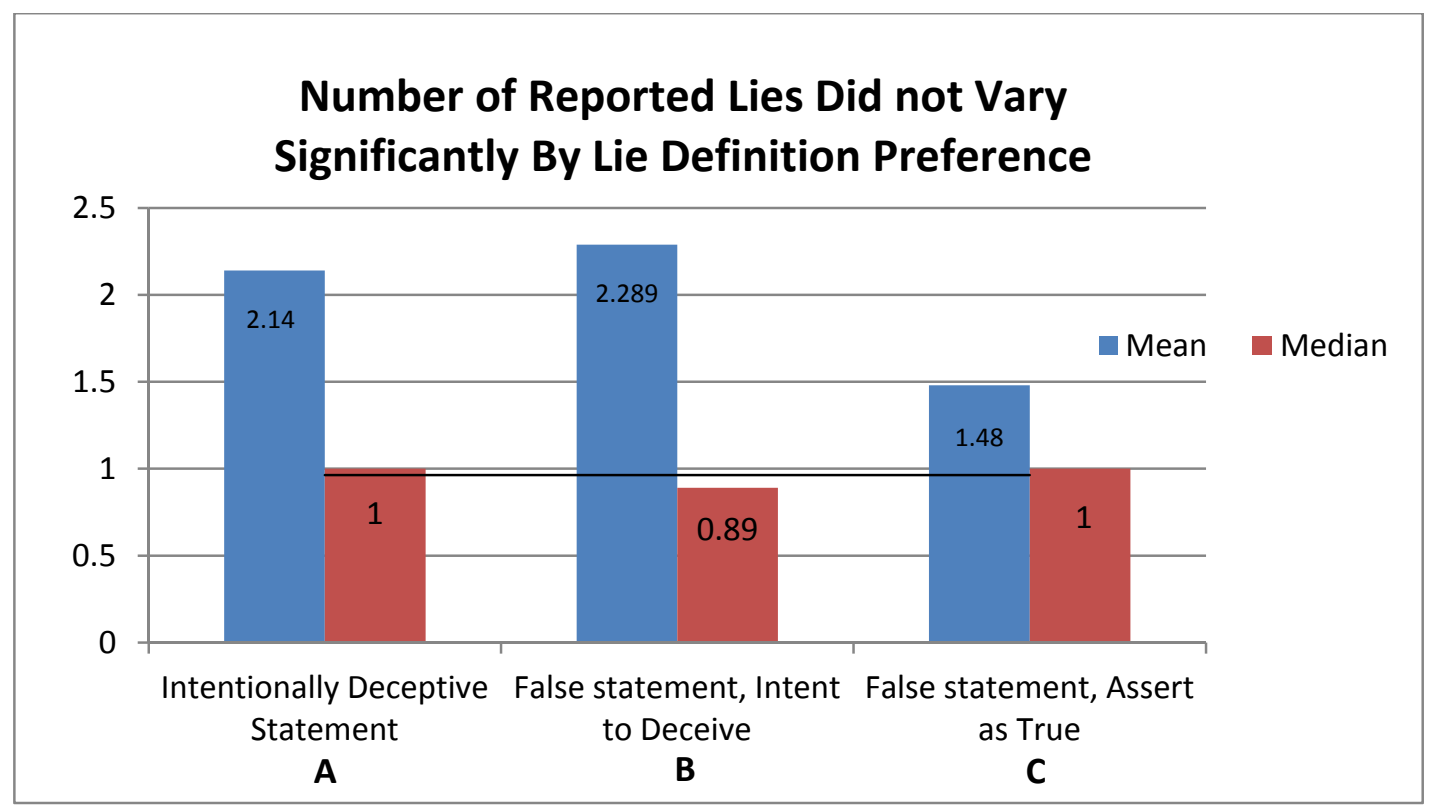

All staff-weighted who preferred "a false statement that the author asserts as true" (Definition C) reported slightly lower mean number of lies told than those who preferred a "false statement with intent to deceive" (Definition B) or "any intentionally deceptive statement" (Definition A). The two-sample, two-tailed t-statistic was not significant for the difference in mean number of lies told between those who preferred Definition A and those who preferred Definition $\mathrm{B}, t(174)=0.311, p=.7560$, or between those who preferred definition B over definition $\mathrm{C}, \mathrm{t}(104)=0.980, \mathrm{p}=.3292$. The null hypothesis that there is no difference in population mean between groups who preferred the definitions cannot be rejected. 


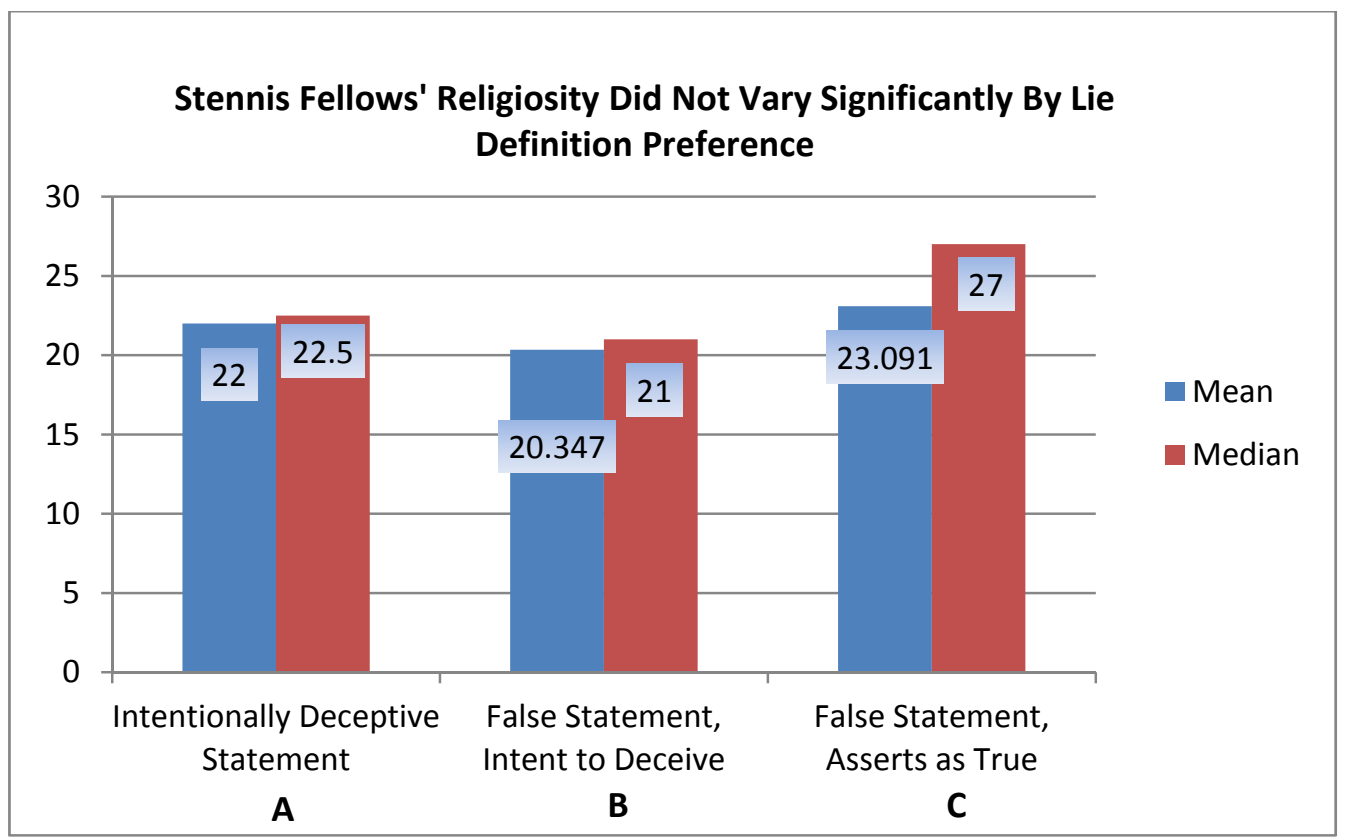

Most Stennis Fellows selected "a false statement that is intended to deceive someone"(48.5\%) and "any intentionally deceptive statement" (38.6\%) as their preferred definitions of lying. Stennis Fellows who selected the second definition $(M=20.3$, $M d n=21$ ) had lower mean and median religiosity scores than those who selected the first $(M=22, M d n-22.5)$ and third definitions $(M=23.1, M d n=27) . \quad$ The two-sample, twotailed t-statistic for the difference in mean religiosity scores was not significant at the .05 level for the difference in mean religiosity scores between those who selected "any intentionally deceptive statement and those who selected a "false statement that is intended to deceive someone," $t(85)=1.109, p=.2704$. The $t$-statistic for the difference in mean religiosity was also not significant at the .05 level for the difference between respondents who selected a "false statement that is intended to deceive" and a "false statement that the author asserts/claims is true whether he or she expects to succeed in deceiving someone or not," $t(58)=1.128, p=.2641$. 
The Mann-Whitney U test, a non-parametric test, revealed no significant difference in the religiosity between respondents who selected definition $\mathrm{A}(M d n=22.5, n=38)$ and definition $\mathrm{B}(M d n=21, n=49), \mathrm{U}=791, z=-1.2, p=.230$. The Mann-Whitney U test also revealed no significant difference in religiosity between respondents who selected definition B $(M d n=21, n=49)$ and definition C $(M d n=27, n=11)$ or between respondents who selected definition A and definition $\mathrm{C}$.

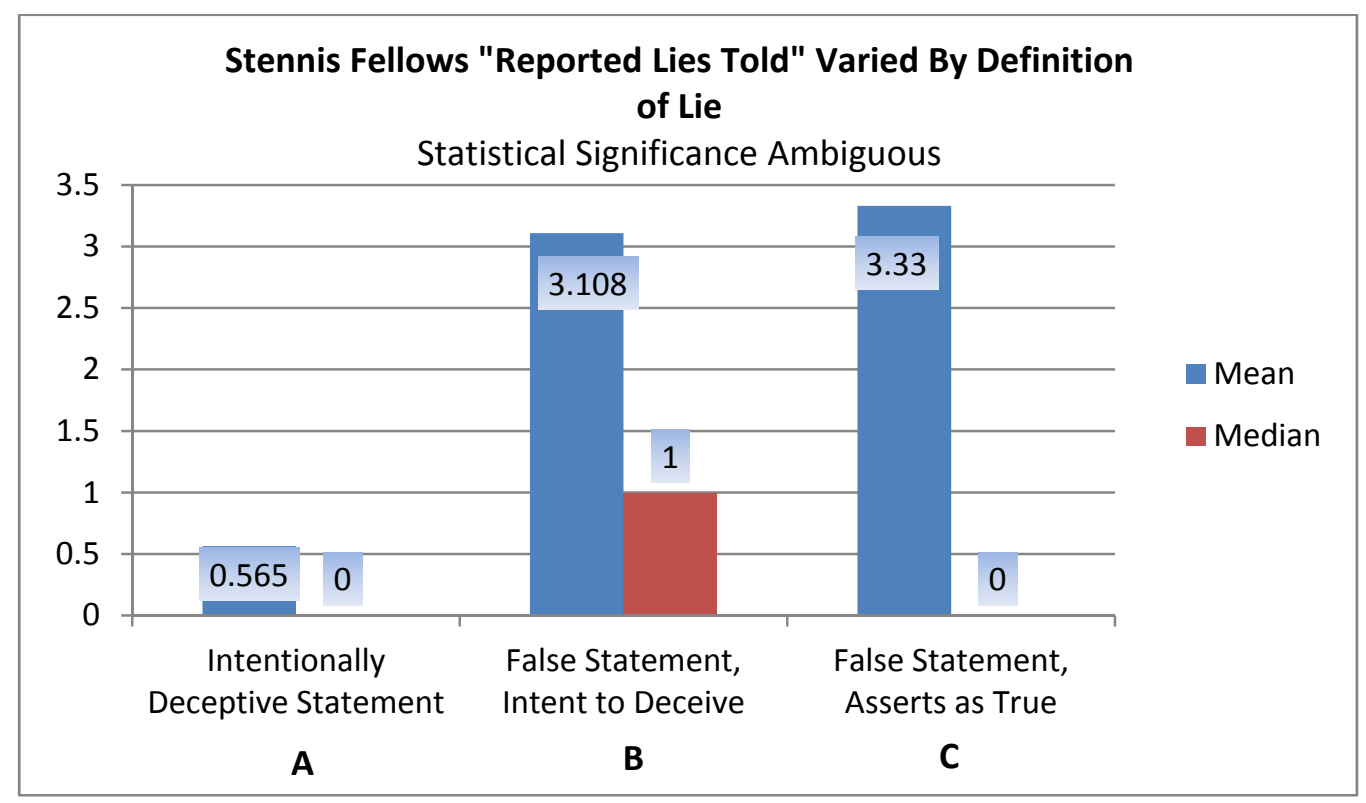

Stennis Fellows who preferred the definition "any intentionally deceptive statement" reported telling fewer mean lies than those who selected the other two definitions. The two-sample, two-tailed t-statistic for the difference in mean-reported lies between respondents who selected "any intentionally deceptive statement" and those who selected "a false statement with the intent to deceive" was not significant at the .05 level, $t(58)=1.946, \mathrm{p}=.0565$. The two-sample, two-tailed t-statistic for the difference in mean 
religiosity between those who selected definition $\mathrm{A}$ and definition $\mathrm{C}$ was significant at the .05 level, $t(30)=2.400, p=.0228$.

The Mann-Whitney U test, however, revealed a statistically significant difference in the reported lying by respondents who selected definition $\mathrm{A}(\mathrm{Mdn}=0, \mathrm{n}=23)$ and definition $\mathrm{B}$ $(\mathrm{Mdn}=1, \mathrm{n}=37), \mathrm{U}=272.5, \mathrm{z}=-2.6, \mathrm{p}=.009$. The Mann-Whitney $\mathrm{U}$ test was not significant for the difference in religiosity between respondents who selected definition A and definition $\mathrm{C}(\mathrm{Mdn}=0, \mathrm{n}=9), \mathrm{U}=73.5, \mathrm{z}=-1.587, \mathrm{p}=.213)$, or for the difference between those who selected definition B and definition C.

Two of the Stennis Fellows groups had fewer than 23 respondents within them. This falls below the threshold required to permit us to assume that the distribution of sample means is normal. The Mann-Whitney $U$ test does not require the assumption that the distribution is normal and is the appropriate test for evaluating the difference in lying between these groups.

People have different definitions of lying. Which of the following definitions most closely reflects your own personal definition of a lie?

\begin{tabular}{|c|c|c|c|c|c|}
\hline \multicolumn{2}{|l|}{ Chamber } & \multirow{2}{*}{$\frac{\text { Frequency }}{68}$} & \multirow{2}{*}{$\frac{\text { Percent }}{36.8}$} & \multirow{2}{*}{$\frac{\text { Valid Percent }}{50.4}$} & \multirow{2}{*}{$\frac{\begin{array}{c}\text { Cumulative } \\
\text { Percent }\end{array}}{50.4}$} \\
\hline House Valid & $\begin{array}{l}\text { Any intentionally deceptive } \\
\text { statement }\end{array}$ & & & & \\
\hline & $\begin{array}{l}\text { A false statement that is } \\
\text { intended to deceive } \\
\text { someone }\end{array}$ & 40 & 21.6 & 29.6 & 80.0 \\
\hline & $\begin{array}{l}\text { A false statement that the } \\
\text { author asserts/claims is } \\
\text { true whether he or she } \\
\text { expects to succeed in } \\
\text { deceiving someone or not }\end{array}$ & 23 & 12.4 & 17.0 & 97.0 \\
\hline & Other & 4 & 2.2 & 3.0 & 100.0 \\
\hline
\end{tabular}




\begin{tabular}{|c|c|c|c|c|c|c|}
\hline & & Total & 135 & 73.0 & 100.0 & \\
\hline & Missing & System & 50 & 27.0 & & \\
\hline & Total & & 185 & 100.0 & & \\
\hline \multirow[t]{7}{*}{ Senate } & Valid & $\begin{array}{l}\text { Any intentionally deceptive } \\
\text { statement }\end{array}$ & 66 & 37.1 & 47.8 & 47.8 \\
\hline & & $\begin{array}{l}\text { A false statement that is } \\
\text { intended to deceive } \\
\text { someone }\end{array}$ & 48 & 27.0 & 34.8 & 82.6 \\
\hline & & $\begin{array}{l}\text { A false statement that the } \\
\text { author asserts/claims is } \\
\text { true whether he or she } \\
\text { expects to succeed in } \\
\text { deceiving someone or not }\end{array}$ & 21 & 11.8 & 15.2 & 97.8 \\
\hline & & Other & 3 & 1.7 & 2.2 & 100.0 \\
\hline & & Total & 138 & 77.5 & 100.0 & \\
\hline & Missing & System & 40 & 22.5 & & \\
\hline & Total & & 178 & 100.0 & & \\
\hline
\end{tabular}

People have different definitions of lying. Which of the following definitions most closely reflects your own personal definition of a lie?

\begin{tabular}{|c|c|c|c|c|c|}
\hline \multicolumn{2}{|c|}{ All Staff-weighted } & \multirow{2}{*}{$\frac{\text { Frequency }}{134}$} & \multirow{2}{*}{$\frac{\text { Percent }}{36.9}$} & \multirow{2}{*}{$\frac{\text { Valid Percent }}{49.4}$} & \multirow{2}{*}{$\begin{array}{c}\begin{array}{c}\text { Cumulative } \\
\text { Percent }\end{array} \\
49.4\end{array}$} \\
\hline Valid & $\begin{array}{l}\text { Any intentionally deceptive } \\
\text { statement }\end{array}$ & & & & \\
\hline & $\begin{array}{l}\text { A false statement that is } \\
\text { intended to deceive } \\
\text { someone }\end{array}$ & 86 & 23.7 & 31.7 & 81.0 \\
\hline & $\begin{array}{l}\text { A false statement that the } \\
\text { author asserts/claims is true } \\
\text { whether he or she expects to } \\
\text { succeed in deceiving } \\
\text { someone or not }\end{array}$ & 44 & 12.2 & 16.3 & 97.4 \\
\hline & Other & 7 & 2.0 & 2.6 & 100.0 \\
\hline & Total & 272 & 74.7 & 100.0 & \\
\hline Missing & System & 92 & 25.3 & & \\
\hline Total & & 364 & 100.0 & & \\
\hline
\end{tabular}

People have different definitions of lying. Which of the following definitions most closely reflects reflect your views?

\begin{tabular}{llcccc}
\hline \hline All Staff-Unweighted & Frequency & Percent & Valid Percent & $\begin{array}{c}\text { Cumulative } \\
\text { Percent }\end{array}$ \\
\hline Valid & $\begin{array}{l}\text { Any intentionally deceptive } \\
\text { statement }\end{array}$ & 134 & 36.9 & 49.1 & 49.1 \\
& $\begin{array}{l}\text { A false statement that is } \\
\text { intended to deceive } \\
\text { someone }\end{array}$ & 88 & 24.2 & 32.2 & 81.3
\end{tabular}




\begin{tabular}{|c|c|c|c|c|c|}
\hline & $\begin{array}{l}\text { A false statement that the } \\
\text { author asserts/claims is true } \\
\text { whether he or she expects to } \\
\text { succeed in deceiving } \\
\text { someone or not }\end{array}$ & 44 & 12.1 & 16.1 & 97.4 \\
\hline & Other & 7 & 1.9 & 2.6 & 100.0 \\
\hline & Total & 273 & 75.2 & 100.0 & \\
\hline Missing & System & 90 & 24.8 & & \\
\hline Total & & 363 & 100.0 & & \\
\hline
\end{tabular}

People have different definitions of lying. Which of the following definitions most closely reflects your own personal definition of a lie?

\begin{tabular}{|c|c|c|c|c|c|}
\hline \multicolumn{2}{|c|}{ Stennis Fellows } & \multirow{2}{*}{$\frac{\text { Frequency }}{39}$} & \multirow{2}{*}{$\frac{\text { Percent }}{32.0}$} & \multirow{2}{*}{$\frac{\text { Valid Percent }}{38.6}$} & \multirow{2}{*}{$\begin{array}{c}\begin{array}{c}\text { Cumulative } \\
\text { Percent }\end{array} \\
38.6\end{array}$} \\
\hline Valid & $\begin{array}{l}\text { Any intentionally deceptive } \\
\text { statement }\end{array}$ & & & & \\
\hline & $\begin{array}{l}\text { A false statement that is } \\
\text { intended to deceive } \\
\text { someone }\end{array}$ & 49 & 40.2 & 48.5 & 87.1 \\
\hline & $\begin{array}{l}\text { A false statement that the } \\
\text { author asserts/claims is true } \\
\text { whether he or she expects to } \\
\text { succeed in deceiving } \\
\text { someone or not }\end{array}$ & 12 & 9.8 & 11.9 & 99.0 \\
\hline & Other & 1 & .8 & 1.0 & 100.0 \\
\hline & Total & 101 & 82.8 & 100.0 & \\
\hline Missing & System & 21 & 17.2 & & \\
\hline Total & & 122 & 100.0 & & \\
\hline
\end{tabular}

Respondents were next provided with a series of more complex definitions designed to tease out their views about some of the more complex elements of the definitions of lying contained within the philosophical literature. Respondents were provided six statements; asked to reflect on their own personal definition of lying; and indicate whether they believed the statement was or was not a lie. 


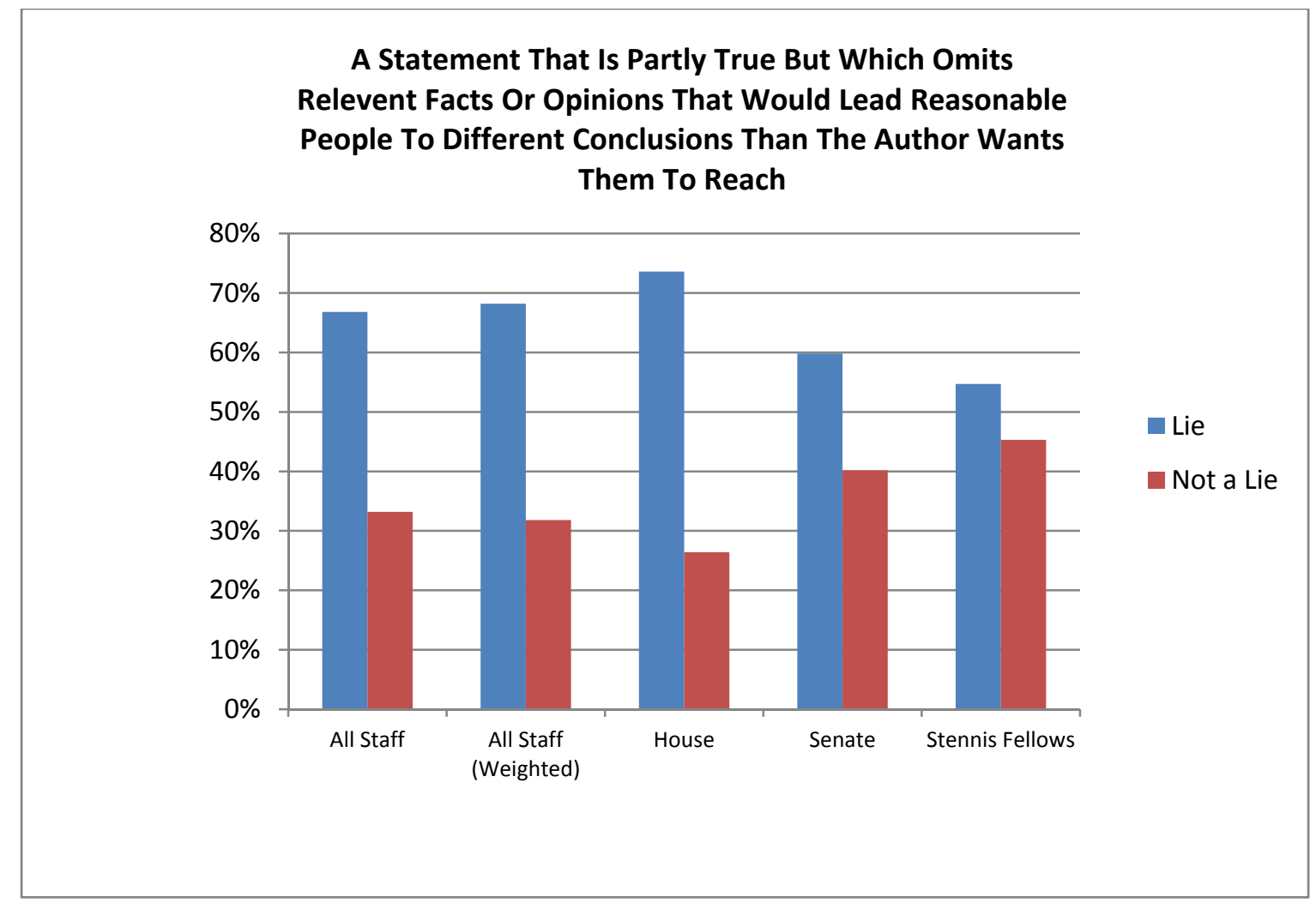

Respondents were asked whether a statement that is "partly true but which omits relevant facts or opinions that would lead reasonable people to different conclusions than the author wants them to reach" would be a lie. The question described what some might think of as "spin" and what others might describe as a lie. For Carson, this might constitute a form of "evasion" or "bullshit." A majority of the respondents indicated that they thought this was a lie.

Confidence intervals were calculated for each of the groups. The widest confidence interval for the House was $\pm 7.8 \%$, for the Senate was $\pm 8.7 \%$, for all staff-weighted was $\pm 5.8 \%$ and for Stennis Fellows was $\pm 8.1 \%$. 
House staff (73.6\%) were more likely to respond that a "statement that is partly true but which omits relevant facts or opinions that would lead reasonable people to different conclusions than the author wants them to reach" met their definition of a lie than Senate staff (59.8\%) or Stennis Fellows (54.7\%). The t-statistic was significant at the .05 level for the difference between House and Senate staff, $t(245)=2.3, p=.02$; for the difference between House staff and Stennis Fellows, $t(218)=2.9, p=.004$; and for the difference between Stennis Fellows and all staff-weighted, $t(341)=2.34, p=.02$. The t-statistic was not significant at the .05 level for the difference between Senate staff and Stennis Fellows, $t(215=-.75, p=.45$.

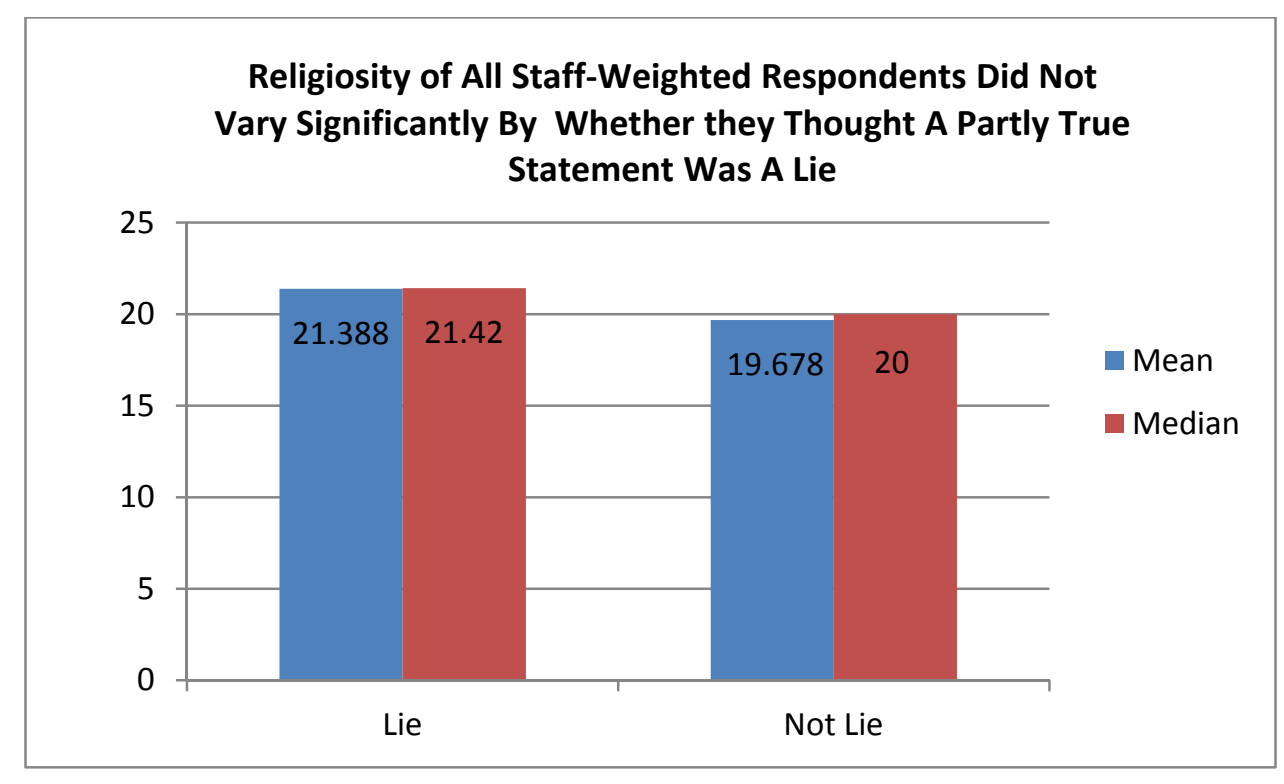

all staff-weighted respondents who indicated that the partly true statement was a lie had slightly higher mean and median religiosity scores than those who indicated that it was not a lie. The two-sample, two-tailed t-test was not significant at the .05 level for the difference in mean religiosity scores between respondents who believed this was a lie and 
those who did not believe this was a lie, $t(240)=1.593, p=.1125$. The null hypothesis that there was no difference in population means cannot be rejected.

A Mann-Whitney U test also revealed no significant difference in the religiosity of individuals who indicated this was a lie $(M d n=21.42, n=163)$ and individuals who indicated this was not a lie $(M d n=20.0, n=79), U=5714.5, z=-1.571, p=.116$.

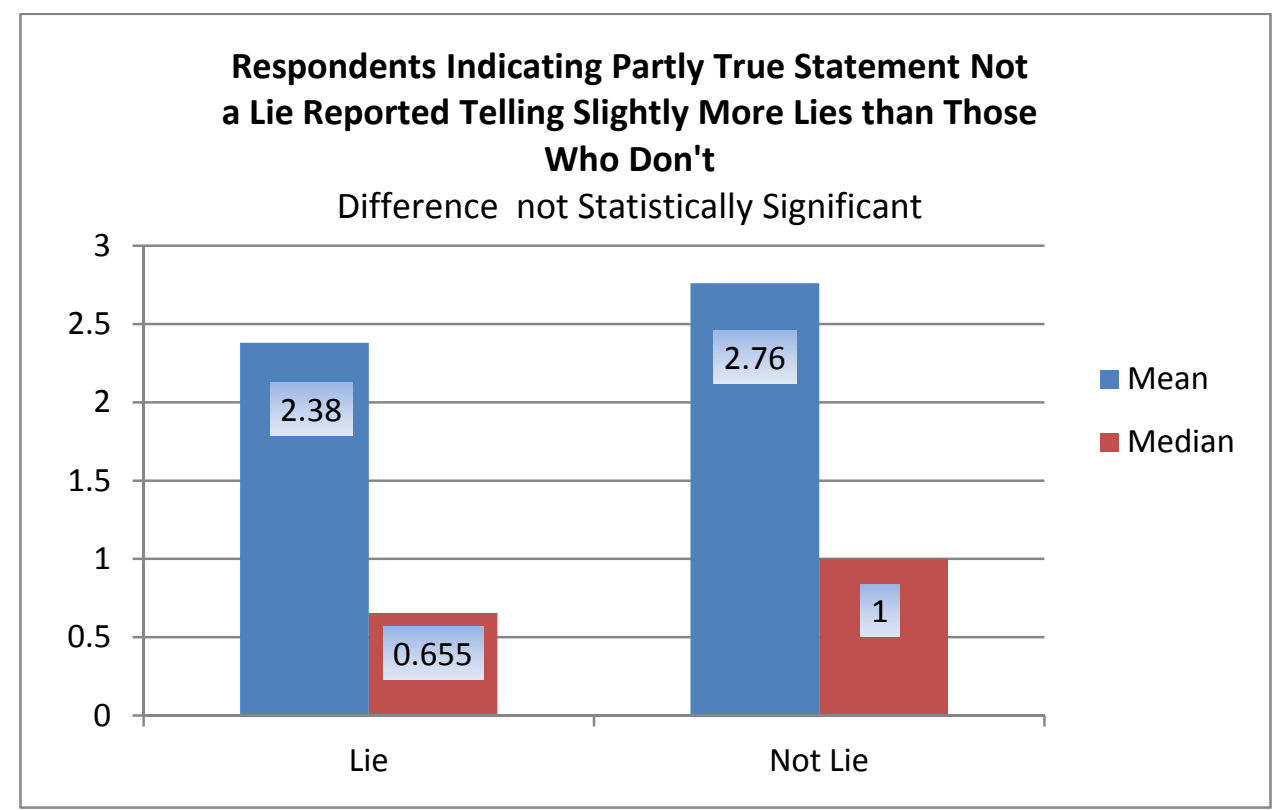

All staff-weighted who indicated that this was a lie reported slightly fewer mean and median lies than those who reported that this was not a lie. The two-sample, two-tailed ttest was not significant at the .05 level for the difference in mean-reported lying between those who indicated this was a lie and those who indicated that it was not, $t(197)=0.388$, $p=.6981$. The null hypothesis that there was no difference in means cannot be rejected. A Mann-Whitney U test was performed on the all staff-weighted responses and also indicated that there were no significant differences in the number of lies told by 
individuals who indicated this was a lie $(M d n=.655, n=130)$ and individuals who indicated this was not a lie $(M d n=1.0, n=68), U=4306.500, z=-.315, p=.752 .{ }^{130}$

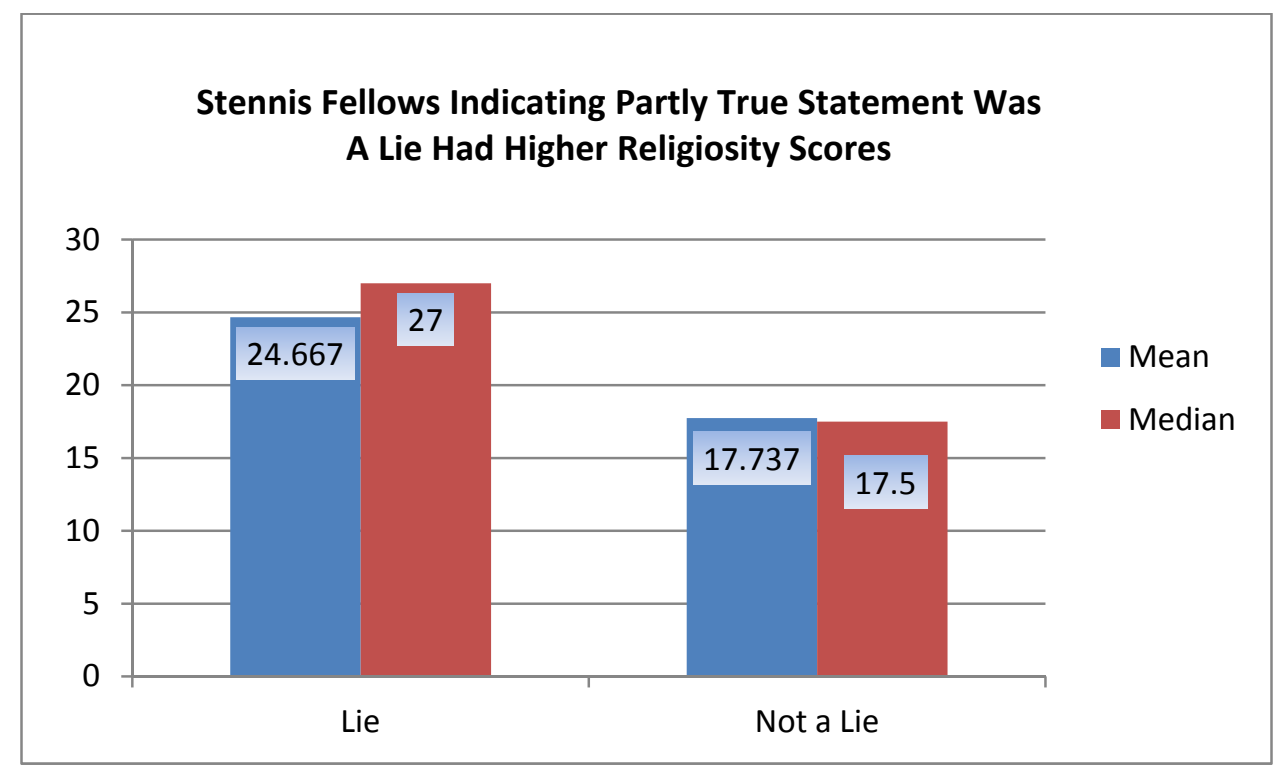

Stennis Fellows who reported that "a statement that is partly true but which omits relevant facts or opinions" had higher religiosity scores than those who indicated this was not a lie. The two-sample, two-tailed t-statistic for the difference in mean religiosity was significant at the .05 level, $t(91)=5.137, p=.0000$. The Mann-Whitney U test also revealed a significant strong relationship between mean religiosity of respondents who believed this was a lie $(M d n=27, n=51)$ and respondents who believed this was not a lie $(M d n=17.5, n=42), U=469, z=-4.654, p=.000, r=.482$.

\footnotetext{
${ }^{130}$ Mann-Whitney U Test is a non-parametric alternative to the t-test for independent samples when testing for differences between two independent (dichotomous) groups on a continuous measure. Many authorities suggest that the t-test (which assumes normality) can be used with observed non-normal distributions when sample sizes exceed 30 . Where possible, I have used both parametric and nonparametric techniques.
} 


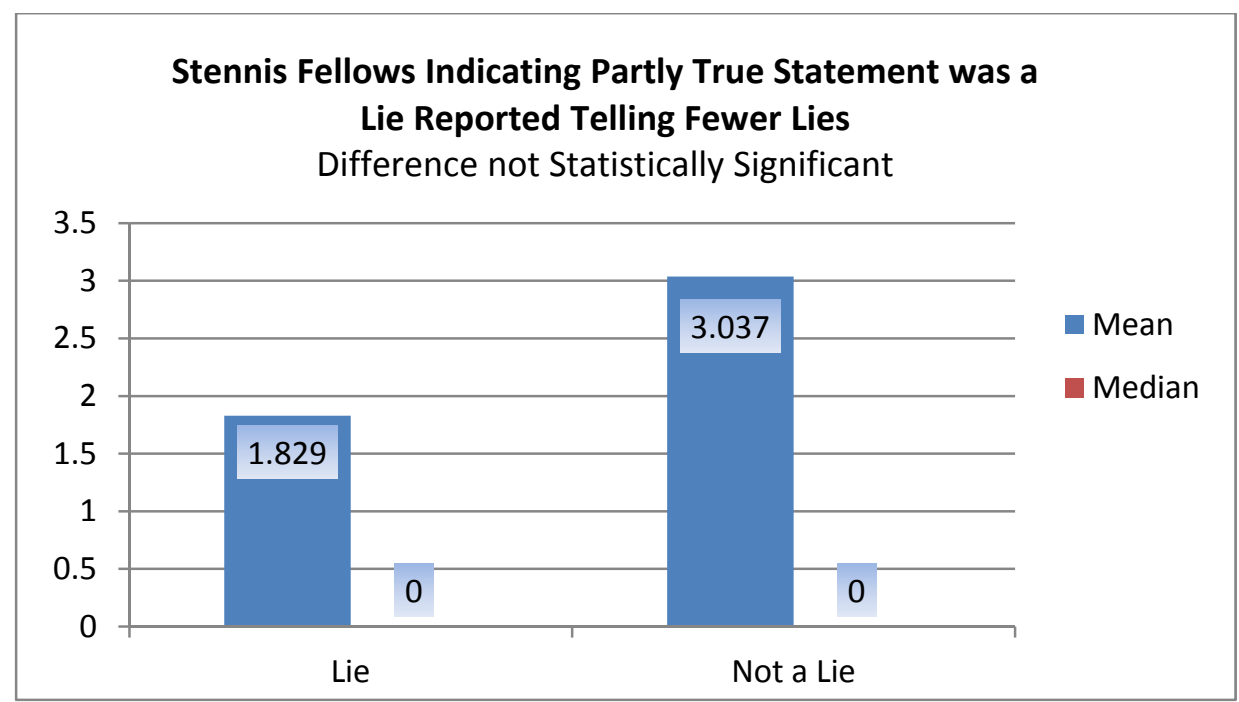

Stennis Fellows who indicated a partly true statement was a lie reported telling fewer mean but not median lies during the prior 24 hours. The two-sample, two-tailed t-statistic for the difference in means was not significant at the .05 level, $t(66)=0.962, p=.3393$.

The Mann-Whitney U Test also did not reveal a significant difference in lying between those who believed this was a lie $(M d n=0, n=41)$ and those who did not $(M d n=0, n=27)$, $U=496, z=-.808, p=.419$.

Reflecting on your own personal definition of lying, which of the following do you believe is or is not a lie?

A statement that is partly true but which omits relevant facts or opinions that would lead reasonable people to different conclusions than the author wants them to reach

\begin{tabular}{|c|c|c|c|c|c|c|}
\hline \multicolumn{3}{|c|}{ Chamber } & \multirow{2}{*}{$\frac{\text { Frequency }}{92}$} & \multirow{2}{*}{$\frac{\text { Percent }}{49.7}$} & \multirow{2}{*}{$\frac{\text { Valid Percent }}{73.6}$} & \multirow{2}{*}{$\begin{array}{c}\begin{array}{c}\text { Cumulative } \\
\text { Percent }\end{array} \\
73.6\end{array}$} \\
\hline House & Valid & Lie & & & & \\
\hline & & Not a Lie & 33 & 17.8 & 26.4 & 100.0 \\
\hline & & Total & 125 & 67.6 & 100.0 & \\
\hline & Missing & System & 60 & 32.4 & & \\
\hline & Total & & 185 & 100.0 & & \\
\hline \multirow[t]{5}{*}{ Senate } & Valid & Lie & 73 & 41.0 & 59.8 & 59.8 \\
\hline & & Not a Lie & 49 & 27.5 & 40.2 & 100.0 \\
\hline & & Total & 122 & 68.5 & 100.0 & \\
\hline & Missing & System & 56 & 31.5 & & \\
\hline & Total & & 178 & 100.0 & & \\
\hline
\end{tabular}


Reflecting on your own personal definition of lying, which of the following do you believe is or is or is not a lie? A statement that is partly true but which omits relevant facts or opinions that would lead reasonable people to different conclusions than the author wants them to reach

\begin{tabular}{llrrrr}
\hline \hline All Staff-weighted & & & & \\
& & & & \multicolumn{2}{c}{$\begin{array}{c}\text { Cumulative } \\
\text { Percent }\end{array}$} \\
\hline Valid & Lie & 169 & 46.4 & 68.2 & 68.2 \\
& Not a Lie & 79 & 21.6 & 31.8 & 100.0 \\
& Total & 248 & 67.9 & 100.0 & \\
Missing & System & 117 & 32.1 & & \\
Total & & 364 & 100.0 & & \\
& & & & & \\
\hline \hline
\end{tabular}

Reflecting on your own personal definition of lying, which of the following do you believe is or is not a lie. A statement that is partly true but which omits relevant facts or opinions that would lead reasonable people to different conclusions than the author wants them to reach

\begin{tabular}{|c|c|c|c|c|c|}
\hline \multicolumn{2}{|c|}{$\begin{array}{l}\text { ALL STAFF- } \\
\text { unweighted }\end{array}$} & \multirow{2}{*}{$\frac{\text { Frequency }}{165}$} & \multirow{2}{*}{$\frac{\text { Percent }}{45.5}$} & \multirow{2}{*}{$\frac{\text { Valid Percent }}{66.8}$} & \multirow{2}{*}{$\begin{array}{r}\begin{array}{c}\text { Cumulative } \\
\text { Percent }\end{array} \\
66.8\end{array}$} \\
\hline Valid & Lie & & & & \\
\hline & Not a Lie & 82 & 22.6 & 33.2 & 100.0 \\
\hline & Total & 247 & 68.0 & 100.0 & \\
\hline Missing & System & 116 & 32.0 & & \\
\hline Total & & 363 & 100.0 & & \\
\hline
\end{tabular}

Reflecting on your own personal definition of lying, which of the following do you believe is or is or is not a lie? A statement that is partly true but which omits relevant facts or opinions that would lead reasonable people to different conclusions than the author wants them to reach

\begin{tabular}{lccccc}
\hline \hline Stennis Fellows & Frequency & Percent & Valid Percent & $\begin{array}{c}\text { Cumulative } \\
\text { Percent }\end{array}$ \\
\hline Valid & Lie & 52 & 42.6 & 54.7 & 54.7 \\
& Not a Lie & 43 & 35.2 & 45.3 & 100.0 \\
& Total & 95 & 77.9 & 100.0 & \\
Missing & System & 27 & 22.1 & & \\
Total & 122 & 100.0 & & \\
\hline \hline
\end{tabular}




\section{A Statement that is Untrue but is Issued in a Situation Where People may not Expect Fully Truthful Statements}

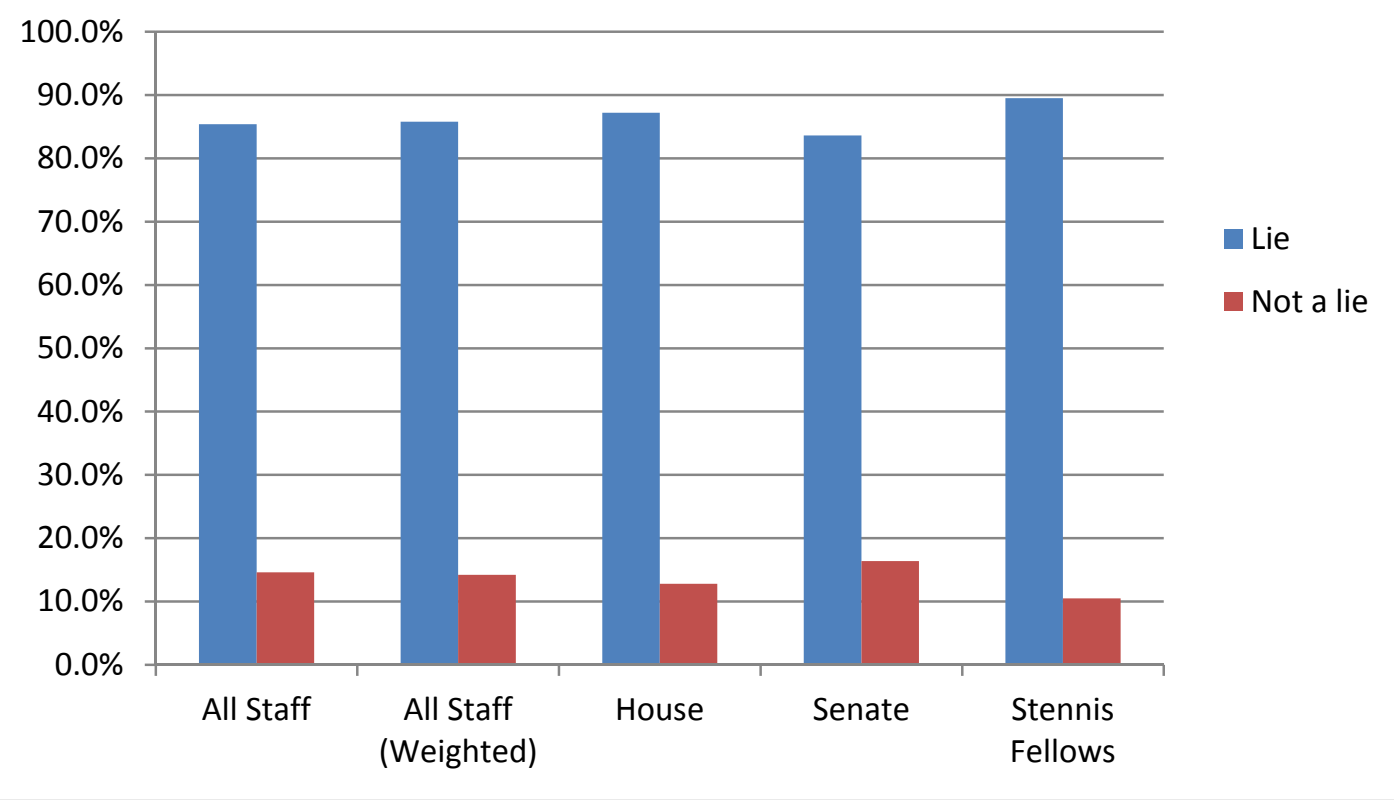

Respondents were asked whether they thought a statement that is "untrue but is issued in a situation where people may not expect fully truthful statements" was a lie. In some contexts, this question might capture "bluffing" in the context of negotiations. In other contexts, this question might capture more cynical perspectives on the legislative process and campaigns. The cases in the next section were designed to tease out additional detail. Staff overwhelmingly viewed this as a lie.

Confidence intervals were calculated for each of the respondent groups. The widest confidence interval for the House was $\pm 5.9 \%$, for the Senate was $\pm 6.6 \%$, for all staffweighted was $\pm 4.3 \%$ and for Stennis Fellows was $\pm 5 \%$. 
Stennis Fellows $(89.5 \%)$ were slightly more likely to respond that "a statement that is untrue but is issued in a situation where people may not expect fully truthful statements" was a lie than House $(87.2 \%)$ or Senate staff $(83.6 \%)$. The t-statistic was not significant at the .05 level for the difference between Stennis Fellows and Senate staff, $t(215)=1.3$, $p=.21$. The null hypothesis that there was no difference in the proportions between the Stennis Fellows and the Senate staff could not be rejected.

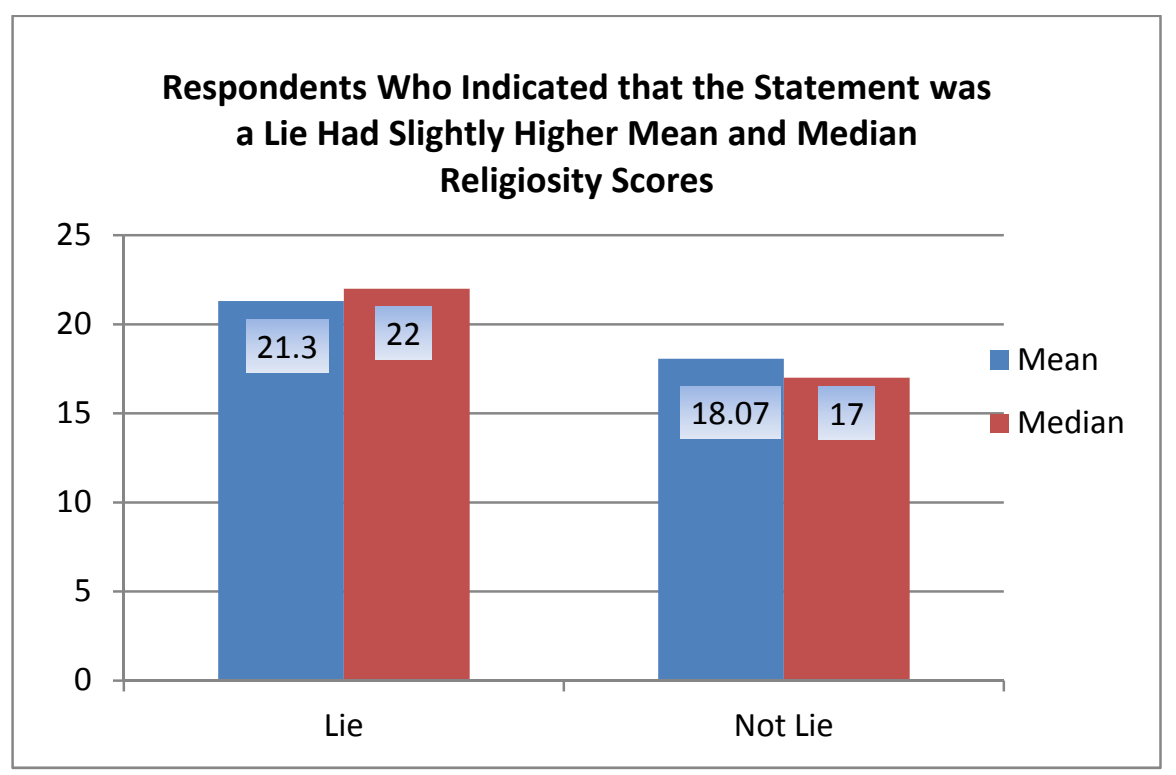

All staff-weighted respondents who indicated that an untrue statement issued in circumstances where people did not expect the truth was a lie had slightly higher mean and median religiosity scores than those who indicated that it was not a lie. The twosample, two-tailed t-test was significant at the .05 level for the difference in mean religiosity scores between respondents who believed this was a lie and those who did not believe this was a lie, $t(239)=2.266, p=.0243$. 
A Mann-Whitney U test also revealed a statistically significant difference in the religiosity of individuals who indicated this was a lie $(M d n=22, n=206)$ and individuals who indicated this was not a lie $(M d n=17, n=35), U=2894, z=-2.065, p=.039$.

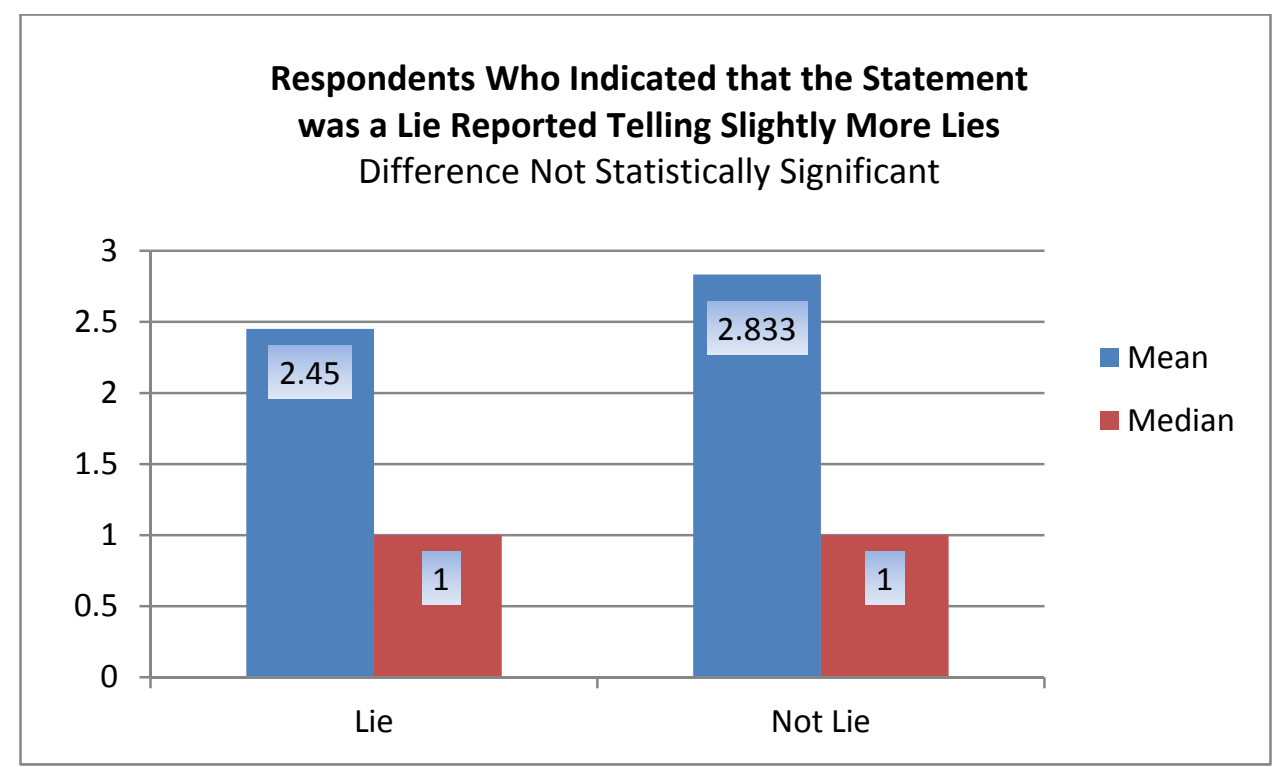

All staff-weighted respondents who indicated that the statement was a lie reported having told fewer mean but not median lies than those who indicated that it was not a lie. The two-sample, two-tailed t-test was not significant at the .05 level for the difference in mean lying between respondents who believed this was a lie and those who did not believe this was a lie, $t(198)=0.298, p=.7662$.

A Mann-Whitney U test also revealed no statistically significant difference in the reported lying of respondents who indicated this was a lie $(M d n=1, n=170)$ and individuals who indicated this was not a lie $(M d n=1, n=30), U=2261, z=-.951, p=.341$. 


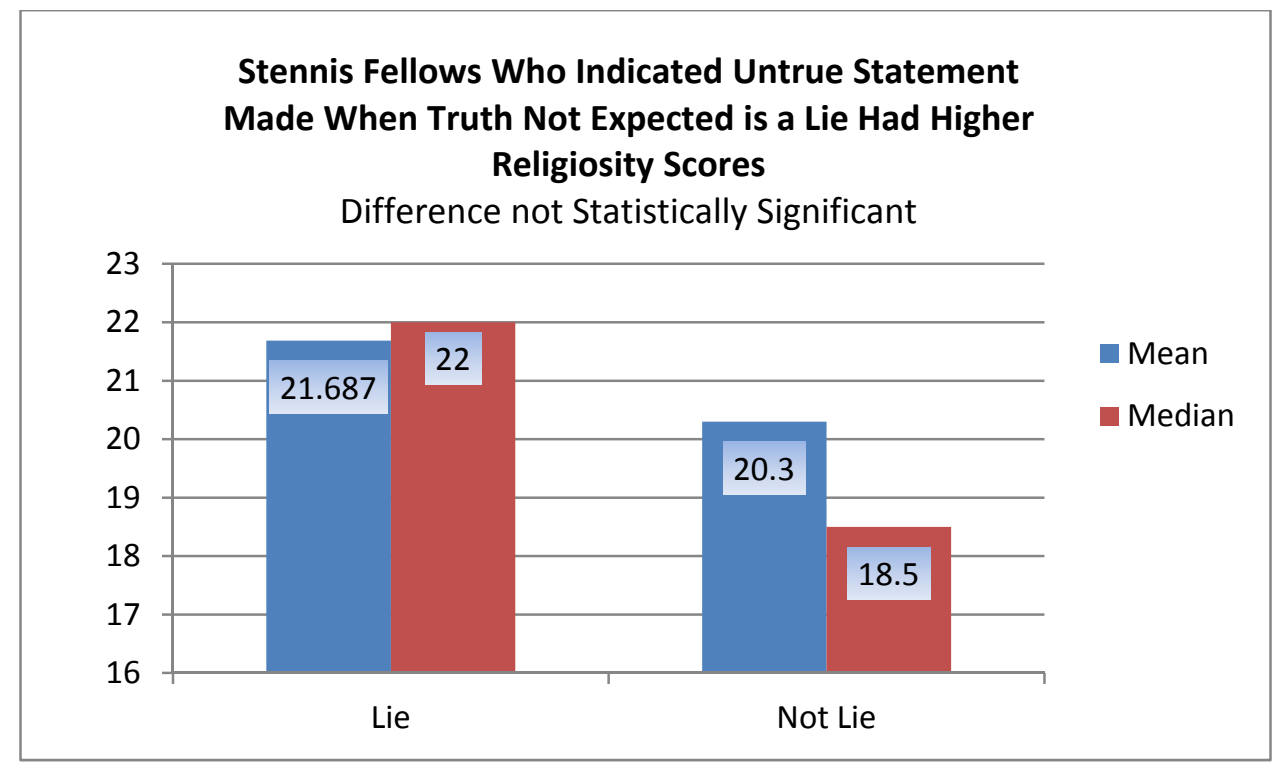

Stennis Fellows who indicated that a statement which is "untrue but issued in a situation where people may not expect fully truthful statements" is a lie had higher mean and median religiosity scores than those who indicated this was not a lie. The two-sample, two-tailed t-statistic for the difference in means was not significant at the .05 level for the difference in religiosity between the two groups, $t(91)=0.563, p=.5745$. The MannWhitney U Test also revealed no significant difference in religiosity between those who thought this was a lie $(M d n=22, n=83)$ and those who thought this was not a lie $(M d n=18$, $n=10), U=369, z=-.571, p=.568$. 


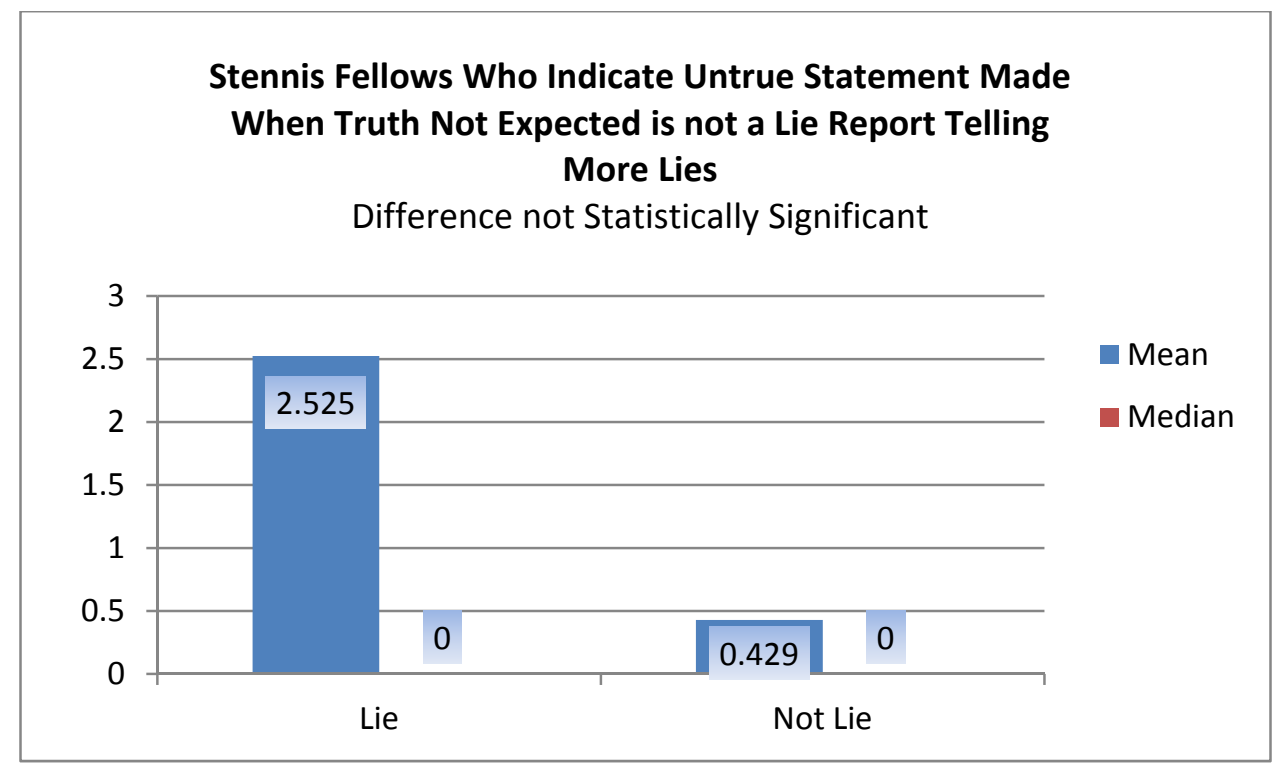

Stennis Fellows who report that an untrue statement that is made when people may not expect fully truthful statements is a lie reported higher mean but not median rates of lying. The two-sample, two-tailed t-statistic for the difference in means was not significant at the .05 level, $t(66)=1.038, p=.3029$. The Mann-Whitney U Test also did not reveal a significant difference in religiosity between respondents who indicated this was a lie $(M d n=0, n=61)$ and those who indicated this was not a lie $(M d n=0, n=7)$, $U=168.5, z=-1.019, p=.308$.

Reflecting on your own personal definition of lying, which of the following do you believe is or is not a lie?

A statement that is untrue but is issued in a situation where people may not expect fully truthful statements.

\begin{tabular}{|c|c|c|c|c|c|c|}
\hline \multicolumn{3}{|c|}{ Chamber } & \multirow{2}{*}{$\frac{\text { Frequency }}{109}$} & \multirow{2}{*}{$\frac{\text { Percent }}{58.9}$} & \multirow{2}{*}{$\frac{\text { Valid Percent }}{87.2}$} & \multirow{2}{*}{$\begin{array}{c}\begin{array}{c}\text { Cumulative } \\
\text { Percent }\end{array} \\
87.2\end{array}$} \\
\hline House & Valid & Lie & & & & \\
\hline & & Not a Lie & 16 & 8.6 & 12.8 & 100.0 \\
\hline & & Total & 125 & 67.6 & 100.0 & \\
\hline & Missing & System & 60 & 32.4 & & \\
\hline & Total & & 185 & 100.0 & & \\
\hline \multirow[t]{2}{*}{ Senate } & Valid & Lie & 102 & 57.3 & 83.6 & 83.6 \\
\hline & & Not a Lie & 20 & 11.2 & 16.4 & 100.0 \\
\hline
\end{tabular}




\begin{tabular}{llccc}
\hline & Total & 122 & 68.5 & 100.0 \\
Missing & System & 56 & 31.5 & \\
Total & & 178 & 100.0 & \\
\hline \hline
\end{tabular}

Reflecting on your own personal definition of lying, which of the following do you believe is or is or is not a lie? A statement that is untrue but is issued in a situation where people may not expect fully truthful statements

\begin{tabular}{llcccc}
\hline \hline All Staff-weighted & Frequency & Percent & Valid Percent & $\begin{array}{c}\text { Cumulative } \\
\text { Percent }\end{array}$ \\
\hline Valid & Lie & 212 & 58.3 & 85.8 & 85.8 \\
& Not a Lie & 35 & 9.6 & 14.2 & 100.0 \\
& Total & 248 & 67.9 & 100.0 & \\
Missing & System & 117 & 32.1 & & \\
Total & & 364 & 100.0 & & \\
\hline \hline
\end{tabular}

Reflecting on your own personal definition of lying, which of the following do you believe is or is...-A statement that is untrue but is issued in a situation where people may not expect fully truthful statements

\begin{tabular}{|c|c|c|c|c|c|}
\hline \multicolumn{2}{|c|}{$\begin{array}{l}\text { ALL STAFF- } \\
\text { unweighted }\end{array}$} & \multirow{2}{*}{$\frac{\text { Frequency }}{211}$} & \multirow{2}{*}{$\frac{\text { Percent }}{58.1}$} & \multirow{2}{*}{$\frac{\text { Valid Percent }}{85.4}$} & \multirow{2}{*}{$\begin{array}{c}\begin{array}{c}\text { Cumulative } \\
\text { Percent }\end{array} \\
85.4\end{array}$} \\
\hline Valid & Lie & & & & \\
\hline & Not a Lie & 36 & 9.9 & 14.6 & 100.0 \\
\hline & Total & 247 & 68.0 & 100.0 & \\
\hline Missing & System & 116 & 32.0 & & \\
\hline Total & & 363 & 100.0 & & \\
\hline
\end{tabular}

Reflecting on your own personal definition of lying, which of the following do you believe is or is or is not a lie? A statement that is untrue but is issued in a situation where people may not expect fully truthful statements

\begin{tabular}{lccccc}
\hline \hline Stennis Fellows & & & & & Cumulative \\
Valid & Lie & 85 & 69.7 & 89.5 & 89.5 \\
& Not a Lie & 10 & 8.2 & 10.5 & 100.0 \\
& Total & 95 & 77.9 & 100.0 & \\
\multirow{2}{*}{ Missing } & System & 27 & 22.1 & & \\
Total & 122 & 100.0 & & \\
\hline \hline
\end{tabular}




\section{A Statement that is Untrue but that is Made in order to Avoid Hurting Someone's Feelings}

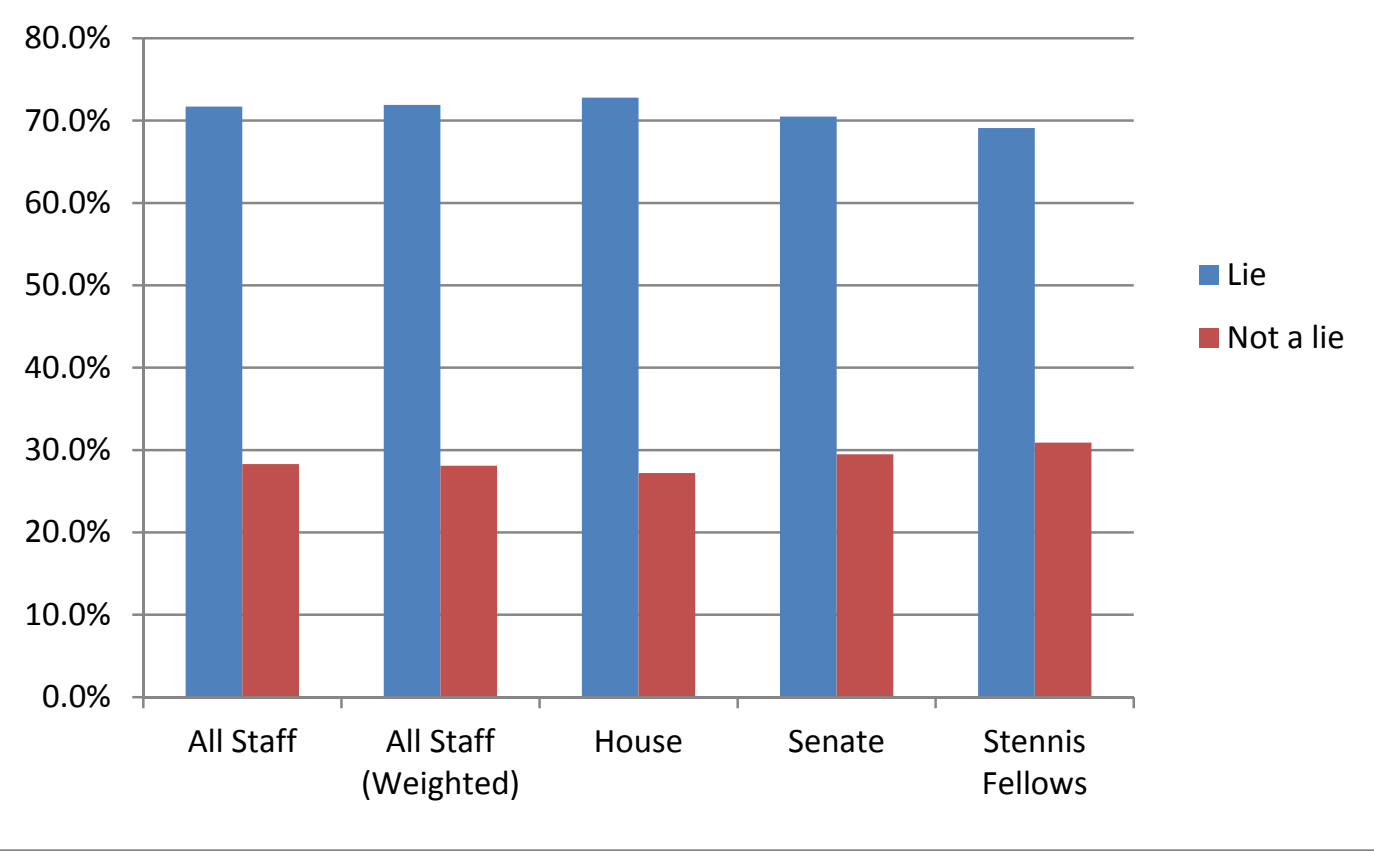

Respondents were asked whether a statement that is "untrue but that is made in order to avoid hurting someone's feelings" was a lie. Staff across all groups overwhelmingly indicated that this was a lie.

Confidence intervals were calculated for each of the respondent groups. The widest confidence interval for the House was $\pm 7.9 \%$, for the Senate was $\pm 8.1 \%$, for all staffweighted was $\pm 5.6 \%$ and for Stennis Fellows was $\pm 7.6 \%$.

House staff (72.8\%) were slightly more likely to respond that "a statement that is untrue but that is made in order to avoid hurting someone's feelings" was a lie than Senate staff (70.5\%) or Stennis Fellows (69.1\%). The t-statistic was not significant at the .05 level 
for the difference between Stennis Fellows and House staff, $t(217)=-.0599, p=.549$. The null hypothesis that there was no difference in the proportions between the Stennis Fellows and the House staff could not be rejected. Respondents across all the samples viewed this statement to be a lie in comparable proportions.

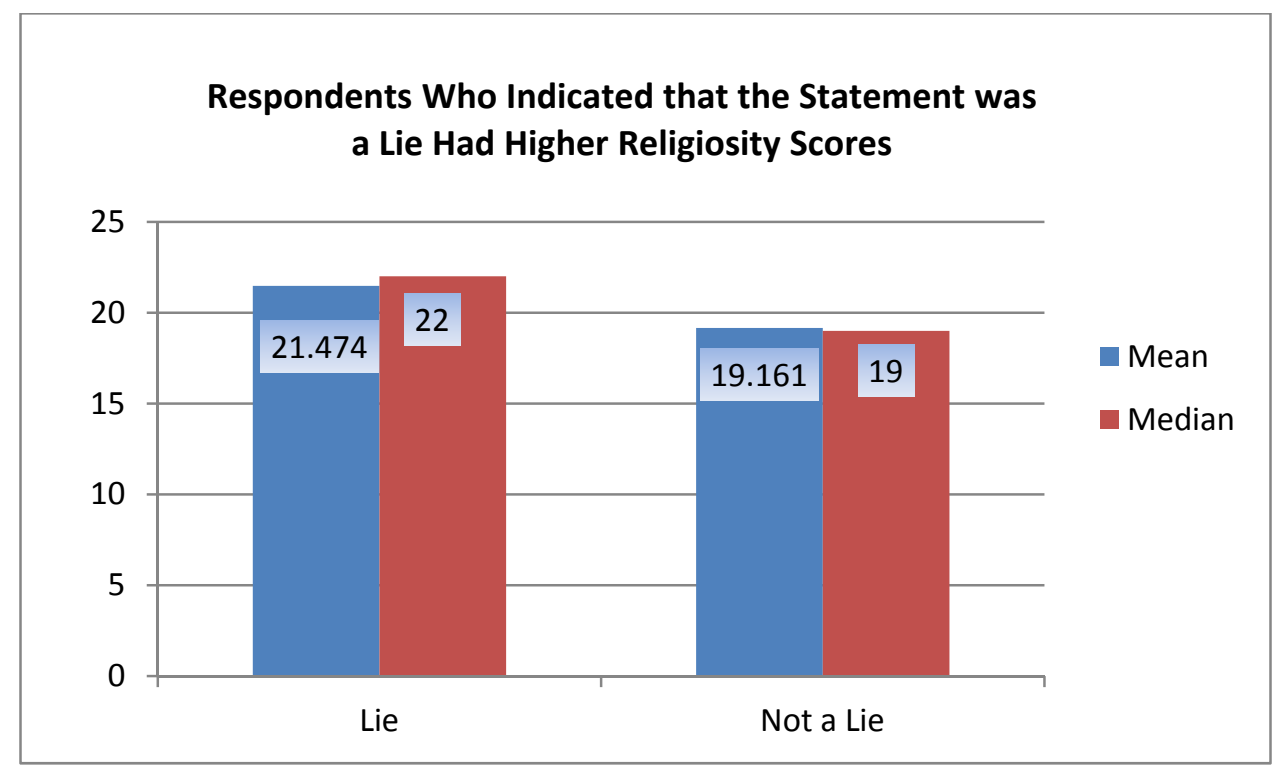

All staff-weighted respondents who indicated that the statement was a lie reported higher mean and median religiosity scores than those who indicated that it was not a lie. The two-sample, two-tailed t-test was significant at the .05 level for the difference in mean religiosity scores between respondents who believed this was a lie and those who did not believe this was a lie, $t(239)=2.061, p=.0404$.

A Mann-Whitney U test indicated no statistically significant difference in the religiosity of respondents who indicated this was a lie $(M d n=22, n=174)$ and individuals who indicated this was not a lie $(M d n=19, n=67), U=4964, z=-1.886, p=.059$. 
The central limit theorem provides that when samples are large enough, the sampling distribution of the mean will be normal regardless of shape of the population. Experts recommend that sample sizes be at least 30 (others select a more conservative number of 50) before assuming normality. ${ }^{131}$ When sample sizes exceed these parameters, it is commonly believed that parametric tests such as the t-statistic are appropriate. The sample sizes for these samples each exceed 50. The results of the t-statistic can be accepted.

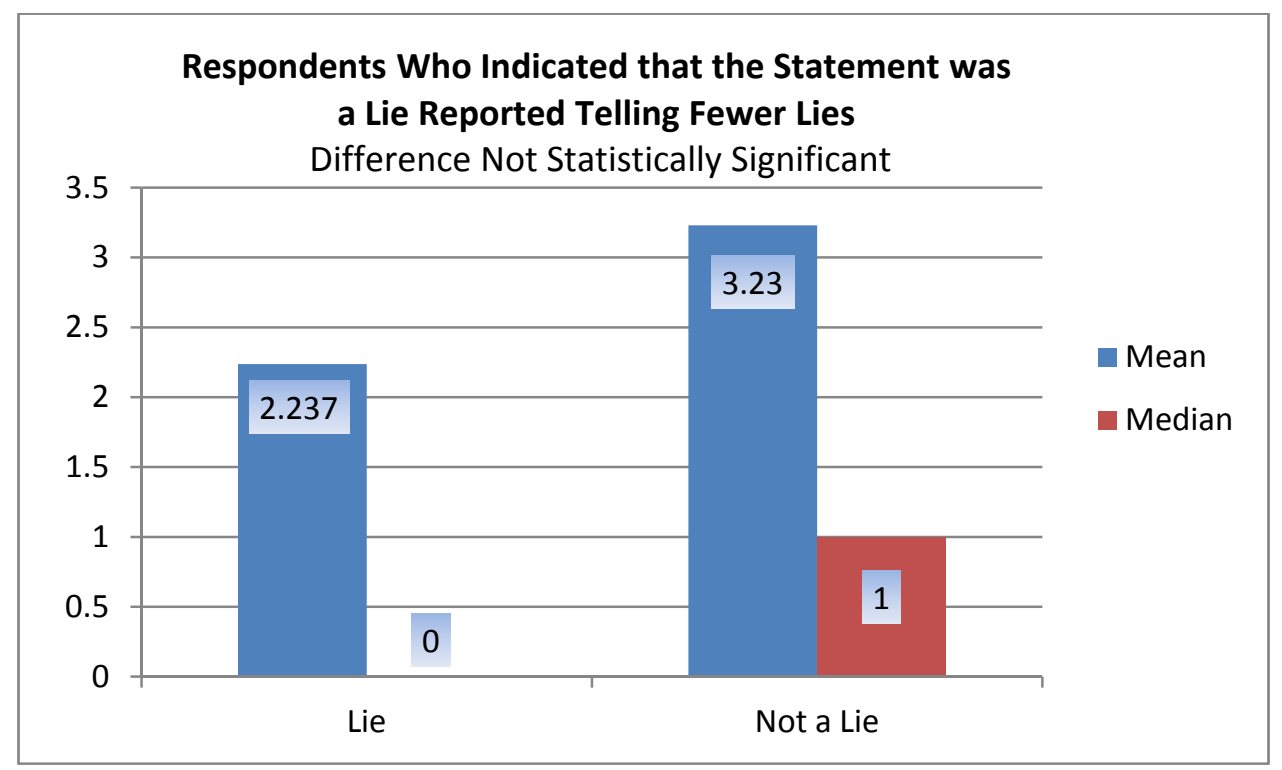

All staff-weighted respondents who indicated that the statement was a lie reported lower mean and median lying than those who indicated that it was not a lie. The two-sample, two-tailed t-test was not significant at the .05 level for the difference in reported lying between respondents who believed this was a lie and those who did not believe this was a lie, $t(197)=0.964, \mathrm{p}=.336$.

${ }^{131}$ Chava Frankfort-Nachmias and Anna Leon-Guerrero, Social Statistics for a Diverse Society, 6th Edition, 6th ed. (London: Sage, 2011). 
A Mann-Whitney U test also revealed no statistically significant difference in the religiosity of respondents who indicated this was a lie $(M d n=.000, n=145)$ and individuals who indicated this was not a lie $(M d n=1.0, n=54), U=3247, z=-1.899$, $p=.058$.

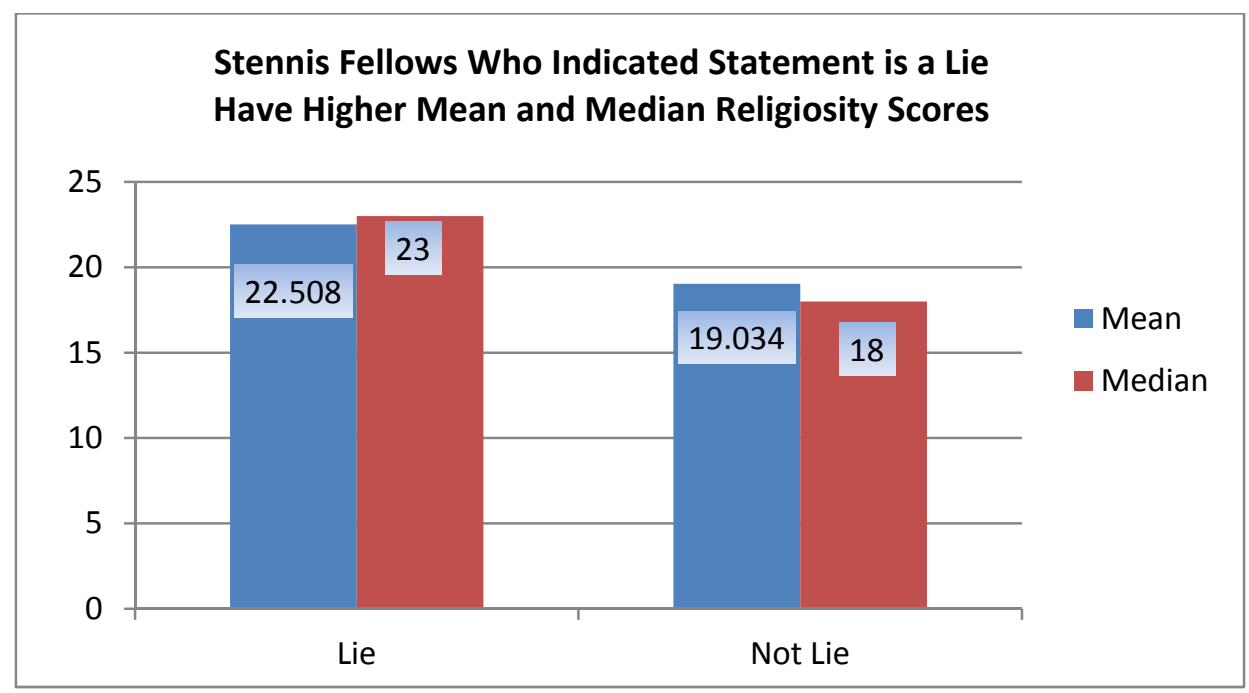

Stennis Fellows who indicated that a statement that is "untrue but that is made in order to avoid hurting someone's feelings" is a lie have higher religiosity scores than those who do not believe it is a lie. The two-sample, two-tailed t-statistic was significant at the .05 level for the difference in mean religiosity between the two groups of Fellows, $t(90)=2.173, p=.0324$. The Mann-Whitney U Test also revealed a significant difference between respondents who indicated the statement is a lie $(\mathrm{Mdn}=23, \mathrm{n}=63)$ and respondents who did not $(\mathrm{Mdn}=18, \mathrm{n}=29), \mathrm{U}=649, \mathrm{z}=-2.226, \mathrm{p}=.026, \mathrm{r}=.23$. 


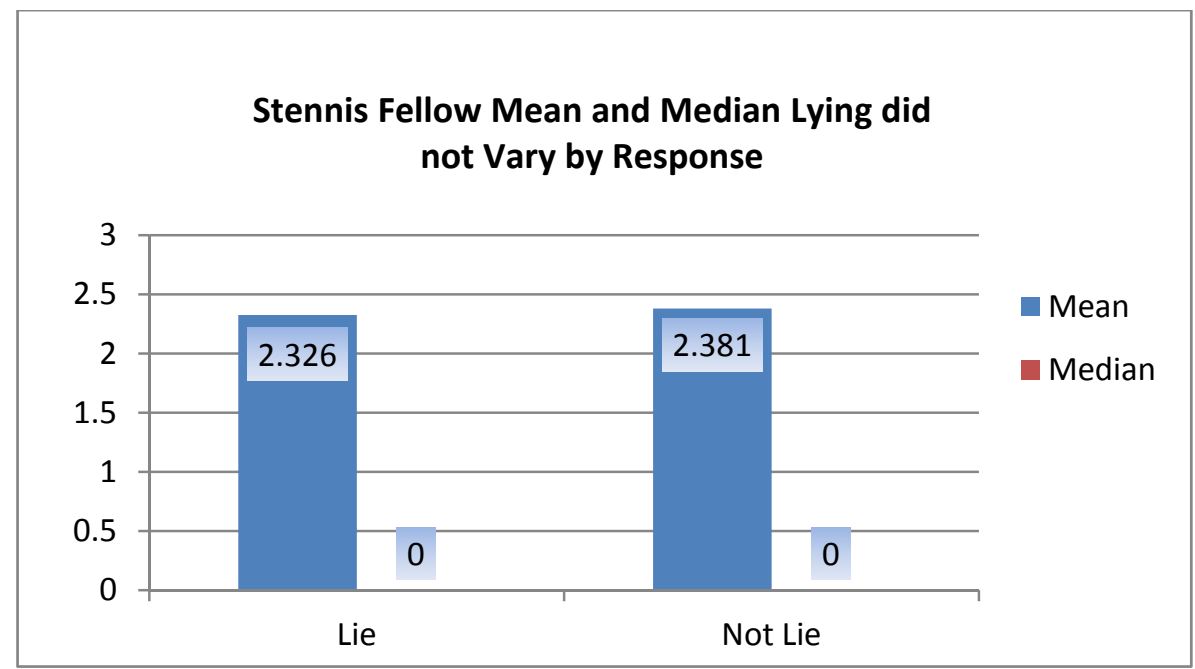

Stennis Fellows who indicated that the statement was a lie reported mean and median lying at rates that were equal to those of respondents who indicated that the statement was not a lie. The two-sample, two-tailed t-statistic was not significant at the .05 level, $t(65)=0.041, p=.9677$. The Mann Whitney U Test also revealed no significant difference between the two groups.

Reflecting on your own personal definition of lying, which of the following do you believe is or is or not a lie?

A statement that is untrue but that is made in order to avoid hurting someone's feelings

\begin{tabular}{|c|c|c|c|c|c|c|}
\hline \multicolumn{3}{|c|}{ Chamber } & \multirow{2}{*}{$\frac{\text { Frequency }}{91}$} & \multirow{2}{*}{$\frac{\text { Percent }}{49.2}$} & \multirow{2}{*}{$\frac{\text { Valid Percent }}{72.8}$} & \multirow{2}{*}{$\begin{array}{c}\begin{array}{c}\text { Cumulative } \\
\text { Percent }\end{array} \\
72.8\end{array}$} \\
\hline House & Valid & Lie & & & & \\
\hline & & Not a Lie & 34 & 18.4 & 27.2 & 100.0 \\
\hline & & Total & 125 & 67.6 & 100.0 & \\
\hline & Missing & System & 60 & 32.4 & & \\
\hline & Total & & 185 & 100.0 & & \\
\hline \multirow[t]{5}{*}{ Senate } & Valid & Lie & 86 & 48.3 & 70.5 & 70.5 \\
\hline & & Not a Lie & 36 & 20.2 & 29.5 & 100.0 \\
\hline & & Total & 122 & 68.5 & 100.0 & \\
\hline & Missing & System & 56 & 31.5 & & \\
\hline & Total & & 178 & 100.0 & & \\
\hline
\end{tabular}


Reflecting on your own personal definition of lying, which of the following do you believe is or is not a lie?

A statement that is untrue but that is made in order to avoid hurting someone's feelings

\begin{tabular}{llcccc}
\hline \hline All Staff-weighted & Frequency & Percent & Valid Percent & $\begin{array}{c}\text { Cumulative } \\
\text { Percent }\end{array}$ \\
\hline Valid & Lie & 178 & 48.9 & 71.9 & 71.9 \\
& Not a Lie & 70 & 19.1 & 28.1 & 100.0 \\
& Total & 248 & 67.9 & 100.0 & \\
Missing & System & 117 & 32.1 & & \\
Total & & 364 & 100.0 & & \\
\hline \hline
\end{tabular}

Reflecting on your own personal definition of lying, which of the following do you believe is or is not a lie? A statement that is untrue but that is made in order to avoid hurting someone's feelings.

\begin{tabular}{|c|c|c|c|c|c|}
\hline \multicolumn{2}{|c|}{$\begin{array}{l}\text { ALL STAFF- } \\
\text { unweighted }\end{array}$} & \multirow{2}{*}{$\frac{\text { Frequency }}{177}$} & \multirow{2}{*}{$\frac{\text { Percent }}{48.8}$} & \multirow{2}{*}{$\frac{\text { Valid Percent }}{71.7}$} & \multirow{2}{*}{$\begin{array}{c}\begin{array}{c}\text { Cumulative } \\
\text { Percent }\end{array} \\
71.7\end{array}$} \\
\hline Valid & Lie & & & & \\
\hline & Not a Lie & 70 & 19.3 & 28.3 & 100.0 \\
\hline & Total & 247 & 68.0 & 100.0 & \\
\hline Missing & System & 116 & 32.0 & & \\
\hline Total & & 363 & 100.0 & & \\
\hline
\end{tabular}

Reflecting on your own personal definition of lying, which of the following do you believe is or is not a lie? A statement that is untrue but that is made in order to avoid hurting someone's feelings.

\begin{tabular}{lccccc}
\hline \hline Stennis Fellows & Frequency & Percent & Valid Percent & $\begin{array}{c}\text { Cumulative } \\
\text { Percent }\end{array}$ \\
\hline Valid & Lie & 65 & 53.3 & 69.1 & 69.1 \\
& Not a Lie & 29 & 23.8 & 30.9 & 100.0 \\
& Total & 94 & 77.0 & 100.0 & \\
Missing & System & 28 & 23.0 & & \\
Total & 122 & 100.0 & & \\
\hline \hline
\end{tabular}




\section{A statement that You Assert/claim is True when You are Actually Uncertain About the Truth or Falsehood of Your Statement}

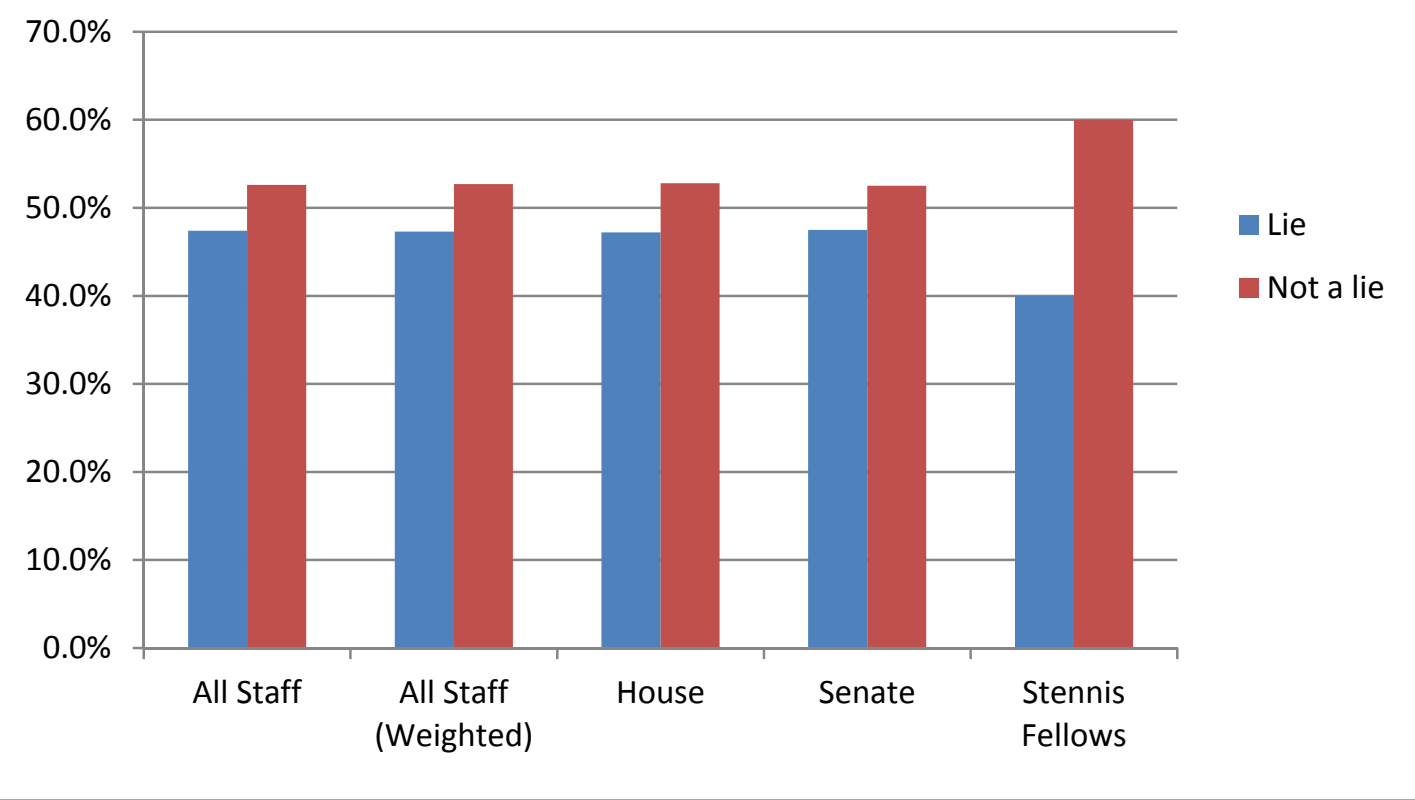

Respondents were asked whether they thought that a statement that "You assert/claim is true when you are actually uncertain about the truth or falsehood of your statement" was a lie. This question was designed to capture what Frankfurt and others have referred to as "bullshit." Staff were clearly divided in their assessment as to whether this constituted a lie.

Confidence intervals were calculated for each of the respondent groups. The widest confidence interval for the House was $\pm 8.8 \%$, for the Senate was $\pm 8.9 \%$, for all staffweighted was $\pm 6.2 \%$ and for Stennis Fellows was $\pm 8.0 \%$. 
Stennis Fellows (40\%) were less likely to respond that "a statement that you assert/claim is true when you are actually uncertain about the truth or falsehood of your statement" was a lie than House (47.2\%) or Senate staff (47.5\%). The t-statistic was not significant at the .05 level for the difference between Stennis Fellows and House staff, $t(218)=1.07$, $p=.29$. The null hypothesis that there was no difference in the proportions between the Stennis Fellows and the House staff could not be rejected.

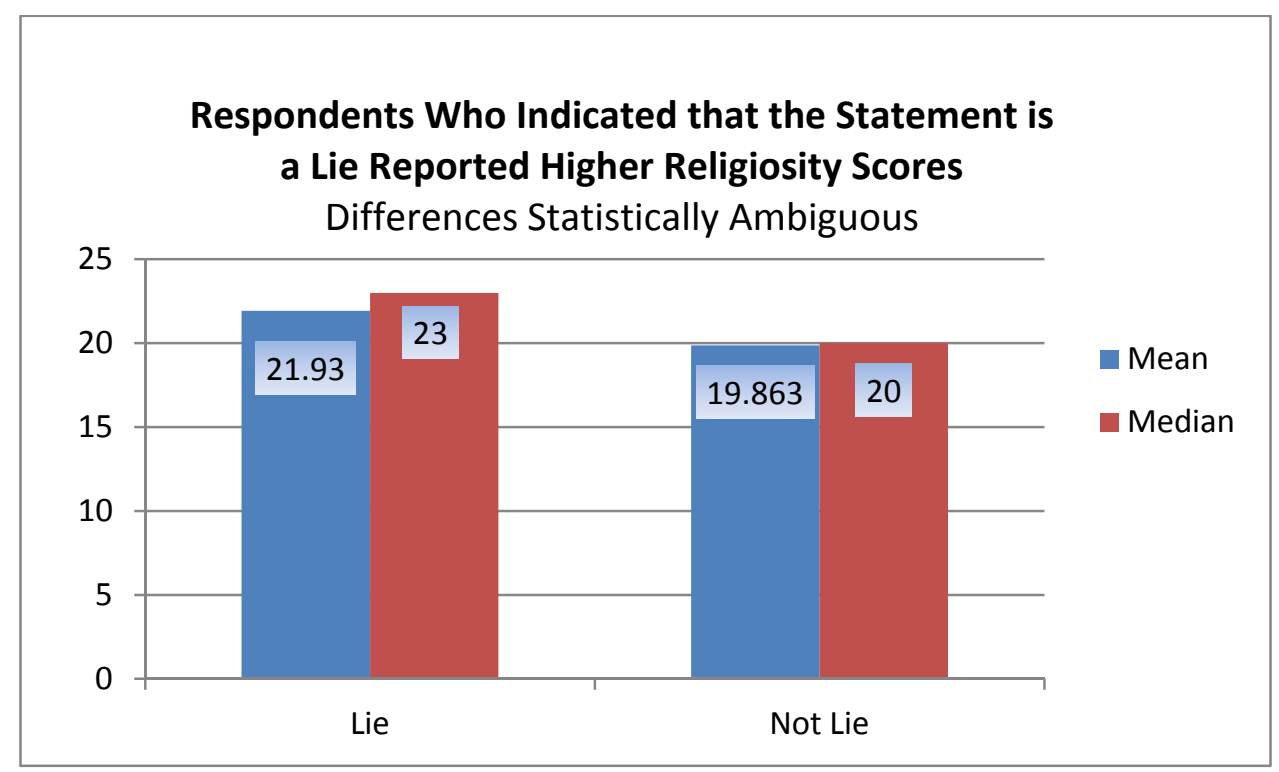

All staff-weighted respondents who indicated that the statement was a lie reported higher mean and median religiosity scores than those who indicated that it was not a lie. The two-sample, two-tailed t-test was significant at the .05 level for the difference in mean religiosity scores between respondents who believed this was a lie and those who did not believe this was a lie, $t(239)=2.051, \mathrm{p}=.0413$. 
A Mann-Whitney $U$ test revealed no statistically significant difference in the religiosity of respondents who indicated this was a lie $(M d n=23.0, n=113)$ and individuals who indicated this was not a lie $(M d n=20.0, n=128), U=6305, z=-1.718, p=.086$.

As discussed earlier, the central limit theorem provides that when samples are large enough the sampling distribution of the mean will be normal regardless of the shape of the population. When comparison groups exceed 30-50 respondents, one can assume that the sampling distribution of the mean is normal. This permits us to accept the results of the two-sample, two-tailed t-statistic that there is a statistically significant difference in religiosity between the groups.

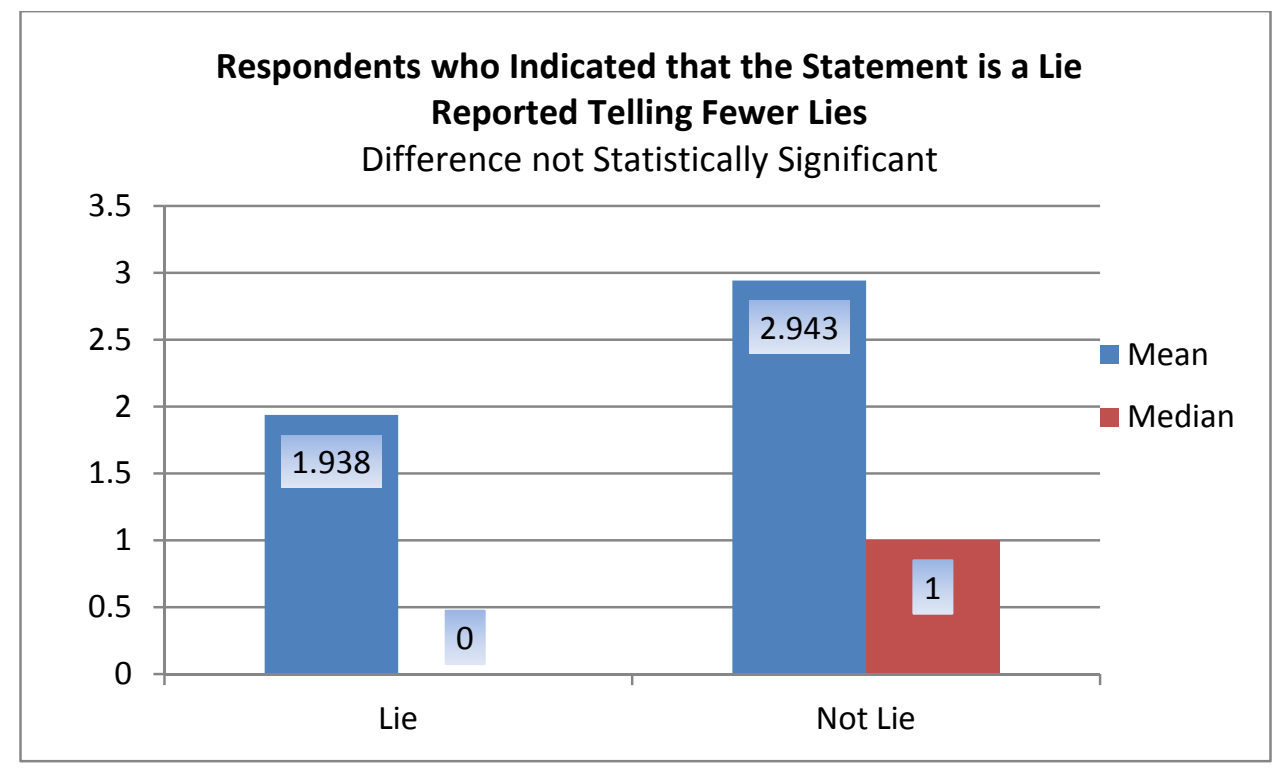

All staff-weighted respondents who indicated that the statement was a lie reported lower mean and median lying than those who indicated that it was not a lie. The two-sample, two-tailed t-test was not significant at the .05 level for the difference in mean religiosity 
scores between respondents who believed this was a lie and those who did not believe this was a lie, $t(197)=1.082, p=.2804$.

A Mann-Whitney U test also revealed no statistically significant difference in the reported lying of respondents who indicated this was a lie $(M d n=.00, n=86)$ and individuals who indicated this was not a lie $(M d n=1.0, n=113), U=4315.5, z=-1.332$, $p=.184$.

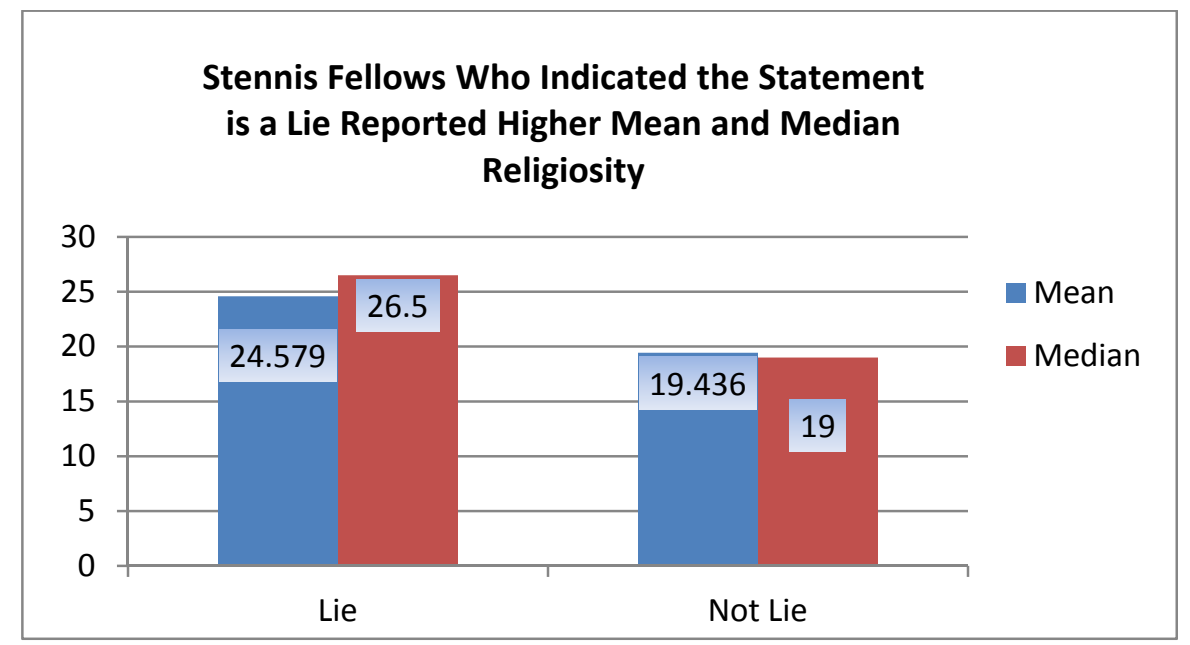

Stennis Fellows who indicated that a statement that you "assert/claim is true when you are actually uncertain about the truth of falsehood of your statement" is a lie have higher religiosity scores than those who indicated it is not a lie. The two-sample, two-tailed tstatistic for the difference in means was significant at the .05 level, $t(91)=3.528, p=.0007$. The Mann-Whitney U Test also revealed a significant difference between the reported lies of those who indicated this is a lie $(\mathrm{Mdn}=26.5, \mathrm{n}=38)$ and those who indicated this is not a lie $(\mathrm{Mdn}=19, \mathrm{n}=55), \mathrm{U}=627, \mathrm{z}=-3.271, \mathrm{p}=.001, \mathrm{r}=.34$. 


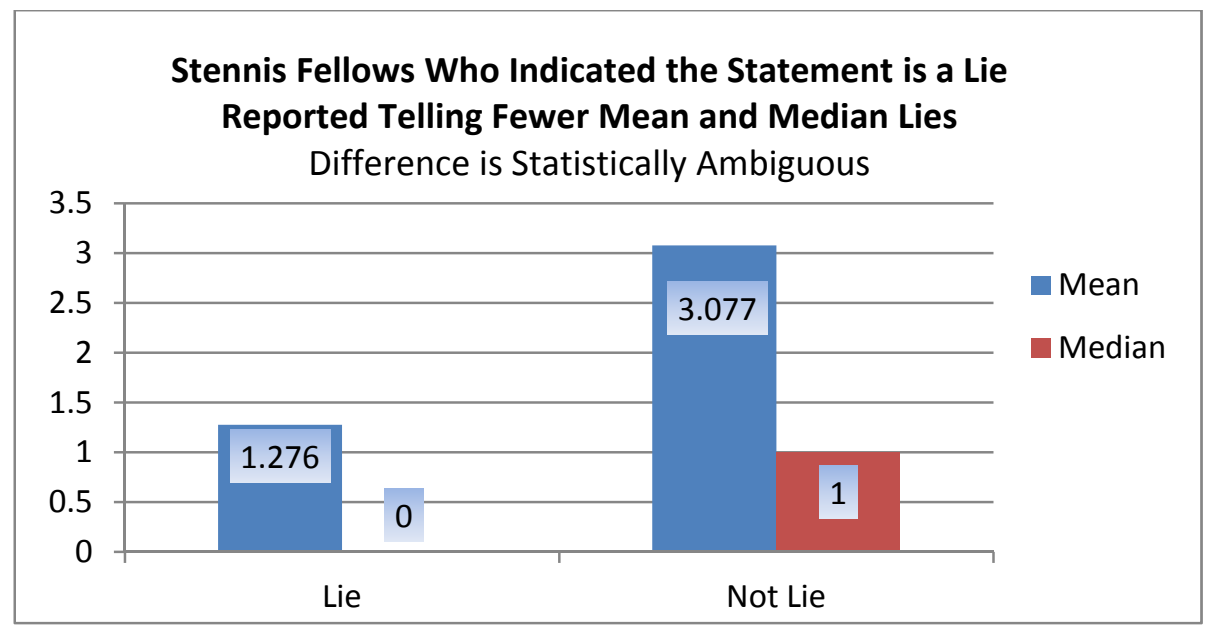

Stennis Fellows who indicated that the statement is a lie reported telling fewer mean and median lies than those who indicated that the statement is not a lie. The two-sample, two-tailed t-statistic for the difference in means was not significant at the .05 level, $t(66)=1.463, p=.1481$. The Mann-Whitney U Test, however, revealed a statistically significant difference between Fellows who indicated this is a lie $(M d n=0, n=29)$ and Fellows who reported this is not a lie $(M d n=1, n=39), U=423.5, z=-1.975, p=.048, r=.24$.

The two-sample, two-tailed t-statistic is a parametric test that requires a normal distribution of means. As noted earlier, as a general guideline, the sampling distribution of means can be assumed to be normal when sample sizes are greater than 30 (some argue for 50). The Mann-Whitney U Test is a nonparametric test that does not assume normalcy. Given that the number of respondents is only slightly above 30, the MannWhitney U Test may be the more appropriate test. This permits a tentative conclusion that Fellows who indicated this is a lie themselves told fewer lies. 
This result, if accepted, raises a possible paradox. On one hand, one might expect that individuals with broader definitions of lying might be expected to report lying more frequently because their definition captures a wider range of communications. On the other hand, the wider definition of lying may be indicative of the application of a more restrictive model of what counts as ethical communications.

Reflecting on your own personal definition of lying, which of the following do you believe is or is not a lie?

A statement that you assert/claim is true when you are actually uncertain about the truth or falsehood of your statement.

\begin{tabular}{|c|c|c|c|c|c|c|}
\hline \multicolumn{3}{|c|}{ Chamber } & \multirow{2}{*}{$\begin{array}{r}\text { Frequency } \\
59\end{array}$} & \multirow{2}{*}{$\frac{\text { Percent }}{31.9}$} & \multirow{2}{*}{$\frac{\text { Valid Percent }}{47.2}$} & \multirow{2}{*}{$\begin{array}{r}\begin{array}{l}\text { Cumulative } \\
\text { Percent }\end{array} \\
47.2\end{array}$} \\
\hline House & Valid & Lie & & & & \\
\hline & & Not a Lie & 66 & 35.7 & 52.8 & 100.0 \\
\hline & & Total & 125 & 67.6 & 100.0 & \\
\hline & Missing & System & 60 & 32.4 & & \\
\hline & Total & & 185 & 100.0 & & \\
\hline \multirow[t]{5}{*}{ Senate } & Valid & Lie & 58 & 32.6 & 47.5 & 47.5 \\
\hline & & Not a Lie & 64 & 36.0 & 52.5 & 100.0 \\
\hline & & Total & 122 & 68.5 & 100.0 & \\
\hline & Missing & System & 56 & 31.5 & & \\
\hline & Total & & 178 & 100.0 & & \\
\hline
\end{tabular}

Reflecting on your own personal definition of lying, which of the following do you believe is or is not a lie?

A statement that you assert/claim is true when you are actually uncertain about the truth or falsehood of your statement.

\begin{tabular}{|c|c|c|c|c|c|}
\hline \multicolumn{2}{|c|}{ All Staff-weighted } & \multirow{2}{*}{$\frac{\text { Frequency }}{117}$} & \multirow{2}{*}{$\frac{\text { Percent }}{32.2}$} & \multirow{2}{*}{$\frac{\text { Valid Percent }}{47.3}$} & \multirow{2}{*}{$\begin{array}{c}\text { Cumulative } \\
\text { Percent }\end{array}$} \\
\hline Valid & Lie & & & & \\
\hline & Not a Lie & 130 & 35.8 & 52.7 & 100.0 \\
\hline & Total & 248 & 67.9 & 100.0 & \\
\hline Missing & System & 117 & 32.1 & & \\
\hline Total & & 364 & 100.0 & & \\
\hline
\end{tabular}

Reflecting on your own personal definition of lying, which of the following do you believe is or is not a lie?

A statement that you assert/claim is true when you are actually uncertain about the truth or falsehood of your statement.

\begin{tabular}{lcccc}
\hline \hline ALL STAFF- & & & & \\
unweighted & Frequency & Percent & Valid Percent & $\begin{array}{c}\text { Cumulative } \\
\text { Percent }\end{array}$ \\
\hline Valid Lie & 117 & 32.2 & 47.4 & 47.4
\end{tabular}




\begin{tabular}{llcccc}
\hline & Not a Lie & 130 & 35.8 & 52.6 & 100.0 \\
& Total & 247 & 68.0 & 100.0 & \\
Missing & System & 116 & 32.0 & \\
Total & & 363 & 100.0 & \\
\hline \hline
\end{tabular}

Reflecting on your own personal definition of lying, which of the following do you believe is or is not a lie?

A statement that you assert/claim is true when you are actually uncertain about the truth or falsehood of your statement.

\begin{tabular}{lccccc}
\hline \hline Stennis Fellows & Frequency & Percent & Valid Percent & $\begin{array}{c}\text { Cumulative } \\
\text { Percent }\end{array}$ \\
\hline Valid & Lie & 38 & 31.1 & 40.0 & 40.0 \\
& Not a Lie & 57 & 46.7 & 60.0 & 100.0 \\
& Total & 95 & 77.9 & 100.0 & \\
Missing & System & 27 & 22.1 & & \\
Total & & 122 & 100.0 & &
\end{tabular}

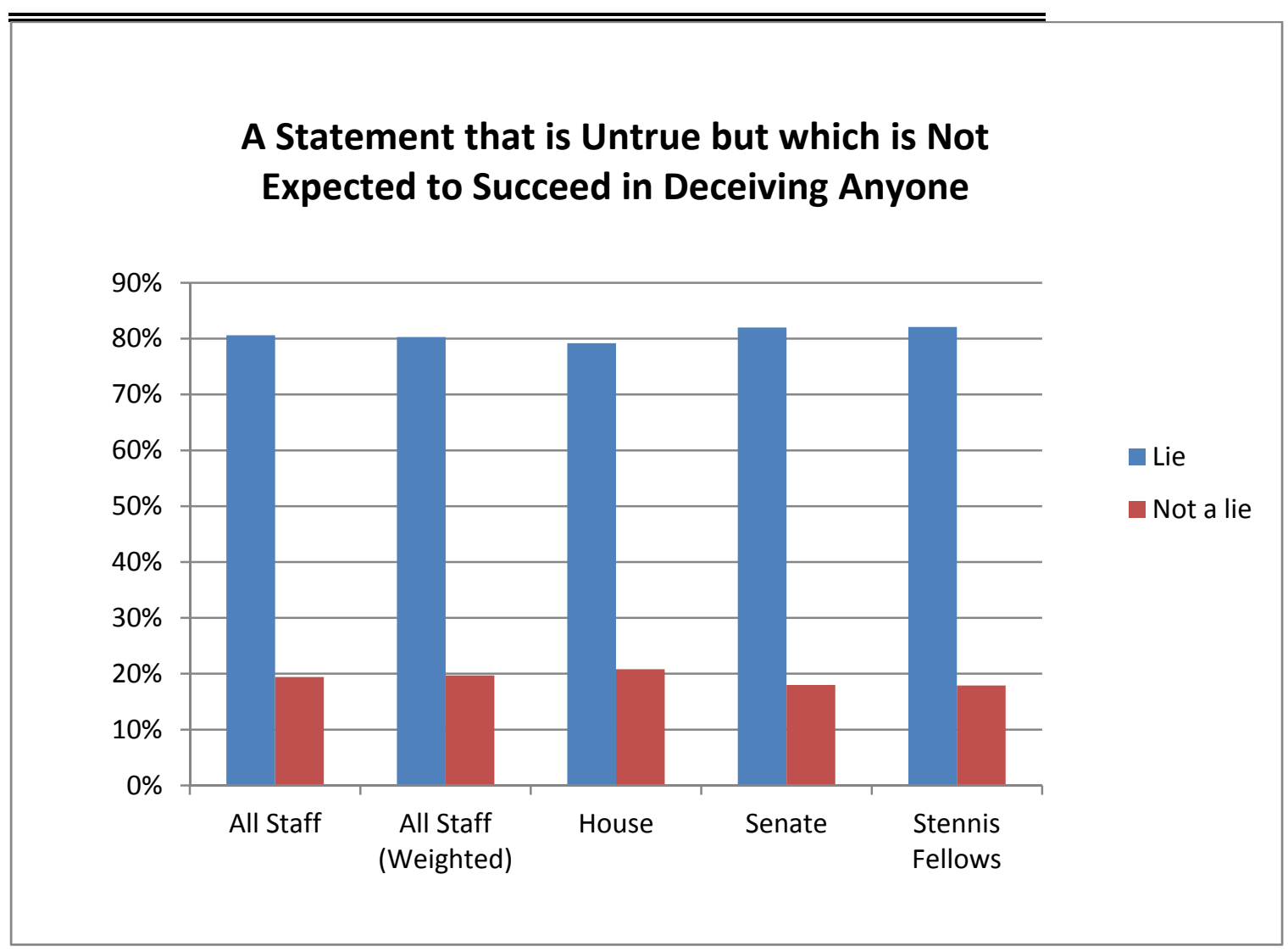

Respondents were asked whether they believed a statement that is "untrue but which is not expected to succeed in deceiving anyone" was a lie. This definition trades to some 
extent on the role of intent to deceive. Staff overwhelmingly indicated they believe this to be a lie. Roughly $20 \%$ of staff believe this not to be a lie.

Confidence intervals were calculated for each of the respondent groups. The widest confidence interval for the House was $\pm 7.2 \%$, for the Senate was $\pm 6.8 \%$, for all staffweighted was $\pm 4.9 \%$ and for Stennis Fellows was $\pm 6.3 \%$.

Stennis Fellows $(82.1 \%)$ were slightly more likely to respond that "a statement that is untrue but which is not expected to succeed in deceiving anyone" was a lie than House $(79.2 \%)$ or Senate staff $(82 \%)$. The two-sample, two-tailed t-statistic was not significant at the .05 level for the difference between Stennis Fellows and House staff, $t(215)=.537$, $p=.59$. The null hypothesis that there was no difference in the proportions between the Stennis Fellows and the House staff could not be rejected.

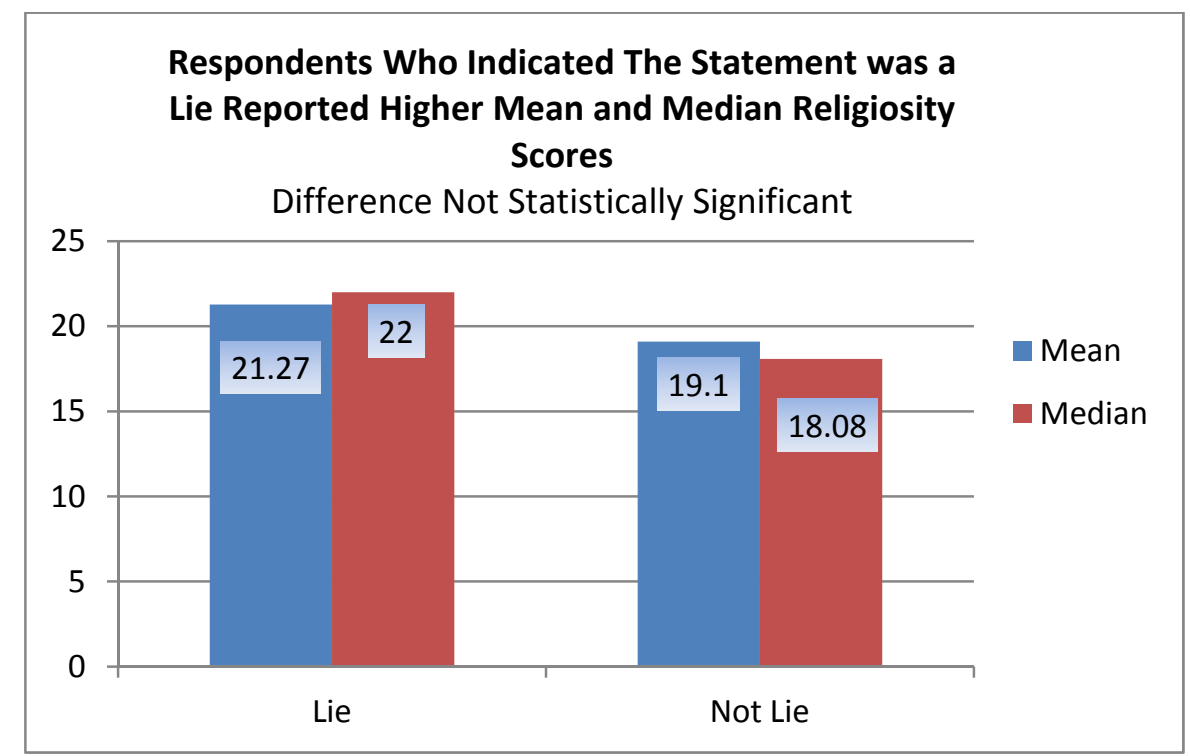


All staff-weighted respondents who indicated that the statement was a lie reported higher mean and median religiosity scores. The two-sample, two-tailed t-statistic for the difference in means was not significant at the .05 level, $t(240)=1.734, p=.0843$.

A Mann-Whitney U test also revealed no statistically significant difference in the religiosity of respondents who indicated this was a lie $(M d n=21.27, n=193)$ and individuals who indicated this was not a lie $(M d n=19.1, n=49), U=4069, z=-1.304$, $\mathrm{p}=.192$.

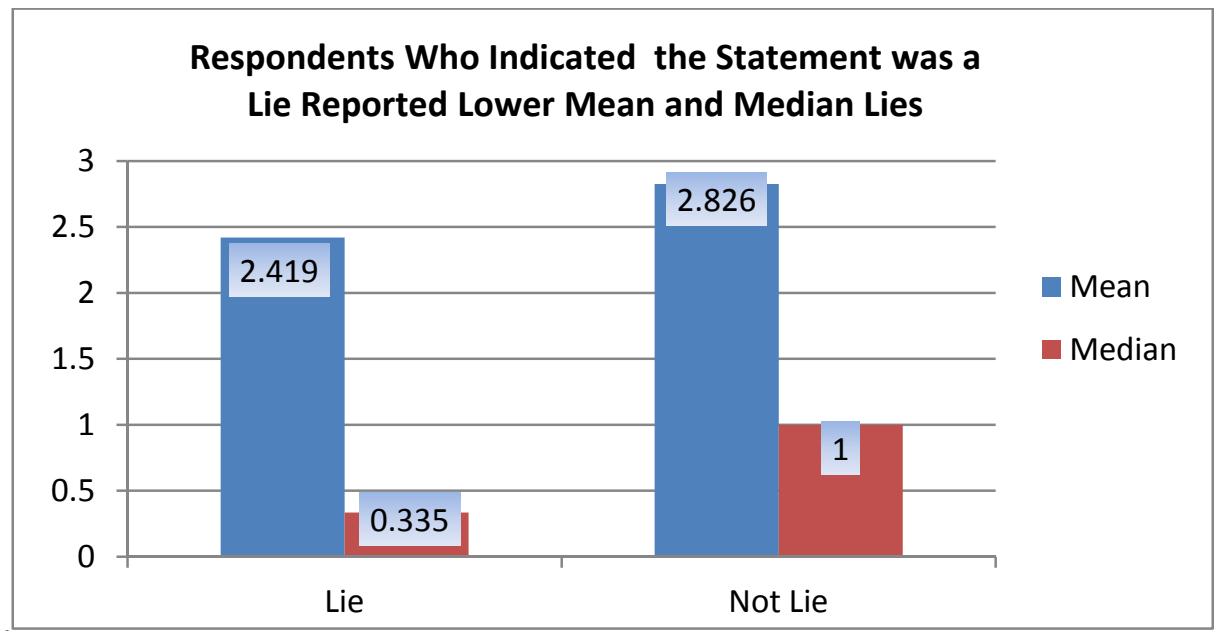

All staff-weighted respondents who indicated that the statement was a lie reported slightly lower mean and median lying. The two-sample, two-tailed t-statistic for the difference in means was not significant at the .05 level, $t(197)=.336, p=.7145$.

A Mann-Whitney U test also revealed no statistically significant difference in the number of lies told by respondents who indicated this was a lie $(M d n=.335, n=156)$ and 
individuals who indicated this was not a lie $(M d n=1.0, n=43), U=2817, z=-1.482$, $\mathrm{p}=.138$.

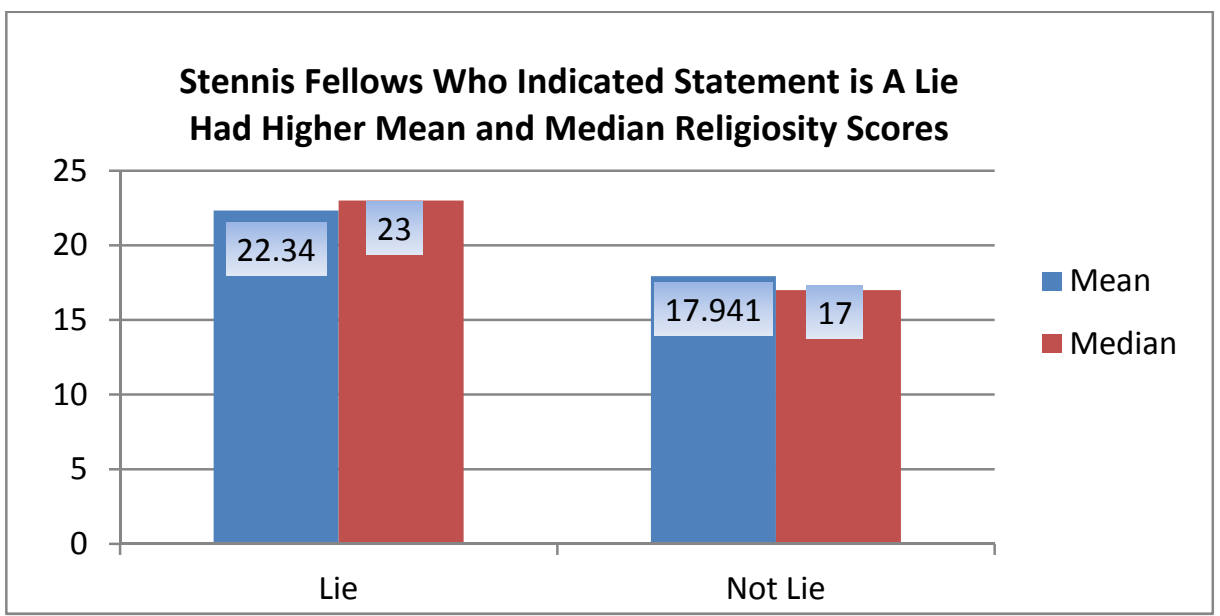

Stennis Fellows who indicated that a statement that "is untrue but which is not expected to succeed in deceiving anyone" is a lie have higher religiosity scores than those who indicated that it is not a lie. The two-sample, two-tailed t-statistic was significant at the .05 level for the difference in mean religiosity, $t(91)=2.290, p=.0243$. The MannWhitney U Test also revealed a significant difference between respondents who indicated this was a lie $(M d n=23, n=76)$ and those who indicated it was not a lie $(\operatorname{Mdn}=17, n=17)$, $\mathrm{U}=428, \mathrm{z}=-2.170, \mathrm{p}=0.30, \mathrm{r}=.23$. 


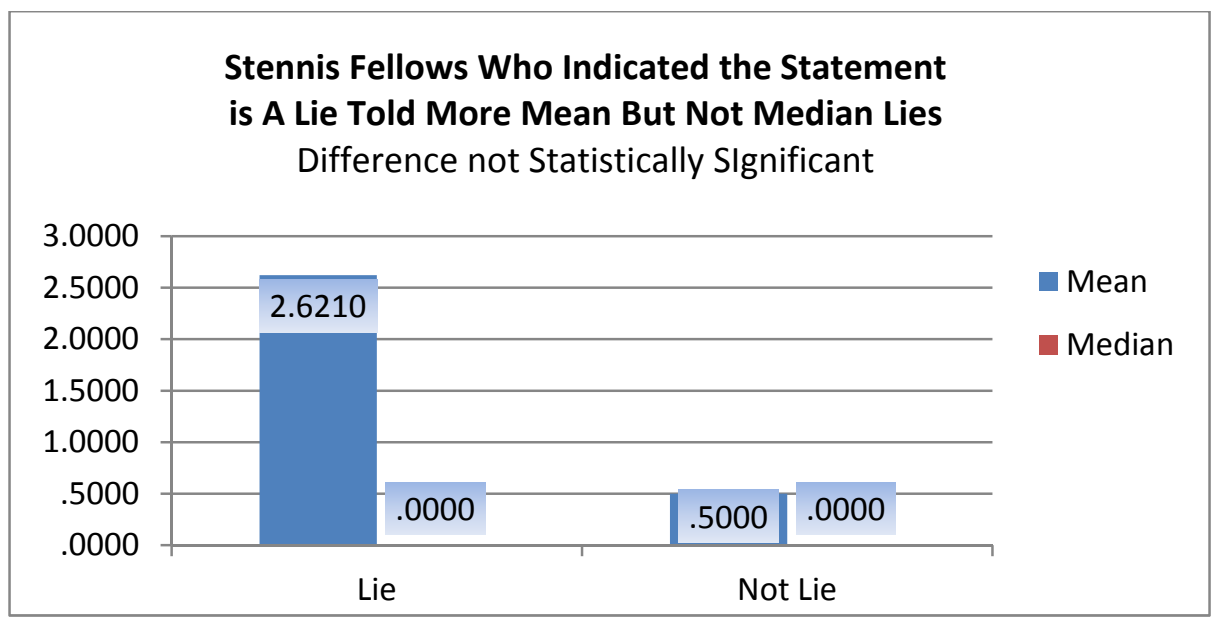

Stennis Fellows who indicated that the statement is a lie reported telling more mean but not more median lies than those who reported that this was not a lie. The two-sample, two-tailed t-statistic was not significant at the .05 level for the difference in religiosity between the two groups, $\mathrm{t}(66)=1.228, \mathrm{p}=.2236$. The Mann-Whitney U Test also revealed no significant difference in religiosity between those who indicated this is a lie $(M d n=0$, $n=58)$ and those who indicated this is not a lie $(M d n=0, n=10), U=232.5, z=-1.117$, $p=.264$.

Reflecting on your own personal definition of lying, which of the following do you believe is or is not a lie? A statement that is untrue but which is not expected to succeed in deceiving anyone.

\begin{tabular}{|c|c|c|c|c|c|c|}
\hline Chamber & & & Frequency & Percent & Valid Percent & $\begin{array}{c}\text { Cumulative } \\
\text { Percent }\end{array}$ \\
\hline \multirow[t]{5}{*}{ House } & Valid & Lie & 99 & 53.5 & 79.2 & 79.2 \\
\hline & & Not a Lie & 26 & 14.1 & 20.8 & 100.0 \\
\hline & & Total & 125 & 67.6 & 100.0 & \\
\hline & Missing & System & 60 & 32.4 & & \\
\hline & Total & & 185 & 100.0 & & \\
\hline \multirow[t]{5}{*}{ Senate } & Valid & Lie & 100 & 56.2 & 82.0 & 82.0 \\
\hline & & Not a Lie & 22 & 12.4 & 18.0 & 100.0 \\
\hline & & Total & 122 & 68.5 & 100.0 & \\
\hline & Missing & System & 56 & 31.5 & & \\
\hline & Total & & 178 & 100.0 & & \\
\hline
\end{tabular}


Reflecting on your own personal definition of lying, which of the following do you believe is or is not a lie? A statement that is untrue but which is not expected to succeed in deceiving anyone

\begin{tabular}{lccccc}
\hline \hline All Staff-weighted & Frequency & Percent & Valid Percent & $\begin{array}{c}\text { Cumulative } \\
\text { Percent }\end{array}$ \\
\hline Valid & Lie & 199 & 54.5 & 80.3 & 80.3 \\
& Not a Lie & 49 & 13.4 & 19.7 & 100.0 \\
& Total & 248 & 67.9 & 100.0 & \\
Missing & System & 117 & 32.1 & & \\
Total & 364 & 100.0 & & \\
\hline \hline
\end{tabular}

Reflecting on your own personal definition of lying, which of the following do you believe is or is not a lie? A statement that is untrue but which is not expected to succeed in deceiving anyone.

\begin{tabular}{|c|c|c|c|c|c|}
\hline \multicolumn{2}{|c|}{$\begin{array}{l}\text { ALL STAFF- } \\
\text { unweighted }\end{array}$} & \multirow{2}{*}{$\frac{\text { Frequency }}{199}$} & \multirow{2}{*}{$\frac{\text { Percent }}{54.8}$} & \multirow{2}{*}{$\frac{\text { Valid Percent }}{80.6}$} & \multirow{2}{*}{$\begin{array}{c}\begin{array}{c}\text { Cumulative } \\
\text { Percent }\end{array} \\
80.6\end{array}$} \\
\hline Valid & Lie & & & & \\
\hline & Not a Lie & 48 & 13.2 & 19.4 & 100.0 \\
\hline & Total & 247 & 68.0 & 100.0 & \\
\hline Missing & System & 116 & 32.0 & & \\
\hline Total & & 363 & 100.0 & & \\
\hline
\end{tabular}

Reflecting on your own personal definition of lying, which of the following do you believe is or is not a lie? A statement that is untrue but which is not expected to succeed in deceiving anyone

\begin{tabular}{llcccc}
\hline \hline & & & & \\
\hline Valid & Lie & Frequency & Percent & Valid Percent & $\begin{array}{c}\text { Cumulative } \\
\text { Percent }\end{array}$ \\
& Not a Lie & 78 & 63.9 & 82.1 & 82.1 \\
& Total & 95 & 17.9 & 17.9 & 100.0 \\
\multirow{3}{*}{ Missing } & System & 27 & 77.9 & 100.0 & \\
Total & & 122 & 100.0 & & \\
\hline \hline
\end{tabular}




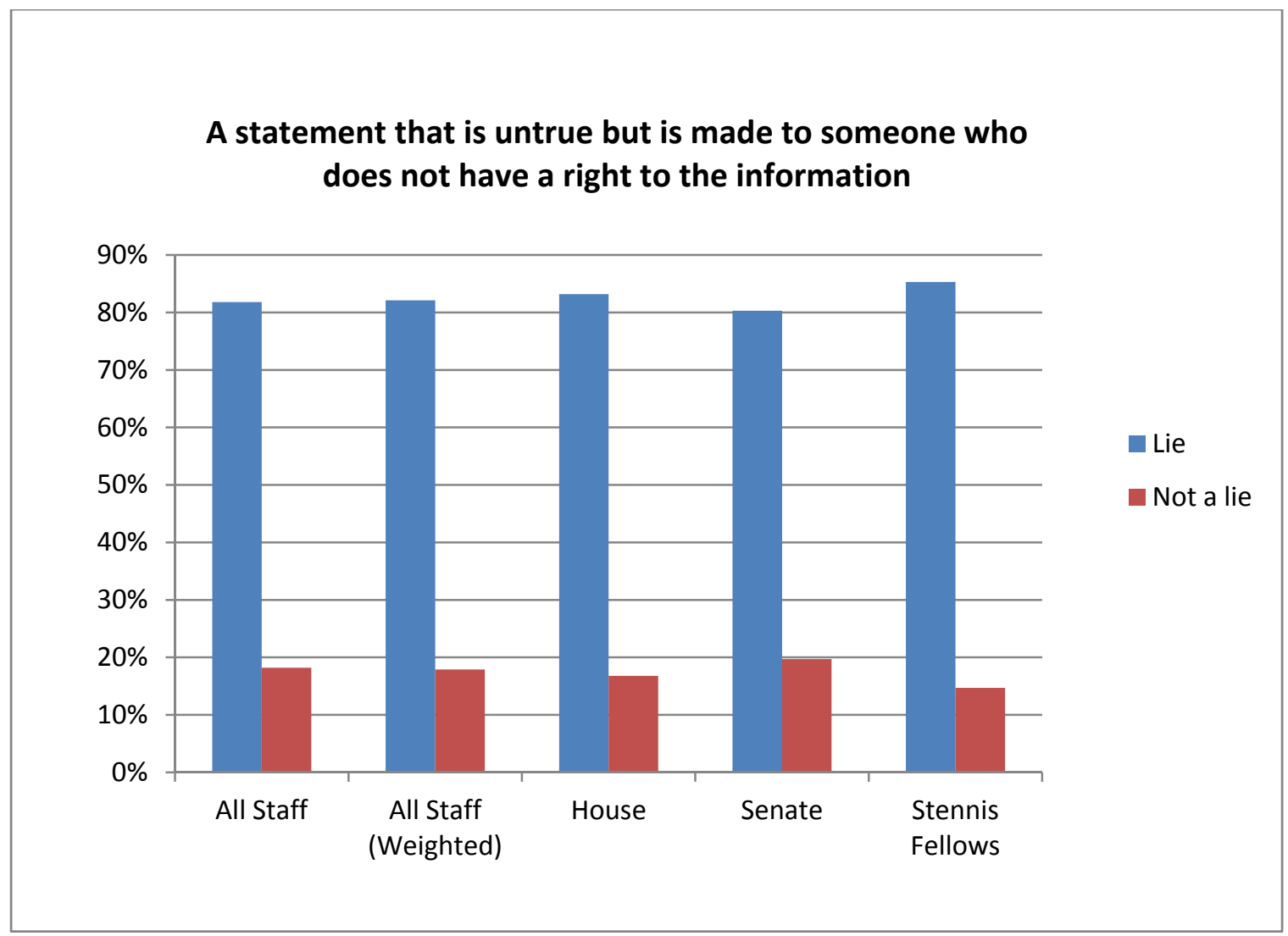

Respondents were asked whether a statement that is "untrue but is made to someone who does not have a right to the information" was a lie. This question reflects Grotius' idea that a lie involves untruthful statements to people who have a right to the information. The issues raised by this definition are explored again later in the survey through the case pertaining to classified information. Staff and Fellows overwhelmingly believed that this constituted a lie while $15-20 \%$ of respondents follow Grotius and believe this was not a lie.

Confidence intervals were calculated for each of the respondent groups. The widest confidence interval for the House was $\pm 6.6 \%$, for the Senate was $\pm 7.1 \%$, for all staffweighted was $\pm 4.8 \%$ and for Stennis Fellows was $\pm 5.8 \%$. 
Stennis Fellows $(85.3 \%)$ were slightly more likely to respond that "a statement that is untrue but is made to someone who does not have a right to the information" was a lie than House $(83.2 \%)$ or Senate staff $(80.3 \%)$. The t-statistic was not significant at the .05 level for the difference between Stennis Fellows and Senate staff, $t(215)=.96, p=.34$. The null hypothesis that there was no difference in the proportions between the Stennis Fellows and the Senate staff could not be rejected.

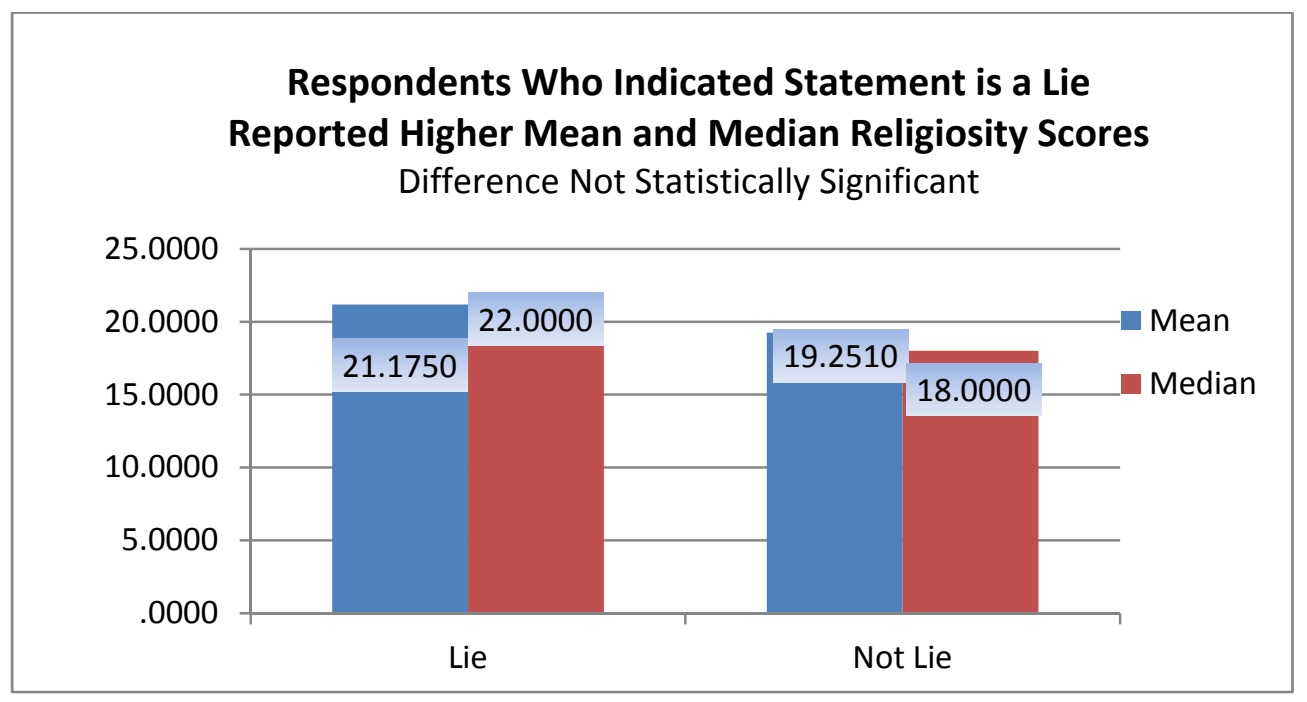

All staff-weighted respondents who indicated that the statement was a lie reported higher mean and median religiosity scores. The two-sample, two-tailed t-statistic for the difference in means was not significant at the .05 level, $t(239)=1.459, p=.146$.

A Mann-Whitney U test also revealed no statistically significant difference in the religiosity of respondents who indicated this was a lie $(M d n=22, n=198)$ and individuals who indicated this was not a lie $(M d n=19.251, n=43), U=15990.5, z=-1.271, \mathrm{p}=.204$. 


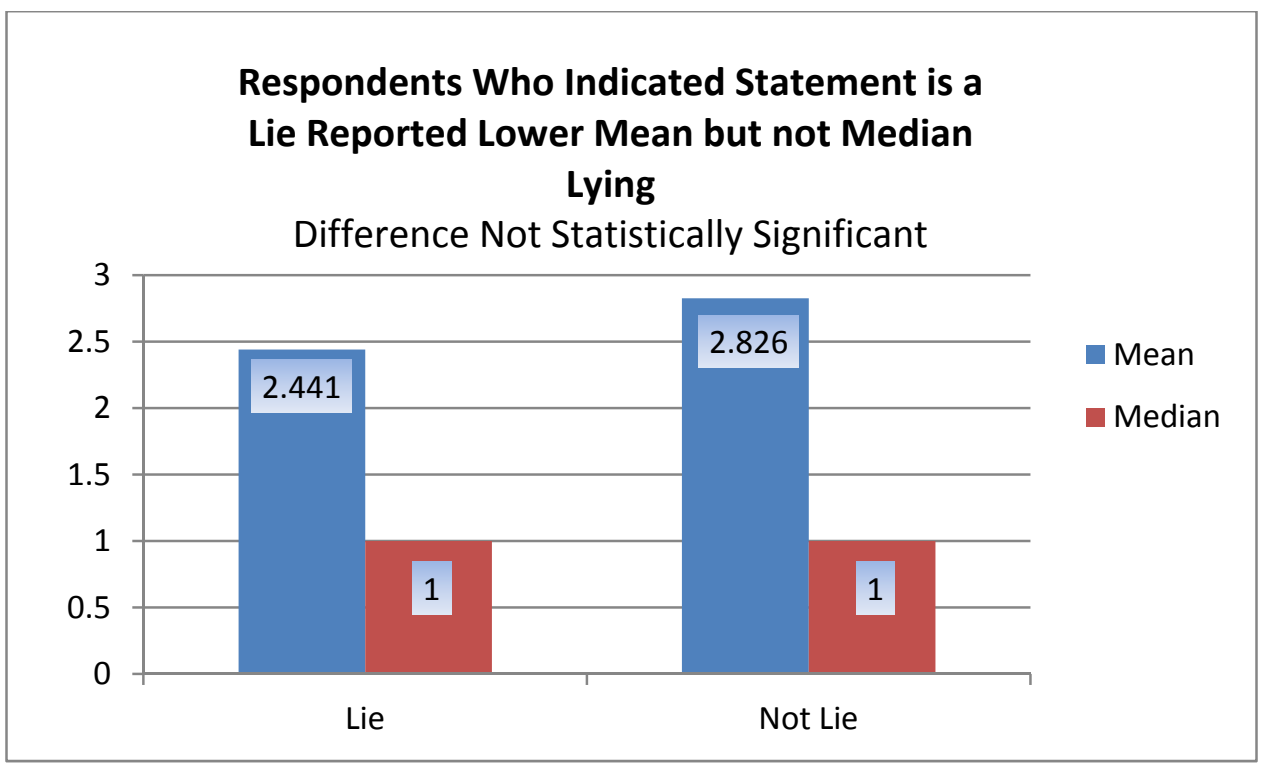

All staff-weighted respondents who indicated that the statement was a lie reported lower mean but not median religiosity scores. The two-sample, two-tailed t-statistic for the difference in means was not significant at the .05 level, $t((197)=0.314, p=.7536$. A Mann-Whitney U test also revealed no statistically significant difference in the number of lies told by respondents who indicated this was a lie $(M d n=.1, n=165)$ and individuals who indicated this was not a lie $(M d n=1.0, n=34), U=2624.5, z=-.789, \mathrm{p}=.430$.

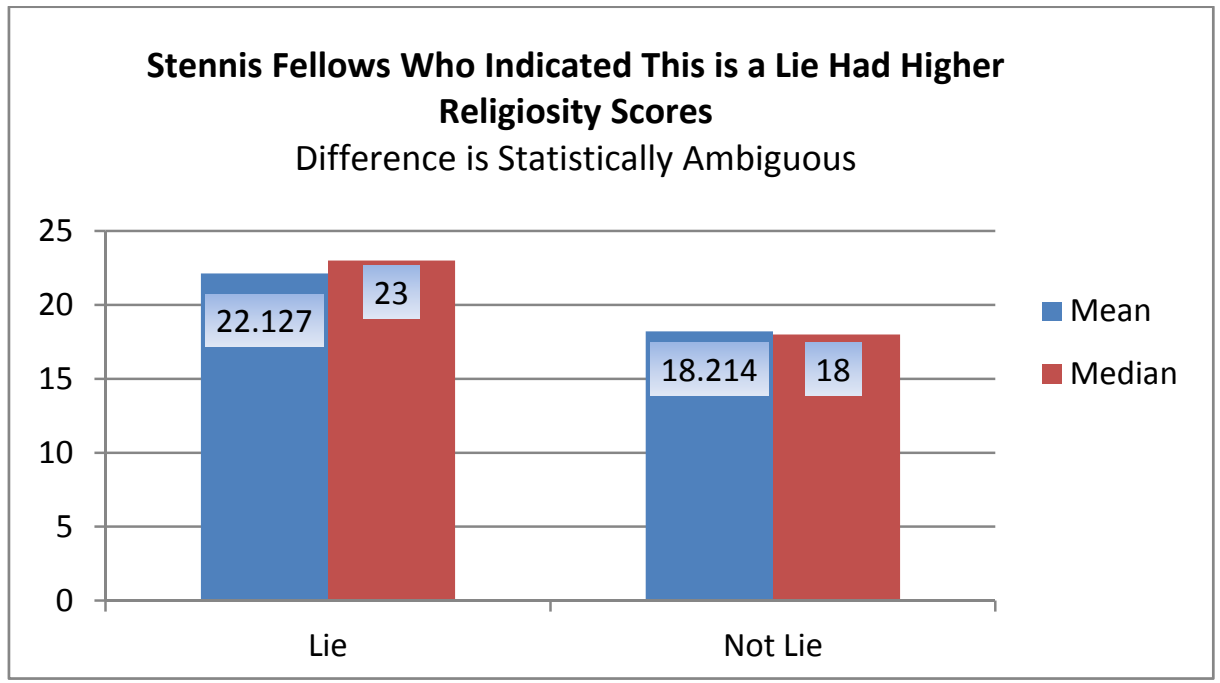


Stennis Fellows who indicated that this is a lie had higher mean and median religiosity scores. The two-sample, two-tailed t-statistic for the difference in mean religiosity was not significant at the .05 level, $\mathrm{t}(91)=1.867, p=.0652$. The Mann-Whitney U Test, however, revealed a significant difference in the religiosity of Fellows who indicated this was a lie $(M d n=23, n=79)$ and Fellows who indicated this is not a lie $(M d n=18, n=14)$, $U=365, z=-2.023, p=.043, r=.21$.

The parametric t-statistic requires the assumption that sampling distribution of means is normal. To safely make this assumption, the sample sizes need to exceed 30 . Because the sample size for Fellows who indicated this was not a lie was below 30, it is appropriate to accept the results of the nonparametric Mann-Whitney U Test.

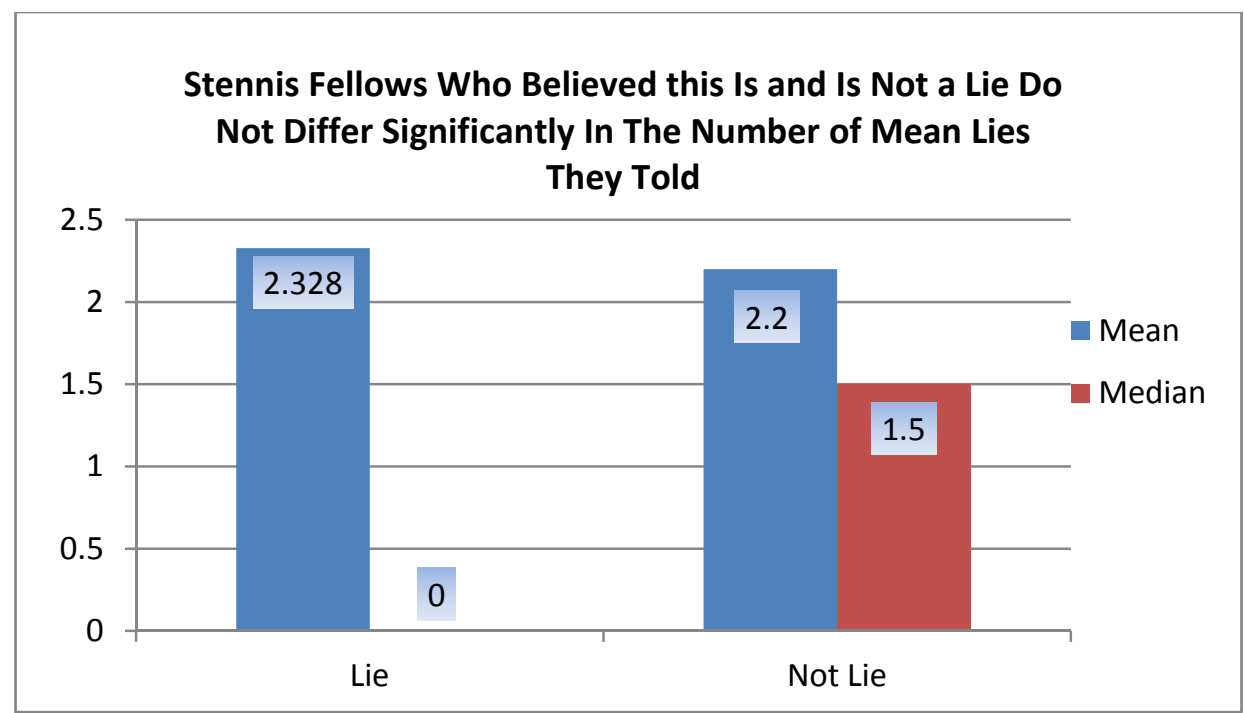

Stennis Fellows who indicated that a statement that is "untrue but is made to someone who does not have a right to the information" was a lie reported telling slightly more mean lies and slightly fewer median lies than those who did not believe this was a lie. The two-sample, two-tailed t-statistic for the difference in means was not significant at 
the .05 level, $t(66)=0.073, p=.9418$. The Mann-Whitney U Test also revealed no significant difference in lying between Fellows who believe this is a lie $(M d n=0, n=58)$ and Fellows who do not believe this is a lie $(M d n=1.5, n=10), U=209, z=-1.573, p=.116$.

Reflecting on your own personal definition of lying, which of the following do you believe is or is not a lie?

A statement that is untrue but is made to someone who does not have a right to the information.

\begin{tabular}{|c|c|c|c|c|c|c|}
\hline \multicolumn{3}{|c|}{ Chamber } & \multirow{2}{*}{$\frac{\text { Frequency }}{104}$} & \multirow{2}{*}{$\frac{\text { Percent }}{56.2}$} & \multirow{2}{*}{$\frac{\text { Valid Percent }}{83.2}$} & \multirow{2}{*}{$\begin{array}{c}\text { Cumulative } \\
\text { Percent }\end{array}$} \\
\hline House & Valid & Lie & & & & \\
\hline & & Not a Lie & 21 & 11.4 & 16.8 & 100.0 \\
\hline & & Total & 125 & 67.6 & 100.0 & \\
\hline & Missing & System & 60 & 32.4 & & \\
\hline & Total & & 185 & 100.0 & & \\
\hline \multirow[t]{5}{*}{ Senate } & Valid & Lie & 98 & 55.1 & 80.3 & 80.3 \\
\hline & & Not a Lie & 24 & 13.5 & 19.7 & 100.0 \\
\hline & & Total & 122 & 68.5 & 100.0 & \\
\hline & Missing & System & 56 & 31.5 & & \\
\hline & Total & & 178 & 100.0 & & \\
\hline
\end{tabular}

Reflecting on your own personal definition of lying, which of the following do you believe is or is not a lie?

A statement that is untrue but is made to someone who does not have a right to the information.

\begin{tabular}{llcccc}
\hline \hline All Staff-weighted & Frequency & Percent & Valid Percent & $\begin{array}{c}\text { Cumulative } \\
\text { Percent }\end{array}$ \\
\hline Valid & Lie & 203 & 55.8 & 82.1 & 82.1 \\
& Not a Lie & 44 & 12.2 & 17.9 & 100.0 \\
& Total & 248 & 67.9 & 100.0 & \\
Missing & System & 117 & 32.1 & & \\
Total & 364 & 100.0 & & \\
\hline \hline
\end{tabular}

Reflecting on your own personal definition of lying, which of the following do you believe is or is not a lie?

A statement that is untrue but is made to someone who does not have a right to the information

\begin{tabular}{|c|c|c|c|c|c|}
\hline \multicolumn{2}{|c|}{$\begin{array}{l}\text { ALL Staff- } \\
\text { unweighted }\end{array}$} & \multirow{2}{*}{$\frac{\text { Frequency }}{202}$} & \multirow{2}{*}{$\frac{\text { Percent }}{55.6}$} & \multirow{2}{*}{$\frac{\text { Valid Percent }}{81.8}$} & \multirow{2}{*}{$\begin{array}{c}\begin{array}{c}\text { Cumulative } \\
\text { Percent }\end{array} \\
81.8\end{array}$} \\
\hline Valid & Lie & & & & \\
\hline & Not a Lie & 45 & 12.4 & 18.2 & 100.0 \\
\hline & Total & 247 & 68.0 & 100.0 & \\
\hline
\end{tabular}


Missing System $\quad 116 \quad 32.0$

Total $363 \quad 100.0$

Reflecting on your own personal definition of lying, which of the following do you believe is or is or is not a lie?

A statement that is untrue but is made to someone who does not have a right to the information

\begin{tabular}{lccccc}
\hline \hline Stennis Fellows & Frequency & Percent & Valid Percent & $\begin{array}{c}\text { Cumulative } \\
\text { Percent }\end{array}$ \\
\hline Valid & Lie & 81 & 66.4 & 85.3 & 85.3 \\
& Not a Lie & 14 & 11.5 & 14.7 & 100.0 \\
& Total & 95 & 77.9 & 100.0 & \\
Missing & System & 27 & 22.1 & & \\
Total & & 122 & 100.0 & & \\
\hline \hline
\end{tabular}




\section{Chapter VIII. Justification for Telling A Lie}

In order to assess whether and under what conditions respondents believed that it was justified to tell a lie, they were presented with 10 statements. Each statement provided a different justification for telling a lie. Respondents were asked to indicate whether the statement did or did not reflect their views. This section provided a way to assess the opinions of congressional staff and Stennis Fellows about justifications that frequent the theological and philosophical literature. As described in the previous chapter, religiosity was at least directionally associated with more restrictive perspectives on lying. This pattern continued for the justifications for lying. More restrictive approaches to when and if a lie is justified were associated with higher religiosity and, perhaps not surprisingly, lower reported lying.

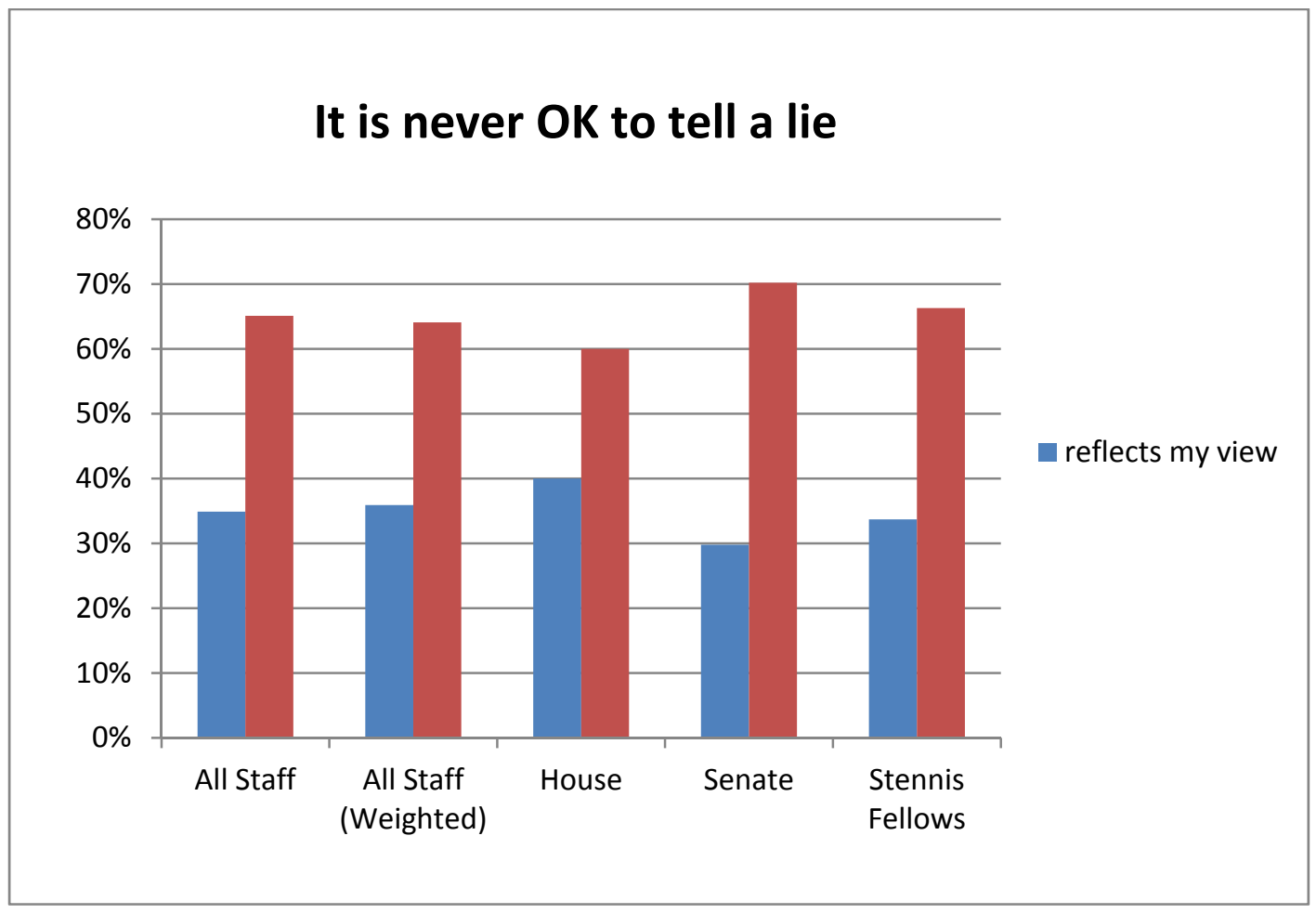


Respondents were asked to indicate whether the statement "it is never OK to tell a lie" reflected or did not reflect their views. Respondents overwhelmingly indicated that this did not reflect their views, while $30 \%$ to $40 \%$ indicated that it did reflect their views. Confidence intervals were calculated for each of the respondent groups. The widest confidence interval for the House was $\pm 8.8 \%$, for the Senate was $\pm 8.2 \%$, for all staffweighted was $\pm 6.1 \%$ and for Stennis Fellows was $\pm 7.7 \%$.

House staff (40\%) were more likely to respond that "it is never OK to tell a lie" than Senate staff (29.8\%) or Stennis Fellows (33.7\%). The two-sample, two-tailed t-statistic was not significant at the .05 level for the difference between House and Senate staff, $t(239)=.1 .66, p=.098$. The null hypothesis that there was no difference in the proportions between the House and Senate staff could not be rejected.

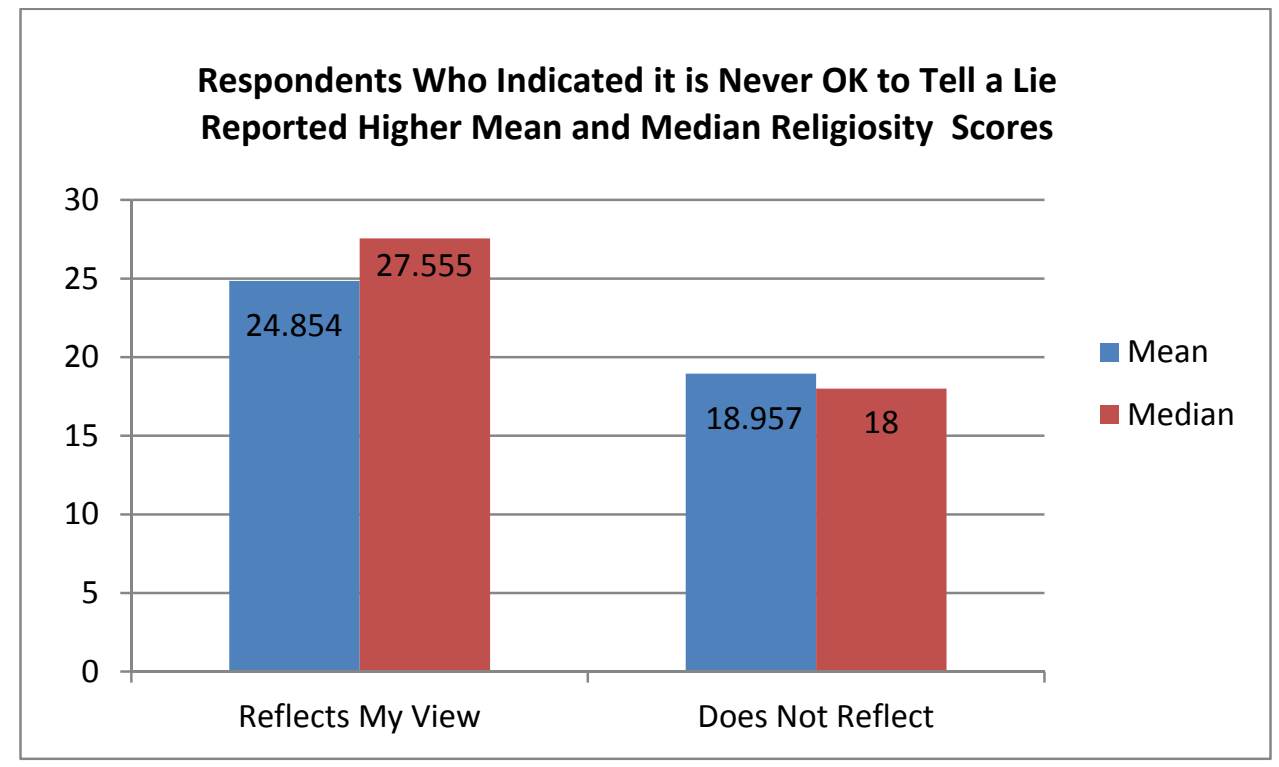

All staff-weighted respondents who indicated it was never OK to tell a lie reported higher mean and median religiosity scores. The two-sample, two-tailed t-statistic for the 
difference in mean religiosity scores between staff who indicated it is never OK to tell a lie and those who believed otherwise was significant at the .05 level, $t(234)=5.952$, $\mathrm{p}=.0000$.

A Mann-Whitney $U$ test also revealed a statistically significant difference in the religiosity of respondents who indicated this was a lie $(M d n=27.555, n=83)$ and those who indicated this was not a lie $(M d n=18.957, n=153), U=3549.4, z=-5.425, p=.000$.

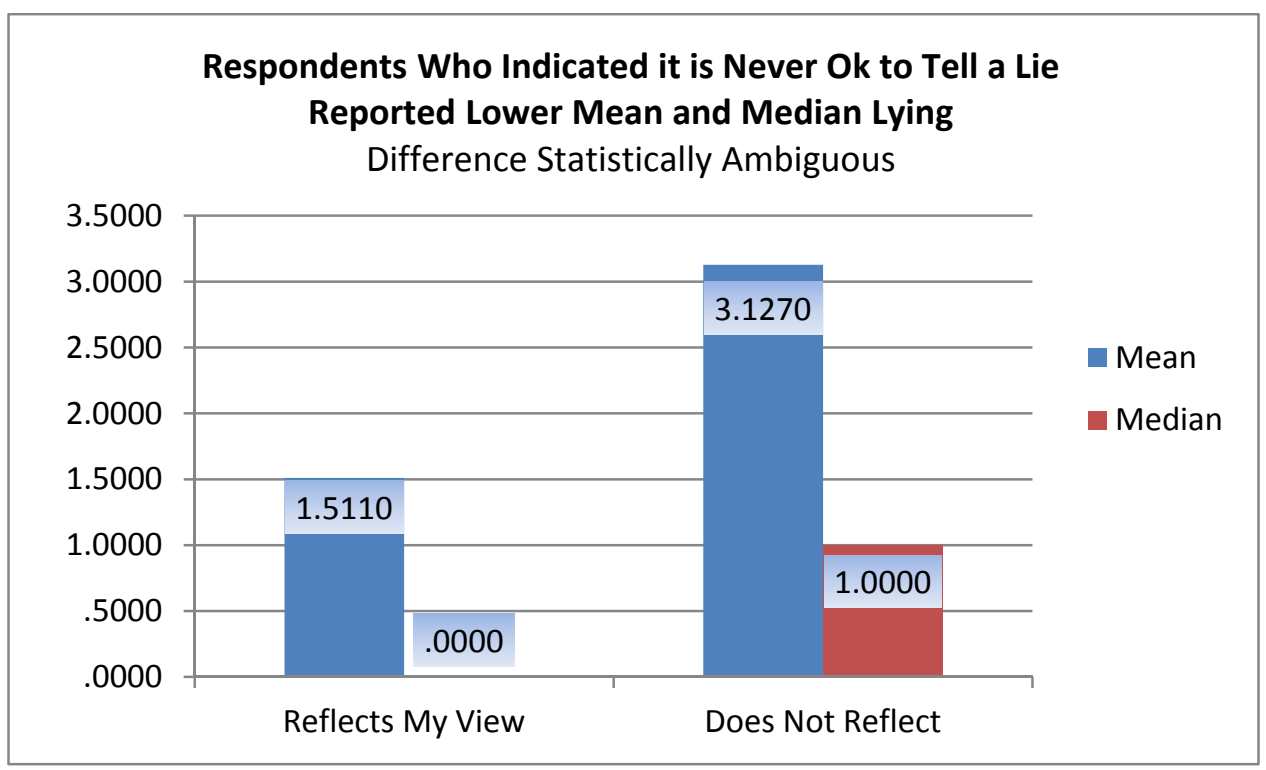

All staff-weighted respondents who indicated that it was never OK to tell a lie reported lower mean and median lying. The two-sample, two-tailed t-statistic for the difference in means was not significant at the .05 level, $t(194)=1.679, \mathrm{p}=.0948$. The null hypothesis that there is no difference in means cannot be rejected.

A Mann-Whitney U test, however, revealed a statistically significant medium effect difference in the number of lies told by respondents who indicated it was never OK to lie 
$(M d n=.000, n=72)$ and individuals who indicated this was not a lie $(M d n=1.0, n=124)$, $U=3198.5, z=-3.239, \mathrm{p}=.001, r=.232$.

We know from the earlier section on reported lying that the distribution of reported lying is not normal and that most lies are told by a relatively small percentage of respondents. As discussed earlier, the central limit theorem suggests, however, that with sample sizes exceeding 30 to 50, the sampling distribution of the mean should approximate a normal distribution regardless of the population distribution. Both samples exceed these parameters, so it is appropriate to accept the t-statistic which indicates that the null hypothesis cannot be rejected.

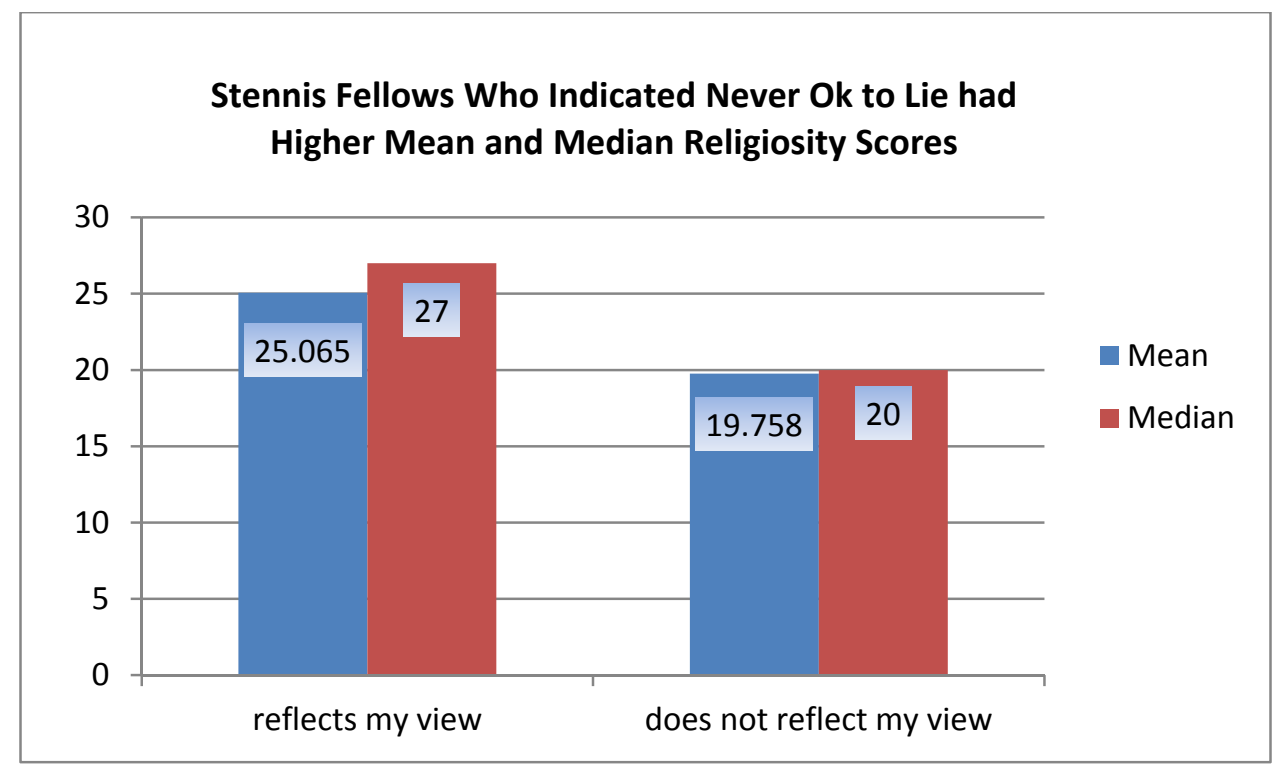

Stennis Fellows who agreed with the statement, "it is never OK to tell a lie" had higher mean and median religiosity scores than those who did not agree. The two-sample, twotailed t-statistic was significant at the .05 level for the difference in religiosity between the two groups, $t(91)=3.487, p=.0008$. The Mann-Whitney U Test also revealed a 
significant difference in religiosity between respondents who agreed $(M d n=27, n=31)$ and respondents who disagreed $(M d n=20, n=62), U=564, z=-3.240, p=.001, r=.336$.

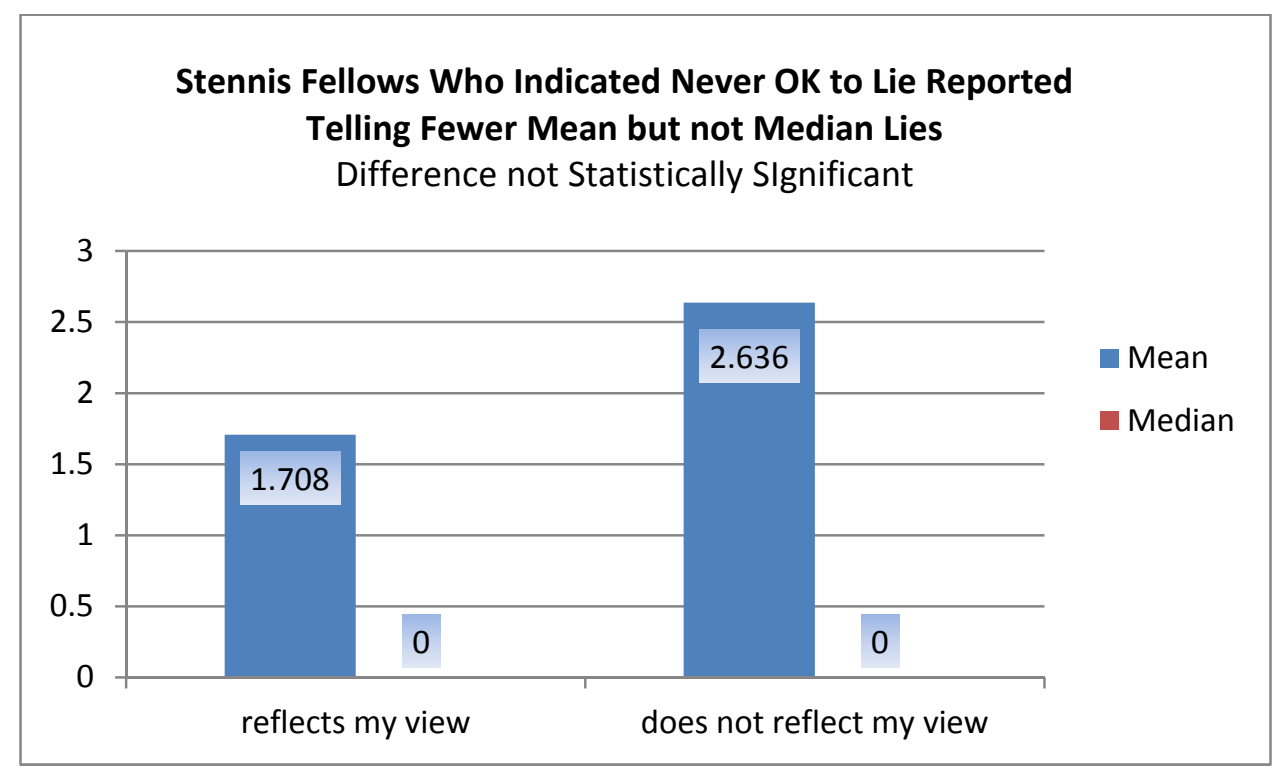

Stennis Fellows who indicated that they agreed with the statement that is never OK to lie reported telling fewer lies than those who indicated that they disagreed with the statement. The two-sample, two-tailed t-statistic was not significant at the .05 level for the difference in mean lies told, $t(66)=0.720, p=.474$. The Mann-Whitney U Test also revealed no significant difference between Fellows who agreed with the statement ( $M d n=0, n=24)$ and Fellows who disagreed with the statement ( $M d n=0, n=44), U=486.5$, $z=-.597, p=.550$. 
People have different ideas about whether lying is ever morally permissible. Which of the following statements most closely reflect your view?

It is never OK to tell a lie.

\begin{tabular}{|c|c|c|c|c|c|c|}
\hline \multicolumn{3}{|c|}{ Chamber } & \multirow{2}{*}{$\frac{\text { Frequency }}{48}$} & \multirow{2}{*}{$\frac{\text { Percent }}{25.9}$} & \multirow{2}{*}{$\frac{\text { Valid Percent }}{40.0}$} & \multirow{2}{*}{$\begin{array}{r}\begin{array}{l}\text { Cumulative } \\
\text { Percent }\end{array} \\
40.0\end{array}$} \\
\hline House & Valid & Reflects my View & & & & \\
\hline & & Does not Reflect my View & 72 & 38.9 & 60.0 & 100.0 \\
\hline & & Total & 120 & 64.9 & 100.0 & \\
\hline & Missing & System & 65 & 35.1 & & \\
\hline & Total & & 185 & 100.0 & & \\
\hline \multirow[t]{5}{*}{ Senate } & Valid & Reflects my View & 36 & 20.2 & 29.8 & 29.8 \\
\hline & & Does not Reflect my View & 85 & 47.8 & 70.2 & 100.0 \\
\hline & & Total & 121 & 68.0 & 100.0 & \\
\hline & Missing & System & 57 & 32.0 & & \\
\hline & Total & & 178 & 100.0 & & \\
\hline
\end{tabular}

People have different ideas about whether lying is ever morally permissible. Which of the following statements most closely reflects your view?

It is never OK to tell a lie.

\begin{tabular}{|c|c|c|c|c|c|}
\hline \multicolumn{2}{|c|}{ All Staff-weighted } & \multirow{2}{*}{$\frac{\text { Frequency }}{87}$} & \multirow{2}{*}{$\frac{\text { Percent }}{23.7}$} & \multirow{2}{*}{$\frac{\text { Valid Percent }}{35.9}$} & \multirow{2}{*}{$\begin{array}{c}\text { Cumulative } \\
\text { Percent }\end{array}$} \\
\hline Valid & Reflects my View & & & & \\
\hline & Does not Reflect my View & 154 & 42.3 & 64.1 & 100.0 \\
\hline & Total & 241 & 66.1 & 100.0 & \\
\hline Missing & System & 124 & 33.9 & & \\
\hline Total & & 364 & 100.0 & & \\
\hline
\end{tabular}

People have different ideas about whether lying is ever morally permissible. Which of the following statements most closely reflects your view?

It is never OK to tell a lie.

\begin{tabular}{|c|c|c|c|c|c|}
\hline \multicolumn{2}{|c|}{ ALL STAFF-unweighted } & \multirow{2}{*}{$\frac{\text { Frequency }}{84}$} & \multirow{2}{*}{$\frac{\text { Percent }}{23.1}$} & \multirow{2}{*}{$\frac{\text { Valid Percent }}{34.9}$} & \multirow{2}{*}{$\begin{array}{c}\begin{array}{c}\text { Cumulative } \\
\text { Percent }\end{array} \\
34.9\end{array}$} \\
\hline Valid & Reflects my View & & & & \\
\hline & Does not Reflect my View & 157 & 43.3 & 65.1 & 100.0 \\
\hline & Total & 241 & 66.4 & 100.0 & \\
\hline Missing & System & 122 & 33.6 & & \\
\hline Total & & 363 & 100.0 & & \\
\hline
\end{tabular}

People have different ideas about whether lying is ever morally permissible. Which of the following statements most closely reflects your view?

It is never OK to tell a lie.

\begin{tabular}{lccccc}
\hline Stennis Fellows & & & & \\
\hline \multicolumn{2}{l}{ Valid } & Reflects my View & 32 & 26.2 & Cumulative \\
& Does not Reflect my View & 63 & 51.6 & 63.7 & 33.7 \\
& Dercent
\end{tabular}




\begin{tabular}{llccc}
\hline & Total & 95 & 77.9 & 100.0 \\
Missing & System & 27 & 22.1 & \\
Total & & 122 & 100.0 & \\
\hline \hline
\end{tabular}

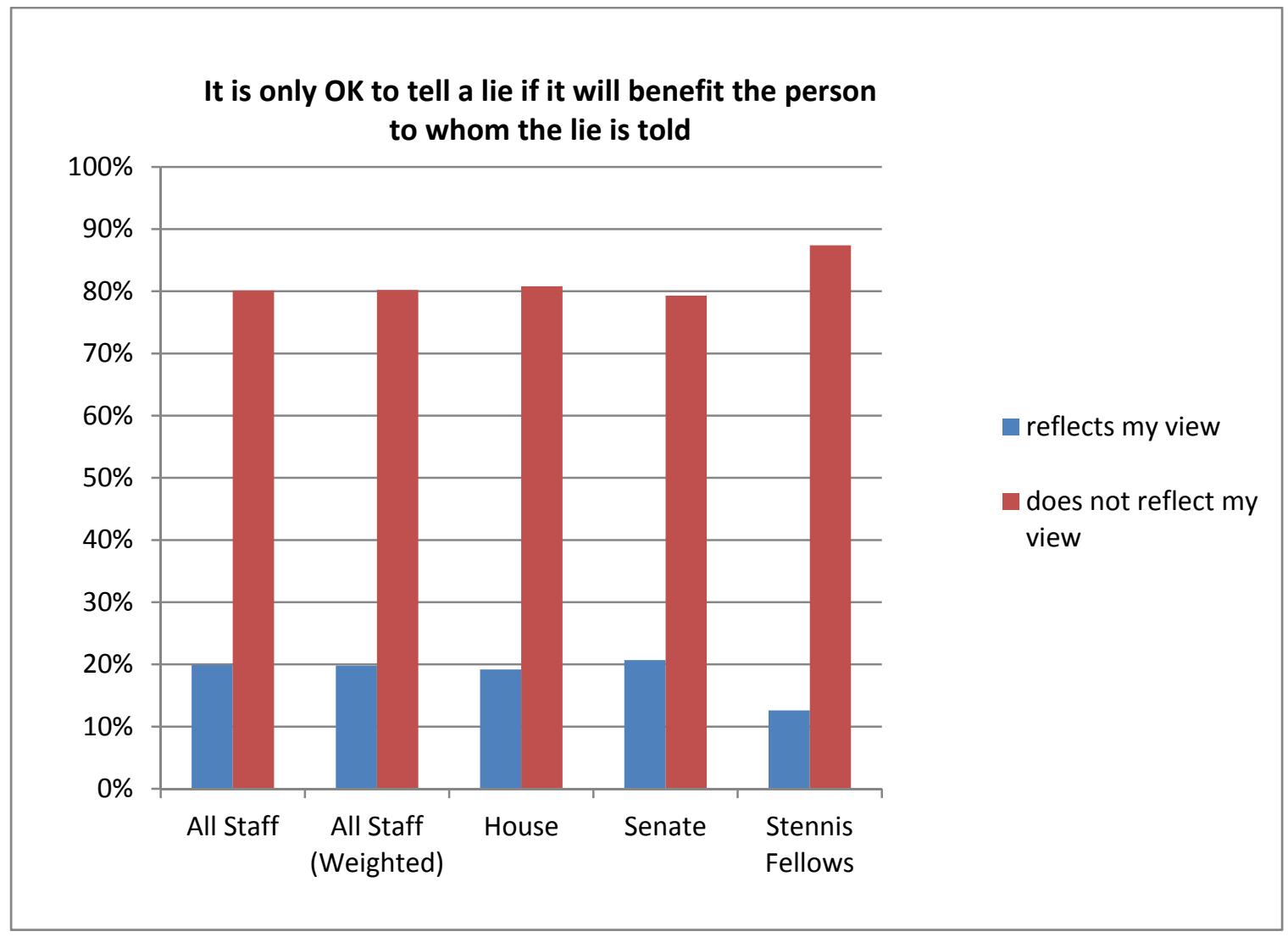

Respondents were asked whether "it is only OK to tell a lie if it will benefit the person to whom the lie is told." Staff overwhelmingly indicated this does not reflect their views. The question was originally drawn to identify individuals who believed that benefit to the individual was the primary justification for telling a lie. In hindsight, the word "only" makes it difficult to interpret the results. This formulation likely eliminated respondents who believe there is more than one justification for telling a lie. Nonetheless, $20 \%$ of Staff respondents and $13 \%$ of Stennis Fellows indicated this was the only justification for telling a lie. 
Confidence intervals were calculated for each of the respondent groups. The widest confidence interval for the House was $\pm 7.1 \%$, for the Senate was $\pm 7.2 \%$, for all staffweighted was $\pm 5.0 \%$ and for Stennis Fellows was $\pm 5.4 \%$.

Stennis Fellows (87.4\%) were slightly more likely to respond that "it is only OK to tell a lie if it will benefit the person to whom the lie is told" did not reflect their views than House $(83.2 \%)$ or Senate staff $(80.3 \%)$. The two-sample, two-tailed t-statistic was not significant at the .05 level for the difference between Stennis Fellows and Senate staff, $t(215)=1.4, p=.164$. The null hypothesis that there was no difference in the proportions between the Stennis Fellows and the Senate staff could not be rejected.

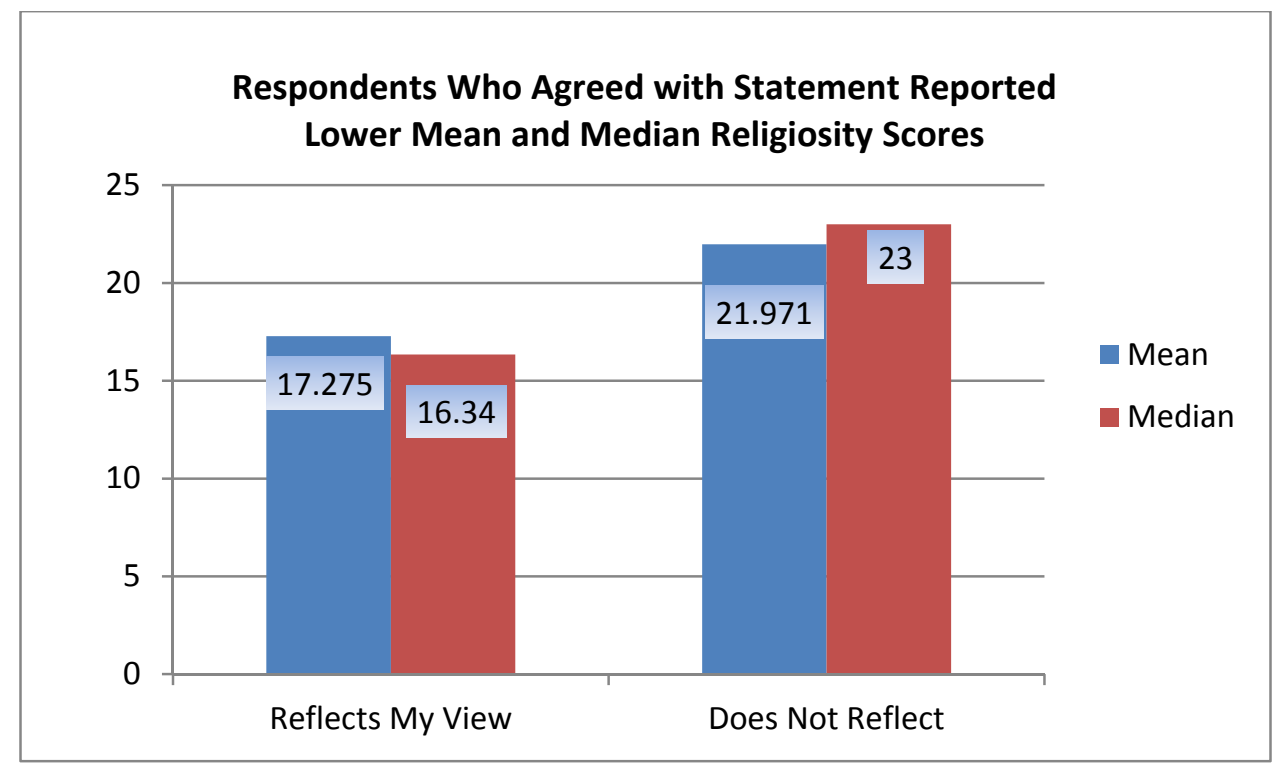

All staff-weighted respondents who indicated that the statement reflected their views reported lower mean and median religiosity scores. The two-sample, two-tailed tstatistic for the difference in mean religiosity scores between staff who indicated it is only 
OK to tell a lie if it will benefit the person to whom it is told and those for whom this did not reflect their view was significant at the .05 level, $t(234)=3.840, p=.0002$.

A Mann-Whitney $U$ test also revealed a statistically significant difference in the religiosity of respondents who indicated that it was only OK to tell a lie if it benefits the person to whom it is told $(M d n=16.34, n=48)$ and those who indicated this was not a lie $(M d n=23, n=188), U=2902.5, z=-3.816, p=.000$.

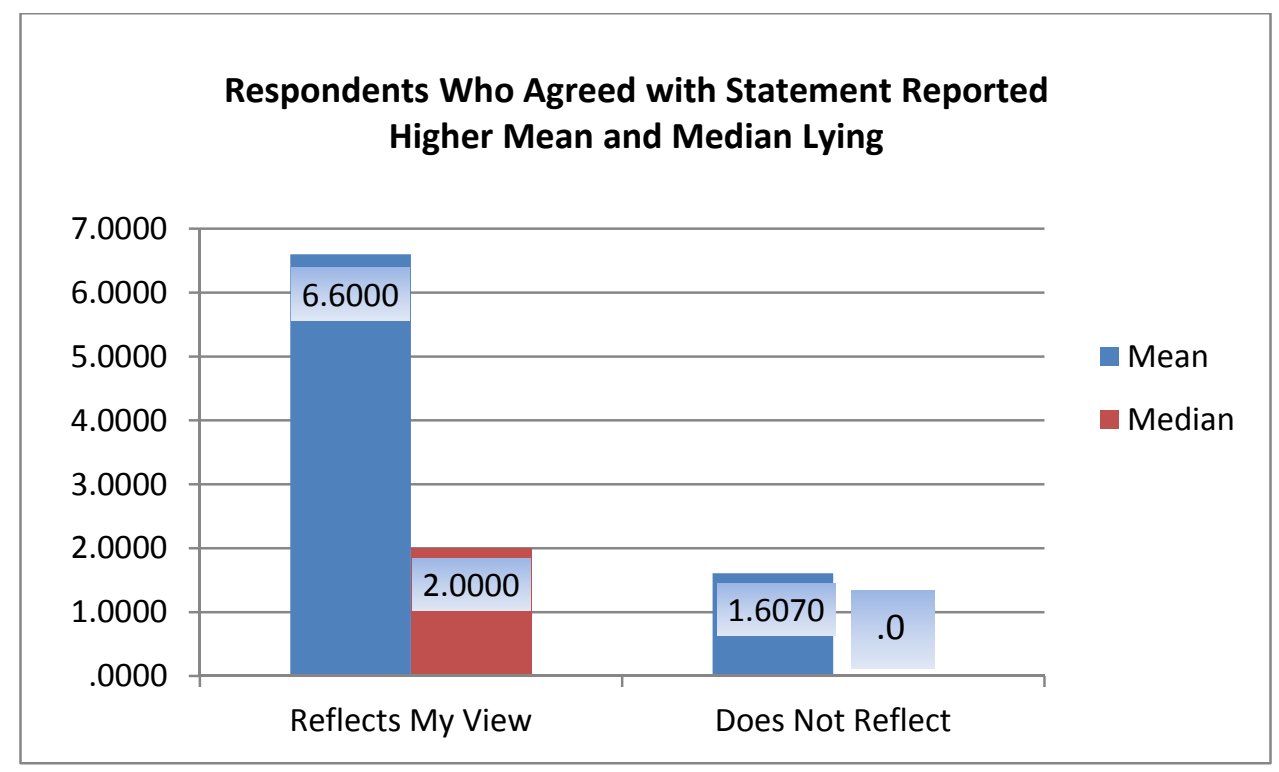

All staff-weighted respondents who indicated that it was only OK to tell a lie if it benefited the person to whom it was told reported lower mean and median lying. The two-sample, two-tailed t-statistic for the difference in means was significant at the .05 level, $t(234)=3.840, p=.0002$.

A Mann-Whitney $U$ test also revealed a statistically significant medium effect difference in the number of lies told by respondents who indicated it was only OK to lie if it will 
benefit the person to whom it is told $(M d n=2.0, n=36)$ and individuals who indicated this did not reflect their view $(M d n=.00, n=160), U=1913.5, z=-3.297, \mathrm{p}=.001, r=.225$.

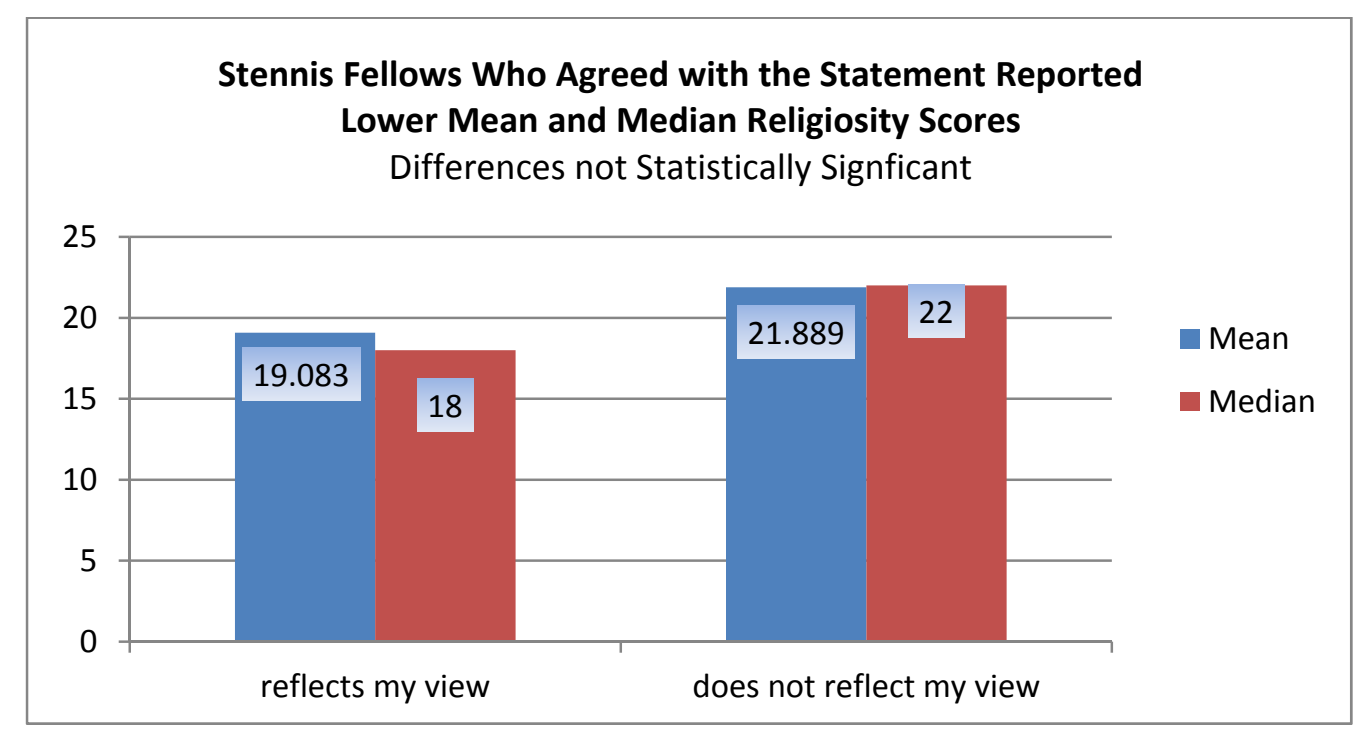

Stennis Fellows who agreed with the statement it is "only OK to tell a lie if it will benefit the person to whom the lie is told" had lower religiosity scores than Fellows who disagreed with the statement. The two-sample, two-tailed t-statistic was not significant at the .05 level for the difference in religiosity between the two groups, $t(91)=1.242$, $p=.2175$. The Mann-Whitney U Test also indicated there was no significant difference in religiosity between those who agreed with the statement $(M d n=18, n=12)$ and those who disagreed with the statement $(M d n=22, n=81), U=366, z=-1.377, p=.169$. 


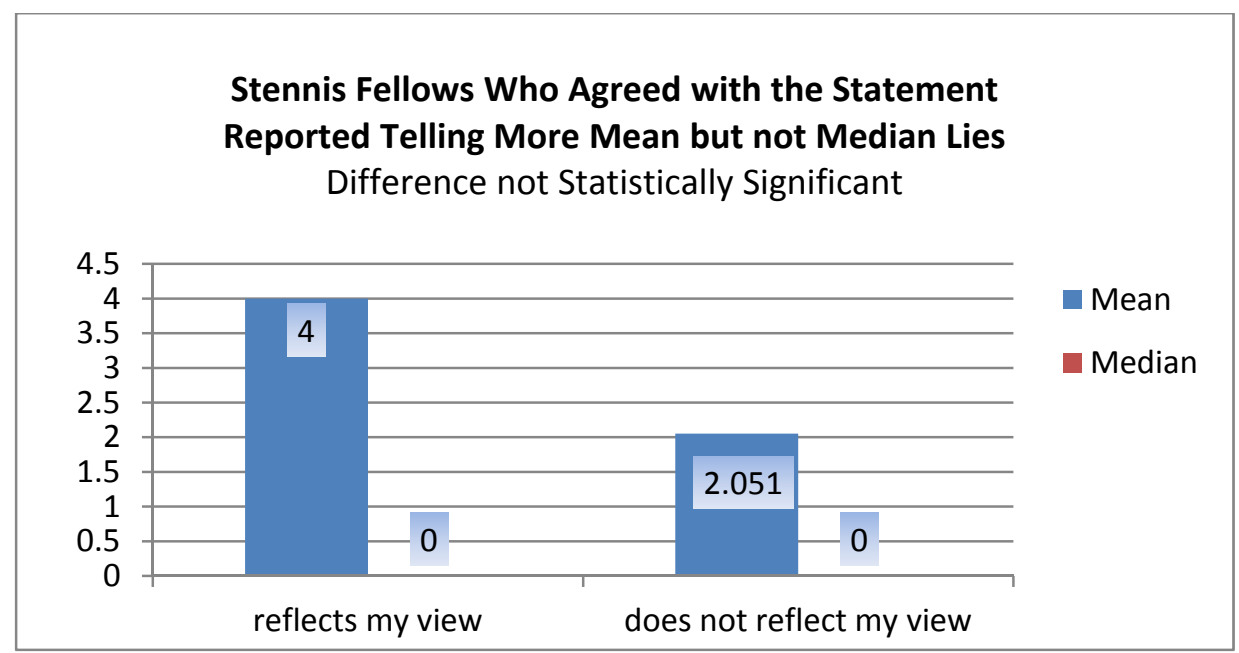

Stennis Fellows who agreed with the statement reported telling more mean lies but not more median lies than Stennis Fellows who did not agree with the statement. The twosample, two-tailed t-statistic was not significant at the .05 level for the difference in reported lying between the two groups, $t(66)=1.077, p=.2853$. The Mann-Whitney U Test also revealed no significant difference in reported lying between those who agreed with the statement $(M d n=0, n=9)$ and those who disagreed $(M d n=0, n=59), U=239.5$, $z=-.528, p=.598$.

People have different ideas about whether lying is ever morally permissible. Which of the following statements most closely reflect your view?

It is only OK to tell a lie if it will benefit the person to whom the lie is told.

\begin{tabular}{|c|c|c|c|c|c|c|}
\hline \multicolumn{3}{|c|}{ Chamber } & \multirow{2}{*}{$\frac{\text { Frequency }}{23}$} & \multirow{2}{*}{$\frac{\text { Percent }}{12.4}$} & \multirow{2}{*}{$\frac{\text { Valid Percent }}{19.2}$} & \multirow{2}{*}{$\begin{array}{c}\text { Cumulative } \\
\text { Percent }\end{array}$} \\
\hline House & Valid & Reflects my View & & & & \\
\hline & & Does not Reflect my View & 97 & 52.4 & 80.8 & 100.0 \\
\hline & & Total & 120 & 64.9 & 100.0 & \\
\hline & Missing & System & 65 & 35.1 & & \\
\hline & Total & & 185 & 100.0 & & \\
\hline \multirow[t]{5}{*}{ Senate } & Valid & Reflects my View & 25 & 14.0 & 20.7 & 20.7 \\
\hline & & Does not Reflect my View & 96 & 53.9 & 79.3 & 100.0 \\
\hline & & Total & 121 & 68.0 & 100.0 & \\
\hline & Missing & System & 57 & 32.0 & & \\
\hline & Total & & 178 & 100.0 & & \\
\hline
\end{tabular}


People have different ideas about whether lying is ever morally permissible. Which of the following statements most closely reflect your view?

It is only OK to tell a lie if it will benefit the person to whom the lie is told.

\begin{tabular}{|c|c|c|c|c|c|}
\hline \multicolumn{2}{|c|}{ ALL STAFF(Weighted) } & \multirow{2}{*}{$\frac{\text { Frequency }}{48}$} & \multirow{2}{*}{$\frac{\text { Percent }}{13.1}$} & \multirow{2}{*}{$\frac{\text { Valid Percent }}{19.8}$} & \multirow{2}{*}{$\begin{array}{c}\begin{array}{c}\text { Cumulative } \\
\text { Percent }\end{array} \\
19.8\end{array}$} \\
\hline Valid & Reflects my View & & & & \\
\hline & Does not Reflect my View & 193 & 53.0 & 80.2 & 100.0 \\
\hline & Total & 241 & 66.1 & 100.0 & \\
\hline Missing & System & 124 & 33.9 & & \\
\hline Total & & 364 & 100.0 & & \\
\hline
\end{tabular}

People have different ideas about whether lying is ever morally permissible. Which of the following statements most closely reflects your view?

It is only OK to tell a lie if it will benefit the person to whom the lie is told.

\begin{tabular}{|c|c|c|c|c|c|}
\hline \multicolumn{2}{|c|}{ ALL STAFF-unweighted } & \multirow{2}{*}{$\frac{\text { Frequency }}{48}$} & \multirow{2}{*}{$\frac{\text { Percent }}{13.2}$} & \multirow{2}{*}{$\frac{\text { Valid Percent }}{19.9}$} & \multirow{2}{*}{$\begin{array}{c}\begin{array}{c}\text { Cumulative } \\
\text { Percent }\end{array} \\
19.9\end{array}$} \\
\hline Valid & Reflects my View & & & & \\
\hline & Does not Reflect my View & 193 & 53.2 & 80.1 & 100.0 \\
\hline & Total & 241 & 66.4 & 100.0 & \\
\hline Missing & System & 122 & 33.6 & & \\
\hline Total & & 363 & 100.0 & & \\
\hline
\end{tabular}

People have different ideas about whether lying is ever morally permissible. Which of the following statements most closely reflects your view?

It is only OK to tell a lie if it will benefit the person to whom the lie is told

\begin{tabular}{llcccc}
\hline \hline Stennis Fellows & & & & Cumulative \\
Valid & Reflects my View & Frequency & Percent & Valid Percent & \begin{tabular}{c} 
Percent \\
\cline { 2 - 5 }
\end{tabular} \\
& Does not Reflect my View & 12 & 9.8 & 12.6 & 12.6 \\
& Total & 83 & 68.0 & 87.4 & 100.0 \\
Missing & System & 95 & 77.9 & 100.0 & \\
Total & 27 & 22.1 & \\
\hline \hline
\end{tabular}




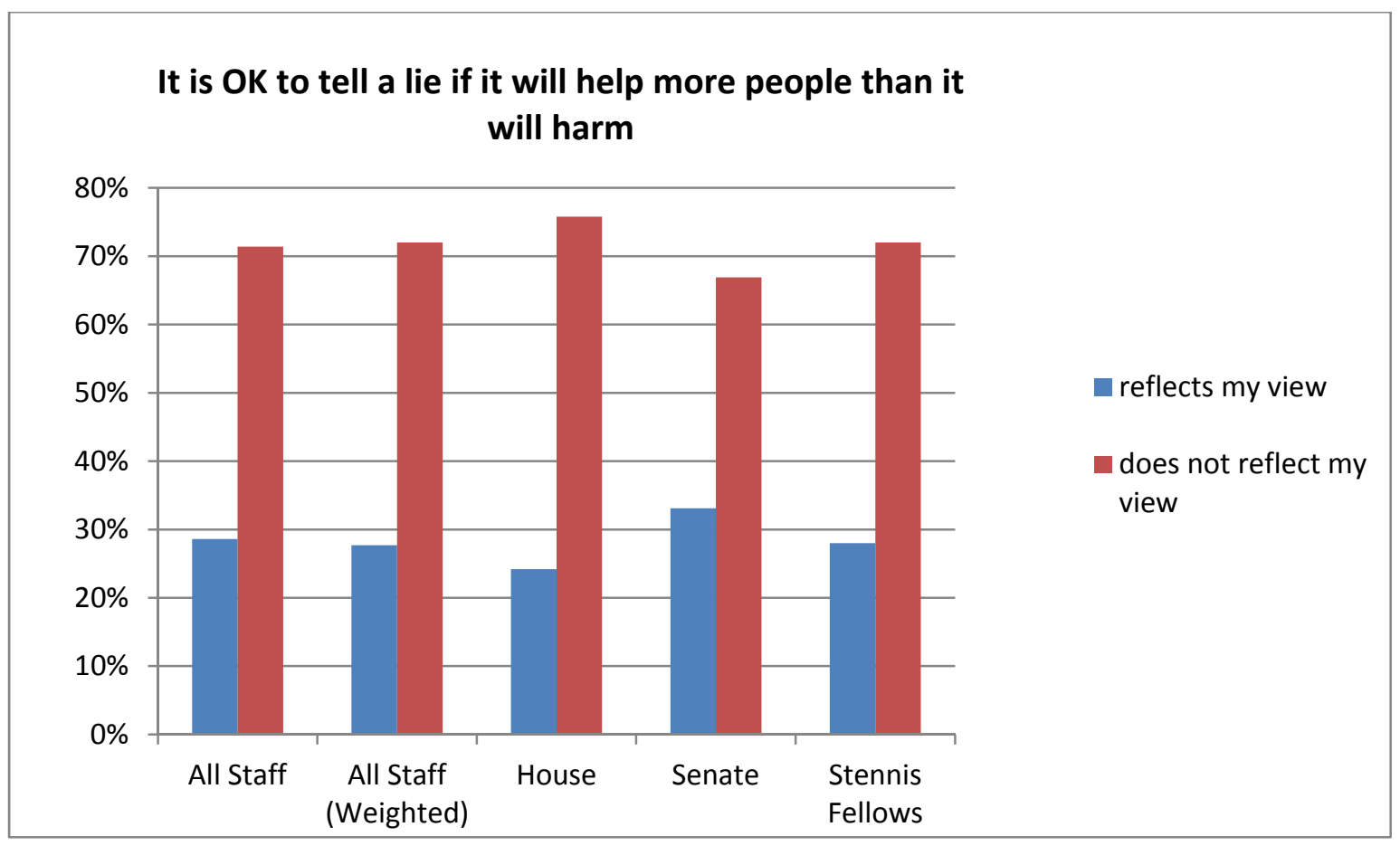

Respondents were asked whether they agreed with the statement, "it is OK to tell a lie if it will help more people than it will harm." The majority of respondents disagreed with this statement, while $24 \%$ to $33 \%$ agreed with it.

Confidence intervals were calculated for each of the respondent groups. The widest confidence interval for the House was $\pm 8.9 \%$, for the Senate was $\pm 10.4 \%$, for all staffweighted was $\pm 5.6 \%$, and for Stennis Fellows was $\pm 7.5 \%$.

House staff (75.8\%) were slightly more likely to respond that they disagree with the statement "It is OK to tell a lie if it will help more people than it will harm," than Senate staff $(66.9 \%)$ or Stennis Fellows (72\%). The t-statistic was not significant at the .05 level for the difference between House and Senate staff, $t(239)=1.53, p=.127$. The null 
hypothesis that there was no difference in the proportions between the Houses and Senate staff cannot be rejected.

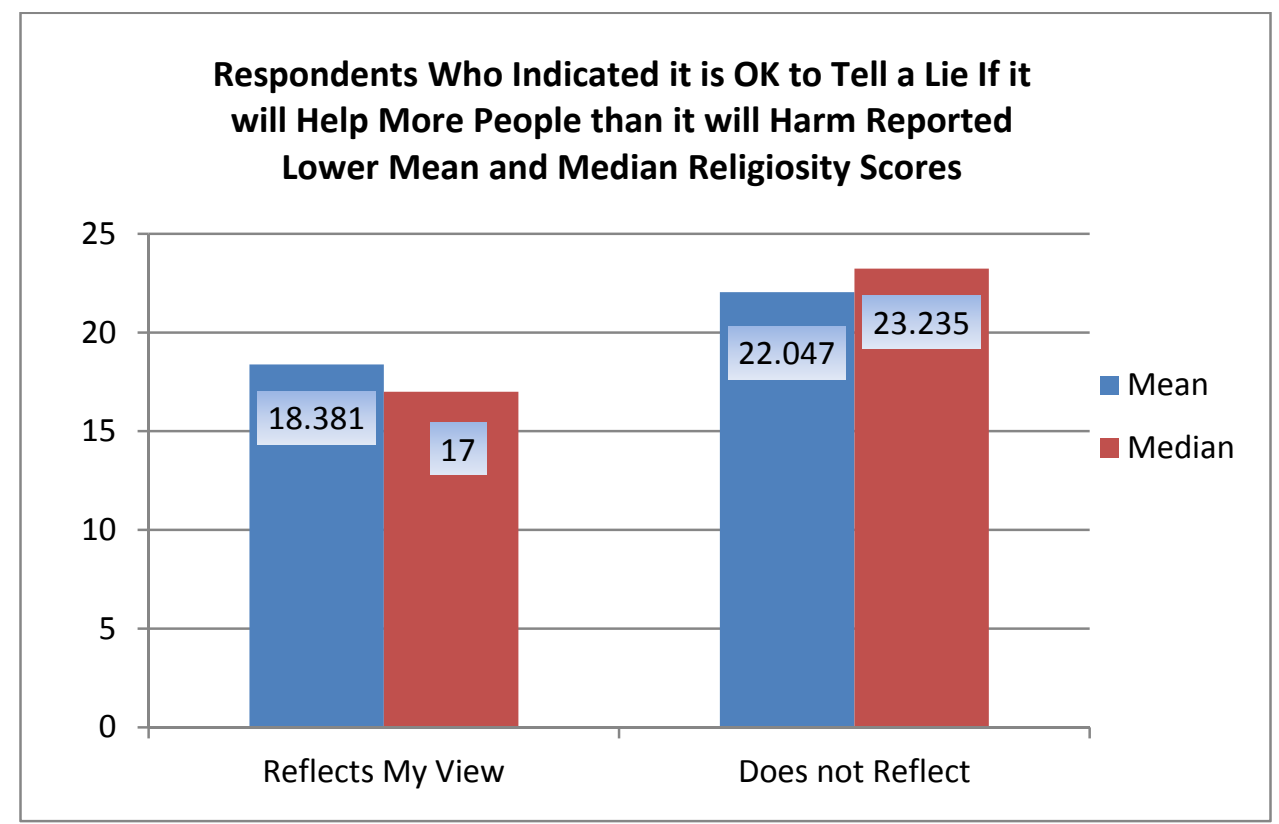

All staff-weighted respondents who indicated that the statement reflected their view reported lower mean and median religiosity scores. The two-sample, two-tailed tstatistic for the difference in mean religiosity scores between staff who indicated it is OK to tell a lie if it will help more people than it will harm and those for whom this did not reflect their view was significant at the .05 level, $t(234)=3.317, p=.0011$.

A Mann-Whitney U test also revealed a statistically significant difference in the religiosity of respondents who indicated that it was OK to tell a lie if it benefits more people than it will harm $(M d n=17, n=66)$ and those who indicated this did not reflect their view $(M d n=23.235, n=170), U=4099.5, z=-3.398, p=.001, r=.221$. 


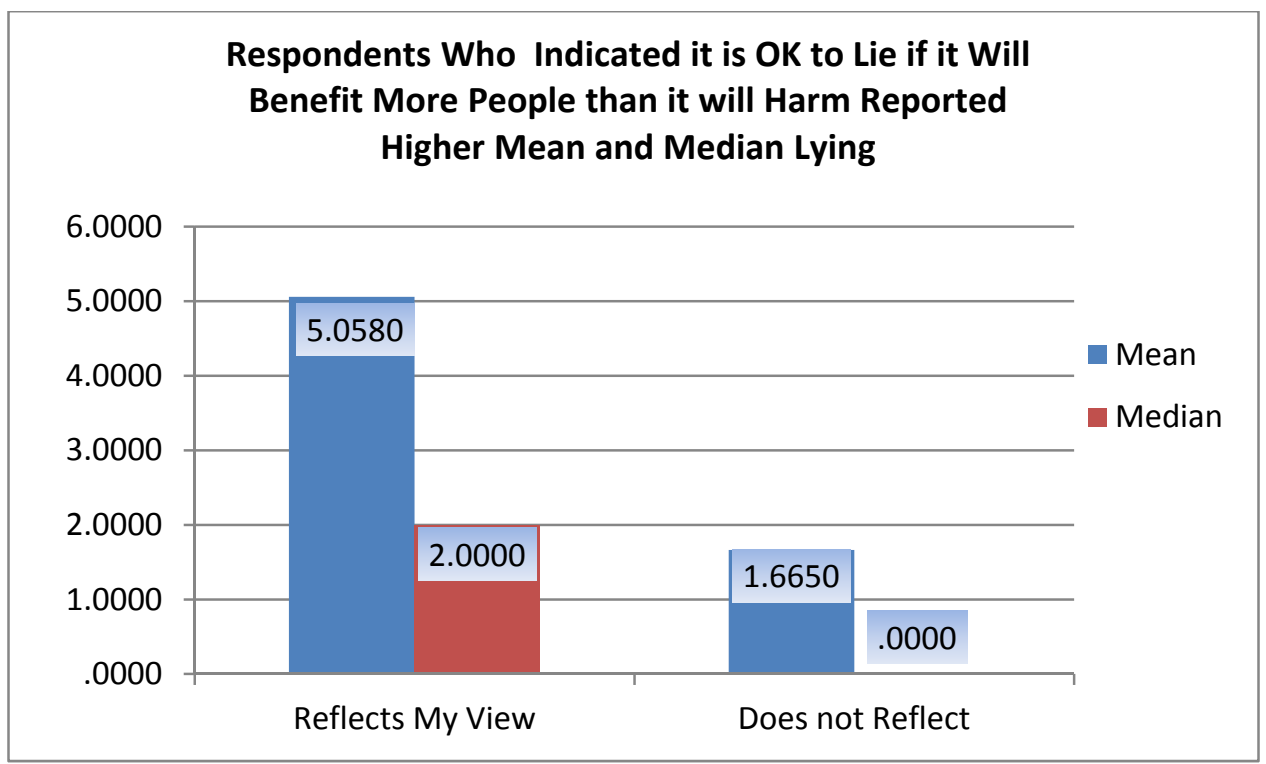

All staff-weighted respondents who indicated that it was OK to tell a lie if it will help more people than it will harm reported lower mean and median lying. The two-sample, two-tailed t-statistic for the difference in means was significant at the .05 level, $t$ $(194)=3.254, p=.0013$.

A Mann-Whitney $U$ test also revealed a statistically significant difference in lying by respondents who indicated it was OK to lie if it will benefit more people than it will harm $(M d n=2.0, n=50)$ and individuals who indicated this did not reflect their view $(M d n=.00$, $n=146), U=2506.5, z=-3.695, \mathrm{p}=.000, r=.265$. 


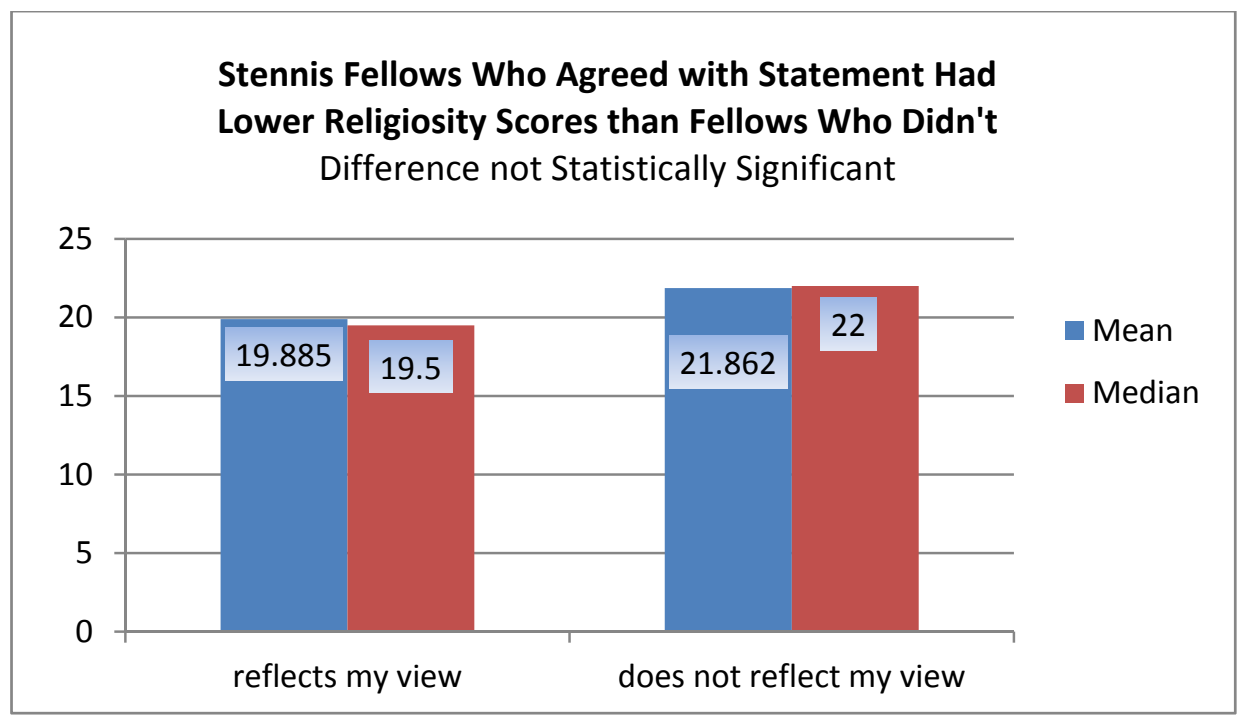

Stennis Fellows who agreed with the statement it is "OK to tell a lie if it will help more people than it will harm" reported lower mean and median religiosity scores than those who indicated this does not reflect their view. The two-sample, two-tailed t-statistic for the difference in mean religiosity was not significant at the .05 level for the fellows who agreed and those who disagreed, $t(89)=1.180, p=.2412$. The Mann-Whitney U Test also revealed no significant difference in religiosity between fellows who agreed $(M d n=19.5$, $n=26)$ and fellows who disagreed $(M d n=22, n=65), U=698.5 . z=-1.289, p=.197$.

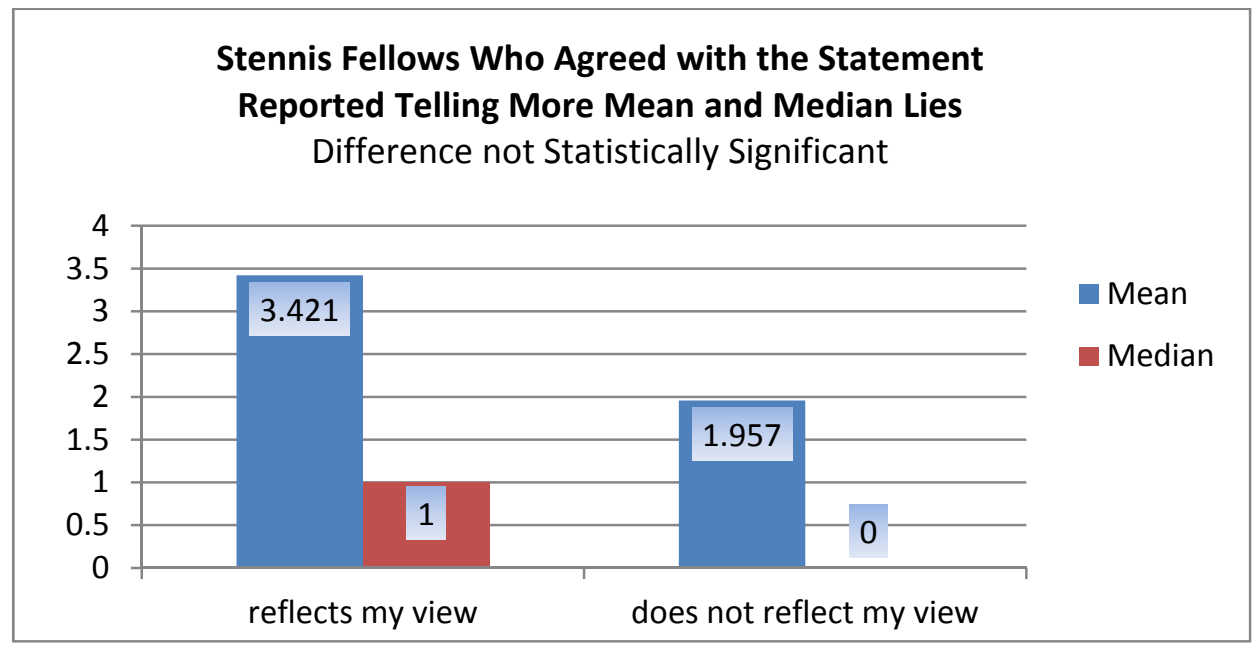


Stennis Fellows who agreed with the statement reported higher mean and median lying than fellows who did not. The two-sample, two-tailed t-statistic was not significant to the .05 level for the difference in reported lying between the groups, $t(64)=1.052, p=.2967$.

The Mann-Whitney U Test also revealed no significant difference in lying between fellows who agreed with the statement $(M d n=1, n=19)$ and fellows who did not agree $(M d n=0, n=47), U=332.5, z=-1.797, p=.072$.

People have different ideas about whether lying is ever morally permissible. Which of the following statements most closely reflect your views?

It is OK to tell a lie if it will help more people than it will harm.

\begin{tabular}{|c|c|c|c|c|c|c|}
\hline \multicolumn{3}{|c|}{ Chamber } & \multirow{2}{*}{$\frac{\text { Frequency }}{29}$} & \multirow{2}{*}{$\frac{\text { Percent }}{15.7}$} & \multirow{2}{*}{$\frac{\text { Valid Percent }}{24.2}$} & \multirow{2}{*}{$\begin{array}{c}\begin{array}{c}\text { Cumulative } \\
\text { Percent }\end{array} \\
24.2\end{array}$} \\
\hline House & Valid & Reflects my View & & & & \\
\hline & & Does not Reflect my View & 91 & 49.2 & 75.8 & 100.0 \\
\hline & & Total & 120 & 64.9 & 100.0 & \\
\hline & Missing & System & 65 & 35.1 & & \\
\hline & Total & & 185 & 100.0 & & \\
\hline \multirow[t]{5}{*}{ Senate } & Valid & Reflects my View & 40 & 22.5 & 33.1 & 33.1 \\
\hline & & Does not Reflect my View & 81 & 45.5 & 66.9 & 100.0 \\
\hline & & Total & 121 & 68.0 & 100.0 & \\
\hline & Missing & System & 57 & 32.0 & & \\
\hline & Total & & 178 & 100.0 & & \\
\hline
\end{tabular}

People have different ideas about whether lying is ever morally permissible. Which of the following statements most closely reflect your views?

It is OK to tell a lie if it will help more people than it will harm.

\begin{tabular}{|c|c|c|c|c|c|}
\hline \multicolumn{2}{|c|}{ All Staff-weighted } & \multirow{2}{*}{$\frac{\text { Frequency }}{67}$} & \multirow{2}{*}{$\frac{\text { Percent }}{18.3}$} & \multirow{2}{*}{$\frac{\text { Valid Percent }}{27.7}$} & \multirow{2}{*}{$\begin{array}{c}\begin{array}{c}\text { Cumulative } \\
\text { Percent }\end{array} \\
27.7\end{array}$} \\
\hline Valid & Reflects my View & & & & \\
\hline & Does not Reflect my View & 174 & 47.8 & 72.3 & 100.0 \\
\hline & Total & 241 & 66.1 & 100.0 & \\
\hline Missing & System & 124 & 33.9 & & \\
\hline Total & & 364 & 100.0 & & \\
\hline
\end{tabular}


People have different ideas about whether lying is ever morally permissible. Which of the following statements most closely reflects your views?

It is OK to tell a lie if it will help more people than it will harm.

\begin{tabular}{|c|c|c|c|c|c|}
\hline \multicolumn{2}{|c|}{ ALL STAFF-unweighted } & \multirow{2}{*}{$\frac{\text { Frequency }}{69}$} & \multirow{2}{*}{$\frac{\text { Percent }}{19.0}$} & \multirow{2}{*}{$\frac{\text { Valid Percent }}{28.6}$} & \multirow{2}{*}{$\begin{array}{c}\text { Cumulative } \\
\text { Percent } \\
28.6\end{array}$} \\
\hline Valid & Reflects my View & & & & \\
\hline & Does not Reflect my View & 172 & 47.4 & 71.4 & 100.0 \\
\hline & Total & 241 & 66.4 & 100.0 & \\
\hline Missing & System & 122 & 33.6 & & \\
\hline Total & & 363 & 100.0 & & \\
\hline
\end{tabular}

People have different ideas about whether lying is ever morally permissible. Which of the following statements most closely reflects your views?

It is OK to tell a lie if it will help more people than it will harm.

\begin{tabular}{llcccc}
\hline \hline Stennis Fellows & & & & Cumulative \\
Valid & Reflects my View & Frequency & Percent & Valid Percent & Percent \\
& Does not Reflect my View & 26 & 21.3 & 28.0 & 28.0 \\
& Total & 67 & 54.9 & 72.0 & 100.0 \\
\multirow{2}{*}{ Missing } & System & 93 & 76.2 & 100.0 & \\
Total & & 29 & 23.8 & \\
\hline \hline
\end{tabular}

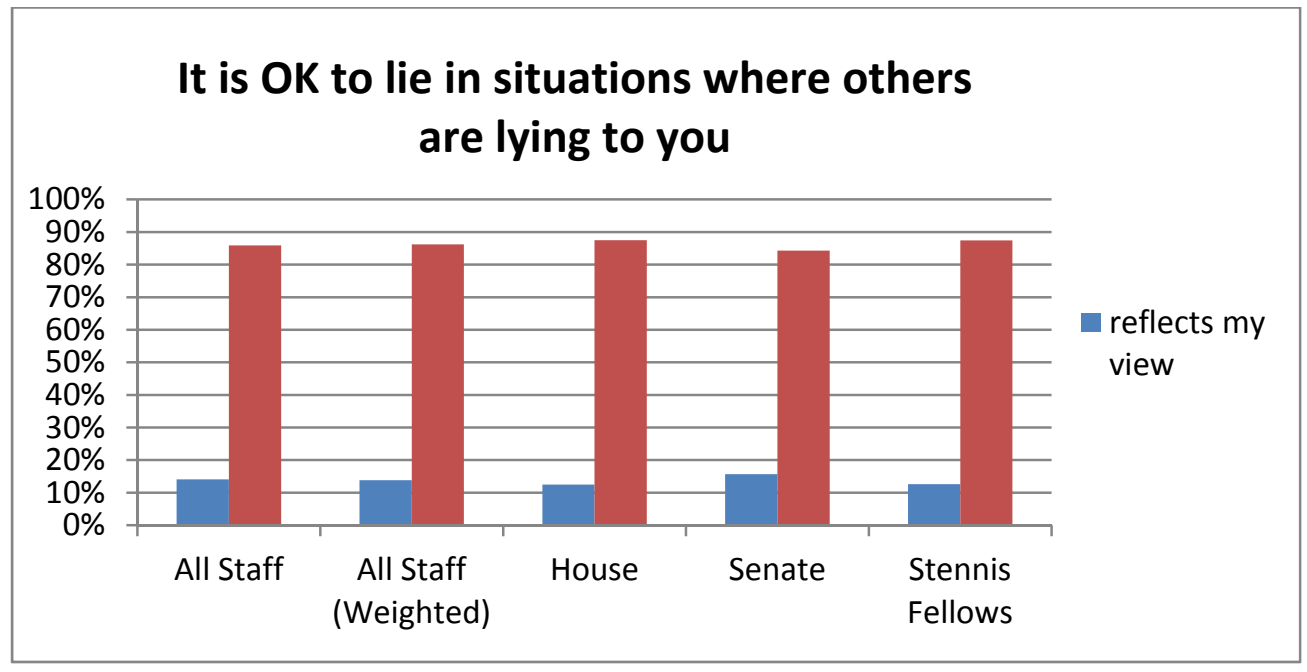

Respondents were asked whether the statement it is " $\mathrm{OK}$ to lie in situations where others are lying to you" reflected their view. The statement was designed to identify individuals who believed that "defensive" lying might be justified. Cramton and Dees posit that lying is commonplace in business negotiations and offer the Mutual Trust Principle as a 
way of explaining and limiting lying in this context. As a result, it might be expected that this statement would appeal to a substantial proportion of respondents. In actuality, however, a strong majority of respondents did not agree with the statement. Only 13$16 \%$ of respondents indicated that this did reflect their view. This discrepancy between the responses to this question and the frequency posited by Cramton and Dees could reflect the absence of context provided later in the cases.

Confidence intervals were calculated for each of the respondent groups. The widest confidence interval for the House was $\pm 6.4 \%$, for the Senate was $\pm 7.1 \%$, for all staffweighted was $\pm 4.7 \%$ and for Stennis Fellows was $\pm 6 \%$.

House staff (87.5\%) were slightly more likely to respond that they disagree with the statement "it is OK to tell a lie in situations where others are lying to you," than Senate staff (84.3\%) or Stennis Fellows (87.4\%). The t-statistic was not significant at the .05 level for the difference between House and Senate staff, $t(239)=.71, p=.48$. The null hypothesis that there was no difference in the proportions between the Houses and Senate staff cannot be rejected. 


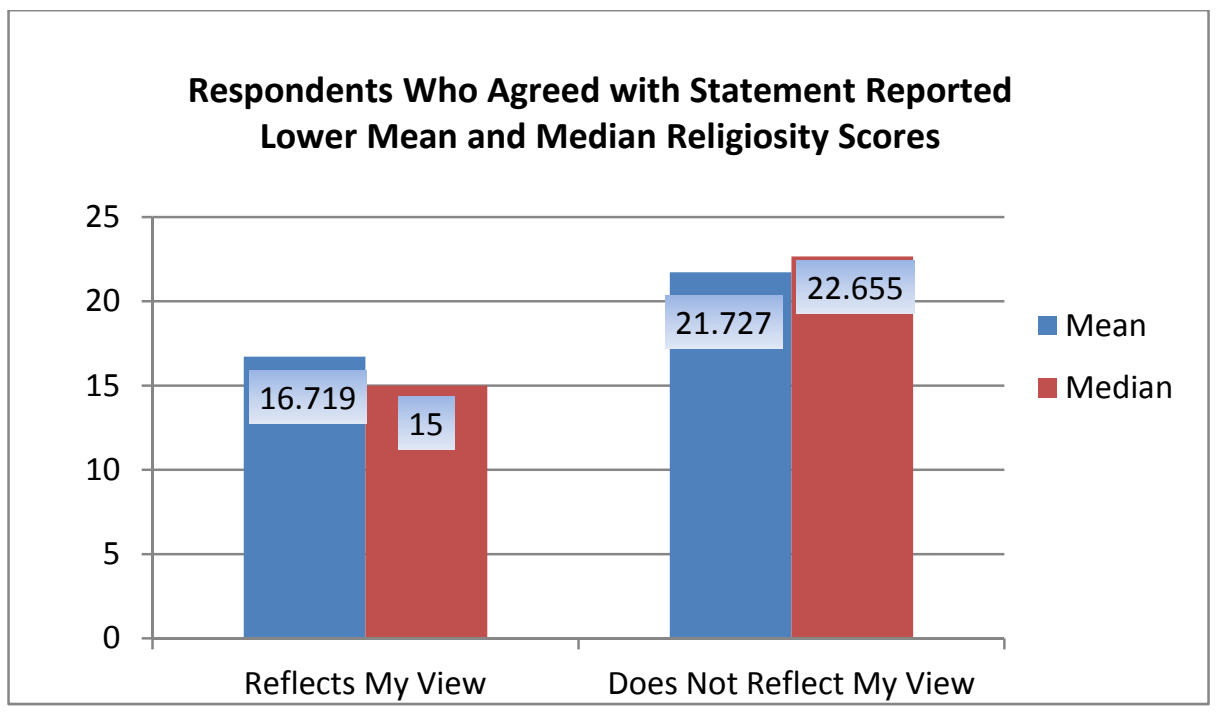

All staff-weighted respondents who indicated that the statement reflected their view reported lower mean and median religiosity scores. The two-sample, two-tailed tstatistic for the difference in mean religiosity scores between staff who indicated it is OK to tell a lie in situations where others are lying to you and those for whom this did not reflect their view was significant at the .05 level, $t(233)=3.510, p=.0005$.

A Mann-Whitney $U$ test also revealed a statistically significant difference in the religiosity of respondents who indicated that it was OK to tell a lie if others are lying to you $(M d n=15, n=33)$ and those who indicated this did not reflect their view $(M d n=22.655, n=202), U=2101.5, z=-3.622, p=.000, r=.236$. 


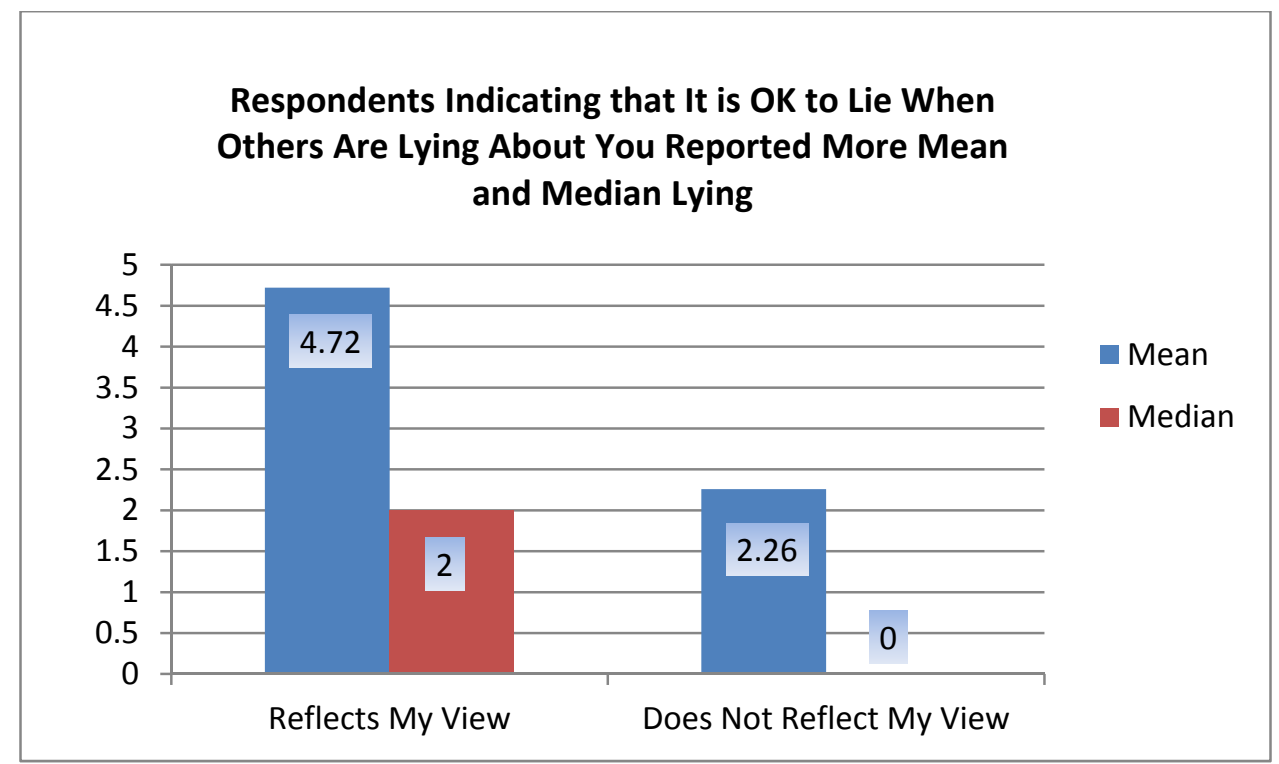

All staff-weighted respondents who indicated that it was OK to tell a lie in situations where someone is lying to you reported higher mean and median lying. The two-sample, two-tailed t-statistic for the difference in means was not significant at the .05 level, $t(194)=1.672, p=.0962$.

A Mann-Whitney $U$ test, however, revealed a statistically significant difference in the number of lies told by respondents who indicated it was $\mathrm{OK}$ to lie if someone is lying to you $(M d n=2.0, n=22)$ and individuals who indicated this did not reflect their view $(M d n=.00, n=174), U=1355.0, z=-2.336, \mathrm{p}=.019, r=.167$.

The two-sample, two-tailed t-statistic requires that the sample distribution of means can be assumed to be normal. As discussed earlier, this threshold can be assumed to be met with sample sizes that exceed 30 to 50 . The two-samples in this analysis do not meet this threshold. As a result, it is appropriate to accept the results of the nonparametric MannWhitney U test. 


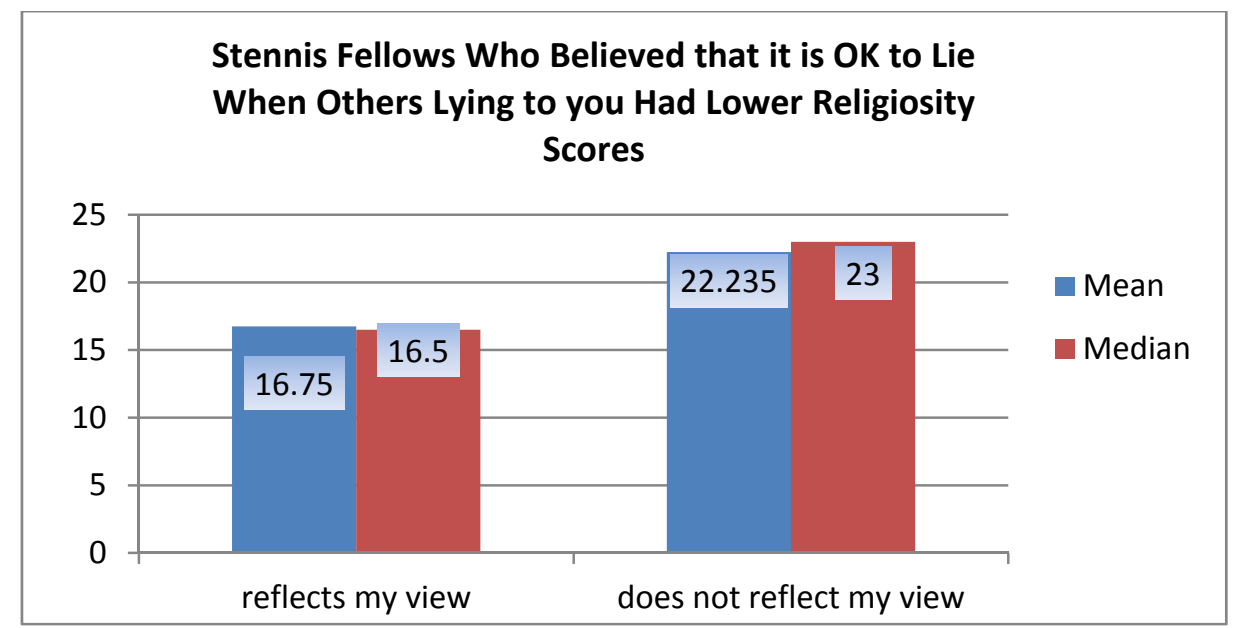

Stennis Fellows who indicated that they agree with the statement "it is OK to lie in situations where others are lying to you" had lower religiosity scores than those who disagreed with the statement. The two-sample, two-tailed t-statistic for the difference in mean religiosity was significant at the .05 level, $t(91)=2.487, p=.015$. The MannWhitney U Test was also revealed a significant difference in religiosity between fellows who agreed with the statement $(\mathrm{Mdn}=16.5, \mathrm{n}=12)$ and fellows who disagreed $(\mathrm{Mdn}=23$, $\mathrm{n}-81), \mathrm{U}=353, \mathrm{z}=-2.421, \mathrm{p}=.015, \mathrm{r}=.25$.

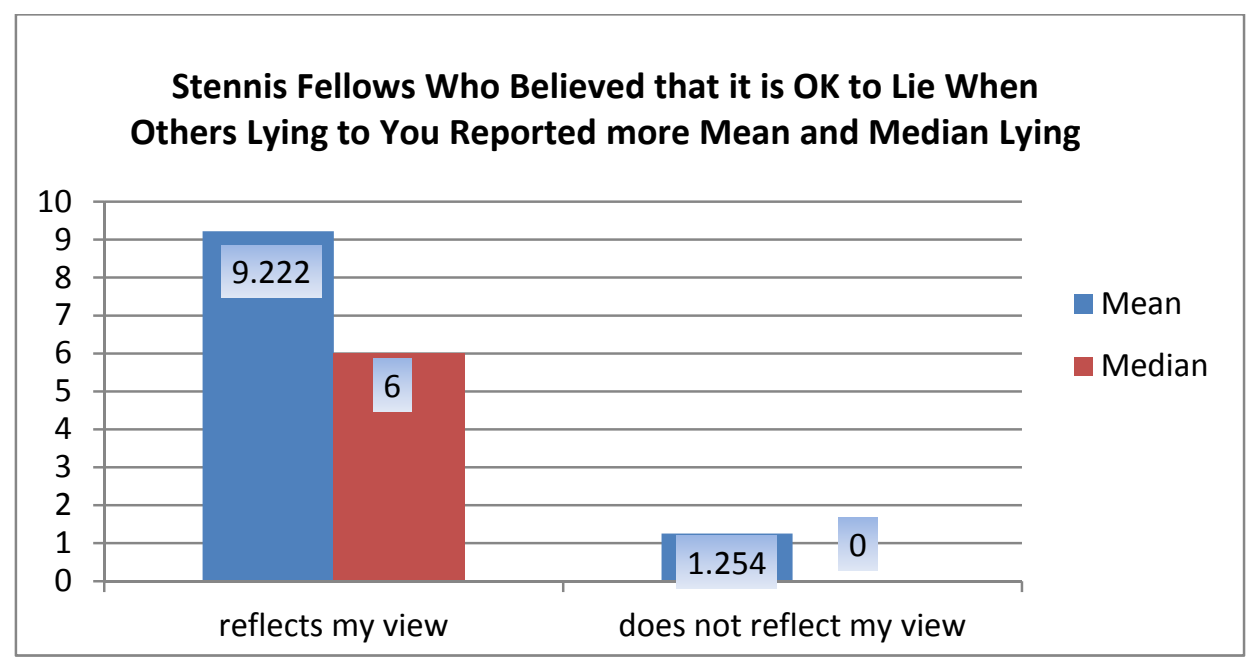


Stennis Fellows who indicated that they agree with the statement also reported telling more mean and median lies than fellows who disagreed. The two-sample, two-tailed tstatistic was signifcant at the .05 level for the difference in mean lying, $t(66)=5.177$, $p=.0000$. The Mann-Whitney U Test also revealed a significant difference between the fellows who agreed with the statement $(\operatorname{Mdn}=6, n=9)$ "it is OK to lie in situations where others are lying to you" and fellows who disagreed with the statement ( $M d n=0, n=59)$, $\mathrm{U}=59, \mathrm{z}=-4.192, \mathrm{p}=.000, \mathrm{r}=.508$.

People have different ideas about whether lying is ever morally permissible. Which of the following statements most closely reflect your view?

It is OK to lie in situations where others are lying to you.

\begin{tabular}{|c|c|c|c|c|c|c|}
\hline \multicolumn{3}{|c|}{ Chamber } & \multirow{2}{*}{$\frac{\text { Frequency }}{15}$} & \multirow{2}{*}{$\frac{\text { Percent }}{8.1}$} & \multirow{2}{*}{$\frac{\text { Valid Percent }}{12.5}$} & \multirow{2}{*}{$\begin{array}{c}\begin{array}{c}\text { Cumulative } \\
\text { Percent }\end{array} \\
12.5\end{array}$} \\
\hline House & Valid & Reflects my View & & & & \\
\hline & & Does not Reflect my View & 105 & 56.8 & 87.5 & 100.0 \\
\hline & & Total & 120 & 64.9 & 100.0 & \\
\hline & Missing & System & 65 & 35.1 & & \\
\hline & Total & & 185 & 100.0 & & \\
\hline \multirow[t]{5}{*}{ Senate } & Valid & Reflects my View & 19 & 10.7 & 15.7 & 15.7 \\
\hline & & Does not Reflect my View & 102 & 57.3 & 84.3 & 100.0 \\
\hline & & Total & 121 & 68.0 & 100.0 & \\
\hline & Missing & System & 57 & 32.0 & & \\
\hline & Total & & 178 & 100.0 & & \\
\hline
\end{tabular}

People have different ideas about whether lying is ever morally permissible. Which of the following statements most closely reflect your view?

It is OK to lie in situations where others are lying to you.

\begin{tabular}{|c|c|c|c|c|c|}
\hline \multicolumn{2}{|c|}{ All Staff-weighted } & \multirow{2}{*}{$\frac{\text { Frequency }}{33}$} & \multirow{2}{*}{$\frac{\text { Percent }}{9.1}$} & \multirow{2}{*}{$\frac{\text { Valid Percent }}{13.8}$} & \multirow{2}{*}{$\begin{array}{c}\begin{array}{c}\text { Cumulative } \\
\text { Percent }\end{array} \\
13.8\end{array}$} \\
\hline Valid & Reflects my View & & & & \\
\hline & Does not Reflect my View & 208 & 57.0 & 86.2 & 100.0 \\
\hline & Total & 241 & 66.1 & 100.0 & \\
\hline Missing & System & 124 & 33.9 & & \\
\hline Total & & 364 & 100.0 & & \\
\hline
\end{tabular}


People have different ideas about whether lying is ever morally permissible. Which of the following statements most closely reflect your view?

It is OK to lie in situations where others are lying to you.

\begin{tabular}{|c|c|c|c|c|c|}
\hline \multicolumn{2}{|c|}{ ALL Staff-unweighted } & \multirow{2}{*}{$\frac{\text { Frequency }}{34}$} & \multirow{2}{*}{$\frac{\text { Percent }}{9.4}$} & \multirow{2}{*}{$\frac{\text { Valid Percent }}{14.1}$} & \multirow{2}{*}{$\begin{array}{c}\begin{array}{c}\text { Cumulative } \\
\text { Percent }\end{array} \\
14.1\end{array}$} \\
\hline Valid & Reflects my View & & & & \\
\hline & Does not Reflect my View & 207 & 57.0 & 85.9 & 100.0 \\
\hline & Total & 241 & 66.4 & 100.0 & \\
\hline Missing & System & 122 & 33.6 & & \\
\hline Total & & 363 & 100.0 & & \\
\hline
\end{tabular}

People have different ideas about whether lying is ever morally permissible. Which of the following statements most closely reflects your view?

It is OK to lie in situations where others are lying to you

\begin{tabular}{llcccc}
\hline \hline Stennis & Fellows & & & & Cumulative \\
Palid & Reflects my View & Frequency & Percent & Valid Percent & \begin{tabular}{c} 
Percent \\
\cline { 2 - 5 }
\end{tabular} \\
& Does not Reflect my View & 12 & 9.8 & 12.6 & 12.6 \\
& Total & 83 & 68.0 & 87.4 & 100.0 \\
Missing & System & 95 & 77.9 & 100.0 & \\
Total & & 27 & 22.1 & & \\
& & 122 & 100.0 &
\end{tabular}

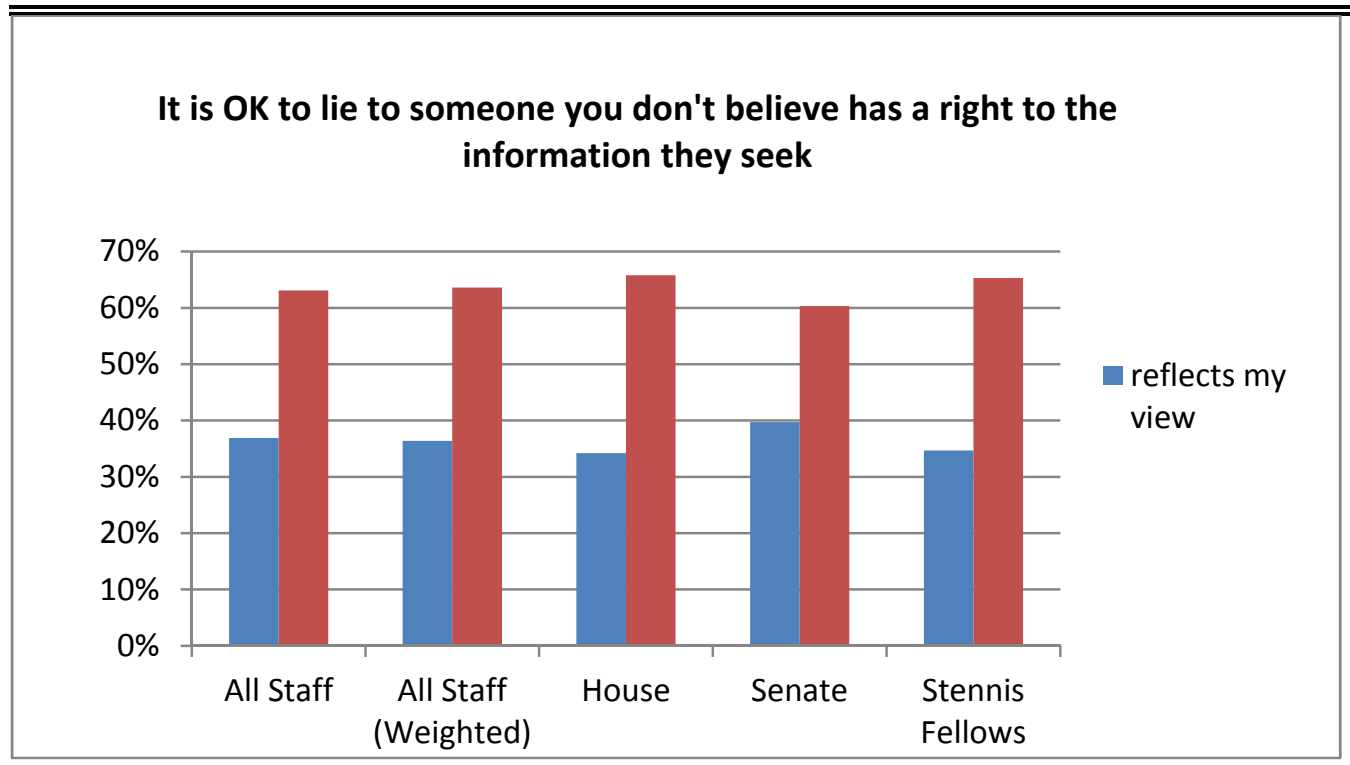

Respondents were asked whether they agreed with the statement "it is all right to lie to someone you don't believe has a right to the information they seek." The majority of respondents disagreed with this statement, while $34-40 \%$ of respondents agreed with it. 
The application of this justification was further tested in the case regarding classified information.

Confidence intervals were calculated for each of the respondent groups. The widest confidence interval for the House was $\pm 8.6 \%$, for the Senate was $\pm 8.7 \%$, for all staffweighted was $\pm 6.1 \%$ and for Stennis Fellows was $\pm 7.8 \%$.

Senate staff $(39.7 \%)$ were slightly more likely to respond that they agree with the statement, "it is OK to tell a lie to someone you don't believe has a right to the information they seek," than House staff (34.2\%) or Stennis Fellows (34.7\%). The tstatistic was not significant at the .05 level for the difference between House and Senate staff, $t(239)=.88, p=.38$. The null hypothesis that there was no difference in the proportions between the House and Senate staff cannot be rejected.

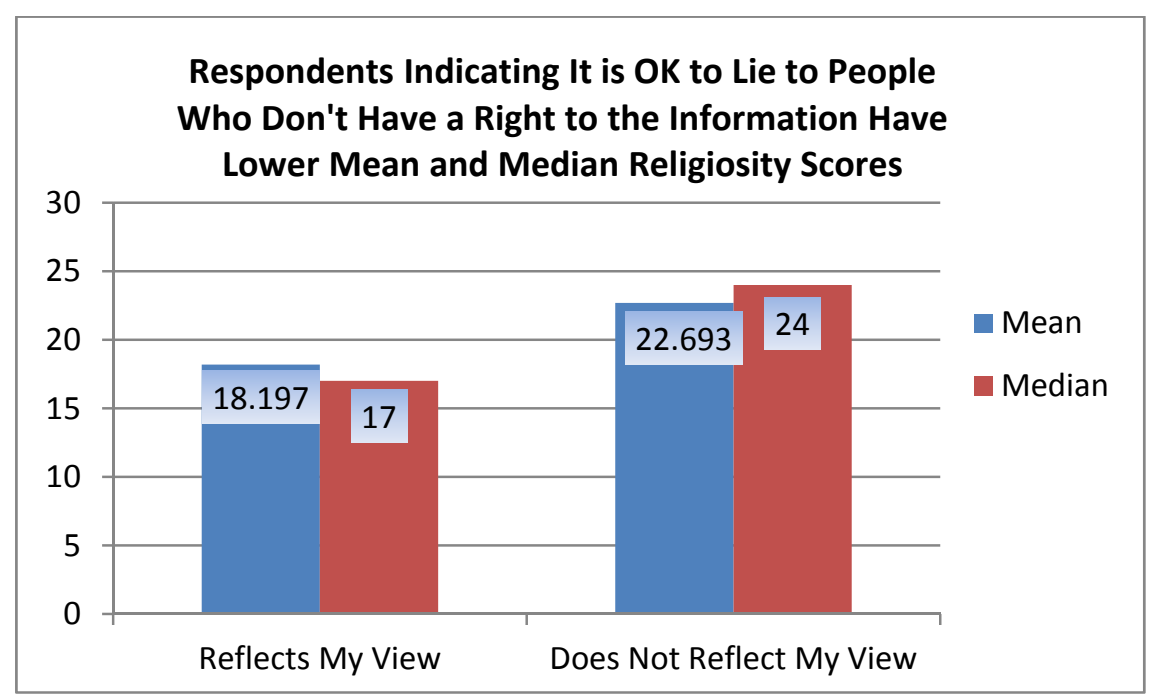


All staff-weighted respondents who indicated that the statement "it is OK to lie to someone you don't believe has a right to the information they seek" reflected their view reported lower mean and median religiosity scores. The two-sample, two-tailed tstatistic for the difference in mean religiosity scores between staff who indicated this represented their view and for those for whom this did not reflect their view was significant at the .05 level, $t(234)=4.462, \mathrm{p}=.0000$.

A Mann-Whitney $U$ test also revealed a statistically significant difference in the religiosity of respondents who indicated that it was OK to lie to people who don't have a right to the information they seek $(M d n=17, n=88)$ and those who indicated this did not reflect their view $(M d n=24, n=148), U=4340, z=-4.335, p=.000, r=.282$.

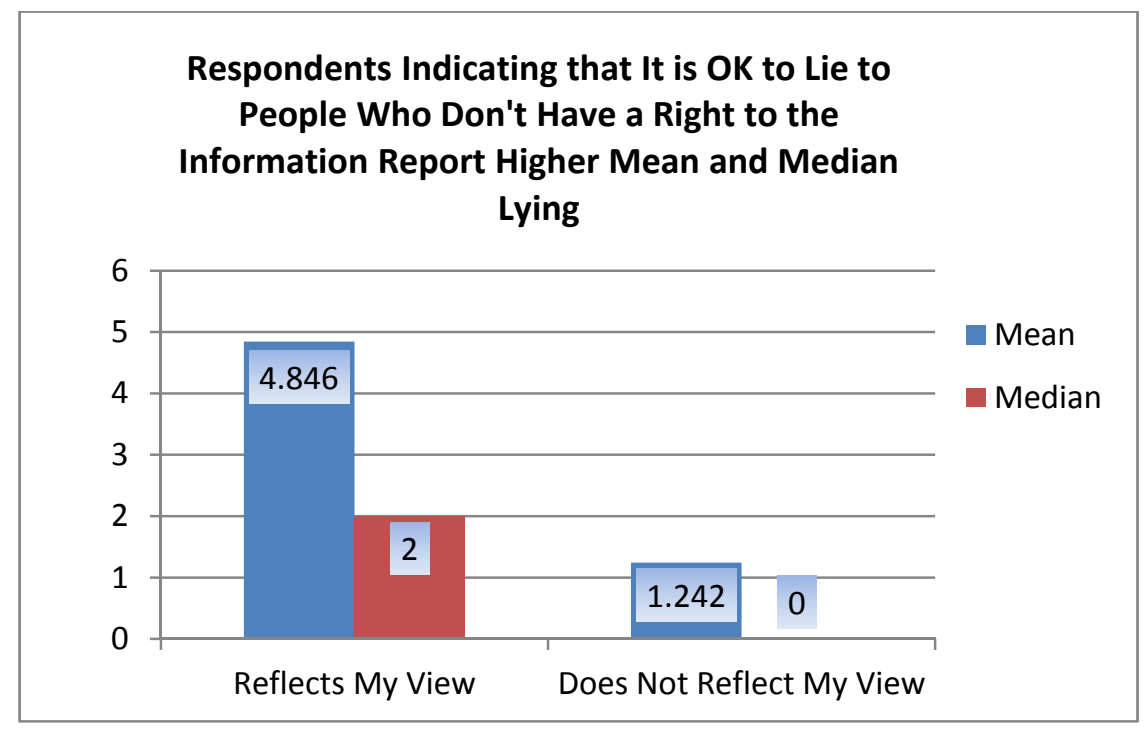

All staff-weighted respondents who indicated that it was OK to tell a lie in situations when someone does not have the right to the information they seek reported higher mean and median lying. The two-sample, two-tailed t-statistic for the difference in means was significant at the .05 level, $t(194)=3.452, p=.0007$. 
A Mann-Whitney U test also revealed a statistically significant difference in the number of lies told by respondents who indicated it was OK to lie to someone who does not have the right to the information they seek $(M d n=2.0, n=70)$ and individuals who indicated this did not reflect their view $(M d n=.00, n=126), U=2740.5, z=-4.657, \mathrm{p}=.000, r=.333$.

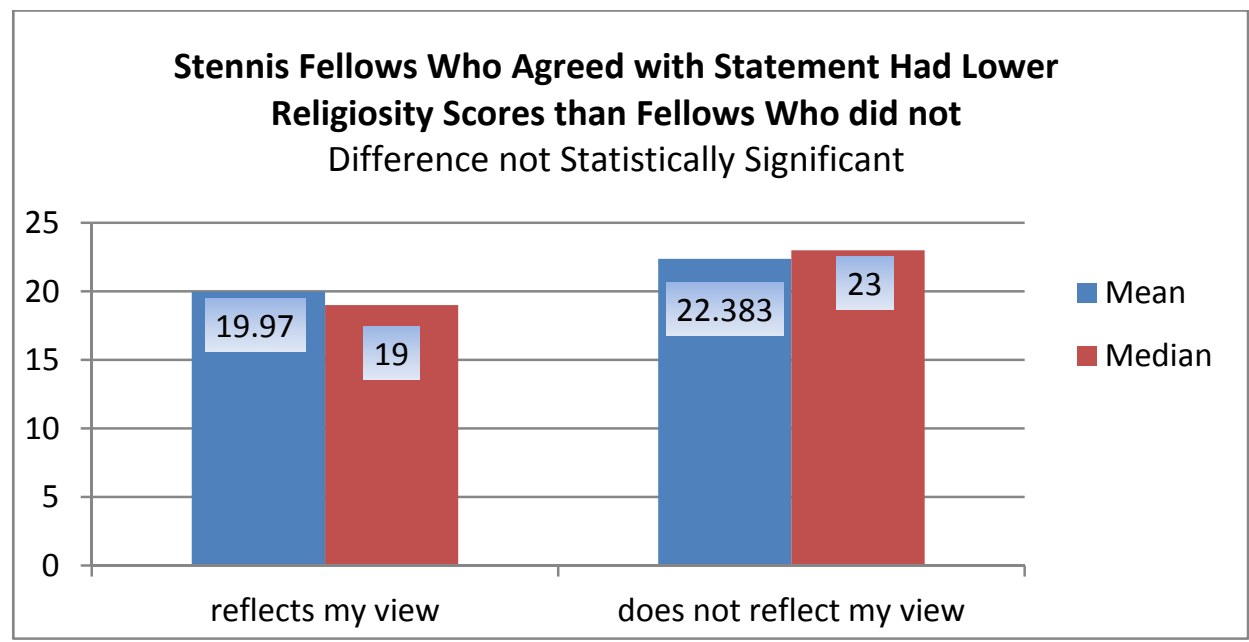

Stennis Fellows who agreed with the statement "it is OK to lie to someone you don't believe has a right to the information they seek" had lower mean and median religiosity scores than those who did not agree with the statement. The two-sample, two-tailed tstatistic was not significant at the .05 level for the difference in mean religiosity between the two groups of fellows, $t(91)=1.531, p=.1293$. The Mann-Whitney U Test also revealed no significant difference in religiosity between fellows who agreed with the statement $(M d n=19, n=33)$ and fellows who disagreed $(M d n=23, n=60), U=783, z=-$ $1.664, p=.096$. 


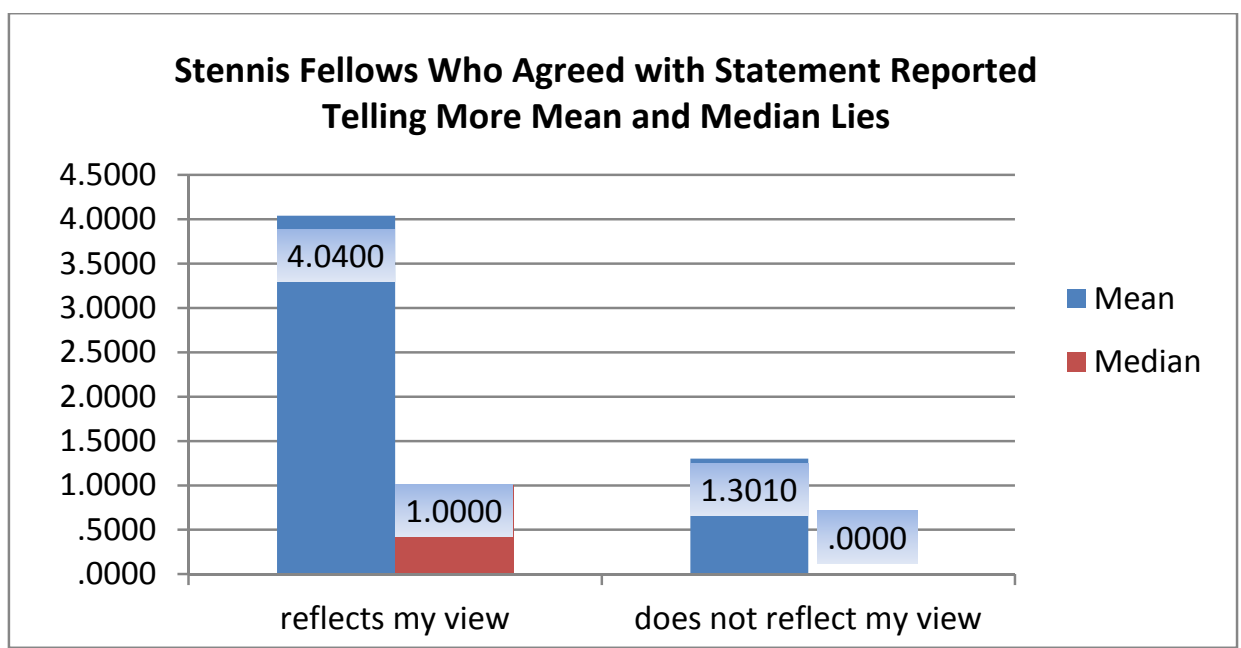

Stennis Fellows who agreed with the statement it is "OK to lie to someone you don't believe has a right to the information they seek" reported telling fewer mean and median lies. The two-sample, two-tailed t-statistic was significant at the .05 level for the difference in mean religiosity between the two groups, $t(66)=2.212, p=.0304$. The MannWhitney U Test also revealed a significant difference in lying between fellows who reported they agreed with the statement $(M d n=1, n=25)$ and fellows who reported they disagreed with the statement $(M d n=0, n=43), U=384.5, z=-2.183, p=.029, r=.265$.

People have different ideas about whether lying is ever morally permissible. Which of the following statements most closely reflect your views?

It is OK to lie to someone you don't believe has a right to the information they seek

\begin{tabular}{|c|c|c|c|c|c|c|}
\hline \multicolumn{3}{|c|}{ Chamber } & \multirow{2}{*}{$\frac{\text { Frequency }}{41}$} & \multirow{2}{*}{$\frac{\text { Percent }}{22.2}$} & \multirow{2}{*}{$\frac{\text { Valid Percent }}{34.2}$} & \multirow{2}{*}{$\begin{array}{c}\begin{array}{c}\text { Cumulative } \\
\text { Percent }\end{array} \\
34.2\end{array}$} \\
\hline House & Valid & Reflects my View & & & & \\
\hline & & Does not Reflect my View & 79 & 42.7 & 65.8 & 100.0 \\
\hline & & Total & 120 & 64.9 & 100.0 & \\
\hline & Missing & System & 65 & 35.1 & & \\
\hline & Total & & 185 & 100.0 & & \\
\hline \multirow[t]{5}{*}{ Senate } & Valid & Reflects my View & 48 & 27.0 & 39.7 & 39.7 \\
\hline & & Does not Reflect my View & 73 & 41.0 & 60.3 & 100.0 \\
\hline & & Total & 121 & 68.0 & 100.0 & \\
\hline & Missing & System & 57 & 32.0 & & \\
\hline & Total & & 178 & 100.0 & & \\
\hline
\end{tabular}


People have different ideas about whether lying is ever morally permissible. Which of the following statements most closely reflect your views?

It is OK to lie to someone you don't believe has a right to the information they seek.

\begin{tabular}{|c|c|c|c|c|c|}
\hline \multicolumn{2}{|c|}{ All Staff-weighted } & \multirow{2}{*}{$\frac{\text { Frequency }}{88}$} & \multirow{2}{*}{$\frac{\text { Percent }}{24.0}$} & \multirow{2}{*}{$\frac{\text { Valid Percent }}{36.4}$} & \multirow{2}{*}{$\begin{array}{c}\text { Cumulative } \\
\text { Percent }\end{array}$} \\
\hline Valid & Reflects my View & & & & \\
\hline & Does not Reflect my View & 153 & 42.0 & 63.6 & 100.0 \\
\hline & Total & 241 & 66.1 & 100.0 & \\
\hline Missing & System & 124 & 33.9 & & \\
\hline Total & & 364 & 100.0 & & \\
\hline
\end{tabular}

People have different ideas about whether lying is ever morally permissible. Which of the following statements most closely reflects your view?

It is OK to lie to someone you don't believe has a right to the information they seek.

\begin{tabular}{|c|c|c|c|c|c|}
\hline \multicolumn{2}{|c|}{ ALL STAFF-unweighted } & \multirow{2}{*}{$\frac{\text { Frequency }}{89}$} & \multirow{2}{*}{$\frac{\text { Percent }}{24.5}$} & \multirow{2}{*}{$\begin{array}{r}\text { Valid Percent } \\
36.9\end{array}$} & \multirow{2}{*}{$\begin{array}{r}\begin{array}{l}\text { Cumulative } \\
\text { Percent }\end{array} \\
36.9\end{array}$} \\
\hline Valid & Reflects my View & & & & \\
\hline & Does not Reflect my View & 152 & 41.9 & 63.1 & 100.0 \\
\hline & Total & 241 & 66.4 & 100.0 & \\
\hline Missing & System & 122 & 33.6 & & \\
\hline Total & & 363 & 100.0 & & \\
\hline
\end{tabular}

People have different ideas about whether lying is ever morally permissible. Which of the following statements most closely reflects your view?

It is OK to lie to someone you don't believe has a right to the information they seek.

\begin{tabular}{|c|c|c|c|c|c|}
\hline \multicolumn{2}{|c|}{ Stennis Fellows } & \multirow{2}{*}{$\frac{\text { Frequency }}{33}$} & \multirow{2}{*}{$\frac{\text { Percent }}{27.0}$} & \multirow{2}{*}{$\frac{\text { Valid Percent }}{34.7}$} & \multirow{2}{*}{$\begin{array}{c}\begin{array}{c}\text { Cumulative } \\
\text { Percent }\end{array} \\
34.7\end{array}$} \\
\hline Valid & Reflects my View & & & & \\
\hline & Does not Reflect my View & 62 & 50.8 & 65.3 & 100.0 \\
\hline & Total & 95 & 77.9 & 100.0 & \\
\hline Missing & System & 27 & 22.1 & & \\
\hline Total & & 122 & 100.0 & & \\
\hline
\end{tabular}




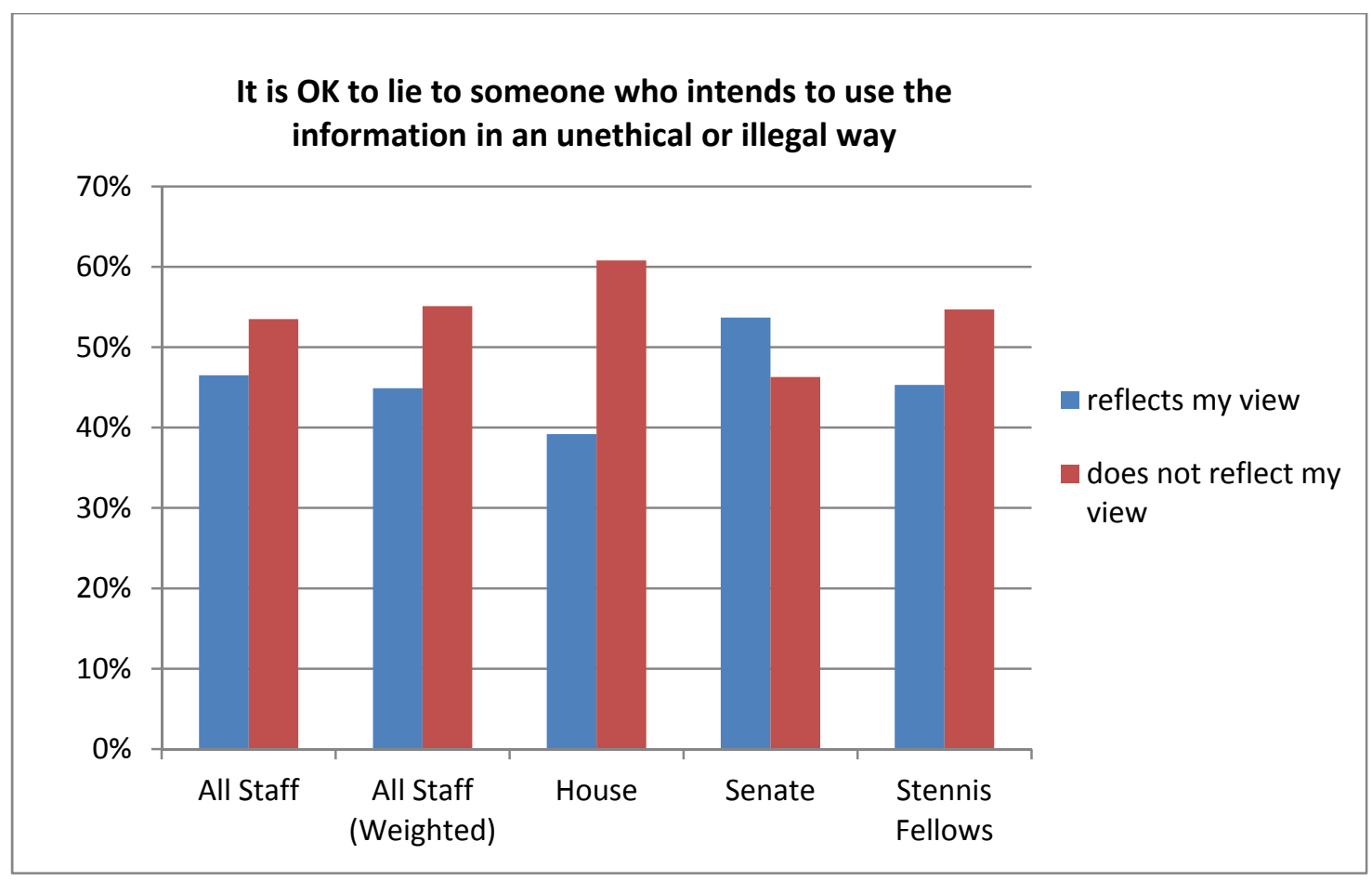

Respondents were asked whether they agreed with the statement it is "OK to lie to someone who intends to use the information in an illegal or unethical way." Staff were divided on the question, with a narrow majority indicating that this did not reflect their views.

Confidence intervals were calculated for each of the respondent groups. The widest confidence interval for the House was $\pm 8.8 \%$, for the Senate was $\pm 8.9 \%$, for all staffweighted was $\pm 6.3 \%$ and for Stennis Fellows was $\pm 8.1 \%$.

Senate staff $(53.7 \%)$ were more likely to respond that they agree with the statement "It is OK to lie to someone who intends to use the information in an unethical or illegal way" than House staff (39.2\%) or Stennis Fellows (45.3\%). The two-sample, two-tailed tstatistic was significant at the .05 level for the difference between House and Senate staff, 
$t(239)=2.26, p=.025$. The two-sample, two-tailed t-statistic was not significant at the .05 level for the difference between Senate staff and Stennis Fellows, $t(214)=1.23, p=.22$. The null hypothesis that there is no difference between Senate staff and Stennis Fellows cannot be rejected.

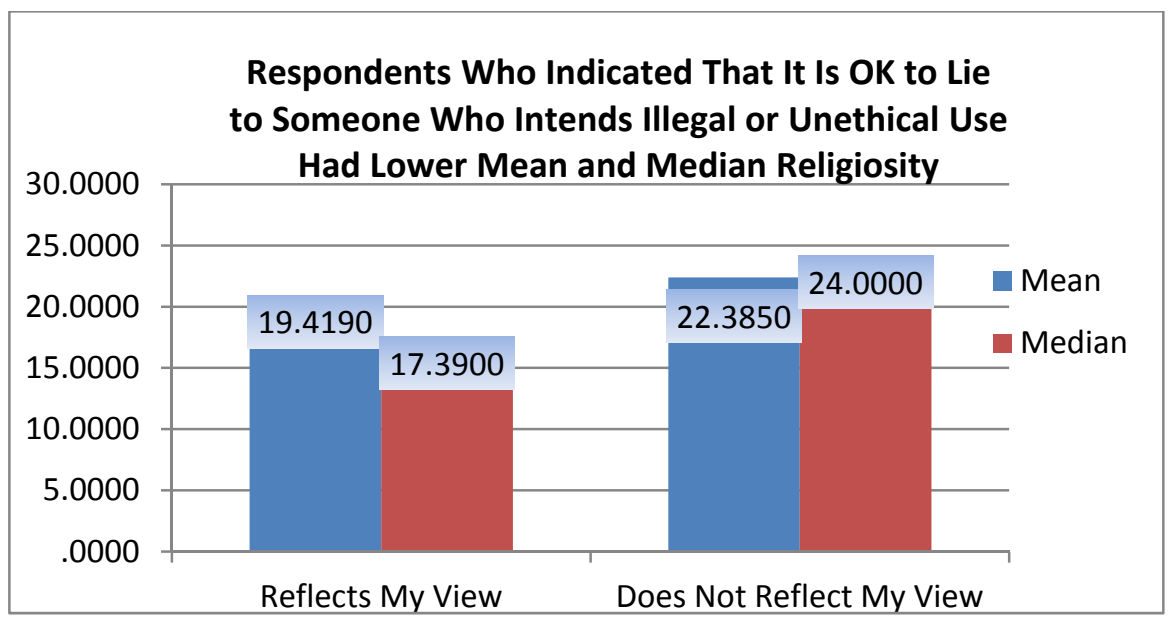

All staff-weighted respondents who indicated that the statement "it is OK to lie to someone who intends to use the information in an unethical or illegal way" reflected their view reported lower mean and median religiosity scores. The two-sample, two-tailed tstatistic for the difference in mean religiosity scores between staff who indicated this represented their view and for those for whom this did not reflect their view was significant at the .05 level, $t(233)=2.961, p=.0034$.

A Mann-Whitney U test also revealed a statistically significant difference in the religiosity of respondents who indicated that it was OK to tell a lie if person would use information in an illegal or unethical way $(M d n=17.39, n=108)$ and those who indicated this did not reflect their view $(M d n=24, n=127), U=5354, z=-3.039, p=.002, r=.198$. 


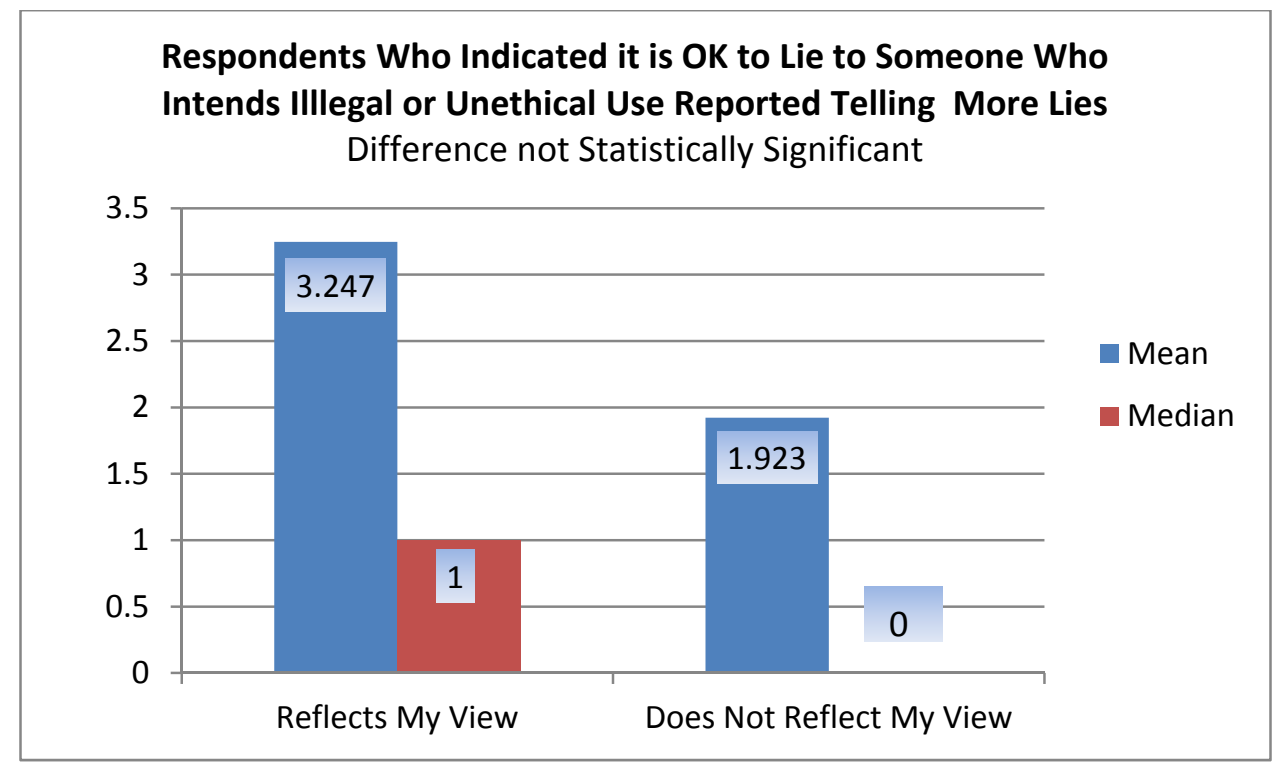

All staff-weighted respondents who indicated that it was OK to tell a lie to someone intending to use the information in an illegal or unethical way reported higher mean and median lying. The two-sample, two-tailed t-statistic for the difference in means was not significant at the .05 level, $t(194)=1.417, p=.1581$.

A Mann-Whitney U test also revealed no statistically significant difference in the number of lies told by respondents who indicated it was $\mathrm{OK}$ to lie to someone who intends to use the information in an unethical or illegal way $(M d n=1.0, n=91)$ and individuals who indicated this did not reflect their view $(M d n=.00, n=105), U=4052.5$, $z=-1.864, \mathrm{p}=.062, r=.134$. 


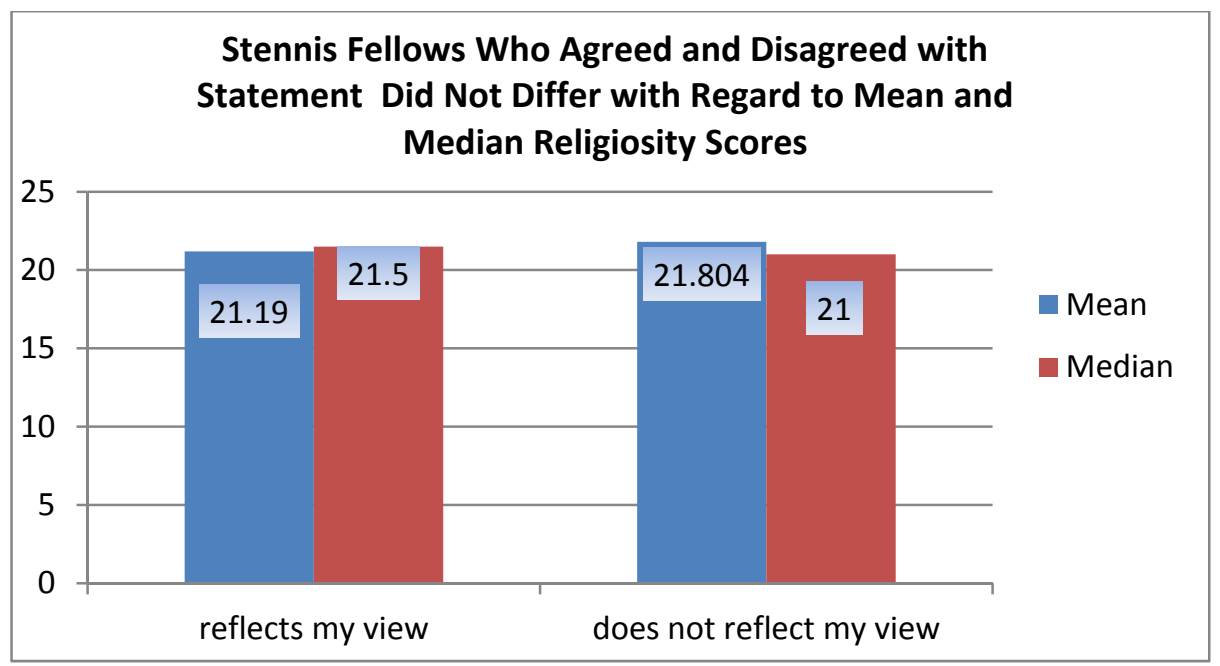

Stennis Fellows who agreed with the statement, "it is OK to lie to someone who intends to use the information in an unethical or illegal way," had mean and median religiosity scores that were nearly identical to the religiosity scores of those who disagreed with the statement. The two-sample, two-tailed t-statistic was not significant at the .05 level for the difference in mean religiosity scores between the two groups of fellows, $t(91)=0.400$, $p=.6899$. The Mann-Whitney U Test also revealed no significant difference in religiosity between fellows who agreed with the statement $(M d n=21.5, n=42)$ and fellows who did not agree with the statement $(M d n=21, n=51), U=1018, z=-.410, p=.682$.

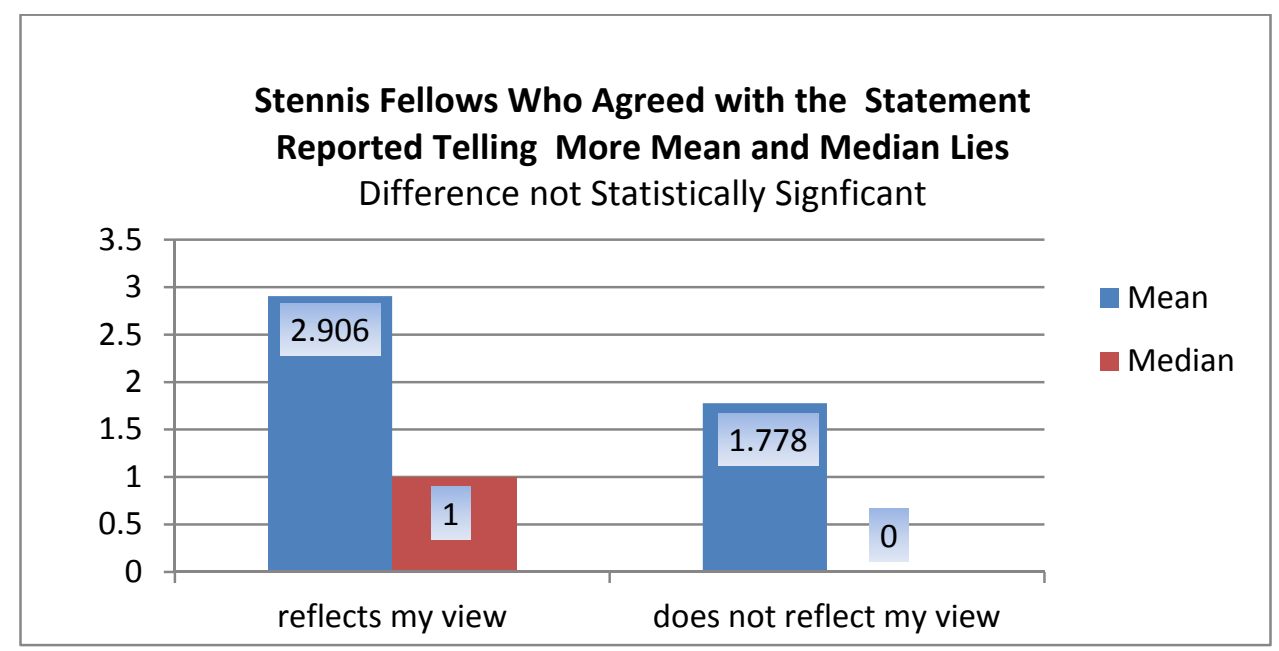


Stennis Fellows who agreed with the statement, "it is OK to lie to someone who intends to use the information in an unethical or illegal way," reported more frequent mean and median lying than fellows who disagreed with the statement. The two-sample, two-tailed t-statistic was not significant at the .05 level for the difference in mean lying between the two groups, $t(66)=0.916, p=.3629$. The Mann-Whitney U Test also revealed that there was no significant difference in religiosity between Stennis Fellows who agreed with the statement $(M d n=1, n=32)$ and fellows who disagreed $(M d n=0, n=36), U=454, z=-1.682$, $p=.093$.

People have different ideas about whether lying is ever morally permissible. Which of the following statements most closely reflect your view?

It is OK to lie to someone who intends to use the information in an unethical or illegal way

\begin{tabular}{|c|c|c|c|c|c|c|}
\hline \multicolumn{3}{|c|}{ Chamber } & \multirow{2}{*}{$\frac{\text { Frequency }}{47}$} & \multirow{2}{*}{$\frac{\text { Percent }}{25.4}$} & \multirow{2}{*}{$\frac{\text { Valid Percent }}{39.2}$} & \multirow{2}{*}{$\begin{array}{c}\begin{array}{c}\text { Cumulative } \\
\text { Percent }\end{array} \\
39.2\end{array}$} \\
\hline House & Valid & Reflects my View & & & & \\
\hline & & Does not Reflect my View & 73 & 39.5 & 60.8 & 100.0 \\
\hline & & Total & 120 & 64.9 & 100.0 & \\
\hline & Missing & System & 65 & 35.1 & & \\
\hline & Total & & 185 & 100.0 & & \\
\hline \multirow[t]{5}{*}{ Senate } & Valid & Reflects my View & 65 & 36.5 & 53.7 & 53.7 \\
\hline & & Does not Reflect my View & 56 & 31.5 & 46.3 & 100.0 \\
\hline & & Total & 121 & 68.0 & 100.0 & \\
\hline & Missing & System & 57 & 32.0 & & \\
\hline & Total & & 178 & 100.0 & & \\
\hline
\end{tabular}

People have different ideas about whether lying is ever morally permissible. Which of the following statements most closely reflect your view?

It is OK to lie to someone who intends to use the information in an unethical or illegal way.

\begin{tabular}{|c|c|c|c|c|c|}
\hline \multicolumn{2}{|c|}{ All Staff-weighted } & \multirow{2}{*}{$\frac{\text { Frequency }}{108}$} & \multirow{2}{*}{$\frac{\text { Percent }}{29.7}$} & \multirow{2}{*}{$\frac{\text { Valid Percent }}{44.9}$} & \multirow{2}{*}{$\begin{array}{c}\text { Cumulative } \\
\text { Percent }\end{array}$} \\
\hline Valid & Reflects my View & & & & \\
\hline & Does not Reflect my View & 133 & 36.4 & 55.1 & 100.0 \\
\hline & Total & 241 & 66.1 & 100.0 & \\
\hline Missing & System & 124 & 33.9 & & \\
\hline Total & & 364 & 100.0 & & \\
\hline
\end{tabular}


People have different ideas about whether lying is ever morally permissible. Which of the following statements most closely reflect your view?

It is OK to lie to someone who intends to use the information in an unethical or illegal way.

\begin{tabular}{|c|c|c|c|c|c|}
\hline \multicolumn{2}{|c|}{ ALL STAFF-unweighted } & \multirow{2}{*}{$\frac{\text { Frequency }}{112}$} & \multirow{2}{*}{$\frac{\text { Percent }}{30.9}$} & \multirow{2}{*}{$\frac{\text { Valid Percent }}{46.5}$} & \multirow{2}{*}{$\begin{array}{c}\begin{array}{c}\text { Cumulative } \\
\text { Percent }\end{array} \\
46.5\end{array}$} \\
\hline Valid & Reflects my View & & & & \\
\hline & Does not Reflect my View & 129 & 35.5 & 53.5 & 100.0 \\
\hline & Total & 241 & 66.4 & 100.0 & \\
\hline Missing & System & 122 & 33.6 & & \\
\hline Total & & 363 & 100.0 & & \\
\hline
\end{tabular}

People have different ideas about whether lying is ever morally permissible. Which of the following statements most closely reflects your view?

It is OK to lie to someone who intends to use the information in an unethical or illegal way.

\begin{tabular}{|c|c|c|c|c|c|}
\hline \multicolumn{2}{|c|}{ Stennis Fellows } & \multirow{2}{*}{$\frac{\text { Frequency }}{43}$} & \multirow{2}{*}{$\frac{\text { Percent }}{35.2}$} & \multirow{2}{*}{$\frac{\text { Valid Percent }}{45.3}$} & \multirow{2}{*}{$\begin{array}{c}\begin{array}{c}\text { Cumulative } \\
\text { Percent }\end{array} \\
45.3\end{array}$} \\
\hline Valid & Reflects my View & & & & \\
\hline & Does not Reflect my View & 52 & 42.6 & 54.7 & 100.0 \\
\hline & Total & 95 & 77.9 & 100.0 & \\
\hline Missing & System & 27 & 22.1 & & \\
\hline Total & & 122 & 100.0 & & \\
\hline
\end{tabular}

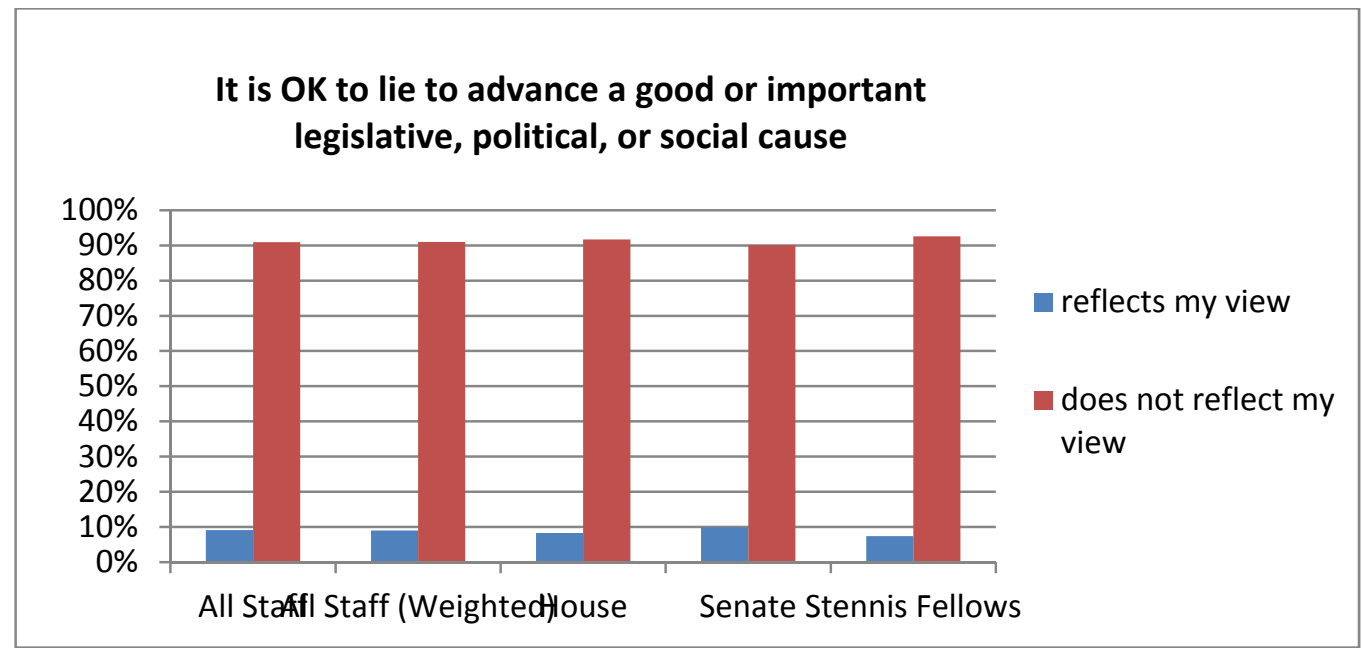

Respondents were asked whether they agreed with the statement that it is "OK to lie to advance a good or important, political or social cause." Staff overwhelmingly rejected the statement, with only $7 \%-10 \%$ indicating that they agreed with it. 
Confidence intervals were calculated for each of the respondent groups. The widest confidence interval for the House was $\pm 5.0 \%$, for the Senate was $\pm 5.3 \%$, for all staffweighted was $\pm 3.6 \%$ and for Stennis Fellows was $\pm 4.3 \%$.

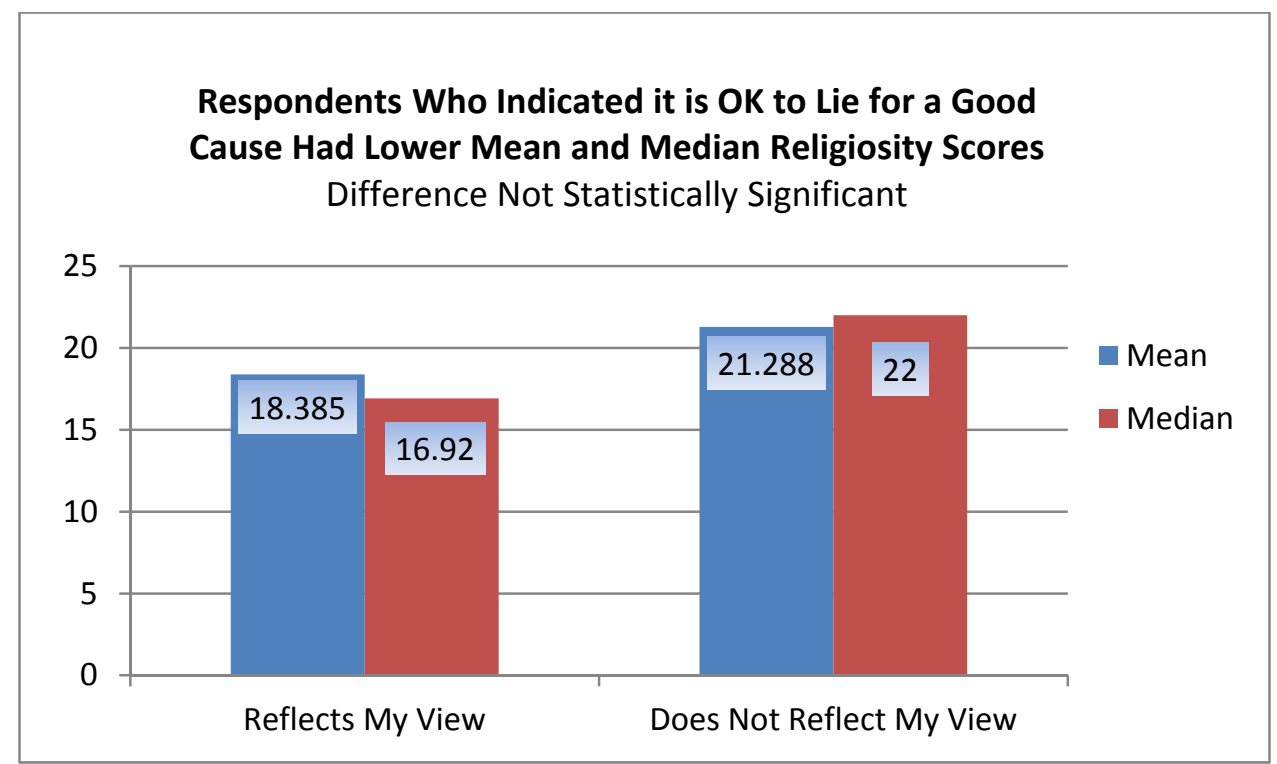

All staff-weighted respondents who indicated that the statement, "it is OK to lie to advance a good or important legislative, political, or social cause," reflected their view reported lower mean and median religiosity scores. The two-sample, two-tailed tstatistic for the difference in mean religiosity scores between staff who indicated this represented their view and for those for whom this did not reflect their view was not significant at the .05 level, $t(234)=1.673, \mathrm{p}=.0957$.

A Mann-Whitney $U$ test also revealed that there was no statistically significant difference in the religiosity of respondents who indicated that it was OK to lie to advance a good or important legislative, political or social cause $(M d n=16.92, n=22)$ and those who indicated this did not reflect their view $(M d n=22, n=214), U=1831, z=-1.717, p=.086$. 


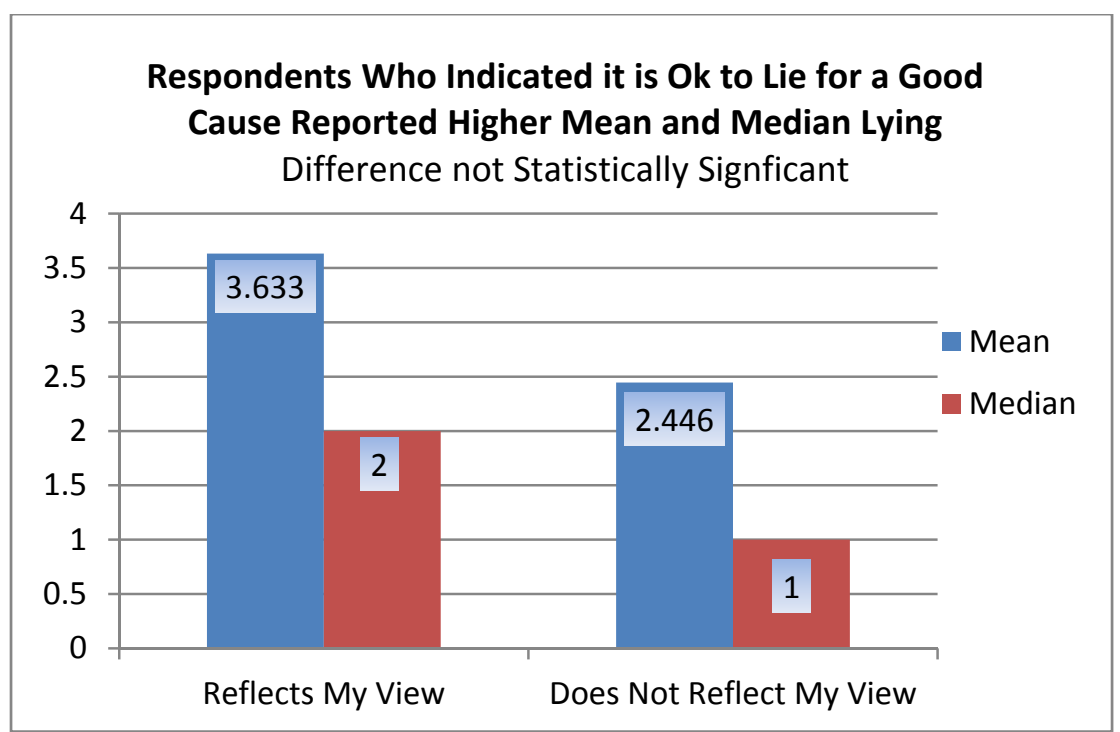

All staff-weighted respondents who indicated that it was OK to tell a lie to advance a good or important cause reported higher mean and median lying. The two-sample, twotailed t-statistic for the difference in means was not significant at the .05 level, $t(194)=0.675, p=.5003$.

A Mann-Whitney $U$ test also revealed no statistically significant difference in the number of lies told by respondents who indicated it was OK to lie to advance a good or important cause $(M d n=2.0, n=15)$ and individuals who indicated this did not reflect their view $(M d n=1.0, n=181), U=1036, z=-1.589, \mathrm{p}=.112$. 


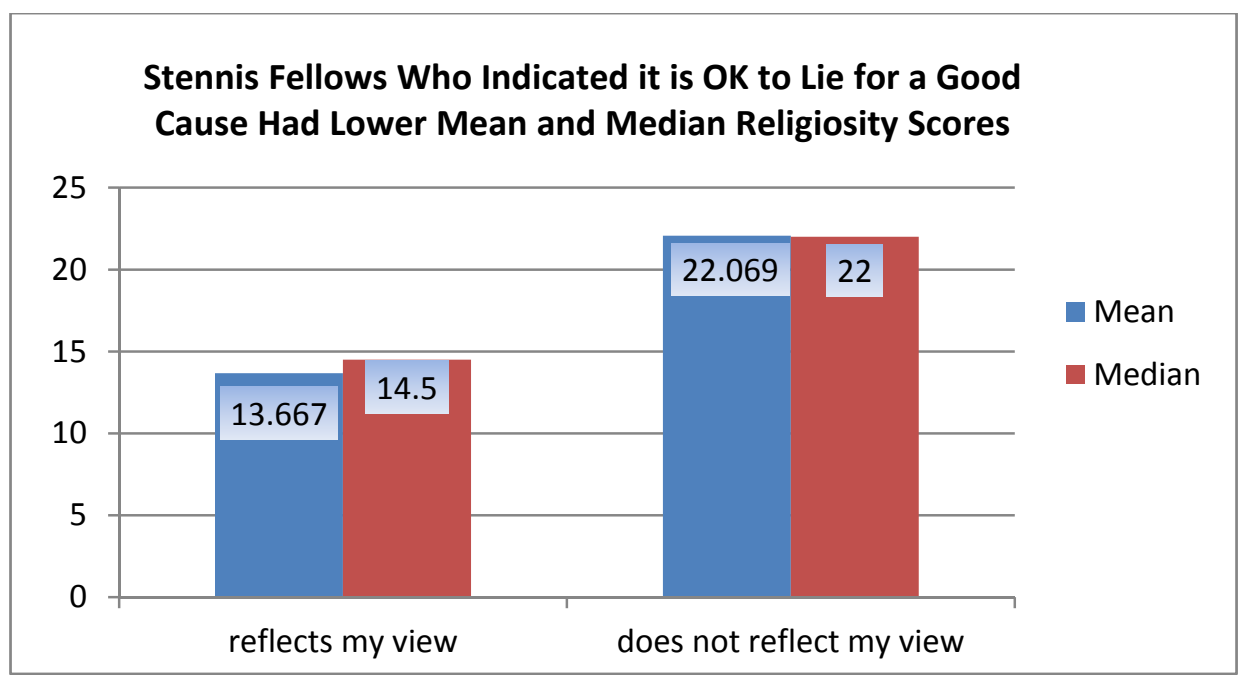

$7.4 \%$ of Stennis Fellows indicated that they agreed with the statement that "it was OK to lie to advance a good or important legislative, political, or social cause." These fellows had substantially lower religiosity scores than those who did not agree. The two-sample, two-tailed t-statistic for the difference in mean religiosity was significant at the .05 level, $t(91)=2.817, p=.0059$. The Mann-Whitney U Test also revealed significant differences in religiosity between fellows who agreed with the statement $(M d n=14.5, n=6)$ and fellows who disagreed with the statement $(M d n=22, n=87), U=87.5, z=-2.717, p=.007, r=.28$.

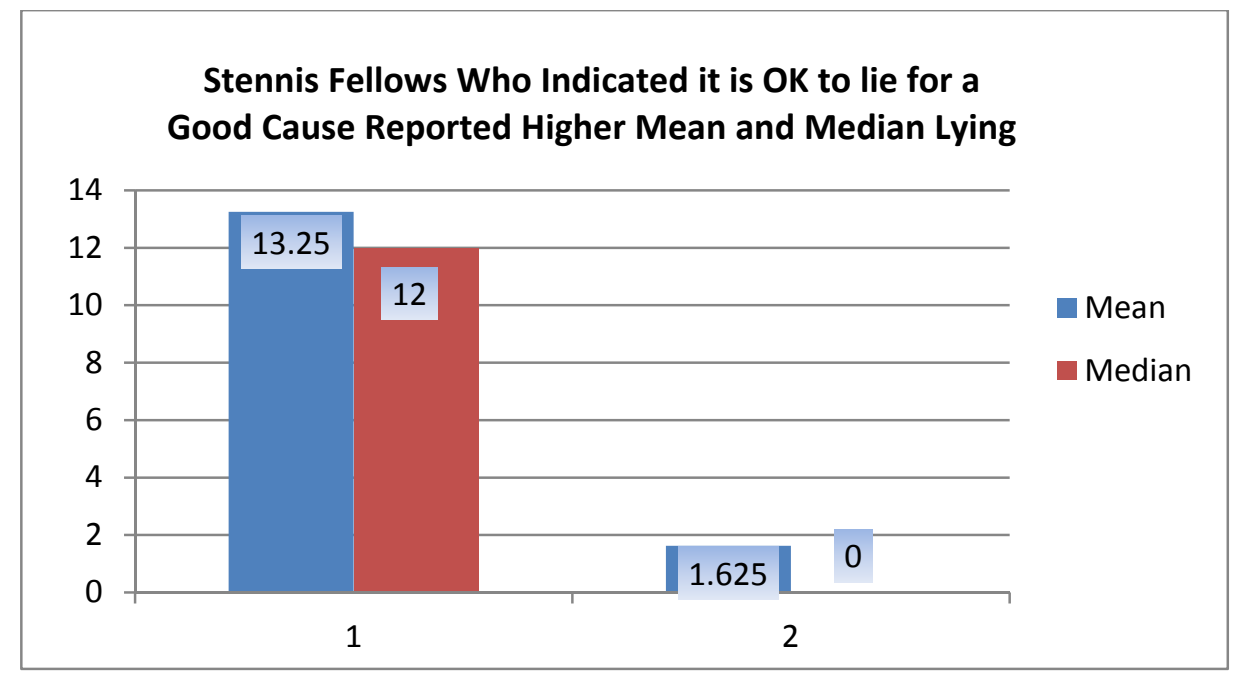


Stennis Fellows who indicated that they agreed with the statement reported higher mean and median lying than fellows who disagreed with the statement. The two-sample, twotailed t-statistic for the difference in mean religiosity was significant at the .05 level, $t(66)=5.273, p=.0000$. The Mann-Whitney $U$ Test also revealed a significant difference in lying between fellows who agreed with the statement $(M d n=12, n=4)$ and fellows who disagreed with the statement $(M d n=0, n=64), U=60.5, z=-1.974, p=.048, r=.24$.

People have different ideas about whether lying is ever morally permissible. Which of the following statements most closely reflect your view?

It is OK to lie to advance a good or important legislative, political, or social cause

\begin{tabular}{|c|c|c|c|c|c|c|}
\hline \multicolumn{3}{|c|}{ Chamber } & \multirow{2}{*}{$\frac{\text { Frequency }}{10}$} & \multirow{2}{*}{$\frac{\text { Percent }}{5.4}$} & \multirow{2}{*}{$\frac{\text { Valid Percent }}{8.3}$} & \multirow{2}{*}{$\begin{array}{c}\begin{array}{c}\text { Cumulative } \\
\text { Percent }\end{array} \\
8.3\end{array}$} \\
\hline House & Valid & Reflects my View & & & & \\
\hline & & Does not Reflect my View & 110 & 59.5 & 91.7 & 100.0 \\
\hline & & Total & 120 & 64.9 & 100.0 & \\
\hline & Missing & System & 65 & 35.1 & & \\
\hline & Total & & 185 & 100.0 & & \\
\hline \multirow[t]{5}{*}{ Senate } & Valid & Reflects my View & 12 & 6.7 & 9.9 & 9.9 \\
\hline & & Does not Reflect my View & 109 & 61.2 & 90.1 & 100.0 \\
\hline & & Total & 121 & 68.0 & 100.0 & \\
\hline & Missing & System & 57 & 32.0 & & \\
\hline & Total & & 178 & 100.0 & & \\
\hline
\end{tabular}

People have different ideas about whether lying is ever morally permissible. Which of the following statements most closely reflect your view?

It is OK to lie to advance a good or important legislative, political, or social cause.

\begin{tabular}{|c|c|c|c|c|c|}
\hline \multicolumn{2}{|c|}{ All Staff-weighted } & \multirow{2}{*}{$\frac{\text { Frequency }}{22}$} & \multirow{2}{*}{$\frac{\text { Percent }}{5.9}$} & \multirow{2}{*}{$\frac{\text { Valid Percent }}{9.0}$} & \multirow{2}{*}{$\begin{array}{c}\begin{array}{c}\text { Cumulative } \\
\text { Percent }\end{array} \\
9.0\end{array}$} \\
\hline Valid & Reflects my View & & & & \\
\hline & Does not Reflect my View & 219 & 60.1 & 91.0 & 100.0 \\
\hline & Total & 241 & 66.1 & 100.0 & \\
\hline Missing & System & 124 & 33.9 & & \\
\hline Total & & 364 & 100.0 & & \\
\hline
\end{tabular}


People have different ideas about whether lying is ever morally permissible. Which of the following statements most closely reflect your view?

It is OK to lie to advance a good or important legislative, political, or social cause.

\begin{tabular}{llcccc}
\hline \hline ALL STAFF-unweighted & Frequency & Percent & Valid Percent & $\begin{array}{c}\text { Cumulative } \\
\text { Percent }\end{array}$ \\
\hline Valid & Reflects my View & 22 & 6.1 & 9.1 & 9.1 \\
& Does not Reflect my View & 219 & 60.3 & 90.9 & 100.0 \\
& Total & 241 & 66.4 & 100.0 & \\
Missing & System & 122 & 33.6 & \\
Total & & 363 & 100.0 & \\
\hline \hline
\end{tabular}

People have different ideas about whether lying is ever morally permissible. Which of the following statements most closely reflect your view?

It is OK to lie to advance a good or important legislative, political, or social cause.

\begin{tabular}{llcccc}
\hline \hline Stennis Fellows & & & & Cumulative \\
Valid & Reflects my View & Frequency & Percent & Valid Percent & \begin{tabular}{c} 
Percent \\
\cline { 2 - 5 }
\end{tabular} \\
& Does not Reflect my View & 7 & 5.7 & 7.4 & 7.4 \\
& Total & 88 & 72.1 & 92.6 & 100.0 \\
Missing & System & 95 & 77.9 & 100.0 & \\
Total & & 27 & 22.1 & \\
\hline \hline
\end{tabular}

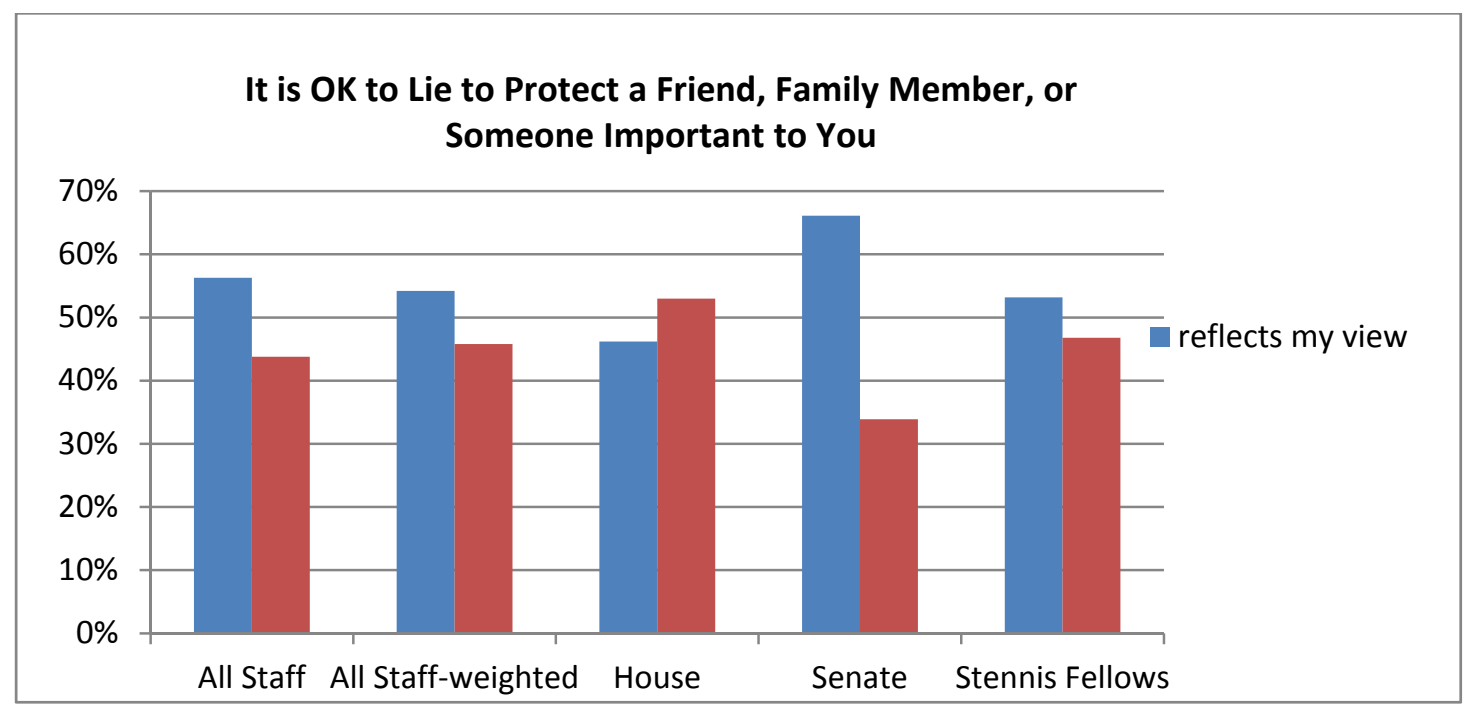

Respondents were asked whether they agreed with the statement that, "it is OK to lie to protect a friend, family member, or someone important to you." Staff were fairly divided on the question, with a slight majority of House staff indicating they disagreed with the 
statement and a sizeable majority of Senate staff indicating that they agreed with it. This is one of the few justifications for lying that split staff this dramatically. It is clear from these results that a substantial portion of the respondents find something more compelling about relationships than other factors that have been introduced by the survey thus far. This question gets explored further in the pornography case, which invokes a possible conflict between truth-telling, obligations to employers, and keeping promises to friends. As will be seen later, nearly $75 \%$ of all staff-weighted indicated that they would tell the truth in this case.

Confidence intervals were calculated for each of the respondent groups. The widest confidence interval for the House was $\pm 9.0 \%$, for the Senate was $\pm 8.5 \%$, for all staffweighted was $\pm 6.3 \%$ and for Stennis Fellows was $\pm 8.2 \%$.

Senate staff $(66.1 \%)$ were more likely to respond that they agree with the statement, "it is OK to lie to protect a friend, family member or someone important to you," than House staff $(46.2 \%)$ or Stennis Fellows (53.2\%). The two-sample, two-tailed t-statistic was significant at the .05 level for the difference between House and Senate staff, $t(238)=3.1$, $p=.002$. The two-sample, two-tailed t-statistic was not significant at the .05 level for the difference between Senate staff and Stennis Fellows, $t(213)=1.92, p=.056$. The null hypothesis that there is no difference between Senate staff and Stennis Fellows cannot be rejected. 


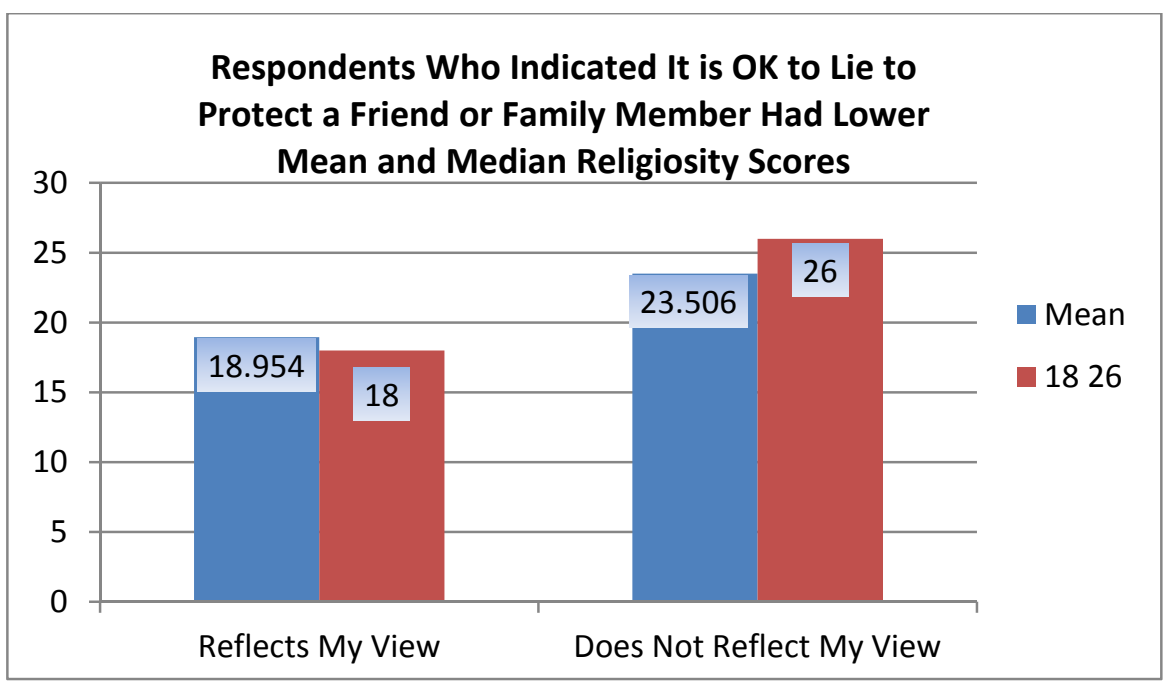

All staff-weighted respondents who indicated that the statement, "it is OK to lie to protect a friend, family member, or someone important to you," reflected their view reported lower mean and median religiosity scores. The two-sample, two-tailed t-statistic for the difference in mean religiosity scores between staff who indicated this represented their view and for those for whom this did not reflect their view was significant at the .05 level, $t(232)=4.635, p=.0000$.

A Mann-Whitney $U$ test also revealed a statistically significant difference in the religiosity of respondents who indicated that it was $\mathrm{OK}$ to tell a lie to protect a friend or family member $(M d n=18.0, n=129)$ and those who indicated this did not reflect their view $(M d n=26, n=105), U=4598.5, z=-4.208, p=.000, r=275$. 


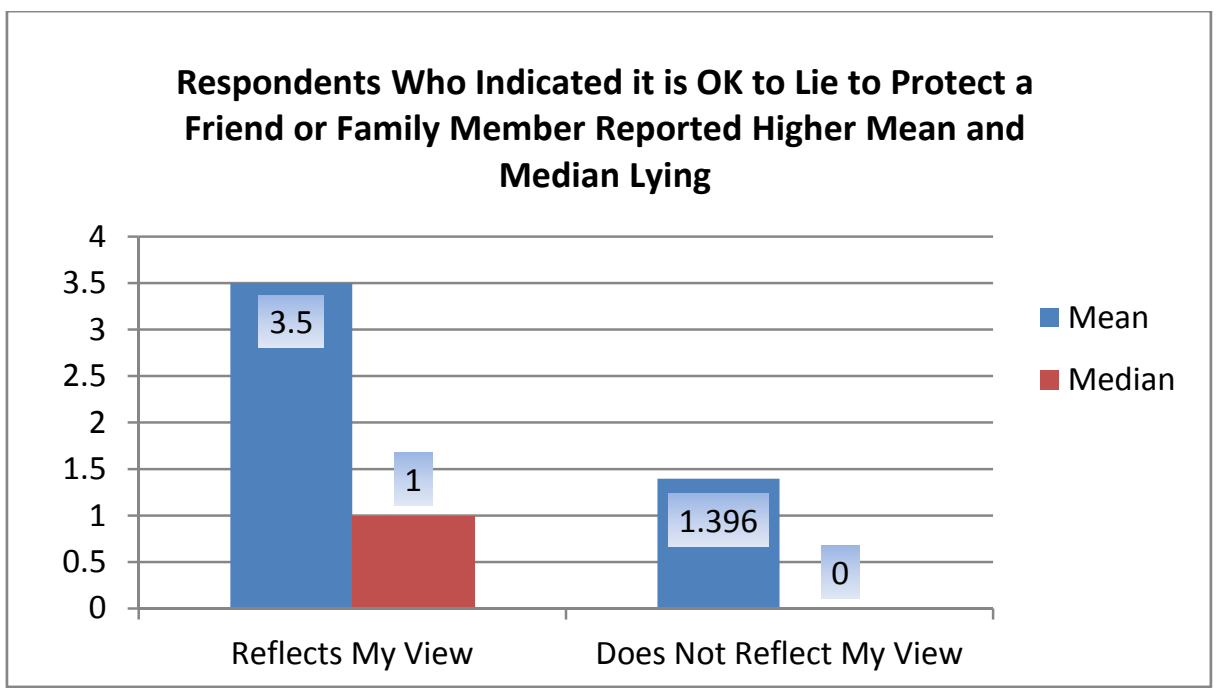

All staff-weighted respondents who indicated that the statement "it is OK to lie to protect a friend, family member, or someone important to you" reflected their view reported lower mean and median lying. The two-sample, two-tailed t-statistic for the difference in mean lie scores between staff who indicated this represented their view and for those for whom this did not reflect their view was significant at the .05 level, $t(193)=2.256$, $\mathrm{p}=.0252$.

A Mann-Whitney $U$ test also revealed a statistically significant difference in lying by respondents who indicated that it was $\mathrm{OK}$ to lie to protect a friend, family member or someone important to you $(M d n=1.0, n=107)$ and those who indicated this did not reflect their view $(M d n=.00, n=88), U=3505, z=-3.023, p=.003$. 


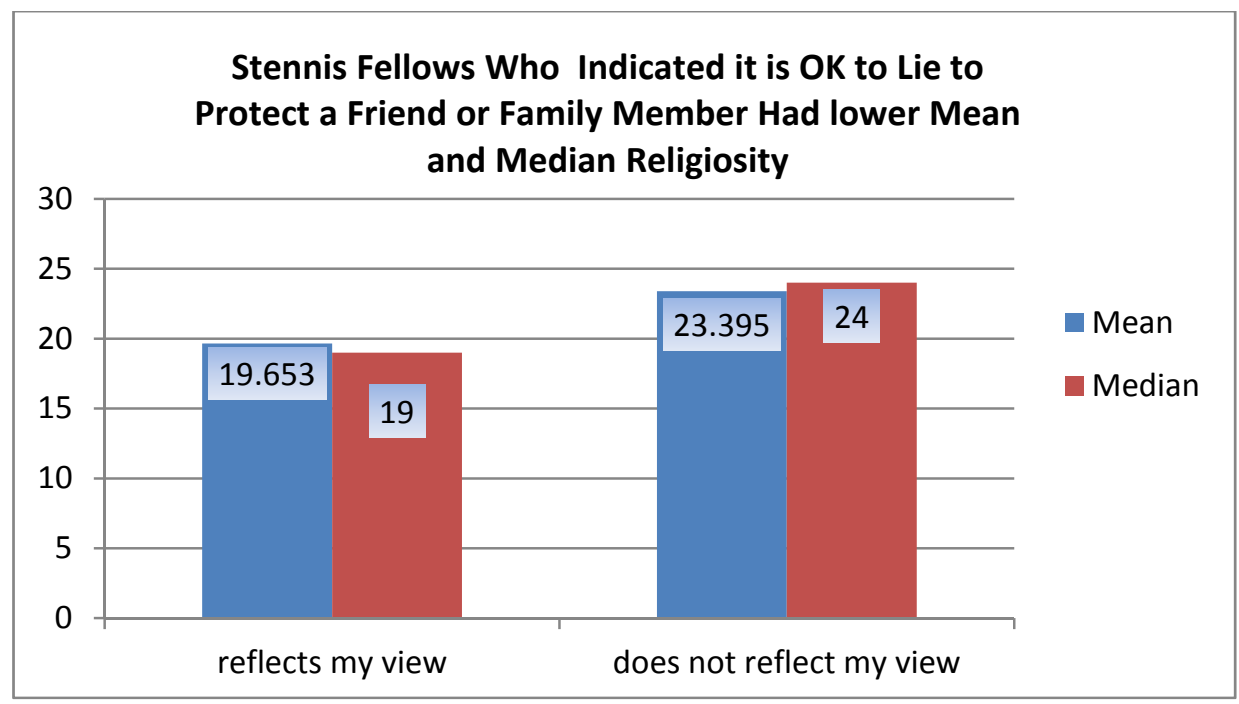

Stennis Fellows who agreed with the statement, "it is OK to lie to protect a friend, family member, or someone important to you," had lower religiosity scores than fellows who disagreed. The two-sample, two-tailed t-statistic was significant at the .05 level for the difference in mean religiosity between the two groups, $t(90)=2.537, p=.0129$. The Mann-Whitney U Test also revealed a significant difference in religiosity between fellows who agreed with the statement $(M d n=19, n=49)$ and fellows who disagreed with the statement $(M d n=24, n=43), U=702, z=-2.754, p=.006, r=.287$.

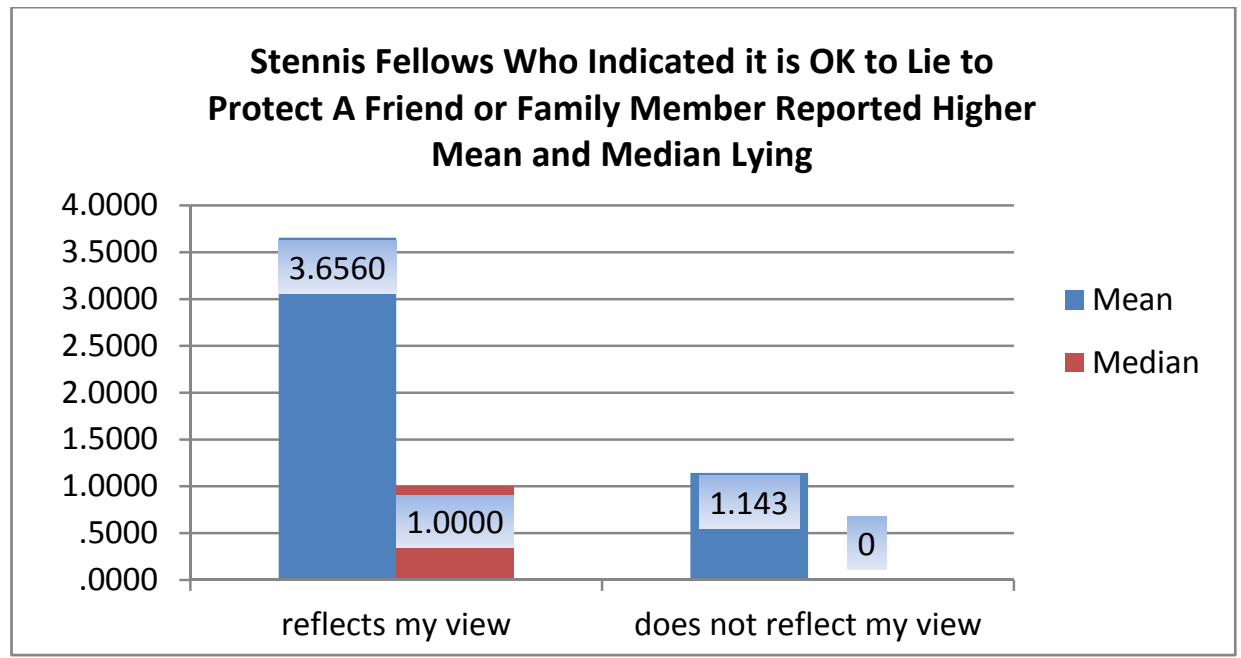


Stennis Fellows who agreed with the statement reported telling more mean and median lies than fellows who disagreed with the statement. The two-sample, two-tailed t-statistic was significant at the .05 level for the difference in mean lying between the two groups, $t(65)=2.067, p=.0427$. The Mann-Whitney $U$ Test also revealed a significant difference in lying between fellows who agreed with the statement $(M d n=1, n=32)$ and fellows who disagreed with the statement $(M d n=0, n=35), U=382, z=-2.497, p=.013, r=.305$.

People have different ideas about whether lying is ever morally permissible. Which of the following statements most closely reflect your view?

It is OK to lie to protect a friend, family member, or someone important to you

\begin{tabular}{|c|c|c|c|c|c|c|}
\hline \multicolumn{3}{|c|}{ Chamber } & \multirow{2}{*}{$\frac{\text { Frequency }}{55}$} & \multirow{2}{*}{$\frac{\text { Percent }}{29.7}$} & \multirow{2}{*}{$\frac{\text { Valid Percent }}{46.2}$} & \multirow{2}{*}{$\begin{array}{c}\text { Cumulative } \\
\text { Percent }\end{array}$} \\
\hline House & Valid & Reflects my View & & & & \\
\hline & & Does not Reflect my View & 64 & 34.6 & 53.8 & 100.0 \\
\hline & & Total & 119 & 64.3 & 100.0 & \\
\hline & Missing & System & 66 & 35.7 & & \\
\hline & Total & & 185 & 100.0 & & \\
\hline \multirow[t]{5}{*}{ Senate } & Valid & Reflects my View & 80 & 44.9 & 66.1 & 66.1 \\
\hline & & Does not Reflect my View & 41 & 23.0 & 33.9 & 100.0 \\
\hline & & Total & 121 & 68.0 & 100.0 & \\
\hline & Missing & System & 57 & 32.0 & & \\
\hline & Total & & 178 & 100.0 & & \\
\hline
\end{tabular}

People have different ideas about whether lying is ever morally permissible. Which of the following statements most closely reflect your view?

It is OK to lie to protect a friend, family member, or someone important to you.

\begin{tabular}{|c|c|c|c|c|c|}
\hline \multicolumn{2}{|c|}{ All Staff-weighted } & \multirow{2}{*}{$\frac{\text { Frequency }}{130}$} & \multirow{2}{*}{$\frac{\text { Percent }}{35.6}$} & \multirow{2}{*}{$\frac{\text { Valid Percent }}{54.2}$} & \multirow{2}{*}{$\begin{array}{c}\text { Cumulative } \\
\text { Percent }\end{array}$} \\
\hline Valid & Reflects my View & & & & \\
\hline & Does not Reflect my View & 110 & 30.1 & 45.8 & 100.0 \\
\hline & Total & 240 & 65.7 & 100.0 & \\
\hline Missing & System & 125 & 34.3 & & \\
\hline Total & & 364 & 100.0 & & \\
\hline
\end{tabular}


People have different ideas about whether lying is ever morally permissible. Which of the following statements most closely reflect your view?

It is OK to lie to protect a friend, family member, or someone important to you.

\begin{tabular}{llcccc}
\hline \hline ALL STAFF-unweighted & Frequency & Percent & Valid Percent & $\begin{array}{c}\text { Cumulative } \\
\text { Percent }\end{array}$ \\
\hline Valid & Reflects my View & 135 & 37.2 & 56.3 & 56.3 \\
& Does not Reflect my View & 105 & 28.9 & 43.8 & 100.0 \\
& Total & 240 & 66.1 & 100.0 & \\
Missing & System & 123 & 33.9 & \\
Total & & 363 & 100.0 & \\
\hline \hline
\end{tabular}

People have different ideas about whether lying is ever morally permissible. Which of the following statements most closely reflect your view?

It is OK to lie to protect a friend, family member, or someone important to you.

\begin{tabular}{llcccc}
\hline \hline Stennis Fellows & & & & Cumulative \\
Valid & Reflects my View & Frequency & Percent & Valid Percent & \begin{tabular}{c} 
Percent \\
\cline { 2 - 5 }
\end{tabular} \\
& Does not Reflect my View & 50 & 41.0 & 53.2 & 53.2 \\
& Total & 44 & 36.1 & 46.8 & 100.0 \\
Missing & System & 94 & 77.0 & 100.0 & \\
Total & & 28 & 23.0 & & \\
\hline \hline
\end{tabular}

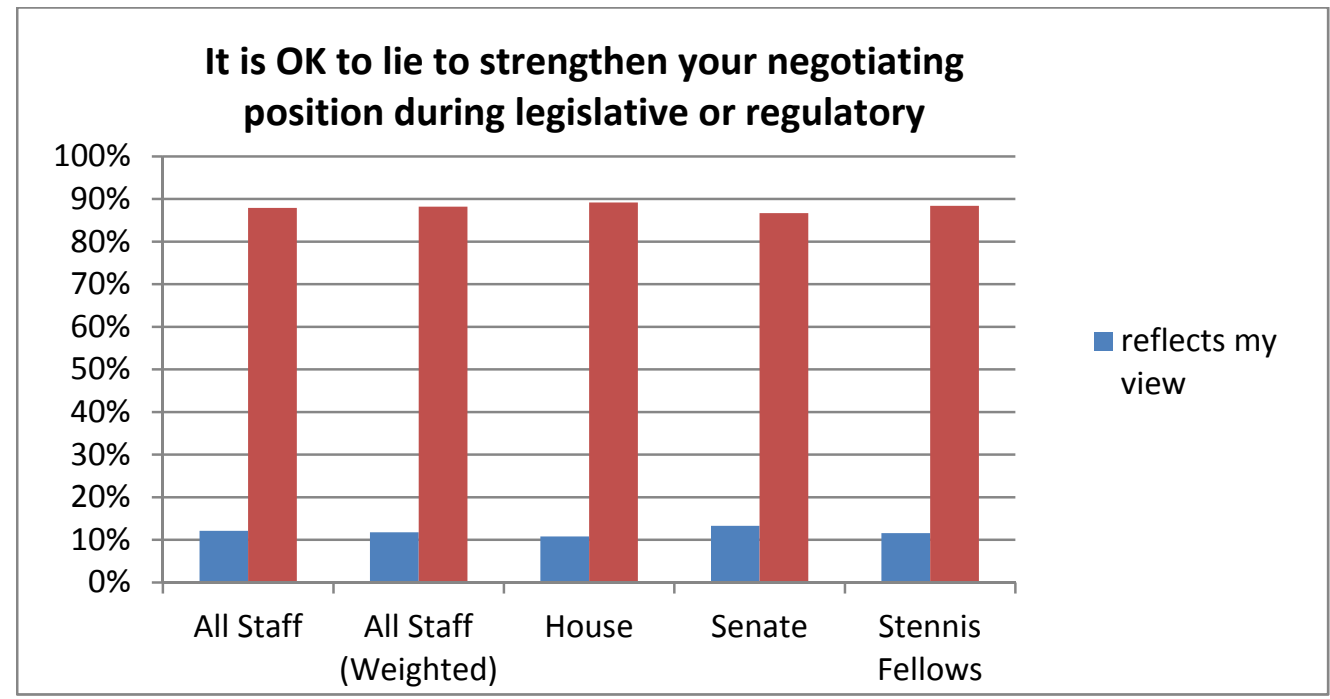

The role and justification of lying in negotiations is a matter of significant debate.

Carson suggests that, to the extent that misstating the nature and strength of one's negotiating position is commonplace and widely understood, it is not clear that negotiators are "warranting" or "intending to warrant" the truth of their statements (and 296 | P a g e 
therefore not lying). ${ }^{132}$ Even when the deception is understood as lying, Carson draws upon the analogy of self-defense to suggest that it may be justified to lie during negotiations in which the other party is lying to you. Cramton and Dees offer the following norm for negotiators:

"It is unfair to require an individual to take a significant risk or incur significant cost out of respect for the interests or moral rights of others, if that individual has no reasonable grounds for trusting that the relevant others will (or would) take the same risk or make the same sacrifice.",133

To test whether congressional staff believe that lying is justified to strengthen their position in negotiations, respondents were asked whether they agreed with the statement, "it is OK to lie to strengthen your position during legislative or regulatory negotiations." This statement was overwhelmingly rejected by respondents, with only $11-13 \%$ affirming it. Staff attitudes toward lying in negotiations are discussed further in the cases relating to the conference report and the bill promise that can be found in Chapter IX. ${ }^{134}$

Confidence intervals were calculated for each of the respondent groups. The widest confidence interval for the House was $\pm 5.6 \%$, for the Senate was $\pm 6.1 \%$, for all staffweighted was $\pm 4.1 \%$ and for Stennis Fellows was $\pm 5.2 \%$.

\footnotetext{
132 Carson, Lying and Deception: Theory and Practice.

${ }^{133}$ Dees and Cramton, "Shrewd Bargaining on the Moral Frontier: Toward a Theory of Morality in Practice."

${ }^{134}$ There is a strong relationship between indicating that one would lie in the bill promise case and anticipating that the other staff member would lie if the circumstances were reversed.
} 


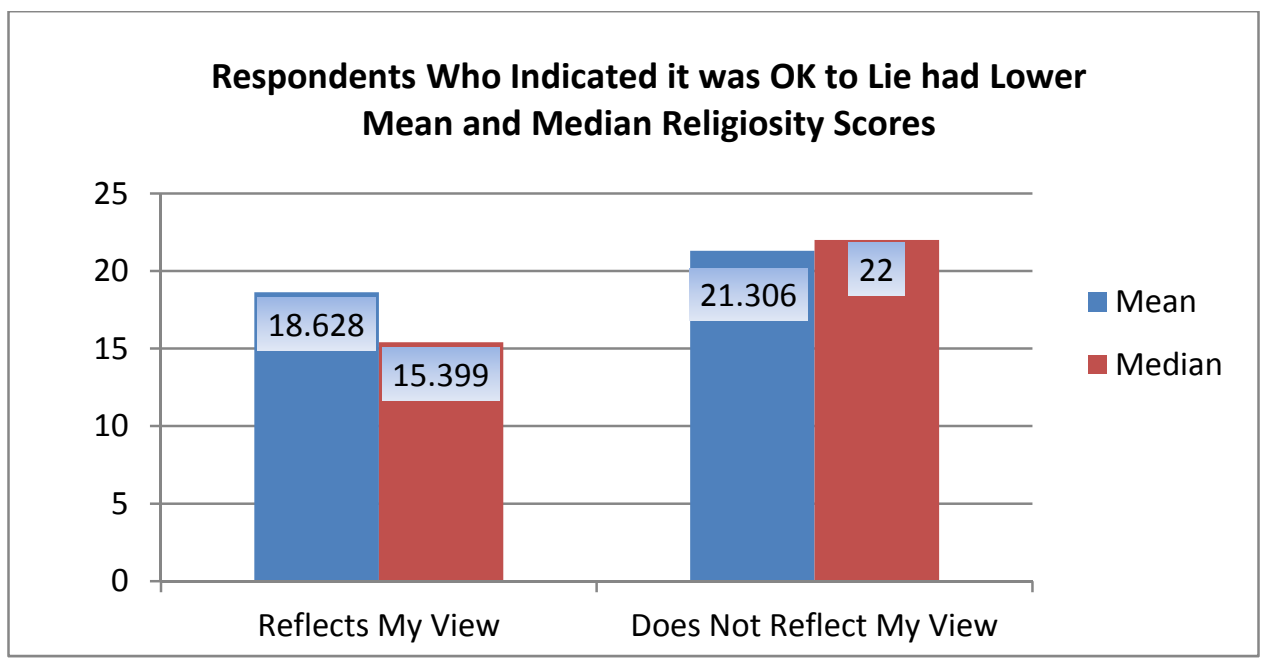

All staff-weighted respondents who indicated that the statement, "it is OK to lie to strengthen your negotiating position," reflected their view reported lower mean and median religiosity scores. The two-sample, two-tailed t-statistic for the difference in mean religiosity scores between staff who indicated this represented their view and for those for whom this did not reflect their view was not significant at the .05 level, $t(232)=1.720, p=.0867$.

A Mann-Whitney U test also revealed no statistically significant difference in the religiosity of respondents who indicated that it was $\mathrm{OK}$ to lie to strengthen your negotiating position $(M d n=15.399, n=28)$ and those who indicated this did not reflect their view $(M d n=22, n=206), U=2386, z=-1.755, p=.079$. 


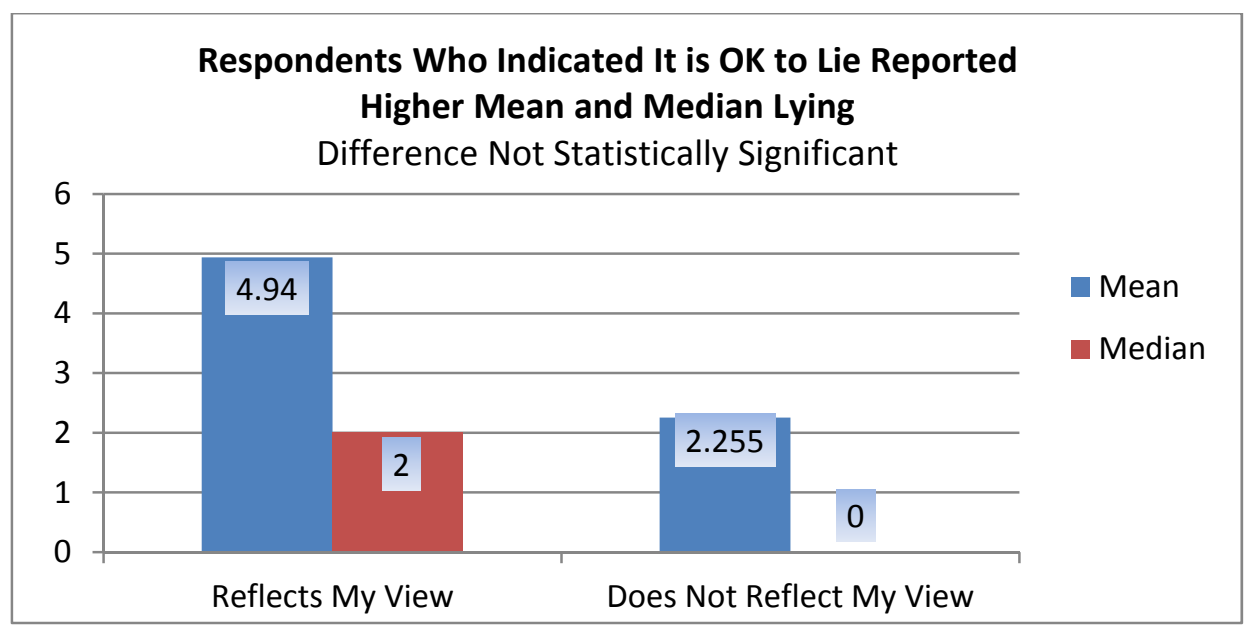

All staff-weighted respondents who indicated that the statement, "it is OK to lie to strengthen your negotiating position," reflected their view reported higher mean and median lying. The two-sample, two-tailed t-statistic for the difference in mean lies between staff who indicated this represented their view and for those for whom it did not reflect their view was not significant at the .05 level, $t(193)=1.786, p=.0757$.

A Mann-Whitney U test, however, revealed a statistically significant difference in lying of respondents who indicated that it was $\mathrm{OK}$ to lie to strengthen your negotiating position $(M d n=2.0, n=21)$ and those who indicated this did not reflect their view $(M d n=.00$, $n=174), U=3505, z=-2.918, p=.004$.

The two-sample, two-tailed t-statistic is a parametric test that assumes that the sample distribution of means is normal. This condition can be assumed to be met when sample sizes exceed 30-50. One of the groups includes only 21 respondents. As a result, we cannot assume a normal distribution, and the nonparametric Mann-Whitney U Test is the appropriate test for evaluating the difference in lying between the two groups. 


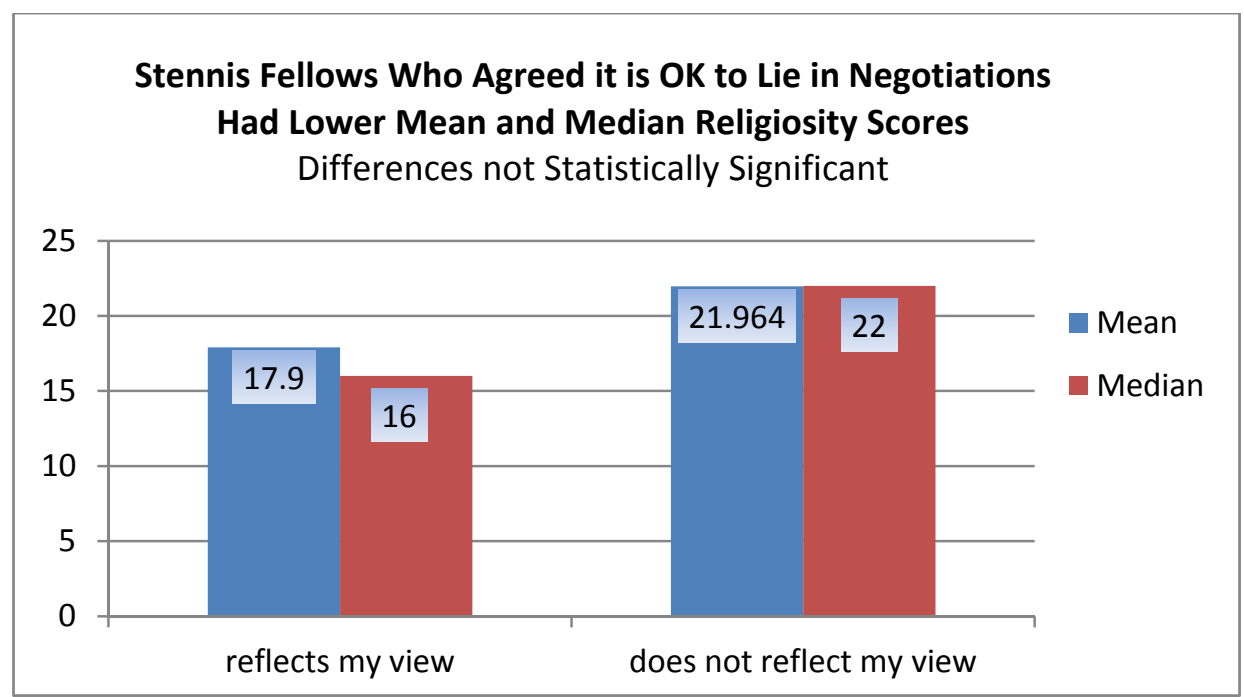

$11.6 \%$ of Stennis Fellows agreed that it is " $\mathrm{OK}$ to lie to strengthen your negotiating position during legislative or regulatory negotiations." These fellows had lower mean and median religiosity scores than their colleagues who did not agree with the statement. The two-sample, two-tailed t-statistic was not significant at the .05 level for the difference in religiosity between the two groups, $t(91)=1.673, p=.0977$. The MannWhitney U Test also revealed no significant difference in religiosity between fellows who agreed with the statement $(M d n=16, n=10)$ and fellows who disagreed with the statement $(M d n=22, n=83), U=282, z=-1.652, p=.099$. 


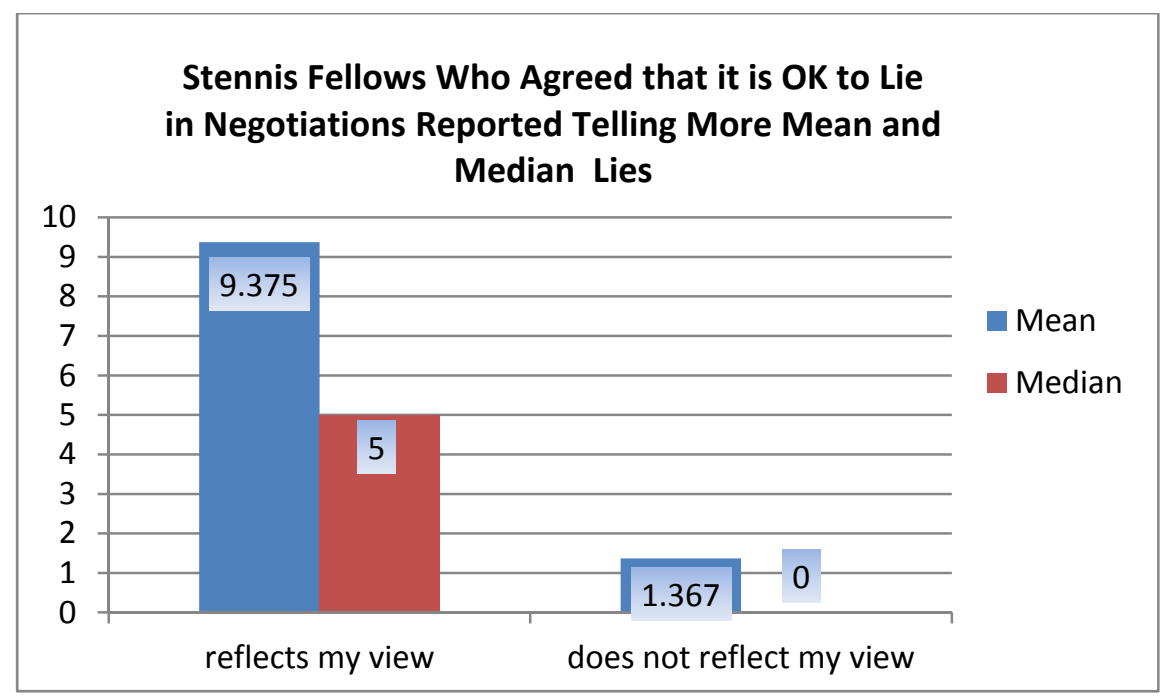

Stennis Fellows who agreed with the statement that it is "OK to lie to strengthen your negotiating position in legislative or regulatory negotiations" reported telling more mean and median lies than colleagues who disagreed with the statement. The two-sample, twotailed t-statistic was significant at the .05 level for the difference in mean lying between the two groups, $t(66)=4.862, p=.0000$. The Mann-Whitney U Test also revealed a significant difference in lying between fellows who agreed with the statement $(M d n=5$, $n=8)$ and fellows who disagreed with the statement $(M d n=0, n=60), U=86.5, z=-3.278$, $p=.001, z=.398$.

People have different ideas about whether lying is ever morally permissible. Which of the following statements most closely reflect your view?

It is OK to lie to strengthen your negotiating position during legislative or regulatory negotiations.

\begin{tabular}{|c|c|c|c|c|c|c|}
\hline \multicolumn{3}{|c|}{ Chamber } & \multirow{2}{*}{$\frac{\text { Frequency }}{13}$} & \multirow{2}{*}{$\frac{\text { Percent }}{7.0}$} & \multirow{2}{*}{$\frac{\text { Valid Percent }}{10.8}$} & \multirow{2}{*}{$\begin{array}{c}\begin{array}{c}\text { Cumulative } \\
\text { Percent }\end{array} \\
10.8\end{array}$} \\
\hline House & Valid & Reflects my View & & & & \\
\hline & & Does not Reflect my View & 107 & 57.8 & 89.2 & 100.0 \\
\hline & & Total & 120 & 64.9 & 100.0 & \\
\hline & Missing & System & 65 & 35.1 & & \\
\hline & Total & & 185 & 100.0 & & \\
\hline \multirow[t]{2}{*}{ Senate } & Valid & Reflects my View & 16 & 9.0 & 13.3 & 13.3 \\
\hline & & Does not Reflect my View & 104 & 58.4 & 86.7 & 100.0 \\
\hline
\end{tabular}




\begin{tabular}{llccc}
\hline & Total & 120 & 67.4 & 100.0 \\
Missing & System & 58 & 32.6 & \\
Total & & 178 & 100.0 \\
\hline \hline
\end{tabular}

People have different ideas about whether lying is ever morally permissible. Which of the following statements most closely reflect your view?

It is $\mathrm{OK}$ to lie to strengthen your negotiating position during legislative or regulatory negotiations.

\begin{tabular}{llcccc}
\hline \hline All Staff-weighted & & & & Cumulative \\
Valid & Reflects my View & Frequency & Percent & Valid Percent & \begin{tabular}{c} 
Percent \\
\cline { 2 - 5 }
\end{tabular} \\
& Does not Reflect my View & 28 & 7.8 & 11.8 & 11.8 \\
& Total & 212 & 58.1 & 88.2 & 100.0 \\
Missing & System & 240 & 65.8 & 100.0 & \\
Total & & 124 & 34.2 & & \\
\hline \hline
\end{tabular}

People have different ideas about whether lying is ever morally permissible. Which of the following statements most closely reflect your view?

It is OK to lie to strengthen your negotiating position during legislative or regulatory negotiations.

\begin{tabular}{|c|c|c|c|c|c|}
\hline \multicolumn{2}{|c|}{ ALL STAFF-unweighted } & \multirow{2}{*}{$\frac{\text { Frequency }}{29}$} & \multirow{2}{*}{$\frac{\text { Percent }}{8.0}$} & \multirow{2}{*}{$\frac{\text { Valid Percent }}{12.1}$} & \multirow{2}{*}{$\begin{array}{c}\begin{array}{c}\text { Cumulative } \\
\text { Percent }\end{array} \\
12.1\end{array}$} \\
\hline Valid & Reflects my View & & & & \\
\hline & Does not Reflect my View & 211 & 58.1 & 87.9 & 100.0 \\
\hline & Total & 240 & 66.1 & 100.0 & \\
\hline Missing & System & 123 & 33.9 & & \\
\hline Total & & 363 & 100.0 & & \\
\hline
\end{tabular}

People have different ideas about whether lying is ever morally permissible. Which of the following statements most closely reflect your view?

It is OK to lie to strengthen your negotiating position during legislative or regulatory negotiations.

\begin{tabular}{llcccc}
\hline \hline Stennis & Fellows & & & & Cumulative \\
Palid & Reflects my View & Frequency & Percent & Valid Percent & \begin{tabular}{c} 
Percent \\
\hline
\end{tabular} \\
& Does not Reflect my View & 11 & 9.0 & 11.6 & 11.6 \\
& Total & 84 & 68.9 & 88.4 & 100.0 \\
Missing & System & 95 & 77.9 & 100.0 & \\
Total & & 27 & 22.1 & \\
\hline \hline
\end{tabular}




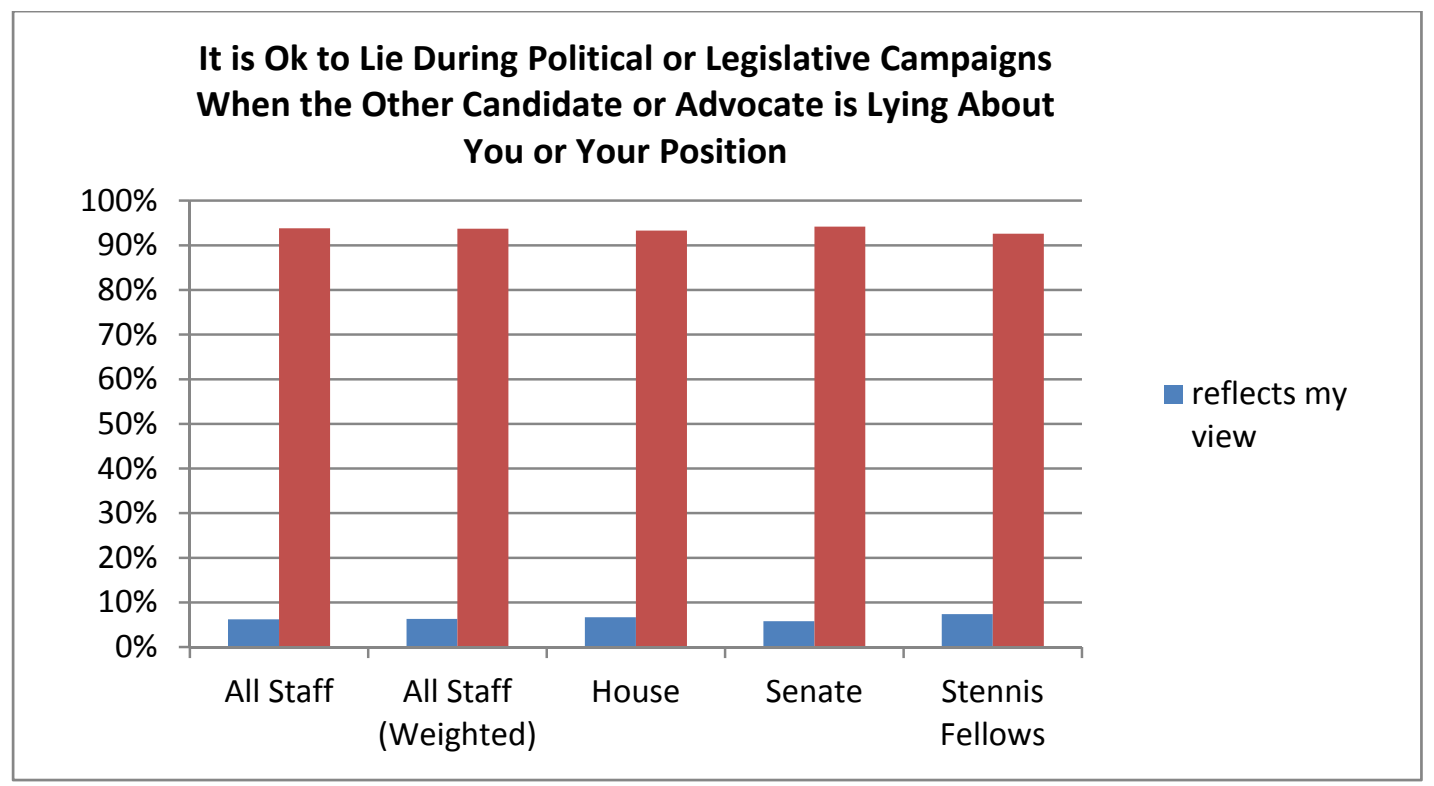

Respondents were asked whether they agreed with the statement, "it is OK to lie during political or legislative campaigns when the other candidate or advocate is lying about you or your position." The question was designed, in part, to assess whether staff accept the notion of defensive lying. Staff overwhelmingly disagreed with the statement while only $6 \%-8 \%$ of respondents agreed with it.

Confidence intervals were calculated for each of the respondent groups. The widest confidence interval for the House was $\pm 4.5 \%$, for the Senate was $\pm 4.2 \%$, for all staffweighted was $\pm 3.1 \%$ and for Stennis Fellows was $\pm 4.3 \%$.

Stennis Fellows $(7.4 \%)$ were more likely to respond that they agreed with the statement, "it is $\mathrm{OK}$ to lie during political or legislative campaigns when the other candidate or advocate is lying about you," than House staff (6.7\%) or Senate staff (5.8\%). The twosample, two-tailed t-statistic was not significant at the .05 level for the difference 
between Stennis Fellows and Senate staff, $t(214)=.474, p=.64$. The null hypothesis that there is no difference between Senate staff and Stennis Fellows cannot be rejected.

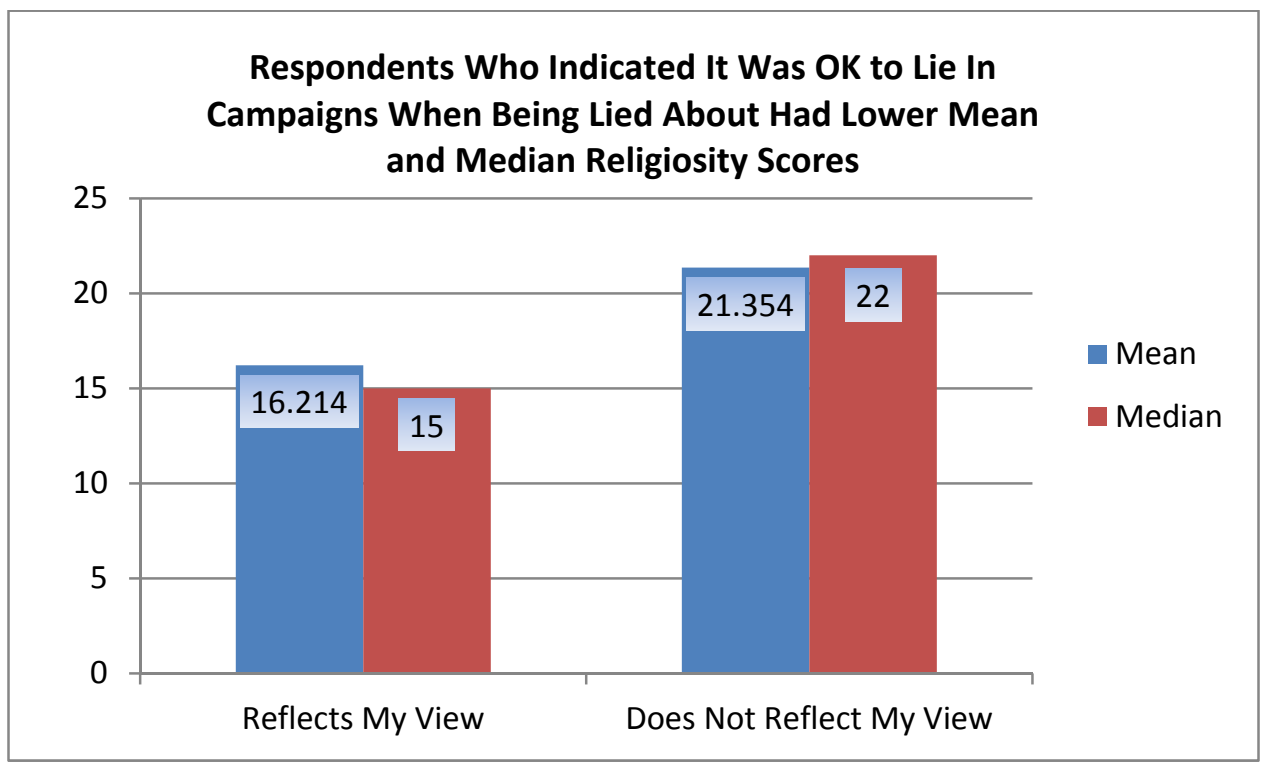

All staff-weighted respondents who indicated that the statement, "it is OK to lie during political or legislative campaigns when the other candidate or advocate are lying about you," reflected their view reported lower mean and median religiosity scores. The twosample, two-tailed t-statistic for the difference in mean religiosity scores between staff who indicated this represented their view and for those for whom this did not reflect their view was significant at the .05 level, $t(233)=2.503, \mathrm{p}=.0130$.

A Mann-Whitney U test also revealed a statistically significant difference in the religiosity of respondents who indicated that it was $\mathrm{OK}$ to tell a lie during a campaign when others are lying about you $(M d n=15 ., n=15)$ and those who indicated this did not reflect their view $(M d n=22, n=220), U=1030, z=-2.455, p=.014$. 


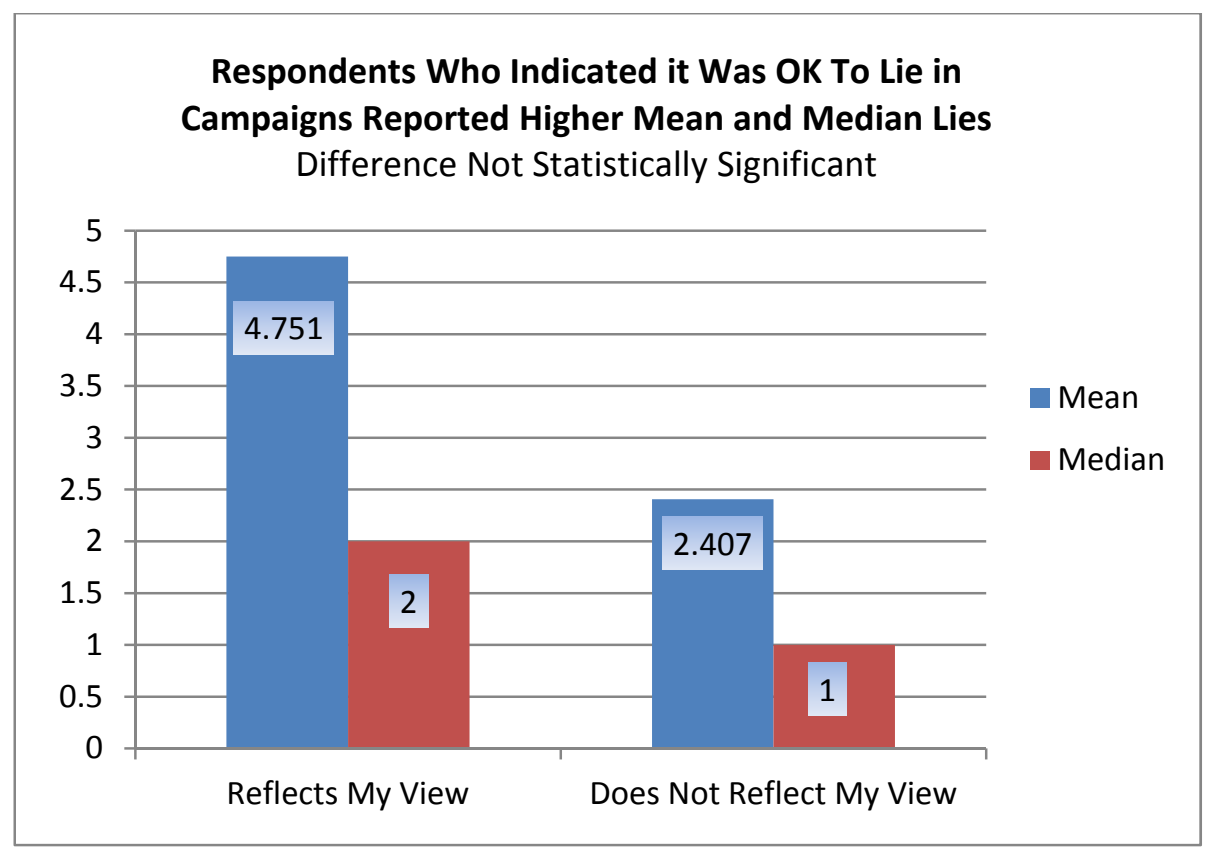

All staff-weighted respondents who indicated that the statement, "it is OK to lie during political campaigns," reflected their view reported higher mean and median lying. The two-sample, two-tailed t-statistic for the difference in mean lie scores between staff who indicated this represented their view and for those for whom this did not reflect their view was not significant at the .05 level, $t(194)=1.157, p=.2488$.

A Mann-Whitney U test also revealed no statistically significant difference in lying between respondents who indicated that it was $\mathrm{OK}$ to lie during political campaigns $(M d n=2.0, n=11)$ and those who indicated this did not reflect their view $(M d n=1.0$, $n=185), U=781.5, z=-1.347, p=.178$. 


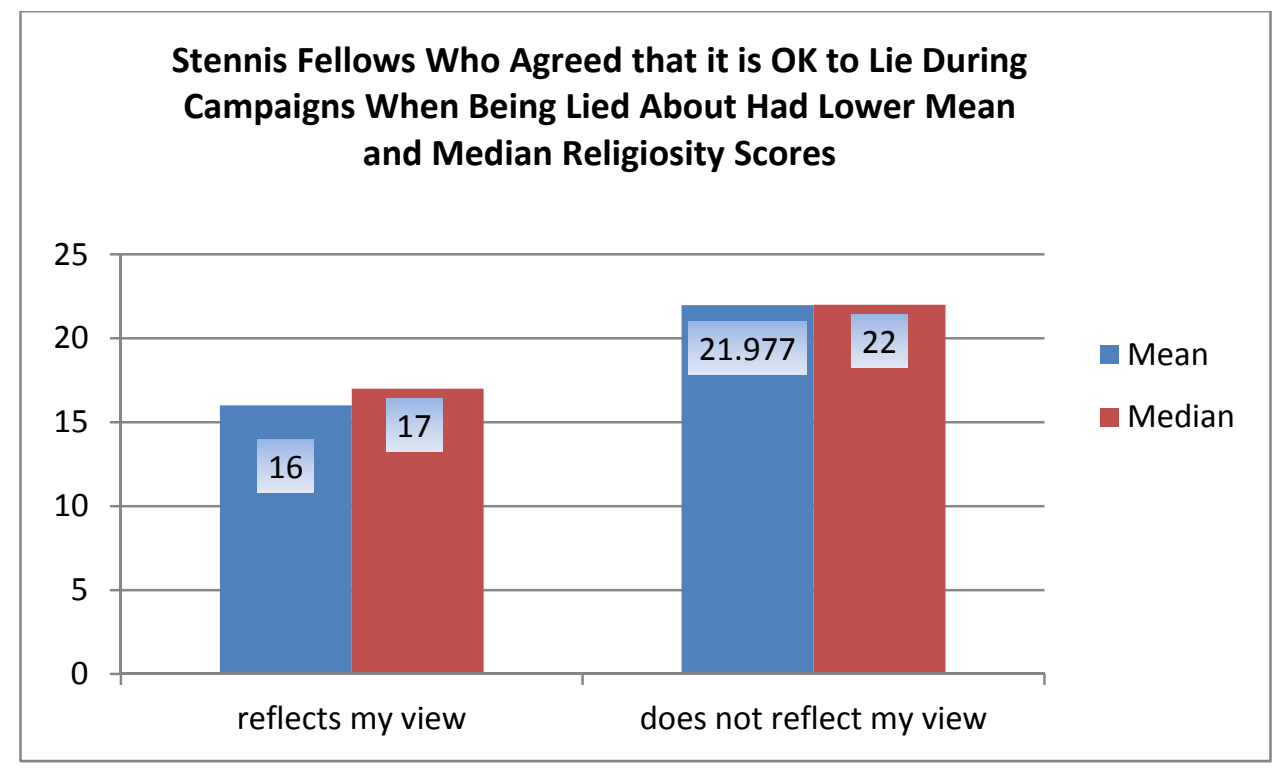

Stennis Fellows who indicated that they agreed with the statement, "it is OK to lie during political or legislative campaigns when the other candidate or advocate is lying about you or your position," had lower religiosity scores than those who disagreed. The twosample, two-tailed t-statistic was significant at the .05 level for the difference between the groups of fellows, $t(91)=2.114, p=.0372$. The Mann-Whitney U Test also revealed statistically significant differences in religiosity between fellows who agreed with the statement $(M d n=17, n=7)$ and fellows who disagreed $(M d n=22, n=86), U=163, z=-2.012$, $p=.044, r=.209$. 


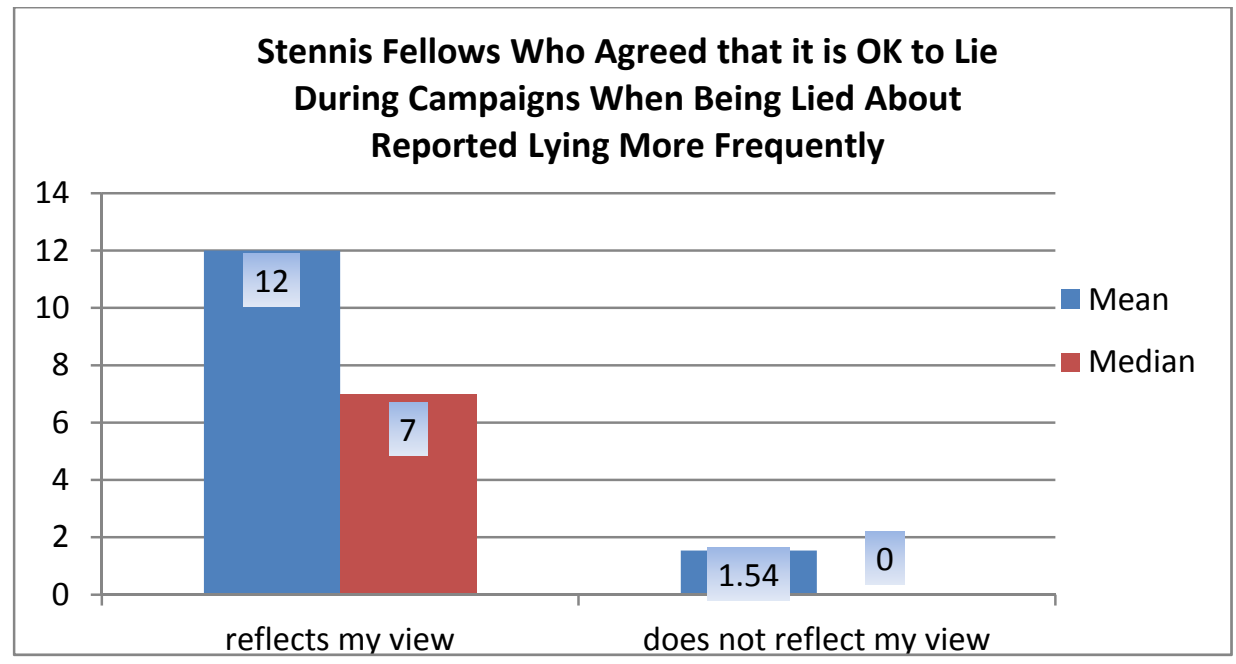

$7.4 \%$ of Stennis Fellows agreed with the statement that it is "OK to lie during political or legislative campaigns when the other candidate or advocate is lying about you or your position." These fellows reported lying more frequently than their colleagues who did not agree with the statement. The two-sample, two-tailed t-statistic for the difference in mean lying was significant at the .05 level, $t(66)=5.259, p=.0000$. The Mann-Whitney U Test also revealed a significant difference in lying between the fellows who agreed with the statement $(M d n=7, n=5)$ and fellows who disagreed $(M d n=0, n=63), U=62, z=-2.517$, $p=.012, \mathrm{r}=.305$.

People have different ideas about whether lying is ever morally permissible. Which of the following statements most closely reflect your view?

It is OK to lie during political or legislative campaigns when the other candidate or advocate is lying about you or your position.

\begin{tabular}{|c|c|c|c|c|c|c|}
\hline \multicolumn{3}{|c|}{ Chamber } & \multirow{2}{*}{$\frac{\text { Frequency }}{8}$} & \multirow{2}{*}{$\frac{\text { Percent }}{4.3}$} & \multirow{2}{*}{$\frac{\text { Valid Percent }}{6.7}$} & \multirow{2}{*}{$\begin{array}{c}\begin{array}{c}\text { Cumulative } \\
\text { Percent }\end{array} \\
6.7\end{array}$} \\
\hline House & Valid & Reflects my View & & & & \\
\hline & & Does not Reflect my View & 112 & 60.5 & 93.3 & 100.0 \\
\hline & & Total & 120 & 64.9 & 100.0 & \\
\hline & Missing & System & 65 & 35.1 & & \\
\hline & Total & & 185 & 100.0 & & \\
\hline \multirow[t]{3}{*}{ Senate } & Valid & Reflects my View & 7 & 3.9 & 5.8 & 5.8 \\
\hline & & Does not Reflect my View & 114 & 64.0 & 94.2 & 100.0 \\
\hline & & Total & 121 & 68.0 & 100.0 & \\
\hline
\end{tabular}




\begin{tabular}{|c|c|c|c|}
\hline Missing & System & 57 & 32.0 \\
\hline Total & & 178 & 100.0 \\
\hline
\end{tabular}

People have different ideas about whether lying is ever morally permissible. Which of the following statements most closely reflect your view?

It is OK to lie during political or legislative campaigns when the other candidate or advocate is lying about you or your position.

\begin{tabular}{|c|c|c|c|c|c|}
\hline \multicolumn{2}{|c|}{ All Staff-weighted } & \multirow{2}{*}{$\frac{\text { Frequency }}{15}$} & \multirow{2}{*}{$\frac{\text { Percent }}{4.2}$} & \multirow{2}{*}{$\frac{\text { Valid Percent }}{6.3}$} & \multirow{2}{*}{$\begin{array}{c}\begin{array}{c}\text { Cumulative } \\
\text { Percent }\end{array} \\
6.3\end{array}$} \\
\hline Valid & Reflects my View & & & & \\
\hline & Does not Reflect my View & 226 & 61.9 & 93.7 & 100.0 \\
\hline & Total & 241 & 66.1 & 100.0 & \\
\hline Missing & System & 124 & 33.9 & & \\
\hline Total & & 364 & 100.0 & & \\
\hline
\end{tabular}

People have different ideas about whether lying is ever morally permissible. Which of the following statements most closely reflect your view?

It is OK to lie during political or legislative campaigns when the other candidate or advocate is lying about you or your position.

\begin{tabular}{llcccc}
\hline \hline ALL STAFF-unweighted & Frequency & Percent & Valid Percent & $\begin{array}{c}\text { Cumulative } \\
\text { Percent }\end{array}$ \\
\hline Valid & Reflects my View & 15 & 4.1 & 6.2 & 6.2 \\
& Does not Reflect my View & 226 & 62.3 & 93.8 & 100.0 \\
& Total & 241 & 66.4 & 100.0 & \\
Missing & System & 122 & 33.6 & & \\
Total & & 363 & 100.0 & & \\
\hline \hline
\end{tabular}

People have different ideas about whether lying is ever morally permissible. Which of the following statements most closely reflect your view?

It is OK to lie during political or legislative campaigns when the other candidate or advocate is lying about you or your position.

\begin{tabular}{|c|c|c|c|c|c|}
\hline \multicolumn{2}{|c|}{ Stennis Fellows } & \multirow{2}{*}{$\frac{\text { Frequency }}{7}$} & \multirow{2}{*}{$\frac{\text { Percent }}{5.7}$} & \multirow{2}{*}{$\frac{\text { Valid Percent }}{7.4}$} & \multirow{2}{*}{$\begin{array}{c}\begin{array}{c}\text { Cumulative } \\
\text { Percent }\end{array} \\
7.4\end{array}$} \\
\hline Valid & Reflects my View & & & & \\
\hline & Does not Reflect my View & 88 & 72.1 & 92.6 & 100.0 \\
\hline & Total & 95 & 77.9 & 100.0 & \\
\hline Missing & System & 27 & 22.1 & & \\
\hline Total & & 122 & 100.0 & & \\
\hline
\end{tabular}




\section{The Relationship between Religiosity and definition of a Lie}

Respondents were asked seven questions about their definition of a lie. In all cases, all staff-weighted and Stennis Fellow respondents who indicated that the statement was a lie appeared to have at least nominally higher religiosity scores. The difference in religiosity was only statistically significant for two of the definitions for all staffweighted and for four of the definitions for Stennis Fellows. The difference in religiosity was statistically significant for both groups for only one definition-a statement that is "untrue but made in order to avoid hurting someone's feelings." For both staff and for fellows, indicating that this is a lie is associated with higher religiosity scores.

Respondents were asked 10 questions about whether and under what circumstances it was "OK" to tell a lie. The difference in religiosity was statistically significant in eight out of the 10 cases for all staff-weighted. The difference in religiosity was significant in five out of the 10 cases for Stennis Fellows. The difference in religiosity was statistically significant for both groups for four of the responses: It is never OK to tell a lie; it is OK to tell a lie when others are lying to you; it is all right to lie to protect friends or family; and it is $\mathrm{OK}$ to lie in campaigns when others are lying about you. Agreement with the statement, "it is never OK to tell a lie," was associated with higher religiosity. For the remaining three responses, lower religiosity was associated with agreement that it was OK to lie under those circumstances or conditions.

\section{Relationship between Definition and Justification and Frequency of Reported Lying}

The frequency of lying was not statistically significant for all staff-weighted for any of the variants on the definition of a lie. The frequency of lying was statistically significant 
for Stennis Fellows for only one definition - "a statement that you assert/claim is true when you are actually uncertain about the truth or falsehood of your statement."

The frequency of lying was statistically significant for all staff-weighted for four of the 10 justifications. The frequency of lying was statistically significant for Stennis Fellows for six of the justifications. The difference in lying was statistically significant for both groups for three justifications: it is OK to lie when others are lying to you; it is OK to lie to people who have no right to the information, and it is OK to lie to protect family and friends. In all three cases, agreement with the statement was associated with more reported lies. 


\section{Chapter IX. The Cases}

In the previous two sections of the survey, respondents were provided with definitions of lying and potential justifications for lying. These definitions were presented without any contextual information that might have influenced their practical reasoning or intuitions. The next section provided respondents with eight cases designed to test the consistency of their previous answers as well as gain a window into how they handled real or apparent conflicts between relationships, principals, and values. The cases were drawn to try to force a "lie" or "not lie" answer. Respondents always had the opportunity to choose "other" and offer their own response. These "other" responses were then reviewed and catalogued into new response categories where appropriate.

The response "other" serves two purposes in this part of the questionnaire. On a structural level, it provides, along with the ability to skip a question, an outlet for respondents who find a given question too uncomfortable to answer. Just as importantly, however, it provides both a window into practical reasoning and a measure of the significance or import that the respondents give the question before them. Respondents were presented with black and white "yes" or "no" responses. In many instances these responses met their needs. There is, however, always the possibility of a "third way" that is not captured by the categorical response options. Cases in which "other" is the predominate response (and assuming the question was not poorly drawn) signal that these are the types of problems that respondents find the most ethically complex. As will be discussed, the relationship between responses and religiosity was complex. 


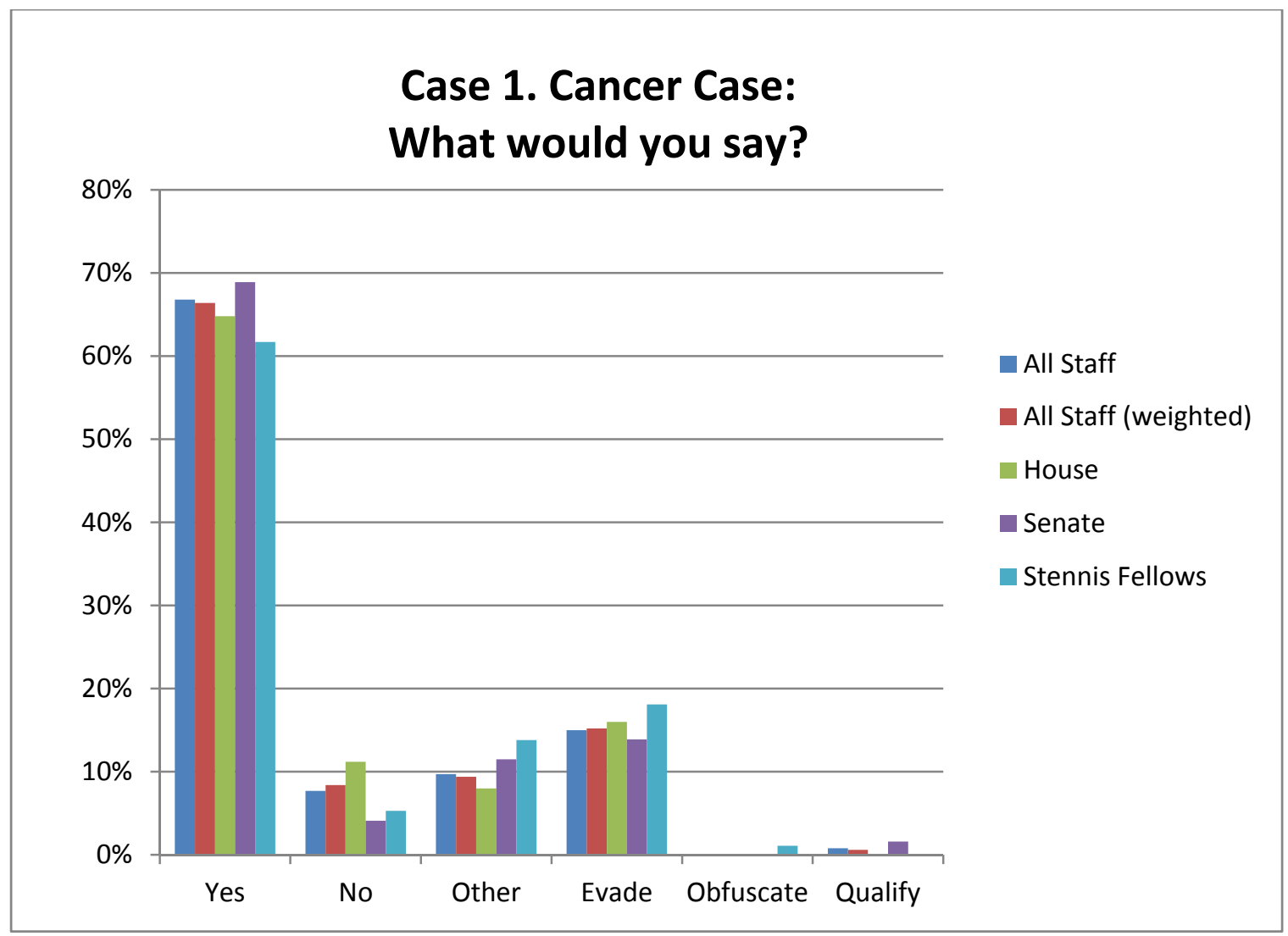

The cancer case was drawn to ease respondents into case analysis by offering them a relatively unthreatening case in which little stigma would be attached to lying or deception. Respondents were provided with the following scenario:

\footnotetext{
"One of your colleagues has been diagnosed with cancer and has been undergoing radiation and chemotherapy. You have confided to another friend that she appears to be getting progressively sicker and weaker each time you see her. She has come back to the office to keep her mind off of the treatment and she tells you that she thinks she is looking better than last time you met and asks if you agree. Would you answer":
}

A significant majority of respondents would answer "yes." Four to $11 \%$ would say "no" and the remainder originally indicated "other." Review of "other" created three new categories: "evade," "obfuscate," and "qualify." "Evade" captured responses that were not untruthful but failed to answer the question directly. "Obfuscate" captured responses in which the person told a falsehood but the falsehood did not pertain to the facts of the 
direct question (e.g., I haven’t been paying attention, I haven't noticed...). "Qualify" captured responses that included some form of "yes, but..."

Confidence intervals were calculated for each of the respondent groups. The widest confidence interval for the House was $\pm 8.4 \%$, for the Senate was $\pm 8.2 \%$, for all staffweighted was $\pm 5.9 \%$ and for Stennis Fellows was $\pm 8.0 \%$.

Senate staff (68.9\%) were more likely than House staff (64.8\%) or Stennis Fellows $(61.7 \%)$ to respond that they would answer "yes" to the question regarding whether they agree that their colleague looks better. The two-sample, two-tailed t-statistic was not significant at the .05 level for the difference between Stennis Fellows and Senate staff, $t(214)=1.1, p=.27$. The null hypothesis that there is no difference between Senate staff and Stennis Fellows cannot be rejected.

House staff (11.2\%) were more likely than Senate staff (4.1\%) or Stennis Fellows (5.3\%) to answer "no." The two-sample, two-tailed t-statistic was significant at the .05 level for the difference between House and Senate staff, $t(245)=2.09, p=.037$. The two-sample, two-tailed t-statistic was not significant at the .05 level for the difference between House staff and Stennis Fellows, $t(217)=1.5, p=.125$. The null hypothesis that there is no difference between House staff and Stennis Fellows cannot be rejected. 
Case 1. One of your colleagues has been diagnosed with cancer and has been undergoing radiation and chemotherapy.

\begin{tabular}{|c|c|c|c|c|c|c|}
\hline \multicolumn{3}{|c|}{ Chamber } & \multirow{2}{*}{$\begin{array}{r}\text { Frequency } \\
81\end{array}$} & \multirow{2}{*}{$\frac{\text { Percent }}{43.8}$} & \multirow{2}{*}{$\begin{array}{r}\text { Valid Percent } \\
64.8\end{array}$} & \multirow{2}{*}{$\begin{array}{r}\begin{array}{l}\text { Cumulative } \\
\text { Percent }\end{array} \\
64.8\end{array}$} \\
\hline House & Valid & yes & & & & \\
\hline & & No & 14 & 7.6 & 11.2 & 76.0 \\
\hline & & Other & 10 & 5.4 & 8.0 & 84.0 \\
\hline & & Evade & 20 & 10.8 & 16.0 & 100.0 \\
\hline & & Total & 125 & 67.6 & 100.0 & \\
\hline & Missing & System & 60 & 32.4 & & \\
\hline & Total & & 185 & 100.0 & & \\
\hline \multirow[t]{8}{*}{ Senate } & Valid & yes & 84 & 47.2 & 68.9 & 68.9 \\
\hline & & No & 5 & 2.8 & 4.1 & 73.0 \\
\hline & & Other & 14 & 7.9 & 11.5 & 84.4 \\
\hline & & Evade & 17 & 9.6 & 13.9 & 98.4 \\
\hline & & Qualify & 2 & 1.1 & 1.6 & 100.0 \\
\hline & & Total & 122 & 68.5 & 100.0 & \\
\hline & Missing & System & 56 & 31.5 & & \\
\hline & Total & & 178 & 100.0 & & \\
\hline
\end{tabular}

Case 1. One of your colleagues has been diagnosed with cancer and has been undergoing radiation and chemotherapy.

\begin{tabular}{llcccc}
\hline \hline All Staff-weighted & Frequency & Percent & Valid Percent & $\begin{array}{c}\text { Cumulative } \\
\text { Percent }\end{array}$ \\
\hline Valid & yes & 164 & 45.1 & 66.4 & 66.4 \\
& No & 21 & 5.7 & 8.4 & 74.8 \\
& Other & 23 & 6.4 & 9.4 & 84.2 \\
& Evade & 38 & 10.3 & 15.2 & 99.4 \\
& Qualify & 2 & .4 & .6 & 100.0 \\
& Total & 248 & 67.9 & 100.0 & \\
Missing & System & 117 & 32.1 & & \\
\hline \hline
\end{tabular}

Case 1. One of your colleagues has been diagnosed with cancer and has been undergoing radiation and chemotherapy.

\begin{tabular}{lccccc}
\hline \hline ALL STAFF- & \multicolumn{3}{c}{} & & \\
unweighted & Frequency & Percent & Valid Percent & $\begin{array}{c}\text { Cumulative } \\
\text { Percent }\end{array}$ \\
\hline \multicolumn{7}{l}{ Valid } & yes & 165 & 45.5 & 66.8 & 66.8 \\
& No & 19 & 5.2 & 7.7 & 74.5 \\
& Other & 24 & 6.6 & 9.7 & 84.2 \\
& Evade & 37 & 10.2 & 15.0 & 99.2 \\
& Qualify & 2 & .6 & .8 & 100.0 \\
& Total & 247 & 68.0 & 100.0 & \\
Missing & System & 116 & 32.0 & & \\
Total & 363 & 100.0 & & \\
\hline \hline
\end{tabular}


Case 1. One of your colleagues has been diagnosed with cancer and has been undergoing radiation and...

\begin{tabular}{llcccc}
\hline \hline Stennis Fellows & Frequency & Percent & Valid Percent & $\begin{array}{c}\text { Cumulative } \\
\text { Percent }\end{array}$ \\
\hline Valid & yes & 58 & 47.5 & 61.7 & 61.7 \\
& No & 5 & 4.1 & 5.3 & 67.0 \\
& Other & 13 & 10.7 & 13.8 & 80.9 \\
& Evade & 17 & 13.9 & 18.1 & 98.9 \\
& Obfuscate & 1 & .8 & 1.1 & 100.0 \\
& Total & 94 & 77.0 & 100.0 & \\
Missing & System & 28 & 23.0 & & \\
\hline \hline
\end{tabular}

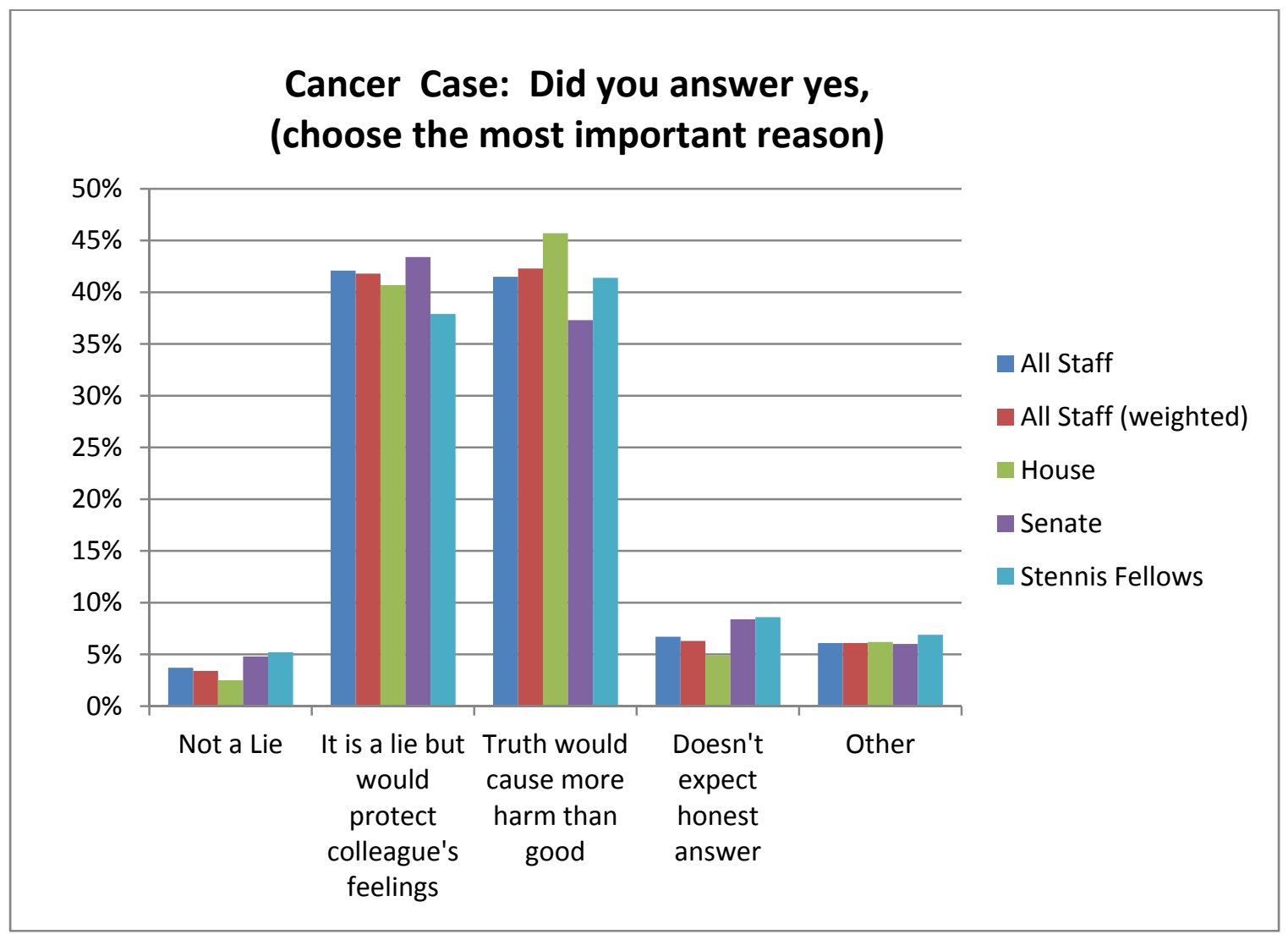

The two most common reasons offered by staff who indicated that they would answer "yes" were "it is a lie but it would protect my colleague's feelings" and the "truth would cause more harm than good." A small percentage indicated that this would not be a lie and $7 \%$ to $8 \%$ indicated that she "doesn't expect an honest answer." For the majority of these respondents, the statement constituted a lie but the prohibition against lying was not 
absolute and was outweighed by alternate considerations related to compassion for their colleague or the belief that truth would cause more harm than good.

Did you answer yes, because (choose the most important reason)

\begin{tabular}{|c|c|c|c|c|c|c|}
\hline \multicolumn{3}{|c|}{ Chamber } & \multirow{2}{*}{$\frac{\text { Frequency }}{2}$} & \multirow{2}{*}{$\frac{\text { Percent }}{1.1}$} & \multirow{2}{*}{$\frac{\text { Valid Percent }}{2.5}$} & \multirow{2}{*}{$\begin{array}{c}\begin{array}{c}\text { Cumulative } \\
\text { Percent }\end{array} \\
2.5\end{array}$} \\
\hline House & Valid & $\begin{array}{l}\text { You believe that this would } \\
\text { not be a lie }\end{array}$ & & & & \\
\hline & & $\begin{array}{l}\text { You believe this would be a } \\
\text { lie but it will protect your } \\
\text { colleague's feelings }\end{array}$ & 33 & 17.8 & 40.7 & 43.2 \\
\hline & & $\begin{array}{l}\text { The truth would cause more } \\
\text { harm than good }\end{array}$ & 37 & 20.0 & 45.7 & 88.9 \\
\hline & & $\begin{array}{l}\text { She doesn't really expect } \\
\text { you to be totally honest }\end{array}$ & 4 & 2.2 & 4.9 & 93.8 \\
\hline & & Other & 5 & 2.7 & 6.2 & 100.0 \\
\hline & & Total & 81 & 43.8 & 100.0 & \\
\hline & Missing & System & 104 & 56.2 & & \\
\hline & Total & & 185 & 100.0 & & \\
\hline \multirow[t]{8}{*}{ Senate } & Valid & $\begin{array}{l}\text { You believe that this would } \\
\text { not be a lie }\end{array}$ & 4 & 2.2 & 4.8 & 4.8 \\
\hline & & $\begin{array}{l}\text { You believe this would be a } \\
\text { lie but it will protect your } \\
\text { colleague's feelings }\end{array}$ & 36 & 20.2 & 43.4 & 48.2 \\
\hline & & $\begin{array}{l}\text { The truth would cause more } \\
\text { harm than good }\end{array}$ & 31 & 17.4 & 37.3 & 85.5 \\
\hline & & $\begin{array}{l}\text { She doesn't really expect } \\
\text { you to be totally honest }\end{array}$ & 7 & 3.9 & 8.4 & 94.0 \\
\hline & & Other & 5 & 2.8 & 6.0 & 100.0 \\
\hline & & Total & 83 & 46.6 & 100.0 & \\
\hline & Missing & System & 95 & 53.4 & & \\
\hline & Total & & 178 & 100.0 & & \\
\hline
\end{tabular}

Did you answer yes, because (choose the most important reason)

\begin{tabular}{llcccc}
\hline \hline All Staff-weighted & Frequency & Percent & Valid Percent & $\begin{array}{c}\text { Cumulative } \\
\text { Percent }\end{array}$ \\
\hline Valid & $\begin{array}{l}\text { You believe that this would } \\
\text { not be a lie }\end{array}$ & 6 & 1.5 & 3.4 & 3.4
\end{tabular}




\begin{tabular}{|c|c|c|c|c|c|}
\hline & $\begin{array}{l}\text { You believe this would be a } \\
\text { lie but it will protect your } \\
\text { colleague's feelings }\end{array}$ & 68 & 18.8 & 41.8 & 45.2 \\
\hline & $\begin{array}{l}\text { The truth would cause more } \\
\text { harm than good }\end{array}$ & 69 & 19.0 & 42.3 & 87.5 \\
\hline & $\begin{array}{l}\text { She doesn't really expect } \\
\text { you to be totally honest }\end{array}$ & 10 & 2.8 & 6.3 & 93.9 \\
\hline & Other & 10 & 2.7 & 6.1 & 100.0 \\
\hline & Total & 164 & 44.9 & 100.0 & \\
\hline Missing & System & 201 & 55.1 & & \\
\hline Total & & 364 & 100.0 & & \\
\hline
\end{tabular}

Did you answer yes, because (choose the most important reason)

\begin{tabular}{|c|c|c|c|c|c|}
\hline \multicolumn{2}{|c|}{ ALL STAFF-unweighted } & \multirow{2}{*}{$\frac{\text { Frequency }}{6}$} & \multirow{2}{*}{$\frac{\text { Percent }}{1.7}$} & \multirow{2}{*}{$\frac{\text { Valid Percent }}{3.7}$} & \multirow{2}{*}{$\begin{array}{c}\begin{array}{c}\text { Cumulative } \\
\text { Percent }\end{array} \\
3.7\end{array}$} \\
\hline Valid & $\begin{array}{l}\text { You believe that this would } \\
\text { not be a lie }\end{array}$ & & & & \\
\hline & $\begin{array}{l}\text { You believe this would be a } \\
\text { lie but it will protect your } \\
\text { colleague's feelings }\end{array}$ & 69 & 19.0 & 42.1 & 45.7 \\
\hline & $\begin{array}{l}\text { The truth would cause more } \\
\text { harm than good }\end{array}$ & 68 & 18.7 & 41.5 & 87.2 \\
\hline & $\begin{array}{l}\text { She doesn't really expect } \\
\text { you to be totally honest }\end{array}$ & 11 & 3.0 & 6.7 & 93.9 \\
\hline & Other & 10 & 2.8 & 6.1 & 100.0 \\
\hline & Total & 164 & 45.2 & 100.0 & \\
\hline Missing & System & 199 & 54.8 & & \\
\hline Total & & 363 & 100.0 & & \\
\hline
\end{tabular}

Did you answer yes, because (choose the most important reason)

\begin{tabular}{|c|c|c|c|c|c|}
\hline \multicolumn{2}{|c|}{ Stennis Fellows } & \multirow{2}{*}{$\frac{\text { Frequency }}{3}$} & \multirow{2}{*}{$\frac{\text { Percent }}{2.5}$} & \multirow{2}{*}{$\frac{\text { Valid Percent }}{5.2}$} & \multirow{2}{*}{$\begin{array}{c}\begin{array}{c}\text { Cumulative } \\
\text { Percent }\end{array} \\
5.2\end{array}$} \\
\hline Valid & $\begin{array}{l}\text { You believe that this would } \\
\text { not be a lie }\end{array}$ & & & & \\
\hline & $\begin{array}{l}\text { You believe this would be a } \\
\text { lie but it will protect your } \\
\text { colleague's feelings }\end{array}$ & 22 & 18.0 & 37.9 & 43.1 \\
\hline & $\begin{array}{l}\text { The truth would cause more } \\
\text { harm than good }\end{array}$ & 24 & 19.7 & 41.4 & 84.5 \\
\hline & $\begin{array}{l}\text { She doesn't really expect } \\
\text { you to be totally honest }\end{array}$ & 5 & 4.1 & 8.6 & 93.1 \\
\hline & Other & 4 & 3.3 & 6.9 & 100.0 \\
\hline & Total & 58 & 47.5 & 100.0 & \\
\hline
\end{tabular}




\begin{tabular}{|c|c|}
\hline Missing & System \\
\hline Total & \\
\hline
\end{tabular}

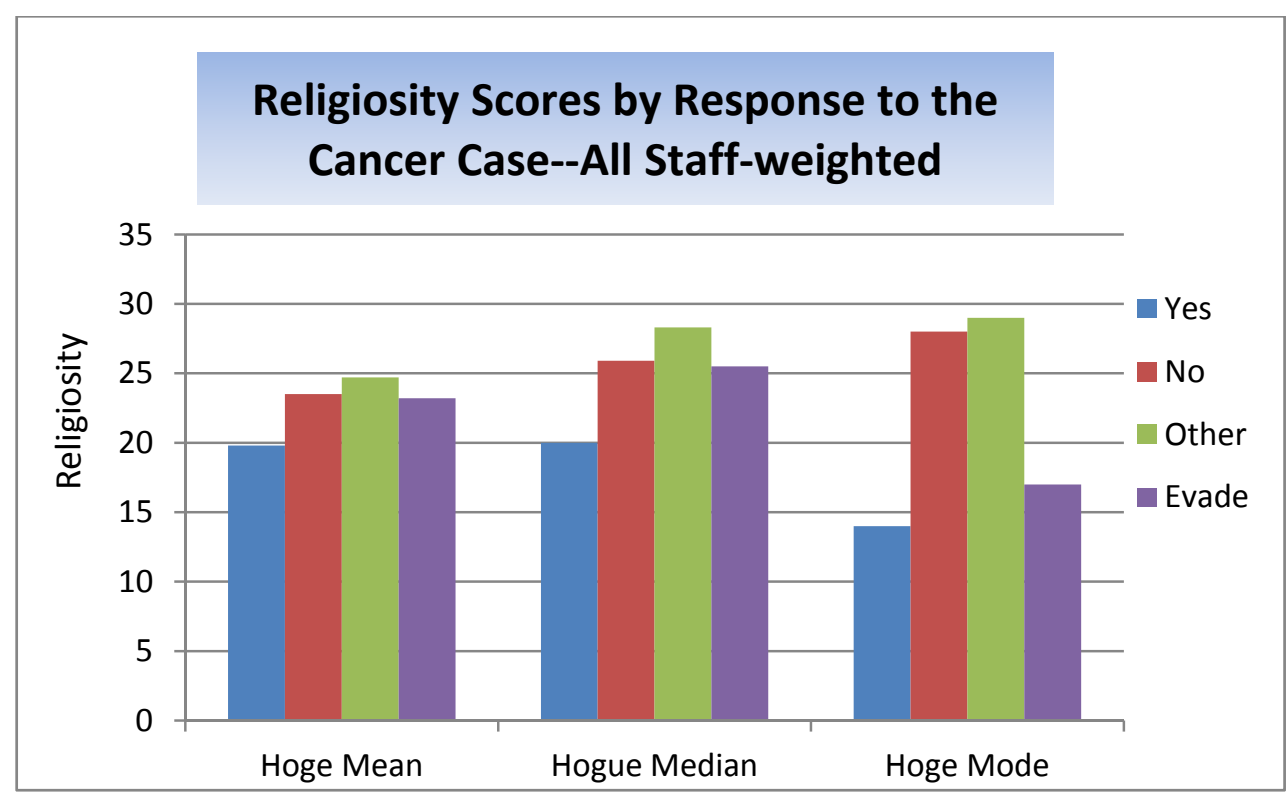

The all staff-weighted respondents who indicated they would answer "yes" to the colleague with cancer had lower mean religiosity scores, lower median religiosity scores, and a lower religiosity score mode than respondents who indicated they would either answer "no" or provide an "other" response to the question. The two-sample, two-tailed t-statistic was significant at the .05 level for the difference between staff who responded “yes" and staff who responded "no," $t(180)=-2.06, p=.041$.

Using SPSS, the results of the total religiosity scores were binned into three groups using equal percentiles based on the scanned cases function. The three groups included respondents with religiosity scores equal to or less than 15 , respondents with religiosity scores equal to and between 16 and 25, and respondents with religiosity scores equal to or greater than 26 . 
A chi-square test for independence also indicated a statistically significant association at the .05 level between one-third binned religiosity and responses to the cancer case, $X^{2}(8$, $\mathrm{n}=243)=20.6, \mathrm{p}=.008$, Cramer's $V=.206$. Following guidelines provided by Pallant, the strength of the association is medium to strong. ${ }^{135}$

Respondents were filtered to select only individuals who indicated that the statement, "it is never OK to lie," most closely reflected their views. Despite their earlier response, $48 \%$ of these respondents indicated that they would tell their colleague that she looked better. Among those who answered "yes," $7.3 \%$ indicated that this would not be a lie, $39 \%$ thought it was a lie but that they would protect their colleague's feelings, and $31.7 \%$ indicated that the truth would cause more harm than good.

The Stennis Fellows who responded "yes" also had lower mean $(M=20.1)$ and median $(M d n=20)$ religiosity scores than respondents who indicated "no" $(M=25.25, M d n=29.5)$, other $(M=22.5, M d n=21)$, or who indicated that they would "evade" the question $(M=24.2, M d n=27)$. The two-sample, two-tailed t-statistic was not significant at the .05 level for the difference between fellows who responded "yes" and fellows who responded "no," $t(59)=1.64, p=.292$ or "other," $t(68)=1.088, p=.28$. The two-sample, two-tailed tstatistic was significant at the .05 level for the difference in mean religiosity between fellows who responded "no" and fellows who "evaded" the question, $t(72)=2.05, p=.044$.

\footnotetext{
${ }^{135}$ Pallant, Spss Survival Guide. For tables with a variable with four or more categories: small=.06, medium $=.17$ and large $=.29$.
} 
A chi-square for independence was run to test the association between one-third binned religiosity and responses to the cancer case. Nine of the cells $(60 \%)$ had expected counts of less than five, thus violating the assumptions underlying the chi-square test. ${ }^{136}$ As a result the chi-square could not be performed.

Respondents were once again filtered to select only the 31 fellows who indicated that the statement, "it is never OK to lie," most closely reflected their view. $42 \%$ of these fellows indicated they would tell their colleague that she looked better, 9.7\% would answer "no," and the remainder would find a way to "evade" the question (16.1\%) or respond in an “other" way (29\%). $7.7 \%$ indicated this would not be a lie, $46.2 \%$ thought it was a lie but would protect their colleague's feelings, and 30.8\% though the truth would cause more harm than good. Although the number of respondents was too small to reliably draw general conclusions, it is striking that the proportions are directionally very similar to those found in the all staff-weighted sample.

One implication of the difference in the responses between the definition and justification section of the survey and this case, is that the absence of context makes it difficult for an individual to measure a definition or statement of justification against his or her own practice. The provision of cases, with the additional messiness and detail that attend them, may provide a better platform for understanding the practical reasoning or intuitions of survey respondents.

${ }^{136}$ Ibid., p. 277. 
Case 1. One of your colleagues has been diagnosed with cancer and has been undergoing radiation and chemotherapy.

\begin{tabular}{|c|c|c|c|c|c|}
\hline \multicolumn{2}{|c|}{$\begin{array}{l}\text { All Staff- } \\
\text { unweighted Who } \\
\text { Responded It is } \\
\text { Never OK to Lie }\end{array}$} & \multirow{2}{*}{$\begin{array}{r}\text { Frequency } \\
41\end{array}$} & \multirow{2}{*}{$\frac{\text { Percent }}{48.8}$} & \multirow{2}{*}{$\frac{\text { Valid Percent }}{48.8}$} & \multirow{2}{*}{$\begin{array}{r}\begin{array}{l}\text { Cumulative } \\
\text { Percent }\end{array} \\
48.8\end{array}$} \\
\hline Valid & yes & & & & \\
\hline & No & 9 & 10.7 & 10.7 & 59.5 \\
\hline & Other & 16 & 19.0 & 19.0 & 78.6 \\
\hline & Evade & 18 & 21.4 & 21.4 & 100.0 \\
\hline & Total & 84 & 100.0 & 100.0 & \\
\hline
\end{tabular}

Did you answer yes, because (choose the most important reason)--

\begin{tabular}{|c|c|c|c|c|c|}
\hline & & Frequency & Percent & $\begin{array}{c}\text { Valid } \\
\text { Percent }\end{array}$ & $\begin{array}{c}\text { Cumulative } \\
\text { Percent }\end{array}$ \\
\hline \multirow[t]{6}{*}{ Valid } & $\begin{array}{l}\text { You believe that this } \\
\text { would not be a lie }\end{array}$ & 3 & 3.6 & 7.3 & 7.3 \\
\hline & $\begin{array}{l}\text { You believe this would } \\
\text { be a lie but it will protect } \\
\text { your colleague's } \\
\text { feelings }\end{array}$ & 16 & 19.0 & 39.0 & 46.3 \\
\hline & $\begin{array}{l}\text { The truth would cause } \\
\text { more harm than good }\end{array}$ & 13 & 15.5 & 31.7 & 78.0 \\
\hline & $\begin{array}{l}\text { She doesn't really } \\
\text { expect you to be totally } \\
\text { honest }\end{array}$ & 4 & 4.8 & 9.8 & 87.8 \\
\hline & Other & 5 & 6.0 & 12.2 & 100.0 \\
\hline & Total & 41 & 48.8 & 100.0 & \\
\hline Missing & System & 43 & 51.2 & & \\
\hline Total & & 84 & 100.0 & & \\
\hline
\end{tabular}




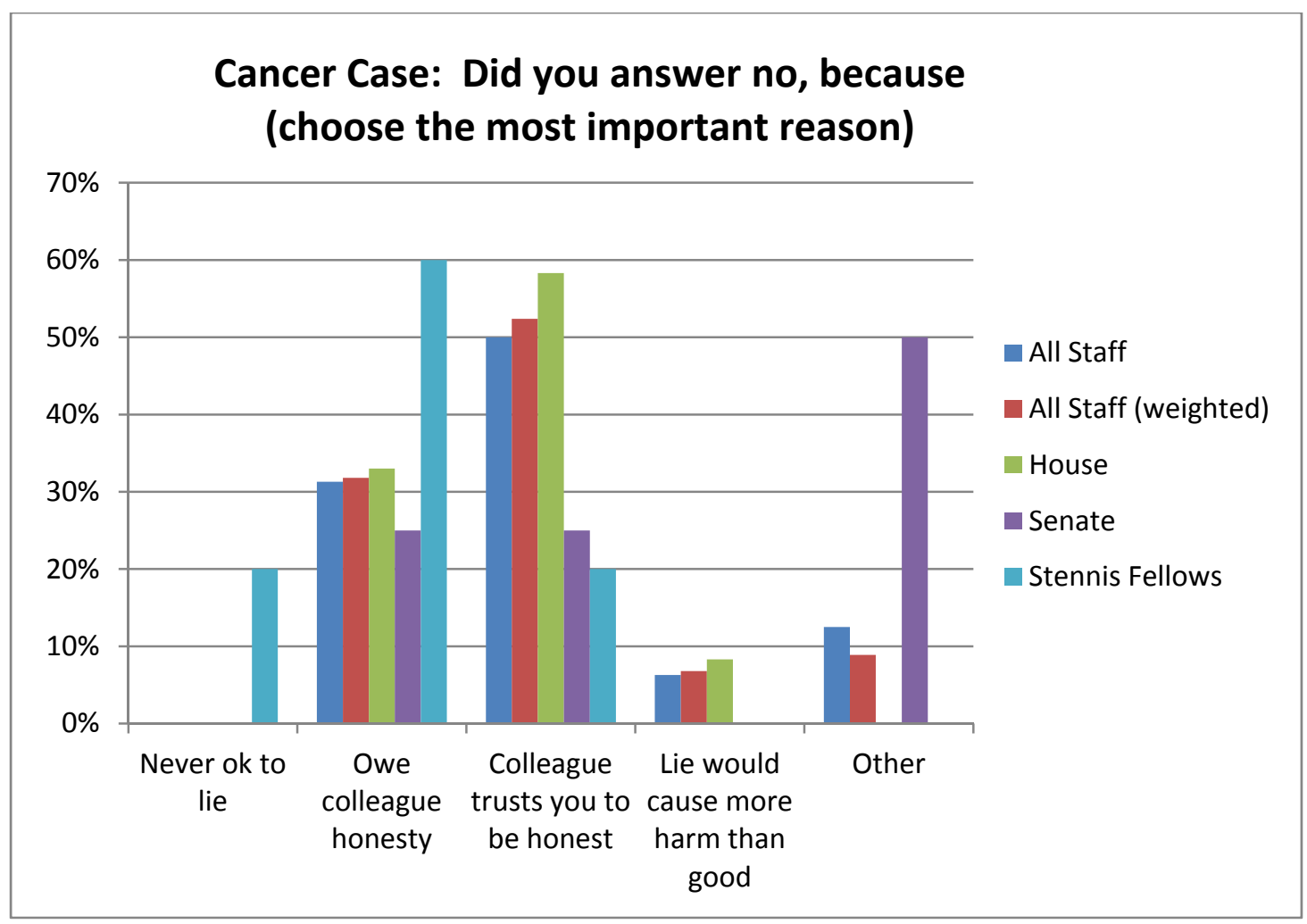

A very small percentage of respondents chose to tell their colleague that they did not think she looked better. The numbers were too small to draw conclusions about the broader populations. Interestingly, despite the fact that $35.9 \%$ of staff indicated that it is "never Ok to tell a lie" only one person (a Stennis Fellow) cited this as the reason that he would not "lie" in this case. Respondents who answered "no" were more likely to invoke the relationship, the idea that they owed honesty to their colleague, or that their colleague trusted them to be completely honest.

Did you answer no, because (choose the most important reason)

\begin{tabular}{|c|c|c|c|c|c|c|}
\hline \multicolumn{3}{|c|}{ Chamber } & \multirow{2}{*}{$\frac{\text { Frequency }}{4}$} & \multirow{2}{*}{$\frac{\text { Percent }}{2.2}$} & \multirow{2}{*}{$\frac{\text { Valid Percent }}{33.3}$} & \multirow{2}{*}{$\begin{array}{c}\begin{array}{c}\text { Cumulative } \\
\text { Percent }\end{array} \\
33.3\end{array}$} \\
\hline House & Valid & $\begin{array}{l}\text { You believe you owe your } \\
\text { colleague complete honesty }\end{array}$ & & & & \\
\hline & & $\begin{array}{l}\text { You believe that your } \\
\text { colleague trusts you to be } \\
\text { completely honest }\end{array}$ & 7 & 3.8 & 58.3 & 91.7 \\
\hline
\end{tabular}




\begin{tabular}{|c|c|c|c|c|c|c|}
\hline & \multirow{4}{*}{$\begin{array}{l}\text { Missing } \\
\text { Total }\end{array}$} & $\begin{array}{l}\text { A lie could cause more good } \\
\text { than harm }\end{array}$ & 1 & .5 & 8.3 & 100.0 \\
\hline & & \multirow{3}{*}{$\begin{array}{l}\text { Total } \\
\text { System }\end{array}$} & 12 & 6.5 & 100.0 & \\
\hline & & & 173 & 93.5 & & \\
\hline & & & 185 & 100.0 & & \\
\hline \multirow[t]{6}{*}{ Senate } & Valid & $\begin{array}{l}\text { You believe you owe your } \\
\text { colleague complete honesty }\end{array}$ & 1 & .6 & 25.0 & 25.0 \\
\hline & & $\begin{array}{l}\text { You believe that your } \\
\text { colleague trusts you to be } \\
\text { completely honest }\end{array}$ & 1 & .6 & 25.0 & 50.0 \\
\hline & & Other & 2 & 1.1 & 50.0 & 100.0 \\
\hline & & Total & 4 & 2.2 & 100.0 & \\
\hline & Missing & System & 174 & 97.8 & & \\
\hline & Total & & 178 & 100.0 & & \\
\hline
\end{tabular}

Did you answer no, because (choose the most important reason)

\begin{tabular}{|c|c|c|c|c|c|}
\hline \multicolumn{2}{|c|}{ All Staff-weighted } & \multirow{2}{*}{$\frac{\text { Frequency }}{6}$} & \multirow{2}{*}{$\frac{\text { Percent }}{1.5}$} & \multirow{2}{*}{$\frac{\text { Valid Percent }}{31.8}$} & \multirow{2}{*}{$\begin{array}{c}\begin{array}{c}\text { Cumulative } \\
\text { Percent }\end{array} \\
31.8\end{array}$} \\
\hline Valid & $\begin{array}{l}\text { You believe you owe your } \\
\text { colleague complete honesty }\end{array}$ & & & & \\
\hline & $\begin{array}{l}\text { You believe that your } \\
\text { colleague trusts you to be } \\
\text { completely honest }\end{array}$ & 9 & 2.5 & 52.4 & 84.2 \\
\hline & $\begin{array}{l}\text { A lie could cause more good } \\
\text { than harm }\end{array}$ & 1 & .3 & 6.8 & 91.1 \\
\hline & Other & 2 & .4 & 8.9 & 100.0 \\
\hline & Total & 18 & 4.9 & 100.0 & \\
\hline Missing & System & 347 & 95.1 & & \\
\hline Total & & 364 & 100.0 & & \\
\hline
\end{tabular}

Did you answer no, because (choose the most important reason)

\begin{tabular}{llcccc}
\hline \hline All Staff-unweighted & Frequency & Percent & Valid Percent & $\begin{array}{c}\text { Cumulative } \\
\text { Percent }\end{array}$ \\
\hline Valid & $\begin{array}{l}\text { You believe you owe your } \\
\text { colleague complete honesty }\end{array}$ & 5 & 1.4 & 31.3 & 31.3 \\
$\quad \begin{array}{l}\text { You believe that your } \\
\text { colleague trusts you to be } \\
\text { completely honest }\end{array}$ & 8 & 2.2 & 50.0 & 81.3 \\
$\begin{array}{l}\text { A lie could cause more good } \\
\text { than harm }\end{array}$ & 1 & .3 & 6.3 & 87.5
\end{tabular}




\begin{tabular}{llcccc}
\hline & Other & 2 & .6 & 12.5 & 100.0 \\
& Total & 16 & 4.4 & 100.0 & \\
Missing & System & 347 & 95.6 & & \\
Total & & 363 & 100.0 & \\
\hline \hline
\end{tabular}

Did you answer no, because (choose the most important reason)

\begin{tabular}{|c|c|c|c|c|c|}
\hline \multicolumn{2}{|c|}{ Stennis Fellows } & \multirow{2}{*}{$\frac{\text { Frequency }}{1}$} & \multirow{2}{*}{$\frac{\text { Percent }}{.8}$} & \multirow{2}{*}{$\frac{\text { Valid Percent }}{20.0}$} & \multirow{2}{*}{$\begin{array}{c}\begin{array}{c}\text { Cumulative } \\
\text { Percent }\end{array} \\
20.0\end{array}$} \\
\hline Valid & $\begin{array}{l}\text { You believe it is never OK to } \\
\text { lie }\end{array}$ & & & & \\
\hline & $\begin{array}{l}\text { You believe you owe your } \\
\text { colleague complete honesty }\end{array}$ & 3 & 2.5 & 60.0 & 80.0 \\
\hline & $\begin{array}{l}\text { You believe that your } \\
\text { colleague trusts you to be } \\
\text { completely honest }\end{array}$ & 1 & .8 & 20.0 & 100.0 \\
\hline & Total & 5 & 4.1 & 100.0 & \\
\hline Missing & System & 117 & 95.9 & & \\
\hline Total & & 122 & 100.0 & & \\
\hline
\end{tabular}

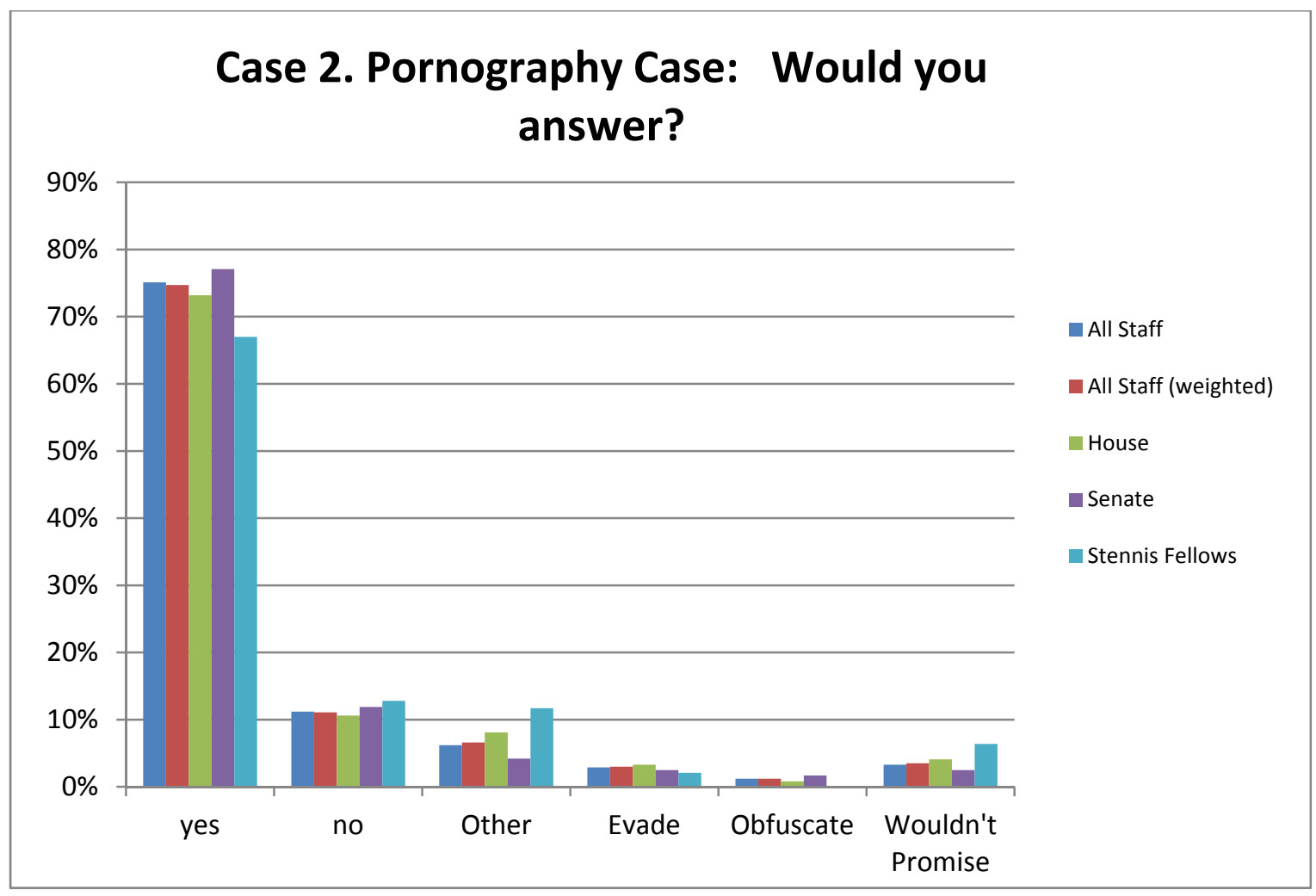


The Pornography case was drawn, in part, to test the relative strength of the prohibition on lying when located within a context that included a promise and potentially competing relationships. Respondents were provided with the following case:

\footnotetext{
"You are working late one night in the office with a close friend and colleague. You discover that he is downloading pornographic material on an office computer. You confront him, he promises to stop and you promise not to tell anyone. The next day your Member/Senator tells you that a reporter is asking her questions about rumors that House and Senate staff are using illicit web sites and asks you directly whether you have seen anyone on the staff download pornographic material on their office computers. Would you answer.."
}

Confidence intervals were calculated for each of the respondent groups. The widest confidence interval at the $95 \%$ level for the House was $\pm 7.9 \%$, for the Senate was $\pm 7.6 \%$, for all staff-weighted was $\pm 5.5 \%$ and for Stennis Fellows was $\pm 7.7 \%$.

Respondents were fairly consistent across all three groups in their responses with the exception that Stennis Fellows were more likely to try to find an alternative to answering the question "yes" or "no" (as will be noted later, this was also associated with higher religiosity scores). The majority of staff (67\%-77\%) would break their promise to their colleague and tell their boss that they knew of someone downloading inappropriate material. Ten to $12 \%$ would keep their promise and answer "no," and the rest would attempt to avoid breaking the promise or lying. Excluded from the staff who responded "yes" are a small group (3\% to 5\%) who made the point that the conflict between truthtelling and promisekeeping was artificial because the promise should not, could not, or would not have been made. 
Respondents were filtered to select only the 64 individuals who indicated that the statement, "it is never OK to lie," most closely reflected their view. Seventy-seven percent of these respondents indicated that they would breach their promise and inform their boss, $6.5 \%$ indicated that they would inform their boss that they did not know of anyone, $5.6 \%$ would find another way to respond, $3.7 \%$ would "evade" the question, and $7.4 \%$ indicated that they never would have made the promise in the first place.

15 respondents thought that the obligation to be truthful was more important than the promise, while four respondents believed the reverse.

Stennis Fellows (67\%) were less likely to answer "yes" than House (73.2\%) or Senate staff (77.1\%). Stennis Fellows (11.7\%) were also more likely to answer "other" than House $(8.1 \%)$ or Senate staff $(4.2 \%)$. The two-sample, two-tailed t-statistic for the difference between two proportions was not significant at the .05 level for the difference between Stennis Fellows and Senate staff answering "yes," $t(210)=-1.64, p=.103$. The two-sample, two-tailed t-statistic for the difference between two proportions was significant at the .05 level for the difference between Senate staff and Stennis Fellows answering “other," $t(210)=2.05, p=.042$.

Case 2. You are working late one night in the office with a close friend and colleague. You discover that he is downloading pornographic material.

\begin{tabular}{|c|c|c|c|c|c|c|}
\hline \multicolumn{3}{|c|}{ Chamber } & \multirow{2}{*}{$\frac{\text { Frequency }}{90}$} & \multirow{2}{*}{$\frac{\text { Percent }}{48.6}$} & \multirow{2}{*}{$\frac{\text { Valid Percent }}{73.2}$} & \multirow{2}{*}{$\begin{array}{c}\text { Cumulative } \\
\text { Percent }\end{array}$} \\
\hline House & Valid & Yes & & & & \\
\hline & & No & 13 & 7.0 & 10.6 & 83.7 \\
\hline & & Other & 10 & 5.4 & 8.1 & 91.9 \\
\hline & & Evade & 4 & 2.2 & 3.3 & 95.1 \\
\hline & & Obfuscate & 1 & .5 & .8 & 95.9 \\
\hline & & Wouldn't Promise & 5 & 2.7 & 4.1 & 100.0 \\
\hline & & Total & 123 & 66.5 & 100.0 & \\
\hline
\end{tabular}




\begin{tabular}{lllcccc}
\hline & Missing & System & 62 & 33.5 & & \\
& Total & & 185 & 100.0 & & \\
\hline Senate & Valid & Yes & 91 & 51.1 & 77.1 & 77.1 \\
& & No & 14 & 7.9 & 11.9 & 89.0 \\
& & 5 & 2.8 & 4.2 & 93.2 \\
& & Other & 3 & 1.7 & 2.5 & 95.8 \\
& Evade & 2 & 1.1 & 1.7 & 100.0 \\
& Obfuscate & 3 & 1.7 & 2.5 & 100.0 & \\
& Wouldn't Promise & 118 & 66.3 & & \\
& Motal & 60 & 33.7 & & \\
& Missing & System & 178 & 100.0 & & \\
\hline \hline
\end{tabular}

Case 2. You are working late one night in the office with a close friend and colleague. You discover that he is downloading pornographic material.

\begin{tabular}{llcccc}
\hline \hline All Staff-weighted & Frequency & Percent & Valid Percent & $\begin{array}{c}\text { Cumulative } \\
\text { Percent }\end{array}$ \\
\hline Valid & Yes & 181 & 49.6 & 74.7 & 74.7 \\
& No & 27 & 7.4 & 11.1 & 85.8 \\
& Other & 16 & 4.4 & 6.6 & 92.4 \\
& Evade & 7 & 2.0 & 3.0 & 95.4 \\
& Obfuscate & 3 & .8 & 1.2 & 96.5 \\
& Wouldn't Promise & 8 & 2.3 & 3.5 & 100.0 \\
Missing & Total & 242 & 66.4 & 100.0 & \\
Total & System & 122 & 33.6 & & \\
\hline \hline
\end{tabular}

Case 2. You are working late one night in the office with a close friend and colleague. You discover that he is downloading pornographic material.

\begin{tabular}{|c|c|c|c|c|c|}
\hline \multicolumn{2}{|c|}{ All Staff-unweighted } & \multirow{2}{*}{$\frac{\text { Frequency }}{181}$} & \multirow{2}{*}{$\frac{\text { Percent }}{49.9}$} & \multirow{2}{*}{$\frac{\text { Valid Percent }}{75.1}$} & \multirow{2}{*}{$\begin{array}{c}\begin{array}{c}\text { Cumulative } \\
\text { Percent }\end{array} \\
75.1\end{array}$} \\
\hline Valid & Yes & & & & \\
\hline & No & 27 & 7.4 & 11.2 & 86.3 \\
\hline & Other & 15 & 4.1 & 6.2 & 92.5 \\
\hline & Evade & 7 & 1.9 & 2.9 & 95.4 \\
\hline & Obfuscate & 3 & .8 & 1.2 & 96.7 \\
\hline & Wouldn't Promise & 8 & 2.2 & 3.3 & 100.0 \\
\hline & Total & 241 & 66.4 & 100.0 & \\
\hline Missing & System & 122 & 33.6 & & \\
\hline Total & & 363 & 100.0 & & \\
\hline
\end{tabular}

Case 2. You are working late one night in the office with a close friend and colleague. You discover that he is downloading pornographic material.

\begin{tabular}{lccccc}
\hline \hline Stennis Fellows & & & & Cumulative \\
Valid & Yes & Frequency & Percent & Valid Percent & Percent \\
& No & 63 & 51.6 & 67.0 & 67.0 \\
& 12 & 9.8 & 12.8 & 79.8
\end{tabular}




\begin{tabular}{|c|c|c|c|c|c|}
\hline & Other & 11 & 9.0 & 11.7 & 91.5 \\
\hline & Evade & 2 & 1.6 & 2.1 & 93.6 \\
\hline & Wouldn't Promise & 6 & 4.9 & 6.4 & 100.0 \\
\hline & Total & 94 & 77.0 & 100.0 & \\
\hline Missing & System & 28 & 23.0 & & \\
\hline Total & & 122 & 100.0 & & \\
\hline
\end{tabular}

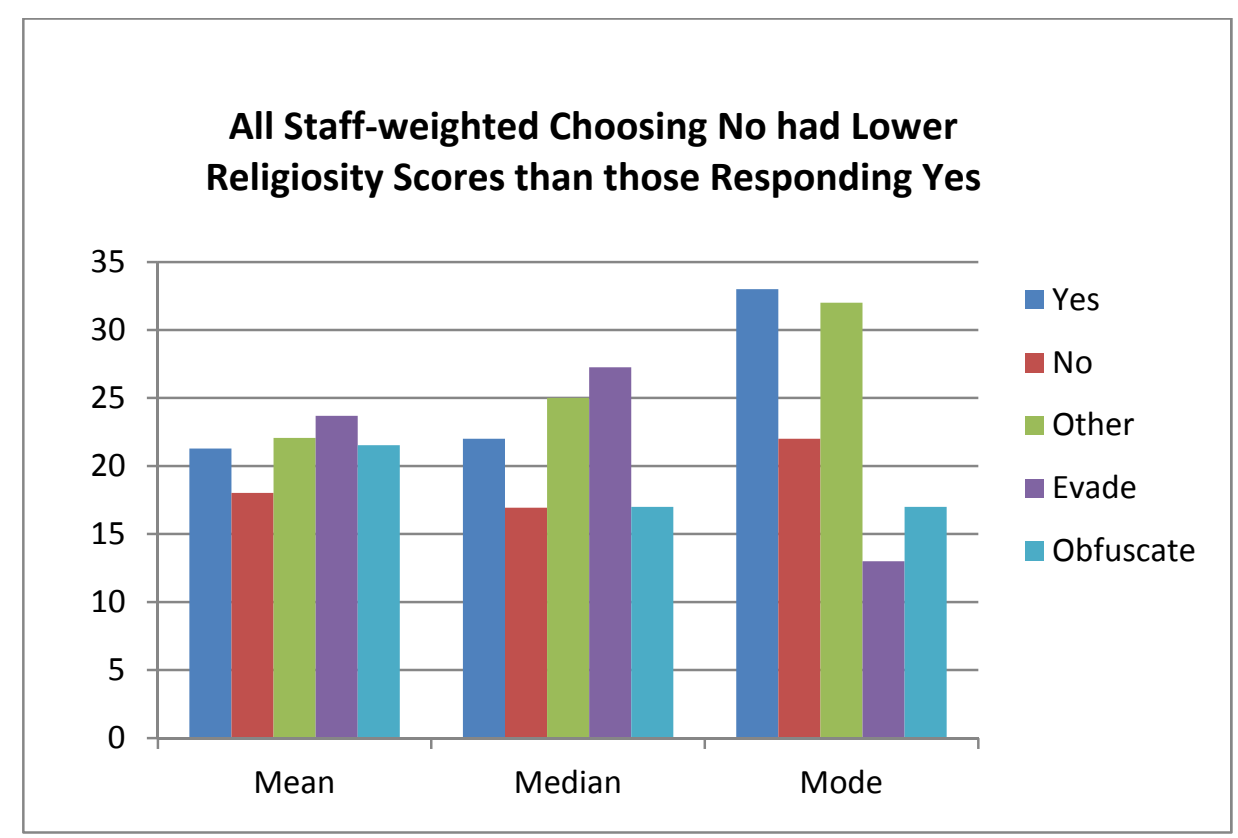

All staff-weighted who answered "no" $(M=18, M d n=16.9)$ had lower religiosity scores than staff who responded "yes" $(M=21.3, M d n=22)$, "other" $(M=22.1, M d n=25)$, "evade" $(M=23.7, M d n=27.3)$, or "obfuscate" $(M=21.5, M d n=17)$. The two-sample, two-tailed tstatistic was significant at the .05 level for the difference in mean religiosity between staff answering "yes" and staff answering "no," $t(201)=2.061, p=.04$ and for the difference in mean religiosity between those who responded "no" and those who evaded the question, $t(41)=2.14, p=.038$. The two-sample, two-tailed t-statistic was not significant at the .05 level for the difference in mean religiosity between staff answering "no" and staff who "obfuscated," $t(28)=.681, p=.501$, or for the difference in mean 
religiosity between staff who answered "no" and staff who responded "other," $t(41)=1.53, p=.134$.

A chi-square test for independence could not be conducted because 10 cells $(55.6 \%)$ had an expected count of less than five. The Mann-Whitney U Test also revealed a statistically significant difference in religiosity between respondents who answered "yes" $(M d n=22, n=176)$ and respondents who answered "no" $(M d n=16.930, n=27), U=1792.5$, $z=-2.055, p=04$.

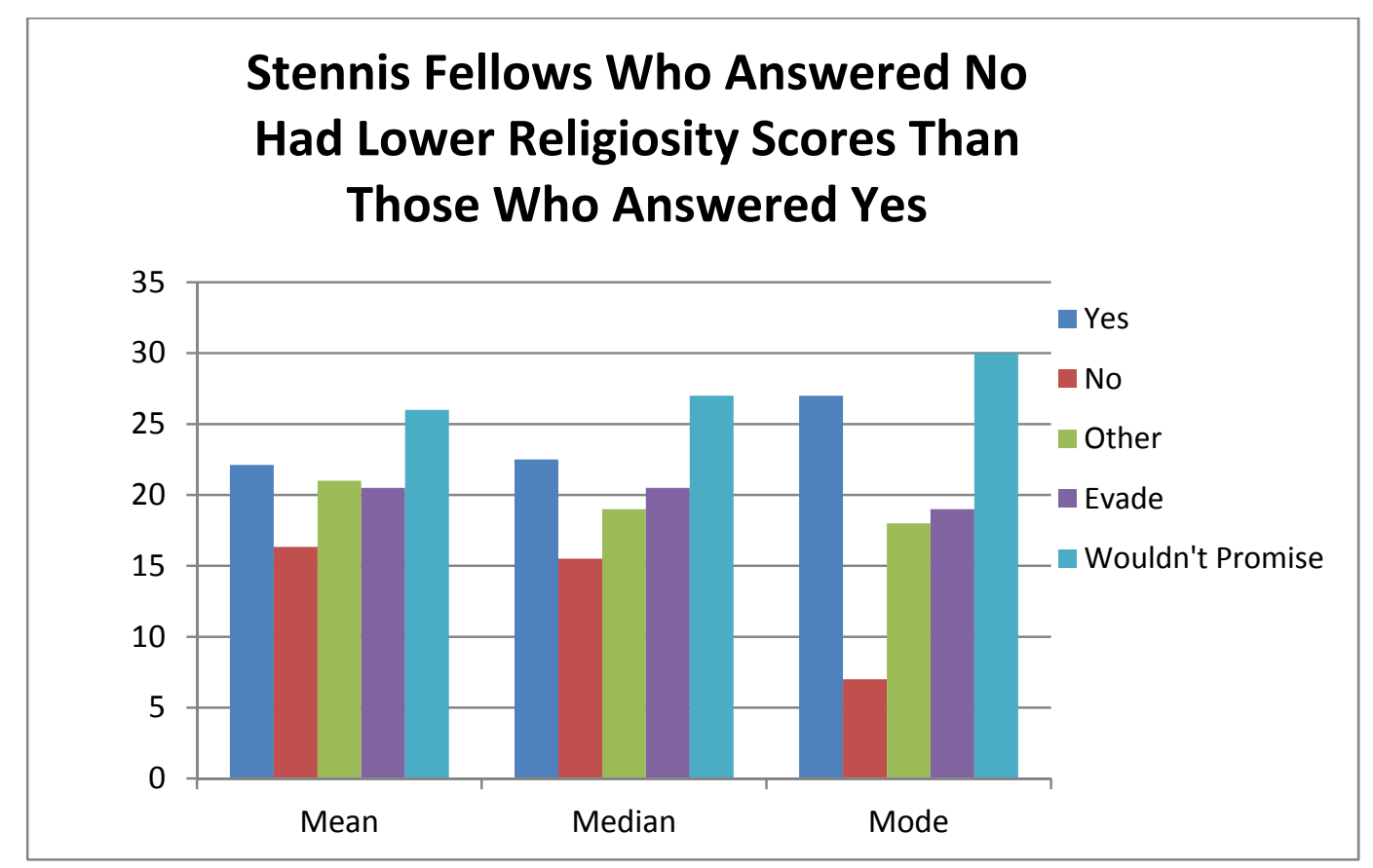

Stennis Fellows who answered "no" $(M=16.3, M d n=15.5)$ had lower religiosity scores than staff who responded "yes" $(M=22.1, M d n=22.5)$, "other" $(M=21, M d n=19)$, "evade" $(M=20.5, M d n=20.5)$, or "wouldn't promise" $(M=26, M d n=17)$. The two-sample, twotailed t-statistic was significant at the .05 level for the difference in mean religiosity 
between staff answering "yes" and staff answering "no," $t(72)=2.44, p=.017$ and for the difference in mean religiosity between staff answering "no" and staff who wouldn't have made the promise, $t(15)=2.733, p=.015$.

The two-sample, two-tailed t-statistic was not significant at the .05 level for the difference in mean religiosity between fellows answering "no" and fellows who answered "other," $t(21)=1.77, p=.09$, or for the difference in mean religiosity between those who responded "no" and those who attempted to "evade," $t(12)=.804, p=.044$. Only two fellows indicated they would "evade" and only five fellows indicated they wouldn't promise, potentially violating assumptions underlying the value of t-statistics that would otherwise be overcome by sample size.

The Mann-Whitney U Test also revealed a significant difference in religiosity between staff who responded "yes" ( $M d n=22.5, n=62)$ and staff who responded "no" $(M d n=15.5$, $n=12), U=210.5, z=-2.371, p=0.18$. 


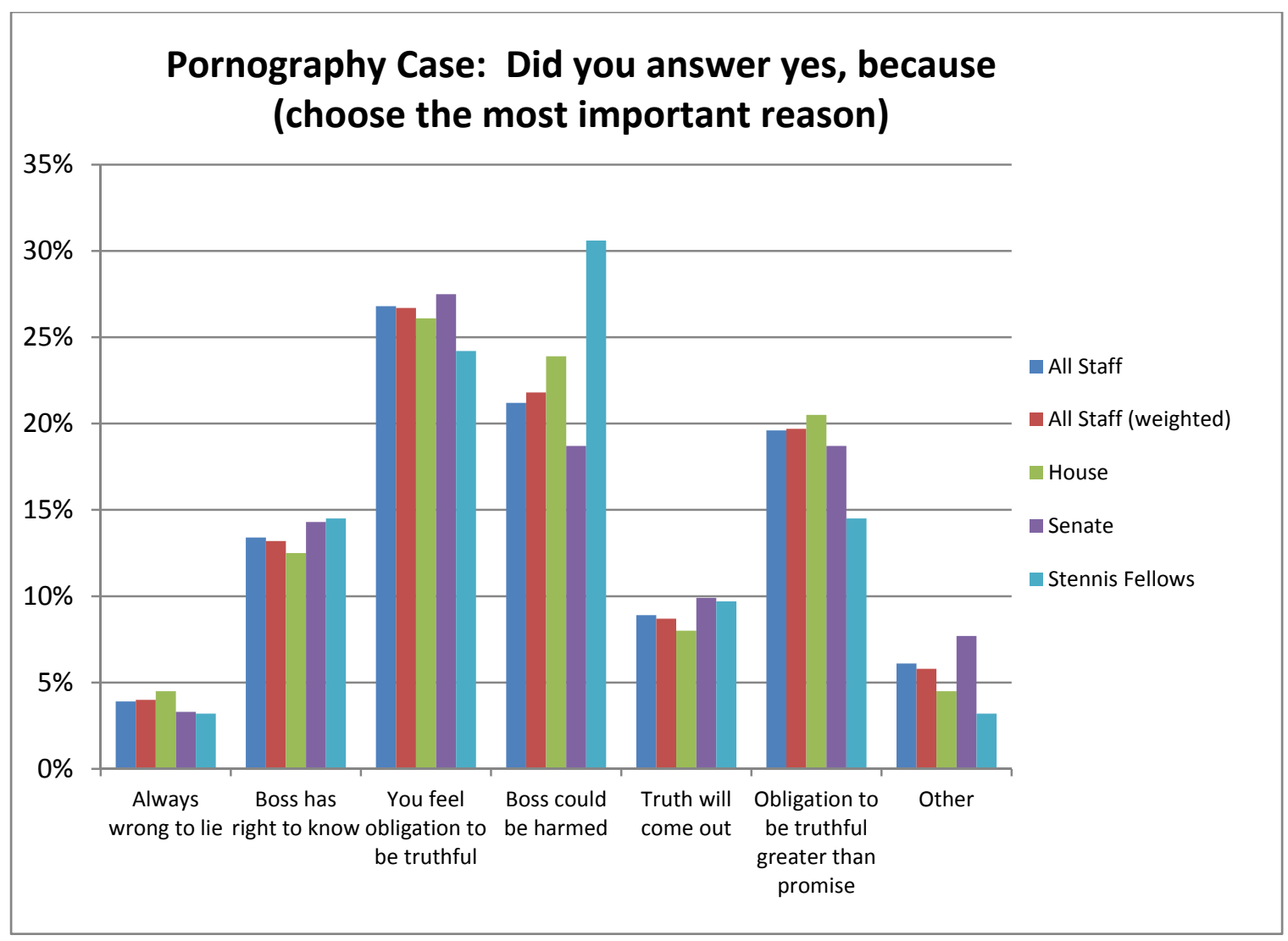

Stennis Fellows (30.6\%) were more likely than House $(23.9 \%)$ or Senate $(18.7 \%)$ staff or all staff-weighted (21.8\%) to emphasize that their boss could be harmed if they did not answer "yes." The two-sample, two-tailed t-statistic for the difference between two proportions was not significant at the .05 level for the difference between Stennis Fellows and Senate staff, $t(151)=1.7, p=.09$. The null hypothesis that there is no difference between Stennis Fellows and Senate staff cannot be rejected.

Did you answer yes because (choose the most important reason)

\begin{tabular}{|c|c|c|c|c|c|}
\hline Chamber & & Frequency & Percent & Valid Percent & $\begin{array}{l}\text { Cumulative } \\
\text { Percent }\end{array}$ \\
\hline \multirow[t]{2}{*}{ House } & $\begin{array}{l}\text { You believe it is always } \\
\text { wrong to lie }\end{array}$ & 4 & 2.2 & 4.5 & 4.5 \\
\hline & $\begin{array}{l}\text { You believe that your boss } \\
\text { has a right to know }\end{array}$ & 11 & 5.9 & 12.5 & 17.0 \\
\hline
\end{tabular}




\begin{tabular}{|c|c|c|c|c|c|c|}
\hline & & $\begin{array}{l}\text { You feel an obligation to } \\
\text { your boss to be truthful }\end{array}$ & 23 & 12.4 & 26.1 & 43.2 \\
\hline & & $\begin{array}{l}\text { You believe that your boss } \\
\text { could be harmed if you do } \\
\text { not answer truthfully }\end{array}$ & 21 & 11.4 & 23.9 & 67.0 \\
\hline & & $\begin{array}{l}\text { You believe the truth will } \\
\text { come out eventually and you } \\
\text { might be implicated if you } \\
\text { protect your colleague }\end{array}$ & 7 & 3.8 & 8.0 & 75.0 \\
\hline & & $\begin{array}{l}\text { You believe the obligation to } \\
\text { be truthful is more important } \\
\text { than the promise to your } \\
\text { colleague not to tell anyone }\end{array}$ & 18 & 9.7 & 20.5 & 95.5 \\
\hline & & Other & 4 & 2.2 & 4.5 & 100.0 \\
\hline & & Total & 88 & 47.6 & 100.0 & \\
\hline & Missing & System & 97 & 52.4 & & \\
\hline & Total & & 185 & 100.0 & & \\
\hline Senate & Valid & $\begin{array}{l}\text { You believe it is always } \\
\text { wrong to lie }\end{array}$ & 3 & 1.7 & 3.3 & 3.3 \\
\hline & & $\begin{array}{l}\text { You believe that your boss } \\
\text { has a right to know }\end{array}$ & 13 & 7.3 & 14.3 & 17.6 \\
\hline & & $\begin{array}{l}\text { You feel an obligation to } \\
\text { your boss to be truthful }\end{array}$ & 25 & 14.0 & 27.5 & 45.1 \\
\hline & & $\begin{array}{l}\text { You believe that your boss } \\
\text { could be harmed if you do } \\
\text { not answer truthfully }\end{array}$ & 17 & 9.6 & 18.7 & 63.7 \\
\hline & & $\begin{array}{l}\text { You believe the truth will } \\
\text { come out eventually and you } \\
\text { might be implicated if you } \\
\text { protect your colleague }\end{array}$ & 9 & 5.1 & 9.9 & 73.6 \\
\hline & & $\begin{array}{l}\text { You believe the obligation to } \\
\text { be truthful is more important } \\
\text { than the promise to your } \\
\text { colleague not to tell anyone }\end{array}$ & 17 & 9.6 & 18.7 & 92.3 \\
\hline & & Other & 7 & 3.9 & 7.7 & 100.0 \\
\hline & & Total & 91 & 51.1 & 100.0 & \\
\hline & Missing & System & 87 & 48.9 & & \\
\hline & Total & & 178 & 100.0 & & \\
\hline
\end{tabular}


Did you answer yes because (choose the most important reason)

\begin{tabular}{|c|c|c|c|c|c|}
\hline \multicolumn{2}{|c|}{ All Staff-weighted } & \multirow{2}{*}{$\frac{\text { Frequency }}{7}$} & \multirow{2}{*}{$\frac{\text { Percent }}{2.0}$} & \multirow{2}{*}{$\frac{\text { Valid Percent }}{4.0}$} & \multirow{2}{*}{$\begin{array}{c}\begin{array}{c}\text { Cumulative } \\
\text { Percent }\end{array} \\
4.0\end{array}$} \\
\hline Valid & $\begin{array}{l}\text { You believe it is always } \\
\text { wrong to lie }\end{array}$ & & & & \\
\hline & $\begin{array}{l}\text { You believe that your boss } \\
\text { has a right to know }\end{array}$ & 24 & 6.5 & 13.2 & 17.3 \\
\hline & $\begin{array}{l}\text { You feel an obligation to } \\
\text { your boss to be truthful }\end{array}$ & 48 & 13.1 & 26.7 & 43.9 \\
\hline & $\begin{array}{l}\text { You believe that your boss } \\
\text { could be harmed if you do } \\
\text { not answer truthfully }\end{array}$ & 39 & 10.7 & 21.8 & 65.7 \\
\hline & $\begin{array}{l}\text { You believe the truth will } \\
\text { come out eventually and you } \\
\text { might be implicated if you } \\
\text { protect your colleague }\end{array}$ & 16 & 4.3 & 8.7 & 74.4 \\
\hline & $\begin{array}{l}\text { You believe the obligation to } \\
\text { be truthful is more important } \\
\text { than the promise to your } \\
\text { colleague not to tell anyone }\end{array}$ & 35 & 9.7 & 19.7 & 94.2 \\
\hline & Other & 10 & 2.8 & 5.8 & 100.0 \\
\hline & Total & 178 & 48.9 & 100.0 & \\
\hline Missing & System & 186 & 51.1 & & \\
\hline Total & & 364 & 100.0 & & \\
\hline
\end{tabular}

Did you answer yes because (choose the most important reason)

\begin{tabular}{|c|c|c|c|c|c|}
\hline \multicolumn{2}{|c|}{ All Staff-unweighted } & \multirow{2}{*}{$\frac{\text { Frequency }}{7}$} & \multirow{2}{*}{$\frac{\text { Percent }}{1.9}$} & \multirow{2}{*}{$\frac{\text { Valid Percent }}{3.9}$} & \multirow{2}{*}{$\begin{array}{c}\begin{array}{c}\text { Cumulative } \\
\text { Percent }\end{array} \\
3.9\end{array}$} \\
\hline Valid & $\begin{array}{l}\text { You believe it is always } \\
\text { wrong to lie }\end{array}$ & & & & \\
\hline & $\begin{array}{l}\text { You believe that your boss } \\
\text { has a right to know }\end{array}$ & 24 & 6.6 & 13.4 & 17.3 \\
\hline & $\begin{array}{l}\text { You feel an obligation to } \\
\text { your boss to be truthful }\end{array}$ & 48 & 13.2 & 26.8 & 44.1 \\
\hline & $\begin{array}{l}\text { You believe that your boss } \\
\text { could be harmed if you do } \\
\text { not answer truthfully }\end{array}$ & 38 & 10.5 & 21.2 & 65.4 \\
\hline & $\begin{array}{l}\text { You believe the truth will } \\
\text { come out eventually and you } \\
\text { might be implicated if you } \\
\text { protect your colleague }\end{array}$ & 16 & 4.4 & 8.9 & 74.3 \\
\hline & $\begin{array}{l}\text { You believe the obligation to } \\
\text { be truthful is more important } \\
\text { than the promise to your } \\
\text { colleague not to tell anyone }\end{array}$ & 35 & 9.6 & 19.6 & 93.9 \\
\hline
\end{tabular}




\begin{tabular}{llcccc}
\hline & Other & 11 & 3.0 & 6.1 & 100.0 \\
& Total & 179 & 49.3 & 100.0 & \\
Missing & System & 184 & 50.7 & & \\
Total & & 363 & 100.0 & & \\
\hline \hline
\end{tabular}

Did you answer yes because (choose the most important reason)

\begin{tabular}{|c|c|c|c|c|c|}
\hline \multicolumn{2}{|c|}{ Stennis Fellows } & \multirow{2}{*}{$\frac{\text { Frequency }}{2}$} & \multirow{2}{*}{$\frac{\text { Percent }}{1.6}$} & \multirow{2}{*}{$\frac{\text { Valid Percent }}{3.2}$} & \multirow{2}{*}{$\begin{array}{c}\begin{array}{c}\text { Cumulative } \\
\text { Percent }\end{array} \\
3.2\end{array}$} \\
\hline Valid & $\begin{array}{l}\text { You believe it is always } \\
\text { wrong to lie }\end{array}$ & & & & \\
\hline & $\begin{array}{l}\text { You believe that your boss } \\
\text { has a right to know }\end{array}$ & 9 & 7.4 & 14.5 & 17.7 \\
\hline & $\begin{array}{l}\text { You feel an obligation to } \\
\text { your boss to be truthful }\end{array}$ & 15 & 12.3 & 24.2 & 41.9 \\
\hline & $\begin{array}{l}\text { You believe that your boss } \\
\text { could be harmed if you do } \\
\text { not answer truthfully }\end{array}$ & 19 & 15.6 & 30.6 & 72.6 \\
\hline & $\begin{array}{l}\text { You believe the truth will } \\
\text { come out eventually and you } \\
\text { might be implicated if you } \\
\text { protect your colleague }\end{array}$ & 6 & 4.9 & 9.7 & 82.3 \\
\hline & $\begin{array}{l}\text { You believe the obligation to } \\
\text { be truthful is more important } \\
\text { than the promise to your } \\
\text { colleague not to tell anyone }\end{array}$ & 9 & 7.4 & 14.5 & 96.8 \\
\hline & Other & 2 & 1.6 & 3.2 & 100.0 \\
\hline & Total & 62 & 50.8 & 100.0 & \\
\hline Missing & System & 60 & 49.2 & & \\
\hline Total & & 122 & 100.0 & & \\
\hline
\end{tabular}

Did you answer yes because (choose the most important reason)

\begin{tabular}{|c|c|c|c|c|c|}
\hline \multicolumn{2}{|c|}{$\begin{array}{l}\text { All Staff-unweighted indicating it is } \\
\text { never OK to tell a lie }\end{array}$} & \multirow{2}{*}{$\frac{\text { Frequency }}{7}$} & \multirow{2}{*}{$\frac{\text { Percent }}{8.3}$} & \multirow{2}{*}{$\frac{\text { Valid Percent }}{10.9}$} & \multirow{2}{*}{$\begin{array}{l}\begin{array}{l}\text { Cumulative } \\
\text { Percent }\end{array} \\
10.9\end{array}$} \\
\hline Valid & $\begin{array}{l}\text { You believe it is always } \\
\text { wrong to lie }\end{array}$ & & & & \\
\hline & $\begin{array}{l}\text { You believe that your boss } \\
\text { has a right to know }\end{array}$ & 7 & 8.3 & 10.9 & 21.9 \\
\hline & $\begin{array}{l}\text { You feel an obligation to your } \\
\text { boss to be truthful }\end{array}$ & 16 & 19.0 & 25.0 & 46.9 \\
\hline & $\begin{array}{l}\text { You believe that your boss } \\
\text { could be harmed if you do } \\
\text { not answer truthfully }\end{array}$ & 10 & 11.9 & 15.6 & 62.5 \\
\hline
\end{tabular}




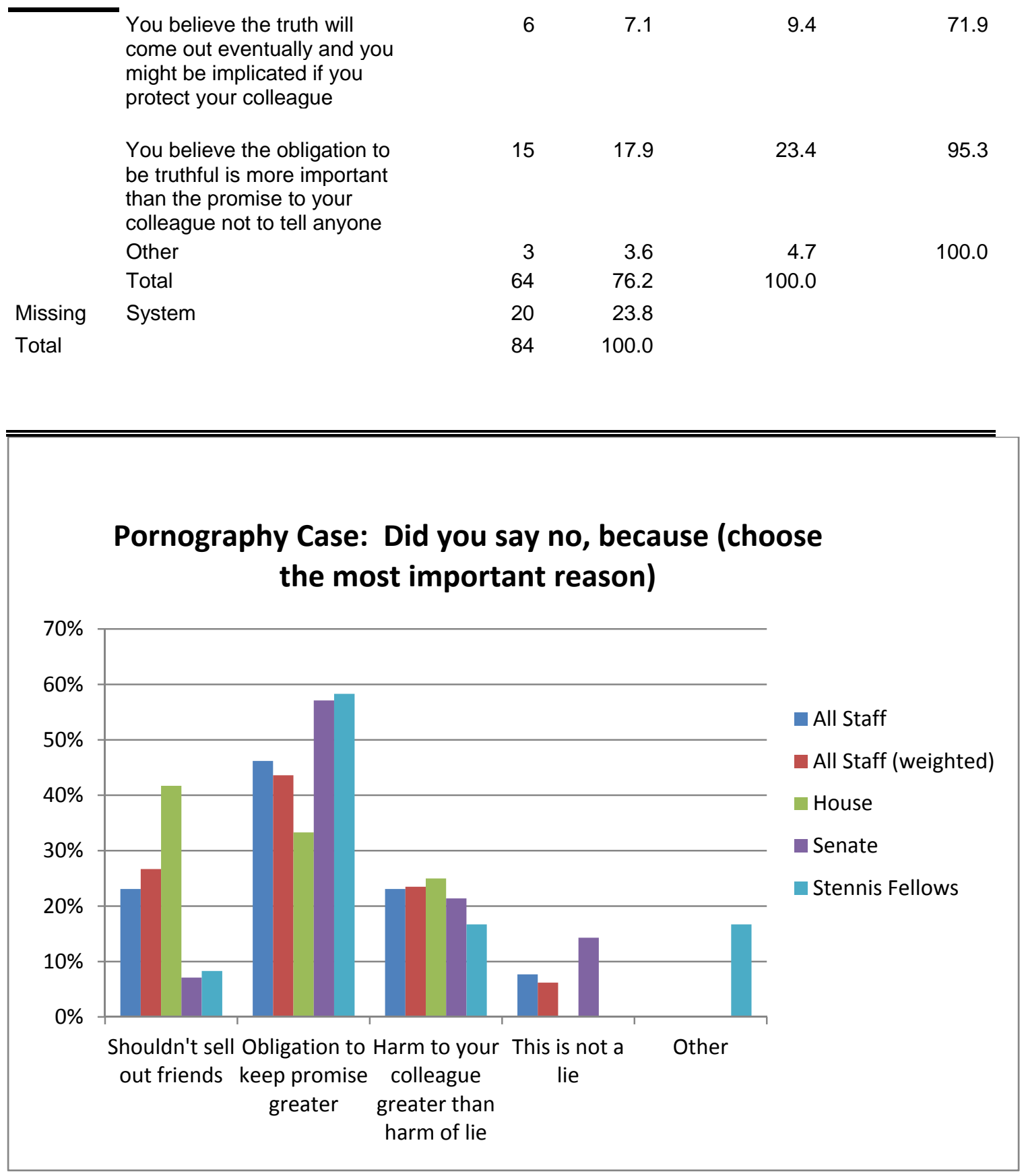

Twenty-six respondents from all staff-weighted indicated they would tell their boss "no," that they had not seen anyone on the staff download pornographic material. The sample was not large enough to draw conclusions about the sample frame. There were, however, similarities across the samples. Three justifications were drawn upon to explain their 
decision to tell their boss "no": a belief that the preceding "obligation to keep a promise was greater than the obligation to answer truthfully," that "you should not sell out your friends," and that the "harm that would come to your friend is greater than the possible harm of the lie." Two Senate staff traded on the idea that they did not actually "see" the download and indicated that this was not a lie.

Did you answer no because (choose the most important reason)

\begin{tabular}{|c|c|c|c|c|c|c|}
\hline \multicolumn{3}{|c|}{ Chamber } & \multirow{2}{*}{$\frac{\text { Frequency }}{5}$} & \multirow{2}{*}{$\frac{\text { Percent }}{2.7}$} & \multirow{2}{*}{$\frac{\text { Valid Percent }}{41.7}$} & \multirow{2}{*}{$\begin{array}{c}\begin{array}{c}\text { Cumulative } \\
\text { Percent }\end{array} \\
41.7\end{array}$} \\
\hline House & Valid & $\begin{array}{l}\text { You should not "sell out" } \\
\text { your friends }\end{array}$ & & & & \\
\hline & & $\begin{array}{l}\text { The obligation to keep your } \\
\text { promise outweighs the } \\
\text { obligation to answer } \\
\text { truthfully in this particular } \\
\text { situation }\end{array}$ & 4 & 2.2 & 33.3 & 75.0 \\
\hline & & $\begin{array}{l}\text { The harm that would come } \\
\text { to your friend is greater than } \\
\text { the possible harm of the lie }\end{array}$ & 3 & 1.6 & 25.0 & 100.0 \\
\hline & & Total & 12 & 6.5 & 100.0 & \\
\hline & Missing & System & 173 & 93.5 & & \\
\hline & Total & & 185 & 100.0 & & \\
\hline \multirow[t]{7}{*}{ Senate } & Valid & $\begin{array}{l}\text { You should not "sell out" } \\
\text { your friends }\end{array}$ & 1 & .6 & 7.1 & 7.1 \\
\hline & & $\begin{array}{l}\text { The obligation to keep your } \\
\text { promise outweighs the } \\
\text { obligation to answer } \\
\text { truthfully in this particular } \\
\text { situation }\end{array}$ & 8 & 4.5 & 57.1 & 64.3 \\
\hline & & $\begin{array}{l}\text { The harm that would come } \\
\text { to your friend is greater than } \\
\text { the possible harm of the lie }\end{array}$ & 3 & 1.7 & 21.4 & 85.7 \\
\hline & & $\begin{array}{l}\text { This is not a lie. You didn't } \\
\text { actually SEE the material } \\
\text { being downloaded }\end{array}$ & 2 & 1.1 & 14.3 & 100.0 \\
\hline & & Total & 14 & 7.9 & 100.0 & \\
\hline & Missing & System & 164 & 92.1 & & \\
\hline & Total & & 178 & 100.0 & & \\
\hline
\end{tabular}


Did you answer no because (choose the most important reason)

\begin{tabular}{|c|c|c|c|c|c|}
\hline \multicolumn{2}{|c|}{ All Staff-weighted } & \multirow{2}{*}{$\frac{\text { Frequency }}{7}$} & \multirow{2}{*}{$\frac{\text { Percent }}{1.9}$} & \multirow{2}{*}{$\frac{\text { Valid Percent }}{26.7}$} & \multirow{2}{*}{$\begin{array}{c}\begin{array}{c}\text { Cumulative } \\
\text { Percent }\end{array} \\
26.7\end{array}$} \\
\hline Valid & $\begin{array}{l}\text { You should not "sell out" } \\
\text { your friends }\end{array}$ & & & & \\
\hline & $\begin{array}{l}\text { The obligation to keep your } \\
\text { promise outweighs the } \\
\text { obligation to answer } \\
\text { truthfully in this particular } \\
\text { situation }\end{array}$ & 11 & 3.1 & 43.6 & 70.4 \\
\hline & $\begin{array}{l}\text { The harm that would come } \\
\text { to your friend is greater than } \\
\text { the possible harm of the lie }\end{array}$ & 6 & 1.6 & 23.5 & 93.8 \\
\hline & $\begin{array}{l}\text { This is not a lie. You didn't } \\
\text { actually SEE the material } \\
\text { being downloaded }\end{array}$ & 2 & .4 & 6.2 & 100.0 \\
\hline & Total & 26 & 7.0 & 100.0 & \\
\hline Missing & System & 339 & 93.0 & & \\
\hline Total & & 364 & 100.0 & & \\
\hline
\end{tabular}

Did you answer no because (choose the most important reason)--

\begin{tabular}{|c|c|c|c|c|c|}
\hline \multicolumn{2}{|c|}{ All Staff-unweighted } & \multirow{2}{*}{$\frac{\text { Frequency }}{6}$} & \multirow{2}{*}{$\frac{\text { Percent }}{1.7}$} & \multirow{2}{*}{$\frac{\text { Valid Percent }}{23.1}$} & \multirow{2}{*}{$\begin{array}{c}\begin{array}{c}\text { Cumulative } \\
\text { Percent }\end{array} \\
23.1\end{array}$} \\
\hline Valid & $\begin{array}{l}\text { You should not "sell out" } \\
\text { your friends }\end{array}$ & & & & \\
\hline & $\begin{array}{l}\text { The obligation to keep your } \\
\text { promise outweighs the } \\
\text { obligation to answer } \\
\text { truthfully in this particular } \\
\text { situation }\end{array}$ & 12 & 3.3 & 46.2 & 69.2 \\
\hline & $\begin{array}{l}\text { The harm that would come } \\
\text { to your friend is greater than } \\
\text { the possible harm of the lie }\end{array}$ & 6 & 1.7 & 23.1 & 92.3 \\
\hline & $\begin{array}{l}\text { This is not a lie. You didn't } \\
\text { actually SEE the material } \\
\text { being downloaded }\end{array}$ & 2 & .6 & 7.7 & 100.0 \\
\hline & Total & 26 & 7.2 & 100.0 & \\
\hline Missing & System & 337 & 92.8 & & \\
\hline Total & & 363 & 100.0 & & \\
\hline
\end{tabular}


Did you answer no because (choose the most important reason)

\begin{tabular}{|c|c|c|c|c|c|}
\hline \multicolumn{2}{|c|}{ Stennis Fellows } & \multirow{2}{*}{$\frac{\text { Frequency }}{1}$} & \multirow{2}{*}{$\frac{\text { Percent }}{.8}$} & \multirow{2}{*}{$\frac{\text { Valid Percent }}{8.3}$} & \multirow{2}{*}{$\begin{array}{c}\begin{array}{c}\text { Cumulative } \\
\text { Percent }\end{array} \\
8.3\end{array}$} \\
\hline Valid & $\begin{array}{l}\text { You should not "sell out" } \\
\text { your friends }\end{array}$ & & & & \\
\hline & $\begin{array}{l}\text { The obligation to keep your } \\
\text { promise outweighs the } \\
\text { obligation to answer } \\
\text { truthfully in this particular } \\
\text { situation }\end{array}$ & 7 & 5.7 & 58.3 & 66.7 \\
\hline & $\begin{array}{l}\text { The harm that would come } \\
\text { to your friend is greater than } \\
\text { the possible harm of the lie }\end{array}$ & 2 & 1.6 & 16.7 & 83.3 \\
\hline & Other & 2 & 1.6 & 16.7 & 100.0 \\
\hline & Total & 12 & 9.8 & 100.0 & \\
\hline Missing & System & 110 & 90.2 & & \\
\hline Total & & 122 & 100.0 & & \\
\hline
\end{tabular}

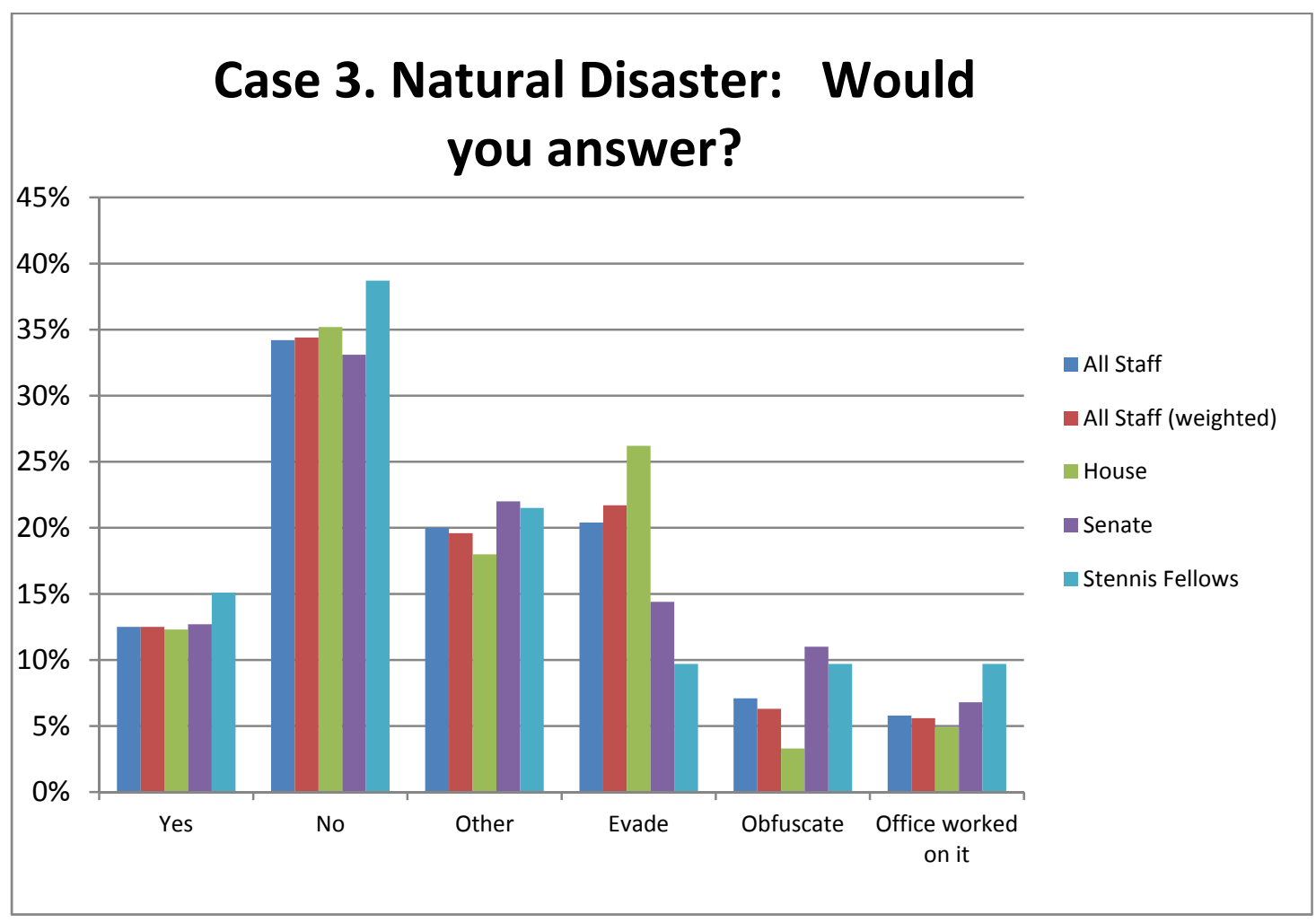

The natural disaster case was drawn to appeal to press staff and to test a common scenario in which there may be incentive to "spin," provide partial truths, or lie with the 
pressure of a looming political campaign. Respondents were presented with the following case and invited to answer "yes," "no," or "other":

"A natural disaster has devastated portions of your state. Your constituents are struggling to get cooperation from various federal agencies. Newspapers have questioned the effectiveness of your boss and a local official is considering a primary challenge. You have spent three weeks unsuccessfully trying to get your boss to contact an agency on behalf of a prominent constituent business.

Congressional Affairs calls you out of the blue and notifies you that your constituent has been awarded a large contract. During the press calls, the editor of one of your most important papers asks you whether your Member/Senator personally called the Administrator to advocate for the grant. Would you answer..."

As with the previous case, "other" answers were reviewed to see whether they fit into a category of responses. As with the cancer case, some staff attempted to "evade" the question, while some staff tried to "obfuscate" ("I don't know or I'm not sure whether my boss spoke to the agency"). A new category emerged with this case: "the office worked on it." Some respondents indicated they would answer "yes" because they themselves had worked on it and the member/senator is responsible for the priorities of the office. Other respondents offered, "the office worked on it," in lieu of a direct answer to the question.

Twelve to $15 \%$ of the respondents were prepared to tell the editor "yes," that their boss had personally advocated on the constituent's behalf, while $33 \%$ to $37 \%$ were prepared to answer "no," that their boss had not advocated for the grant. The remainder of respondents attempted to find ways to avoid telling a direct lie while leaving the editor with the impression that the member/senator had directly intervened. 
Confidence intervals were calculated for each of the respondent groups. The widest confidence interval at the $95 \%$ level for the House was $\pm 8.5 \%$, for the Senate was $\pm 8.5 \%$, for all staff-weighted was $\pm 6.0 \%$ and for Stennis Fellows was $\pm 8.1 \%$.

Stennis Fellows (38.7\%) were more likely to respond "no" than House (35.2\%) or Senate (33.1\%) staff or all staff-weighted (34.4\%). The two-sample, two-tailed t-statistic for the difference in proportions between Stennis Fellows and Senate staff was not significant at the .05 level, $t(209)=.84, p=.4$. The null hypothesis that there is no difference between the Stennis Fellows and Senate staff cannot be rejected.

All staff-weighted respondents were filtered to select only the 85 individuals who indicated that the statement, "it is never OK to lie," most closely reflected their view. Seven percent of these respondents indicated they would respond "yes." $33.9 \%$ indicated they would tell the editor "no," $22.4 \%$ would provide an "other" response, $24.9 \%$ would "evade" the question, and 7.1\% would "obfuscate."

All staff-weighted respondents who indicated that it was never OK to tell a lie were less likely to answer "yes" (7\%) and more likely to answer "other" $(22.4 \%)$ or to "evade" $(24.9 \%)$ the question than those who disagreed. The two-sample, two-tailed t-statistic for the difference between proportions of those who responded "yes" was not significant at the .05 level, $t(235)=-1.95, p=.052$. The null hypothesis that there was no difference in the proportion of respondents who selected "yes" cannot be rejected. 
The $7 \%$ of respondents who indicated they would tell the editor "yes" was similar in proportion to the $6.5 \%$ who indicated they would tell their boss "no" in the pornography case.

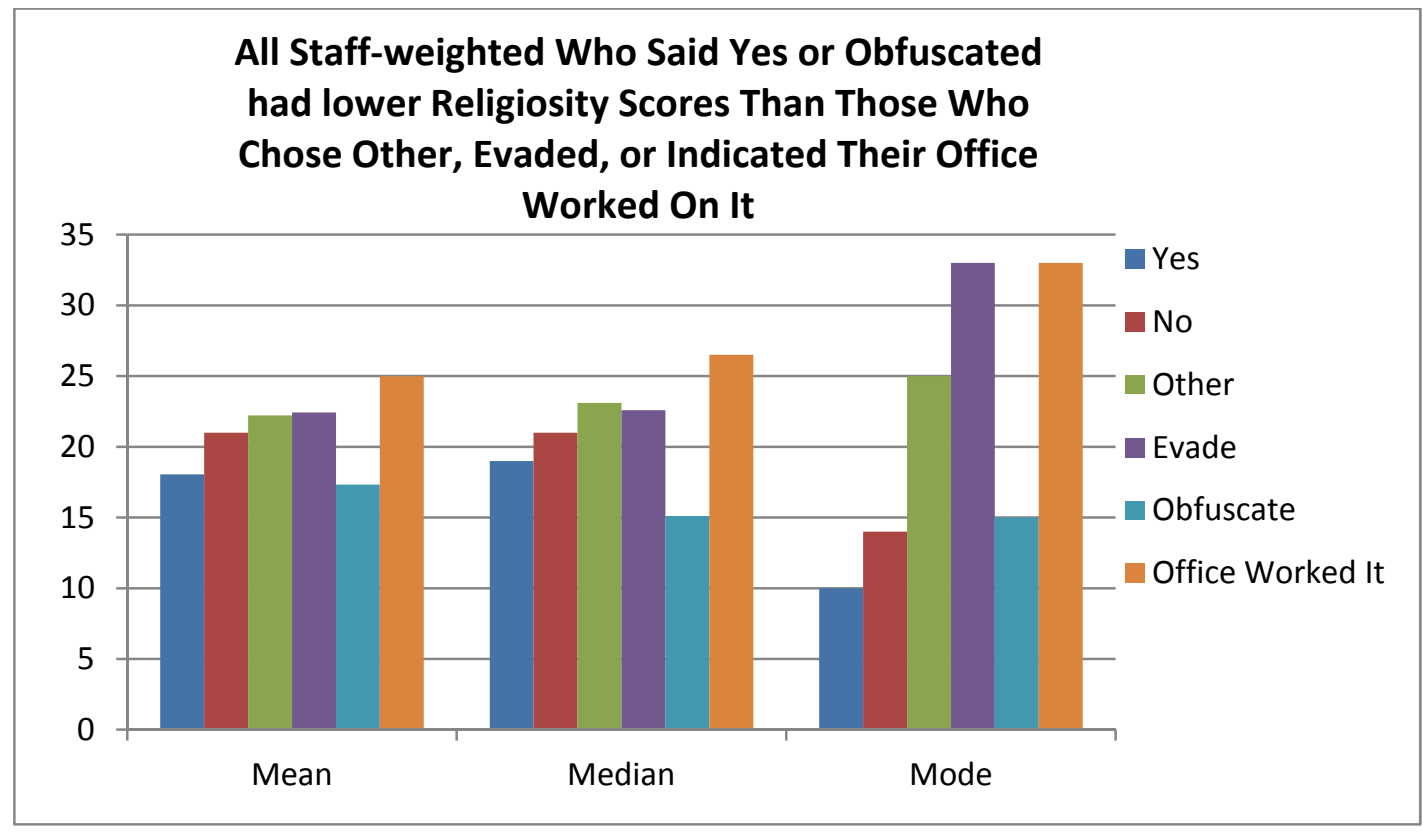

All staff-weighted who answered "yes" $(M=18, M d n=19)$ and who "obfuscated" $(M=17.3, M d n=15.1)$ had lower religiosity scores than staff who responded "no" $(M=21$, $M d n=21)$, "other" $(M=22.2, M d n=23.1)$, "evade" $(M=22.4, M d n=22.6)$, or "my office worked on it" $(M=25, M d n=26.5)$.

The two-sample, two-tailed t-statistic was not significant at the .05 level for the difference in mean religiosity between staff answering "yes" and staff answering "no," $t(109)=1.79, p=.08$, or for the difference in mean religiosity between staff answering "yes" and staff who "obfuscated," $t(43)=.303, p=.76$. The Mann-Whitney U Test also revealed no significant difference in religiosity between respondents who answered "yes" 
( $M d n=19, n=30)$ and respondents who answered "no" $(M d n=21, n=81), U=955, z=-1.642$, $p=.100$.

The two-sample, two-tailed t-statistic was significant at the .05 level for the difference in mean religiosity between staff who answered "yes" and who responded "other," $t(72)=2.5, p=.02$; between staff who answered "yes" and staff who attempted to "evade," $t(80)=2.5, p=.02$; and between staff who answered "yes" and those who answered that their office "worked on it," $t(42)=3.03, p=.004$.

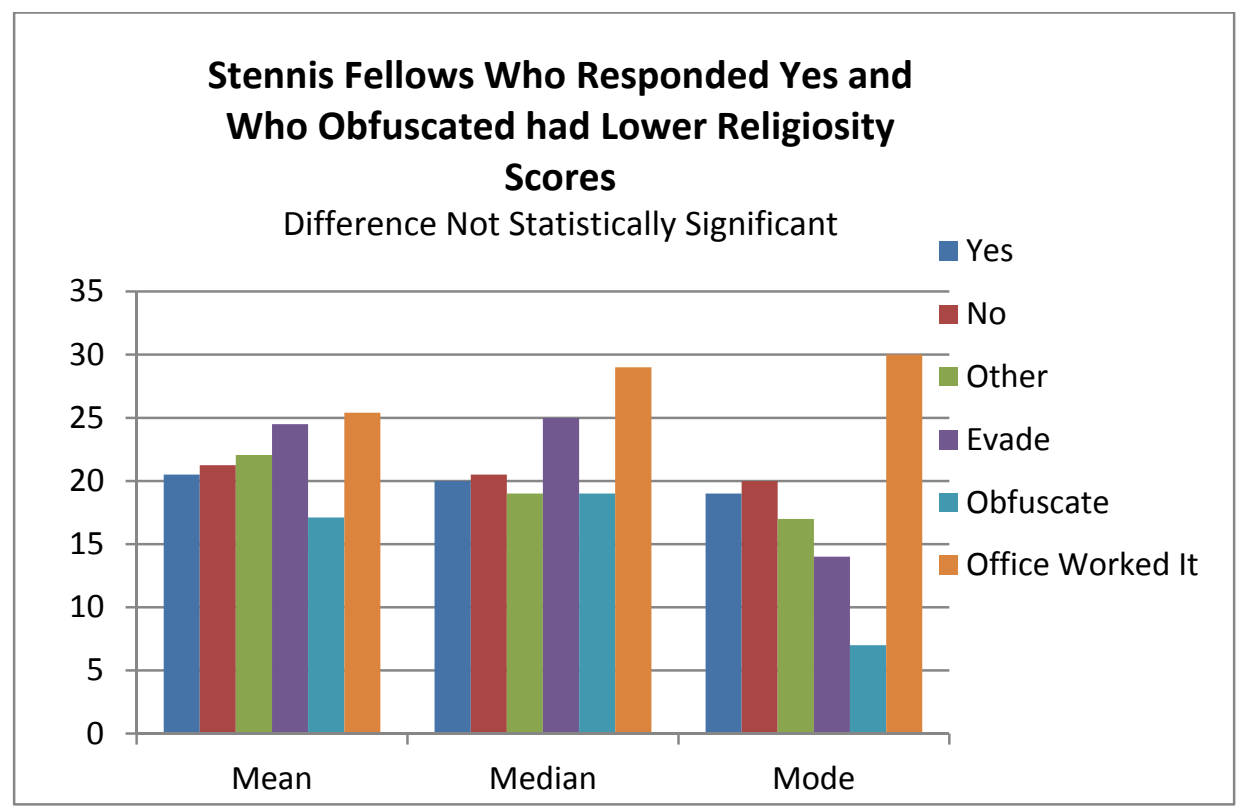

In a pattern strikingly similar to that presented by the all staff-weighted respondents, Stennis Fellows who answered "yes" $(M=20.5, M d n=20)$ and who "obfuscated" $(M=17.1$, $M d n=19)$ had lower religiosity scores than fellows who responded "no" $(M=21.3$ $M d n=20.5)$, "other" $(M=22, M d n=19)$, "evade" $(M=24.5, M d n=25)$, or "my office worked on it" (M=25.4, Mdn=29). 
The two-sample, two-tailed t-statistic was not significant at the .05 level for the difference in mean religiosity between fellows answering "yes" and fellows answering "no," $t(48)=-.46, p=.64$; for the difference in mean religiosity between fellows answering "yes" and fellows answering "other," $t(31)=-1.09, p=.284$; for the difference in mean religiosity between fellows who answered "yes" and fellows who "evaded," $t(20)=1.45$, $p=.16$; between fellows who answered "yes" and fellows who "obfuscated," $t(21)=1.00$, $p=.2884$; or between fellows who answered "yes" and fellows who answered that their office "worked on it," $t(17)=1.55 p=.143$.

The Mann-Whitney U Test also revealed no significant difference in religiosity between fellows who answered "yes" $(\mathrm{Mdn}=20, \mathrm{n}=14)$ and fellows who answered "no" $(M d n=20.5, n=36), U=237, z=-.325, p=.745$.

Case 3. A natural disaster has devastated portions of your state.

\begin{tabular}{|c|c|c|c|c|c|c|}
\hline \multicolumn{7}{|l|}{ All Staff-weighted } \\
\hline \multicolumn{3}{|c|}{ It is never OK to tell a lie } & Frequency & Percent & Valid Percent & $\begin{array}{c}\text { Cumulative } \\
\text { Percent }\end{array}$ \\
\hline \multirow[t]{9}{*}{ Reflects my View } & \multirow[t]{7}{*}{ Valid } & Yes & 6 & 6.9 & 7.0 & 7.0 \\
\hline & & No & 29 & 33.5 & 33.9 & 41.0 \\
\hline & & Other & 19 & 22.1 & 22.4 & 63.4 \\
\hline & & Evade & 21 & 24.6 & 24.9 & 88.3 \\
\hline & & Obfuscate & 4 & 4.6 & 4.6 & 92.9 \\
\hline & & $\begin{array}{l}\text { Office Worked On } \\
\text { It }\end{array}$ & 6 & 7.0 & 7.1 & 100.0 \\
\hline & & Total & 85 & 98.6 & 100.0 & \\
\hline & Missing & System & 1 & 1.4 & & \\
\hline & Total & & 87 & 100.0 & & \\
\hline \multirow{6}{*}{$\begin{array}{l}\text { Does not Reflect my } \\
\text { View }\end{array}$} & \multirow[t]{6}{*}{ Valid } & Yes & 24 & 15.6 & 15.8 & 15.8 \\
\hline & & No & 53 & 34.2 & 34.7 & 50.5 \\
\hline & & Other & 27 & 17.4 & 17.7 & 68.2 \\
\hline & & Evade & 31 & 20.0 & 20.3 & 88.5 \\
\hline & & obfuscate & 10 & 6.4 & 6.6 & 95.0 \\
\hline & & $\begin{array}{l}\text { Office Worked On } \\
\text { It }\end{array}$ & 8 & 4.9 & 5.0 & 100.0 \\
\hline
\end{tabular}




\begin{tabular}{llccc}
\hline & Total & 152 & 98.5 & 100.0 \\
Missing & System & 2 & 1.5 & \\
Total & & 154 & 100.0 \\
\hline \hline
\end{tabular}

Case 3. A natural disaster has devastated portions of your state. Your constituents are struggling to get cooperation from various federal agencies.

\begin{tabular}{|c|c|c|c|c|c|c|}
\hline \multicolumn{3}{|c|}{ Chamber } & \multirow{2}{*}{$\frac{\text { Frequency }}{15}$} & \multirow{2}{*}{$\frac{\text { Percent }}{8.1}$} & \multirow{2}{*}{$\frac{\text { Valid Percent }}{12.3}$} & \multirow{2}{*}{$\begin{array}{c}\begin{array}{c}\text { Cumulative } \\
\text { Percent }\end{array} \\
12.3\end{array}$} \\
\hline House & Valid & Yes & & & & \\
\hline & & No & 43 & 23.2 & 35.2 & 47.5 \\
\hline & & Other & 22 & 11.9 & 18.0 & 65.6 \\
\hline & & Evade & 32 & 17.3 & 26.2 & 91.8 \\
\hline & & Obfuscate & 4 & 2.2 & 3.3 & 95.1 \\
\hline & & Office Worked On It & 6 & 3.2 & 4.9 & 100.0 \\
\hline & & Total & 122 & 65.9 & 100.0 & \\
\hline & Missing & System & 63 & 34.1 & & \\
\hline & Total & & 185 & 100.0 & & \\
\hline \multirow[t]{9}{*}{ Senate } & Valid & Yes & 15 & 8.4 & 12.7 & 12.7 \\
\hline & & No & 39 & 21.9 & 33.1 & 45.8 \\
\hline & & Other & 26 & 14.6 & 22.0 & 67.8 \\
\hline & & Evade & 17 & 9.6 & 14.4 & 82.2 \\
\hline & & Obfuscate & 13 & 7.3 & 11.0 & 93.2 \\
\hline & & Office Worked On It & 8 & 4.5 & 6.8 & 100.0 \\
\hline & & Total & 118 & 66.3 & 100.0 & \\
\hline & Missing & System & 60 & 33.7 & & \\
\hline & Total & & 178 & 100.0 & & \\
\hline
\end{tabular}

Case 3. A natural disaster has devastated portions of your state. Your constituents are struggling to get cooperation from various federal agencies.

\begin{tabular}{|c|c|c|c|c|c|}
\hline \multicolumn{2}{|c|}{ All Staff-weighted } & \multirow{2}{*}{$\frac{\text { Frequency }}{30}$} & \multirow{2}{*}{$\frac{\text { Percent }}{8.2}$} & \multirow{2}{*}{$\frac{\text { Valid Percent }}{12.5}$} & \multirow{2}{*}{$\begin{array}{c}\begin{array}{c}\text { Cumulative } \\
\text { Percent }\end{array} \\
12.5\end{array}$} \\
\hline Valid & Yes & & & & \\
\hline & No & 83 & 22.7 & 34.4 & 46.9 \\
\hline & Other & 47 & 12.9 & 19.6 & 66.4 \\
\hline & Evade & 52 & 14.3 & 21.7 & 88.1 \\
\hline & Obfuscate & 15 & 4.1 & 6.3 & 94.4 \\
\hline & Office Worked On It & 14 & 3.7 & 5.6 & 100.0 \\
\hline & Total & 241 & 66.1 & 100.0 & \\
\hline Missing & System & 124 & 33.9 & & \\
\hline Total & & 364 & 100.0 & & \\
\hline
\end{tabular}

Case 3. A natural disaster has devastated portions of your state. Your constituents are struggling to get cooperation from various federal agencies.

\begin{tabular}{|c|c|c|c|c|}
\hline All Staff-unweighted & Frequency & Percent & Valid Percent & $\begin{array}{c}\text { Cumulative } \\
\text { Percent }\end{array}$ \\
\hline Valid & 30 & 8.3 & 12.5 & 12.5 \\
\hline No & 82 & 22.6 & 34.2 & 46.7 \\
\hline
\end{tabular}




\begin{tabular}{llcccc}
\hline & Other & 48 & 13.2 & 20.0 & 66.7 \\
& Evade & 49 & 13.5 & 20.4 & 87.1 \\
& Obfuscate & 17 & 4.7 & 7.1 & 94.2 \\
& Office Worked On It & 14 & 3.9 & 5.8 & 100.0 \\
& Total & 240 & 66.1 & 100.0 & \\
Missing & System & 123 & 33.9 & \\
Total & & 363 & 100.0 & \\
\hline \hline
\end{tabular}

Case 3. A natural disaster has devastated portions of your state. Your constituents are struggling to get cooperation from various agencies.

\begin{tabular}{llcccc}
\hline \hline Stennis Fellows & Frequency & Percent & Valid Percent & $\begin{array}{c}\text { Cumulative } \\
\text { Percent }\end{array}$ \\
\hline Valid & Yes & 14 & 11.5 & 15.1 & 15.1 \\
& No & 36 & 29.5 & 38.7 & 53.8 \\
& Other & 20 & 16.4 & 21.5 & 75.3 \\
& Evade & 9 & 7.4 & 9.7 & 84.9 \\
& Obfuscate & 9 & 7.4 & 9.7 & 94.6 \\
& Office Worked On It & 5 & 4.1 & 5.4 & 100.0 \\
& Total & 93 & 76.2 & 100.0 & \\
Missing & System & 29 & 23.8 & & \\
\hline \hline
\end{tabular}

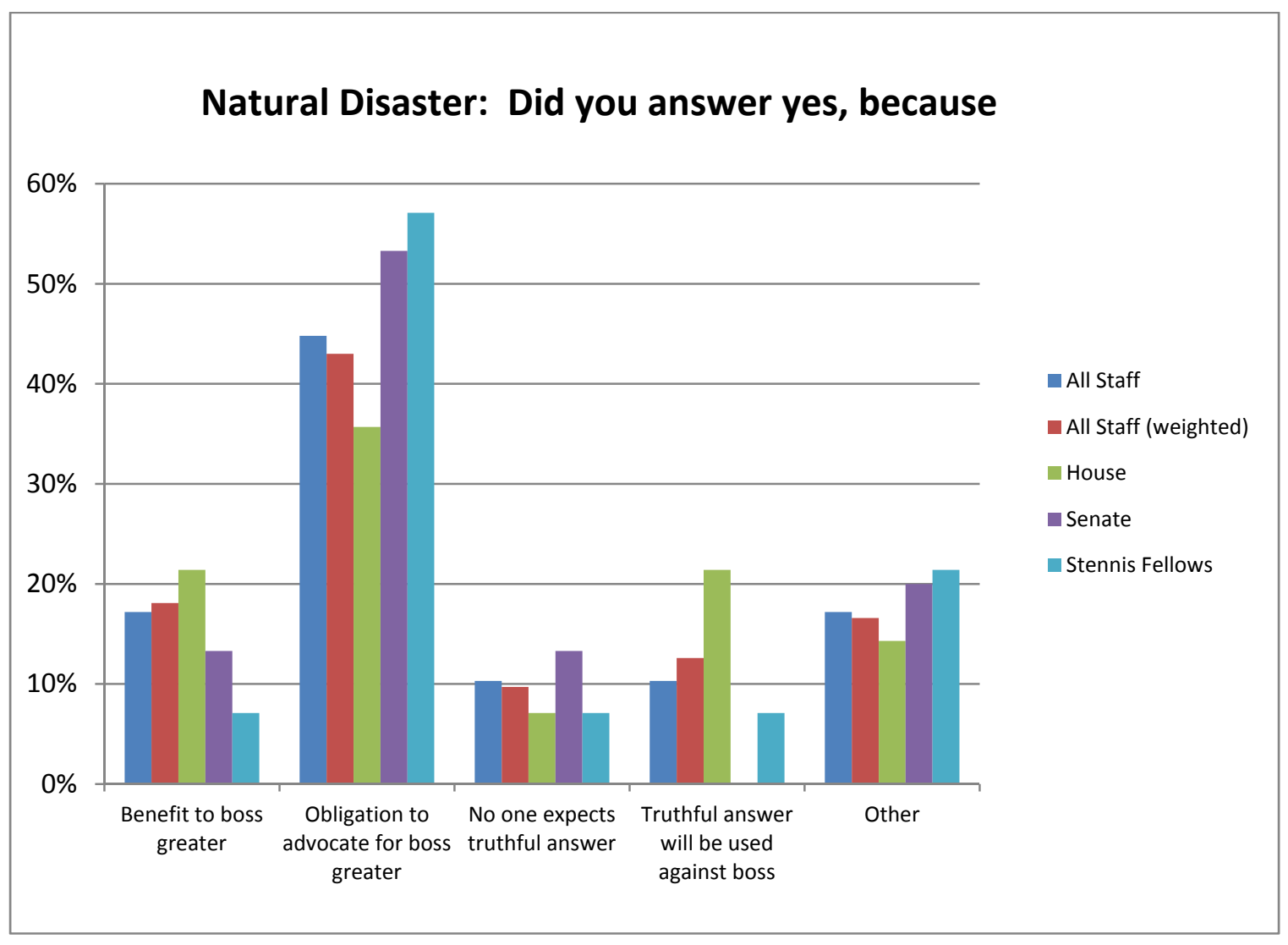


Twenty-nine staff (all staff-weighted) indicated that they would lie by answering "yes."

The numbers were too small to permit meaningful generalizations about the populations

from which these staff were drawn. The most frequently selected justification for lying

to the editor was that "the obligation to advocate for your boss is more important than

your obligation to be truthful to the press." Eighteen percent of all staff-weighted drew

upon consequentialist argument about benefit to boss. $13 \%$ argued that the truth would

be used against their boss.

Did you answer yes because (choose the most important reason)

\begin{tabular}{|c|c|c|c|c|c|c|}
\hline \multicolumn{3}{|c|}{ Chamber } & \multirow{2}{*}{$\frac{\text { Frequency }}{3}$} & \multirow{2}{*}{$\frac{\text { Percent }}{1.6}$} & \multirow{2}{*}{$\frac{\text { Valid Percent }}{21.4}$} & \multirow{2}{*}{$\begin{array}{c}\begin{array}{c}\text { Cumulative } \\
\text { Percent }\end{array} \\
21.4\end{array}$} \\
\hline House & Valid & $\begin{array}{l}\text { The benefit to your boss is } \\
\text { greater than any harm the lie } \\
\text { might cause }\end{array}$ & & & & \\
\hline & & $\begin{array}{l}\text { Your obligation to advocate } \\
\text { for your boss is more } \\
\text { important than your } \\
\text { obligation to be truthful to the } \\
\text { press in this instance }\end{array}$ & 5 & 2.7 & 35.7 & 57.1 \\
\hline & & $\begin{array}{l}\text { No one expects a completely } \\
\text { truthful answer in this } \\
\text { situation }\end{array}$ & 1 & .5 & 7.1 & 64.3 \\
\hline & & $\begin{array}{l}\text { A truthful answer will be } \\
\text { used by the editor against } \\
\text { your boss }\end{array}$ & 3 & 1.6 & 21.4 & 85.7 \\
\hline & & Other & 2 & 1.1 & 14.3 & 100.0 \\
\hline & & Total & 14 & 7.6 & 100.0 & \\
\hline & Missing & System & 171 & 92.4 & & \\
\hline & Total & & 185 & 100.0 & & \\
\hline \multirow[t]{3}{*}{ Senate } & Valid & $\begin{array}{l}\text { The benefit to your boss is } \\
\text { greater than any harm the lie } \\
\text { might cause }\end{array}$ & 2 & 1.1 & 13.3 & 13.3 \\
\hline & & $\begin{array}{l}\text { Your obligation to advocate } \\
\text { for your boss is more } \\
\text { important than your } \\
\text { obligation to be truthful to the } \\
\text { press in this instance }\end{array}$ & 8 & 4.5 & 53.3 & 66.7 \\
\hline & & $\begin{array}{l}\text { No one expects a completely } \\
\text { truthful answer in this } \\
\text { situation }\end{array}$ & 2 & 1.1 & 13.3 & 80.0 \\
\hline
\end{tabular}




\begin{tabular}{llcccc}
\hline & Other & 3 & 1.7 & 20.0 & 100.0 \\
& Total & 15 & 8.4 & 100.0 & \\
Missing & System & 163 & 91.6 & & \\
Total & & 178 & 100.0 & \\
\hline \hline
\end{tabular}

Did you answer yes because (choose the most important reason)

\begin{tabular}{|c|c|c|c|c|c|}
\hline \multicolumn{2}{|c|}{ All Staff-weighted } & \multirow{2}{*}{$\frac{\text { Frequency }}{5}$} & \multirow{2}{*}{$\frac{\text { Percent }}{1.4}$} & \multirow{2}{*}{$\frac{\text { Valid Percent }}{18.1}$} & \multirow{2}{*}{$\begin{array}{c}\begin{array}{c}\text { Cumulative } \\
\text { Percent }\end{array} \\
18.1\end{array}$} \\
\hline Valid & $\begin{array}{l}\text { The benefit to your boss is } \\
\text { greater than any harm the lie } \\
\text { might cause }\end{array}$ & & & & \\
\hline & $\begin{array}{l}\text { Your obligation to advocate } \\
\text { for your boss is more } \\
\text { important than your } \\
\text { obligation to be truthful to the } \\
\text { press in this instance }\end{array}$ & 12 & 3.4 & 43.0 & 61.1 \\
\hline & $\begin{array}{l}\text { No one expects a completely } \\
\text { truthful answer in this } \\
\text { situation }\end{array}$ & 3 & .8 & 9.7 & 70.8 \\
\hline & $\begin{array}{l}\text { A truthful answer will be } \\
\text { used by the editor against } \\
\text { your boss }\end{array}$ & 4 & 1.0 & 12.6 & 83.4 \\
\hline & Other & 5 & 1.3 & 16.6 & 100.0 \\
\hline & Total & 29 & 7.9 & 100.0 & \\
\hline Missing & System & 336 & 92.1 & & \\
\hline Total & & 364 & 100.0 & & \\
\hline
\end{tabular}

Did you answer yes because (choose the most important reason)

\begin{tabular}{|c|c|c|c|c|c|}
\hline \multicolumn{2}{|c|}{ All Staff-unweighted } & \multirow{2}{*}{$\frac{\text { Frequency }}{5}$} & \multirow{2}{*}{$\frac{\text { Percent }}{1.4}$} & \multirow{2}{*}{$\frac{\text { Valid Percent }}{17.2}$} & \multirow{2}{*}{$\begin{array}{c}\text { Cumulative } \\
\text { Percent }\end{array}$} \\
\hline Valid & $\begin{array}{l}\text { The benefit to your boss is } \\
\text { greater than any harm the lie } \\
\text { might cause }\end{array}$ & & & & \\
\hline & $\begin{array}{l}\text { Your obligation to advocate } \\
\text { for your boss is more } \\
\text { important than your } \\
\text { obligation to be truthful to the } \\
\text { press in this instance }\end{array}$ & 13 & 3.6 & 44.8 & 62.1 \\
\hline & $\begin{array}{l}\text { No one expects a completely } \\
\text { truthful answer in this } \\
\text { situation }\end{array}$ & 3 & .8 & 10.3 & 72.4 \\
\hline & $\begin{array}{l}\text { A truthful answer will be } \\
\text { used by the editor against } \\
\text { your boss }\end{array}$ & 3 & .8 & 10.3 & 82.8 \\
\hline & Other & 5 & 1.4 & 17.2 & 100.0 \\
\hline & Total & 29 & 8.0 & 100.0 & \\
\hline
\end{tabular}




\begin{tabular}{|c|c|c|}
\hline Missing & System & 334 \\
\hline Total & & 363 \\
\hline
\end{tabular}

Did you answer yes because (choose the most important reason)

\begin{tabular}{|c|c|c|c|c|c|}
\hline \multicolumn{2}{|c|}{ Stennis Fellows } & \multirow{2}{*}{$\frac{\text { Frequency }}{1}$} & \multirow{2}{*}{$\frac{\text { Percent }}{.8}$} & \multirow{2}{*}{$\frac{\text { Valid Percent }}{7.1}$} & \multirow{2}{*}{$\begin{array}{c}\begin{array}{c}\text { Cumulative } \\
\text { Percent }\end{array} \\
7.1\end{array}$} \\
\hline Valid & $\begin{array}{l}\text { The benefit to your boss is } \\
\text { greater than any harm the lie } \\
\text { might cause }\end{array}$ & & & & \\
\hline & $\begin{array}{l}\text { Your obligation to advocate } \\
\text { for your boss is more } \\
\text { important than your } \\
\text { obligation to be truthful to the } \\
\text { press in this instance }\end{array}$ & 8 & 6.6 & 57.1 & 64.3 \\
\hline & $\begin{array}{l}\text { No one expects a completely } \\
\text { truthful answer in this } \\
\text { situation }\end{array}$ & 1 & .8 & 7.1 & 71.4 \\
\hline & $\begin{array}{l}\text { A truthful answer will be } \\
\text { used by the editor against } \\
\text { your boss }\end{array}$ & 1 & .8 & 7.1 & 78.6 \\
\hline & Other & 3 & 2.5 & 21.4 & 100.0 \\
\hline & Total & 14 & 11.5 & 100.0 & \\
\hline Missing & System & 108 & 88.5 & & \\
\hline Total & & 122 & 100.0 & & \\
\hline
\end{tabular}




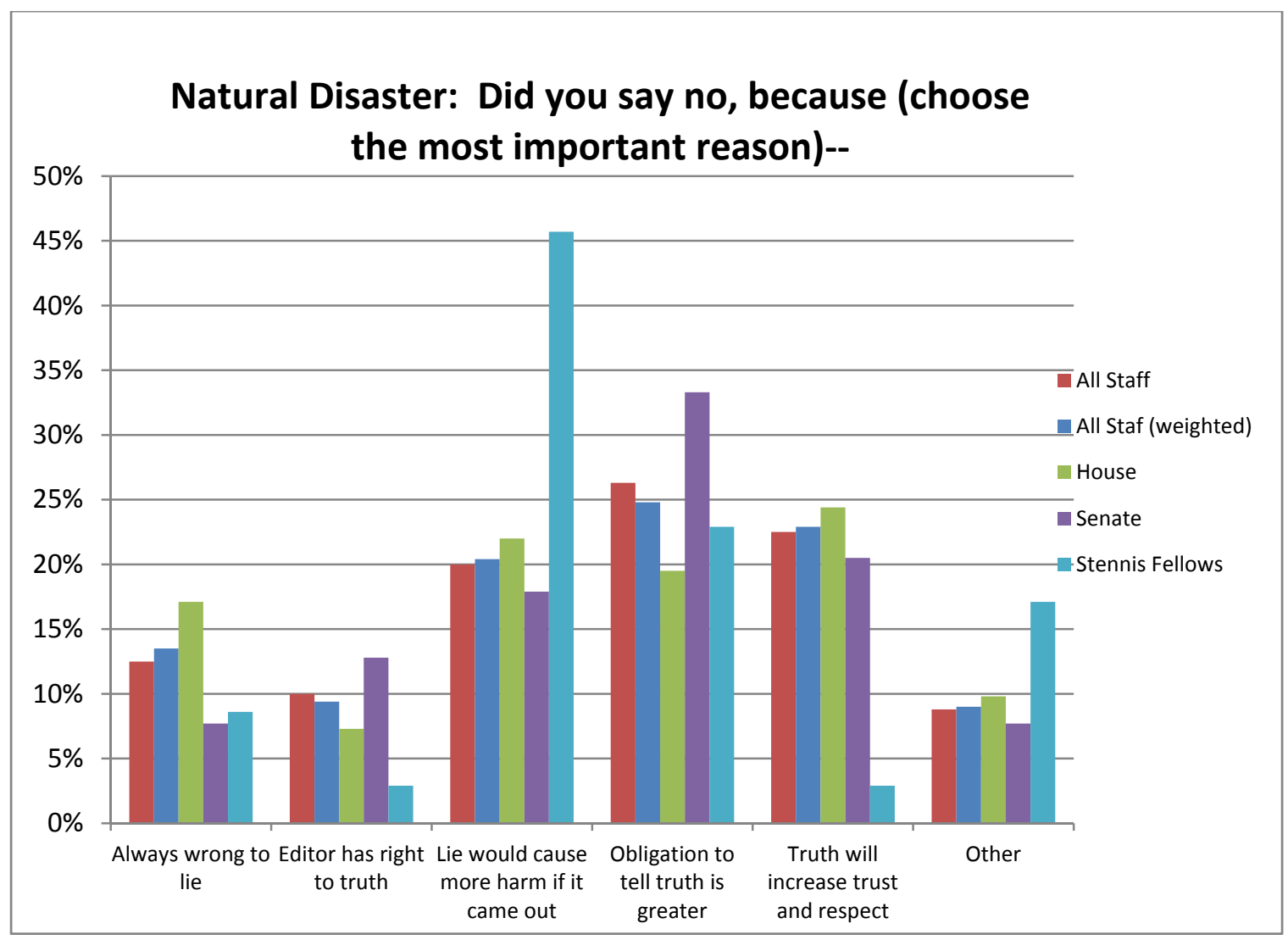

Staff were widely dispersed with regard to which justifications they offered for their decision to answer truthfully. The three most frequently cited justifications were that "the obligation to tell the truth is greater than you obligation to help your boss in this particular situation" (20\%-33\%); "telling the truth will increase the level of trust and respect your constituent holds for you and your boss" (3\%-24\%); and the assessment that "the lie would cause more harm than good if it came out during the campaign" $(18 \%$ to $46 \%)$.

Eight percent to $17 \%$ of staff indicated that they believe "it is always wrong to lie" and $3 \%$ to $13 \%$ believe that the "editor has a right to the truth." Stennis Fellows were more focused on the risks associated with a lie and with the strength of the obligation to tell the 
truth. Emails from staff, as well as elaborations in "other," also suggested they believed their relationships with the media to be governed by mutual skepticism and were less persuaded by the idea that the editor had a particular or special right to the truth or that truth-telling would result in an additional increase in trust or respect. One possible reason for this focus on consequences may be that Stennis Fellows, by virtue of longer tenure and greater seniority and responsibility, may take a longer view or have greater experience with the consequences of exposed deception.

Did you answer no because (choose the most important reason)

\begin{tabular}{|c|c|c|c|c|c|c|}
\hline \multicolumn{3}{|c|}{ Chamber } & \multirow{2}{*}{$\frac{\text { Frequency }}{7}$} & \multirow{2}{*}{$\frac{\text { Percent }}{3.8}$} & \multirow{2}{*}{$\frac{\text { Valid Percent }}{17.1}$} & \multirow{2}{*}{$\begin{array}{c}\begin{array}{c}\text { Cumulative } \\
\text { Percent }\end{array} \\
17.1\end{array}$} \\
\hline House & Valid & $\begin{array}{l}\text { You believe it is always } \\
\text { wrong to lie }\end{array}$ & & & & \\
\hline & & $\begin{array}{l}\text { You believe the editor has a } \\
\text { right to the truth }\end{array}$ & 3 & 1.6 & 7.3 & 24.4 \\
\hline & & $\begin{array}{l}\text { The lie would cause more } \\
\text { harm than good if it came } \\
\text { out during the campaign }\end{array}$ & 9 & 4.9 & 22.0 & 46.3 \\
\hline & & $\begin{array}{l}\text { The obligation to tell the truth } \\
\text { is more important than your } \\
\text { obligation to help your boss } \\
\text { in this particular situation }\end{array}$ & 8 & 4.3 & 19.5 & 65.9 \\
\hline & & $\begin{array}{l}\text { Telling the truth will increase } \\
\text { the level of trust and respect } \\
\text { your constituent holds for } \\
\text { you and your boss }\end{array}$ & 10 & 5.4 & 24.4 & 90.2 \\
\hline & & Other & 4 & 2.2 & 9.8 & 100.0 \\
\hline & & Total & 41 & 22.2 & 100.0 & \\
\hline & Missing & System & 144 & 77.8 & & \\
\hline & Total & & 185 & 100.0 & & \\
\hline \multirow[t]{3}{*}{ Senate } & Valid & $\begin{array}{l}\text { You believe it is always } \\
\text { wrong to lie }\end{array}$ & 3 & 1.7 & 7.7 & 7.7 \\
\hline & & $\begin{array}{l}\text { You believe the editor has a } \\
\text { right to the truth }\end{array}$ & 5 & 2.8 & 12.8 & 20.5 \\
\hline & & $\begin{array}{l}\text { The lie would cause more } \\
\text { harm than good if it came } \\
\text { out during the campaign }\end{array}$ & 7 & 3.9 & 17.9 & 38.5 \\
\hline
\end{tabular}




\begin{tabular}{|c|c|c|c|c|c|}
\hline & $\begin{array}{l}\text { The obligation to tell the truth } \\
\text { is more important than your } \\
\text { obligation to help your boss } \\
\text { in this particular situation }\end{array}$ & 13 & 7.3 & 33.3 & 71.8 \\
\hline & $\begin{array}{l}\text { Telling the truth will increase } \\
\text { the level of trust and respect } \\
\text { your constituent holds for } \\
\text { you and your boss }\end{array}$ & 8 & 4.5 & 20.5 & 92.3 \\
\hline & Other & 3 & 1.7 & 7.7 & 100.0 \\
\hline & Total & 39 & 21.9 & 100.0 & \\
\hline Missing & System & 139 & 78.1 & & \\
\hline Total & & 178 & 100.0 & & \\
\hline
\end{tabular}

Did you answer no because (choose the most important reason)

\begin{tabular}{|c|c|c|c|c|c|}
\hline \multicolumn{2}{|c|}{ All Staff-weighted } & \multirow{2}{*}{$\frac{\text { Frequency }}{11}$} & \multirow{2}{*}{$\frac{\text { Percent }}{3.0}$} & \multirow{2}{*}{$\frac{\text { Valid Percent }}{13.5}$} & \multirow{2}{*}{$\begin{array}{c}\begin{array}{c}\text { Cumulative } \\
\text { Percent }\end{array} \\
13.5\end{array}$} \\
\hline Valid & $\begin{array}{l}\text { You believe it is always } \\
\text { wrong to lie }\end{array}$ & & & & \\
\hline & $\begin{array}{l}\text { You believe the editor has a } \\
\text { right to the truth }\end{array}$ & 8 & 2.1 & 9.4 & 22.9 \\
\hline & $\begin{array}{l}\text { The lie would cause more } \\
\text { harm than good if it came } \\
\text { out during the campaign }\end{array}$ & 16 & 4.5 & 20.4 & 43.3 \\
\hline & $\begin{array}{l}\text { The obligation to tell the truth } \\
\text { is more important than your } \\
\text { obligation to help your boss } \\
\text { in this particular situation }\end{array}$ & 20 & 5.5 & 24.8 & 68.1 \\
\hline & $\begin{array}{l}\text { Telling the truth will increase } \\
\text { the level of trust and respect } \\
\text { your constituent holds for } \\
\text { you and your boss }\end{array}$ & 18 & 5.1 & 22.9 & 91.0 \\
\hline & Other & 7 & 2.0 & 9.0 & 100.0 \\
\hline & Total & 80 & 22.1 & 100.0 & \\
\hline Missing & System & 284 & 77.9 & & \\
\hline Total & & 364 & 100.0 & & \\
\hline
\end{tabular}

Did you answer no because (choose the most important reason)

\begin{tabular}{llcccc}
\hline \hline All Staff-unweighted & Frequency & Percent & Valid Percent & $\begin{array}{c}\text { Cumulative } \\
\text { Percent }\end{array}$ \\
\hline Valid & $\begin{array}{l}\text { You believe it is always } \\
\text { wrong to lie }\end{array}$ & 10 & 2.8 & 12.5 & 12.5 \\
& $\begin{array}{l}\text { You believe the editor has a } \\
\text { right to the truth }\end{array}$ & 8 & 2.2 & 10.0 & 22.5
\end{tabular}




\begin{tabular}{|c|c|c|c|c|c|}
\hline & $\begin{array}{l}\text { The lie would cause more } \\
\text { harm than good if it came } \\
\text { out during the campaign }\end{array}$ & 16 & 4.4 & 20.0 & 42.5 \\
\hline & $\begin{array}{l}\text { The obligation to tell the truth } \\
\text { is more important than your } \\
\text { obligation to help your boss } \\
\text { in this particular situation }\end{array}$ & 21 & 5.8 & 26.3 & 68.8 \\
\hline & $\begin{array}{l}\text { Telling the truth will increase } \\
\text { the level of trust and respect } \\
\text { your constituent holds for } \\
\text { you and your boss }\end{array}$ & 18 & 5.0 & 22.5 & 91.3 \\
\hline & Other & 7 & 1.9 & 8.8 & 100.0 \\
\hline & Total & 80 & 22.0 & 100.0 & \\
\hline Missing & System & 283 & 78.0 & & \\
\hline Total & & 363 & 100.0 & & \\
\hline
\end{tabular}

Did you answer no because (choose the most important reason)

\begin{tabular}{|c|c|c|c|c|c|}
\hline \multicolumn{2}{|c|}{ Stennis Fellows } & \multirow{2}{*}{$\frac{\text { Frequency }}{3}$} & \multirow{2}{*}{$\frac{\text { Percent }}{2.5}$} & \multirow{2}{*}{$\frac{\text { Valid Percent }}{8.6}$} & \multirow{2}{*}{$\begin{array}{c}\begin{array}{c}\text { Cumulative } \\
\text { Percent }\end{array} \\
8.6\end{array}$} \\
\hline Valid & $\begin{array}{l}\text { You believe it is always } \\
\text { wrong to lie }\end{array}$ & & & & \\
\hline & $\begin{array}{l}\text { You believe the editor has a } \\
\text { right to the truth }\end{array}$ & 1 & .8 & 2.9 & 11.4 \\
\hline & $\begin{array}{l}\text { The lie would cause more } \\
\text { harm than good if it came } \\
\text { out during the campaign }\end{array}$ & 16 & 13.1 & 45.7 & 57.1 \\
\hline & $\begin{array}{l}\text { The obligation to tell the truth } \\
\text { is more important than your } \\
\text { obligation to help your boss } \\
\text { in this particular situation }\end{array}$ & 8 & 6.6 & 22.9 & 80.0 \\
\hline & $\begin{array}{l}\text { Telling the truth will increase } \\
\text { the level of trust and respect } \\
\text { your constituent holds for } \\
\text { you and your boss }\end{array}$ & 1 & .8 & 2.9 & 82.9 \\
\hline & Other & 6 & 4.9 & 17.1 & 100.0 \\
\hline & Total & 35 & 28.7 & 100.0 & \\
\hline Missing & System & 87 & 71.3 & & \\
\hline Total & & 122 & 100.0 & & \\
\hline
\end{tabular}




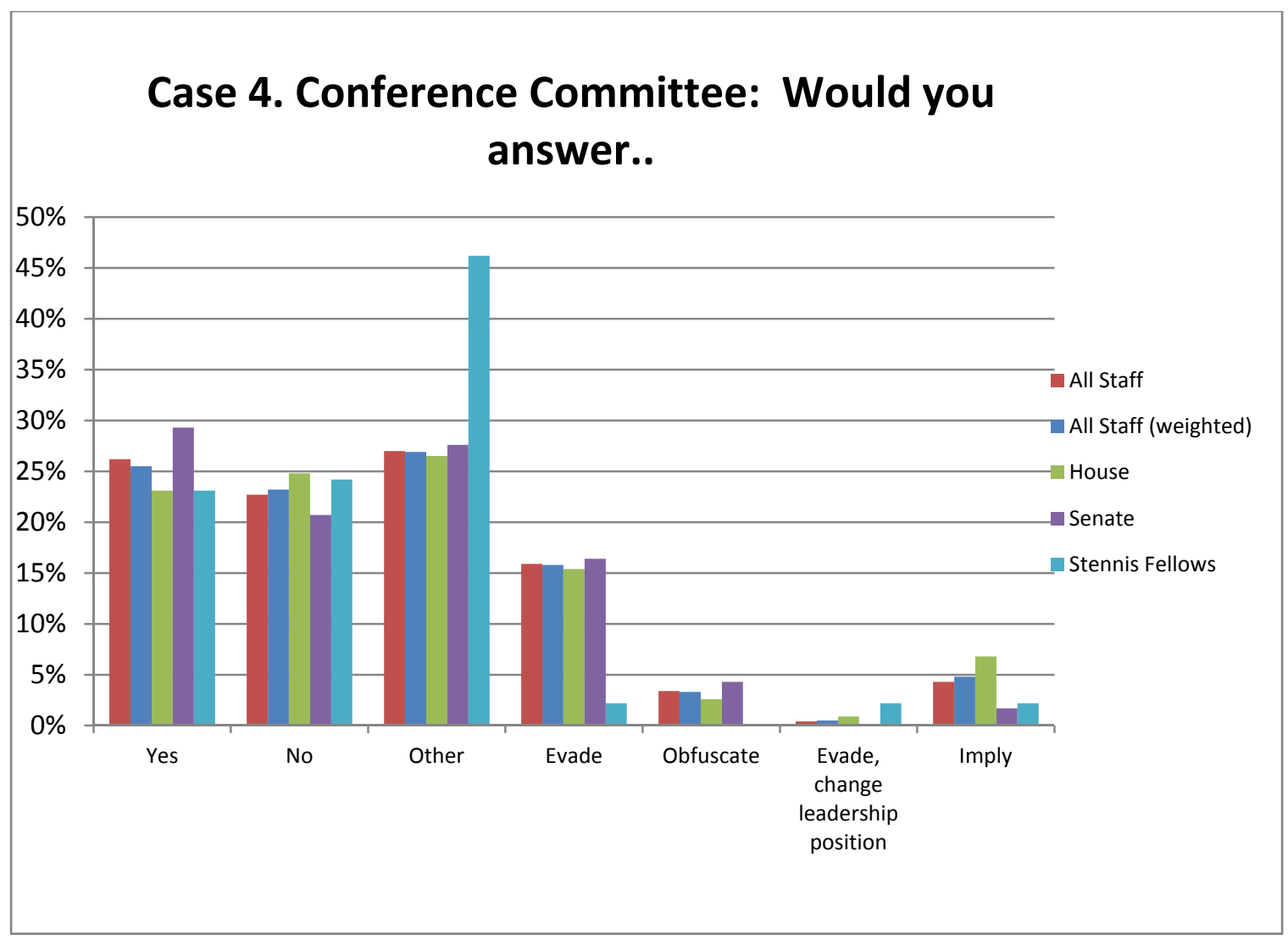

The conference committee case was drawn around a common occurrence in legislative negotiations between the chambers. Staff negotiate on behalf of their members and at times may be deputized to negotiate on behalf of the leadership of their committee, party or coalition. One of the complexities of these negotiations is determining who you are negotiating with, who they represent, and the authority they have to reach and enforce an agreement. There is a great deal of incentive to state your authority and position in the strongest possible terms throughout the negotiations. Respondents were presented with the following case and asked to answer "yes," "no," or "other":

"You are staffing the conference committee on a provision that is very important to you and to your Member/Senator. The conferees from the other body won't move at all on the provision and negotiations are coming down to the wire. You have tepid support from your leadership but have learned that the other side will recede if they believe that your leadership will hold the bill up over the provision. They ask you directly whether your leadership will kill the bill if they do not recede to your provision. Would you answer..." 
A large proportion of staff chose "other" and attempted to employ a variety of different strategies. This suggests that the case presented more complex issues in the practice of legislative staff. Respondents tried to identify strategies that allowed them to avoid telling either the truth or a lie. Some respondents focused on trying to persuade their leadership to oppose the provision (ergo, make the statement true), while others found ways to imply that they had the support from leadership without directly stating that this was the case.

Confidence intervals were calculated for each of the respondent groups. The widest confidence interval at the $95 \%$ level for the House was $\pm 8.1 \%$, for the Senate was $\pm 8.3 \%$, for all staff-weighted was $\pm 5.7 \%$ and for Stennis Fellows was $\pm 8.4 \%$.

Stennis Fellows (23.1\%) and House staff (23.1\%) were less likely than Senate staff $(29.3 \%)$ to answer "yes." The two-sample, two-tailed t-statistic was not significant at the .05 level for the difference in proportions between Stennis Fellows and Senate staff, $t(205)=.61, p=.54$. The null hypothesis that there is no difference in proportions cannot be rejected.

Stennis Fellows $(46.2 \%)$ were significantly more likely to avoid the "yes" or "no" answer and provide an "other" answer than Senate staff $(27.6 \%), t(235)=-1.95, p=.052$. Stennis Fellows (2.2\%) were also less likely to "evade" the question than House $(15.4 \%)$ or Senate $(16.4 \%)$ staff. The two-sample, two-tailed-statistic was significant at the .05 level for the difference in proportions between Stennis Fellows and House staff, $t(206)=-$ $3.2, p=.002$. 
Comparison of the all staff-weighted responses of respondents who agreed with the statement, "it is never Ok to tell a lie," and those who disagreed with the statement yielded significant differences. Only $10.8 \%$ of staff who believed it is always wrong to lie indicated they would answer "yes," while $34.3 \%$ of staff who disagreed with the statement that it is always wrong to lie indicated they would answer "yes." The twosample, two-tailed t-statistic was significant at the .05 level for the difference in proportions between the groups, $t(228)=-3.89, p=.0001$. In addition, $35.7 \%$ of staff who agreed with the statement, "it is never OK to tell a lie," chose to respond "other," while $21.1 \%$ of staff who disagreed chose to respond "other." The two-sample, two-tailed tstatistic for the difference between proportions was significant at the .05 level, $t(228)=2.42, p=.02$.

The chi-square test for independence indicated a significant association between the definition of lying and the case responses, $X^{2}(6, n=230)=18.2, p=.006$, Cramer's $V$ $=.281$. Four cells $(28.6 \%)$ had expected counts of less than five however, and violated one of the assumptions of the chi-square test. It is recommended that no more than $20 \%$ of cells have expected counts of less than five.

Nonetheless, there appears to be a significant relationship between agreement with the statement, "it is never OK to tell a lie," and a respondent's position on this case. $89.2 \%$ of all staff-weighted who agreed with this statement either responded "no" or found a way to say something other than "yes." 
All staff-weighted who indicated they would tell the other staff member "yes" reported being lied to less frequently $(M=6.93, M d n=4.0, n=48)$ than staff who reported they would tell the staff member "no" $(M=7.57, M d n=4, n=42)$. The two-sample, two-tailed t-statistic was not significant at the .05 level for the difference in being lied to, $t(88)=0.271, p=.7870$. The Mann-Whitney $U$ Test also revealed no significant difference, $U=1037.5, z=-.099, p=.921$.

Staff who reported they would tell the other staff member "yes" $(M=4.47, M d n=2, n=48)$ also reported lying more frequently than staff who indicated they would truthfully tell the other staff member "no" $(M=2, M d n=1, n=49)$. The two-sample, two-tailed t-statistic was not significant at the .05 level, $\mathrm{t}(95)=1.446, p=.1514$. The Mann-Whitney U Test also revealed no significant difference in lying, $U=1020.5, z=-1.32, p=.187$.

Twenty-two percent of staff who reported that they would untruthfully indicate their leadership would kill the bill also responded in the justification section of the survey that they did not believe it was OK to lie to strengthen their negotiating position. 


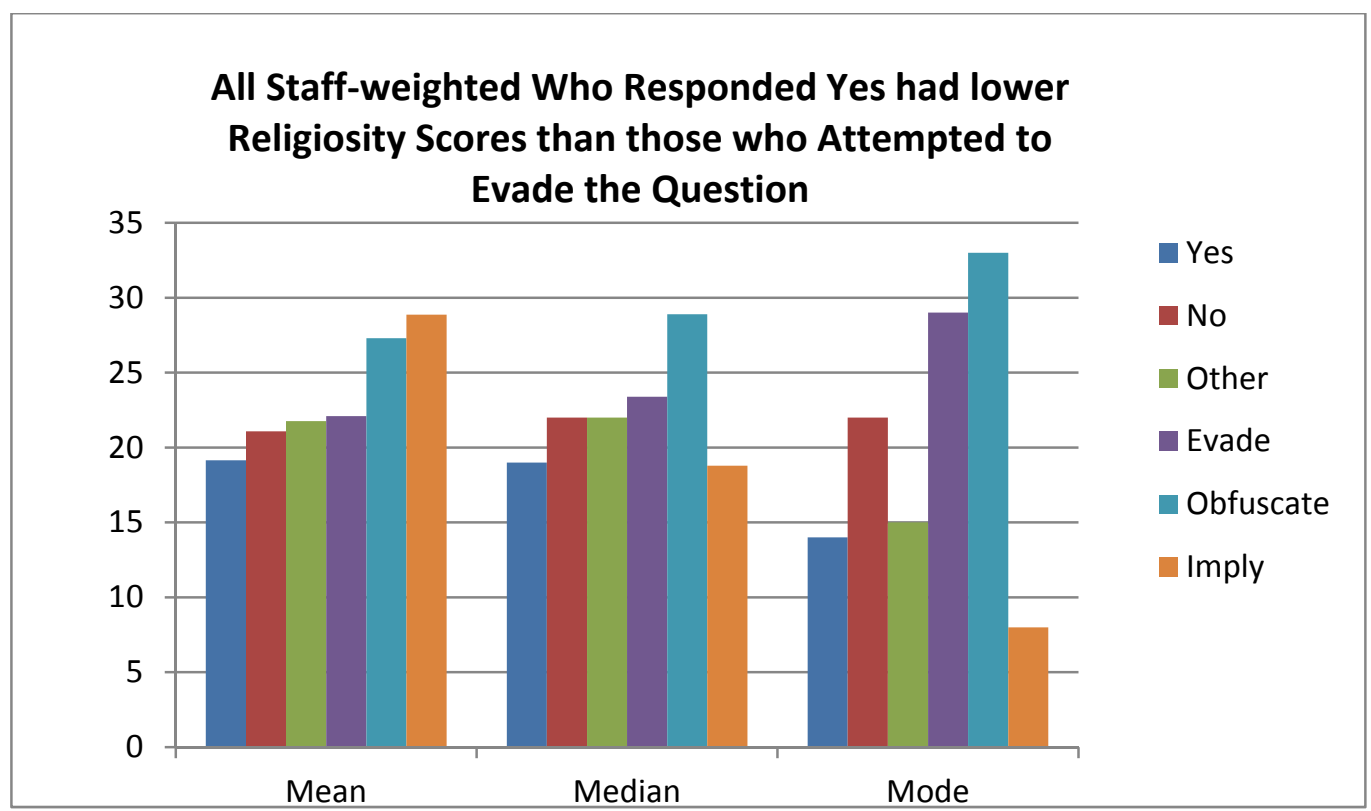

All staff-weighted who answered "yes" $(M=19.2, M d n=19)$ had lower religiosity scores than staff who responded "no" $(M=21.1 M d n=22)$, chose "other" $(M=21.8, M d n=22)$, “evaded" $(M=22.1, M d n=23.4)$, "obfuscated" $(M=27.29, M d n=28.9)$, or implied the provision was drafted as agreed $(\mathrm{M}=28.9, \mathrm{Mdn}=18.8)$. The two-sample, two-tailed tstatistic was not significant at the .05 level for the difference in mean religiosity between staff answering "yes" and staff answering "no," $t(112)=1.35, p=.18$; for the difference in mean religiosity between staff answering "yes" and staff answering "other," $t(118)=1.95$, $p=.054$; or for the difference in mean religiosity between those who answered "yes" and those who evaded the question, $t(95)=1.78, p=.08$. The null hypothesis that there is no difference in mean religiosity cannot be rejected.

The Mann-Whitney U Test also revealed that there was no significant difference in the religiosity of all staff-weighted who answered "yes" $(M d n=24, n=44)$ and staff who answered "no" $(M d n=21.97, n=69), U=1405.5, z=-1.20, p=.230$. 
The two-sample, two-tailed t-statistic was significant at the .05 level for the difference in mean religiosity between staff who answered "yes" and staff who "obfuscated," $t(66)=2.82, p=.006$, and between staff who answered "yes" and staff who implied the provision was as agreed, $t(68)=3.7, p=.0004$. The number of respondents who obfuscated (8) and who implied (10) were sufficiently small to raise questions about the consistency of the sample with the assumptions regarding normality.

The Mann-Whitney U Test was also significant at the .05 level for the difference in religiosity between staff who answered "yes" $(M d n=19, n=61)$ and staff who “obfuscated" $(M d n=28.9, n=8), U=100, z=2.703, p=.007$.

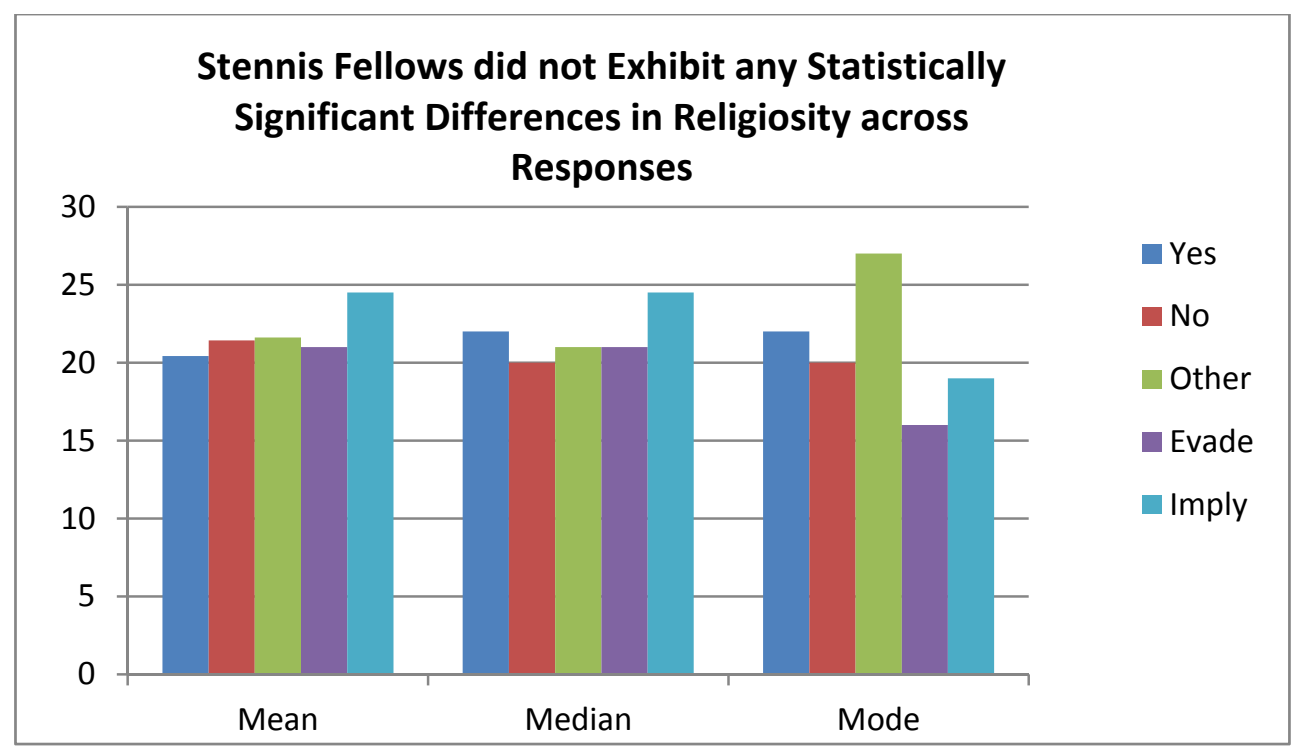

Stennis Fellows who answered "yes" $(M=20.43, M d n=22)$ had lower religiosity scores than staff who responded "no" $(M=21.4 M d n=20)$, "other" $(M=21.6, M d n=21)$, "evade" $(M=21, M d n=21)$, or implied the provision was drafted as agreed upon $(\mathrm{M}=24.5$, Mdn=24.5). The two-sample, two-tailed t-statistic was not significant at the .05 level for 
the difference in mean religiosity between fellows answering "yes" and fellows answering "no," $t(40)=.471, p=.64$; or for the difference in mean religiosity between fellows answering "yes" and fellows answering "other," $t(60)=.566, p=.57$. The null hypothesis that there is no difference in religiosity cannot be rejected. The largest deviation in median religiosity scores was associated with fellows who implied rather than directly answered "yes" or "no." The t-statistic was not calculated for this group because it only contained two fellows.

The Mann-Whitney U Test also revealed no significant difference in the religiosity of fellows who responded "yes" $(M d n=22, n=21)$ and fellows who responded "no" $(M d n=20.0, n=21), U=206, z=-.365, p=.715$.

Case 4. You are staffing the conference committee on a provision that is very important to you and to your member/senator.

\begin{tabular}{|c|c|c|c|c|c|c|}
\hline $\begin{array}{l}\text { All Staff-weighted } \\
\text { It is never OK to tell a lie }\end{array}$ & & & Frequency & Percent & Valid Percent & $\begin{array}{c}\text { Cumulative } \\
\text { Percent }\end{array}$ \\
\hline \multirow[t]{10}{*}{ Reflects my View } & Valid & Yes & 9 & 10.2 & 10.8 & 10.8 \\
\hline & & No & 19 & 22.2 & 23.5 & 34.3 \\
\hline & & Other & 29 & 33.7 & 35.7 & 70.0 \\
\hline & & Evade & 16 & 18.6 & 19.7 & 89.7 \\
\hline & & Obfuscate & 3 & 3.2 & 3.4 & 93.1 \\
\hline & & $\begin{array}{l}\text { Evade Change } \\
\text { Leadership }\end{array}$ & 1 & 1.4 & 1.5 & 94.6 \\
\hline & & Imply & 4 & 5.1 & 5.4 & 100.0 \\
\hline & & Total & 82 & 94.4 & 100.0 & \\
\hline & Missing & System & 5 & 5.6 & & \\
\hline & Total & & 87 & 100.0 & & \\
\hline \multirow{7}{*}{$\begin{array}{l}\text { Does not Reflect my } \\
\text { View }\end{array}$} & Valid & Yes & 51 & 32.9 & 34.3 & 34.3 \\
\hline & & No & 34 & 21.8 & 22.7 & 57.0 \\
\hline & & Other & 31 & 20.2 & 21.1 & 78.1 \\
\hline & & Evade & 21 & 13.4 & 14.0 & 92.1 \\
\hline & & Obfuscate & 5 & 3.1 & 3.2 & 95.4 \\
\hline & & Imply & 7 & 4.4 & 4.6 & 100.0 \\
\hline & & Total & 148 & 95.9 & 100.0 & \\
\hline
\end{tabular}




\begin{tabular}{llcc}
\hline Missing & System & 6 & 4.1 \\
Total & 154 & 100.0 \\
\hline \hline
\end{tabular}

Case 4. You are staffing the conference committee on a provision that is very important to you and to your member/senator.

\begin{tabular}{|c|c|c|c|c|c|c|}
\hline \multicolumn{3}{|c|}{ Chamber } & \multirow{2}{*}{$\frac{\text { Frequency }}{27}$} & \multirow{2}{*}{$\frac{\text { Percent }}{14.6}$} & \multirow{2}{*}{$\frac{\text { Valid Percent }}{23.1}$} & \multirow{2}{*}{$\begin{array}{c}\begin{array}{c}\text { Cumulative } \\
\text { Percent }\end{array} \\
23.1\end{array}$} \\
\hline House & Valid & Yes & & & & \\
\hline & & No & 29 & 15.7 & 24.8 & 47.9 \\
\hline & & Other & 31 & 16.8 & 26.5 & 74.4 \\
\hline & & Evade & 18 & 9.7 & 15.4 & 89.7 \\
\hline & & Obfuscate & 3 & 1.6 & 2.6 & 92.3 \\
\hline & & Evade Change Leadership & 1 & .5 & .9 & 93.2 \\
\hline & & Imply & 8 & 4.3 & 6.8 & 100.0 \\
\hline & & Total & 117 & 63.2 & 100.0 & \\
\hline & Missing & System & 68 & 36.8 & & \\
\hline & Total & & 185 & 100.0 & & \\
\hline \multirow[t]{9}{*}{ Senate } & Valid & Yes & 34 & 19.1 & 29.3 & 29.3 \\
\hline & & No & 24 & 13.5 & 20.7 & 50.0 \\
\hline & & Other & 32 & 18.0 & 27.6 & 77.6 \\
\hline & & Evade & 19 & 10.7 & 16.4 & 94.0 \\
\hline & & Obfuscate & 5 & 2.8 & 4.3 & 98.3 \\
\hline & & Imply & 2 & 1.1 & 1.7 & 100.0 \\
\hline & & Total & 116 & 65.2 & 100.0 & \\
\hline & Missing & System & 62 & 34.8 & & \\
\hline & Total & & 178 & 100.0 & & \\
\hline
\end{tabular}

Case 4. You are staffing the conference committee on a provision that is very important to you and to your member/senator.

\begin{tabular}{|c|c|c|c|c|c|}
\hline \multicolumn{2}{|c|}{ All Staff-weighted } & \multirow{2}{*}{$\frac{\text { Frequency }}{60}$} & \multirow{2}{*}{$\frac{\text { Percent }}{16.3}$} & \multirow{2}{*}{$\frac{\text { Valid Percent }}{25.5}$} & \multirow{2}{*}{$\begin{array}{c}\begin{array}{c}\text { Cumulative } \\
\text { Percent }\end{array} \\
25.5\end{array}$} \\
\hline Valid & Yes & & & & \\
\hline & No & 54 & 14.8 & 23.2 & 48.7 \\
\hline & Other & 63 & 17.2 & 26.9 & 75.6 \\
\hline & Evade & 37 & 10.1 & 15.8 & 91.4 \\
\hline & Obfuscate & 8 & 2.1 & 3.3 & 94.7 \\
\hline & Evade, Change Leadership & 1 & .3 & .5 & 95.2 \\
\hline & Imply & 11 & 3.1 & 4.8 & 100.0 \\
\hline & Total & 233 & 64.0 & 100.0 & \\
\hline Missing & System & 131 & 36.0 & & \\
\hline Total & & 364 & 100.0 & & \\
\hline
\end{tabular}

Case 4. You are staffing the conference committee on a provision that is very important to you and to your member/senator.

\begin{tabular}{llll}
\hline \hline All Staff-unweighted & Cumulative \\
Percent
\end{tabular}




\begin{tabular}{llcccc}
\hline Valid & Yes & 61 & 16.8 & 26.2 & 26.2 \\
& No & 53 & 14.6 & 22.7 & 48.9 \\
& Other & 63 & 17.4 & 27.0 & 76.0 \\
& Evade & 37 & 10.2 & 15.9 & 91.8 \\
& Obfuscate & 8 & 2.2 & 3.4 & 95.3 \\
& Evade Change Leadership & 1 & .3 & .4 & 95.7 \\
& Imply & 10 & 2.8 & 4.3 & 100.0 \\
& Total & 233 & 64.2 & 100.0 & \\
Missing & System & 130 & 35.8 & & \\
Total & & 363 & 100.0 & & \\
\hline \hline
\end{tabular}

Case 4. You are staffing the conference committee on a provision that is very important to you and to your member/senator.

\begin{tabular}{llcccc}
\hline \hline Stennis Fellows & Frequency & Percent & Valid Percent & $\begin{array}{c}\text { Cumulative } \\
\text { Percent }\end{array}$ \\
\hline Valid & Yes & 21 & 17.2 & 23.1 & 23.1 \\
& No & 22 & 18.0 & 24.2 & 47.3 \\
& Other & 42 & 34.4 & 46.2 & 93.4 \\
& Evade & 2 & 1.6 & 2.2 & 95.6 \\
& Evade, Change Leadership & 2 & 1.6 & 2.2 & 97.8 \\
& Imply & 2 & 1.6 & 2.2 & 100.0 \\
& Total & 91 & 74.6 & 100.0 & \\
Missing & System & 31 & 25.4 & & \\
Total & 122 & 100.0 & & \\
\hline \hline
\end{tabular}




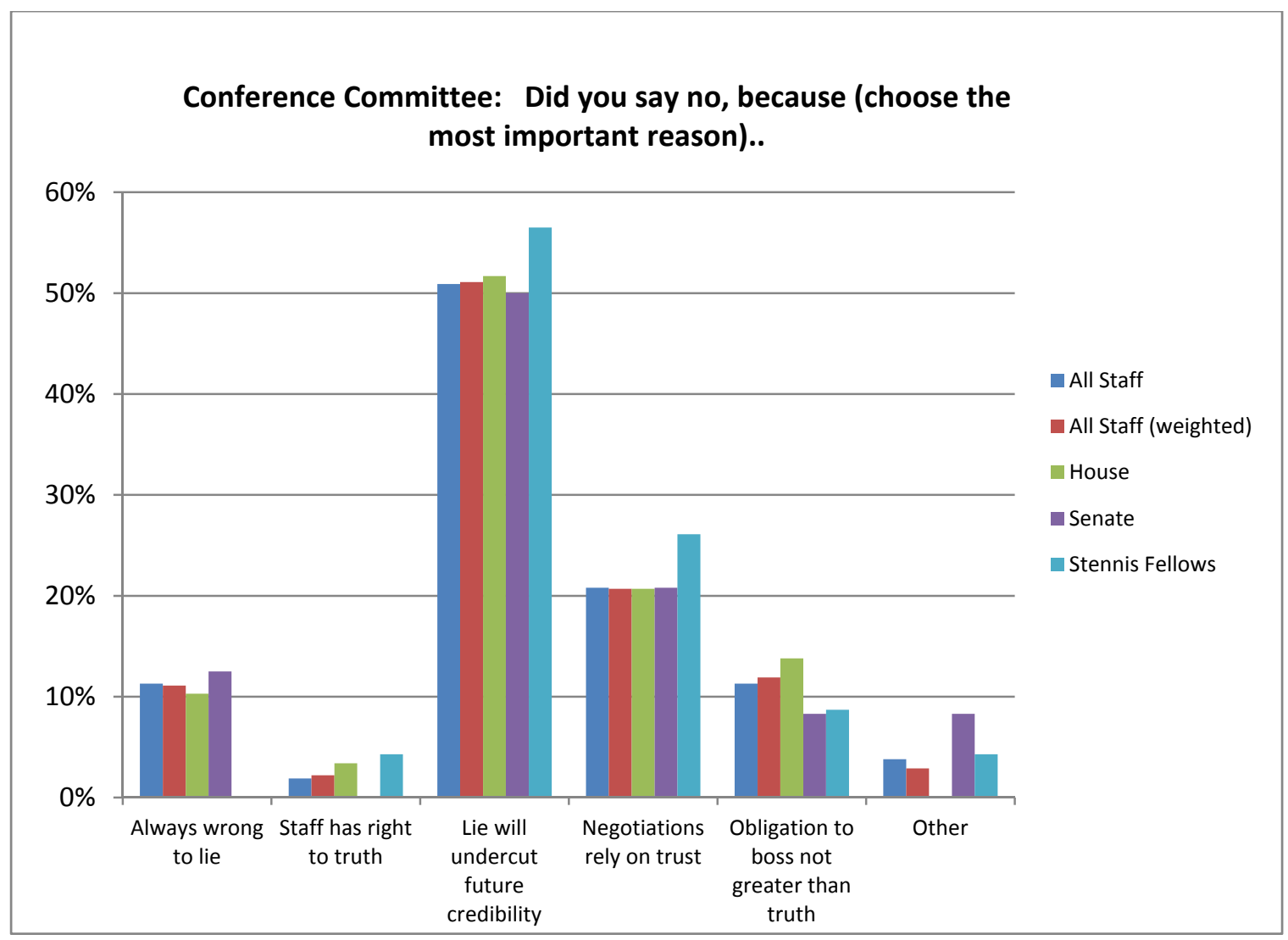

Did you answer no because (choose the most important reason)

\begin{tabular}{|c|c|c|c|c|c|c|}
\hline \multicolumn{3}{|c|}{ Chamber } & \multirow{2}{*}{$\frac{\text { Frequency }}{3}$} & \multirow{2}{*}{$\frac{\text { Percent }}{1.6}$} & \multirow{2}{*}{$\frac{\text { Valid Percent }}{10.3}$} & \multirow{2}{*}{$\begin{array}{c}\begin{array}{c}\text { Cumulative } \\
\text { Percent }\end{array} \\
10.3\end{array}$} \\
\hline House & Valid & It is always wrong to lie & & & & \\
\hline & & $\begin{array}{l}\text { The other staff member has } \\
\text { a right to the truth }\end{array}$ & 1 & .5 & 3.4 & 13.8 \\
\hline & & $\begin{array}{l}\text { The lie, when discovered, } \\
\text { will undermine your ability to } \\
\text { negotiate successfully in the } \\
\text { future }\end{array}$ & 15 & 8.1 & 51.7 & 65.5 \\
\hline & & $\begin{array}{l}\text { Successful negotiations rely } \\
\text { on mutual trust }\end{array}$ & 6 & 3.2 & 20.7 & 86.2 \\
\hline & & $\begin{array}{l}\text { Your obligation to secure the } \\
\text { strongest provision does not } \\
\text { override the prohibition on } \\
\text { lying in this particular } \\
\text { instance }\end{array}$ & 4 & 2.2 & 13.8 & 100.0 \\
\hline & & Total & 29 & 15.7 & 100.0 & \\
\hline & Missing & System & 156 & 84.3 & & \\
\hline & Total & & 185 & 100.0 & & \\
\hline Senate & Valid & It is always wrong to lie & 3 & 1.7 & 12.5 & 12.5 \\
\hline
\end{tabular}




\begin{tabular}{|c|c|c|c|c|c|}
\hline & $\begin{array}{l}\text { The lie, when discovered, } \\
\text { will undermine your ability to } \\
\text { negotiate successfully in the } \\
\text { future }\end{array}$ & 12 & 6.7 & 50.0 & 62.5 \\
\hline & $\begin{array}{l}\text { Successful negotiations rely } \\
\text { on mutual trust }\end{array}$ & 5 & 2.8 & 20.8 & 83.3 \\
\hline & $\begin{array}{l}\text { Your obligation to secure the } \\
\text { strongest provision does not } \\
\text { override the prohibition on } \\
\text { lying in this particular } \\
\text { instance }\end{array}$ & 2 & 1.1 & 8.3 & 91.7 \\
\hline & Other & 2 & 1.1 & 8.3 & 100.0 \\
\hline & Total & 24 & 13.5 & 100.0 & \\
\hline Missing & System & 154 & 86.5 & & \\
\hline Total & & 178 & 100.0 & & \\
\hline
\end{tabular}

Did you answer no because (choose the most important reason)

\begin{tabular}{|c|c|c|c|c|c|}
\hline \multicolumn{2}{|c|}{ All Staff-weighted } & \multirow{2}{*}{$\frac{\text { Frequency }}{6}$} & \multirow{2}{*}{$\frac{\text { Percent }}{1.6}$} & \multirow{2}{*}{$\frac{\text { Valid Percent }}{11.1}$} & \multirow{2}{*}{$\begin{array}{c}\begin{array}{c}\text { Cumulative } \\
\text { Percent }\end{array} \\
11.1\end{array}$} \\
\hline Valid & It is always wrong to lie & & & & \\
\hline & $\begin{array}{l}\text { The other staff member has } \\
\text { a right to the truth }\end{array}$ & 1 & .3 & 2.2 & 13.3 \\
\hline & $\begin{array}{l}\text { The lie, when discovered, } \\
\text { will undermine your ability to } \\
\text { negotiate successfully in the } \\
\text { future }\end{array}$ & 28 & 7.6 & 51.1 & 64.5 \\
\hline & $\begin{array}{l}\text { Successful negotiations rely } \\
\text { on mutual trust }\end{array}$ & 11 & 3.1 & 20.7 & 85.2 \\
\hline & $\begin{array}{l}\text { Your obligation to secure the } \\
\text { strongest provision does not } \\
\text { override the prohibition on } \\
\text { lying in this particular } \\
\text { instance }\end{array}$ & 6 & 1.8 & 11.9 & 97.1 \\
\hline & Other & 2 & .4 & 2.9 & 100.0 \\
\hline & Total & 54 & 14.8 & 100.0 & \\
\hline Missing & System & 310 & 85.2 & & \\
\hline Total & & 364 & 100.0 & & \\
\hline
\end{tabular}

Did you answer no because (choose the most important reason)

\begin{tabular}{llcccc}
\hline \hline ALL STAFF-unweighted & Frequency & Percent & Valid Percent & $\begin{array}{c}\text { Cumulative } \\
\text { Percent }\end{array}$ \\
\hline Valid & It is always wrong to lie & 6 & 1.7 & 11.3 & 11.3 \\
& $\begin{array}{l}\text { The other staff member has } \\
\text { a right to the truth }\end{array}$ & 1 & .3 & 1.9 & 13.2
\end{tabular}




\begin{tabular}{|c|c|c|c|c|c|}
\hline & $\begin{array}{l}\text { The lie, when discovered, } \\
\text { will undermine your ability to } \\
\text { negotiate successfully in the } \\
\text { future }\end{array}$ & 27 & 7.4 & 50.9 & 64.2 \\
\hline & $\begin{array}{l}\text { Successful negotiations rely } \\
\text { on mutual trust }\end{array}$ & 11 & 3.0 & 20.8 & 84.9 \\
\hline & $\begin{array}{l}\text { Your obligation to secure the } \\
\text { strongest provision does not } \\
\text { override the prohibition on } \\
\text { lying in this particular } \\
\text { instance }\end{array}$ & 6 & 1.7 & 11.3 & 96.2 \\
\hline & Other & 2 & .6 & 3.8 & 100.0 \\
\hline & Total & 53 & 14.6 & 100.0 & \\
\hline Missing & System & 310 & 85.4 & & \\
\hline Total & & 363 & 100.0 & & \\
\hline & Did you answer no be & ause (choos & he most & portant reason & \\
\hline Stennis & ellows & Frequency & Percent & Valid Percent & $\begin{array}{l}\text { Cumulative } \\
\text { Percent }\end{array}$ \\
\hline Valid & $\begin{array}{l}\text { The other staff member has } \\
\text { a right to the truth }\end{array}$ & 1 & .8 & 4.3 & 4.3 \\
\hline & $\begin{array}{l}\text { The lie, when discovered, } \\
\text { will undermine your ability to } \\
\text { negotiate successfully in the } \\
\text { future }\end{array}$ & 13 & 10.7 & 56.5 & 60.9 \\
\hline & $\begin{array}{l}\text { Successful negotiations rely } \\
\text { on mutual trust }\end{array}$ & 6 & 4.9 & 26.1 & 87.0 \\
\hline & $\begin{array}{l}\text { Your obligation to secure the } \\
\text { strongest provision does not } \\
\text { override the prohibition on } \\
\text { lying in this particular } \\
\text { instance }\end{array}$ & 2 & 1.6 & 8.7 & 95.7 \\
\hline & Other & 1 & .8 & 4.3 & 100.0 \\
\hline & Total & 23 & 18.9 & 100.0 & \\
\hline Missing & System & 99 & 81.1 & & \\
\hline Total & & 122 & 100.0 & & \\
\hline
\end{tabular}




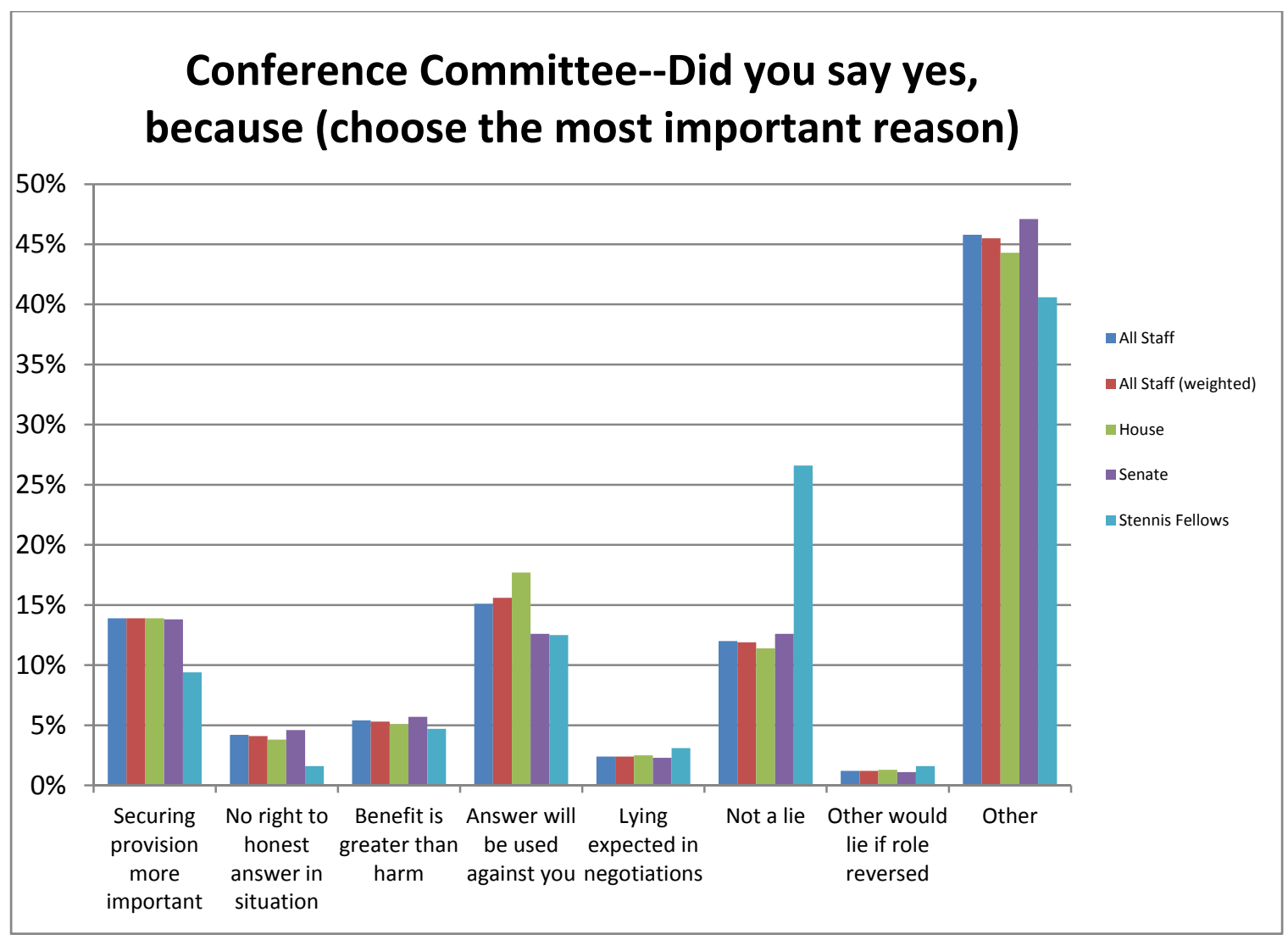

Reasons offered by House and Senate staff for saying "yes" were distributed in very similar proportions, with the exception of "the answer will be used against you." The two-sample, two-tailed t-statistic was not significant at the .05 level, $t(164)=.92, p=.36$. The null hypothesis that there is no difference in the proportion between House and Senate staff could not be rejected.

Fourteen percent of staff believed that securing the provision was more important than the obligation to tell the truth and $12 \%$ to $27 \%$ suggested that this was not a lie.

Comments suggested that respondents were trading on the impossibility of knowing with absolute certainty what someone else (in this case, leadership) would actually say or do in the future. 
$26.6 \%$ of Stennis Fellows who answered "yes" indicated that this would not be a lie as opposed to $11.4 \%$ of House staff, $12.6 \%$ of Senate staff, and $11.9 \%$ of all staff-weighted. The two-sample, two-tailed t-statistic was significant at the .05 level for the difference in proportions between Stennis Fellows and Senate staff, $t(149)=2.19, p=.03$.

Did you answer yes because (choose the most important reason)

\begin{tabular}{|c|c|c|c|c|c|c|}
\hline \multicolumn{3}{|c|}{ Chamber } & \multirow{2}{*}{$\frac{\text { Frequency }}{11}$} & \multirow{2}{*}{$\frac{\text { Percent }}{5.9}$} & \multirow{2}{*}{$\frac{\text { Valid Percent }}{13.9}$} & \multirow{2}{*}{$\begin{array}{c}\begin{array}{c}\text { Cumulative } \\
\text { Percent }\end{array} \\
13.9\end{array}$} \\
\hline House & Valid & $\begin{array}{l}\text { Your job is to secure the } \\
\text { provision for your } \\
\text { Member/Senator and that } \\
\text { overrides any concerns you } \\
\text { might have about lying }\end{array}$ & & & & \\
\hline & & $\begin{array}{l}\text { They do not have a right to } \\
\text { an honest answer in this } \\
\text { situation }\end{array}$ & 3 & 1.6 & 3.8 & 17.7 \\
\hline & & $\begin{array}{l}\text { The benefit of securing the } \\
\text { provision is greater than the } \\
\text { cost or harm of telling a lie }\end{array}$ & 4 & 2.2 & 5.1 & 22.8 \\
\hline & & $\begin{array}{l}\text { You don't have an obligation } \\
\text { to provide information that } \\
\text { will be used against you }\end{array}$ & 14 & 7.6 & 17.7 & 40.5 \\
\hline & & $\begin{array}{l}\text { Lying is an expected part of } \\
\text { negotiations }\end{array}$ & 2 & 1.1 & 2.5 & 43.0 \\
\hline & & This would not be a lie & 9 & 4.9 & 11.4 & 54.4 \\
\hline & & $\begin{array}{l}\text { The staff would lie to you if } \\
\text { your roles were reversed }\end{array}$ & 1 & .5 & 1.3 & 55.7 \\
\hline & & Other & 35 & 18.9 & 44.3 & 100.0 \\
\hline & & Total & 79 & 42.7 & 100.0 & \\
\hline & Missing & System & 106 & 57.3 & & \\
\hline & Total & & 185 & 100.0 & & \\
\hline \multirow[t]{2}{*}{ Senate } & Valid & $\begin{array}{l}\text { Your job is to secure the } \\
\text { provision for your } \\
\text { Member/Senator and that } \\
\text { overrides any concerns you } \\
\text { might have about lying }\end{array}$ & 12 & 6.7 & 13.8 & 13.8 \\
\hline & & $\begin{array}{l}\text { They do not have a right to } \\
\text { an honest answer in this } \\
\text { situation }\end{array}$ & 4 & 2.2 & 4.6 & 18.4 \\
\hline
\end{tabular}




\begin{tabular}{|c|c|c|c|c|c|}
\hline & $\begin{array}{l}\text { The benefit of securing the } \\
\text { provision is greater than the } \\
\text { cost or harm of telling a lie }\end{array}$ & 5 & 2.8 & 5.7 & 24.1 \\
\hline & $\begin{array}{l}\text { You don't have an obligation } \\
\text { to provide information that } \\
\text { will be used against you }\end{array}$ & 11 & 6.2 & 12.6 & 36.8 \\
\hline & $\begin{array}{l}\text { Lying is an expected part of } \\
\text { negotiations }\end{array}$ & 2 & 1.1 & 2.3 & 39.1 \\
\hline & This would not be a lie & 11 & 6.2 & 12.6 & 51.7 \\
\hline & $\begin{array}{l}\text { The staff would lie to you if } \\
\text { your roles were reversed }\end{array}$ & 1 & .6 & 1.1 & 52.9 \\
\hline & Other & 41 & 23.0 & 47.1 & 100.0 \\
\hline & Total & 87 & 48.9 & 100.0 & \\
\hline Missing & System & 91 & 51.1 & & \\
\hline Total & & 178 & 100.0 & & \\
\hline
\end{tabular}

Did you answer yes because (choose the most important reason)

\begin{tabular}{|c|c|c|c|c|c|}
\hline \multicolumn{2}{|c|}{ All Staff-weighted } & \multirow{2}{*}{$\frac{\text { Frequency }}{23}$} & \multirow{2}{*}{$\frac{\text { Percent }}{6.3}$} & \multirow{2}{*}{$\frac{\text { Valid Percent }}{13.9}$} & \multirow{2}{*}{$\begin{array}{c}\begin{array}{c}\text { Cumulative } \\
\text { Percent }\end{array} \\
13.9\end{array}$} \\
\hline Valid & $\begin{array}{l}\text { Your job is to secure the } \\
\text { provision for your }\end{array}$ & & & & \\
\hline & $\begin{array}{l}\text { Member/Senator and that } \\
\text { overrides any concerns you } \\
\text { might have about lying }\end{array}$ & & & & \\
\hline & $\begin{array}{l}\text { They do not have a right to } \\
\text { an honest answer in this } \\
\text { situation }\end{array}$ & 7 & 1.9 & 4.1 & 18.0 \\
\hline & $\begin{array}{l}\text { The benefit of securing the } \\
\text { provision is greater than the } \\
\text { cost or harm of telling a lie }\end{array}$ & 9 & 2.4 & 5.3 & 23.4 \\
\hline & $\begin{array}{l}\text { You don't have an obligation } \\
\text { to provide information that } \\
\text { will be used against you }\end{array}$ & 26 & 7.0 & 15.6 & 38.9 \\
\hline & $\begin{array}{l}\text { Lying is an expected part of } \\
\text { negotiations }\end{array}$ & 4 & 1.1 & 2.4 & 41.4 \\
\hline & This would not be a lie & 20 & 5.4 & 11.9 & 53.3 \\
\hline & $\begin{array}{l}\text { The staff would lie to you if } \\
\text { your roles were reversed }\end{array}$ & 2 & .5 & 1.2 & 54.5 \\
\hline & Other & 75 & 20.5 & 45.5 & 100.0 \\
\hline & Total & 164 & 45.1 & 100.0 & \\
\hline Missing & System & 200 & 54.9 & & \\
\hline Total & & 364 & 100.0 & & \\
\hline
\end{tabular}


Did you answer yes because (choose the most important reason)

\begin{tabular}{|c|c|c|c|c|c|}
\hline \multicolumn{2}{|c|}{ All Staff-unweighted } & \multirow{2}{*}{$\frac{\text { Frequency }}{23}$} & \multirow{2}{*}{$\frac{\text { Percent }}{6.3}$} & \multirow{2}{*}{$\frac{\text { Valid Percent }}{13.9}$} & \multirow{2}{*}{$\begin{array}{r}\begin{array}{l}\text { Cumulative } \\
\text { Percent }\end{array} \\
13.9\end{array}$} \\
\hline Valid & $\begin{array}{l}\text { Your job is to secure the } \\
\text { provision for your } \\
\text { Member/Senator and that } \\
\text { overrides any concerns you } \\
\text { might have about lying }\end{array}$ & & & & \\
\hline & $\begin{array}{l}\text { They do not have a right to } \\
\text { an honest answer in this } \\
\text { situation }\end{array}$ & 7 & 1.9 & 4.2 & 18.1 \\
\hline & $\begin{array}{l}\text { The benefit of securing the } \\
\text { provision is greater than the } \\
\text { cost or harm of telling a lie }\end{array}$ & 9 & 2.5 & 5.4 & 23.5 \\
\hline & $\begin{array}{l}\text { You don't have an obligation } \\
\text { to provide information that } \\
\text { will be used against you }\end{array}$ & 25 & 6.9 & 15.1 & 38.6 \\
\hline & $\begin{array}{l}\text { Lying is an expected part of } \\
\text { negotiations }\end{array}$ & 4 & 1.1 & 2.4 & 41.0 \\
\hline & This would not be a lie & 20 & 5.5 & 12.0 & 53.0 \\
\hline & $\begin{array}{l}\text { The staff would lie to you if } \\
\text { your roles were reversed }\end{array}$ & 2 & .6 & 1.2 & 54.2 \\
\hline & Other & 76 & 20.9 & 45.8 & 100.0 \\
\hline & Total & 166 & 45.7 & 100.0 & \\
\hline Missing & System & 197 & 54.3 & & \\
\hline Total & & 363 & 100.0 & & \\
\hline
\end{tabular}

Did you answer yes because (choose the most important reason)

\begin{tabular}{|c|c|c|c|c|c|}
\hline \multicolumn{2}{|c|}{ Stennis Fellows } & \multirow{2}{*}{$\frac{\text { Frequency }}{6}$} & \multirow{2}{*}{$\frac{\text { Percent }}{4.9}$} & \multirow{2}{*}{$\frac{\text { Valid Percent }}{9.4}$} & \multirow{2}{*}{$\begin{array}{c}\begin{array}{c}\text { Cumulative } \\
\text { Percent }\end{array} \\
9.4\end{array}$} \\
\hline Valid & $\begin{array}{l}\text { Your job is to secure the } \\
\text { provision for your } \\
\text { Member/Senator and that } \\
\text { overrides any concerns you } \\
\text { might have about lying }\end{array}$ & & & & \\
\hline & $\begin{array}{l}\text { They do not have a right to } \\
\text { an honest answer in this } \\
\text { situation }\end{array}$ & 1 & .8 & 1.6 & 10.9 \\
\hline & $\begin{array}{l}\text { The benefit of securing the } \\
\text { provision is greater than the } \\
\text { cost or harm of telling a lie }\end{array}$ & 3 & 2.5 & 4.7 & 15.6 \\
\hline & $\begin{array}{l}\text { You don't have an obligation } \\
\text { to provide information that } \\
\text { will be used against you }\end{array}$ & 8 & 6.6 & 12.5 & 28.1 \\
\hline
\end{tabular}




\begin{tabular}{|c|c|c|c|c|c|}
\hline & $\begin{array}{l}\text { Lying is an expected part of } \\
\text { negotiations }\end{array}$ & 2 & 1.6 & 3.1 & 31.3 \\
\hline & This would not be a lie & 17 & 13.9 & 26.6 & 57.8 \\
\hline & $\begin{array}{l}\text { The staff would lie to you if } \\
\text { your roles were reversed }\end{array}$ & 1 & .8 & 1.6 & 59.4 \\
\hline & Other & 26 & 21.3 & 40.6 & 100.0 \\
\hline & Total & 64 & 52.5 & 100.0 & \\
\hline Missing & System & 58 & 47.5 & & \\
\hline Total & & 122 & 100.0 & & \\
\hline
\end{tabular}

\section{Conference Committee: Assume the circumstances} are reversed. What do you believe the other staff member would say?

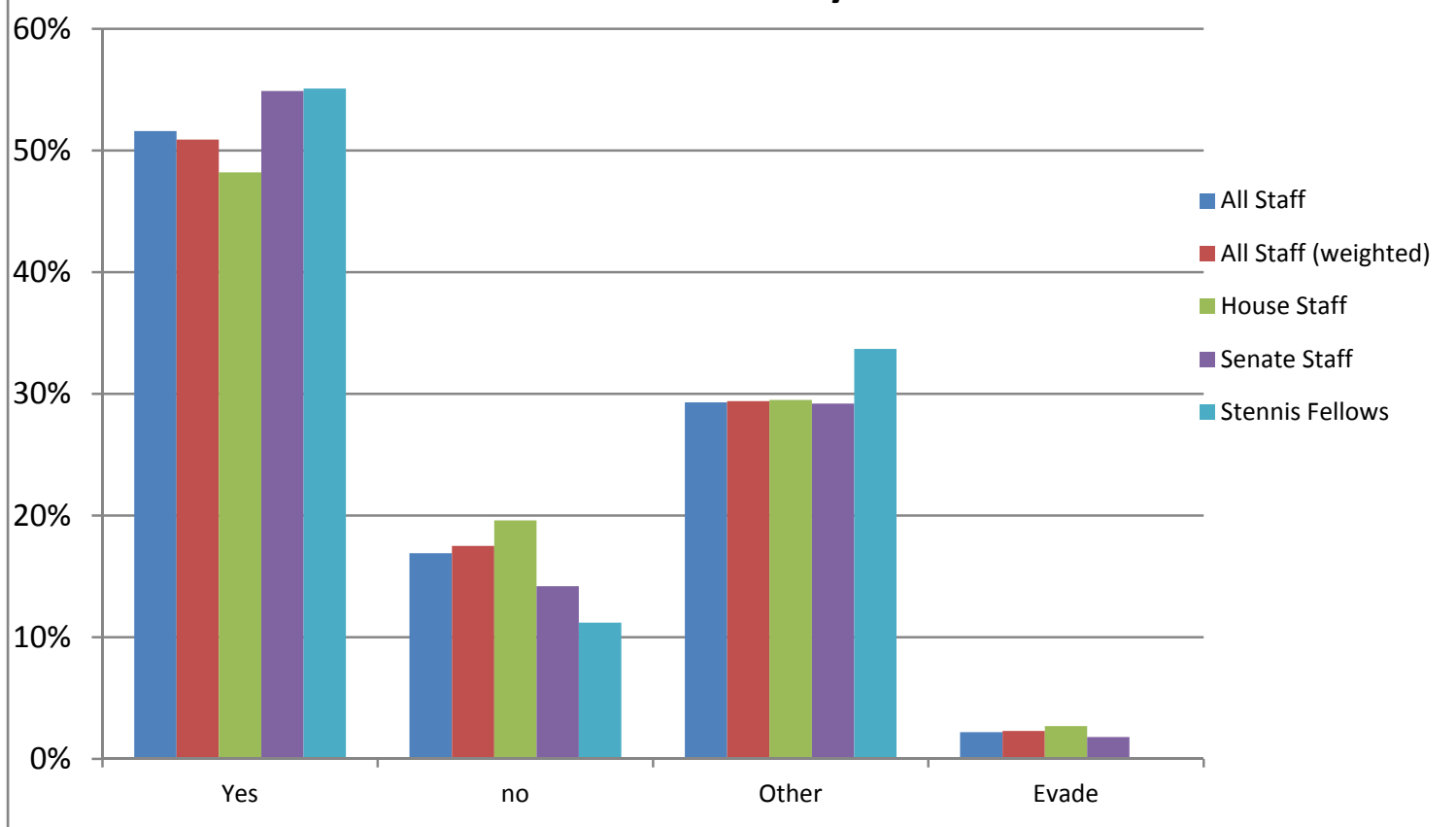

One way to measure the impact that social desirability bias may have on responses to survey questions is to include questions about a respondent's expectations of the behaviors or responses of others. Only $25 \%$ of staff reported that they themselves would say "yes," but $48 \%$ to $55 \%$ of respondents indicated that the other staff member would respond "yes" in the same circumstances. This raises questions as to whether 
respondents really believe that other staff lie more than they do or whether they are underestimating their own lying behavior.

This finding is consistent with the large difference in the mean number of lies that respondents believe were told to them in the prior 24 hours and the mean number of lies they reported telling in Chapter VII. House staff reported being lied to an average of 8.96 times $(M d n=4)$ and lying an average of 2.6 times $(M d n=1)$. Senate staff reported being lied to an average of 6.3 times $(M d n=3)$ and lying an average of 2.2 times $(M d n=1)$. Stennis Fellows reported being lied to an average of 7.1 times $(M d n=2)$ and lying an average of 2.3 times $(M d n=0)$.

All staff-weighted were binned into three groups of respondents who indicated they would say "yes," "no," or "other." Eighty-four percent of staff who said "yes" reported that they expected the other staff to say "yes" if their circumstances were reversed. Fiftythree percent of staff who indicated that they would answer "no" reported that they expected the other staff member to say "yes" if their circumstances were reversed. Only $38 \%$ of staff who indicated that they would say "no" expected that the other staff member would say "no" in the same situation.

The categories "imply," "evade, change leadership," "obfuscate" and "evade" were collapsed back into "other." The chi-square test for independence indicated a statistically significant strong association between an all staff-weighted respondent's willingness to answer "yes," "no" or "other" and their expectations regarding whether the other staff 
member would say "yes," "no," or "other" if their roles were reversed, $X^{2}(4, n=224)=$ $78.875, p=.000$, Cramer's $V=.420$.

Eighty-six percent of Stennis Fellows who indicated that they would answer "yes" expected that the other staff member would also answer "yes" if their roles were reversed. Similar to what was seen with all staff-weighted, only $40 \%$ of Stennis Fellows who indicated they would answer "no," expected that the other staff member would answer "yes." The chi-square could not be calculated because the number of expected responses of less than five exceeded the assumptions (no more than $20 \%$ ) for the chisquare for independence.

Although it is clear that there is a strong relationship between what respondents would say in this situation and their expectations of the behavior of the other staff member, at least $50 \%$ of staff who answered truthfully "no" did not expect the other staff member to respond truthfully. For these respondents, the expectation of potential lying behavior did not justify lying on their part.

Confidence intervals were calculated for each of the variable categories of the House and Senate samples. The widest confidence intervals were $\pm 9.3 \%$ for the House sample and $\pm 9.2 \%$ for the Senate sample. The widest confidence interval for Stennis Fellows was $\pm 8.5 \%$. The widest confidence interval for the all staff-weighted sample was $\pm 6.5 \%$. House staff (19.6\%) were more likely to respond that the other staff member would respond "no" than Senate staff (14.2\%) or Stennis Fellows (11.2\%). The two-sample, two-tailed t-statistic for the difference in proportions between House staff and Stennis 
Fellows was not significant at the .05 level, $t(199)=1.62, p=.11$. The null hypothesis that there is no difference in the proportions cannot be rejected.

The two-sample, two-tailed t-statistic for the difference in mean religiosity between all staff-weighted who believed the other staff would answer "yes" (20.445) and those who believed she would say "no" (22.765) was not significant at the .05 level, $t(150)=1.59$, $p=.11$. The Mann-Whitney U Test also revealed no significant difference in religiosity between staff who believed the other staff member would answer "yes" (Mdn=20, $n=114)$ and staff who believed the other staff member would answer "no" ( $M d n=22, n=38)$, $U=1789.5, z=-1.520, p=.128$.

The two-sample, two-tailed t-statistic for the difference in mean religiosity between Stennis Fellows who believed the other staff member would answer "yes" and those who believed she would say "no" was not significant at the .05 level, $t(50)=1.01, p=.32$. The two-sample, two-tailed t-statistic for the difference in mean religiosity between those who predicted the other staff member would answer "no" and those who believed she would give an "other" answer was also not significant at the .05 level, $t(74)=.76, p=.45$.

The Mann-Whitney U Test also revealed that there was no difference in religiosity between fellows who indicated that the other staff member would answer "yes" $(\mathrm{Mdn}=22, \mathrm{n}=49)$ and fellows who indicated the other staff member would answer "no" $(M d n=20.0, n=9), U=207.5, z=-.280, p=.780$. 
All staff-weighted who indicated that the other staff member would answer "yes" reported telling more lies $(M=3.22, M d n=1, n=100)$ than did respondents who indicated that the other staff member would answer "no" $(M=2.36, M d n=1, n=34)$. The twosample, two-tailed t-statistic for the difference in mean lying was not significant at the .05 level, $t(132)=0.576, p=.5658$. The Mann-Whitney U Test also revealed no significant difference in reported lying between staff who believed the other staff member would lie and those who did not, $U=2395.5, z=-1.088, p=.277$.

Somewhat counterintuitively, all staff-weighted who indicated that the other staff member $(M=7.84, M d n=5, n=94)$ would lie by answering "yes" reported being lied to less frequently than staff who reported that the other staff member would answer "no" $(M=9.445, M d n=2, n=30)$. The two-sample, two-tailed t-statistic for the difference in mean "being lied to" was not significant at the .05 level, $t(122)=0.462, p=.6452$. The Mann-Whitney U Test also revealed no significant difference in the number of times the staff who believed the other staff member would answer "yes" believed they were lied to compared with staff who believed the other staff member would answer "no," $U=2147$, $z=-.050, p=.960$.

Stennis Fellows who indicated that the other staff member would answer "yes" $(M=6.237, M d n=2.5, n=38)$ reported being lied to less frequently than fellows who indicated that the other staff member would answer "no" $(M=17.5, M d n=2.5, n=6)$. The two-sample, two-tailed t-statistic for the difference in mean-reported "being lied to" was not significant at the .05 level, $t(42)=1.677, p=.1009$. The Mann-Whitney U Test also 
revealed no significant difference in being lied to by fellows who indicated the other staff would say "yes" and fellows who indicated the other staff would say "no," $U=109.5$, $z=-.156, p=.881$.

Stennis Fellows who indicated that the other staff member would answer "yes" $(M=2.95$, $M d n=1, n=40$ ) reported telling more lies than fellows who indicated that the other staff member would answer "no" $(M=0, M d n=0, n=6)$. The Mann-Whitney U Test revealed a significant difference in reported lying between fellows who anticipated that the other staff member would answer "yes" and fellows who anticipated the other staff member would answer "no," $U=57, z=-2.245, p=.025$.

Let's assume the circumstances are reversed. What do you believe the other staff member would say?

\begin{tabular}{|c|c|c|c|c|c|c|}
\hline \multicolumn{3}{|c|}{ Chamber } & \multirow{2}{*}{$\frac{\text { Frequency }}{54}$} & \multirow{2}{*}{$\frac{\text { Percent }}{29.2}$} & \multirow{2}{*}{$\frac{\text { Valid Percent }}{48.2}$} & \multirow{2}{*}{$\begin{array}{c}\text { Cumulative } \\
\text { Percent }\end{array}$} \\
\hline House & Valid & Yes & & & & \\
\hline & & No & 22 & 11.9 & 19.6 & 67.9 \\
\hline & & Other & 33 & 17.8 & 29.5 & 97.3 \\
\hline & & Evade & 3 & 1.6 & 2.7 & 100.0 \\
\hline & & Total & 112 & 60.5 & 100.0 & \\
\hline & Missing & System & 73 & 39.5 & & \\
\hline & Total & & 185 & 100.0 & & \\
\hline \multirow[t]{7}{*}{ Senate } & Valid & Yes & 62 & 34.8 & 54.9 & 54.9 \\
\hline & & No & 16 & 9.0 & 14.2 & 69.0 \\
\hline & & Other & 33 & 18.5 & 29.2 & 98.2 \\
\hline & & Evade & 2 & 1.1 & 1.8 & 100.0 \\
\hline & & Total & 113 & 63.5 & 100.0 & \\
\hline & Missing & System & 65 & 36.5 & & \\
\hline & Total & & 178 & 100.0 & & \\
\hline
\end{tabular}

Let's assume the circumstances are reversed. What do you believe the other staff member would say?

\begin{tabular}{lccccc}
\hline \hline All Staff-weighted & Frequency & Percent & Valid Percent & $\begin{array}{c}\text { Cumulative } \\
\text { Percent }\end{array}$ \\
\hline Valid & Yes & 114 & 31.4 & 50.9 & 50.9 \\
& No & 39 & 10.8 & 17.5 & 68.3 \\
& Other & 66 & 18.1 & 29.4 & 97.7
\end{tabular}




\begin{tabular}{llcccc}
\hline & Evade & 5 & 1.4 & 2.3 & 100.0 \\
& Total & 225 & 61.7 & 100.0 & \\
Missing & System & 140 & 38.3 & & \\
Total & & 364 & 100.0 & & \\
\hline \hline
\end{tabular}

Let's assume the circumstances are reversed. What do you believe the other staff member would say?

\begin{tabular}{|c|c|c|c|c|c|}
\hline \multicolumn{2}{|c|}{$\begin{array}{l}\text { All Staff- } \\
\text { unweighted }\end{array}$} & \multirow{2}{*}{$\frac{\text { Frequency }}{116}$} & \multirow{2}{*}{$\frac{\text { Percent }}{32.0}$} & \multirow{2}{*}{$\begin{array}{r}\text { Valid Percent } \\
51.6\end{array}$} & \multirow{2}{*}{$\frac{\begin{array}{l}\text { Cumulative } \\
\text { Percent }\end{array}}{51.6}$} \\
\hline Valid & Yes & & & & \\
\hline & No & 38 & 10.5 & 16.9 & 68.4 \\
\hline & Other & 66 & 18.2 & 29.3 & 97.8 \\
\hline & Evade & 5 & 1.4 & 2.2 & 100.0 \\
\hline & Total & 225 & 62.0 & 100.0 & \\
\hline Missing & System & 138 & 38.0 & & \\
\hline Total & & 363 & 100.0 & & \\
\hline
\end{tabular}

Let's assume the circumstances are reversed. What do you believe the other staff member would say?

\begin{tabular}{lccccc}
\hline \hline Stennis Fellows & Frequency & Percent & Valid Percent & $\begin{array}{c}\text { Cumulative } \\
\text { Percent }\end{array}$ \\
\hline Valid & Yes & 49 & 40.2 & 55.1 & 55.1 \\
& No & 10 & 8.2 & 11.2 & 66.3 \\
& Other & 30 & 24.6 & 33.7 & 100.0 \\
& Total & 89 & 73.0 & 100.0 & \\
Missing & System & 33 & 27.0 & & \\
Total & 122 & 100.0 & & \\
\hline \hline
\end{tabular}




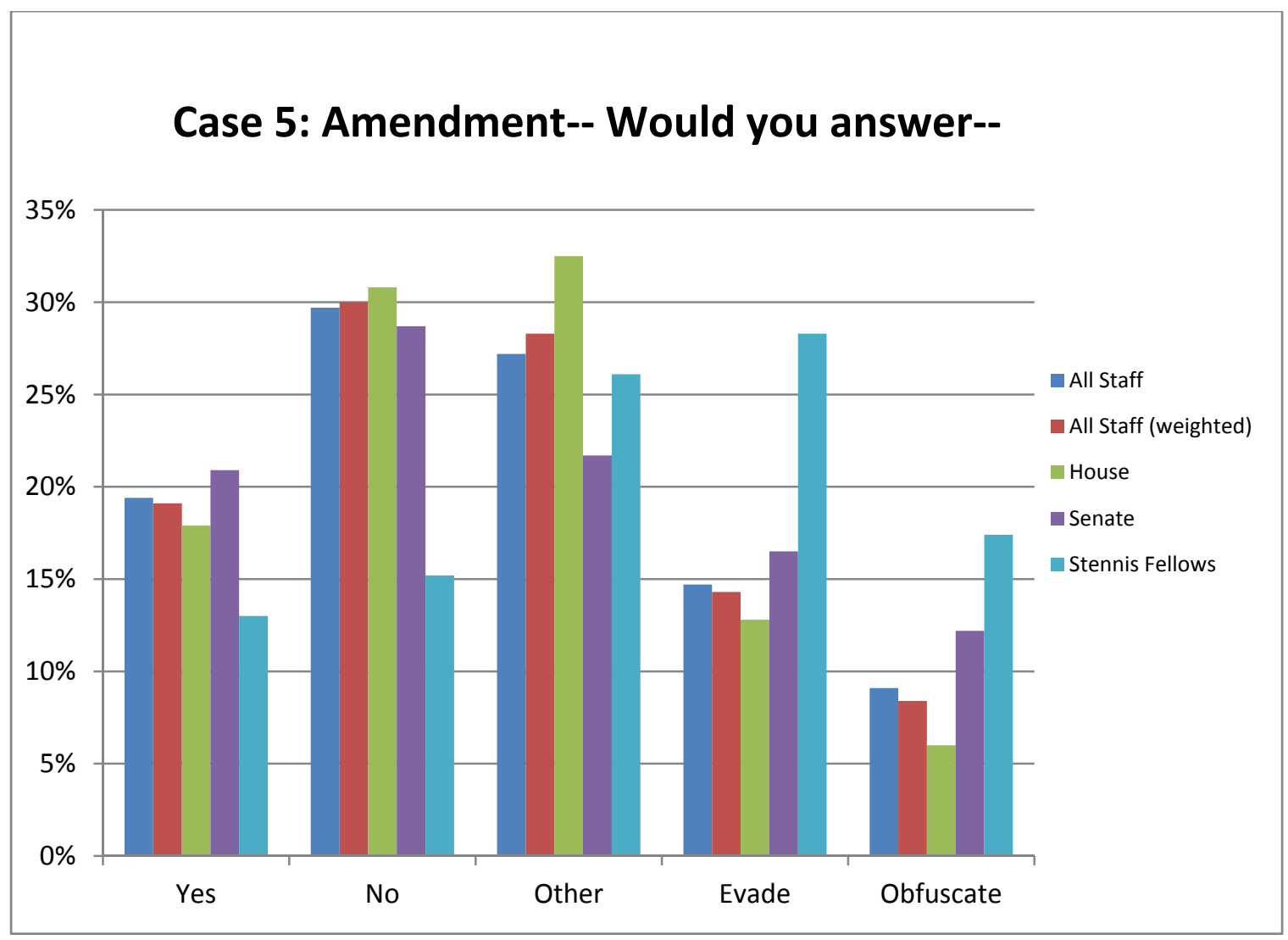

The Amendment case was drawn to highlight a situation in which a negotiation relationship has not been established and in which disclosure could negatively affect the desired outcome. Recent Congresses have permitted relatively few open amendment processes, so it was possible that this case might have more salience for older and more senior staff. Emails from a few respondents challenging the plausibility of the case provided some evidence for this hypothesis.

The stakes were raised above those in the prior case by moving from a description that indicated that the provision "was important to you and your boss" to a description that indicated the respondent believed the bill would cause "the loss of millions of lives." Adding to the complexity, the staff in the case is asked a direct question by a power 
figure - the chairman - and the staff is part of a team of other offices whose interests and relationships are also at stake. Respondents were asked if they would answer "yes," "no," "other":

"You are working to oppose a bill sponsored by the other political party that you believe will result in the loss of millions of lives. The only chance you have to defeat the bill is to offer a surprise amendment that the bill sponsors have not prepared for. The amendment is drafted and a small group of offices are quietly working to secure support. The chairman is suspicious and asks you directly whether your boss plans to offer an amendment. You believe you are very close to having the votes. Would you answer..."

Thirteen percent to $21 \%$ of respondents reported they would answer the direct question "yes." Fifteen percent to $31 \%$ reported they would answer the direct question with a "no." A number of respondents answering "no" employed a form of mental reservation and traded on the idea that that there was always uncertainty (despite the certainty they may have at the moment) up to the last minute regarding whether or not the amendment would be offered. The majority of the respondents who stated "other" directed the chairman to speak directly with his or her member/senator. Stennis Fellows continued to avoid selecting "yes" or "no" and used "other" to provide nuanced responses that avoided responding to the question directly.

Confidence intervals were calculated for each of the respondent groups. The widest confidence interval for the House was $\pm 8.6 \%$, for the Senate was $\pm 8.3 \%$, for all staffweighted was $\pm 5.9 \%$ and for Stennis Fellows was $\pm 7.5 \%$.

Senate staff (20.9\%) were more likely than House staff (17.9\%) or Stennis Fellows (13\%) to answer "yes" to the chairman's inquiry. The two-sample, two-tailed t-statistics for the 
difference in proportions between Senate and House staff, $t(230)=.58, p=.56$ and the difference between Senate staff and Stennis Fellows, $t(205)=1.49, p=.14$, were not significant at the .05 level.

Stennis Fellows (15.2\%) were less likely to answer "no" than either House (30.8\%) or Senate $(28.7 \%)$ staff. The two-sample, two-tailed t-statistic for the difference in proportions between Stennis Fellows and Senate staff was significant at the .05 level, $t(205)=-2.3, p=.02$.

House staff (32.5\%) were more likely than Senate staff (21.7\%) or Stennis Fellows $(26.1 \%)$ to attempt to provide an "other" answer. The two-sample, two-tailed t-statistic for the difference in proportions between House and Senate staff was not significant at the .05 level, $t(230)=1.85, p=.07$. The null hypothesis that there was no difference in proportions cannot be rejected.

Stennis Fellows $(28.3 \%)$ were more likely than House $(12.8 \%)$ or Senate staff $(16.5 \%)$ to attempt to "evade" the question. The two-sample, two-tailed t-statistic was significant at the .05 level for the difference in proportions between Stennis Fellows and Senate staff, $t(205)=2.05, p=.04$.

Stennis Fellows (17.4\%) were also more likely to "obfuscate" than House $(6 \%)$ or Senate staff $(12.2 \%)$. The two-sample, two-tailed t-statistic was significant at the .05 level for the difference in proportions between Stennis Fellows and House staff, $t(207)=2.6$, $p=.001$, but not the difference between Stennis Fellows and Senate staff, $t(205)=1.05$, 
$p=.29$. The two-sample, two-tailed t-statistic was significant at the .05 level for the difference in proportions between Stennis Fellows and all staff-weighted, $t(322)=2.32$, $p=.02$.

All staff-weighted respondents who answered "yes" $(M=22.1, M d n=24)$ and who chose “other" $(M=22.6, M d n=23.4)$ had the highest religiosity scores. Respondents who selected "no" $(M=20.7, M d n=22)$, who selected to "evade" $(M=21.1, M d n=20.6)$, and who chose to obfuscate $(M=15.3, M d n=13.3)$ had the lowest religiosity scores. The twosample, two-tailed t-statistic for the difference in mean religiosity between those who answered "yes" and those who answered "no" was not significant at the .05 level, $t(111)=.95, p=.34$. The null hypothesis that there is no difference in religiosity between those who responded "yes" and those who responded "no" cannot be rejected. The Mann-Whitney U Test also revealed no significant difference in religiosity between staff who answered "yes" $(M d n=24, n=44)$ and staff who answered "no" $(M d n=21.97, n=69)$, $U=1327, z=-1.192, p=.233$.

The two-sample, two-tailed t-statistic was significant at the .05 level for the difference between those who responded "yes" and those who "obfuscated," $t(62)=3.2, p=.002$ and for the difference between those who responded "no" and those who "obfuscated," $t(87)=2.9, p=.005$.

Stennis Fellows who answered "yes" $(M=25.42, M d n=26)$ reported higher religiosity scores than fellows who answered "no" $(M=16.385, M d n=16)$, fellows who answered “other" $(M=22.88, M d n=23.5)$, fellows who evaded the question $(M=21.8, M d n=22)$ or 
fellows who attempted to obfuscate $(M=20.4, M d n=21)$. The two-sample, two-tailed tstatistic for the difference in mean religiosity between those who answered "yes" and those who answered "no" was significant at the .05 level, $t(23)=3.64, p=.0013$. The twosample, two-tailed t-statistic was not significant at the .05 level for the difference in mean religiosity between those who answered "no" and those who answered "other," $t(35)=.486, p=.63$.

The Mann-Whitney U Test also revealed a significant difference in religiosity between Stennis fellows who answered "yes" $(M d n=26, n=12)$ and fellows who answered "no" $(M d n=16, n=13), U=20.5, z=-3.134, p=.002$.

All staff-weighted who answered that they would tell the chairman "yes" reported being lied to more frequently $(M=8.964, M d n=5, n=34)$ than staff who indicated they would tell the chairman "no" $(M=7.2, M d n=3.7, n=52)$. The two-sample, two-tailed t-statistic for the difference in mean "being lied to" was not significant at the .05 level, $t(84)=0.691$, $p=.4915$. The Mann-Whitney U Test also revealed no significant difference in being lied to, $U=816, z=-.530, p=596$. Staff indicating they would truthfully answer "yes" reported telling fewer lies $(M=1.99, M d n=1, n=37)$ than those who would answer "no" $(M=2.365$, $M d n=1.895, n=58)$. The two-sample, two-tailed t-statistic was not significant at the .05 level, $t(93)=0.604, p=.5471$. The Mann-Whitney $\mathrm{U}$ Test revealed no significant difference in lying, $U=1053, z=-.235, p=.814$.

Stennis Fellows who indicated they would tell the chairman "yes" $(M=8.96, M d n=5)$ reported being lied to less frequently than fellows who indicated they would tell the 
chairman "no" $(M=7.177, M d n=3.71)$. The two-sample, two-tailed t-statistic was not significant at the .05 level for the difference in being lied to, $t(84)=0.689, p=.4925$.

Stennis Fellows who indicated they would tell the chairman "yes" reported telling fewer lies $(\mathrm{M}=1.99, \mathrm{Mdn}=1)$ than fellows indicating they would tell chairman "no" $(\mathrm{M}=2.356$, Mdn=1.895). The two-sample, two-tailed t-statistic was not significant at the .05 level, $t(93)=1.007, p=.3164$. The Mann-Whitney U Test also revealed no significant difference in being lied to, $U=816, z=-.530, p=.596$ or in lying, $U=1053, z=-.235, p=.814$.

All staff-weighted who agreed earlier in the survey with the statement that it was "OK to lie to advance a good or important legislative, political, or social cause" (56.1\%) were significantly more likely to tell the chairman "no" than staff who did not agree with the statement (27.8\%). Staff who disagreed with the statement (19.2\%) were no more likely to answer "yes" than staff who agreed with the statement $(20 \%)$. They were far more likely to try to find a way to "evade" (15.4\%), or offer an "other" response $(29.6 \%)$.

Case 5. You are working to oppose a bill sponsored by the other political party that you believe will result in the loss of millions of lives.

\begin{tabular}{|c|c|c|c|c|c|c|}
\hline \multicolumn{3}{|c|}{ Chamber } & \multirow{2}{*}{$\frac{\text { Frequency }}{21}$} & \multirow{2}{*}{$\frac{\text { Percent }}{11.4}$} & \multirow{2}{*}{$\frac{\text { Valid Percent }}{17.9}$} & \multirow{2}{*}{$\begin{array}{c}\begin{array}{c}\text { Cumulative } \\
\text { Percent }\end{array} \\
17.9\end{array}$} \\
\hline House & Valid & Yes & & & & \\
\hline & & No & 36 & 19.5 & 30.8 & 48.7 \\
\hline & & Other & 38 & 20.5 & 32.5 & 81.2 \\
\hline & & Evade & 15 & 8.1 & 12.8 & 94.0 \\
\hline & & Obfuscate & 7 & 3.8 & 6.0 & 100.0 \\
\hline & & Total & 117 & 63.2 & 100.0 & \\
\hline & Missing & System & 68 & 36.8 & & \\
\hline & Total & & 185 & 100.0 & & \\
\hline \multirow[t]{5}{*}{ Senate } & Valid & Yes & 24 & 13.5 & 20.9 & 20.9 \\
\hline & & No & 33 & 18.5 & 28.7 & 49.6 \\
\hline & & Other & 25 & 14.0 & 21.7 & 71.3 \\
\hline & & Evade & 19 & 10.7 & 16.5 & 87.8 \\
\hline & & Obfuscate & 14 & 7.9 & 12.2 & 100.0 \\
\hline
\end{tabular}




\begin{tabular}{llccc}
\hline & Total & 115 & 64.6 & 100.0 \\
Missing & System & 63 & 35.4 & \\
Total & & 178 & 100.0 \\
\hline \hline
\end{tabular}

Case 5. You are working to oppose a bill sponsored by the other political party that you believe will result in the loss of millions of lives.

\begin{tabular}{llcccc}
\hline \hline All Staff-weighted & Frequency & Percent & Valid Percent & $\begin{array}{c}\text { Cumulative } \\
\text { Percent }\end{array}$ \\
\hline Valid & Yes & 44 & 12.2 & 19.1 & 19.1 \\
& No & 70 & 19.1 & 30.0 & 49.1 \\
& Other & 66 & 18.0 & 28.3 & 77.3 \\
& Evade & 33 & 9.1 & 14.3 & 91.6 \\
& Obfuscate & 20 & 5.4 & 8.4 & 100.0 \\
\cline { 4 - 5 } Missing & Total & 232 & 63.8 & 100.0 & \\
Total & System & 132 & 36.2 & & \\
\hline \hline
\end{tabular}

Case 5. You are working to oppose a bill sponsored by the other political party that you believe will result in the loss of millions of lives.

\begin{tabular}{|c|c|c|c|c|c|}
\hline \multicolumn{2}{|c|}{$\begin{array}{l}\text { All Staff- } \\
\text { unweighted }\end{array}$} & \multirow{2}{*}{$\frac{\text { Frequency }}{45}$} & \multirow{2}{*}{$\frac{\text { Percent }}{12.4}$} & \multirow{2}{*}{$\frac{\text { Valid Percent }}{19.4}$} & \multirow{2}{*}{$\begin{array}{c}\begin{array}{c}\text { Cumulative } \\
\text { Percent }\end{array} \\
19.4\end{array}$} \\
\hline Valid & Yes & & & & \\
\hline & No & 69 & 19.0 & 29.7 & 49.1 \\
\hline & Other & 63 & 17.4 & 27.2 & 76.3 \\
\hline & Evade & 34 & 9.4 & 14.7 & 90.9 \\
\hline & Obfuscate & 21 & 5.8 & 9.1 & 100.0 \\
\hline & Total & 232 & 63.9 & 100.0 & \\
\hline Missing & System & 131 & 36.1 & & \\
\hline Total & & 363 & 100.0 & & \\
\hline
\end{tabular}

Case 5. You are working to oppose a bill sponsored by the other political party that you believe will result in the loss of millions of lives.

\begin{tabular}{llcccc}
\hline \hline Stennis Fellows & Frequency & Percent & Valid Percent & $\begin{array}{c}\text { Cumulative } \\
\text { Percent }\end{array}$ \\
\hline Valid & Yes & 12 & 9.8 & 13.0 & 13.0 \\
& No & 14 & 11.5 & 15.2 & 28.3 \\
& Other & 24 & 19.7 & 26.1 & 54.3 \\
& Evade & 26 & 21.3 & 28.3 & 82.6 \\
& Obfuscate & 16 & 13.1 & 17.4 & 100.0 \\
& Total & 92 & 75.4 & 100.0 & \\
Missing & System & 30 & 24.6 & & \\
\hline \hline
\end{tabular}




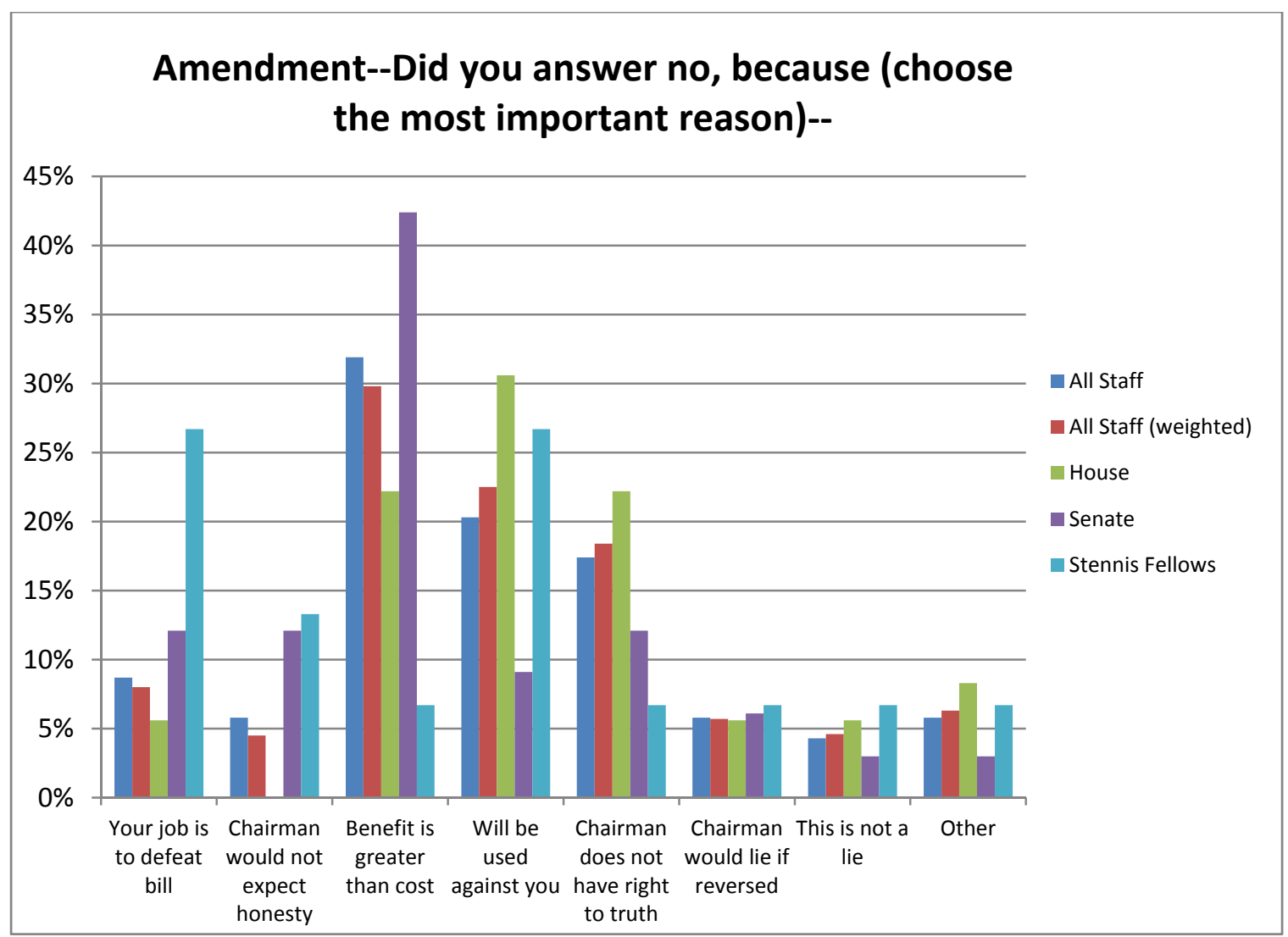

Seventy all staff-weighted respondents indicated that they would tell the chairman "no." Thirty percent of these respondents indicated that the "benefit of saving lives is greater than the cost of telling a lie." Twenty-three percent suggested that, "you don't have an obligation to provide information that will be used against you," and $18 \%$ indicated that the "chairman does not have a right to the truth."

The House and Senate widely diverged with regard to their reasons for telling the chairman "no." Senate staff (12.1\%) were more likely than House staff (5.6\%) to indicate that their job is to defeat the bill. Senate staff $(42.4 \%)$ were more likely than House staff $(22.2 \%)$ to indicate that the benefit of saving lives is greater than the cost of telling a lie. House staff (30.6\%) were more likely than Senate staff $(9.1 \%)$ to indicate 
that they didn't have an obligation to provide information that would be used against them.

The two-sample, two-tailed t-statistic for the difference in proportions between House and Senate staff saying that the benefit is greater than the cost was not significant at the .05 level, $t(67)=1.799, p=.076$. The two-sample, two-tailed t-statistic was significant at the .05 level for the difference between House and Senate staff who indicate that you don't have an obligation to provide information that will be used against you, $t(67)=2.218, p=.03$.

Did you answer no because (choose the most important reason)

\begin{tabular}{|c|c|c|c|c|c|c|}
\hline \multicolumn{3}{|c|}{ Chamber } & \multirow{2}{*}{$\frac{\text { Frequency }}{2}$} & \multirow{2}{*}{$\frac{\text { Percent }}{1.1}$} & \multirow{2}{*}{$\frac{\text { Valid Percent }}{5.6}$} & \multirow{2}{*}{$\begin{array}{c}\begin{array}{c}\text { Cumulative } \\
\text { Percent }\end{array} \\
5.6\end{array}$} \\
\hline House & Valid & $\begin{array}{l}\text { Your job is to defeat the bill } \\
\text { and this overrides any } \\
\text { concerns you might have } \\
\text { about lying }\end{array}$ & & & & \\
\hline & & $\begin{array}{l}\text { The benefit of saving lives is } \\
\text { greater than the cost of } \\
\text { telling a lie }\end{array}$ & 8 & 4.3 & 22.2 & 27.8 \\
\hline & & $\begin{array}{l}\text { You don't have an obligation } \\
\text { to provide information that } \\
\text { will be used against you }\end{array}$ & 11 & 5.9 & 30.6 & 58.3 \\
\hline & & $\begin{array}{l}\text { The chairman does not have } \\
\text { a right to the information }\end{array}$ & 8 & 4.3 & 22.2 & 80.6 \\
\hline & & $\begin{array}{l}\text { The chairman would lie to } \\
\text { you if your roles were } \\
\text { reversed }\end{array}$ & 2 & 1.1 & 5.6 & 86.1 \\
\hline & & This is not a lie & 2 & 1.1 & 5.6 & 91.7 \\
\hline & & Other & 3 & 1.6 & 8.3 & 100.0 \\
\hline & & Total & 36 & 19.5 & 100.0 & \\
\hline & Missing & System & 149 & 80.5 & & \\
\hline & Total & & 185 & 100.0 & & \\
\hline Senate & Valid & $\begin{array}{l}\text { Your job is to defeat the bill } \\
\text { and this overrides any } \\
\text { concerns you might have } \\
\text { about lying }\end{array}$ & 4 & 2.2 & 12.1 & 12.1 \\
\hline
\end{tabular}




\begin{tabular}{|c|c|c|c|c|c|}
\hline & $\begin{array}{l}\text { The chairman should not } \\
\text { expect an honest answer in } \\
\text { this situation }\end{array}$ & 4 & 2.2 & 12.1 & 24.2 \\
\hline & $\begin{array}{l}\text { The benefit of saving lives is } \\
\text { greater that the cost of telling } \\
\text { a lie }\end{array}$ & 14 & 7.9 & 42.4 & 66.7 \\
\hline & $\begin{array}{l}\text { You don't have an obligation } \\
\text { to provide information that } \\
\text { will be used against you }\end{array}$ & 3 & 1.7 & 9.1 & 75.8 \\
\hline & $\begin{array}{l}\text { The chairman does not have } \\
\text { a right to the information }\end{array}$ & 4 & 2.2 & 12.1 & 87.9 \\
\hline & $\begin{array}{l}\text { The chairman would lie to } \\
\text { you if your roles were } \\
\text { reversed }\end{array}$ & 2 & 1.1 & 6.1 & 93.9 \\
\hline & This is not a lie & 1 & .6 & 3.0 & 97.0 \\
\hline & Other & 1 & 6 & 3.0 & 100.0 \\
\hline & Total & 33 & 18.5 & 100.0 & \\
\hline Missing & System & 145 & 81.5 & & \\
\hline Total & & 178 & 100.0 & & \\
\hline
\end{tabular}

Did you answer no because (choose the most important reason)

\begin{tabular}{|c|c|c|c|c|c|}
\hline \multicolumn{2}{|c|}{ All Staff-weighted } & \multirow{2}{*}{$\frac{\text { Frequency }}{6}$} & \multirow{2}{*}{$\frac{\text { Percent }}{1.5}$} & \multirow{2}{*}{$\frac{\text { Valid Percent }}{8.0}$} & \multirow{2}{*}{$\begin{array}{c}\text { Cumulative } \\
\text { Percent }\end{array}$} \\
\hline Valid & $\begin{array}{l}\text { Your job is to defeat the bill } \\
\text { and this overrides any } \\
\text { concerns you might have } \\
\text { about lying }\end{array}$ & & & & \\
\hline & $\begin{array}{l}\text { The chairman should not } \\
\text { expect an honest answer in } \\
\text { this situation }\end{array}$ & 3 & .9 & 4.5 & 12.6 \\
\hline & $\begin{array}{l}\text { The benefit of saving lives is } \\
\text { greater that the cost of telling } \\
\text { a lie }\end{array}$ & 21 & 5.7 & 29.8 & 42.3 \\
\hline & $\begin{array}{l}\text { You don't have an obligation } \\
\text { to provide information that } \\
\text { will be used against you }\end{array}$ & 16 & 4.3 & 22.5 & 64.9 \\
\hline & $\begin{array}{l}\text { The chairman does not have } \\
\text { a right to the information }\end{array}$ & 13 & 3.5 & 18.4 & 83.3 \\
\hline & $\begin{array}{l}\text { The chairman would lie to } \\
\text { you if your roles were } \\
\text { reversed }\end{array}$ & 4 & 1.1 & 5.7 & 89.0 \\
\hline & This is not a lie & 3 & .9 & 4.6 & 93.7 \\
\hline & Other & 4 & 1.2 & 6.3 & 100.0 \\
\hline & Total & 70 & 19.1 & 100.0 & \\
\hline
\end{tabular}




\begin{tabular}{|c|c|c|c|}
\hline Missing & System & 295 & 80.9 \\
\hline Total & & 364 & 100.0 \\
\hline
\end{tabular}

Did you answer no because (choose the most important reason)--

\begin{tabular}{|c|c|c|c|c|c|}
\hline \multicolumn{2}{|c|}{ All Staff-unweighted } & \multirow{2}{*}{$\frac{\text { Frequency }}{6}$} & \multirow{2}{*}{$\frac{\text { Percent }}{1.7}$} & \multirow{2}{*}{$\frac{\text { Valid Percent }}{8.7}$} & \multirow{2}{*}{$\begin{array}{c}\begin{array}{c}\text { Cumulative } \\
\text { Percent }\end{array} \\
8.7\end{array}$} \\
\hline Valid & $\begin{array}{l}\text { Your job is to defeat the bill } \\
\text { and this overrides any } \\
\text { concerns you might have } \\
\text { about lying }\end{array}$ & & & & \\
\hline & $\begin{array}{l}\text { The chairman should not } \\
\text { expect an honest answer in } \\
\text { this situation }\end{array}$ & 4 & 1.1 & 5.8 & 14.5 \\
\hline & $\begin{array}{l}\text { The benefit of saving lives is } \\
\text { greater that the cost of telling } \\
\text { a lie }\end{array}$ & 22 & 6.1 & 31.9 & 46.4 \\
\hline & $\begin{array}{l}\text { You don't have an obligation } \\
\text { to provide information that } \\
\text { will be used against you }\end{array}$ & 14 & 3.9 & 20.3 & 66.7 \\
\hline & $\begin{array}{l}\text { The chairman does not have } \\
\text { a right to the information }\end{array}$ & 12 & 3.3 & 17.4 & 84.1 \\
\hline & $\begin{array}{l}\text { The chairman would lie to } \\
\text { you if your roles were } \\
\text { reversed }\end{array}$ & 4 & 1.1 & 5.8 & 89.9 \\
\hline & This is not a lie & 3 & .8 & 4.3 & 94.2 \\
\hline & Other & 4 & 1.1 & 5.8 & 100.0 \\
\hline & Total & 69 & 19.0 & 100.0 & \\
\hline Missing & System & 294 & 81.0 & & \\
\hline Total & & 363 & 100.0 & & \\
\hline
\end{tabular}

Did you answer no because (choose the most important reason)

\begin{tabular}{llcccc}
\hline \hline Stennis Fellows & Frequency & Percent & Valid Percent & $\begin{array}{c}\text { Cumulative } \\
\text { Percent }\end{array}$ \\
\hline Valid & $\begin{array}{l}\text { Your job is to defeat the bill } \\
\text { and this overrides any } \\
\text { concerns you might have } \\
\text { about lying }\end{array}$ & 4 & 3.3 & 26.7 & 26.7 \\
& & & & \\
& $\begin{array}{l}\text { The chairman should not } \\
\text { expect an honest answer in } \\
\text { this situation }\end{array}$ & 2 & 1.6 & 13.3 & 40.0 \\
\\
$\begin{array}{l}\text { The benefit of saving lives is } \\
\text { greater that the cost of telling } \\
\text { a lie }\end{array}$
\end{tabular}




\begin{tabular}{|c|c|c|c|c|c|}
\hline & $\begin{array}{l}\text { You don't have an obligation } \\
\text { to provide information that } \\
\text { will be used against you }\end{array}$ & 4 & 3.3 & 26.7 & 73.3 \\
\hline & $\begin{array}{l}\text { The chairman does not have } \\
\text { a right to the information }\end{array}$ & 1 & .8 & 6.7 & 80.0 \\
\hline & $\begin{array}{l}\text { The chairman would lie to } \\
\text { you if your roles were } \\
\text { reversed }\end{array}$ & 1 & .8 & 6.7 & 86.7 \\
\hline & This is not a lie & 1 & .8 & 6.7 & 93.3 \\
\hline & Other & 1 & .8 & 6.7 & 100.0 \\
\hline & Total & 15 & 12.3 & 100.0 & \\
\hline Missing & System & 107 & 87.7 & & \\
\hline Total & & 122 & 100.0 & & \\
\hline
\end{tabular}

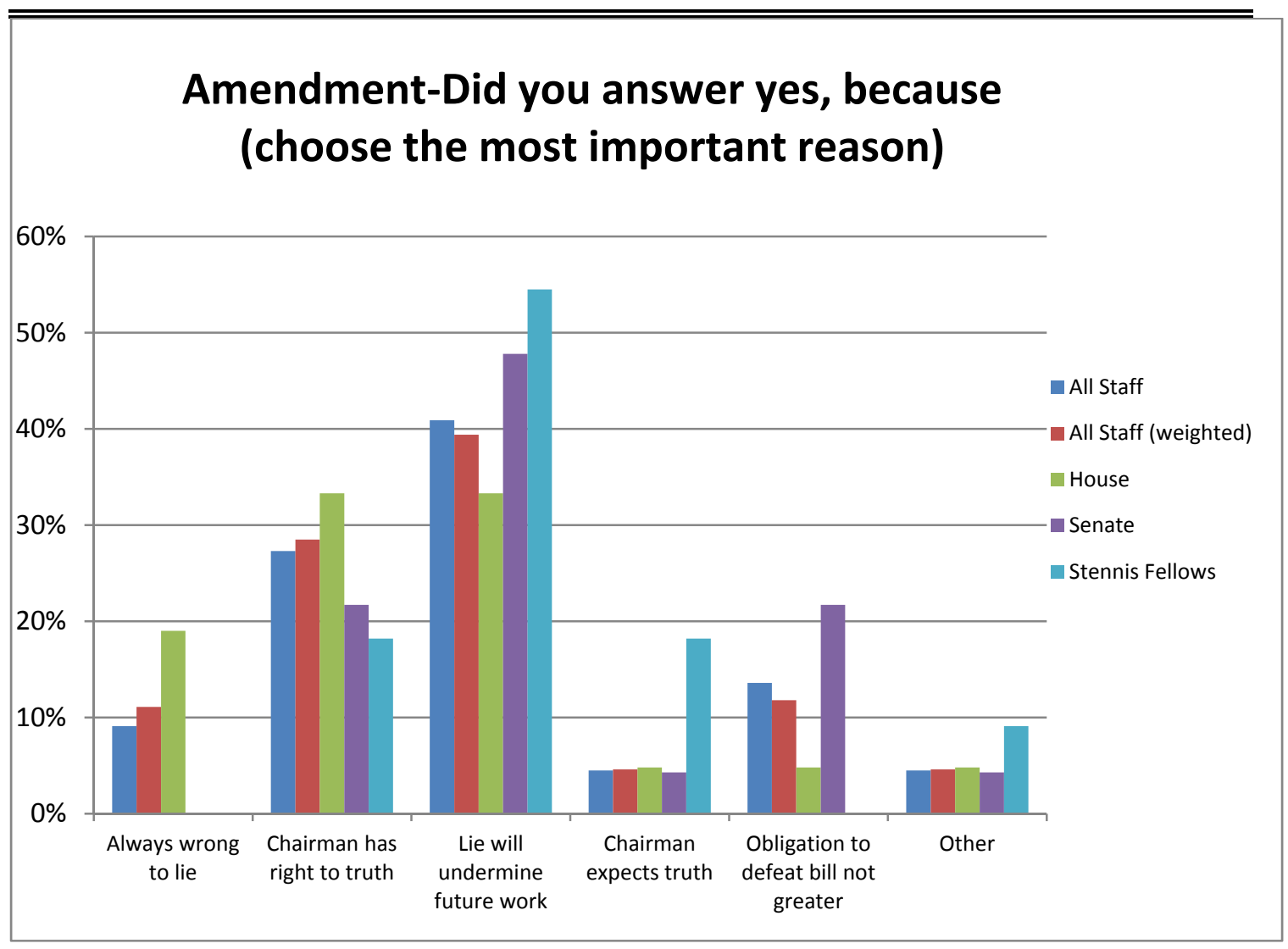

Forty-four all staff-weighted respondents indicated that they would tell the chairman that they were working on an amendment. The two most frequently cited reasons were "the lie when discovered, will undermine your ability to work successfully with the chairman 
in the future" (39\%) and the "chairman has a right to the truth" (29\%). Although the sample sizes are too small to infer anything about the population, Senate staff and Stennis Fellows appeared to rely more heavily upon the long-term consequences of lying to the chairman. As was true with the conference committee case, the seniority and longevity of the Stennis Fellows may have given them greater sensitivity to the long-term risks and consequences of exposed lying and deception.

Did you answer yes because (choose the most important reason)

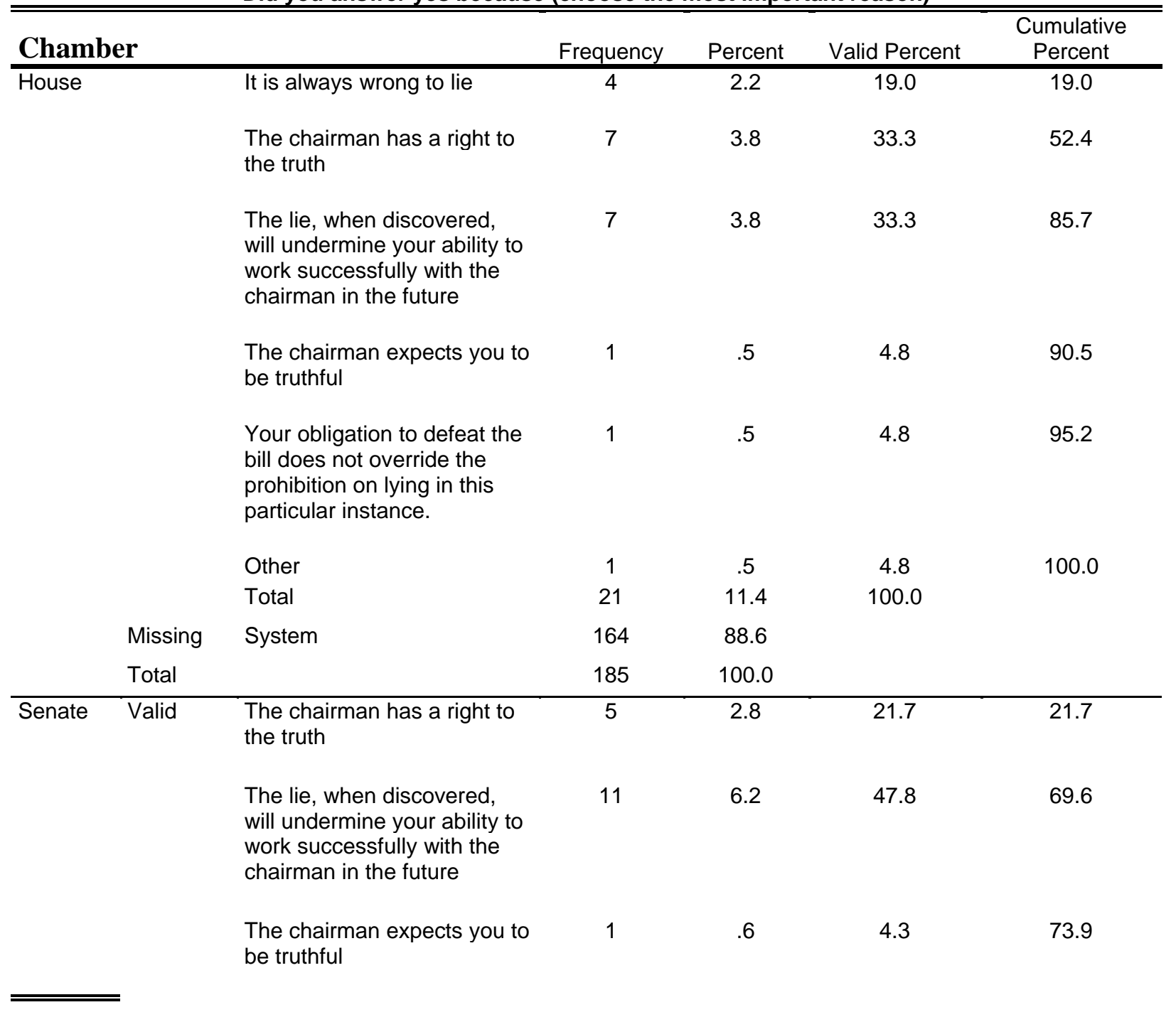




\begin{tabular}{|c|c|c|c|c|c|}
\hline & $\begin{array}{l}\text { Your obligation to defeat the } \\
\text { bill does not override the } \\
\text { prohibition on lying in this } \\
\text { particular instance. }\end{array}$ & 5 & 2.8 & 21.7 & 95.7 \\
\hline & Other & 1 & .6 & 4.3 & 100.0 \\
\hline & Total & 23 & 12.9 & 100.0 & \\
\hline Missing & System & 155 & 87.1 & & \\
\hline Total & & 178 & 100.0 & & \\
\hline
\end{tabular}

Did you answer yes because (choose the most important reason)

\begin{tabular}{|c|c|c|c|c|c|}
\hline \multicolumn{2}{|c|}{ All Staff-weighted } & \multirow{2}{*}{$\frac{\text { Frequency }}{5}$} & \multirow{2}{*}{$\frac{\text { Percent }}{1.3}$} & \multirow{2}{*}{$\frac{\text { Valid Percent }}{11.1}$} & \multirow{2}{*}{$\begin{array}{c}\begin{array}{c}\text { Cumulative } \\
\text { Percent }\end{array} \\
11.1\end{array}$} \\
\hline Valid & It is always wrong to lie & & & & \\
\hline & $\begin{array}{l}\text { The chairman has a right to } \\
\text { the truth }\end{array}$ & 12 & 3.4 & 28.5 & 39.6 \\
\hline & $\begin{array}{l}\text { The lie, when discovered, } \\
\text { will undermine your ability to } \\
\text { work successfully with the } \\
\text { chairman in the future }\end{array}$ & 17 & 4.7 & 39.4 & 79.0 \\
\hline & $\begin{array}{l}\text { The chairman expects you to } \\
\text { be truthful }\end{array}$ & 2 & .5 & 4.6 & 83.6 \\
\hline & $\begin{array}{l}\text { Your obligation to defeat the } \\
\text { bill does not override the } \\
\text { prohibition on lying in this } \\
\text { particular instance } \\
\text {. }\end{array}$ & 5 & 1.4 & 11.8 & 95.4 \\
\hline & Other & 2 & .5 & 4.6 & 100.0 \\
\hline & Total & 44 & 12.0 & 100.0 & \\
\hline Missing & System & 321 & 88.0 & & \\
\hline Total & & 364 & 100.0 & & \\
\hline
\end{tabular}

Did you answer yes because (choose the most important reason)

\begin{tabular}{llcccc}
\hline \hline All Staff-unweighted & Frequency & Percent & Valid Percent & $\begin{array}{c}\text { Cumulative } \\
\text { Percent }\end{array}$ \\
\hline Valid & It is always wrong to lie & 4 & 1.1 & 9.1 & 9.1 \\
& $\begin{array}{l}\text { The chairman has a right to } \\
\text { the truth }\end{array}$ & 12 & 3.3 & 27.3 & 36.4 \\
$\begin{array}{l}\text { The lie, when discovered, } \\
\text { will undermine your ability to } \\
\text { work successfully with the } \\
\text { chairman in the future }\end{array}$ & 18 & 5.0 & 40.9 & 77.3 \\
$\begin{array}{l}\text { The chairman expects you to } \\
\text { be truthful }\end{array}$ & 2 & & & & \\
\end{tabular}




\begin{tabular}{|c|c|c|c|c|c|}
\hline & $\begin{array}{l}\text { Your obligation to defeat the } \\
\text { bill does not override the } \\
\text { prohibition on lying in this } \\
\text { particular instance. }\end{array}$ & 6 & 1.7 & 13.6 & 95.5 \\
\hline & Other & 2 & .6 & 4.5 & 100.0 \\
\hline & Total & 44 & 12.1 & 100.0 & \\
\hline Missing & System & 319 & 87.9 & & \\
\hline Total & & 363 & 100.0 & & \\
\hline
\end{tabular}

Did you answer yes because (choose the most important reason)

\begin{tabular}{llcccc}
\hline \hline Stennis Fellows & Frequency & Percent & Valid Percent & $\begin{array}{c}\text { Cumulative } \\
\text { Percent }\end{array}$ \\
\hline Valid & $\begin{array}{l}\text { The chairman has a right to } \\
\text { the truth }\end{array}$ & 2 & 1.6 & 18.2 & 18.2 \\
& $\begin{array}{l}\text { The lie, when discovered, } \\
\text { will undermine your ability to } \\
\text { work successfully with the } \\
\text { chairman in the future }\end{array}$ & 6 & 4.9 & 54.5 & 72.7 \\
& $\begin{array}{l}\text { The chairman expects you to } \\
\text { be truthful }\end{array}$ & 2 & 1.6 & 18.2 & \\
& & & & \\
& Other & 1 & .8 & 9.9 & \\
& Total & 11 & 9.0 & 100.0 & \\
Missing & System & 111 & 91.0 & & \\
Total & 122 & 100.0 & & \\
\hline \hline
\end{tabular}




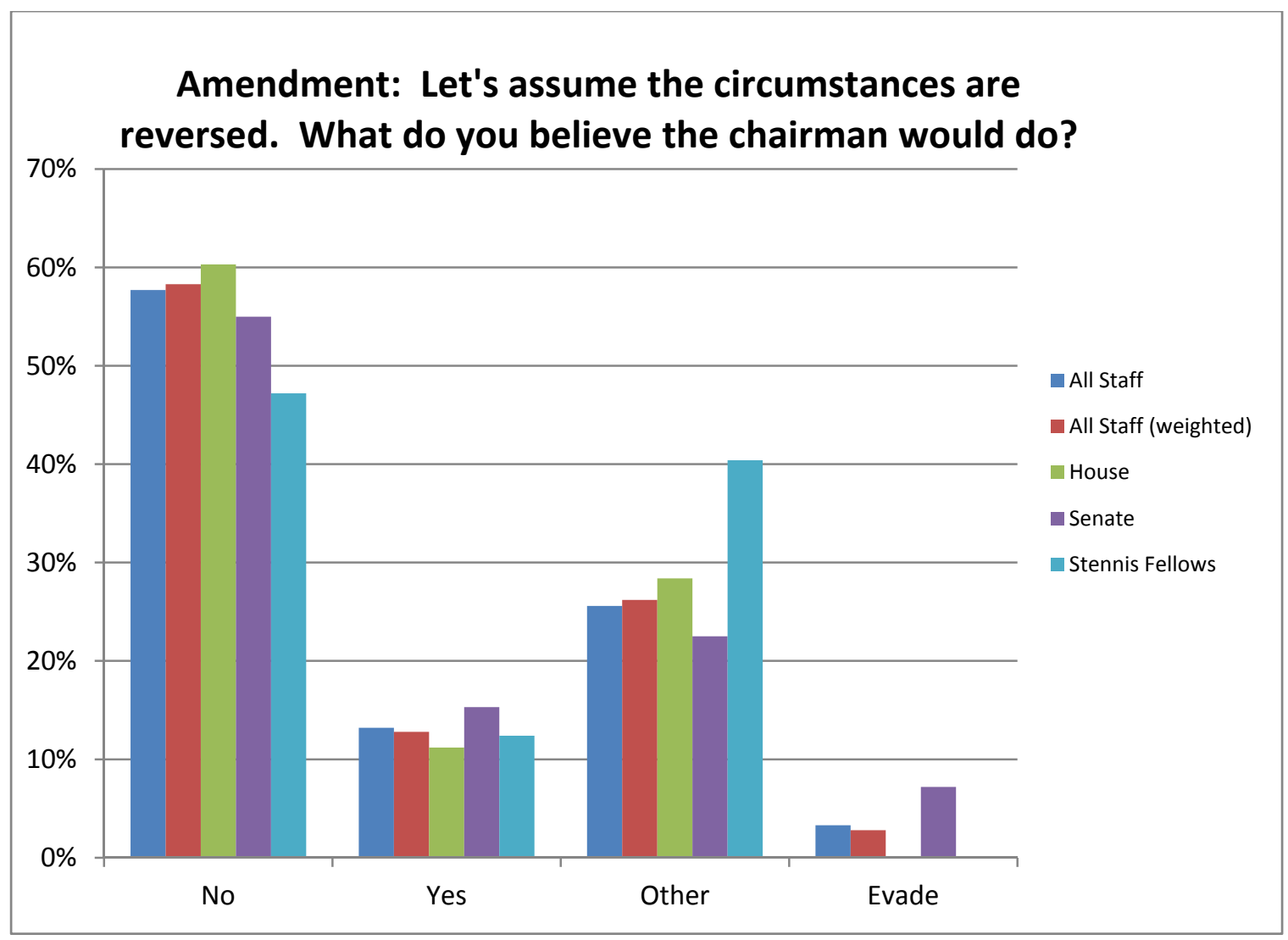

As in the previous case, respondents appeared to believe their colleagues to be less honest than they themselves would be. Roughly $30 \%$ of staff indicated that they would tell the chairman "no." In the role reversal question, when they are asked what they believed the chairman would do if their roles were reversed, $57 \%$ to $60 \%$ indicated that the chairman would tell them "no." As in the prior case, this response raises questions about whether respondents believe their colleagues to be less honest, or whether they are systematically overestimating their own truth-telling relative to their peers. This result is consistent with the findings from the section of the survey dealing with the number of times staff reported lying and being lied to. 
Confidence intervals were calculated for each of the respondent groups. The widest confidence interval for the House was $\pm 9 \%$, for the Senate was $\pm 9.1 \%$, for all staffweighted was $\pm 6.4 \%$ and for Stennis Fellows was $\pm 8.6 \%$.

House staff (60.3\%) were more likely than Senate staff (55\%) or Stennis Fellows $(47.2 \%)$ to believe that the chairman would answer "no" if the roles were reversed. The twosample, two-tailed t-statistic for the difference between House and Senate staff was not significant at the .05 level, $t(225)=.81, p=.42$. The two-sample, two-tailed t-statistic for the difference between House staff and Stennis Fellows was also not significant at the .05 level, $t(203)=1.87, p=.06$.

Stennis Fellows $(40.4 \%)$ were more likely than House $(28.4 \%)$ or Senate staff $(22.5 \%)$ to respond "other." The two-sample, two-tailed t-statistic was not significant at the .05 level for the difference between Stennis Fellows and House staff, $t(203)=1.8, p=.07$, but was significant for the difference between Stennis Fellows and Senate staff, $t(198)=2.73$, $p=.007$, and the difference between Stennis Fellows and all staff-weighted, $t(315)=2.47$, $p=.014$. As discussed earlier, the use of "other" reflects the extent to which these questions are viewed as morally complex and may reflect the greater experience and seniority of fellows.

All staff-weighted respondents who answered "yes" $(M=22.1, M d n=22)$ and who chose "evade" $(M=21.5, M d n=24.5)$ had the highest religiosity scores. Respondents who selected "no" $(M=21.07, M d n=24.76)$ and who selected "other" $(M=20.6, M d n=19)$ had the lowest religiosity scores. 
The two-sample, two-tailed t-statistic for the difference in mean religiosity between all staff-weighted who believed the chairman would answer "yes" and those who believed he would say "no" was not significant at the .05 level, $t(159)=.634, p=.53$. The t-statistic was also not significant at the .05 level for the difference in mean religiosity between staff who believed the chairman would reply "no" and "other," $t(186)=.384, p=.7$, or for staff who believed the chair would reply "no" or attempt to "evade," $t(36)=.14, p=.89$. The Mann-Whitney U Test also revealed no significant difference in religiosity between staff who believed the chairman would answer "no" $(M d n=22, n=132)$ and staff who believed that the chairman would answer "yes" $(M d n=24.76, n=29), \mathrm{U}=1812.5, \mathrm{z}=-.602$, $\mathrm{p}=.547$.

Stennis Fellows who answered "yes" $(\mathrm{M}=23.1, \mathrm{Mdn}=26)$ and who chose "other" $(\mathrm{M}=21.9, \mathrm{Mdn}=23)$ had the highest religiosity scores. Respondents who selected "no" $(\mathrm{M}=20.6, \mathrm{Mdn}=20)$ had the lowest religiosity scores. The two-sample, two-tailed tstatistic for the difference in mean religiosity between Stennis Fellows who believed the chairman would answer "yes" and those who believed she would say "no" was not significant at the .05 level, $t(50)=1.01, p=.32$. The two-sample, two-tailed t-statistic for the difference in mean religiosity between those who predicted the chairman would answer "no" and those who believed she would give an "other" answer was also not significant at the .05 level, $t(74)=-.76, p=.45$. The Mann-Whitney $U$ Test also revealed no significant difference in the religiosity between fellows who answered "no" $(M d n=20$, $n=41)$ and fellows who answered "yes" $(M d n=26, n=11), U=187.5, z=-.853, p=.394$. 
All staff-weighted who expected the chairman to answer "no" reported lying more frequently $(M=3.033, M d n=1.0, n=111)$ than staff who expected the chairman to answer "yes" $(M=2.495, M d n=.845, n=22) . \quad$ The two-sample, two-tailed t-statistic for the difference in mean-reported lying was not significant at the .05 level, $t(131)=0.315$, $p=.7536$. The Mann-Whitney U Test also revealed no significant difference in lying between staff who anticipated that the chairman would answer "yes" and those who anticipated the chair would answer "no," $U=1224, z=-.184, p=.854$.

All staff-weighted who expected the chairman to answer "no" ( $M=8.95, M d n=4.0$, $n=100$ ) reported being lied to at similar rates to staff who expected the chairman to answer "yes" $(M=9.195, M d n=3.34, n=24)$. The two-sample, two-tailed t-statistic for the difference in mean being lied to was not significant at the .05 level, $t(122)=0.064$, $p=.9494$. The Mann-Whitney U Test also revealed no significant difference in being lied to by staff who anticipated the chairman would answer "no" and staff who anticipated the chairman would answer "yes," $U=1142, z=-.220, p=.825$. The null hypothesis that there was no difference in being lied to cannot not be rejected.

Stennis Fellows who expected the chairman to answer "no" $(M=5.714, M d n=3.5, n=28)$ reported being lied to less frequently than fellows who expected the chairman to answer "yes" $(M=22.875, M d n=11.5, n=8) . \quad$ The two-sample, two-tailed t-statistic for the difference in mean "being lied to" between fellows who expected the chairman to answer "no" and those who expected the chairman to answer "yes" was significant at the .05 level, $t(34)=2.693, p=.0109$. The Mann-Whitney U Test, however, did not reveal a significant difference between fellows who expected the chairman to answer "yes" and 
fellows who expected the chairman to answer "no," $U=75.5, z=-1.402, p=.168$. Because the respondent groups were smaller than 30, we cannot assume the normal distribution that is required for the t-statistic. The nonparametric Mann-Whitney U Test is the appropriate test and the null hypothesis that there was no difference cannot be rejected.

Stennis Fellows who expected the chairman to answer "no" $(M=2.036, M d n=0, n=28)$ reported telling fewer lies than fellows who expected the chairman to answer "yes" $(M=3.889, M d n=1.0, n=9)$. The two-sample, two-tailed t-statistic for the difference in mean lying was not significant at the .05 level, $t(35)=1.340, p=.1889$. The MannWhitney U Test also did not reveal a significant difference in lying between fellows who anticipated that the chairman would answer "no" and fellows who anticipated that the chairman would answer "yes," $U=104.5, z=-.820, p=.412$. The null hypothesis that there is no difference in means cannot be rejected.

Ninety-three percent of all staff-weighted who indicated that they would tell the chairman "no" expected that the chairman would also tell them "no" if their situations were reversed. Only $44 \%$ of staff who indicated they would tell the chairman "yes" expected that the chairman would tell them "no" if the situation were reversed. A similar patter followed for staff who responded "other," "evade," and “obfuscate." Forty-five percent of staff who responded "other" expected that the chairman would say "no" and $45 \%$ thought that the chairman would respond "other." Forty-four percent of staff who indicated they would "evade" the question expected the chairman to answer "no" and $34 \%$ expected the chairman to "evade." Thirty-two percent of staff who indicated they 
would "obfuscate" expected the chairman to answer "no" while 58\% expected the chairman to "obfuscate."

\begin{tabular}{|c|c|c|c|c|c|c|}
\hline \multirow[t]{2}{*}{ All Staff-weighted } & & \multicolumn{4}{|c|}{$\begin{array}{l}\text { Let's assume the circumstances are reversed. What do you } \\
\text { believe the chairman would do? }\end{array}$} & \multirow[b]{2}{*}{ Total } \\
\hline & & Tell you no & Tell you yes & Other & Evade & \\
\hline \multirow{5}{*}{$\begin{array}{l}\text { Case 5. Respondent } \\
\text { would answer.... }\end{array}$} & Yes & 20 & 21 & 4 & 0 & 45 \\
\hline & No & 64 & 2 & 3 & 0 & 69 \\
\hline & Other & 29 & 3 & 31 & 1 & 64 \\
\hline & Evade & 14 & 2 & 11 & 5 & 32 \\
\hline & Obfuscate & 6 & 1 & 11 & 1 & 19 \\
\hline Total & & 133 & 29 & 60 & 7 & 229 \\
\hline
\end{tabular}

One hundred percent of the Stennis Fellows who indicated they would answer "no" expected that the chairman would answer "no" if their circumstances were reversed. In contrast, 33\% of Stennis Fellows who answered "yes" expected that the chairman would answer "no" if the circumstances were reversed. As with the all staff-weighted respondents, fellows responses strongly mirrored their expectations (or vice versa).

The responses "evade" and "obfuscate" were collapsed back into "other" for purposes of conducting a chi-square test for independence. The chi-square indicated a significant association between the answer all staff-weighted respondents gave (yes, no, other) and their expectations regarding the answer the chairman would give (yes, no, other) if their roles were reversed, $X^{2}=(4, n=230)=112.989, p=.000$, Cramer's $V=.496$. 


\section{Case 5. Stennis Fellows}

Count

Let's assume the circumstances are reversed. What do you believe the chairman would do?

\begin{tabular}{llrrrr} 
& & Tell you no & Tell you yes & Other & \multicolumn{2}{c}{ Total } \\
\cline { 3 - 5 } Case Respondent would & Yes & 4 & 7 & 1 & 12 \\
answer... & No & 14 & 0 & 0 & 14 \\
& Other & 8 & 1 & 13 & 22 \\
& Evade & 12 & 3 & 10 & 25 \\
& Obfuscate & 4 & 0 & 12 & 16 \\
Total & & 42 & 11 & 36 & 89 \\
\hline \hline
\end{tabular}

Let's assume the circumstances are reversed. What do you believe the chairman would do?

\begin{tabular}{|c|c|c|c|c|c|c|}
\hline \multicolumn{3}{|c|}{ Chamber } & \multirow{2}{*}{$\frac{\text { Frequency }}{70}$} & \multirow{2}{*}{$\frac{\text { Percent }}{37.8}$} & \multirow{2}{*}{$\frac{\text { Valid Percent }}{60.3}$} & \multirow{2}{*}{$\begin{array}{c}\begin{array}{c}\text { Cumulative } \\
\text { Percent }\end{array} \\
60.3\end{array}$} \\
\hline House & Valid & Tell you no & & & & \\
\hline & & Tell you yes & 13 & 7.0 & 11.2 & 71.6 \\
\hline & & Other & 33 & 17.8 & 28.4 & 100.0 \\
\hline & & Total & 116 & 62.7 & 100.0 & \\
\hline & Missing & System & 69 & 37.3 & & \\
\hline & Total & & 185 & 100.0 & & \\
\hline \multirow[t]{7}{*}{ Senate } & Valid & Tell you no & 61 & 34.3 & 55.0 & 55.0 \\
\hline & & Tell you yes & 17 & 9.6 & 15.3 & 70.3 \\
\hline & & Other & 25 & 14.0 & 22.5 & 92.8 \\
\hline & & Evade & 8 & 4.5 & 7.2 & 100.0 \\
\hline & & Total & 111 & 62.4 & 100.0 & \\
\hline & Missing & System & 67 & 37.6 & & \\
\hline & Total & & 178 & 100.0 & & \\
\hline
\end{tabular}

Let's assume the circumstances are reversed. What do you believe the chairman would do?

\begin{tabular}{llcccc}
\hline \hline All Staff-weighted & Frequency & Percent & Valid Percent & $\begin{array}{c}\text { Cumulative } \\
\text { Percent }\end{array}$ \\
\hline Valid & Tell you no & 133 & 36.5 & 58.3 & 58.3 \\
& Tell you yes & 29 & 8.0 & 12.8 & 71.1 \\
& Other & 60 & 16.4 & 26.2 & 97.2 \\
& Evade & 6 & 1.7 & 2.8 & 100.0 \\
& Total & 228 & 62.6 & 100.0 & \\
Missing & System & 136 & 37.4 & & \\
Total & 364 & 100.0 & & \\
\hline \hline
\end{tabular}

Let's assume the circumstances are reversed. What do you believe the chairman would do?

\begin{tabular}{lccccc}
\hline \hline All Staff-unweighted & Frequency & Percent & Valid Percent & $\begin{array}{c}\text { Cumulative } \\
\text { Percent }\end{array}$ \\
\hline \multirow{2}{*}{ Valid } & Tell you no & 131 & 36.1 & 57.7 & 57.7 \\
& Tell you yes & 30 & 8.3 & 13.2 & 70.9
\end{tabular}




\begin{tabular}{llcccc}
\hline & Other & 58 & 16.0 & 25.6 & 96.5 \\
& Evade & 8 & 2.2 & 3.5 & 100.0 \\
& Total & 227 & 62.5 & 100.0 & \\
Missing & System & 136 & 37.5 & & \\
Total & & 363 & 100.0 & & \\
\hline \hline
\end{tabular}

Let's assume the circumstances are reversed. What do you believe the chairman would do?

\begin{tabular}{llcccc}
\hline \hline Stennis Fellows & Frequency & Percent & Valid Percent & $\begin{array}{c}\text { Cumulative } \\
\text { Percent }\end{array}$ \\
\hline Valid & Tell you no & 42 & 34.4 & 47.2 & 47.2 \\
& Tell you yes & 11 & 9.0 & 12.4 & 59.6 \\
& Other & 36 & 29.5 & 40.4 & 100.0 \\
& Total & 89 & 73.0 & 100.0 & \\
Missing & System & 33 & 27.0 & & \\
Total & 122 & 100.0 & & \\
\hline \hline
\end{tabular}

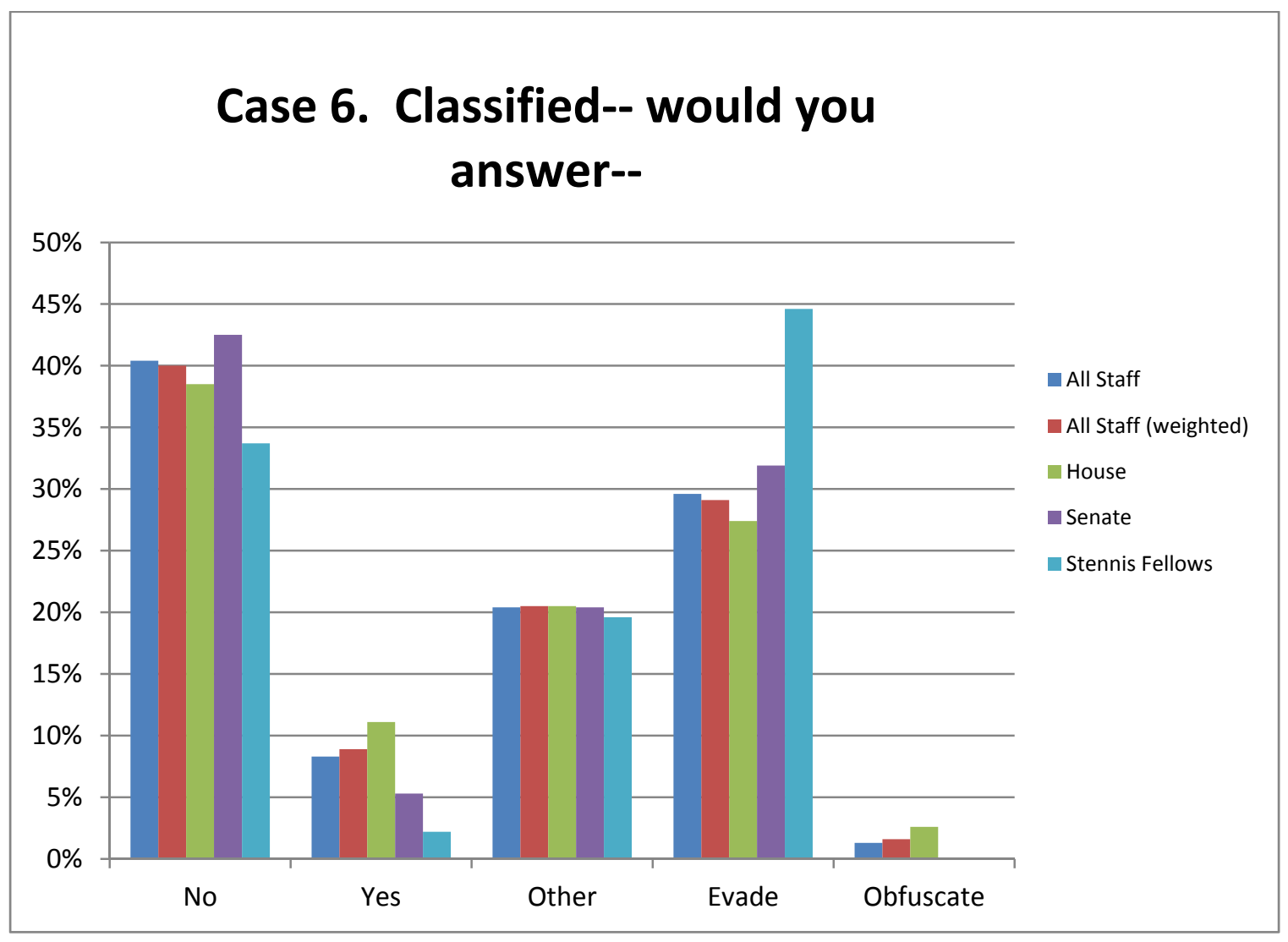

The classified case was drawn to create an opportunity for balancing legal obligations to protect secrets and moral obligations for truth-telling. It also presents a situation to test 
whether staff adhere to Grotius's notion that there are circumstances in which individuals do not have the right to truth. ${ }^{137}$ The scenario was drafted to present a research and development scenario rather than a military scenario to complicate a calculation of the balance of benefits and harms. Respondents were provided with the following case and asked whether they would answer "yes," "no," or "other":

"You have received a classified briefing from the Department of Defense regarding a compartmentalized new research and development program that will revolutionize military surveillance capabilities. The contracts will be worth billions of dollars and will create thousands of jobs. The CEO of a constituent business with expertise in the field knows you have oversight responsibility for this agency and asks you if the R\&D program exists and whether you have been read in. Would you answer..."

Thirty-four percent to $43 \%$ of respondents would give their obligation to preserve secrets priority over their obligation to tell the truth and answer "no" while a majority of respondents would try to find an alternate way to respond. Two percent to $12 \%$ of respondents would answer "yes" rather than fulfill their legal obligation to preserve the secret.

Confidence intervals were calculated for each of the respondent groups. The widest confidence interval for the House was $\pm 8.9 \%$, for the Senate was $\pm 9.2 \%$, for all staff-weighted was $\pm 6.3 \%$ and for Stennis Fellows was $\pm 8.3 \%$.

Senate staff (42.5\%) were more likely to answer "no" than either House (38.5\%) staff or Stennis Fellows (33.7\%). The two-sample, two-tailed t-statistic for the difference in

${ }^{137}$ The scenario became particularly sensitive after newspapers revealed Edward Snowden's leak of the classified documents he obtained from the National Security Agency. 
proportions between Senate staff and Stennis Fellows was not significant at the .05 level, $t(203)=1.29, p=.199$. The null hypothesis that there is no difference in proportions cannot be rejected.

House staff (11.1\%) were more likely than Senate staff (5.3\%) or Stennis Fellows $(2.2 \%)$ to answer "yes" to the CEO. The two-sample, two-tailed t-statistic for the difference in proportions between House and Senate staff was not significant at the .05 level, $t(228)=1.57, p=.12$. The null hypothesis that there is no difference in proportions cannot be rejected. The two-sample, two-tailed t-statistic for the difference in proportions between House staff and Stennis Fellows was significant at the .05 level, $t(207)=2.45$, $p=.015$.

Stennis Fellows (44.6\%) were more likely to evade the question than House $(27.4 \%)$ or Senate staff (31.9\%). The two-sample, two-tailed t-statistic was not significant at the .05 level for the difference in proportions between House and Senate staff, $t(228)=-.75$, $p=.45$, or for the difference in proportions between Senate staff and Stennis Fellows, $t(203)=1.87, p=.06$. The two-sample, two-tailed t-statistic was significant at the .05 level for the difference between Stennis Fellows and House staff, $t(207)=2.59, p=.01$, and the difference between Stennis Fellows and all staff-weighted, $t(321)=2.67, p=.008$. Stennis Fellows continued the pattern of relying more heavily on the response "other" and attempted to find ways to avoid answering the question without a direct lie.

All staff-weighted (19.4\%) who indicated that it was never OK to lie were less likely to answer "no" than those who did not agree with the statement (49\%). The two-sample, 
two-tailed t-statistic for the difference in proportions was significant at the .05 level, $t(227)=-4.36, p=.00002$. These staff (never lie) were also more likely to attempt to evade the question $(33.8 \%$ versus $23.8 \%)$. The two-sample, two-tailed t-statistic was not significant at the .05 level, $t(227)=1.6, p=.11$. The null hypothesis that there was no difference in proportions could not be rejected.

All staff-weighted who indicated it was never OK to tell a lie also were more likely to attempt to provide an "other" answer (27.7\% versus $14.3 \%)$. The two-sample, two-tailed t-statistic for the difference in proportions was significant at the .05 level, $t(227)=2.42$, $p=.002$.

All staff-weighted respondents who answered "no" $(M=18.6, M d n=19)$ had lower mean religiosity scores than respondents who answered "yes" $(M=24.6, M d n=28)$, answered “other" $(M=23.3, M d n=25)$, attempted to "evade" the question $(M=22.2, M d n=23.6)$, or who "obfuscated" $(M=19.7, M d n=16)$. The two-sample, two-tailed t-statistic for the difference in mean religiosity scores between those who answered "no" and those who answered "yes" was significant at the .05 level, $t(108)=-3.4, p=.001$. The Mann-Whitney U Test also revealed a significant difference in religiosity between staff who answered “no" $(M d n=19, n=90)$ and staff who answered "yes" $(M d n=28, n=20), U=425.6, z=-$ $3.476, p=.001$.

The t-statistic was also significant for the difference in mean religiosity scores between those who answered "no" and "other," $t(132)=3.6, p=.0004$. The t-statistic was not 
significant for the difference in mean religiosity scores between those who answered "yes" and those who attempted to "evade" the question, $t(85)=1.13, p=.26$.

Stennis Fellows who answered "no" $(M=20.4, M d n=20)$ had lower mean religiosity scores than those who answered "yes" $(M=26.5, M d n=26.5)$, answered "other" $(M=21.3$, $M d n=19)$, or who attempted to "evade" $(M=22.3, M d n=23)$ the question. The twosample, two-tailed t-statistic for the difference in mean religiosity between those who answered "yes" and those who answered "no" was not significant at the .05 level, $t(31)=1.1, p=.28$. The Mann-Whitney $\mathrm{U}$ Test also revealed no significant difference in religiosity between fellows who answered "yes" $(M d n=26.5, n=2)$ and fellows who answered "no" $(M d n=20, n=31), U=16, z=-1.134, p=.307$.

The two-sample, two-tailed t-statistic was not significant at the .05 level for the difference in mean religiosity scores between those who answered "yes" and those who answered "other," $t(18)=.838, p=.42$, or for the difference between those who answered "yes" and those who attempted to "evade" the question, $t(39)=.87, p=.39$.

Case 6. You have received a classified briefing from the Department of Defense regarding a compartmentalized new research and development program.

\begin{tabular}{|c|c|c|c|c|c|c|}
\hline \multicolumn{3}{|c|}{ Chamber } & \multirow{2}{*}{$\frac{\text { Frequency }}{45}$} & \multirow{2}{*}{$\frac{\text { Percent }}{24.3}$} & \multirow{2}{*}{$\frac{\text { Valid Percent }}{38.5}$} & \multirow{2}{*}{$\begin{array}{c}\begin{array}{c}\text { Cumulative } \\
\text { Percent }\end{array} \\
38.5\end{array}$} \\
\hline House & Valid & No & & & & \\
\hline & & Yes & 13 & 7.0 & 11.1 & 49.6 \\
\hline & & Other & 24 & 13.0 & 20.5 & 70.1 \\
\hline & & Evade & 32 & 17.3 & 27.4 & 97.4 \\
\hline & & Obfuscate & 3 & 1.6 & 2.6 & 100.0 \\
\hline & & Total & 117 & 63.2 & 100.0 & \\
\hline & Missing & System & 68 & 36.8 & & \\
\hline & Total & & 185 & 100.0 & & \\
\hline Senate & Valid & No & 48 & 27.0 & 42.5 & 42.5 \\
\hline
\end{tabular}




\begin{tabular}{llcccc}
\hline & Yes & 6 & 3.4 & 5.3 & 47.8 \\
& Other & 23 & 12.9 & 20.4 & 68.1 \\
& Evade & 36 & 20.2 & 31.9 & 100.0 \\
& Total & 113 & 63.5 & 100.0 & \\
Missing & System & 65 & 36.5 & \\
Total & & 178 & 100.0 & \\
\hline \hline
\end{tabular}

Case 6. You have received a classified briefing from the Department of Defense regarding a compartmentalized classified research and development program.

\begin{tabular}{llcccc}
\hline \hline All Staff-weighted & Frequency & Percent & Valid Percent & $\begin{array}{c}\text { Cumulative } \\
\text { Percent }\end{array}$ \\
\hline \multirow{2}{*}{ Valid } & No & 92 & 25.3 & 40.0 & 40.0 \\
& Yes & 20 & 5.6 & 8.9 & 48.9 \\
& Other & 47 & 13.0 & 20.5 & 69.3 \\
& Evade & 67 & 18.4 & 29.1 & 98.4 \\
& Obfuscate & 4 & 1.0 & 1.6 & 100.0 \\
Missing & Total & 231 & 63.3 & 100.0 & \\
Total & System & 134 & 36.7 & & \\
\hline \hline
\end{tabular}

Case 6. You have received a classified briefing from the Department of Defense regarding a compartmentalized classified research and development program.

\begin{tabular}{|c|c|c|c|c|c|}
\hline \multicolumn{2}{|c|}{$\begin{array}{l}\text { All Staff- } \\
\text { unweighted }\end{array}$} & \multirow{2}{*}{$\frac{\text { Frequency }}{93}$} & \multirow{2}{*}{$\frac{\text { Percent }}{25.6}$} & \multirow{2}{*}{$\frac{\text { Valid Percent }}{40.4}$} & \multirow{2}{*}{$\begin{array}{c}\begin{array}{c}\text { Cumulative } \\
\text { Percent }\end{array} \\
40.4\end{array}$} \\
\hline Valid & No & & & & \\
\hline & Yes & 19 & 5.2 & 8.3 & 48.7 \\
\hline & Other & 47 & 12.9 & 20.4 & 69.1 \\
\hline & Evade & 68 & 18.7 & 29.6 & 98.7 \\
\hline & Obfuscate & 3 & .8 & 1.3 & 100.0 \\
\hline & Total & 230 & 63.4 & 100.0 & \\
\hline Missing & System & 133 & 36.6 & & \\
\hline Total & & 363 & 100.0 & & \\
\hline
\end{tabular}

Case 6. You have received a classified briefing from the Department of Defense regarding a compartmentalized research and development program.

\begin{tabular}{llcccc}
\hline \hline Stennis Fellows & Frequency & Percent & Valid Percent & $\begin{array}{c}\text { Cumulative } \\
\text { Percent }\end{array}$ \\
\hline Valid & No & 31 & 25.4 & 33.7 & 33.7 \\
& Yes & 2 & 1.6 & 2.2 & 35.9 \\
& Other & 18 & 14.8 & 19.6 & 55.4 \\
& Evade & 41 & 33.6 & 44.6 & 100.0 \\
& Total & 92 & 75.4 & 100.0 & \\
Missing & System & 30 & 24.6 & & \\
Total & 122 & 100.0 & & \\
\hline \hline
\end{tabular}


Case 6. You have received a classified briefing from the Department of Defense

\begin{tabular}{|c|c|c|c|c|c|c|}
\hline \multicolumn{3}{|c|}{$\begin{array}{l}\text { All Staff-weighted Sorted by } \\
\text { Never OK to Lie }\end{array}$} & Frequency & \multirow{2}{*}{$\frac{\text { Percent }}{19.4}$} & \multirow{2}{*}{$\begin{array}{r}\begin{array}{c}\text { Valid } \\
\text { Percent }\end{array} \\
20.8\end{array}$} & \multirow{2}{*}{$\begin{array}{r}\begin{array}{c}\text { Cumulative } \\
\text { Percent }\end{array} \\
20.8\end{array}$} \\
\hline Reflects my View & Valid & No & 17 & & & \\
\hline & & Yes & 10 & 11.1 & 11.9 & 32.7 \\
\hline & & Other & 24 & 27.7 & 29.7 & 62.3 \\
\hline & & Evade & 29 & 33.8 & 36.2 & 98.5 \\
\hline & & Obfuscate & 1 & 1.4 & 1.5 & 100.0 \\
\hline & & Total & 81 & 93.5 & 100.0 & \\
\hline & Missing & System & 6 & 6.5 & & \\
\hline & Total & & 87 & 100.0 & & \\
\hline \multirow{8}{*}{$\begin{array}{l}\text { Does not Reflect my } \\
\text { View }\end{array}$} & Valid & No & 76 & 49.0 & 51.2 & 51.2 \\
\hline & & Yes & 11 & 7.0 & 7.3 & 58.6 \\
\hline & & Other & 22 & 14.3 & 14.9 & 73.5 \\
\hline & & Evade & 37 & 23.8 & 24.9 & 98.4 \\
\hline & & Obfuscate & 2 & 1.6 & 1.6 & 100.0 \\
\hline & & Total & 148 & 95.6 & 100.0 & \\
\hline & Missing & System & 7 & 4.4 & & \\
\hline & Total & & 154 & 100.0 & & \\
\hline
\end{tabular}

\begin{tabular}{|c|c|c|}
\hline HogueTotal & All Staff Weigh & \\
\hline \multirow[t]{7}{*}{ No } & Valid & 90 \\
\hline & Missing & 2 \\
\hline & Mean & 18.626 \\
\hline & Median & 19.000 \\
\hline & Mode & 15.0 \\
\hline & Std. Deviation & 7.0512 \\
\hline & Variance & 49.719 \\
\hline \multirow{7}{*}{$\overline{Y e s}$} & $\begin{array}{ll}N & \text { Valid }\end{array}$ & 20 \\
\hline & Missing & 0 \\
\hline & Mean & 24.561 \\
\hline & Median & 28.000 \\
\hline & Mode & 29.0 \\
\hline & Std. Deviation & 7.5375 \\
\hline & Variance & 56.814 \\
\hline \multirow[t]{7}{*}{ Other } & $\begin{array}{ll}\mathrm{N} & \text { Valid }\end{array}$ & 44 \\
\hline & Missing & 3 \\
\hline & Mean & 23.292 \\
\hline & Median & 25.000 \\
\hline & Mode & 28.0 \\
\hline & Std. Deviation & 7.0268 \\
\hline & Variance & 49.375 \\
\hline \multirow[t]{5}{*}{ Evade } & Valid & 67 \\
\hline & Missing & 0 \\
\hline & Mean & 22.194 \\
\hline & Median & 23.555 \\
\hline & Mode & 33.0 \\
\hline
\end{tabular}




\begin{tabular}{|c|c|c|}
\hline & $\begin{array}{l}\text { Std. Deviation } \\
\text { Variance }\end{array}$ & $\begin{array}{l}8.3630 \\
69.939\end{array}$ \\
\hline \multirow[t]{7}{*}{ Obfuscate } & Valid & 4 \\
\hline & Missing & 0 \\
\hline & Mean & 19.667 \\
\hline & Median & 16.000 \\
\hline & Mode & $13.0^{\mathrm{a}}$ \\
\hline & Std. Deviation & 8.7040 \\
\hline & Variance & 75.759 \\
\hline
\end{tabular}

Stennis Fellows

HogueRevTot

\begin{tabular}{|c|c|c|}
\hline \multirow[t]{6}{*}{ No } & $\begin{array}{l}\text { Valid } \\
\text { Missing }\end{array}$ & $\begin{array}{r}31 \\
0\end{array}$ \\
\hline & Mean & 20.419 \\
\hline & Median & 20.000 \\
\hline & Mode & $8.0^{a}$ \\
\hline & Std. Deviation & 7.5665 \\
\hline & Variance & 57.252 \\
\hline \multirow[t]{7}{*}{ Yes } & Valid & 2 \\
\hline & Missing & 0 \\
\hline & Mean & 26.500 \\
\hline & Median & 26.500 \\
\hline & Mode & $21.0^{\mathrm{a}}$ \\
\hline & Std. Deviation & 7.7782 \\
\hline & Variance & 60.500 \\
\hline \multirow[t]{7}{*}{ Other } & Valid & 18 \\
\hline & Missing & 0 \\
\hline & Mean & 21.278 \\
\hline & Median & 19.000 \\
\hline & Mode & 18.0 \\
\hline & Std. Deviation & 8.3512 \\
\hline & Variance & 69.742 \\
\hline \multirow[t]{7}{*}{ Evade } & Valid & 39 \\
\hline & Missing & 2 \\
\hline & Mean & 22.256 \\
\hline & Median & 23.000 \\
\hline & Mode & $17.0^{\mathrm{a}}$ \\
\hline & Std. Deviation & 6.6598 \\
\hline & Variance & 44.354 \\
\hline
\end{tabular}

a. Multiple modes exist. The smallest value is shown 


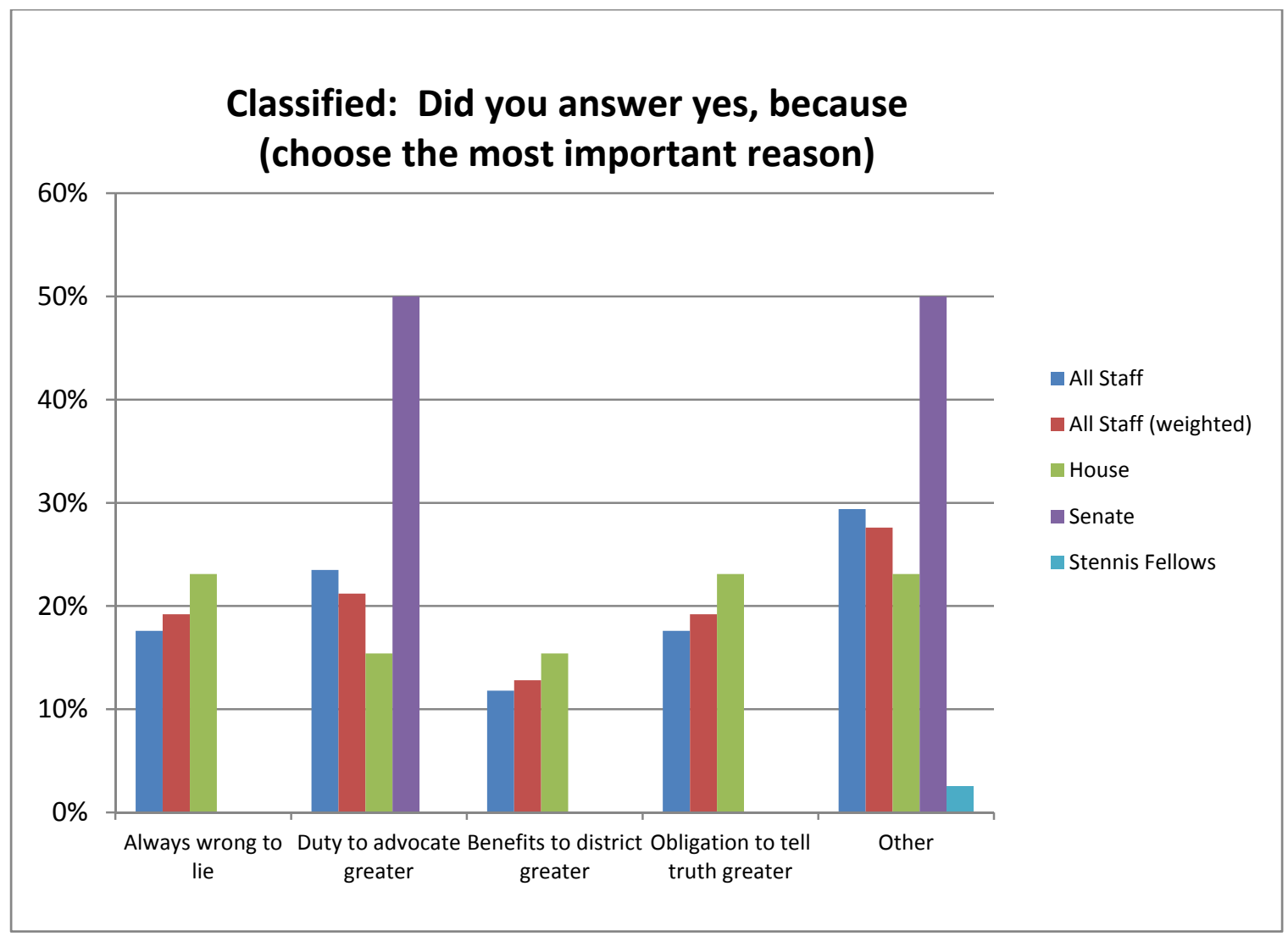

Twenty all staff-weighted respondents indicated that they would answer "yes" rather than preserve the secret. The reasons these staff offered were evenly mixed across all of the options that were presented. A few believed it always wrong to lie, a few believed that their duty to advocate for their boss and constituents was stronger than the duty not to disclose, a few believed the benefits would be greater than the harm, and a few indicated the obligation to truth-telling was greater than obligation not to disclose in this situation. In contrast, only two Stennis Fellows indicated they would answer "yes."

Did you answer yes because (choose the most important reason)

\begin{tabular}{llcccc}
\hline \hline Chamber & & & & & Cumulative \\
Percent
\end{tabular}




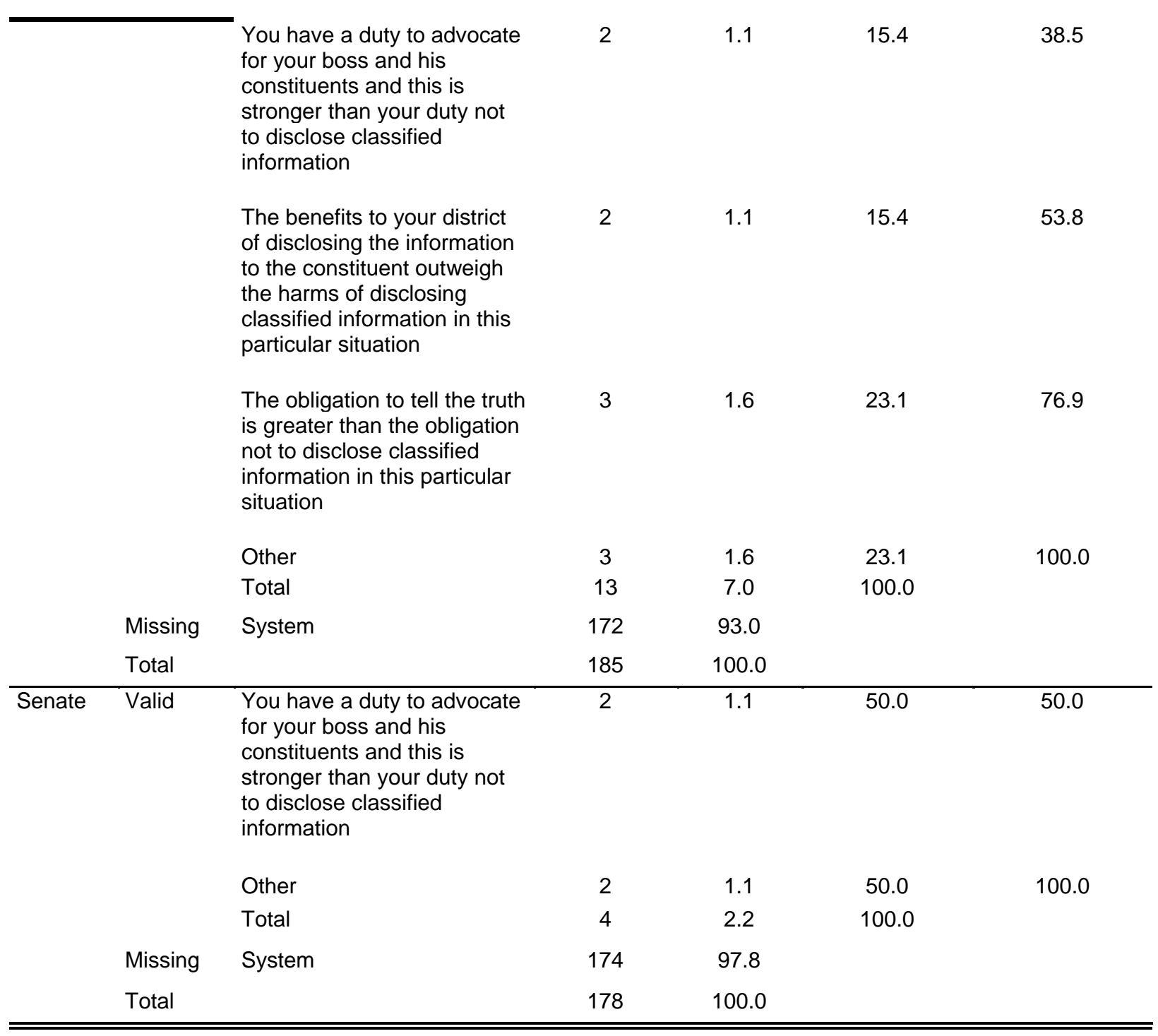

Did you answer yes because (choose the most important reason)--

\begin{tabular}{|c|c|c|c|c|c|}
\hline \multicolumn{2}{|c|}{ All Staff-weighted } & \multirow{2}{*}{$\frac{\text { Frequency }}{4}$} & \multirow{2}{*}{$\frac{\text { Percent }}{1.0}$} & \multirow{2}{*}{$\frac{\text { Valid Percent }}{19.2}$} & \multirow{2}{*}{$\begin{array}{c}\begin{array}{c}\text { Cumulative } \\
\text { Percent }\end{array} \\
19.2\end{array}$} \\
\hline Valid & It is always wrong to lie & & & & \\
\hline & $\begin{array}{l}\text { You have a duty to advocate } \\
\text { for your boss and his } \\
\text { constituents and this is } \\
\text { stronger than your duty not } \\
\text { to disclose classified } \\
\text { information }\end{array}$ & 4 & 1.1 & 21.2 & 40.4 \\
\hline & $\begin{array}{l}\text { The benefits to your district } \\
\text { of disclosing the information } \\
\text { to the constituent outweigh } \\
\text { the harms of disclosing } \\
\text { classified information in this } \\
\text { particular situation }\end{array}$ & 2 & .7 & 12.8 & 53.2 \\
\hline
\end{tabular}




\begin{tabular}{|c|c|c|c|c|c|}
\hline & $\begin{array}{l}\text { The obligation to tell the truth } \\
\text { is greater than the obligation } \\
\text { not to disclose classified } \\
\text { information in this particular } \\
\text { situation }\end{array}$ & 4 & 1.0 & 19.2 & 72.4 \\
\hline & Other & 5 & 1.4 & 27.6 & 100.0 \\
\hline & Total & 19 & 5.2 & 100.0 & \\
\hline Missing & System & 346 & 94.8 & & \\
\hline Total & & 364 & 100.0 & & \\
\hline & Did you answer yes be & luse (choos & he most & portant reason & \\
\hline All Sta & unweighted & Frequency & Percent & Valid Percent & $\begin{array}{c}\text { Cumulative } \\
\text { Percent }\end{array}$ \\
\hline Valid & It is always wrong to lie & 3 & .8 & 17.6 & 17.6 \\
\hline & $\begin{array}{l}\text { You have a duty to advocate } \\
\text { for your boss and his } \\
\text { constituents and this is } \\
\text { stronger than your duty not } \\
\text { to disclose classified } \\
\text { information }\end{array}$ & 4 & 1.1 & 23.5 & 41.2 \\
\hline & $\begin{array}{l}\text { The benefits to your district } \\
\text { of disclosing the information } \\
\text { to the constituent outweigh } \\
\text { the harms of disclosing } \\
\text { classified information in this } \\
\text { particular situation }\end{array}$ & 2 & .6 & 11.8 & 52.9 \\
\hline & $\begin{array}{l}\text { The obligation to tell the truth } \\
\text { is greater than the obligation } \\
\text { not to disclose classified } \\
\text { information in this particular } \\
\text { situation }\end{array}$ & 3 & .8 & 17.6 & 70.6 \\
\hline & Other & 5 & 1.4 & 29.4 & 100.0 \\
\hline & Total & 17 & 4.7 & 100.0 & \\
\hline Missing & System & 346 & 95.3 & & \\
\hline Total & & 363 & 100.0 & & \\
\hline
\end{tabular}




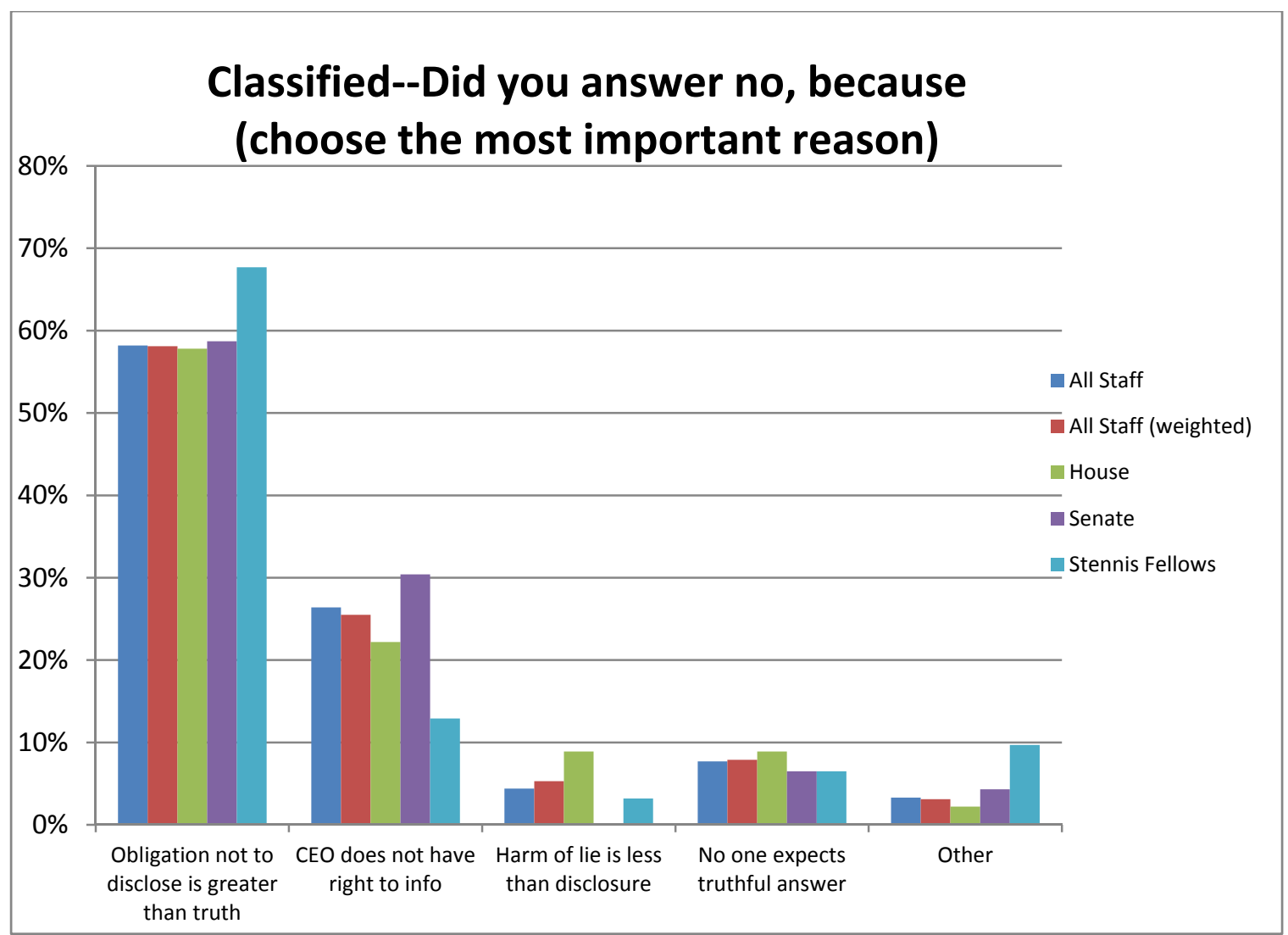

Ninety-two all staff-weighted indicated that they would lie to their constituent rather than disclose the information. The majority of respondents $(58 \%)$ indicated that the obligation not to disclose classified information was stronger than the obligation to tell the truth. Twenty-five percent of respondents followed Grotius and indicated that the CEO did not have a right to the information that she was seeking. Stennis Fellows (68\%) were more likely than House $(58 \%)$ or Senate $(59 \%)$ staff to indicate that the obligation to protect the classified information was greater than the obligation to tell the truth. Senate staff (30\%) were more likely than House staff $(22 \%)$ or Stennis Fellows (13\%) to say that the CEO did not have a right to the information. 
The two-sample, two-tailed t-statistic for the difference in proportions of Stennis Fellows and House staff saying that the obligation not to disclose is greater than the obligation to tell the truth was not significant at the .05 level, $t(31)=1.14, p=.26$. The null hypothesis that there was no difference in population proportions cannot be rejected.

The two-sample, two-tailed t-statistic for the difference in proportions of Senate staff and Stennis Fellows who indicated that the CEO did not have a right to the information was not significant at the .05 level, $t(75)=1.78, p=.079$. The null hypothesis that there was no difference in population proportions cannot be rejected.

Did you answer no because (choose the most important reason)

\begin{tabular}{|c|c|c|c|c|c|c|}
\hline \multicolumn{3}{|c|}{ Chamber } & \multirow{2}{*}{$\frac{\text { Frequency }}{26}$} & \multirow{2}{*}{$\frac{\text { Percent }}{14.1}$} & \multirow{2}{*}{$\frac{\text { Valid Percent }}{57.8}$} & \multirow{2}{*}{$\begin{array}{c}\begin{array}{c}\text { Cumulative } \\
\text { Percent }\end{array} \\
57.8\end{array}$} \\
\hline House & Valid & $\begin{array}{l}\text { The obligation not to } \\
\text { disclose classified } \\
\text { information is stronger than } \\
\text { the obligation to tell the truth }\end{array}$ & & & & \\
\hline & & $\begin{array}{l}\text { The CEO does not have a } \\
\text { right to this information }\end{array}$ & 10 & 5.4 & 22.2 & 80.0 \\
\hline & & $\begin{array}{l}\text { The harm of telling a lie is } \\
\text { less than the harm caused } \\
\text { by disclosing classified } \\
\text { information }\end{array}$ & 4 & 2.2 & 8.9 & 88.9 \\
\hline & & $\begin{array}{l}\text { No one should expect a } \\
\text { truthful answer. Lying is an } \\
\text { expected part of protecting } \\
\text { classified information }\end{array}$ & 4 & 2.2 & 8.9 & 97.8 \\
\hline & & Other & 1 & .5 & 2.2 & 100.0 \\
\hline & & Total & 45 & 24.3 & 100.0 & \\
\hline & Missing & System & 140 & 75.7 & & \\
\hline & Total & & 185 & 100.0 & & \\
\hline Senate & Valid & $\begin{array}{l}\text { The obligation not to } \\
\text { disclose classified } \\
\text { information is stronger than } \\
\text { the obligation to tell the truth }\end{array}$ & 27 & 15.2 & 58.7 & 58.7 \\
\hline
\end{tabular}




\begin{tabular}{|c|c|c|c|c|c|}
\hline & $\begin{array}{l}\text { The CEO does not have a } \\
\text { right to this information }\end{array}$ & 14 & 7.9 & 30.4 & 89.1 \\
\hline & $\begin{array}{l}\text { No one should expect a } \\
\text { truthful answer. Lying is an } \\
\text { expected part of protecting } \\
\text { classified information }\end{array}$ & 3 & 1.7 & 6.5 & 95.7 \\
\hline & Other & 2 & 1.1 & 4.3 & 100.0 \\
\hline & Total & 46 & 25.8 & 100.0 & \\
\hline Missing & System & 132 & 74.2 & & \\
\hline Total & & 178 & 100.0 & & \\
\hline
\end{tabular}

Did you answer no because (choose the most important reason)

\begin{tabular}{|c|c|c|c|c|c|}
\hline \multicolumn{2}{|c|}{ All Staff-weighted } & \multirow{2}{*}{$\frac{\text { Frequency }}{53}$} & \multirow{2}{*}{$\frac{\text { Percent }}{14.5}$} & \multirow{2}{*}{$\frac{\text { Valid Percent }}{58.1}$} & \multirow{2}{*}{$\begin{array}{c}\begin{array}{c}\text { Cumulative } \\
\text { Percent }\end{array} \\
58.1\end{array}$} \\
\hline Valid & $\begin{array}{l}\text { The obligation not to } \\
\text { disclose classified } \\
\text { information is stronger than } \\
\text { the obligation to tell the truth }\end{array}$ & & & & \\
\hline & $\begin{array}{l}\text { The CEO does not have a } \\
\text { right to this information }\end{array}$ & 23 & 6.4 & 25.5 & 83.7 \\
\hline & $\begin{array}{l}\text { The harm of telling a lie is } \\
\text { less than the harm caused } \\
\text { by disclosing classified } \\
\text { information }\end{array}$ & 5 & 1.3 & 5.3 & 89.0 \\
\hline & $\begin{array}{l}\text { No one should expect a } \\
\text { truthful answer. Lying is an } \\
\text { expected part of protecting } \\
\text { classified information }\end{array}$ & 7 & 2.0 & 7.9 & 96.9 \\
\hline & Other & 3 & .8 & 3.1 & 100.0 \\
\hline & Total & 91 & 24.9 & 100.0 & \\
\hline Missing & System & 274 & 75.1 & & \\
\hline Total & & 364 & 100.0 & & \\
\hline
\end{tabular}

Did you answer no because (choose the most important reason)

\begin{tabular}{llcccr}
\hline \hline All Staff-unweighted & Frequency & Percent & Valid Percent & $\begin{array}{c}\text { Cumulative } \\
\text { Percent }\end{array}$ \\
\hline Valid & $\begin{array}{l}\text { The obligation not to } \\
\text { disclose classified } \\
\text { information is stronger than } \\
\text { the obligation to tell the truth }\end{array}$ & & 14.6 & 58.2 & 58.2 \\
& & & & & \\
& $\begin{array}{l}\text { The CEO does not have a } \\
\text { right to this information }\end{array}$ & 24 & 6.6 & 26.4 & 84.6
\end{tabular}




\begin{tabular}{|c|c|c|c|c|c|}
\hline & $\begin{array}{l}\text { The harm of telling a lie is } \\
\text { less than the harm caused } \\
\text { by disclosing classified } \\
\text { information }\end{array}$ & 4 & 1.1 & 4.4 & 89.0 \\
\hline & $\begin{array}{l}\text { No one should expect a } \\
\text { truthful answer. Lying is an } \\
\text { expected part of protecting } \\
\text { classified information }\end{array}$ & 7 & 1.9 & 7.7 & 96.7 \\
\hline & Other & 3 & .8 & 3.3 & 100.0 \\
\hline & Total & 91 & 25.1 & 100.0 & \\
\hline Missing & System & 272 & 74.9 & & \\
\hline Total & & 363 & 100.0 & & \\
\hline
\end{tabular}

Did you answer no because (choose the most important reason)

\begin{tabular}{|c|c|c|c|c|c|}
\hline \multicolumn{2}{|c|}{ Stennis Fellows } & \multirow{2}{*}{$\frac{\text { Frequency }}{21}$} & \multirow{2}{*}{$\frac{\text { Percent }}{17.2}$} & \multirow{2}{*}{$\frac{\text { Valid Percent }}{67.7}$} & \multirow{2}{*}{$\begin{array}{c}\begin{array}{c}\text { Cumulative } \\
\text { Percent }\end{array} \\
67.7\end{array}$} \\
\hline Valid & $\begin{array}{l}\text { The obligation not to } \\
\text { disclose classified } \\
\text { information is stronger than } \\
\text { the obligation to tell the truth }\end{array}$ & & & & \\
\hline & $\begin{array}{l}\text { The CEO does not have a } \\
\text { right to this information }\end{array}$ & 4 & 3.3 & 12.9 & 80.6 \\
\hline & $\begin{array}{l}\text { The harm of telling a lie is } \\
\text { less than the harm caused } \\
\text { by disclosing classified } \\
\text { information }\end{array}$ & 1 & .8 & 3.2 & 83.9 \\
\hline & $\begin{array}{l}\text { No one should expect a } \\
\text { truthful answer. Lying is an } \\
\text { expected part of protecting } \\
\text { classified information }\end{array}$ & 2 & 1.6 & 6.5 & 90.3 \\
\hline & Other & 3 & 2.5 & 9.7 & 100.0 \\
\hline & Total & 31 & 25.4 & 100.0 & \\
\hline Missing & System & 91 & 74.6 & & \\
\hline Total & & 122 & 100.0 & & \\
\hline
\end{tabular}




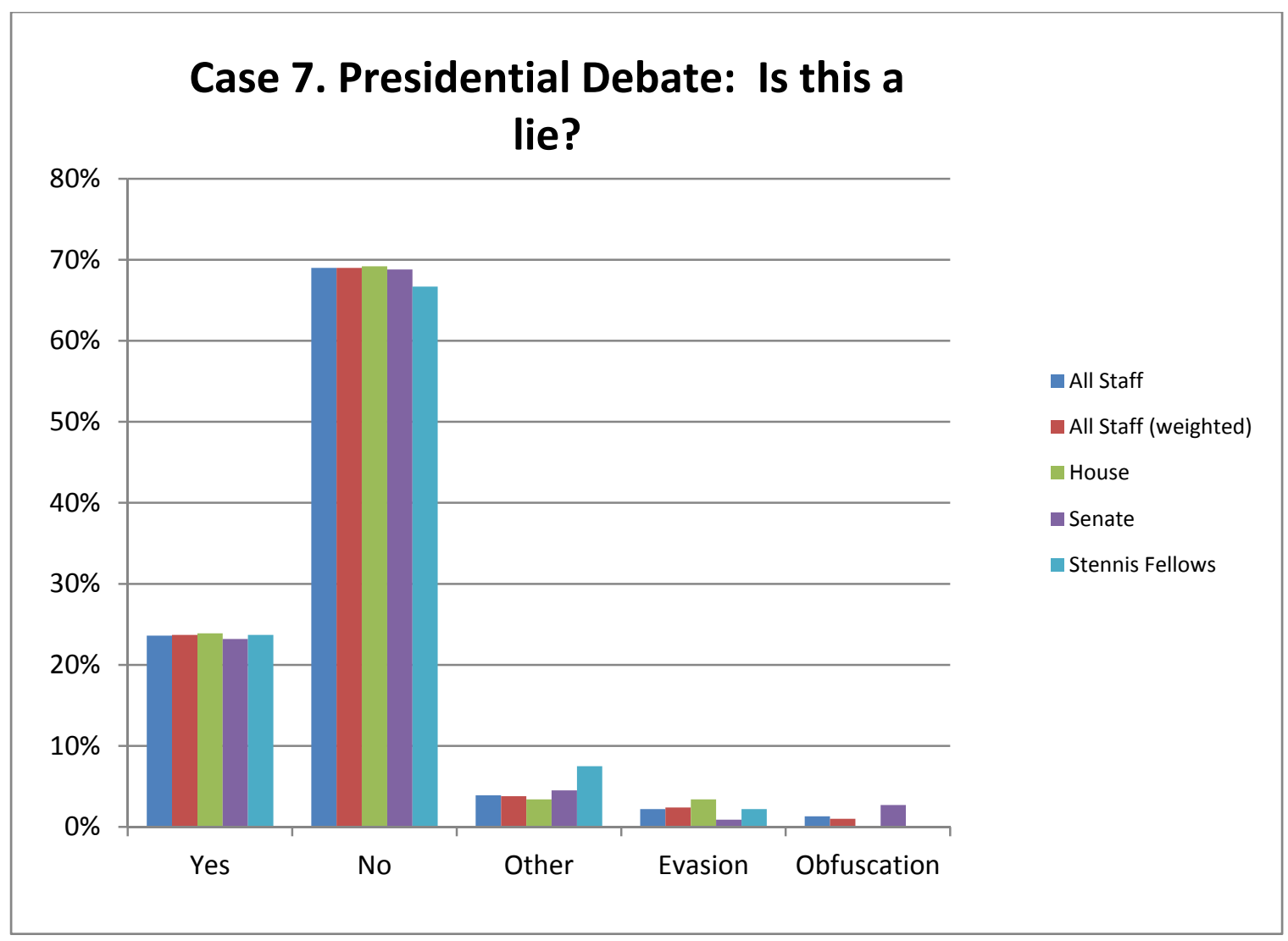

Thomas Carson, in his discussion of "bullshit," suggests that evasion is an overlooked form of bullshit. He provides the example of a debate in which a presidential candidate is asked a question about Supreme Court nominations. If he answers truthfully, he will lose the votes of pro-choice voters. If he lies, he will lose the votes of pro-life voters (leaders to which he has already made promises). The case provides an opportunity to test whether respondents view misleading partial truths as lies, or, following Carson, they find them to be something other than a lie. In order to avoid biasing responses based on this political issue, the case was rendered slightly more neutral so that the candidate could be either pro-life or pro-choice. Respondents were provided with the following case and asked to answer "yes," "no," or "other." “Other" responses were re-categorized where appropriate. 
"In a televised presidential debate, a candidate is asked the following question: 'I want to ask you about your criteria for nominating people to the U.S. Supreme Court. Would you be willing to nominate anyone who opposes your policy on Roe v. Wade? Or will you make support of your policy on Roe v. Wade a requirement for anyone you nominate?' The candidate is not willing to nominate anyone who opposes his policy on Roe v. Wade and has promised activists that he will do this. He answers, 'Look, there are lots of things to be taken into account when nominating someone for the Supreme Court. This isn't the only relevant consideration. More important than their position on any single issue, I want someone with a good legal mind and judicial experience that supports my judicial philosophy of following the constitution.' Is this a lie?"

Roughly $70 \%$ of respondents indicated, consistent with Carson, that this was not a lie. Twenty-three percent to $24 \%$ indicated that this was a lie while the remainder saw this as a form of deception but not a lie.

Confidence intervals were calculated for each of the respondent groups. The widest confidence interval for the House was $\pm 8.4 \%$, for the Senate was $\pm 8.6 \%$, for all staffweighted was $\pm 6.0 \%$ and for Stennis Fellows was $\pm 7.8 \%$.

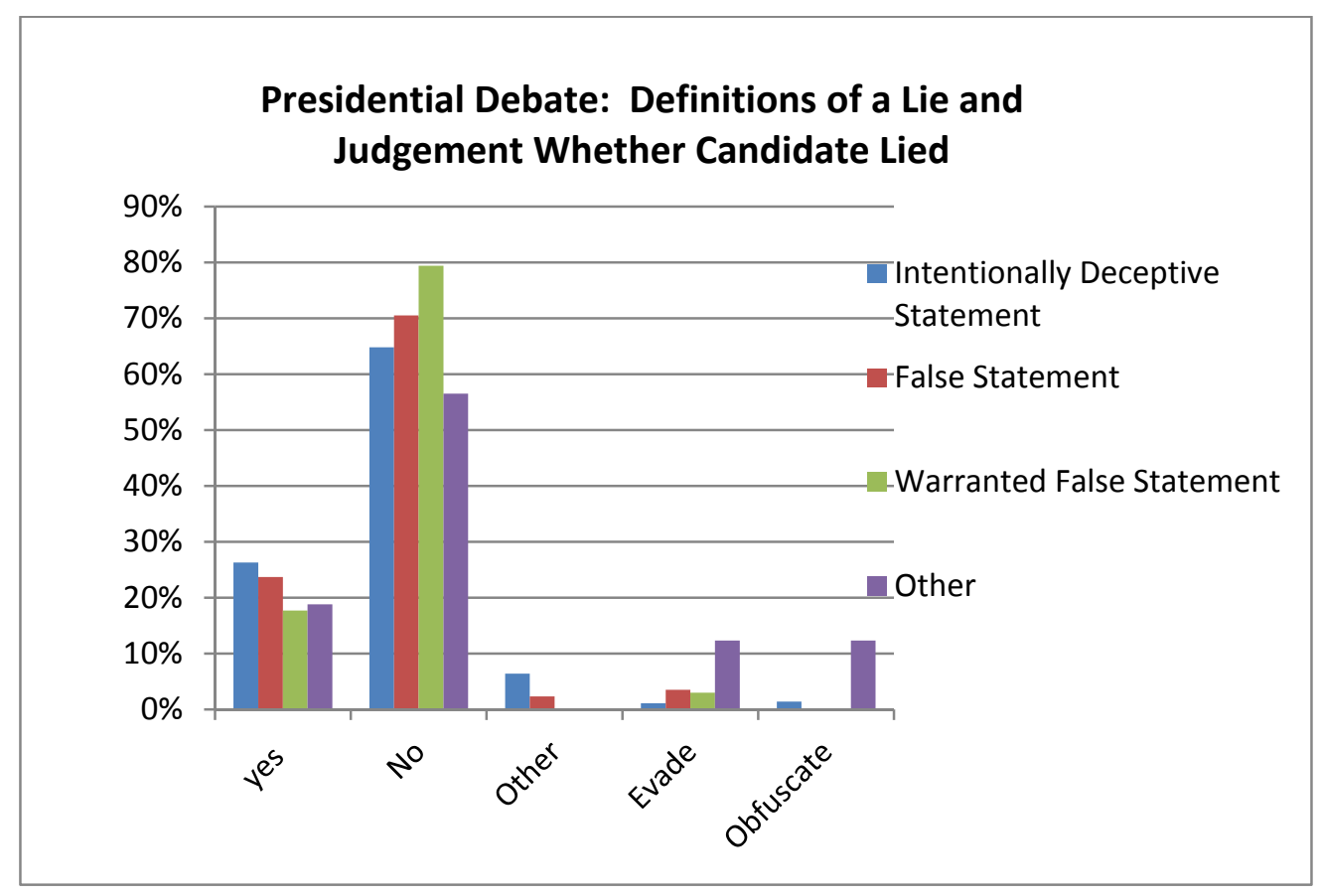


The respondents' preferred definition of a lie did not appear to significantly change the proportion of respondents who gave the presidential candidate's statement a particular assessment. All staff-weighted respondents were similar in their assessment of the case regardless of the definition of lie they preferred.

$64.8 \%$ of all staff-weighted who indicated that a lie was any intentionally deceptive statement indicated that the presidential candidate did not a lie while $26.3 \%$ believed it was a lie. $70.5 \%$ of all staff-weighted who indicated a lie was a false statement intended to deceive someone also indicated that the candidate did not lie, while $23.7 \%$ believed it was a lie. $79.4 \%$ of all staff-weighted who indicated a lie was a warranted false statement indicated that the candidate did not lie, while $17.7 \%$ believed it was a lie.

The two-sample, two-tailed t-statistic for the difference in proportions between those who indicated a lie was an intentionally deceptive statement and those who indicated that a lie was a warranted false statement and who indicated that the candidate lied was not significant at the .05 level, $t(151)=-1.72, p=.09$. The two-sample, two-tailed t-statistic was also not significant at the .05 level for the difference in proportions between those who indicated a lie was a warranted false statement and those who indicated "other," $t(45)=1.24, p=.22$. In both cases, the null hypothesis that there was no difference in proportion could not be rejected. 


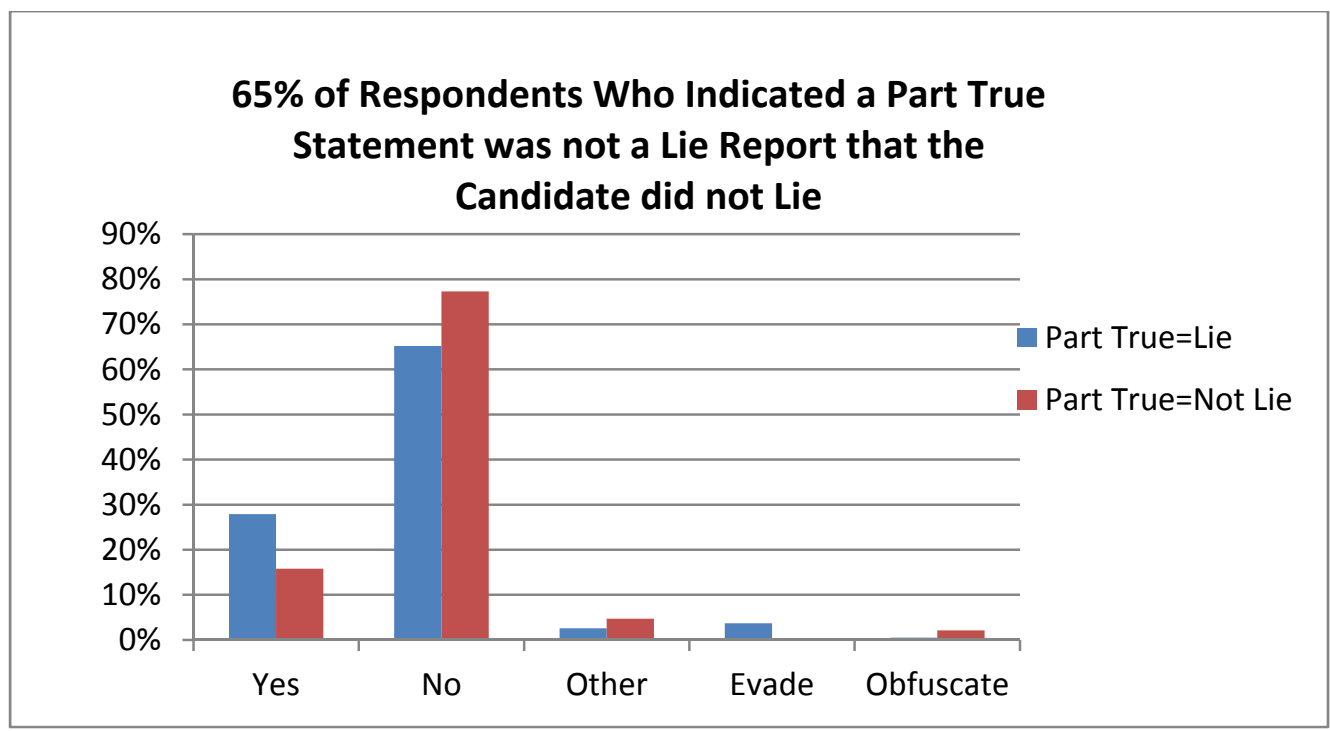

Respondents were filtered to include only those who indicated earlier in the survey that a statement that is partly true but which omits relevant facts or opinions that would lead reasonable people to different conclusions than the author wants them to reach was a lie. Only $27.9 \%$ of these respondents indicated that the candidate lied.

$77.3 \%$ of individuals who indicated that a partly true statement was not a lie indicated that the candidate did not lie, while $15.8 \%$ indicated that the candidate did lie. The twosample, two-tailed t-statistic was significant at the .05 level for the difference in proportions between all staff-weighted who believed that the candidate told a lie, $t(225)=2.01, p=.04$, but not for the difference in proportions between all staff-weighted respondents who did not believe that the candidate told a lie, $t(225)=-1.86, p=.064$.

$27.1 \%$ of the all staff-weighted who indicated that the candidate had not told a lie (and who previously indicated that a partly true statement was a lie) contradicted themselves by responding that this was not a lie because the candidate "did not say anything he did 
not believe" and "a statement that is partly true but which omits relevant facts or opinions that might lead people to a different conclusion than the one you want them to reach is not a lie."

Among all staff-weighted who indicated previously that a partly true statement was not a lie, $53.5 \%$ confirmed this explanation when deciding the candidate case, $14.4 \%$ suggested that the candidate had not lied because it was a "gotcha question designed to make the candidate look bad" and "a false statement that is made to someone seeking information that you believe they will unfairly or unjustly use against you is not a lie." Thirty percent of the respondents who previously indicated a part true statement was not a lie decided the candidate case by indicating that the "statement was not false."

$54.4 \%$ of the all staff-weighted respondents who indicated that the candidate did not lie indicated that the "statement is not false." $12.3 \%$ of all staff-weighted respondents who indicated this was not a lie thought this was a "gotcha" question and that a "false statement that is made to someone seeking information that you believe they will unfairly or unjustly use against you is not a lie." 


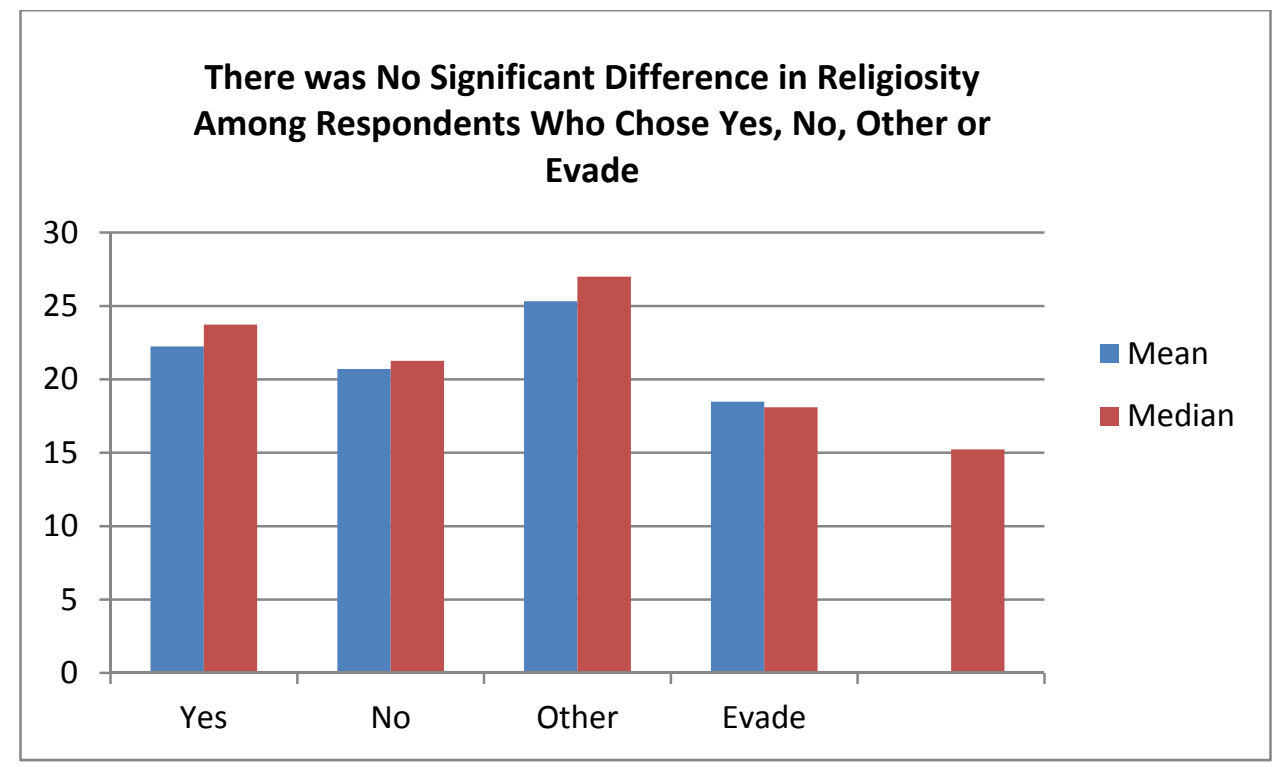

All staff-weighted respondents were evaluated for mean and median religiosity to determine whether there were any statistically significant differences. The two-sample, two-tailed t-statistic for the difference in mean religiosity between staff who answered "yes" and staff who answered "no" was not significant at the .05 level, $t(208)=1.226$, $p=.22$. The Mann-Whitney $\mathrm{U}$ Test also revealed no significant difference in religiosity between staff who answered "yes" $(M d n=23.74, n=52)$ and staff who answered "no" $(M d n=21.26, n=158), U=3512.5, z=-1.316, p=.188$. The null hypothesis that there was no difference in religiosity cannot be rejected.

Stennis Fellows who responded "yes" had higher religiosity scores $(M=24.1, M d n=26)$ than those who responded "no" $(M=20.3, M d n=20)$. The two-sample, two-tailed tstatistic for the difference in religiosity between those who answered "yes" and those who answered "no" was significant at the .05 level, $t(80)=2.2, p=.03$. The MannWhitney U Test also revealed a significant difference in religiosity between fellows who 
indicated this was a lie $(M d n=26, n=21)$ and fellows who indicated this was not a lie $(M d n=20, n=61), U=447.5, z=-2.053, p=.040$.

\section{$56 \%$ of Fellows Who Indicated a Part True Statement was a Lie Responded that the Candidate did not Lie}

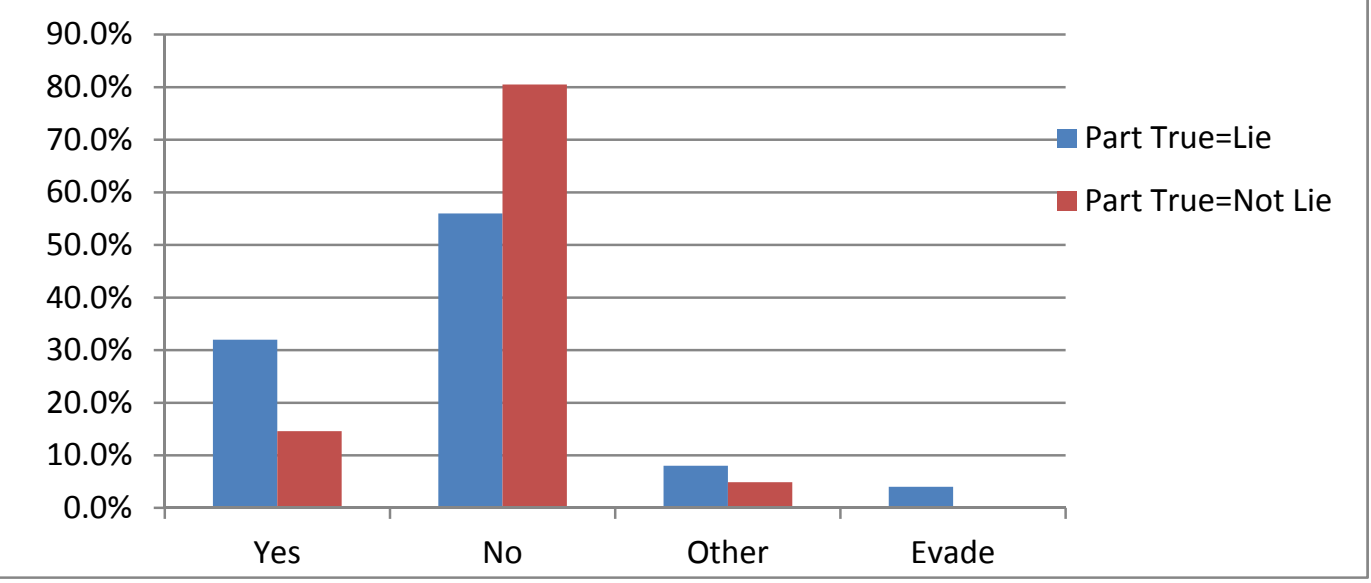

Fifty-six percent of fellows who indicated that a statement that "is partly true but which omits relevant facts or opinions" constituted a lie indicated that the candidate did not lie, while $32 \%$ indicated that it was a lie. $80.5 \%$ of individuals who indicated that a partly true statement was not a lie indicated that the candidate did not tell a lie while $14.6 \%$ indicated it was a lie. The two-sample, two-tailed t-statistic was significant at the .05 level for the difference between fellows who believed that the candidate did not tell a lie, $t(89)=-2.47, p=.015$, but not for the difference between fellows who believed the candidate told a lie, $t(89)=1.93, p=.057$.

$63.9 \%$ of fellows who indicated that a lie was "any intentionally deceptive statement" indicated that they did not believe that the candidate lied. Interestingly, roughly $25 \%$ of fellows who selected each definition believed that the candidate lied. The definition of a 
lie did not appear to have a significant impact on the percentage of fellows who judged the candidate to be lying.

Case 7. In a televised presidential debate, a candidate is asked the following question;

\begin{tabular}{|c|c|c|c|c|c|c|}
\hline \multicolumn{3}{|c|}{ Chamber } & \multirow{2}{*}{$\frac{\text { Frequency }}{28}$} & \multirow{2}{*}{$\frac{\text { Percent }}{15.1}$} & \multirow{2}{*}{$\frac{\text { Valid Percent }}{23.9}$} & \multirow{2}{*}{$\begin{array}{c}\text { Cumulative } \\
\text { Percent } \\
23.9\end{array}$} \\
\hline House & Valid & Yes & & & & \\
\hline & & No & 81 & 43.8 & 69.2 & 93.2 \\
\hline & & Other & 4 & 2.2 & 3.4 & 96.6 \\
\hline & & Evade & 4 & 2.2 & 3.4 & 100.0 \\
\hline & & Total & 117 & 63.2 & 100.0 & \\
\hline & Missing & System & 68 & 36.8 & & \\
\hline & Total & & 185 & 100.0 & & \\
\hline \multirow[t]{8}{*}{ Senate } & Valid & Yes & 26 & 14.6 & 23.2 & 23.2 \\
\hline & & No & 77 & 43.3 & 68.8 & 92.0 \\
\hline & & Other & 5 & 2.8 & 4.5 & 96.4 \\
\hline & & Evade & 1 & .6 & .9 & 97.3 \\
\hline & & Obfuscate & 3 & 1.7 & 2.7 & 100.0 \\
\hline & & Total & 112 & 62.9 & 100.0 & \\
\hline & Missing & System & 66 & 37.1 & & \\
\hline & Total & & 178 & 100.0 & & \\
\hline
\end{tabular}

Case 7. In a televised presidential debate, a candidate is asked the following question;

\begin{tabular}{llrrrr}
\hline \hline All Staff-weighted & Frequency & Percent & Valid Percent & \multicolumn{2}{c}{ Cumulative } \\
Percent
\end{tabular}

Case 7. In a televised presidential debate, a candidate is asked the following question;

\begin{tabular}{|c|c|c|c|c|c|}
\hline \multicolumn{2}{|c|}{$\begin{array}{l}\text { All Staff- } \\
\text { unweighted }\end{array}$} & \multirow{2}{*}{$\frac{\text { Frequency }}{54}$} & \multirow{2}{*}{$\frac{\text { Percent }}{14.9}$} & \multirow{2}{*}{$\frac{\text { Valid Percent }}{23.6}$} & \multirow{2}{*}{$\frac{\begin{array}{c}\text { Cumulative } \\
\text { Percent }\end{array}}{23.6}$} \\
\hline Valid & Yes & & & & \\
\hline & No & 158 & 43.5 & 69.0 & 92.6 \\
\hline & Other & 9 & 2.5 & 3.9 & 96.5 \\
\hline & Evade & 5 & 1.4 & 2.2 & 98.7 \\
\hline & Obfuscate & 3 & .8 & 1.3 & 100.0 \\
\hline & Total & 229 & 63.1 & 100.0 & \\
\hline
\end{tabular}




\begin{tabular}{|c|c|c|c|}
\hline Missing & System & 134 & 36.9 \\
\hline Total & & 363 & 100.0 \\
\hline
\end{tabular}

Case 7. In a televised presidential debate, a candidate is asked the following question; "I want to...

\begin{tabular}{llcccc}
\hline \hline Stennis Fellows & Frequency & Percent & Valid Percent & $\begin{array}{c}\text { Cumulative } \\
\text { Percent }\end{array}$ \\
\hline Valid & Yes & 22 & 18.0 & 23.7 & 23.7 \\
& No & 62 & 50.8 & 66.7 & 90.3 \\
& Other & 7 & 5.7 & 7.5 & 97.8 \\
& Evade & 2 & 1.6 & 2.2 & 100.0 \\
& Total & 93 & 76.2 & 100.0 & \\
Missing & System & 29 & 23.8 & & \\
Total & & 122 & 100.0 & & \\
\hline \hline
\end{tabular}

\section{Presidential Debate: Did you answer yes because (choose the most important answer)}

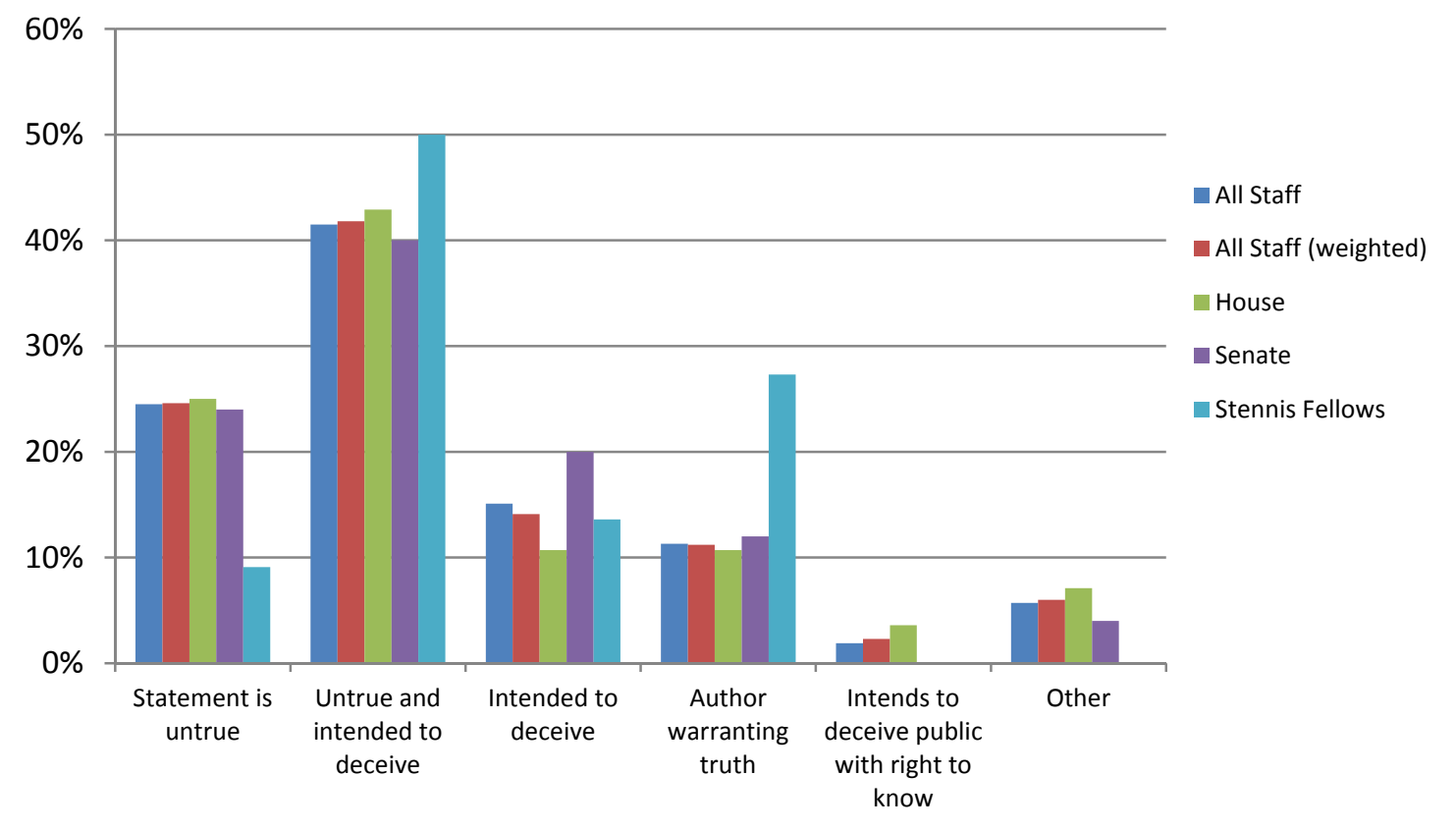

Fifty-four all staff-weighted respondents indicated that the presidential candidate lied.

Forty-two percent of these respondents indicated that the statement was untrue and intended to deceive the audience. Twenty-five percent offered the explanation that they 
thought that the statement was untrue. $72.4 \%$ of the respondents who indicated that their assessment rested on the idea that the statement was both untrue and intended to deceive the public had earlier indicated that their preferred definition of a lie was "any intentionally deceptive statement."

Did you answer yes because (choose the answer that most closely reflects your view)

\begin{tabular}{|c|c|c|c|c|c|c|}
\hline \multicolumn{3}{|c|}{ Chamber } & \multirow{2}{*}{$\frac{\text { Frequency }}{184}$} & \multirow{2}{*}{$\frac{\text { Percent }}{99.5}$} & \multirow{2}{*}{$\begin{array}{c}\text { Valid Percent } \\
99.5\end{array}$} & \multirow{2}{*}{$\begin{array}{c}\begin{array}{c}\text { Cumulative } \\
\text { Percent }\end{array} \\
99.5\end{array}$} \\
\hline House & Valid & & & & & \\
\hline & & $\begin{array}{l}\text { a direct question deserves a } \\
\text { direct truth or a direct } \\
\text { statement of "I am not } \\
\text { saying" }\end{array}$ & 1 & .5 & .5 & 100.0 \\
\hline & & Total & 185 & 100.0 & 100.0 & \\
\hline \multirow[t]{3}{*}{ Senate } & Valid & & 177 & 99.4 & 99.4 & 99.4 \\
\hline & & $\begin{array}{l}\text { There is a contradiction in } \\
\text { his statements--the } \\
\text { candidate is either lying to } \\
\text { the activists or the audience }\end{array}$ & 1 & .6 & .6 & 100.0 \\
\hline & & Total & 178 & 100.0 & 100.0 & \\
\hline
\end{tabular}

Did you answer yes because (choose the answer that most closely reflects your view)

\begin{tabular}{|c|c|c|c|c|c|}
\hline \multicolumn{2}{|c|}{ All Staff-Weighted } & \multirow{2}{*}{$\frac{\text { Frequency }}{13}$} & \multirow{2}{*}{$\frac{\text { Percent }}{3.6}$} & \multirow{2}{*}{$\frac{\text { Valid Percent }}{24.6}$} & \multirow{2}{*}{$\begin{array}{r}\begin{array}{l}\text { Cumulative } \\
\text { Percent }\end{array} \\
24.6\end{array}$} \\
\hline Valid & The statement is untrue & & & & \\
\hline & $\begin{array}{l}\text { The statement is untrue and } \\
\text { is intended to deceive the } \\
\text { public }\end{array}$ & 22 & 6.2 & 41.8 & 66.4 \\
\hline & $\begin{array}{l}\text { The statement is intended to } \\
\text { deceive the public. It doesn't } \\
\text { matter whether it is true or } \\
\text { false. }\end{array}$ & 8 & 2.1 & 14.1 & 80.6 \\
\hline & $\begin{array}{l}\text { The author is } \\
\text { warranting/claiming as true } \\
\text { something he does not } \\
\text { believe in order to deceive } \\
\text { the public at a time and } \\
\text { place where people should } \\
\text { be able to expect to be given } \\
\text { truthful statements }\end{array}$ & 6 & 1.6 & 11.2 & 91.8 \\
\hline
\end{tabular}




\begin{tabular}{|c|c|c|c|c|c|}
\hline & $\begin{array}{l}\text { The author intends to } \\
\text { deceive the audience which } \\
\text { has a right to know the truth. } \\
\text { It would not be a lie if the } \\
\text { individual did not have a } \\
\text { right to the truth. }\end{array}$ & 1 & .3 & 2.3 & 94.0 \\
\hline & Other & 3 & .9 & 6.0 & 100.0 \\
\hline & Total & 54 & 14.7 & 100.0 & \\
\hline Missing & System & 311 & 85.3 & & \\
\hline Total & & 364 & 100.0 & & \\
\hline
\end{tabular}

Did you answer yes because (choose the answer that most closely reflects your view)

\begin{tabular}{|c|c|c|c|c|c|}
\hline \multicolumn{2}{|c|}{ All Staff-unweighted } & \multirow{2}{*}{$\frac{\text { Frequency }}{13}$} & \multirow{2}{*}{$\frac{\text { Percent }}{3.6}$} & \multirow{2}{*}{$\frac{\text { Valid Percent }}{24.5}$} & \multirow{2}{*}{$\begin{array}{c}\begin{array}{c}\text { Cumulative } \\
\text { Percent }\end{array} \\
24.5\end{array}$} \\
\hline Valid & The statement is untrue & & & & \\
\hline & $\begin{array}{l}\text { The statement is untrue and } \\
\text { is intended to deceive the } \\
\text { public }\end{array}$ & 22 & 6.1 & 41.5 & 66.0 \\
\hline & $\begin{array}{l}\text { The statement is intended to } \\
\text { deceive the public. It doesn't } \\
\text { matter whether it is true or } \\
\text { false. }\end{array}$ & 8 & 2.2 & 15.1 & 81.1 \\
\hline & $\begin{array}{l}\text { The author is } \\
\text { warranting/claiming as true } \\
\text { something he does not } \\
\text { believe in order to deceive } \\
\text { the public at a time and } \\
\text { place where people should } \\
\text { be able to expect to be given } \\
\text { truthful statements }\end{array}$ & 6 & 1.7 & 11.3 & 92.5 \\
\hline & $\begin{array}{l}\text { The author intends to } \\
\text { deceive the audience which } \\
\text { has a right to know.the truth. } \\
\text { It would not be a lie if the } \\
\text { individual did not have a } \\
\text { right to the truth. }\end{array}$ & 1 & .3 & 1.9 & 94.3 \\
\hline & Other & 3 & .8 & 5.7 & 100.0 \\
\hline & Total & 53 & 14.6 & 100.0 & \\
\hline Missing & System & 310 & 85.4 & & \\
\hline Total & & 363 & 100.0 & & \\
\hline
\end{tabular}

Did you answer yes because (choose the answer that most closely reflects your view)

\begin{tabular}{lccccc}
\hline \hline Stennis Fellows & Frequency & Percent & Valid Percent & $\begin{array}{c}\text { Cumulative } \\
\text { Percent }\end{array}$ \\
\hline Valid & The statement is untrue & 2 & 1.6 & 9.1 & 9.1
\end{tabular}




$\begin{aligned} & \text { The statement is untrue and } \\ & \text { is intended to deceive the } \\ & \text { public }\end{aligned}$
$\begin{aligned} & \text { The statement is intended to } \\ & \text { deceive the public. It doesn't } \\ & \text { matter whether it is true or } \\ & \text { false. }\end{aligned}$
$\begin{aligned} & \text { The author is } \\ & \text { warranting/claiming as true } \\ & \text { something he does not } \\ & \text { believe in order to deceive } \\ & \text { the public at a time and } \\ & \text { place where people should } \\ & \text { be able to expect to be given } \\ & \text { truthful statements }\end{aligned}$
$\begin{aligned} & \text { Total } \\ & \text { System }\end{aligned}$

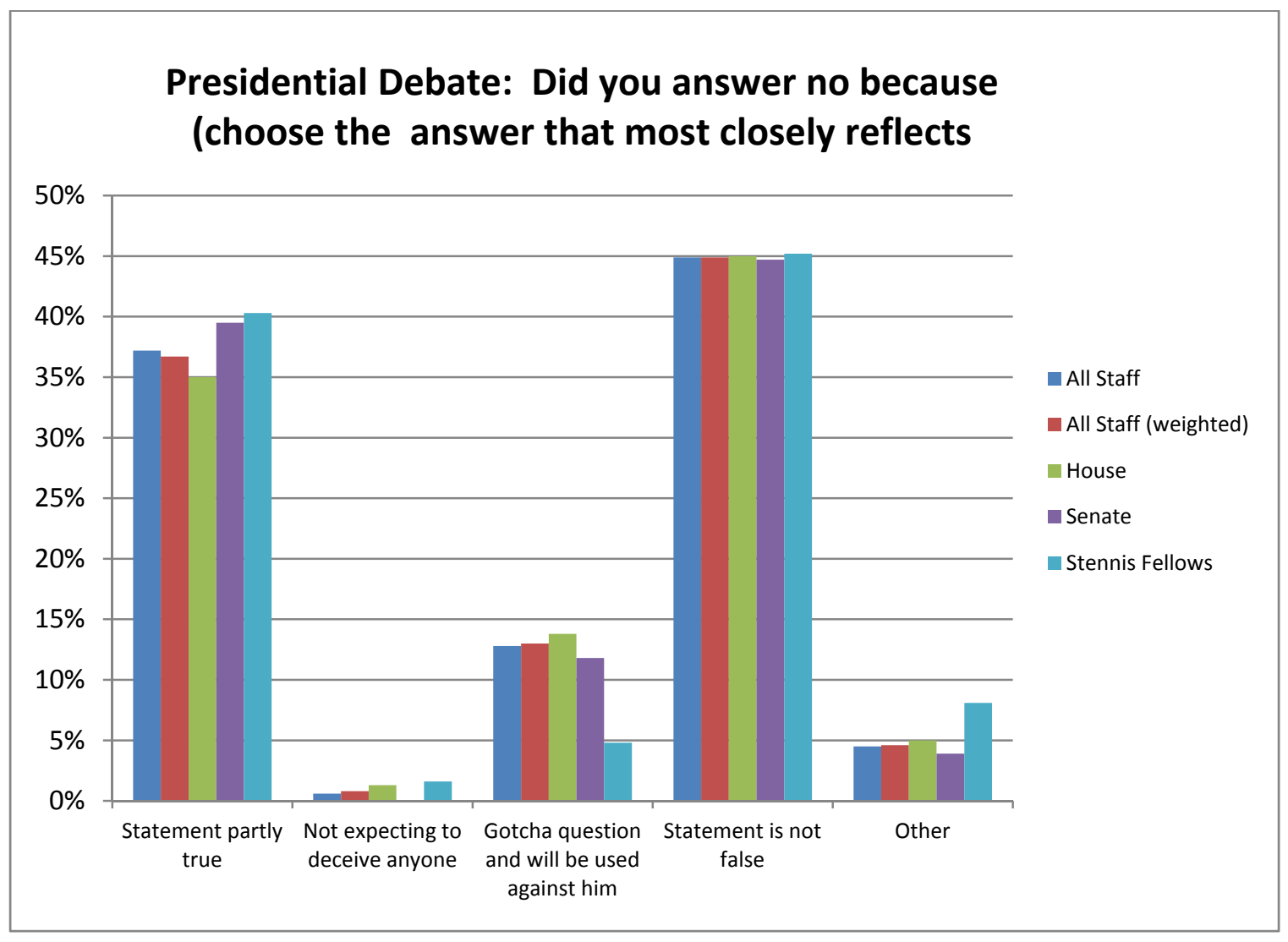


Respondents were consistent across groups in the reasons they preferred for their assessment that the presidential candidate did not lie. Forty-five percent of respondents indicated that the statement was not false. Thirty-five percent to $40 \%$ of respondents indicated that a statement that is partly true but which omits relevant facts or opinions that might lead people to a different conclusion than the one you want them to reach is not a lie.

$44.4 \%$ of the all staff-weighted respondents who indicated that a partly true statement is not a lie, had earlier indicated that their preferred definition of a lie was "any intentionally deceptive statement."

All staff-weighted respondents who selected the "statement is partly true" had lower religiosity scores $(M=19.114, M d n=18)$ than those who indicated that this was a "gotcha question" $(M=23.34, M d n=23)$ or respondents who indicated that the statement is not false $(M=21.02, M d n=22)$. The two-sample, two-tailed t-statistic was significant at the .05 level for the difference in median religiosity scores for those who selected "partly true" and those who selected "gotcha question." One possibility for this difference is that the question may carry historic baggage for active members of religious communities.

\begin{tabular}{|c|c|c|c|c|}
\hline Chamber & Frequency & Percent & Valid Percent & $\begin{array}{c}\text { Cumulative } \\
\text { Percent }\end{array}$ \\
\hline
\end{tabular}




\begin{tabular}{|c|c|c|c|c|c|c|}
\hline \multirow[t]{8}{*}{ House } & Valid & $\begin{array}{l}\text { The candidate did not say } \\
\text { anything he didn't believe. A } \\
\text { statement that is partly true } \\
\text { but which omits relevant } \\
\text { facts or opinions that might } \\
\text { lead people to a different } \\
\text { conclusion than the one you } \\
\text { want them to reach is not a } \\
\text { lie. }\end{array}$ & 28 & 15.1 & 35.0 & 35.0 \\
\hline & & $\begin{array}{l}\text { The candidate knows that } \\
\text { people will not believe him. A } \\
\text { false statement that is not } \\
\text { expected to succeed in } \\
\text { deceiving anyone is not a lie. }\end{array}$ & 1 & .5 & 1.3 & 36.3 \\
\hline & & $\begin{array}{l}\text { It's a "gotcha question" } \\
\text { designed to make the } \\
\text { candidate look bad. A false } \\
\text { statement that is made to } \\
\text { someone seeking } \\
\text { information that you believe } \\
\text { they will unfairly or unjustly } \\
\text { use against you is not a lie. }\end{array}$ & 11 & 5.9 & 13.8 & 50.0 \\
\hline & & The statement is not false. & 36 & 19.5 & 45.0 & 95.0 \\
\hline & & Other & 4 & 2.2 & 5.0 & 100.0 \\
\hline & & Total & 80 & 43.2 & 100.0 & \\
\hline & Missing & System & 105 & 56.8 & & \\
\hline & Total & & 185 & 100.0 & & \\
\hline \multirow[t]{7}{*}{ Senate } & Valid & $\begin{array}{l}\text { The candidate did not say } \\
\text { anything he didn't believe. A } \\
\text { statement that is partly true } \\
\text { but which omits relevant } \\
\text { facts or opinions that might } \\
\text { lead people to a different } \\
\text { conclusion than the one you } \\
\text { want them to reach is not a } \\
\text { lie. }\end{array}$ & 30 & 16.9 & 39.5 & 39.5 \\
\hline & & $\begin{array}{l}\text { It's a "gotcha question" } \\
\text { designed to make the } \\
\text { candidate look bad. A false } \\
\text { statement that is made to } \\
\text { someone seeking } \\
\text { information that you believe } \\
\text { they will unfairly or unjustly } \\
\text { use against you is not a lie. }\end{array}$ & 9 & 5.1 & 11.8 & 51.3 \\
\hline & & The statement is not false. & 34 & 19.1 & 44.7 & 96.1 \\
\hline & & Other & 3 & 1.7 & 3.9 & 100.0 \\
\hline & & Total & 76 & 42.7 & 100.0 & \\
\hline & Missing & System & 102 & 57.3 & & \\
\hline & Total & & 178 & 100.0 & & \\
\hline
\end{tabular}


Did you answer no because (choose the answer that most closely reflects your view)--

\begin{tabular}{|c|c|c|c|c|c|}
\hline \multicolumn{2}{|c|}{ All Staff-weighted } & \multirow{2}{*}{$\frac{\text { Frequency }}{58}$} & \multirow{2}{*}{$\frac{\text { Percent }}{15.8}$} & \multirow{2}{*}{$\frac{\text { Valid Percent }}{36.7}$} & \multirow{2}{*}{$\begin{array}{c}\begin{array}{c}\text { Cumulative } \\
\text { Percent }\end{array} \\
36.7\end{array}$} \\
\hline Valid & $\begin{array}{l}\text { The candidate did not say } \\
\text { anything he didn't believe. A } \\
\text { statement that is partly true } \\
\text { but which omits relevant } \\
\text { facts or opinions that might } \\
\text { lead people to a different } \\
\text { conclusion than the one you } \\
\text { want them to reach is not a } \\
\text { lie. }\end{array}$ & & & & \\
\hline & $\begin{array}{l}\text { The candidate knows that } \\
\text { people will not believe him. A } \\
\text { false statement that is not } \\
\text { expected to succeed in } \\
\text { deceiving anyone is not a lie } \\
\text {. }\end{array}$ & 1 & .3 & .8 & 37.5 \\
\hline & $\begin{array}{l}\text { It's a "gotcha question" } \\
\text { designed to make the } \\
\text { candidate look bad. A false } \\
\text { statement that is made to } \\
\text { someone seeking } \\
\text { information that you believe } \\
\text { they will unfairly or unjustly } \\
\text { use against you is not a lie. }\end{array}$ & 20 & 5.6 & 13.0 & 50.5 \\
\hline & The statement is not false. & 70 & 19.3 & 44.9 & 95.4 \\
\hline & Other & 7 & 2.0 & 4.6 & 100.0 \\
\hline & Total & 157 & 43.0 & 100.0 & \\
\hline Missing & System & 208 & 57.0 & & \\
\hline Total & & 364 & 100.0 & & \\
\hline
\end{tabular}

Did you answer no because (choose the answer that most closely reflects your view)--

\begin{tabular}{|c|c|c|c|c|c|}
\hline \multicolumn{2}{|c|}{ All Staff-unweighted } & \multirow{2}{*}{$\frac{\text { Frequency }}{58}$} & \multirow{2}{*}{$\frac{\text { Percent }}{16.0}$} & \multirow{2}{*}{$\frac{\text { Valid Percent }}{37.2}$} & \multirow{2}{*}{$\begin{array}{c}\begin{array}{c}\text { Cumulative } \\
\text { Percent }\end{array} \\
37.2\end{array}$} \\
\hline Valid & $\begin{array}{l}\text { The candidate did not say } \\
\text { anything he didn't believe. A } \\
\text { statement that is partly true } \\
\text { but which omits relevant } \\
\text { facts or opinions that might } \\
\text { lead people to a different } \\
\text { conclusion than the one you } \\
\text { want them to reach is not a } \\
\text { lie. }\end{array}$ & & & & \\
\hline & $\begin{array}{l}\text { The candidate knows that } \\
\text { people will not believe him. A } \\
\text { false statement that is not } \\
\text { expected to succeed in } \\
\text { deceiving anyone is not a lie. }\end{array}$ & 1 & .3 & .6 & 37.8 \\
\hline
\end{tabular}




\begin{tabular}{|c|c|c|c|c|c|}
\hline & $\begin{array}{l}\text { It's a "gotcha question" } \\
\text { designed to make the } \\
\text { candidate look bad. A false } \\
\text { statement that is made to } \\
\text { someone seeking } \\
\text { information that you believe } \\
\text { they will unfairly or unjustly } \\
\text { use against you is not a lie. }\end{array}$ & 20 & 5.5 & 12.8 & 50.6 \\
\hline & The statement is not false. & 70 & 19.3 & 44.9 & 95.5 \\
\hline & Other & 7 & 1.9 & 4.5 & 100.0 \\
\hline & Total & 156 & 43.0 & 100.0 & \\
\hline Missing & System & 207 & 57.0 & & \\
\hline Total & & 363 & 100.0 & & \\
\hline
\end{tabular}

Did you answer no because (choose the answer that most closely reflects your view)--

\begin{tabular}{|c|c|c|c|c|c|}
\hline \multicolumn{2}{|c|}{ Stennis Fellows } & \multirow{2}{*}{$\frac{\text { Frequency }}{25}$} & \multirow{2}{*}{$\frac{\text { Percent }}{20.5}$} & \multirow{2}{*}{$\frac{\text { Valid Percent }}{40.3}$} & \multirow{2}{*}{$\begin{array}{c}\begin{array}{c}\text { Cumulative } \\
\text { Percent }\end{array} \\
40.3\end{array}$} \\
\hline Valid & $\begin{array}{l}\text { The candidate did not say } \\
\text { anything he didn't believe. A } \\
\text { statement that is partly true } \\
\text { but which omits relevant } \\
\text { facts or opinions that might } \\
\text { lead people to a different } \\
\text { conclusion than the one you } \\
\text { want them to reach is not a } \\
\text { lie. }\end{array}$ & & & & \\
\hline & $\begin{array}{l}\text { The candidate knows that } \\
\text { people will not believe him. A } \\
\text { false statement that is not } \\
\text { expected to succeed in } \\
\text { deceiving anyone is not a lie. }\end{array}$ & 1 & .8 & 1.6 & 41.9 \\
\hline & $\begin{array}{l}\text { It's a "gotcha question" } \\
\text { designed to make the } \\
\text { candidate look bad. A false } \\
\text { statement that is made to } \\
\text { someone seeking } \\
\text { information that you believe } \\
\text { they will unfairly or unjustly } \\
\text { use against you is not a lie. }\end{array}$ & 3 & 2.5 & 4.8 & 46.8 \\
\hline & The statement is not false. & 28 & 23.0 & 45.2 & 91.9 \\
\hline & Other & 5 & 4.1 & 8.1 & 100.0 \\
\hline & Total & 62 & 50.8 & 100.0 & \\
\hline Missing & System & 60 & 49.2 & & \\
\hline Total & & 122 & 100.0 & & \\
\hline
\end{tabular}




\section{Stennis Fellows}

\begin{tabular}{|c|c|c|c|}
\hline \multirow[t]{7}{*}{ Yes } & \multirow[t]{2}{*}{$\mathrm{N}$} & Valid & 21 \\
\hline & & Missing & 1 \\
\hline & \multicolumn{2}{|c|}{ Mean } & 24.143 \\
\hline & \multicolumn{2}{|c|}{ Median } & 26.000 \\
\hline & \multicolumn{2}{|c|}{ Mode } & $26.0^{a}$ \\
\hline & \multicolumn{2}{|c|}{ Std. Deviation } & 6.9662 \\
\hline & \multicolumn{2}{|c|}{ Variance } & 48.529 \\
\hline \multirow[t]{7}{*}{ No } & \multirow[t]{2}{*}{$\mathrm{N}$} & Valid & 61 \\
\hline & & Missing & 1 \\
\hline & \multicolumn{2}{|c|}{ Mean } & 20.311 \\
\hline & \multicolumn{2}{|c|}{ Median } & 20.000 \\
\hline & \multicolumn{2}{|c|}{ Mode } & $17.0^{\mathrm{a}}$ \\
\hline & \multicolumn{2}{|c|}{ Std. Deviation } & 6.8229 \\
\hline & \multicolumn{2}{|c|}{ Variance } & 46.551 \\
\hline \multirow[t]{7}{*}{ Other } & \multirow[t]{2}{*}{$\mathrm{N}$} & Valid & 7 \\
\hline & & Missing & 0 \\
\hline & \multicolumn{2}{|c|}{ Mean } & 21.714 \\
\hline & \multicolumn{2}{|c|}{ Median } & 21.000 \\
\hline & \multicolumn{2}{|c|}{ Mode } & $6.0^{\mathrm{a}}$ \\
\hline & \multicolumn{2}{|c|}{ Std. Deviation } & 9.6904 \\
\hline & \multicolumn{2}{|c|}{ Variance } & 93.905 \\
\hline \multirow[t]{7}{*}{ Evade } & \multirow[t]{2}{*}{$\mathrm{N}$} & Valid & 2 \\
\hline & & Missing & 0 \\
\hline & \multicolumn{2}{|c|}{ Mean } & 31.500 \\
\hline & \multicolumn{2}{|c|}{ Median } & 31.500 \\
\hline & \multicolumn{2}{|c|}{ Mode } & $30.0^{\mathrm{a}}$ \\
\hline & \multicolumn{2}{|c|}{ Std. Deviation } & 2.1213 \\
\hline & \multicolumn{2}{|c|}{ Variance } & 4.500 \\
\hline
\end{tabular}

a. Multiple modes exist. The smallest value is shown 


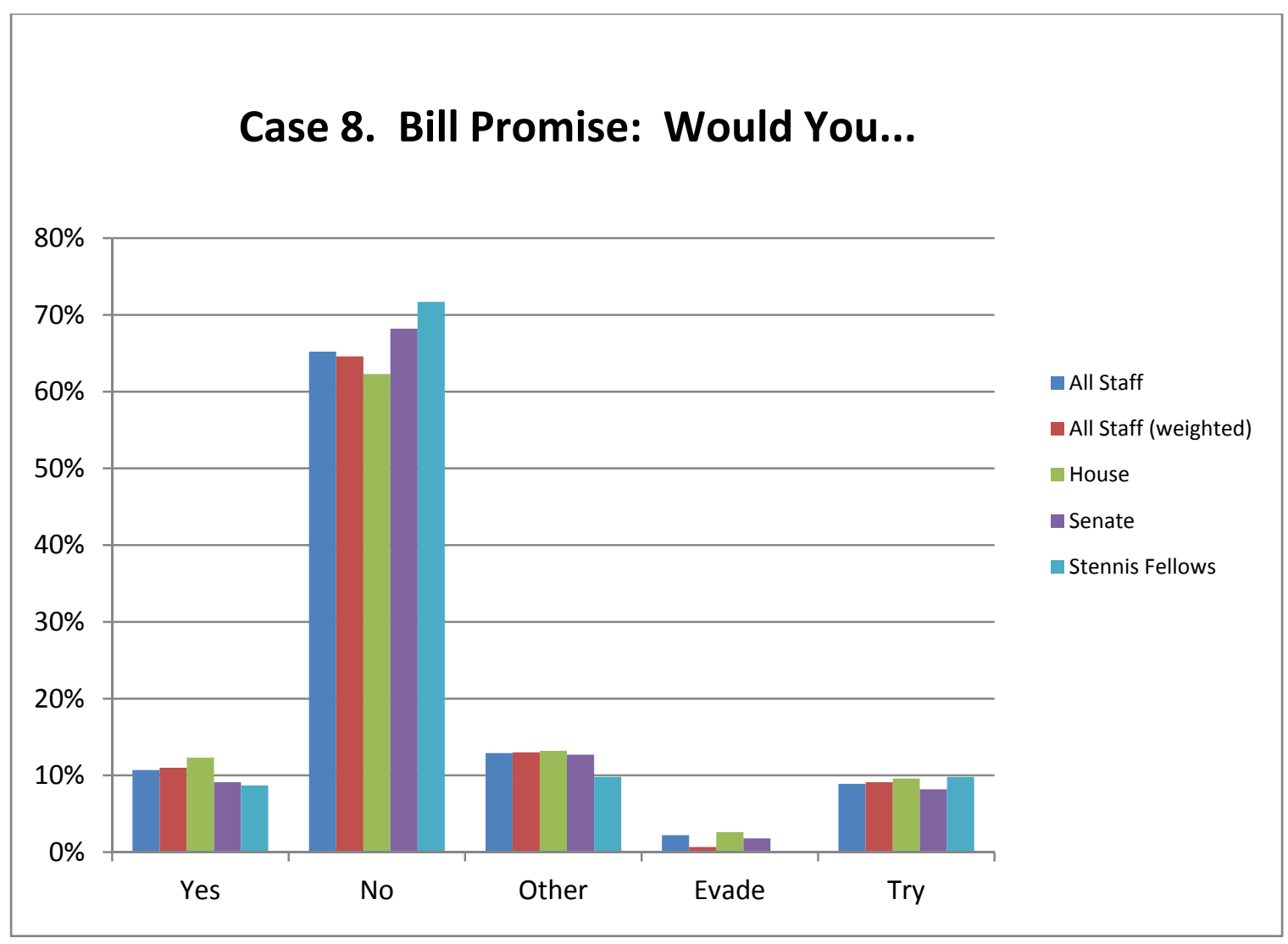

The bill promise case presented respondents with a scenario in which they were invited to make a promise they knew they could not keep. The scenario was followed with a social desirability bias question that asked respondents how they thought the staff member with whom they were conversing would respond if their roles were reversed. As with previous cases, the respondents were asked to respond "yes," "no," or "other."

"You work for the influential chairman of a House/Senate committee. It is February of an election year and one of your committee's major bills is stuck in the other body. You meet with the staff of the other body's committee of jurisdiction. Both sides have accused the other of not acting in good faith. After several years refusing to act, they promise to bring your bill to the floor immediately but only if you will promise to pass a bill they are redrafting but hope to move in April. You know that your leadership opposes their bill and will never allow it to come to the floor. Would you tell them that you will pass their bill?" 
Sixty-two percent to $72 \%$ of respondents indicated that they would not make this promise, while $9 \%$ to $12 \%$ of respondents indicated they would make the promise. "Other" responses were examined and reclassified as "other," "evade," and a new category- “try." The new category reflects a strategy through which the staff member promises best effort rather than passage.

Confidence intervals were calculated for each of the respondent groups. The widest confidence interval for the House was $\pm 9 \%$, for the Senate was $\pm 8.8 \%$, for all staffweighted was $\pm 6.2 \%$ and for Stennis Fellows was $\pm 7.5 \%$.

Stennis Fellows (71.7\%) were more likely to answer "no" than House $(62.3 \%)$ or Senate $(68.2 \%)$ staff or all staff-weighted (64.6\%). The two-sample, two-tailed t-statistic was not significant at the .05 level for the difference between Stennis Fellows and House staff, $t(204)=1.42, p=.16$ or for the difference between Stennis Fellows and all staffweighted, $t(204)=1.22, p=.22$. In neither case can the null hypothesis that there is no difference in the proportions be rejected. 


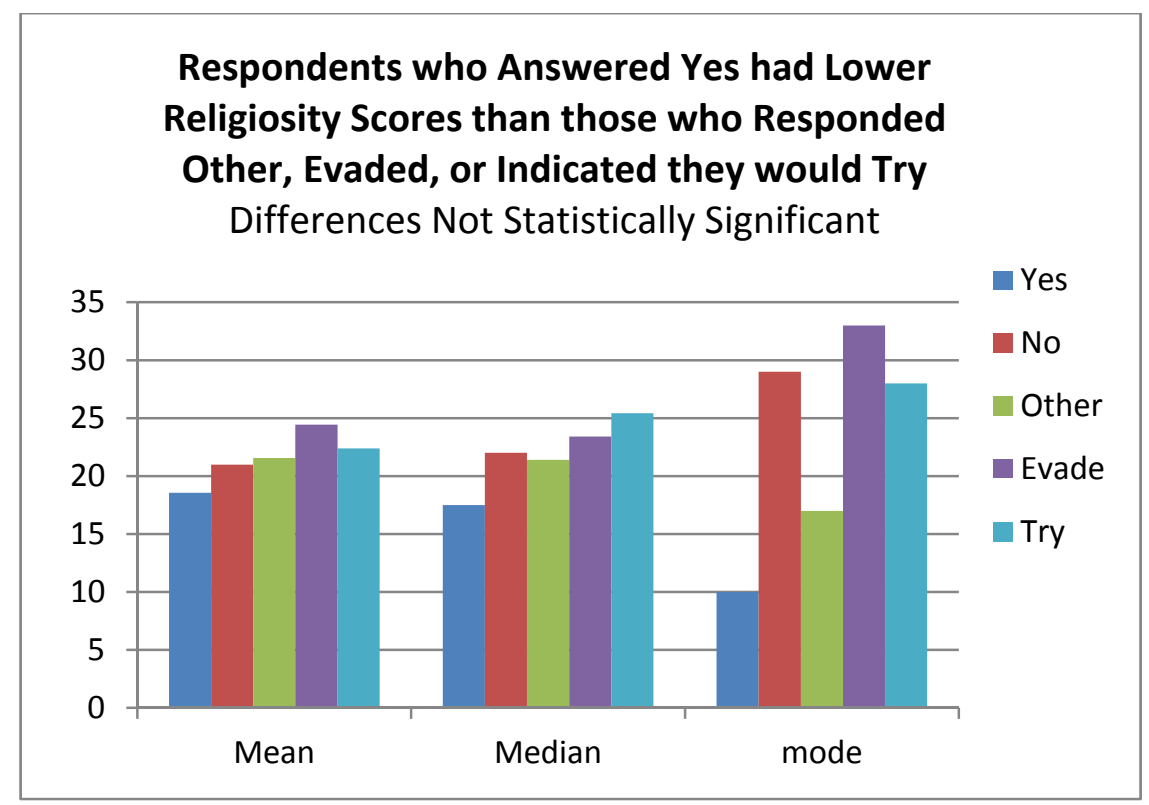

All staff-weighted who responded "yes" had lower religiosity scores $(M=18.6$, $M d n=17.5)$ than those who responded "no" $(M=21, M d n=22)$, "other" $(M=21.6$, $M d n=21.4)$, "evade" $(M=24.4, M d n=23.4)$, or those who indicated they would try $(M=22.4, M d n=25.4)$. The two-sample, two-tailed t-statistic for the difference in mean religiosity was not significant at the .05 level between those who responded "yes" and those who responded "no," $t(165)=1.5, p=.15$; for the difference in mean religiosity between those who responded "yes" and those who responded they would "try," $t(43)=$ $1.74, p=.09$; for those who responded "yes" and those who responded "other," $t(50)=$ $1.46, p=.15$; or between those who responded "yes" and those who attempted to "evade," $t(28)=1.616, p=.12$. The Mann-Whitney $\mathrm{U}$ Test also revealed no significant difference in religiosity between staff who responded "yes" and staff who responded "no," $U=1367$, $z=-1.594, p=.111$. 
Stennis Fellows who answered "yes" $(M=20.25, M d n=19)$ had nominally lower religiosity scores than fellows who answered "no" $(M=20.56, \mathrm{Mdn}=22)$. The twosample, two-tailed t-statistic was not significant for the difference in mean religiosity, $t(70)=0.576, p=.5664$. The Mann-Whitney $\mathrm{U}$ Test also revealed no significant difference in religiosity between the two groups, $U=214.5, z=-.745, p=.456$.

Case 8. You work for the influential chairman of a House/Senate committee.

\begin{tabular}{|c|c|c|c|c|c|c|}
\hline \multicolumn{3}{|c|}{ Chamber } & \multirow{2}{*}{$\frac{\text { Frequency }}{14}$} & \multirow{2}{*}{$\frac{\text { Percent }}{7.6}$} & \multirow{2}{*}{$\frac{\text { Valid Percent }}{12.3}$} & \multirow{2}{*}{$\begin{array}{c}\text { Cumulative } \\
\text { Percent }\end{array}$} \\
\hline House & Valid & Yes & & & & \\
\hline & & No & 71 & 38.4 & 62.3 & 74.6 \\
\hline & & Other & 15 & 8.1 & 13.2 & 87.7 \\
\hline & & Evade & 3 & 1.6 & 2.6 & 90.4 \\
\hline & & Try & 11 & 5.9 & 9.6 & 100.0 \\
\hline & & Total & 114 & 61.6 & 100.0 & \\
\hline & Missing & System & 71 & 38.4 & & \\
\hline & Total & & 185 & 100.0 & & \\
\hline \multirow[t]{8}{*}{ Senate } & Valid & Yes & 10 & 5.6 & 9.1 & 9.1 \\
\hline & & No & 75 & 42.1 & 68.2 & 77.3 \\
\hline & & Other & 14 & 7.9 & 12.7 & 90.0 \\
\hline & & Evade & 2 & 1.1 & 1.8 & 91.8 \\
\hline & & Try & 9 & 5.1 & 8.2 & 100.0 \\
\hline & & Total & 110 & 61.8 & 100.0 & \\
\hline & Missing & System & 68 & 38.2 & & \\
\hline & Total & & 178 & 100.0 & & \\
\hline
\end{tabular}

Case 8. You work for the influential chairman of a House/Senate committee.

\begin{tabular}{llcccc}
\hline \hline All Staff-weighted & Frequency & Percent & Valid Percent & $\begin{array}{c}\text { Cumulative } \\
\text { Percent }\end{array}$ \\
\hline Valid & Yes & 25 & 6.8 & 11.0 & 11.0 \\
& No & 145 & 39.8 & 64.6 & 75.6 \\
& Other & 29 & 8.0 & 13.0 & 88.6 \\
& Evade & 5 & 1.4 & 2.3 & 90.9 \\
& Try & 20 & 5.6 & 9.1 & 100.0 \\
& Total & 225 & 61.7 & 100.0 & \\
Missing & System & 140 & 38.3 & & \\
\hline \hline
\end{tabular}


Case 8. You work for the influential chairman of a House/Senate committee.

\begin{tabular}{lccccc}
\hline \hline $\begin{array}{l}\text { All Staff- } \\
\text { unweighted }\end{array}$ & Frequency & Percent & Valid Percent & $\begin{array}{c}\text { Cumulative } \\
\text { Percent }\end{array}$ \\
\hline \multicolumn{7}{l}{ Valid } & Yes & 24 & 6.6 & 10.7 & 10.7 \\
& No & 146 & 40.2 & 65.2 & 75.9 \\
& Other & 29 & 8.0 & 12.9 & 88.8 \\
& Evade & 5 & 1.4 & 2.2 & 91.1 \\
& Try & 20 & 5.5 & 8.9 & 100.0 \\
Missing & Sotal & 224 & 61.7 & 100.0 & \\
Total & System & 139 & 38.3 & & \\
\hline \hline
\end{tabular}

Case 8. You work for the influential chairman of a House/Senate committee.

\begin{tabular}{|c|c|c|c|c|c|}
\hline \multicolumn{2}{|c|}{ Stennis Fellows } & \multirow{2}{*}{$\frac{\text { Frequency }}{8}$} & \multirow{2}{*}{$\frac{\text { Percent }}{6.6}$} & \multirow{2}{*}{$\begin{array}{r}\text { Valid Percent } \\
8.7\end{array}$} & \multirow{2}{*}{$\begin{array}{r}\begin{array}{c}\text { Cumulative } \\
\text { Percent }\end{array} \\
8.7\end{array}$} \\
\hline Valid & Yes & & & & \\
\hline & No & 66 & 54.1 & 71.7 & 80.4 \\
\hline & Other & 9 & 7.4 & 9.8 & 90.2 \\
\hline & Try & 9 & 7.4 & 9.8 & 100.0 \\
\hline & Total & 92 & 75.4 & 100.0 & \\
\hline Missing & System & 30 & 24.6 & & \\
\hline Total & & 122 & 100.0 & & \\
\hline
\end{tabular}

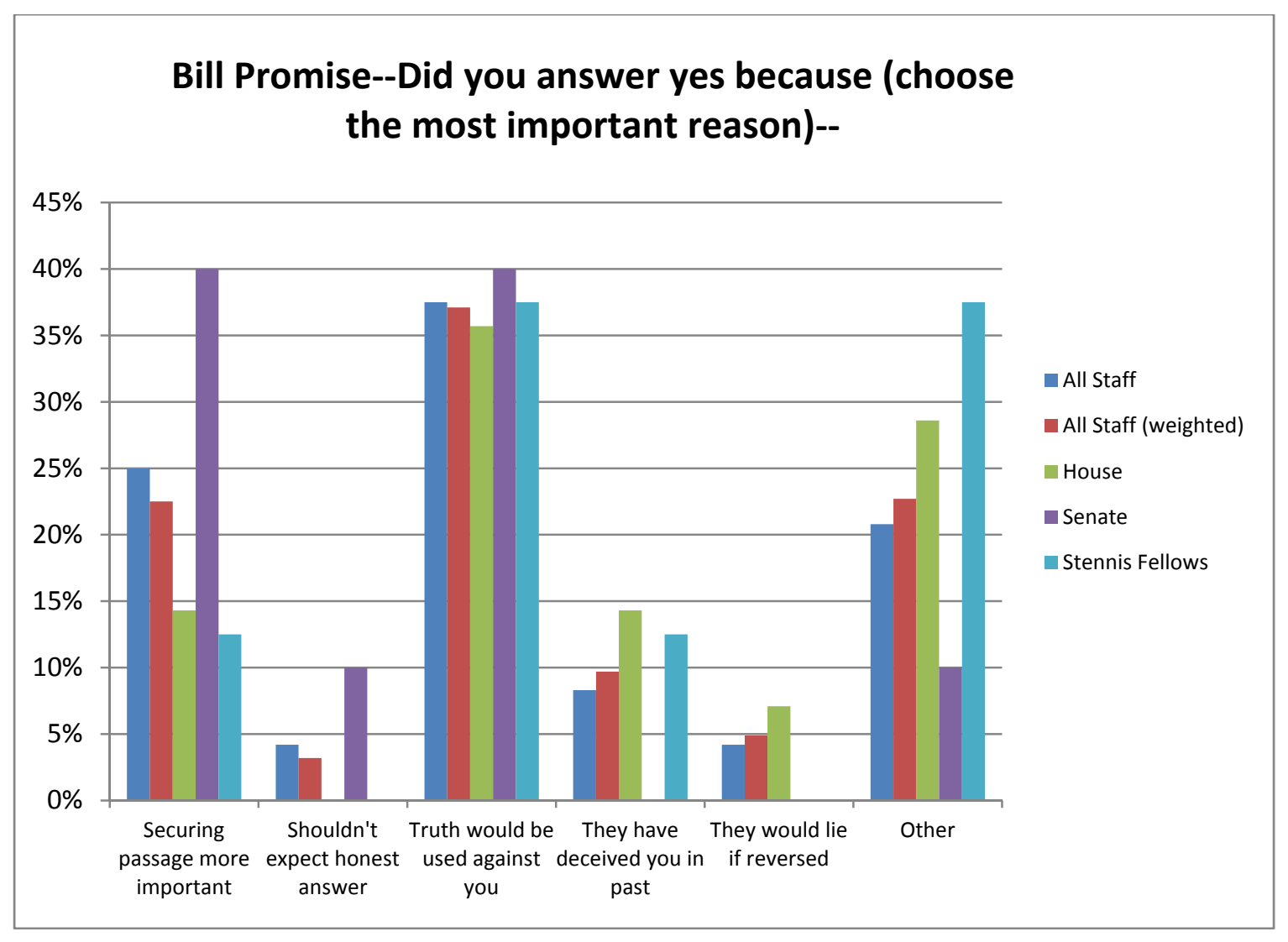


Did you answer yes because (choose all that apply)

\begin{tabular}{|c|c|c|c|c|c|c|}
\hline \multicolumn{3}{|c|}{ Chamber } & \multirow{2}{*}{$\frac{\text { Frequency }}{2}$} & \multirow{2}{*}{$\frac{\text { Percent }}{1.1}$} & \multirow{2}{*}{$\frac{\text { Valid Percent }}{14.3}$} & \multirow{2}{*}{$\begin{array}{c}\begin{array}{c}\text { Cumulative } \\
\text { Percent }\end{array} \\
14.3\end{array}$} \\
\hline House & Valid & $\begin{array}{l}\text { Your job is to secure } \\
\text { passage of the bill and this } \\
\text { overrides any concerns you } \\
\text { might have about lying }\end{array}$ & & & & \\
\hline & & $\begin{array}{l}\text { You do not have an } \\
\text { obligation to reveal } \\
\text { information that will be used } \\
\text { to block your bill }\end{array}$ & 5 & 2.7 & 35.7 & 50.0 \\
\hline & & $\begin{array}{l}\text { They have deceived you in } \\
\text { the past and you don't trust } \\
\text { them to act in good faith }\end{array}$ & 2 & 1.1 & 14.3 & 64.3 \\
\hline & & $\begin{array}{l}\text { They would lie to you if your } \\
\text { roles were reversed }\end{array}$ & 1 & .5 & 7.1 & 71.4 \\
\hline & & Other & 4 & 2.2 & 28.6 & 100.0 \\
\hline & & Total & 14 & 7.6 & 100.0 & \\
\hline & Missing & System & 171 & 92.4 & & \\
\hline & Total & & 185 & 100.0 & & \\
\hline \multirow[t]{7}{*}{ Senate } & Valid & $\begin{array}{l}\text { Your job is to secure } \\
\text { passage of the bill and this } \\
\text { overrides any concerns you } \\
\text { might have about lying }\end{array}$ & 4 & 2.2 & 40.0 & 40.0 \\
\hline & & $\begin{array}{l}\text { The other staff should not } \\
\text { expect an honest answer in } \\
\text { this situation }\end{array}$ & 1 & .6 & 10.0 & 50.0 \\
\hline & & $\begin{array}{l}\text { You do not have an } \\
\text { obligation to reveal } \\
\text { information that will be used } \\
\text { to block your bill }\end{array}$ & 4 & 2.2 & 40.0 & 90.0 \\
\hline & & Other & 1 & .6 & 10.0 & 100.0 \\
\hline & & Total & 10 & 5.6 & 100.0 & \\
\hline & Missing & System & 168 & 94.4 & & \\
\hline & Total & & 178 & 100.0 & & \\
\hline
\end{tabular}

Did you answer yes because (choose all that apply)

\begin{tabular}{llcccc}
\hline \hline All Staff-weighted & Frequency & Percent & Valid Percent & $\begin{array}{c}\text { Cumulative } \\
\text { Percent }\end{array}$ \\
\hline Valid & $\begin{array}{l}\text { Your job is to secure } \\
\text { passage of the bill and this } \\
\text { overrides any concerns you } \\
\text { might have about lying }\end{array}$ & 6 & 1.5 & 22.5 & 22.5 \\
& & & & & \\
\end{tabular}




\begin{tabular}{|c|c|c|c|c|c|}
\hline & $\begin{array}{l}\text { The other staff should not } \\
\text { expect an honest answer in } \\
\text { this situation }\end{array}$ & 1 & .2 & 3.2 & 25.6 \\
\hline & $\begin{array}{l}\text { You do not have an } \\
\text { obligation to reveal } \\
\text { information that will be used } \\
\text { to block your bill }\end{array}$ & 9 & 2.5 & 37.1 & 62.7 \\
\hline & $\begin{array}{l}\text { They have deceived you in } \\
\text { the past and you don't trust } \\
\text { them to act in good faith }\end{array}$ & 2 & .7 & 9.7 & 72.5 \\
\hline & $\begin{array}{l}\text { They would lie to you if your } \\
\text { roles were reversed }\end{array}$ & 1 & .3 & 4.9 & 77.3 \\
\hline & Other & 6 & 1.5 & 22.7 & 100.0 \\
\hline & Total & 25 & 6.8 & 100.0 & \\
\hline Missing & System & 340 & 93.2 & & \\
\hline Total & & 364 & 100.0 & & \\
\hline
\end{tabular}

Did you answer yes because (choose all that apply)

\begin{tabular}{|c|c|c|c|c|c|}
\hline \multicolumn{2}{|c|}{ All Staff-unweighted } & \multirow{2}{*}{$\frac{\text { Frequency }}{6}$} & \multirow{2}{*}{$\frac{\text { Percent }}{1.7}$} & \multirow{2}{*}{$\frac{\text { Valid Percent }}{25.0}$} & \multirow{2}{*}{$\begin{array}{c}\begin{array}{c}\text { Cumulative } \\
\text { Percent }\end{array} \\
25.0\end{array}$} \\
\hline Valid & $\begin{array}{l}\text { Your job is to secure } \\
\text { passage of the bill and this } \\
\text { overrides any concerns you } \\
\text { might have about lying }\end{array}$ & & & & \\
\hline & $\begin{array}{l}\text { The other staff should not } \\
\text { expect an honest answer in } \\
\text { this situation }\end{array}$ & 1 & .3 & 4.2 & 29.2 \\
\hline & $\begin{array}{l}\text { You do not have an } \\
\text { obligation to reveal } \\
\text { information that will be used } \\
\text { to block your bill }\end{array}$ & 9 & 2.5 & 37.5 & 66.7 \\
\hline & $\begin{array}{l}\text { They have deceived you in } \\
\text { the past and you don't trust } \\
\text { them to act in good faith }\end{array}$ & 2 & .6 & 8.3 & 75.0 \\
\hline & $\begin{array}{l}\text { They would lie to you if your } \\
\text { roles were reversed }\end{array}$ & 1 & .3 & 4.2 & 79.2 \\
\hline & Other & 5 & 1.4 & 20.8 & 100.0 \\
\hline & Total & 24 & 6.6 & 100.0 & \\
\hline Missing & System & 339 & 93.4 & & \\
\hline Total & & 363 & 100.0 & & \\
\hline
\end{tabular}


Did you answer yes because (choose all that apply)

\begin{tabular}{|c|c|c|c|c|c|}
\hline \multicolumn{2}{|c|}{ Stennis Fellows } & \multirow{2}{*}{$\frac{\text { Frequency }}{1}$} & \multirow{2}{*}{$\frac{\text { Percent }}{.8}$} & \multirow{2}{*}{$\frac{\text { Valid Percent }}{12.5}$} & \multirow{2}{*}{$\begin{array}{c}\begin{array}{c}\text { Cumulative } \\
\text { Percent }\end{array} \\
12.5\end{array}$} \\
\hline Valid & $\begin{array}{l}\text { Your job is to secure } \\
\text { passage of the bill and this } \\
\text { overrides any concerns you } \\
\text { might have about lying }\end{array}$ & & & & \\
\hline & $\begin{array}{l}\text { You do not have an } \\
\text { obligation to reveal } \\
\text { information that will be used } \\
\text { to block your bill }\end{array}$ & 3 & 2.5 & 37.5 & 50.0 \\
\hline & $\begin{array}{l}\text { They have deceived you in } \\
\text { the past and you don't trust } \\
\text { them to act in good faith }\end{array}$ & 1 & .8 & 12.5 & 62.5 \\
\hline & Other & 3 & 2.5 & 37.5 & 100.0 \\
\hline & Total & 8 & 6.6 & 100.0 & \\
\hline Missing & System & 114 & 93.4 & & \\
\hline Total & & 122 & 100.0 & & \\
\hline
\end{tabular}

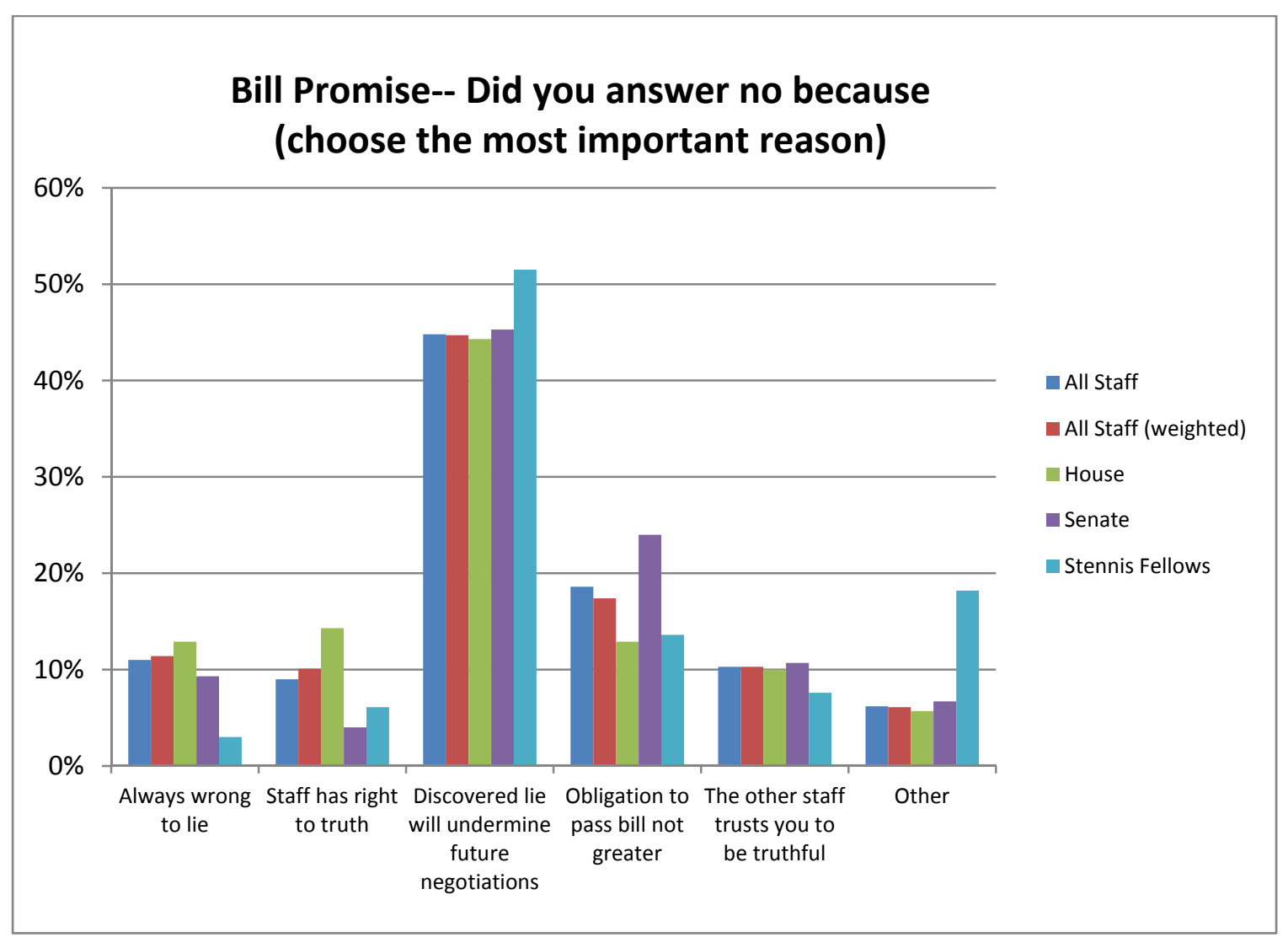


Stennis Fellows (3\%) were less likely to indicate that it is "always wrong to lie" than House staff $(12.9 \%)$ or Senate staff $(9.3 \%)$. The two-sample, two-tailed t-statistic was significant at the .05 level for the difference between Stennis Fellows and House staff, $t(134)=2.115, p=.0362$, but not for the difference between Stennis Fellows and Senate staff, $t(139)=1.531, p=.1281$.

Senate staff $(4.0 \%)$ were less likely to indicate that the other staff have a right to the truth than House staff (14.3\%) or Stennis Fellows (6.1\%). The two-sample, two-tailed tstatistic was significant at the .05 level for the difference between House and Senate staff, $t(143)=2.169, p=.0318$.

Nearly half of staff anchored their judgment about this case on the consequences of discovery and its impact on future negotiations. Stennis Fellows $(51.5 \%)$ were more likely than House staff (44.3\%) or Senate staff (45.3\%) to focus on the consequences of discovery. The two-sample, two-tailed t-statistic was not significant at the .05 level for the difference between Stennis Fellows and House staff, $t(134)=0.840, p=.4023$.

Senate staff (24\%) were more likely than House staff (12.9\%) or Stennis Fellows (13.6\%) to indicate that the obligation to pass the bill did not override the prohibition on lying. The two-sample, two-tailed t-statistic was not significant at the .05 level for the difference between House and Senate staff, $t(143)=1.715, p=.0885$.

Stennis Fellows (18.2\%) were more likely than House $(5.7 \%)$ or Senate $(6.7 \%)$ staff to select "other." The two-sample, two-tailed t-statistic for the difference in proportions 
was significant at the .05 level for the difference between Stennis Fellows and House

staff, $t(134)=2.261, p=.0254$, and for the difference between Stennis Fellows and Senate

staff, $t(139)=2.091, p=.0384$.

Did you answer no because (choose all that apply)

\begin{tabular}{|c|c|c|c|c|c|c|}
\hline \multicolumn{3}{|c|}{ Chamber } & \multirow{2}{*}{$\frac{\text { Frequency }}{9}$} & \multirow{2}{*}{$\frac{\text { Percent }}{4.9}$} & \multirow{2}{*}{$\frac{\text { Valid Percent }}{12.9}$} & \multirow{2}{*}{$\begin{array}{c}\begin{array}{c}\text { Cumulativ } \\
\text { Percent }\end{array} \\
12.9\end{array}$} \\
\hline House & Valid & It is always wrong to lie & & & & \\
\hline & & $\begin{array}{l}\text { The Senate staff have a right } \\
\text { to the truth }\end{array}$ & 10 & 5.4 & 14.3 & 27.1 \\
\hline & & $\begin{array}{l}\text { The lie, when discovered, } \\
\text { will undermine your ability to } \\
\text { work with these staff in the } \\
\text { future }\end{array}$ & 31 & 16.8 & 44.3 & 71.4 \\
\hline & & $\begin{array}{l}\text { Your obligation to pass your } \\
\text { bill does not override the } \\
\text { prohibition on lying }\end{array}$ & 9 & 4.9 & 12.9 & 84.3 \\
\hline & & $\begin{array}{l}\text { The other staff trusts you to } \\
\text { be truthful }\end{array}$ & 7 & 3.8 & 10.0 & 94.3 \\
\hline & & Other & 4 & 2.2 & 5.7 & 100.0 \\
\hline & & Total & 70 & 37.8 & 100.0 & \\
\hline & Missing & System & 115 & 62.2 & & \\
\hline & Total & & 185 & 100.0 & & \\
\hline \multirow[t]{9}{*}{ Senate } & Valid & It is always wrong to lie & 7 & 3.9 & 9.3 & 9.3 \\
\hline & & $\begin{array}{l}\text { The Senate staff have a right } \\
\text { to the truth }\end{array}$ & 3 & 1.7 & 4.0 & 13.3 \\
\hline & & $\begin{array}{l}\text { The lie, when discovered, } \\
\text { will undermine your ability to } \\
\text { work with these staff in the } \\
\text { future }\end{array}$ & 34 & 19.1 & 45.3 & 58.7 \\
\hline & & $\begin{array}{l}\text { Your obligation to pass your } \\
\text { bill does not override the } \\
\text { prohibition on lying }\end{array}$ & 18 & 10.1 & 24.0 & 82.7 \\
\hline & & $\begin{array}{l}\text { The other staff trusts you to } \\
\text { be truthful }\end{array}$ & 8 & 4.5 & 10.7 & 93.3 \\
\hline & & Other & 5 & 2.8 & 6.7 & 100.0 \\
\hline & & Total & 75 & 42.1 & 100.0 & \\
\hline & Missing & System & 103 & 57.9 & & \\
\hline & Total & & 178 & 100.0 & & \\
\hline
\end{tabular}


Did you answer no because (choose all that apply)

\begin{tabular}{|c|c|c|c|c|c|}
\hline \multicolumn{2}{|c|}{ All Staff-weighted } & \multirow{2}{*}{$\frac{\text { Frequency }}{16}$} & \multirow{2}{*}{$\frac{\text { Percent }}{4.5}$} & \multirow{2}{*}{$\frac{\text { Valid Percent }}{11.4}$} & \multirow{2}{*}{$\begin{array}{c}\begin{array}{c}\text { Cumulative } \\
\text { Percent }\end{array} \\
11.4\end{array}$} \\
\hline Valid & It is always wrong to lie & & & & \\
\hline & $\begin{array}{l}\text { The Senate staff have a right } \\
\text { to the truth }\end{array}$ & 14 & 4.0 & 10.1 & 21.5 \\
\hline & $\begin{array}{l}\text { The lie, when discovered, } \\
\text { will undermine your ability to } \\
\text { work with these staff in the } \\
\text { future }\end{array}$ & 64 & 17.7 & 44.7 & 66.2 \\
\hline & $\begin{array}{l}\text { Your obligation to pass your } \\
\text { bill does not override the } \\
\text { prohibition on lying }\end{array}$ & 25 & 6.9 & 17.4 & 83.6 \\
\hline & $\begin{array}{l}\text { The other staff trusts you to } \\
\text { be truthful }\end{array}$ & 15 & 4.1 & 10.3 & 93.9 \\
\hline & Other & 9 & 2.4 & 6.1 & 100.0 \\
\hline & Total & 144 & 39.5 & 100.0 & \\
\hline Missing & System & 221 & 60.5 & & \\
\hline Total & & 364 & 100.0 & & \\
\hline
\end{tabular}

Did you answer no because (choose all that apply)

\begin{tabular}{|c|c|c|c|c|c|}
\hline \multicolumn{2}{|c|}{ All Staff-unweighted } & \multirow{2}{*}{$\frac{\text { Frequency }}{16}$} & \multirow{2}{*}{$\frac{\text { Percent }}{4.4}$} & \multirow{2}{*}{$\frac{\text { Valid Percent }}{11.0}$} & \multirow{2}{*}{$\begin{array}{c}\begin{array}{c}\text { Cumulative } \\
\text { Percent }\end{array} \\
11.0\end{array}$} \\
\hline Valid & It is always wrong to lie & & & & \\
\hline & $\begin{array}{l}\text { The Senate staff have a right } \\
\text { to the truth }\end{array}$ & 13 & 3.6 & 9.0 & 20.0 \\
\hline & $\begin{array}{l}\text { The lie, when discovered, } \\
\text { will undermine your ability to } \\
\text { work with these staff in the } \\
\text { future }\end{array}$ & 65 & 17.9 & 44.8 & 64.8 \\
\hline & $\begin{array}{l}\text { Your obligation to pass your } \\
\text { bill does not override the } \\
\text { prohibition on lying }\end{array}$ & 27 & 7.4 & 18.6 & 83.4 \\
\hline & $\begin{array}{l}\text { The other staff trusts you to } \\
\text { be truthful }\end{array}$ & 15 & 4.1 & 10.3 & 93.8 \\
\hline & Other & 9 & 2.5 & 6.2 & 100.0 \\
\hline & Total & 145 & 39.9 & 100.0 & \\
\hline Missing & System & 218 & 60.1 & & \\
\hline Total & & 363 & 100.0 & & \\
\hline
\end{tabular}


Did you answer no because (choose all that apply)

\begin{tabular}{|c|c|c|c|c|c|}
\hline \multicolumn{2}{|c|}{ Stennis Fellows } & \multirow{2}{*}{$\frac{\text { Frequency }}{2}$} & \multirow{2}{*}{$\frac{\text { Percent }}{1.6}$} & \multirow{2}{*}{$\frac{\text { Valid Percent }}{3.0}$} & \multirow{2}{*}{$\begin{array}{c}\begin{array}{c}\text { Cumulative } \\
\text { Percent }\end{array} \\
3.0\end{array}$} \\
\hline Valid & It is always wrong to lie & & & & \\
\hline & $\begin{array}{l}\text { The Senate staff have a right } \\
\text { to the truth }\end{array}$ & 4 & 3.3 & 6.1 & 9.1 \\
\hline & $\begin{array}{l}\text { The lie, when discovered, } \\
\text { will undermine your ability to } \\
\text { work with these staff in the } \\
\text { future }\end{array}$ & 34 & 27.9 & 51.5 & 60.6 \\
\hline & $\begin{array}{l}\text { Your obligation to pass your } \\
\text { bill does not override the } \\
\text { prohibition on lying }\end{array}$ & 9 & 7.4 & 13.6 & 74.2 \\
\hline & $\begin{array}{l}\text { The other staff trusts you to } \\
\text { be truthful }\end{array}$ & 5 & 4.1 & 7.6 & 81.8 \\
\hline & Other & 12 & 9.8 & 18.2 & 100.0 \\
\hline & Total & 66 & 54.1 & 100.0 & \\
\hline Missing & System & 56 & 45.9 & & \\
\hline Total & & 122 & 100.0 & & \\
\hline
\end{tabular}

Bill Promise: Let's assume the circumstances and roles are reversed. What do you believe the other staff member

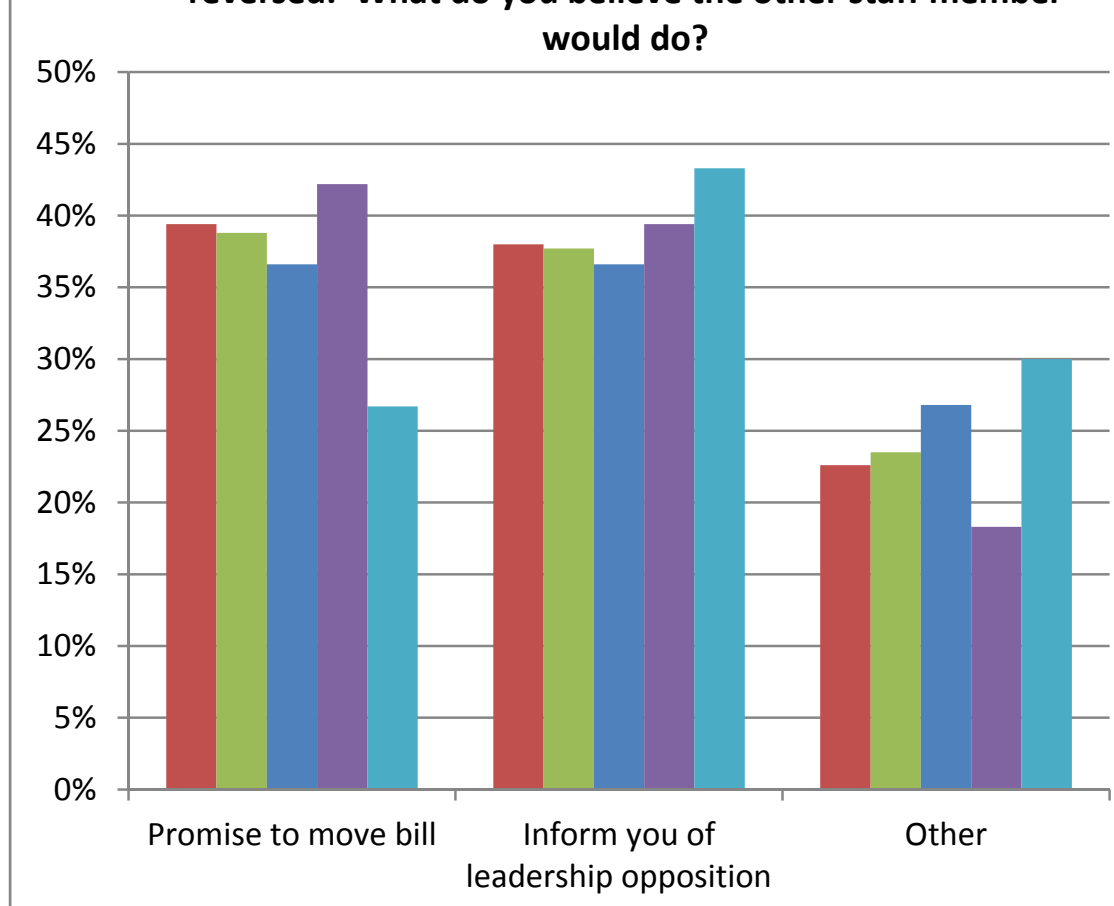

All Staff

All Staff (weighted)

- House

Senate

Stennis Fellows 
Respondents were presented with the social desirability bias indicator question about how the other staff would respond if their situations were reversed. Respondents were more closely divided on this case than on prior cases.

Confidence intervals were calculated at the $95 \%$ level for each of the respondent groups. The widest confidence interval for the House was $\pm 9 \%$, for the Senate was $\pm 9.3 \%$, for all staff-weighted was $\pm 6.4 \%$ and for Stennis Fellows was $\pm 8.4 \%$.

Stennis Fellows (27\%) were less likely to anticipate that the other staff would promise to move the bill than Senate staff (42\%), House staff (37\%) or all staff-weighted (39\%). The two-sample, two-tailed t-statistic for the difference in proportions was significant at the .05 level for the difference between all staff-weighted and Stennis Fellows, $t(310)=2.026, p=.044$, and for the difference between Senate staff and Stennis Fellows, $\mathrm{t}(197)=2.279, \mathrm{p}=.0238$. The two-sample, two-tailed t-statistic was not significant for the difference between House staff and Stennis Fellows, $\mathrm{t}(200)=1.497, \mathrm{p}=.1360$.

All staff-weighted who expected that the staff member would promise to move the bill had higher religiosity scores $(M=21.97, M d n=22.86, n=85)$ than those who expected that the staff member would inform them of leadership opposition $(M=19.45, M d n=19.72$, $n=84$ ) and very similar religiosity to staff who believed that the staff member would respond "other" $(M=21.67, M d n=23, n=49)$. The two-sample, two-tailed t-statistic for the difference in mean religiosity between staff who thought that the staff member would promise to move the bill and staff who believed the staff member would inform them of leadership opposition was significant at the .05 level, $t(167)=2.175, p=.0311$. The 
Mann-Whitney U Test, however, revealed no significant difference in religiosity between staff who believed the staff member would promise and staff who believed the staff member would inform them of leadership opposition, $U=3158, z=-1.417, p=.157$.

The t-statistic assumes that the sampling distribution of means is normal. This threshold can be assumed to have been met when the number of respondents in the group is equal to or greater than 30 . In this instance, both groups have more than 80 respondents and the normal distribution can be assumed. The results of the t-statistic can be accepted. Stennis Fellows who expected the staff member to promise to move the bill have higher religiosity scores $(M=23, M d n=21, n=24)$ than those who expected the staff member to inform them of leadership opposition $(M=19.9, M d n=19.5, n=38)$. The two-sample, two-tailed t-statistic was not significant at the .05 level for the difference in mean religiosity between the two groups, $t(60)=1.794, p=.0778$. The Mann-Whitney U Test also revealed no significant difference in religiosity between the two groups, $U=339.5$, $z=-1.686, p=.092$.

All staff-weighted who expected the staff member to promise to move the bill reported being lied to more frequently $(M=12.309, M d n=5.71, n=60)$ than staff who expected the staff member to inform them of leadership opposition $(M=5.789, M d n=3, n=69)$. The two-sample, two-tailed t-statistic for the difference in mean "being lied to" was significant at the .05 level, $t(127)=3.171, p=.0019$. The Mann-Whitney U Test also revealed a significant difference in "being lied to" between staff who believed the staff member would promise to move the bill and those who believed she would inform them of leadership opposition, $\mathrm{U}=1499.5, \mathrm{z}=-2.822, \mathrm{p}=.005$. 
All staff-weighted who expected the staff member to promise to move the bill reported lying more frequently $(M=4.228, M d n=2, n=70)$ than staff who expected the staff member to inform them of leadership opposition $(M=1.726, M d n=0, n=69)$. The twosample, two-tailed t-statistic for the difference in mean lying was significant at the .05 level, $t(137)=1.991, p=.0485$. The Mann-Whitney U Test also revealed a significant difference in the number of lies told between staff who expected the staff member to promise to move the bill and staff who expected the staff member to inform them of leadership opposition, $U=1894.5, z=-2.416, p=.016$.

Stennis Fellows who expected the staff member to promise to move the bill $(M=11.8$, $M d n=4, n=18$ ) reported being lied to more frequently than fellows who expected the staff member to inform them of leadership opposition $(M=4.33, M d n=2, n=24)$. The twosample, two-tailed t-statistic for the difference in mean-reported being lied to was not significant at the .05 level, $t(40)=1.532, p=.1334$. The Mann-Whitney U Test also revealed no significant difference in the number of times the respondents reported being lied to, $U=162, z=-1.396, p=.163$.

Stennis Fellows who expected the other staff member to promise to move the bill $(M=3.44, M d n=0, n=18)$ reported telling more lies than fellows who expected the staff member to inform them of leadership opposition $(M=1.148, M d n=0, n=27)$. The twosample, two-tailed t-statistic for the difference in mean "lies told" was not significant at the .05 level, $t(43)=1.837, p=.0732$. The Mann-Whitney U Test also revealed no significant difference in the number of lies told by fellows who expected the staff 
member to promise to move the bill and fellows who expected the staff member to inform them of leadership opposition, $U=226.5, z=-.432, p=.67$.

Eighty percent of all staff-weighted respondents who indicated that they would promise to move the bill also believed that the other staff member would make that promise if their roles were reversed. In contrast, only $34 \%$ of respondents who indicated that they would not promise to move the bill expected that the other staff member would make the promise.

One hundred percent of the Stennis Fellows who indicated they would promise to move the bill expected that the other staff member would make that same promise if their roles were reversed. Only $17 \%$ of fellows who indicated they would not make the promise expected that the other staff member would make the promise if their roles were reversed.

The chi-square for independence was calculated for all staff-weighted by collapsing the responses "try" and "evade" back into "other" (to reduce the number of cells with expected counts of less than zero). The chi-square test for independence indicated a significant association between an all staff-weighted respondents' willingness to make the promise and their expectations about whether the other staff member would make the promise if their roles were reversed, $X^{2}=(4, n=222)=52.8, p=.000$.

The role reversal question revealed several things about the way that staff perceived these types of legislative negotiations. On the one hand, only $11 \%$ of congressional staff responded that they would make the promise they knew that they could not keep and 
would fail to disclose that their leadership opposed the bill. At the same time, $39 \%$ of them believed that the other staff member would make this false promise. Either staff believed that they are more honest than their colleagues or they overestimated their own virtue. This pattern is consistent with the results from the questions about the number of times staff believed they were lied to and the number of times they believed they told a lie in the previous 24 hours. In both instances, respondents appeared to believe that they told fewer lies than the individuals with whom they lived and worked. In part, this may be consistent with the results that suggest that a significant portion of the staff do not tell a lie within a given period and that most lies are told by a relatively small proportion of their colleagues.

It is striking, however, that there is a clear relationship between a respondent's willingness to make a false promise and his or her expectation that a colleague would do the same thing were the circumstances reversed. For these staff, there is a low level of trust, and perhaps, following Cramton and Dees, the "mutual trust principle" is in effect. As discussed earlier, Cramton and Dees theorize that lying and deception are more likely to occur and be justified by negotiators in situations involving low levels of trust. ${ }^{138}$

\begin{tabular}{|c|c|c|c|c|c|c|}
\hline \multicolumn{3}{|c|}{ Chamber } & \multirow{2}{*}{$\frac{\text { Frequency }}{41}$} & \multirow{2}{*}{$\frac{\text { Percent }}{22.2}$} & \multirow{2}{*}{$\frac{\text { Valid Percent }}{36.6}$} & \multirow{2}{*}{$\begin{array}{c}\begin{array}{c}\text { Cumulative } \\
\text { Percent }\end{array} \\
36.6\end{array}$} \\
\hline House & Valid & Promise to move the bill & & & & \\
\hline & & $\begin{array}{l}\text { Inform you of their } \\
\text { leadership's opposition }\end{array}$ & 41 & 22.2 & 36.6 & 73.2 \\
\hline & & Other & 30 & 16.2 & 26.8 & 100.0 \\
\hline & & Total & 112 & 60.5 & 100.0 & \\
\hline & Missing & System & 73 & 39.5 & & \\
\hline
\end{tabular}




\begin{tabular}{lllcccc}
\hline & Total & & 185 & 100.0 & & \\
\hline Senate & Valid & Promise to move the bill & 46 & 25.8 & 42.2 & 42.2 \\
& & $\begin{array}{l}\text { Inform you of their } \\
\text { leadership's opposition }\end{array}$ & 43 & 24.2 & 39.4 & 81.7 \\
& Other & 20 & 11.2 & 18.3 & 100.0 \\
& Total & 109 & 61.2 & 100.0 & 38.8 \\
& Missing & System & 69 & 3 & & \\
& & 178 & 100.0 & & \\
\hline \hline
\end{tabular}

Let's assume the circumstances and roles are reversed. What do you believe the other staff would do?

\begin{tabular}{llcccc}
\hline \hline All Staff-weighted & Frequency & Percent & Valid Percent & $\begin{array}{c}\text { Cumulative } \\
\text { Percent }\end{array}$ \\
\hline Valid & Promise to move the bill & 86 & 23.6 & 38.8 & 38.8 \\
& Inform you of their & & & & 76.5 \\
& leadership's opposition & 84 & 22.9 & 37.7 & 100.0 \\
& Other & & & & 23.5 \\
Missing & Total & 52 & 14.3 & 100.0 & \\
Total & System & 222 & 60.8 & & \\
\hline \hline
\end{tabular}

Let's assume the circumstances and roles are reversed. What do you believe the other staff would do?

\begin{tabular}{llcccc}
\hline \hline All Staff-unweighted & Frequency & Percent & Valid Percent & $\begin{array}{c}\text { Cumulative } \\
\text { Percent }\end{array}$ \\
\hline Valid & Promise to move the bill & 87 & 24.0 & 39.4 & 39.4 \\
& Inform you of their & 84 & 23.1 & 38.0 & 77.4 \\
& leadership's opposition & & & & 100.0 \\
& Other & 50 & 13.8 & 22.6 & 100.0 \\
Missing & Total & 221 & 60.9 & & \\
Total & System & 142 & 39.1 & & \\
\hline \hline
\end{tabular}

Let's assume the circumstances and roles are reversed. What do you believe the other staff would do?

\begin{tabular}{|c|c|c|c|c|c|}
\hline \multicolumn{2}{|c|}{ Stennis Fellows } & \multirow{2}{*}{$\frac{\text { Frequency }}{24}$} & \multirow{2}{*}{$\frac{\text { Percent }}{19.7}$} & \multirow{2}{*}{$\frac{\text { Valid Percent }}{26.7}$} & \multirow{2}{*}{$\begin{array}{c}\begin{array}{c}\text { Cumulative } \\
\text { Percent }\end{array} \\
26.7\end{array}$} \\
\hline Valid & Promise to move the bill & & & & \\
\hline & $\begin{array}{l}\text { Inform you of their } \\
\text { leadership's opposition }\end{array}$ & 39 & 32.0 & 43.3 & 70.0 \\
\hline & Other & 27 & 22.1 & 30.0 & 100.0 \\
\hline & Total & 90 & 73.8 & 100.0 & \\
\hline Missing & System & 32 & 26.2 & & \\
\hline Total & & 122 & 100.0 & & \\
\hline
\end{tabular}




\section{Chapter X: Discussion and Findings}

\section{Comparison of the Population in this Study with Prior Studies}

Previously conducted research on the frequency of lying has drawn mainly from two populations: college students and commercial panels of adults. College students are frequently used because of their accessibility to academic investigators and the relative ease with which they can be recruited. There are limitations, however, to the extent to which research with this population can support inferences about the broader adult population. In these research studies, college students (as a population) have differed from the general population in age, gender, education and socioeconomic status. For instance, DePaulo et al. recruited 77 college students (30 men and 47 women) who received partial course credit in their introduction to psychology class as incentive to participate.

To counterbalance these limitations, DePaulo also recruited a sample of 70 community members using flyers posted at a local community college and using names drawn from the phone book. She theorized that any significant convergence of results between the two populations supported extension of the results to the general adult population. ${ }^{139}$ Both populations were significantly younger and better educated than the U.S. adult population. ${ }^{140}$ The median age of the college students was $18.69(\mathrm{SD}=0.91)$ and the median age of the community participants (all of whom were at least 18) was 34.19

\footnotetext{
${ }^{139}$ DePaulo et al., "Lying in Everyday Life."

${ }^{140}$ DePaulo reported that $34 \%$ of participants had no more than a high school education. 2005 NCES data indicates that only $42 \%$ of population has an associate's degree or higher.
} 
$(\mathrm{SD}=12.49)$. In contrast, the median age of the U.S. population, including children under the age of 18 , is 36.8 . To the extent that education is associated with socioeconomic status, the community group is likely to differ from the general population of adults along these measures as well.

Investigators seeking to conduct research that can more confidently be generalized to the adult population traditionally use random samples drawn from the population being studied (e.g., U.S. adults). There is a deep literature on declining response rates and the increasing unwillingness of people to participate in surveys and polls. One strategy, used by Serota et al, and increasingly used by public opinion research companies, is panel research. Panels consist of prescreened adults (most demographics are known in advance) who are willing to participate in survey research.

Analysis of panel data requires close attention to the process of member recruitment and careful weighting of the responses to match known characteristics of the population about which inferences are to be drawn. U.S. Census Current Population Survey (CPS) data are frequently used to establish population weights. Serota matched her sample to the CPS for age, gender, income, and region. In addition, Serota did not report the median age of her participants. One challenge of using panels is that proper weighting of the responses often requires foreknowledge (or a good working hypothesis) of the factors that could confound the results and that must be accounted for. For example, education level was not one of the characteristics that Serota reported collecting or analyzing. It may have been indirectly accounted for through weighting income. 
This study used congressional staff as its sample frame. While there is little to no literature regarding the demographics of congressional staff, conventional wisdom holds that they are younger and better educated (the sample for this study excluded nonprofessional staff) than the population-at-large. ${ }^{141}$ Capitol Hill attracts thousands of recent college graduates, and many committee and leadership staff have professional or advanced degrees. Consistent with estimates that the mean age of Washington-based congressional staff is 31 , respondents to the survey reported a median tenure of five years and a mean tenure of 7.3 years $(\mathrm{SD}=7.29)$.

As was true with the DePaulo study, congressional staff are likely to be both younger and better educated than the general adult population. Serota reports that frequency of lying is correlated with age--younger subjects reported telling more lies than older subjects. To the extent that congressional staff reported telling slightly more lies than did subjects in the Serota study, age cannot be excluded as a factor. Unfortunately, the survey captured tenure rather than age (there was no significant correlation between tenure and lying or between tenure and perceived being lied to).

DePaulo hypothesized that convergence of results across multiple populations lent support for the ability to generalize results. While encouraging, we must acknowledge that there are statistical limitations to this view. It is striking, however, that all of the major studies, including this one, indicate that each population reports mean lying of from one to three lies per day. Moreover, both Serota and this study find that a sizeable

\footnotetext{
${ }^{141}$ Daniel Schuman to, 2010, http://sunlightfoundation.com/blog/2010/12/21/keeping-congress-competentstaff-pay-turnover-and-what-it-means-for-democracy/.
} 
proportion of people tell no lies and that most lies are told by a small percentage of prolific liars.

Congressional staff earn their living navigating competing interests. The venue may change; some focus predominately on policy and legislation, some on regulation, some on casework, and some on campaigns. The "value" that they produce is directly tied to their ability to manage the relationships implied by these interests. One interesting area for future comparative research would be to examine the religiosity, perspectives, and attitudes of similarly situated individuals in law and commerce. As will be noted later, this may present an opportunity to explore whether there are contextual role identities associated with professional practice that have equal or greater impact than religiosity on attitudes toward and the reported frequency of lying.

\section{Religious Affiliation of Respondents in this Study}

The survey revealed that the religious affiliation of congressional staff is similar to that of the general population of U.S. adults with a few exceptions. Protestants are represented among staff at lower rates than in the general population. Jewish and Mormon staff are represented among congressional staff at rates slightly higher than found among U.S. adults. No member of Congress indicated that he or she affiliates with "no religion." In contrast, congressional staff (15.9\%) reported having "no religion" at rates very similar to the U.S. adult population (16.4\%). There are several possible explanations for this difference between staff and the Members they serve. 
In some communities, religious groups form important social communities from which community and political leaders emerge. Active membership in these religious groups is sometimes a prerequisite to building the social and political connections within the broader community that are necessary to be considered for and to attain elected office.

It is also possible that the political process itself, reflecting the perceived expectations of voters, provides strong incentives for members of the House and Senate to identify with a religious community as a demonstration of their faith without regard to the strength or salience of the affiliation.

Finally, and perhaps less charitably, the difference could simply reflect differences in methodologies between this study and the Pew study of Members of the House and Senate. Participants in the staff and GSS were provided confidentiality and the confidence that their responses would not have consequences. In contrast, members of the House and Senate knew that their responses would be made public. It is possible that an anonymous survey of members of the House and Senate would yield results similar to those generated by this study or by the GSS and Pew adult studies.

\section{Religiosity}

A religiosity index was created drawing questions from the 2010 General Social Survey and the Hoge Intrinsic Religious Motivation Scale. The Chronbach's alpha scores ranged from .884 to .903 , indicating high levels of internal consistency. House staff exhibited higher religiosity scores $(M=21.7, S D=7.98)$ than the Senate staff $(M=18.8, S D=7.53)$. 
Stennis Fellows $(M=20.873, S D=7.3)$ also had higher religiosity scores than did Senate staff.

Party affiliation data were available for 264 of the 312 congressional staff who participated in the survey. Republican staff $(M=23.76, M d n=25, S D=7.3)$ exhibited higher religiosity scores than did Democratic staff $(M=17.05, M d n=16, S D=6.9)$. There was a small, but not statistically significant, interaction between party and chamber; House staff of all parties (unknown, bipartisan, Democrat, Republican) reported higher religiosity than did their Senate equivalents. The differences in religiosity between the House and Senate are largely a product of the difference in religiosity between the two main political parties.

\section{Reported Lying and Being Lied to}

Respondents were asked to indicate how many times they believed they had been lied to in the previous 24 hours. Their responses indicated that they believed they were lied to more frequently than has been reported in surveys of other populations. Staff indicated that they believed that they were lied to an average of $7.9(M d n=4)$ times. In contrast, college students in a similar study reported that they were lied to an average of 2.79 times. ${ }^{142}$ This suggests a higher level of mistrust (at least with regards to lying) among congressional staff than is evident in other populations that have been surveyed. A closer look at the data, however, indicates that a significant portion — roughly $30 \%$ —of

${ }^{142}$ Serota, Levine, and Boster, "The Prevalence of Lying in America: Three Studies of Self-Reported
Lies." Lies." 
staff reported not being lied to during the previous 24 hours while a small portion reported being lied to very frequently.

The prior questions provided information about staff and Fellow perceptions of what they experienced across all walks of their life. The social desirability bias questions in the cases provided information about staff expectations regarding the truth-telling of their colleagues. In two of the three cases that contained the social desirability role reversal question, more than $50 \%$ of the staff expected the other party to lie if their situation were reversed. In the third case, $39 \%$ of the staff expected the other party/staff member to lie if their situation were reversed.

Respondents were then asked to indicate how many times they had lied during the previous 24 hours. Staff reported telling an average of $2.5(M d n=1)$ lies, a rate higher than reported by Serota in her population survey (1.65). Following a pattern that has been reported by Serota, $47 \%$ of staff reported they had not told a lie, while $6.5 \%$ of staff accounted for $50 \%$ of all reported lies. Consistent with the finding that staff tell slightly more lies than other populations, fewer congressional staff (47\%) reported telling no lies than did U.S. adults (59.9\%) in the Serota study.

One significant finding of this study was that there was a statistically significant positive correlation between the frequency with which respondents reported being lied to and the frequency with which they reported lying. This correlation was significant for all of the respondent groups (House, Senate, all staff-weighted, Stennis Fellows) but was strongest for Stennis Fellows ( $r h o=.673, n=62, p<.000)$. 
Serota found that reported lying fits a standard power function. Reported being lied to also fits a standard power function that has very similar shape. In both cases the extreme intercepts indicate that a majority of staff report not being lied to and not lying while a small proportion of staff report prolific lying and being lied to frequently.

Two observations might be made about these findings. On the one hand, the data from this study coincides with Serota's findings to suggest that most individuals refrain from lying during a 24-hour period. This poses a challenge to DePaulo's assertion that lying is "ubiquitous" and even necessary for social cohesion. At the same time, a small number of individuals report being prolific liars. The frequency with which these individuals tell lies may reinforce the perception that liars are more prevalent than these data suggest.

The second observation pertains to the relationship between lying and being lied to. Further research should be conducted to explore this relationship, its origins and its limitations. It may be that prolific liars (who also believe they are lied to frequently) follow DePaulo and believe that lying is a ubiquitous behavior. This expectation may in turn encourage defensive lying (response rates were too low to test this in this survey) or indicate that individuals expect others to engage in the same behavior they themselves engage. Regardless of the reason for the relationship between lying and being lied to, it might be possible to use questions about the number of times individuals believe they were lied to as a predictor of their relative proclivity to tell lies. 


\section{Religiosity and Lying}

The mean religiosity of staff who told a lie $(M=21.3, S D=7.7)$ was not statistically significantly different than for staff who reported telling no lies $(M=20.7, S D=8.3)$. The mean religiosity of Stennis Fellows who reported telling no lies $(M=23.6, S D=7.1)$ was slightly higher but also not statistically significantly different from fellows who reported telling lies $(M=20.5, S D=6.8)$.

The mean religiosity of staff $(M=20.8, S D=7.7)$ who reported telling more lies than the mean was not statistically significantly different from staff who reported telling fewer lies than the mean $(M=21.1, S D=8.1)$. The mean religiosity of Stennis Fellows who reported telling fewer lies than the mean $(M=22.7, S D=7.7)$ was nominally higher but not statistically significantly different than fellows who reported telling more than the mean number of lies $(M=20.7, S D=7.7)$.

A Spearman Rank Order Correlation, $\mathrm{r}(210)=-.012, \mathrm{p}=.862$, and a Pearson product moment correlation coefficient, $\mathrm{r}(210)=-.038, \mathrm{p}=.582$, both indicated that there was no statistically significant relationship between the religiosity of congressional staff and frequency with which they reported telling lies.

This result is not unprecedented. There is robust literature on the relationship between religiosity and personality, on coping with stressful situations, health, cheating, altruism, and marriage. These studies have provided conflicting evidence regarding the role of religiosity on behavior. In one example, Smith et al. found no relationship between 
religiosity and acts of cheating and altruism among college students. ${ }^{143}$ In contrast, and perhaps closer to the subjects of this study, Fastenow et al. concluded that models of "legislative decision making that exclude religion are underspecified."144 The models being examined, however, reflected voting patterns and policy positions rather than the professional behavior of the members of the House and Senate. Review of the literature did not reveal any empirical studies examining the relationship between religiosity and lying in professional settings.

As will be discussed later, in the 70 s and 80 s, research was conducted on children and young adults regarding the relationship between religiosity and Eysenck's lie scales. This research provided paradoxical and conflicting results. In some instances, higher religiosity was associated with higher lie scale scores. ${ }^{145}$ Higher lie scale scores are interpreted to reflect a greater propensity to lie.

The survey in this congressional research utilized a religiosity scale that attempted to measure, among other things, the salience of religion in the life of staff, and the impact this had on the act of lying. Professional behavior occurs in an organizational context. Future work should be done to better understand the other organizational norms (e.g., advocacy) that may be counterbalancing the role of religiosity in the professional practice of staff.

\footnotetext{
${ }^{143}$ Ronald E. Smith, Gregory Wheeler, and Edward Diener, "Faith without Works: Jesus People, Resistance to Temptation, and Altruism," Journal of Applied Social Psychology 5, no. 4 (1975).

${ }^{144}$ Chris Fastenow, J. Tobin Grant, and Thomas J. Rudolph, "Holy Roll Calls: Religious Tradition and Voting Behavior in the U.S. House," Social Science Quarterly 80(1999).

${ }^{145}$ Paul R. Pearson and Leslie J. Francis, "The Dual Nature of the Eysenckian Lie Scales: Are Religious Adolescents More Truthful?," Personality and Individual Differences 10, no. 10 (1989).
} 


\section{Definitions of a Lie}

To further test the relationship between religiosity and lying, respondents were presented with three definitions of lying. Bok's definition (any intentionally deceptive statement) was most frequently selected by House and Senate staff, while Stennis Fellows were slightly more likely to select the definition from the OED (to make a false statement with the intent to deceive). The religiosity of respondents did not vary significantly by definition selected, nor did the frequency of reported lying by House and Senate staff vary by definition. No relationship between religiosity and choice of these definitions could be identified.

Stennis Fellows selecting the Bok definition reported telling fewer mean and median lies than fellows who chose the OED definition. It is unclear why a broader definition of a lie would result in fewer reported lies. One possibility is that the broader, more inclusive definition of lying is associated with or reflects more stringent expectations for personal conduct.

Staff were also provided six more technical definitions and asked whether these definitions comported with their own understanding of lying. Although religiosity did not have an impact on reported lying or on the selection of one of the three common definitions, there was an association between religiosity and agreement or disagreement with several of the expanded definitions that were presented. In some cases, the association was statistically significant for both all staff-weighted respondents and for fellows. In other cases, the results were directionally the same but only statistically significant for one of the two groups. In general, more constraining or restrictive 
definitions of a lie were associated at least weakly with higher mean and median religiosity. This provides partial evidence that religiosity affects attitudes toward and the definition of lying in subtle, complex, and possibly inconsistent ways.

\section{Partly True Statement}

For example, $60 \%$ to $70 \%$ of respondents indicated that a partly true statement (what might be viewed as spin) was a lie. All staff-weighted respondents who indicated this was a lie had nominally higher but not statistically significantly higher religiosity scores. Stennis Fellows who indicated this was a lie had higher religiosity scores. In neither case was there a statistically significant association between agreement with this definition and frequency of reported lying.

\section{Untrue in Situation Without Expectation of Truth-telling}

Similarly, a substantial majority of respondents ( $83 \%$ to $89 \%)$ indicated that a statement that is untrue but made in situations where people may not expect the truth was a lie. All staff-weighted respondents who indicated this was a lie had statistically significantly higher religiosity scores. Stennis Fellows who indicated this was a lie had nominally higher but not statistically significantly higher religiosity scores. Agreement with the definition was not associated with a difference in reported lying for either group.

\section{White Lie}

Sixty-nine percent to $72 \%$ of respondents indicated that a "white lie" constituted a lie.

Respondents from both groups who indicated this was a lie had higher mean and median religiosity scores. All staff-weighted respondents indicating this was a lie reported telling 
fewer lies but the difference was not statistically significant. There was no difference in reported lying for Stennis Fellows who indicated this was a lie.

\section{Bullshit}

Respondents were much more divided in whether to classify "bullshit" as a lie or not. Forty percent to $47.5 \%$ believed this to be a lie. All staff-weighted who believed this to be a lie had slightly higher religiosity scores. Fellows who believed this to be a lie had significantly higher religiosity scores. Belief that "bullshit" is a lie was associated with slightly lower reported lying for both groups. This result, if accepted, reveals a paradox. On the one hand, one might expect that individuals with broader definitions of lying would report lying more frequently because their definition captures a wider range of communications. On the other hand, the wider definition of lying may be indicative of the application of a more restrictive model of what counts as ethical communications.

\section{False Statement Without Expectation of Successful Deception}

In contrast with the divide about "bullshit," $80 \%$ of respondents believed that an untrue statement issued without expectation of successfully deceiving someone was a lie. All staff-weighted who believed this to be a lie reported nominally but not statistically significantly higher religiosity scores. Fellows who believed this to be a lie reported higher religiosity scores.

\section{False Statement To Someone Without Right to Truth}

Respondents were equally united around the idea that an untrue statement made to someone who did not have a right to the information (Grotius) was a lie. Eighty percent 
to $85 \%$ of respondents indicated this was a lie. All staff-weighted indicating this was a lie had nominally higher but not statistically significantly higher religiosity scores. Fellows who believed this to be a lie had higher religiosity scores. For fellows, the differences were not insignificant - four points out of a possible score of 33 . This supports the idea that there may be a very slight association between this definition and higher religiosity.

\section{Justifications for Lying}

Religiosity was at least directionally associated with more restrictive perspectives on lying across the technical definitions of lying. This pattern continued for the justifications for lying. More restrictive approaches to if and when a lie is justified were associated with higher religiosity and, perhaps not surprisingly, lower reported lying. The relationship with religiosity appeared to be stronger suggesting that religiosity may have slightly more impact on an individual's abstract and non-contextual reflections about lying than on the actual practice itself.

\section{Never OK}

Thirty percent to $40 \%$ of respondents indicated that it was never OK to tell a lie. All staff-weighted and Stennis Fellows who agreed with this statement reported higher religiosity scores and reported telling nominally, but not statistically significantly, fewer lies. 


\section{OK If Benefits Person to Whom It is Told}

Only $13 \%$ to $21 \%$ of respondents indicated that it was OK to lie if it would benefit the person to whom it was told. All staff-weighted who agreed with this statement had lower religiosity scores and reported telling more lies. Stennis Fellows who agreed with this statement had lower, but not statistically significantly lower, religiosity scores and reported telling more mean and median (but not statistically significantly) lies.

\section{OK IF Benefit More People than It Harms}

Twenty-four percent to $33 \%$ of respondents agreed that it was OK to tell a lie if it would benefit more people than it harmed. All staff-weighted who agreed with the statement had lower religiosity scores and reported telling more lies. Fellows who agreed with the statement had nominally lower but not statistically significantly lower religiosity scores. They also reported telling more mean and median lies but the difference was not statistically significant.

\section{OK to Lie When Others Lie to You}

Only $13 \%$ to $16 \%$ of respondents agreed that it was OK to lie when others are lying to you. All staff-weighted and Stennis Fellows who agreed with the statement had lower religiosity scores and reported telling more mean and median lies. This finding suggests that the Mutual Trust Principle posited by Cramton and Dees is not in play as much as the authors might have expected. Their theory posited that lying about settlement price is widely condoned and widely practiced, and that it is unfair to expect someone to incur the risks associated with being truthful when there is limited reason to believe the other party is being truthful. Staff posit that it is not $\mathrm{OK}$ to lie when others are lying to you. 
The role reversal questions in the case section of the survey raise additional questions about the state of nature described by Cramton and Dees. Staff and fellows who indicate that they would lie also overwhelmingly expected that the other party would lie if their roles were reversed. By itself, this would suggest some evidence for Cramton and Dees' hypothesis. Over and against this, however, the majority of staff said they would be truthful in these cases despite believing that the other staff would be deceitful if their roles were reversed. The minority of staff who condoned lying under these circumstances may well share Cramton and Dees perspective on mutual defense. The majority of staff appeared not to agree with this perspective.

\section{OK To Lie To People Without Right to Truth}

Thirty percent to $40 \%$ of respondents agreed that it was OK to lie to people who did not have a right to the information. All staff-weighted who agreed with the statement had lower religiosity scores and told more lies. Fellows who agreed with the statement had lower but not statistically significantly lower mean and median religiosity scores. They also reported telling more lies.

These percentages were relatively consistent with the approach staff took to the case involving disclosure of classified information. This case was constructed as a paradigm case involving the right to information. Thirty-three percent to $42 \%$ of staff indicated they would lie in the case, with an additional one to three percent indicating they would obfuscate. Only two to $11 \%$ indicated they would provide a direct and truthful answer. 


\section{OK to Lie To People Intending Illegal or Unethical Use}

Thirty-nine percent to $54 \%$ of respondents indicated it was OK to lie to people who intended to use the information in an illegal or unethical way. All staff-weighted who agreed with the statement had lower religiosity scores and reported telling more (but not statistically significantly more) lies. Stennis Fellows reported telling nominally, but not statistically significantly more lies and had no difference in religiosity scores.

\section{OK to Lie to Advance Good Cause}

Only seven percent to $10 \%$ of respondents agreed that it was OK to lie to advance a good cause. All staff-weighted who agreed had lower, but not statistically significantly lower, religiosity scores and reported telling more, but not statistically significantly more, lies. Stennis Fellows who agreed with this statement had lower religiosity scores and told more lies.

This appears to understate the willingness of staff and fellows to provide a less than truthful statement. In the Conference Committee Case, $20-25 \%$ of respondents were willing to lie, while only $22-29 \%$ were willing to offer a direct and truthful statement. This adds to the argument that cases may provide a clearer picture of professional beliefs and practices than abstract definitions and justifications. In addition, as will be discussed later, it may provide some evidence for an argument that staff hold more than one social identity in balance. When considering an abstract definition or justification, the religious identity may be more salient and have greater influence over the respondent assessment. When considering a case that involves professional practice, the professional identity 
may be more salient and have greater influence over the respondent assessment of the case.

\section{OK to Lie to Protect Friend or Family}

Forty-six percent to $66 \%$ of respondents indicated it was OK to lie to protect a friend or family member. All staff-weighted and Stennis Fellows who agreed had lower religiosity scores and reported telling more lies.

\section{OK to Lie to Strengthen Negotiating Position}

Only $11 \%$ to $13 \%$ of respondents indicated it was OK to lie to strengthen their negotiating position. All staff-weighted and Stennis Fellows who agreed with the statement had lower, but not statistically significantly lower, religiosity scores. Both groups reported telling more lies. As alluded to earlier, this challenges the observation by Cramton and Dees that professional negotiators widely condone lies about settlement preferences.

Three cases provided opportunities to test the consistency of these responses: the amendment case, the conference committee case, and the bill promise case. The bill promise case offered the closest analogue. Consistent with responses to this proposed justification for lying, only $9 \%$ to $11 \%$ indicated they would be willing to make the false promise, while $62 \%$ to $72 \%$ indicated they would directly and truthfully answer no. 


\section{OK To Lie In Campaign When Others Lie About You}

Only $6 \%$ to $8 \%$ of respondents agreed that it was OK to lie in a campaign when the other party is lying about you. All staff-weighted who agreed with the statement had lower religiosity scores and reported telling more, but not statistically significantly more, lies. Stennis Fellows who agreed with the statement had lower religiosity scores and reported telling more lies.

\section{Cases}

The cases added complexity to the picture created by the prior survey questions. While the focus of the analysis was on the impact of religiosity, the cases did provide an opportunity to test the consistency of earlier respondent statements about the definition and justification for telling lies. For example, $48 \%$ of respondents who indicated they believed it was never OK to lie indicated that they would lie to their colleague in the cancer case. Only $7.3 \%$ of these respondents indicated that they did not believe this to be a lie.

One implication of these results is that cases, with their richer detail and context, provide a better vehicle than more abstract definitions for illuminating the practical reasoning of research subjects. As will be discussed later, it also provides evidence for the argument that staff may hold multiple social identities in balance and that the professional identity becomes more salient when assessing a case presented in and with professional context. 


\section{Cancer Case}

Sixty-two percent to $69 \%$ of respondents would lie by telling their colleague that they thought she looked better. Congressional staff who would lie reported lower religiosity. Fellows who indicated they would lie also reported lower religiosity, but the difference was not statistically significant. Roughly $30 \%$ of respondents chose "other," indicating that this case raised significant dissonance between individuals' desire to be truthful and their desire not to contradict their colleague's self-assessment. Respondents indicating they would lie drew heavily on their desire to protect their colleague's feelings and concern that the truth would cause more harm than good.

\section{Pornography Case}

In contrast with the cancer case, in the pornography case relatively few respondents chose "other." This suggests that they viewed their obligations to be relatively clear and devoid of conflict. Only $10.6 \%$ to $12.8 \%$ of congressional staff indicated they would keep their promise to their colleague and lie to their boss about the downloading of pornography. These staff and fellows recorded lower religiosity scores than did staff and fellows who indicated they would answer their boss truthfully.

Despite the fact that $30 \%$ to $40 \%$ of respondents indicated it was never OK to lie, only $3.2 \%$ to $4.5 \%$ of respondents who indicated they would answer their boss truthfully cited this as their primary reason. A sizeable portion indicated that they felt an obligation to their boss to tell the truth or that the obligation to tell the truth was stronger than the obligation to keep the promise. Among those who indicated they would lie, the most 
frequent justification was that the obligation to keep the promise was stronger than the obligation not to lie.

\section{Natural Disaster Case}

As discussed previously, desire by respondents to select "other" and avoid one of the provided response options is one indication that they find the case to be morally complex. This case provided respondents with a possible conflict between their desire or obligation to be truthful and their desire to advocate for their employer. Twelve percent to $15 \%$ of respondents indicated that they would lie to the editor and indicate that their member had directly intervened. Respondents indicating they would lie reported lower religiosity scores. The difference, however, was not statistically significant.

Thirty-four percent to $39 \%$ of respondents indicated they would truthfully answer "no," while a majority of respondents chose "other." Respondents choosing "other" presented a variety of strategies for attempting to avoid telling a lie while also not answering the editor truthfully. Some of these respondents attempted to evade the question, some attempted to obfuscate (i.e., I don't know), some indicated that the "office" worked on it, and others implied without directly stating the member's involvement.

This case represents a relatively common type of social transaction for staff. It is clear from the responses that staff are attempting to balance their strong desire to advocate for their boss, so that he or she is presented in the best light, with their desire to be truthful or their concern about the potential risks of exposed deception. 


\section{Conference Committee Case}

The conference committee case continued a pattern of exposing greater complexity the more closely the case involved professional practice. Respondents were asked whether they would answer their negotiating partner truthfully that the conference report language did not reflect the legislative deal they had negotiated.

Respondents were nearly equally divided with regard to whether they would answer truthfully or tell a lie. The largest proportion of respondents would indicate "other." Respondents selecting "other" attempted various strategies to avoid telling a direct lie while also avoiding making truthful statements. About half of them attempted to evade the question, others implied an untrue answer, and some avoided a direct lie by obfuscating. Congressional staff indicating they would lie in this situation had slightly lower religiosity scores. The difference was not statistically significant. There was nearly no difference in religiosity between fellows who answered "yes" and those who answered "no."

Respondents had lower expectations of their colleagues than they did of themselves. Forty-eight percent to $55 \%$ of respondents expected the other staff member to lie if the situation were reversed. While religiosity appeared to have little effect on the respondents' choices, there was a strong relationship between a respondent's willingness to lie and her expectations regarding what the other party would do if circumstances were reversed. Eighty-four percent of staff and $86 \%$ of Stennis Fellows indicating they would lie in the situation expected that the other staff would lie. In contrast, only $53 \%$ of staff 
and $40 \%$ of fellows who indicated they would answer truthfully expected the other staff to lie.

\section{Amendment Case}

The amendment case exposed a diversity of approaches to truth-telling and continued the pattern of respondents seeing greater complexity in cases involving their professional practice. In this case, respondents were asked whether they would sacrifice the strategic value of being able to offer a surprise amendment to their desire or obligation (if they believed they had one) to respond truthfully to a direct question from the chairman of the committee of jurisdiction.

About half of respondents chose "other" in order to find ways to avoid telling a lie while also avoiding a truthful answer. Among respondents choosing "other," evasion and obfuscation were the most common strategies.

Fifteen percent to $31 \%$ of respondents indicated they would lie by telling the chairman "no." There was no difference in religiosity between those who would answer "yes" and those who would answer "no." A significantly greater proportion of respondents indicated they would lie than indicated they would tell the truth. Stennis Fellows were the exception; they relied more on "other" than either House or Senate staff. Among staff answering "no," the most common reasons were that the benefit was greater than the cost, the answer would be used against them, or the chairman did not have a right to the truth. 
Repeating the pattern found in the conference committee case, respondents had significantly lower expectations of their colleagues. Forty-seven percent to $60 \%$ believed that the chairman would lie if the circumstances were reversed. Ninety-three percent of staff and $100 \%$ of fellows who indicated they would lie expected that the chairman would lie under the same circumstances.

\section{Classified Case}

The Classified Case also presented respondents with what they deemed to be a morally complex case. Respondents were asked whether they would violate their obligation not to disclose classified information in order to advance economic development in their employer's state or district. This case held the greatest likelihood of being affected by the Snowden revelations and the debate over the moral and legal issues surrounding them. The easy, and, for those concerned about their privacy, the safe answer was to simply say "no." Roughly half of respondents (64\% of fellows), however, indicated "other" and attempted to avoid telling the truth without telling a lie. Evasion was the most common strategy.

Three percent to $11 \%$ would violate their obligation to preserve national secrets to answer truthfully. These responses were surprisingly high in view of the news (coinciding with launch of the survey) of the Edward Snowden case and the possible legal consequences of disclosing classified information. Respondents were nearly equally divided with regard to their reasons: always wrong to lie, duty to advocate for boss, benefits to district, and obligation to tell the truth greater than obligation to preserve secrets. 
Thirty-four percent to $43 \%$ would lie and tell their constituent "no" in the Classified Case. Staff indicating they would say "no" reported slightly lower religiosity scores. Fellows also had slightly lower religiosity scores but the difference was not statistically significant. Among respondents indicating they would lie, the majority indicated that the obligation not to disclose was greater than the obligation to tell the truth. Roughly a quarter would have followed Grotius and indicated that the CEO did not have the right to the truth.

\section{Presidential Debate}

This case provided respondents with the opportunity to assess the presidential debate case that Carson utilized to describe evasion. In this case, a candidate who had previously made commitments to social activists that she would apply a Roe v. Wade litmus test to her Supreme Court nominees, is asked in a debate whether she would in fact apply such a litmus test. The nominee suggests that this is one but not the only factor that should be taken into account.

Respondents were largely united in their assessment of the presidential debate case put forward by Carson. Carson argued that this case constituted a form of evasion rather than a lie. Roughly $70 \%$ of respondents agreed that this was not a lie. Among respondents indicating this was not a lie, the two most popular explanations were that the statement was not false or that a partly true statement is not a lie. For the small percentage of respondents indicating that the candidate lied, the most popular reason was that the statement was untrue and intended to deceive people. 
The case revealed a contradiction in the respondents' thinking about lying that has bearing for future survey work. Fifty percent of respondents indicated that a "statement that is partly true" constituted a lie in the definitions section of the survey. When presented with this case, however, only $28 \%$ to $32 \%$ of those respondents thought that the candidate lied. Presenting simple, but abstract, definitions appears to yield different results than presenting cases that are imbued with richer texture and detail. Staff and fellows who believed this to be a lie reported slightly higher religiosity scores. In both cases, the differences were not statistically significant.

\section{Bill Promise Case}

In contrast with prior cases on legislative practice, respondents found the bill promise case to be relatively simple. In this case, respondents were asked whether they would make a promise they believed they could not keep in exchange for securing passage of a bill they strongly supported. Only $9 \%$ to $12 \%$ of respondents indicated they would lie and make the false promise. Once again, staff and fellows answering "yes" had slightly lower religiosity scores. In both cases, however, the differences were not statistically significant.

Among staff who indicated they would not lie, $45 \%$ to $51 \%$ indicated that the most important reason was that the discovered lie would undermine future negotiations. Respondents were more than four times more likely to select this reason than any other option provided. This suggests that roughly half of respondents view the role of trust in negotiations important enough to take steps to protect it. 
As was evident in the earlier cases, staff had substantially less confidence in the veracity of their colleagues. Twenty-seven percent to $42 \%$ expected that their colleagues would lie if the circumstances were reversed. This suggests that trust is somewhat fragile. As one senior staff member indicated during field testing, "the key to negotiations in politics is to have a short memory." It may be that staff think about trust in global terms differently than they do in the context of the negotiations that are immediately before them.

Eighty percent of staff and $100 \%$ of fellows who would make the false promise believed that the other staff would lie if the circumstances were reversed. Staff expecting a false promise reported slightly higher religiosity scores. Fellows also reported higher religiosity scores, but the differences were not statistically significant. Staff expecting a false promise reported being lied to more frequently and telling more lies. This pattern was repeated by fellows although the differences were not statistically significant.

\section{The gap between expectation and measurement}

Western religious traditions, with which most congressional staff identify, offer a great deal of guidance and have heightened expectations regarding ethical practice in the personal and professional lives of their adherents. Members of these traditions, as well as the general public, associate religious practice and commitment with higher standards of conduct. Researchers, however, have struggled to identify a clear relationship between religiosity and ethical practice. 
Research with children, young adults and adults examining the relationship between religiosity and scores on Eysenck's lie scales in the 70s and 80s identified a positive correlation between religiosity and lie scale scores (higher religiosity correlated with a greater proclivity to lie). Other studies found no relationship between religiosity and Eysenck lie scores. No studies identified a significant negative correlation between religiosity and Eysenck scores. ${ }^{146}$ Early interpretation of these results varied and included the conclusions that individuals with high religiosity scores told more lies, were more susceptible to social conformity, or, paradoxically, were being more honest than respondents with low religiosity scores. ${ }^{147}$

The findings of this study are consistent with the previous literature on religiosity, ethics, and professional practice. No statistically significant relationship could be identified between religiosity and the frequency with which individuals reported lying or with the frequency with which they reported being lied to. The relationship between religiosity and more complex definitions of lying and analysis of the cases were not always consistent between congressional staff and fellows. To the extent that a pattern could be discerned, there was a tendency toward the acceptance of more restrictive definitions of lying among staff with higher religiosity scores.

These findings are at odds with the common expectations of many people within religious traditions that there is a strong relationship between religion and morality and

\footnotetext{
${ }^{146}$ Ibid.

${ }^{147}$ Ibid.
} 
the moral practice of adherents. ${ }^{148}$ How then to make sense of this apparent disconnect between traditional teaching, expectations and practice?

Although western religious traditions say a great deal about morality, the traditions have long recognized that the practical reasoning through which an agent moves from theory, sentiment, or general cases to concrete cases, rules, and actions is complex and that as a result different agents often reach divergent conclusions. James R. Rest, a moral psychologist, posits a multi-step process for understanding ethical decision making and practice. The first step involves recognizing the moral importance or significance of the circumstance one is in; the second step involves making a decision to act or not act in a particular way; the third step involves establishing the intention to act on the decision; and the final step involves execution of the intention. ${ }^{149}$

This secular psychological model has significant, and to some extent more developed, counterparts within philosophical and theological models of practical reason. If ethical practice is viewed through the lens of practical reason, there are numerous opportunities (rightly or wrongly) for individuals from the same tradition to act in different ways. Nonetheless, one would expect that, given a large enough sample, a convergent pattern would emerge.

Weaver and Agle build upon Rest's work and propose a theoretical frameworksymbolic interactionism-- that may advance future research on the inability of researchers

\footnotetext{
${ }^{148}$ See for example, James Bell, "The World's Muslims: Religion, Politics and Society," (Washington DC: Pew Research Center, 2013).

${ }^{149}$ James R. Rest, Moral Development: Advances in Research and Theory (New York: Praeger, 1986).
} 
to identify a clear relationship between religiosity and actual moral practice. Symbolic interactionism posits that religious traditions provide role expectations that become internalized through repetition and repeated interaction among and within religious communities. ${ }^{150}$ These role expectations become part of what the individual understands it means to be a part of the religious community. Individual differences in the way these role expectations are expressed or lived out reflect individual differences in the salience or centrality of the individual's religious role identity to the individual's social identity. $^{151}$

To the extent that role expectations and identities are established through the myriad social interactions an individual has (e.g., marriage, parent, boss), each individual's social identity is the product of the complex interaction between these roles. Context and the degree to which a particular component is most salient become central to understanding the relationship between particular role identities and moral practice. Simply put, the empirical (as opposed to normative) expectation that religiosity should be positively correlated with religious community views of appropriate moral practice may assume a homogenous (and overly simplistic) view of social identity.

Congressional staff approach the question of lying not just as members of religious communities, but also as members of political communities and in the role of advocate for their employer. Despite efforts in this survey to capture the salience of religious role

\footnotetext{
${ }^{150}$ There are parallels to classical formulations of the role of repetition in character formation as part of virtue models of ethics.

${ }^{151}$ Gary R. Weaver and Bradley R. Agle, "Religiosity and Ethical Behavior in Organizations: A Symbolic Interactionist Perspective," Academy of Management Review 27, no. 1 (2002).
} 
identity, the apparent disconnect betwen religiosity and lying suggests that individual role identities are not homogenous but that component role identities (e.g., religion, spouse, etc.) rise to greater or lesser salience in specific contexts. Evidence for this position may possibly be found in the difference between responses to the abstract definitions and justifications for lying and the responses to the cases. The cases provided a rich, professional context in which respondents engaged in practical reasoning. The professional context may prime the respondent to respond by drawing upon the norms associated with his or her professional rather than those of his or her religious social identity. ${ }^{152}$

Examination of the relationship between religiosity and lying illustrates the challenge that this poses. Lying was chosen for this study because it is commonly believed to be practiced by politicians and because there is equally widespread disapprobation of the practice. Sisela Bok, speaking in strictly secular terms, argued that lying always stands in need of justification. Lying is regarded with at least, if not more, suspicion within Christian and Jewish ethics (the two traditions with which most congressional staff identify).

Most staff reported that they did not lie within a 24 hour period. And contrary to popular belief, on average, staff reported lying at rates only modestly higher than the population at large. Because of the strength of the general disapprobation against lying, it is perhaps

\footnotetext{
${ }^{152}$ Recent research has looked at the role of priming in strengthening the relationship between religiosity and action. For example, providing individuals with religious words immediately prior to asking them to participate in a prisoner's dilemma game increased pro-social behavior. See for example, Ali M. Ahmed and Osvaldo Sala, "Implicit Influences of Christian Religious Representations on Dictator and Prisoner's Dilemma Game Decisions," The Journal of Socio-Economics 40, no. 3 (2011).
} 
not surprising that staff who reported that they did not lie had both high and low religiosity scores.

In contrast, however, a few staff report being very prolific liars. Given the strength of the disapprobation of lying within religious traditions, one might have expected to see a smaller proportion of religious liars. The fact that there is no significant difference in the mean or median religiosity of prolific liars when compared with infrequent liars suggests that something else, perhaps another social/role identity, is influencing behavior.

Future research should examine this possibility in greater detail. Experiments could be drawn to provide cases that are very similar but change the context in ways which might prime different social identities (e.g., religious, familial, professional). To the extent that this priming alters the respondents' understanding and assessment of the case and the actions that are warranted by it, there would be evidence to support the symbolic interactionist perspective posited by Weaver and Agle. This in turn could offer significant and valuable insights for those interested in religious moral education and in the development of professional ethics pedagogy.

\section{Closing observations}

One of the challenges of this and other descriptive work on lying is that it relies upon self-reports. These self-reports are vulnerable to self-deception, the desire to preserve a positive self-image, and/or the desire to project a positive or desirable social image to others. There are numerous ways to attempt to estimate the strength of these factors. One method was employed in this study - the role reversal question. Whether it was 
when reflecting on how many times they had been lied to in the previous 24 hours, or their reflections on the Amendment, Conference Committee, and Bill Promise cases, a significant portion of respondents anticipated that other staff members would lie with greater frequency than they themselves would. It is not unfair to ask whether the $30 \%$ who indicate they would lie or the $60 \%$ who believe the other party would lie if the circumstances were reversed represents a more accurate portrait professional attitudes and practice. Surveys attempt to capture self-reported data about internal attitudes, beliefs, and intentions. Further work should be done to develop a method that allows independent observation and measurement of actual legislative, regulatory and advocacy practice.

Second, despite the widespread belief that religious traditions have something significant to say about and to contribute to the ethics of lying, there is very little systematic historical or theoretical work on specifically religious contributions to this conversation. One exception is Paul Griffith's recent work on Augustine. Looking specifically at modern Christian communities as an example, we see that these issues, when engaged at all, tend to be engaged in pastoral communications delivered in person or from the pulpit.

There would be great value in an in depth historical look at the way religious traditions have thought about and established expectations about lying for members of their communities. ${ }^{153}$ This analysis should attend not only to the content, but to the form and context in which the tradition's position is communicated or delivered.

\footnotetext{
${ }^{153}$ I am reminded of the important work that Gene Outka did to unpack the many ways that agape has been understood and employed within Christian ethics. Lying stands in need of similar explication.
} 
Finally, despite the challenges described earlier, empirical/descriptive ethics have important contributions to make to normative ethics. Research on the role of religiosity and prejudice suggests that individuals exhibit less prejudice toward minority groups if their religious community specifically condemns the associated practices. ${ }^{154}$ To the extent that ethicists and members of religious communities (echoing Cramton and Dees) seek to influence professional practice, descriptive ethics provides insight into ways to bridge the divide between the hypothetical and the actual, and between an individual's religious social identity and an individual's professional social identity.

${ }^{154}$ C. Daniel Batson, Patricia Schoenrade, and W. Larry Ventis, Religion and the Individual: A SocialPsychological Perspective (New York: Oxford University Press, 1993). 


\section{Biography}

Agency, Environmental Protection. "Mail Irradiation." Environmental Protection Agency, http://www.epa.gov/radiation/sources/mail irrad.html.

Ahmed, Ali M., and Osvaldo Sala. "Implicit Influences of Christian Religious Representations on Dictator and Prisoner's Dilemma Game Decisions." The Journal of Socio-Economics 40, no. 3 (2011): 242-46.

Archives, The Association of Religion Data. "General Social Survey Cross-Section and Panel Combined." http://www.thearda.com/Archive/Files/Descriptions/GSS10PAN.asp.

Batson, C. Daniel, Patricia Schoenrade, and W. Larry Ventis. Religion and the Individual: A SocialPsychological Perspective. New York: Oxford University Press, 1993.

Beauchamp, Tom L., and James F. Childress. Principles of Biomedical Ethics. 3 ed. New York: Oxford University Press, 1989.

Bell, James. "The World's Muslims: Religion, Politics and Society." Washington DC: Pew Research Center, 2013.

Bok, Sissela. Lying: Moral Choice in Public and Private Life. New York: Vintage Books, 1989. Carson, Thomas L. "The Definition of Lying." NOÜS 4 (2006).

- - . Lying and Deception: Theory and Practice. New York: Oxford University Press, 2010.

Cohen, Jacob. Statistical Power Analysis for the Behavioral Sciences. 2nd ed. Hillsdale, NJ: Lawrence Erlbaum Associates, 1988.

Curlin, Farr A., Ryan E. Lawrence, Marshall H. Chin, and John D. Lantos. "Religion, Conscience, and Controversial Clinical Practices." New England Journal of Medicine 356, no. 6 (February 8, 2007 2007): 593-600.

Cutting, Marsha, and Michelle Walsh. "Religiosity Scales: What Are We Measuring in Whom?". Archive for the Psychology of Religion 30, no. 1-2 (2008): 137-54.

Dees, J.G., and P.C. Cramton. "Shrewd Bargaining on the Moral Frontier: Toward a Theory of Morality in Practice." Business Ethics Quarterly 1 (1991): :135-67.

DePaulo, B, D Kashy, S Kirkendol, M Wyer, and J Epstein. "Lying in Everyday Life." Journal of Personality and Social Psychology Vol. 70 (1996): 979-95.

DePaulo, Bella. "The Hows and Whys of Lies." Chap. 12 In The Social Psychology of Good and Evil, edited by A.G. Miller, 303-26. New York: Guilford Press, 2004.

Dillman, Don A., Jolene D. Smyth, and Leah Melani Christian. Internet, Mail, and Mixed-Mode Surveys: The Tailored Design Method. 3rd ed. Hoboken, New Jersey: John Wiley \& Sons, 2009.

Eilperin, Juliet. Fight Club Politics: How Partisanship Is Poisoning the House of Representatives. Lanham, MD: Rowman \& Littlefield Publishers, 2006.

Everett L. Worthington, Jr.; Nathaniel G. Wade; Terry L. Hight; Michael E. McCullough; James T. Berry; Jennifer S. Ripley; Jack W. Berry; Michelle M. Schmitt; Kevin H. Bursley. "The Religious Commitment Inventory--10: Development, Refinement, and Validation of a Brief Scale for Research and Counseling." Journal of Counseling Psychology 50, no. No.1 (2003): 84-96.

"Faith on the Hill: The Religious Composition of the 112th Congress." Pew Forum on Religion and Public Life, http://pewforum.org/Government/Faith-on-the-Hill--The-ReligiousComposition-of-the-112th-Congress.aspx.

Fallis, Don. "What Is Lying?". The Journal of Philosophy 106, no. 1 (2009): 29-56. 
Farr A. Curlin, MD, MD John D. Lantos, BS Chad J. Roach, MA Sarah A. Sellergren, and MD Marshall H. Chin, MPH. "Religious Characteristics of U.S. Physicians." J GEN INTERN MED 20 (2005): 629-34.

Fastenow, Chris, J. Tobin Grant, and Thomas J. Rudolph. "Holy Roll Calls: Religious Tradition and Voting Behavior in the U.S. House." Social Science Quarterly 80 (1999): 687-701.

Fisher, Robert J., and James E. Katz. "Social-Desirability Bias and the Validity of Self-Reported Values." Psychology and Marketing 17(2), no. February (2000): 105-20.

Frankfort-Nachmias, Chava, and Anna Leon-Guerrero. Social Statistics for a Diverse Society, 6th Edition. 6th ed. London: Sage, 2011.

Gallup. "Honesty and Ethics Poll Finds Congress' Image Tarnished: For First Time, Majority of Americans Say Its Members Have Low Ethics." http://www.gallup.com/poll/124625/Honesty-Ethics-Poll-Finds-Congress-ImageTarnished.aspx.

George, Joey F., and Alastair Robb. "Deception and Computer-Mediated Communication in Daily Life." Communication Reports 21, no. 2 (2008): 92-103.

Gidda, Mirren. "Edward Snowden and the Nsa Files--Timeline." The Guardian, http://www.theguardian.com/world/2013/jun/23/edward-snowden-nsa-files-timeline.

Goldschmidt, Kathy. "Communicating with Congress--Perceptions of Citizen Advocacy on Capitol Hill." 12. Washington, DC: Congressional Management Foundation, 2011.

Goldzwig, Steven R., and Patricia A. Sullivan. "Electronic Democracy, Virtual Politics, and Local Communities." In Political Communication Ethics: An Oxymoron?, edited by Jr. Robert E. Denton, 51-74. London: Praeger, 2000.

Griffiths, Paul J. Lying: An Augustinian Theology of Duplicity. Eugene, Oregon: Wipf and Stock, 2004.

Grotius, Hugo. The Law of War and Peace. Translated by F.W. Kelsey. Indianapolis: BobbsMerrill., 1925.

- - - The Rights of War and Peace. Translated by A.C. Campbell. . Ithaca: Cornell University Library, 2009.

Groves, RM, FJ Fowler, MP Couper, JM Lepkowski, E Singer, and R Tourangeau. Survey Methodology. Hoboken, NJ: John Wiley \& Sons, Inc., 2004.

Hancock, Jeffrey T., Jennifer Thom-Santelli, and Thompson Ritchie. "Deception and Design: The Impact of Communication Technology on Lying Behavior." CHI Letters 6, no. 1 (2004): 7.

"Hill People Project." http://www.nationaljournal.com/hill-people-who-are-they-and-wheredid-they-come-from-20110616.

Hill, Peter C., and Ralph W. Hood Jr, eds. Measures of Religiosity. Birmingham: Religious Education Press, 1999.

Hoge, D.R. "A Validated Intrinsic Religious Motivation Scale." Journal for the Scientific Study of Religion 11 (1972): 369-76.

Joshua W. Busby, Jonathan Monten, Jordan Tama, and Willian Inboden. "Congress Is Already Post-Partisan: Agreement across the Aisle on U.S. Foreign Policy." Foreign Affairs (January 28, 2013 2013).

Kant, Immanuel. Grounding of Metaphysics of Morals Translated by James Ellington. 3 ed.: Hackett Publishing Company, 1993.

Kohut, Andrew, Scott Keeter, Carroll Doherty, Michael Dimock, Luis Lugo, Alan Cooperman, and Greg Smith. "Religion, Politics and the President: Growing Number of Americans Say Obama Is a Muslim." In 2010 Annual Religion and Public Life Survey: Pew Forum on Religion \& Public Life, 2010. 
Kwak, Nojin, and Barry Radler. "A Comparison between Mail and Web Surveys: Response Pattern, Respondent Profile, and Data Quality." Journal of Official Statistics 18, no. 2 (2002): 257-73.

Lee, Ronald. "Images, Issues, and Political Structure: A Framework for Judging the Ethics of Campaign Discourse." Chap. 2 In Political Communication Ethics: An Oxymoron?, edited by Jr. Robert E. Denton, 23-50. London: Praeger, 2000.

The Compact Edition of the Oxford English Dictionary. 2 vols. Oxford: Oxford University Press, 1971.

Lugo, Luis, Sandra Stencel, John Green, Gregory Smith, Dan Cox, and Allison Pond. "U.S.Religious Landscape Survey: Religious Beliefs and Practices; Diverse and Politically Relevant." Washington, DC: Pew Forum On Religion and Public Life, 2008.

Mahon, James Edwin. "A Definition of Deceiving." International Journal of Applied Philosophy 21, no. 2 (2007): 181-94.

- - . "The Definition of Lying and Deception." In Stanford Encyclopedia of Philosophy, edited by Edward N. Zalta. Stanford: Stanford Metaphysics Research Lab, 2008.

- - . "The Truth About Kant on Lies." Chap. 11 In The Philosophy of Deception, edited by Clancy Martin. Oxford: Oxford University Press, 2009.

- - . "Two Definitions of Lying." International Journal of Applied Philosophy 22, no. 2 (2008): 211-30.

Novack, Dennis H., Barbara J. Detering, Robert Arnold, Lachlan Forrow, Morissa Ladinsky, and John C. Pezzullo. "Physician's Attitudes toward Using Deception to Resolve Difficult Ethical Problems." Journal of the American Medical Association 261, no. 20 (May 26, 1989 1989): 2980-85.

Pallant, Julie. Spss Survival Guide. 5th ed. Berkshire, England: McGraw-Hill Education, 2013.

Pearson, Paul R., and Leslie J. Francis. "The Dual Nature of the Eysenckian Lie Scales: Are Religious Adolescents More Truthful?". Personality and Individual Differences 10, no. 10 (1989): 1041-48.

Peterson, R. Eric, Parker H. Reynolds, and Amber Hope Wilhelm. "House of Representatives and Senate Staff Levels in Member, Committee, Leadership, and Other Offices, 1977-2010." Washington, DC: Library of Congress Congressional Research Service, 2010.

Rehr, David. "The Congressional Communications Report: 2012." 116. Washington, DC: George Washington University Graduate School of Political Management, 2012.

Rehr, David K. "Experience and Age Mismatch on Capitol Hill." In The BLOG, edited by Huffington Post. Huffington Post: Huffington Post, 2013.

Rest, James R. Moral Development: Advances in Research and Theory. New York: Praeger, 1986.

Salant, Priscilla, and Don A. Dillman. How to Conduct Your Own Survey. New York: John Wilely \& Sons, 1994.

Schuman, Daniel. "Keeping Congress Competent: Staff Pay, Turnover, and What It Means for Democracy." The Sunlight Foundation, 2010.

Selnow, Gary W. "Internet Ethics." Chap. 9 In Political Communications Ethics: An Oxymoron?, edited by Jr. Robert E. Denton, 203-40. London: Praeger, 2000.

Serota, Kim B., Timothy R. Levine, and Franklin J. Boster. "The Prevalence of Lying in America: Three Studies of Self-Reported Lies." Human Communication Research 36 (2010).

Slawson, Chip. "Congressional Staff Salaries Plummet to 2008 Levels " LegiStorm, http://www.legistorm.com/blog/congressional-staff-salaries-plummet-to-2008levels.html. 
Smith, Ronald E., Gregory Wheeler, and Edward Diener. "Faith without Works: Jesus People, Resistance to Temptation, and Altruism." Journal of Applied Social Psychology 5, no. 4 (1975): 320-30.

Strudler, Alan. "Deception Unraveled." Journal of Philosophy 102, no. 9 (2005): 458-73.

- - . "The Distinctive Wrong in Lying." Ethical Theory and Moral Practice 13 (2) (2010).

Tavakol, Mohsen, and Reg Dennick. "Making Sense of Cronbach's Alpha." International Journal of Medical Education, no. 2 (2011): 53-55.

Tourangeau, R., L.J. Rips, and K. Rasinksii. The Psychology of Survey Response. Cambridge, England: Cambridge University Press, 2000.

Tourangeau, Roger, and Ting Yan. "Sensitive Questions in Surveys." Psychological Bulleting 133, no. 5 (September 2007 2007): 859-83.

Van der Hei, Jim. "Dean Now Willing to Discuss His Faith; Campaign and Trips to Bible Belt States Changed Him, Candidate Says." Washington Post, January 4, 2004.

Weaver, Gary R., and Bradley R. Agle. "Religiosity and Ethical Behavior in Organizations: A Symbolic Interactionist Perspective." Academy of Management Review 27, no. 1 (2002): 77-97.

Weinberg, Stacey Swain; Joshua Alexander; Jonathan M. "The Instability of Philosophical Intuitions: Running Hot and Cold on Truetemp." Philosophy and Phenomenological Research 76, no. 1 (January 2008 2008): 138-55 


\section{Appendix A--- Web Survey}

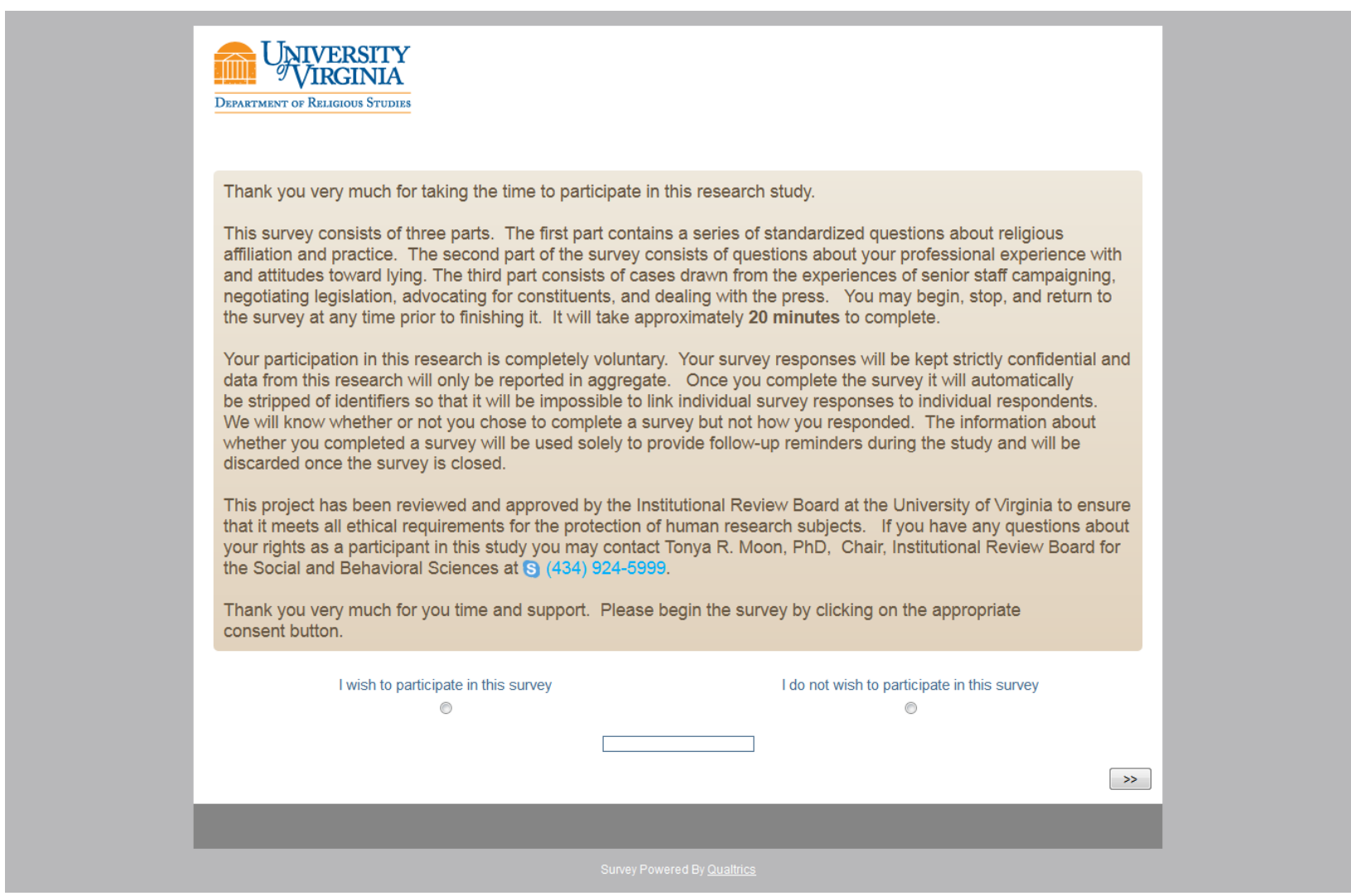

UNIVERSITY
What is your religious preference? Is it:
Buddhist
Catholic
Eastern Orthodox
Hindu
Jewish
Latter Day Saints
Muslim
Protestant
Other
No religion

486 | $\mathrm{P}$ a g e 

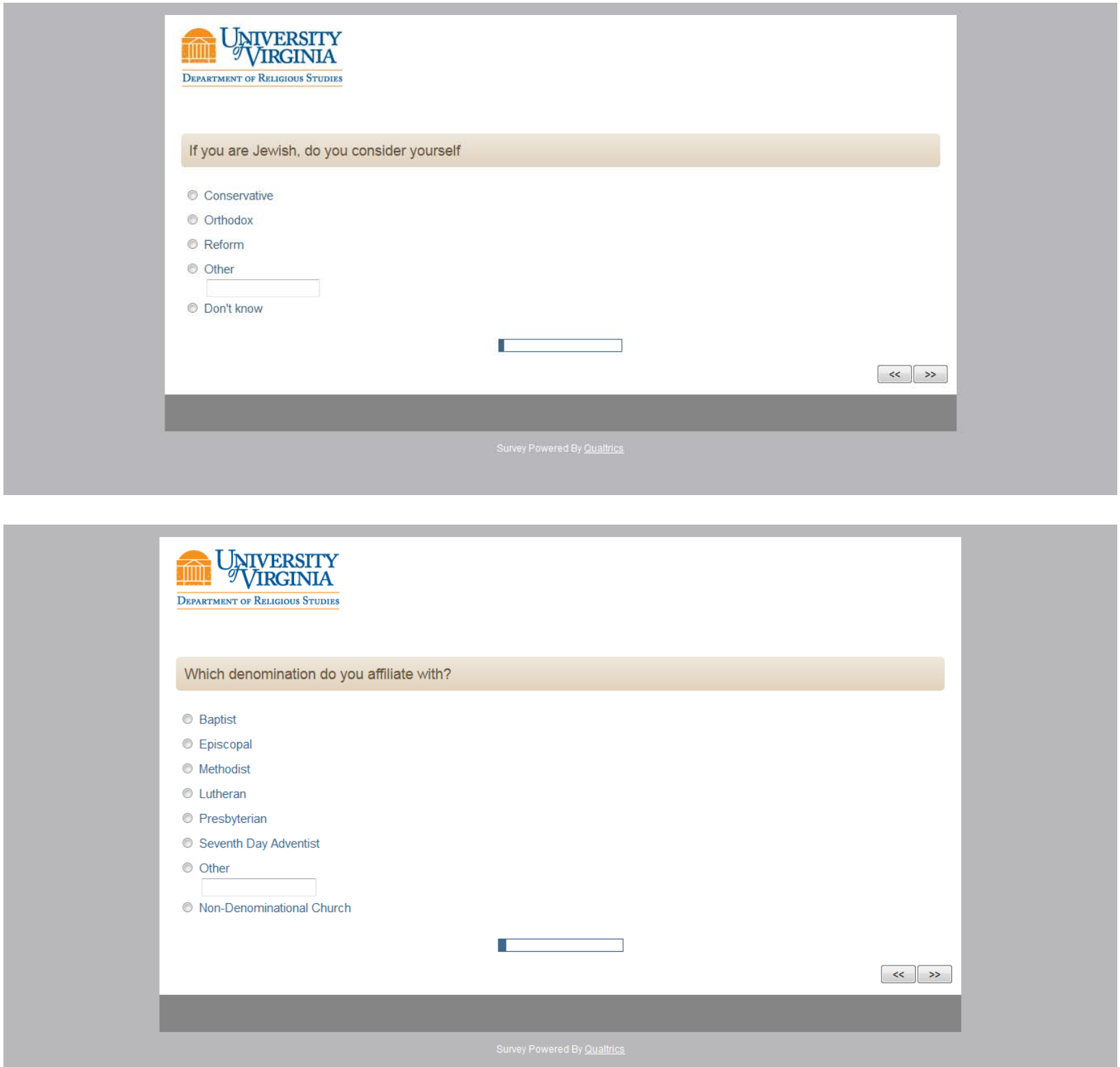

487 | P a g e 

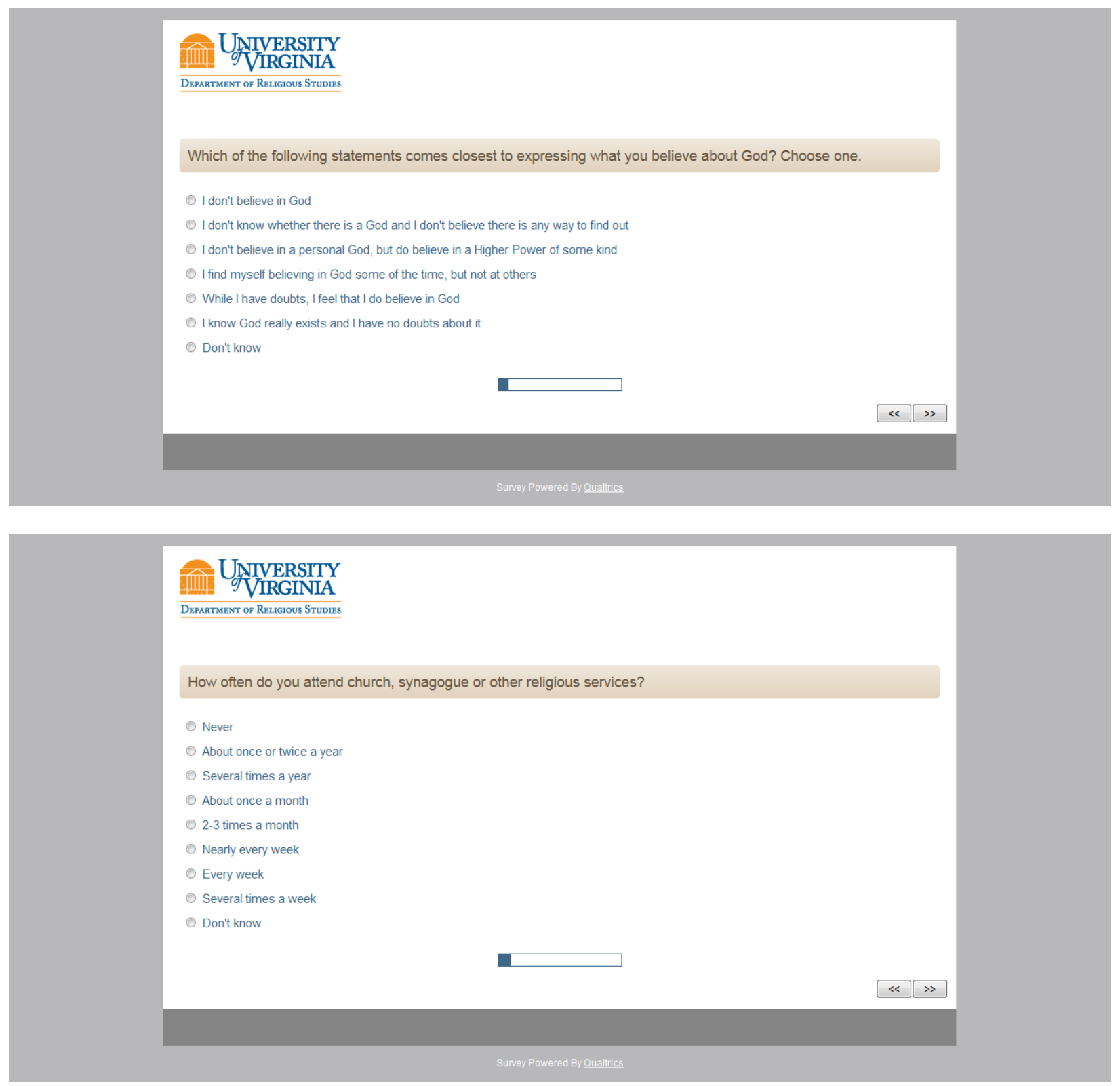

488 | $P$ a g e 

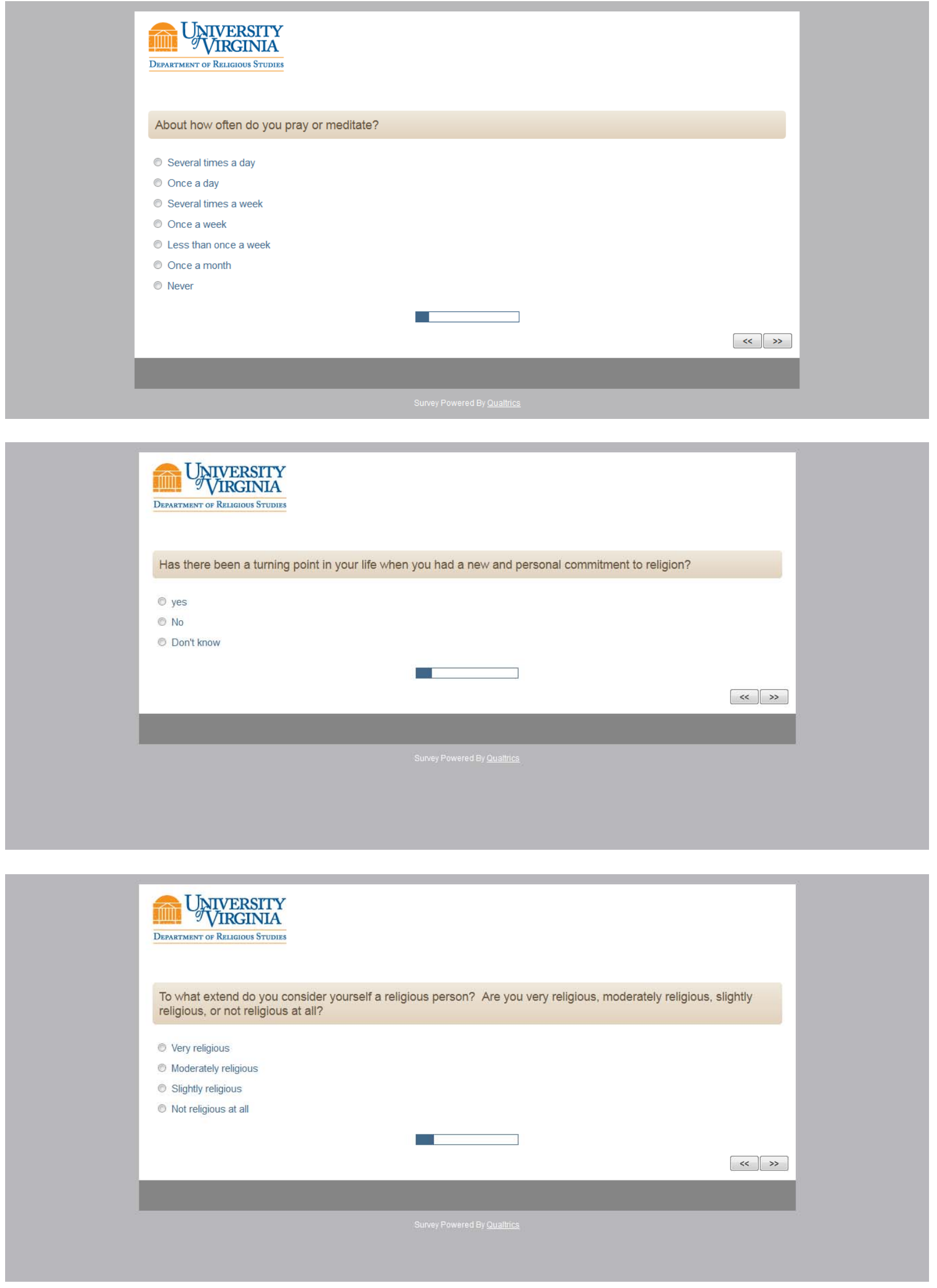

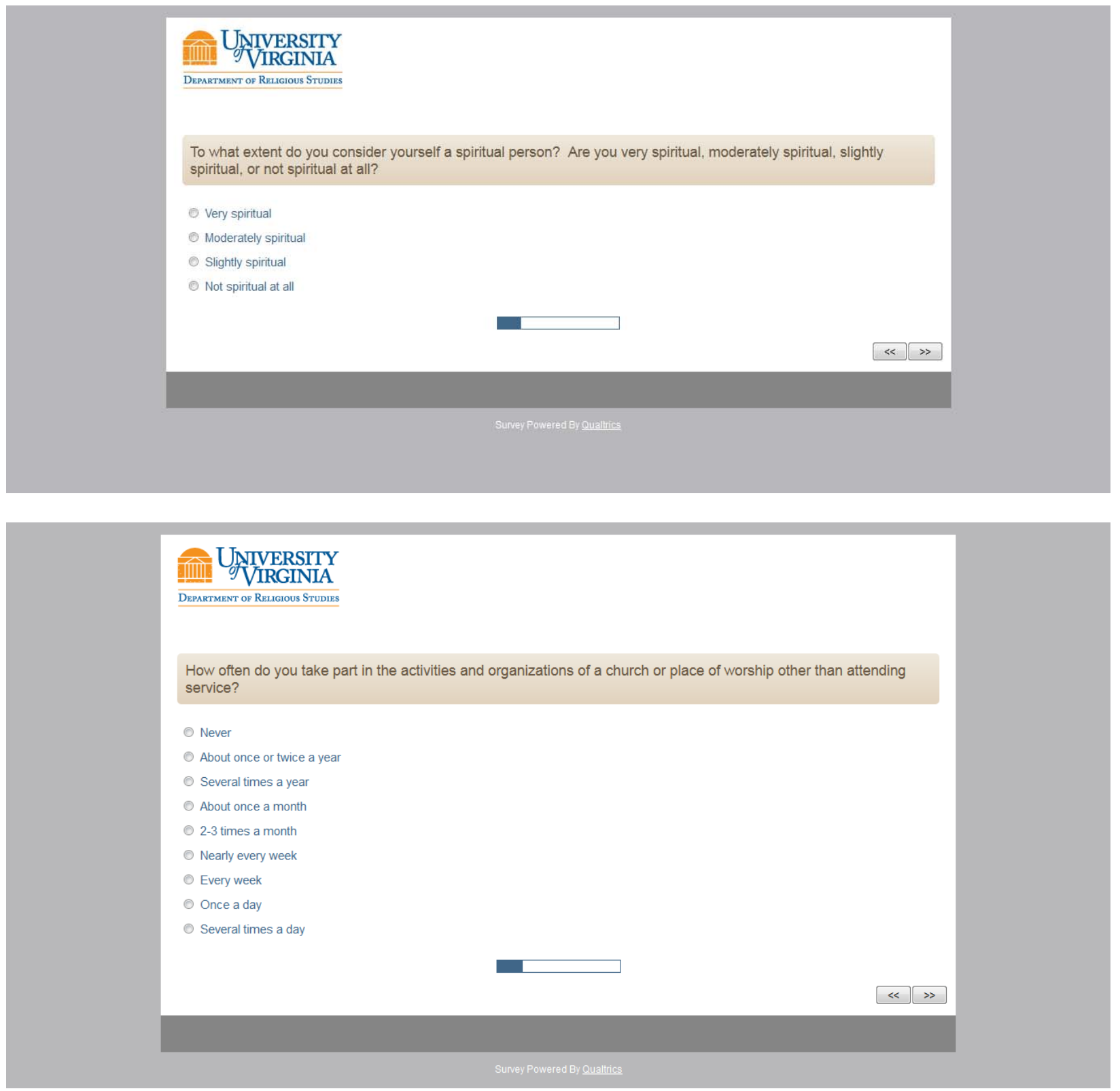

490 | P a g e 

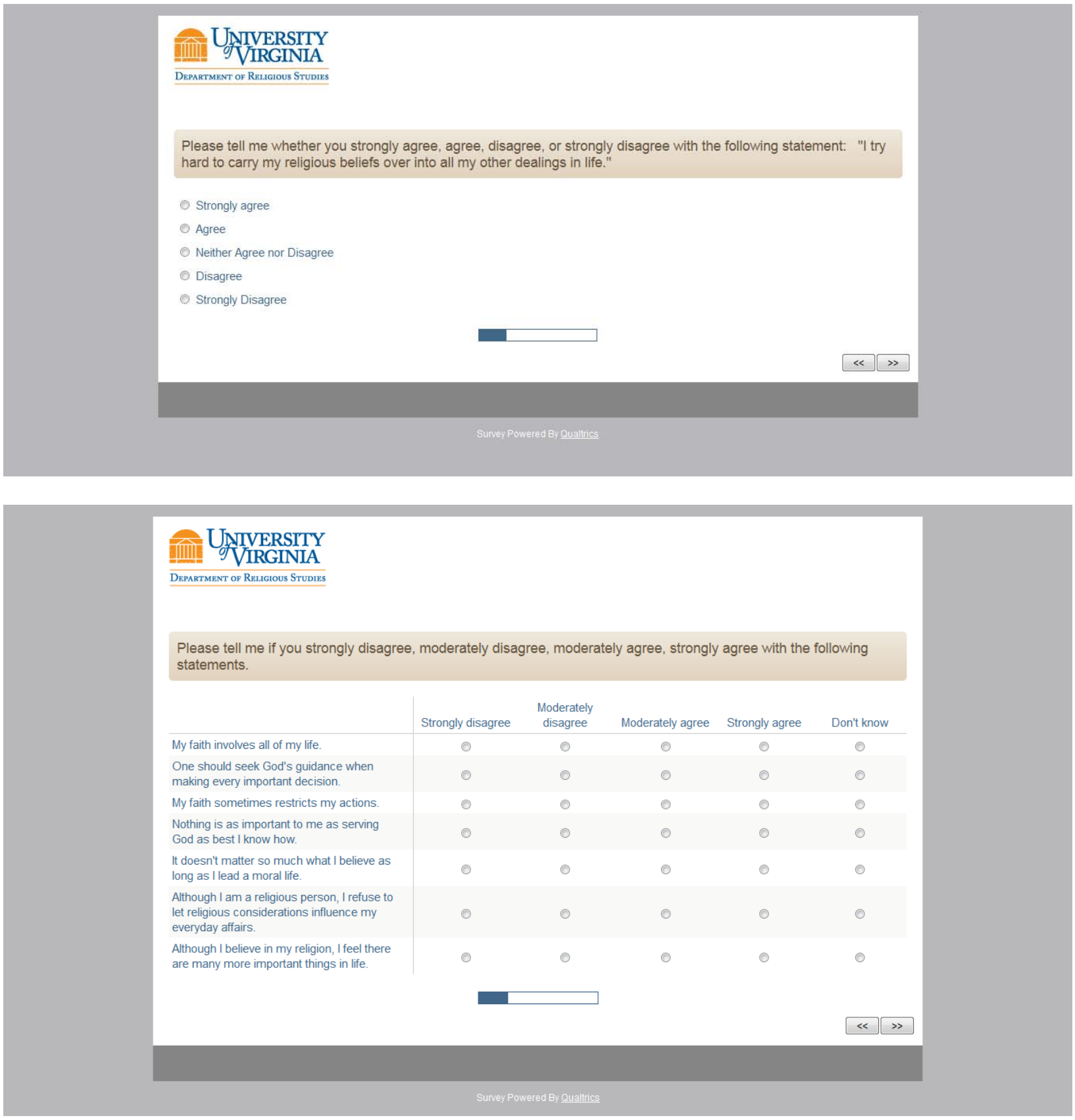

491 | $\mathrm{P}$ a g e 

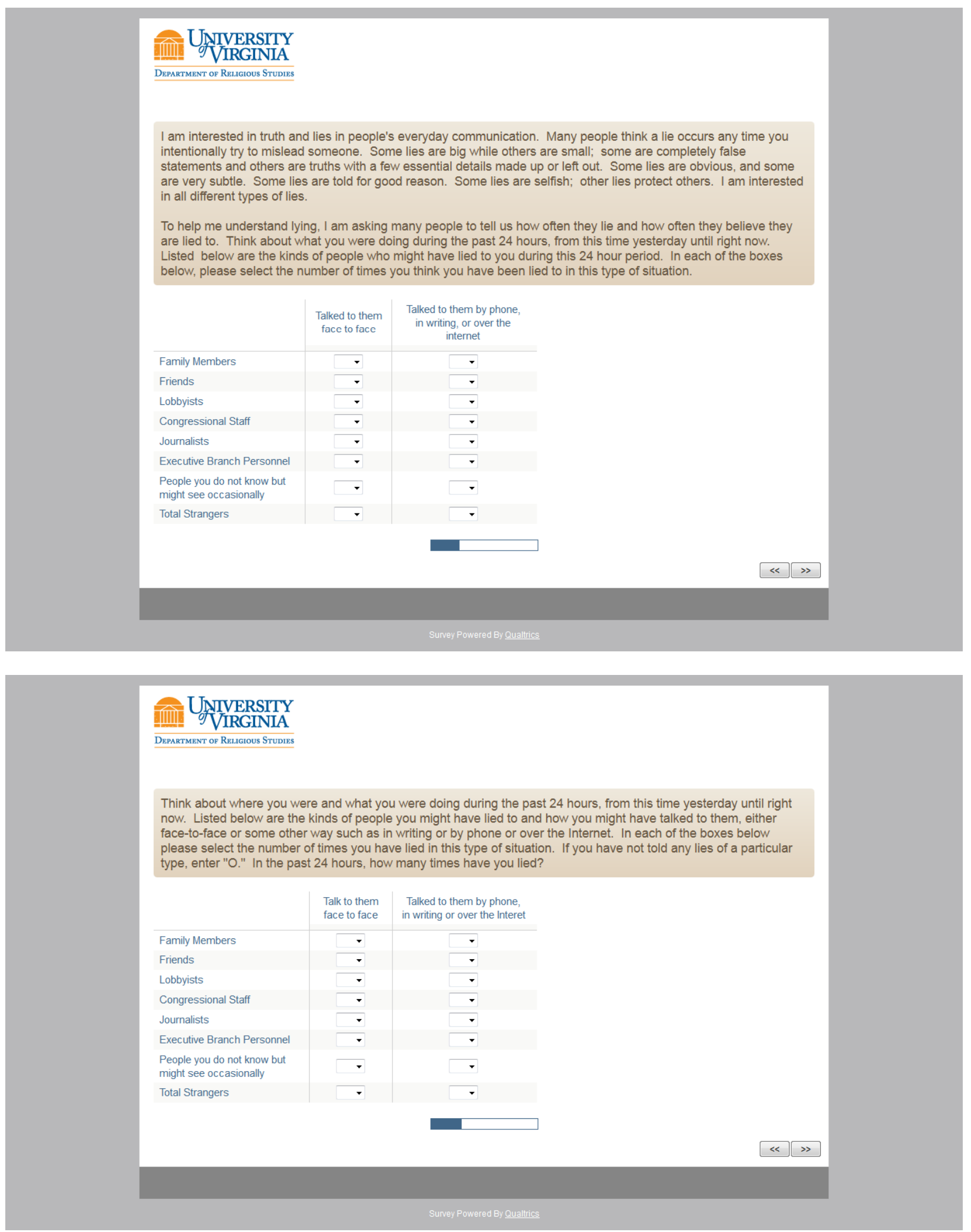

492 | P a g e 


\section{UIIIIIVIVRSITY \\ DEPARTMENT OF RELGous Studies}

People have different definitions of lying. Which of the following definitions most closely reflects your own personal definition of a lie? Choose one.

A false statement that is intended to deceive someone

Any intentionally deceptive statement

A false statement that the author asserts/claims is true whether he or she expects to succeed in deceiving someone or not

Other

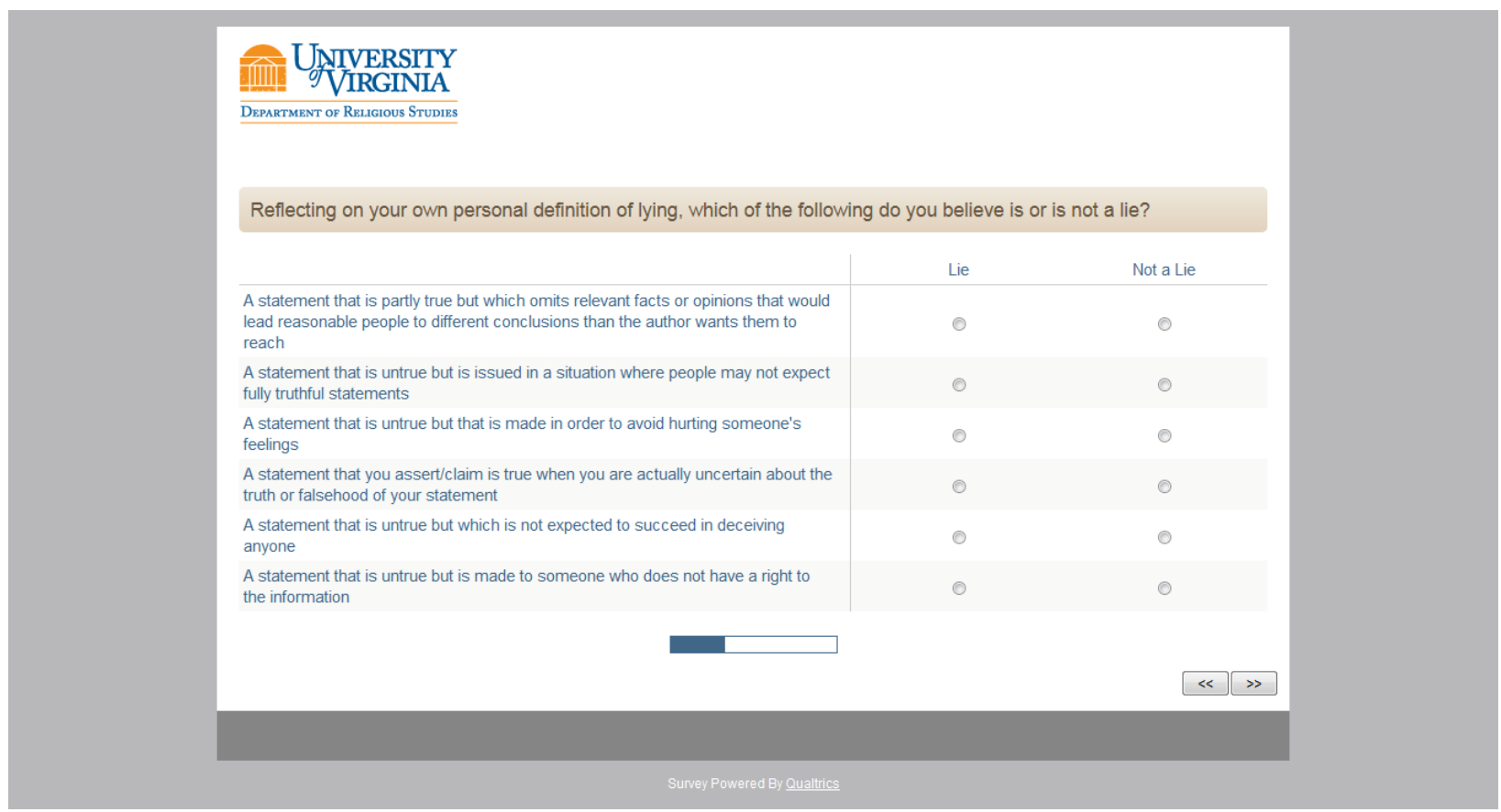




\section{UIIII) UNIVRSITY}

Dimeromer or Rer

People have different ideas about whether lying is ever morally permissible. Which of the following statements most closely reflect your views?

It is OK to lie to someone who intends to use the information in an unethical or
illegal way
It is OK to lie to strengthen your negotiating position during legislative or
regulatory negotiations
It is OK to lie to protect a friend, family member, or someone important to you
It is OK to lie to advance a good or important legislative, political, or social cause
It is OK to lie during political or legislative campaigns when the other candidate
or advocate is lying about you or your position
It is OK to lie to someone you don't believe has a right to the information they
seek
It is only OK to tell a lie if it will benefit the person to whom the lie is told
It is never OK to tell a lie
It is OK to lie in situations where others are lying to you
It is OK to tell a lie if it will help more people than it will harm

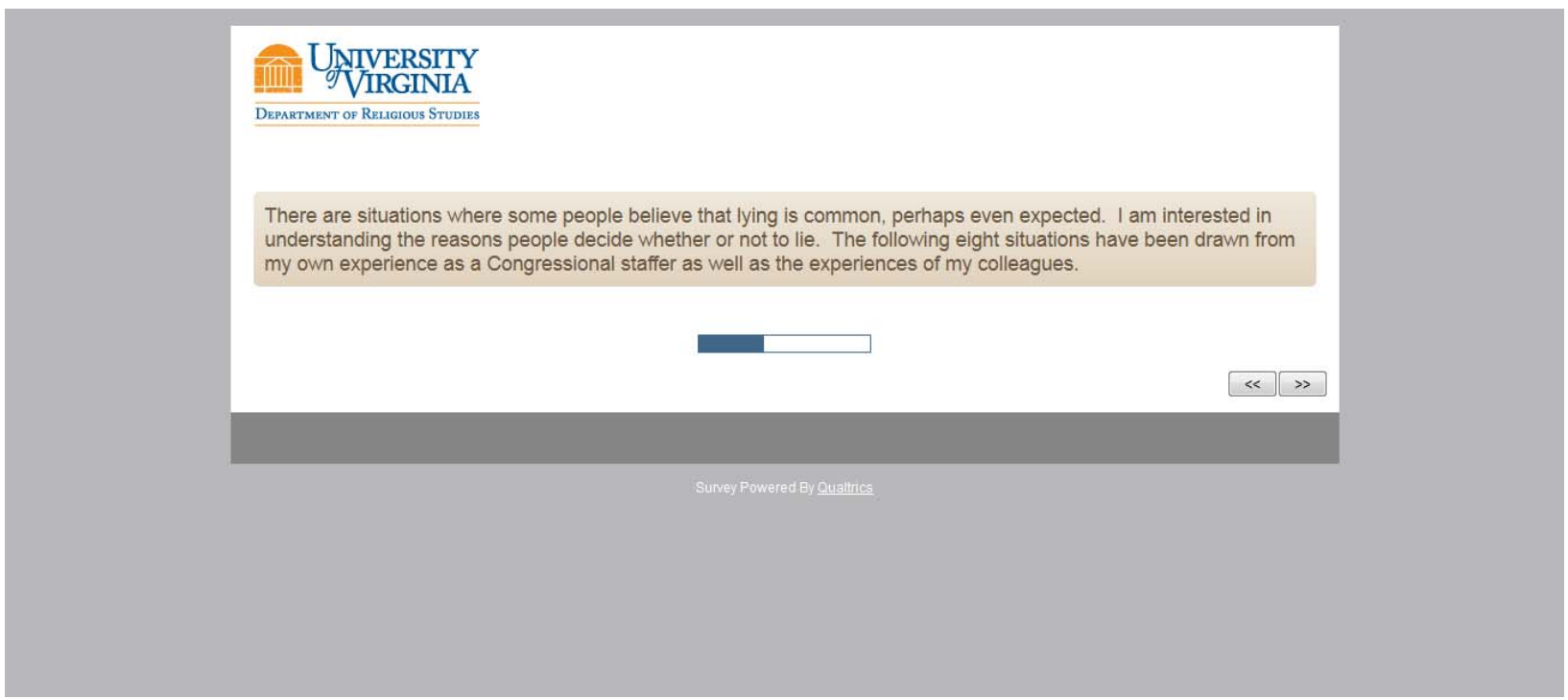



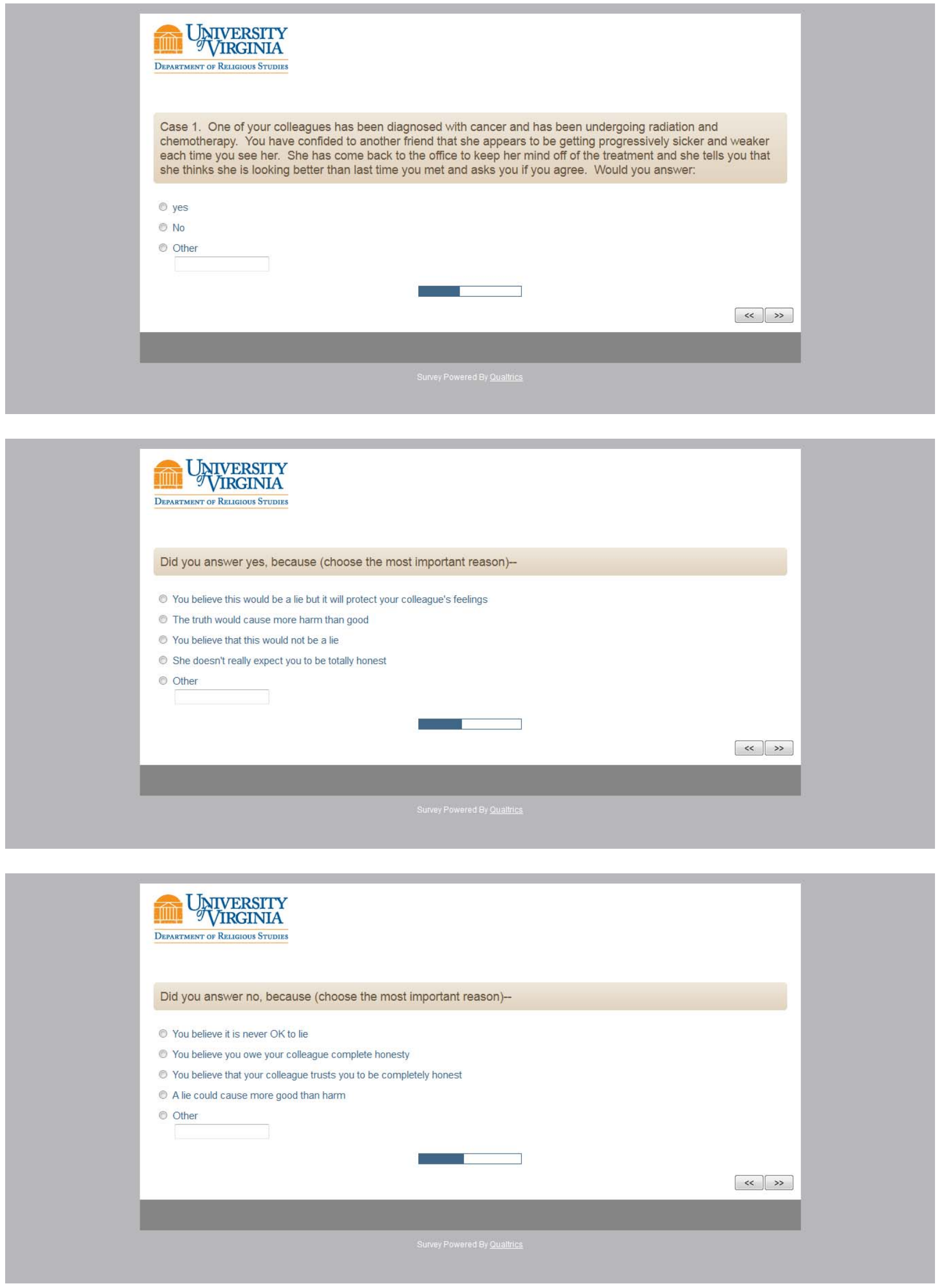

495 | P a g e 

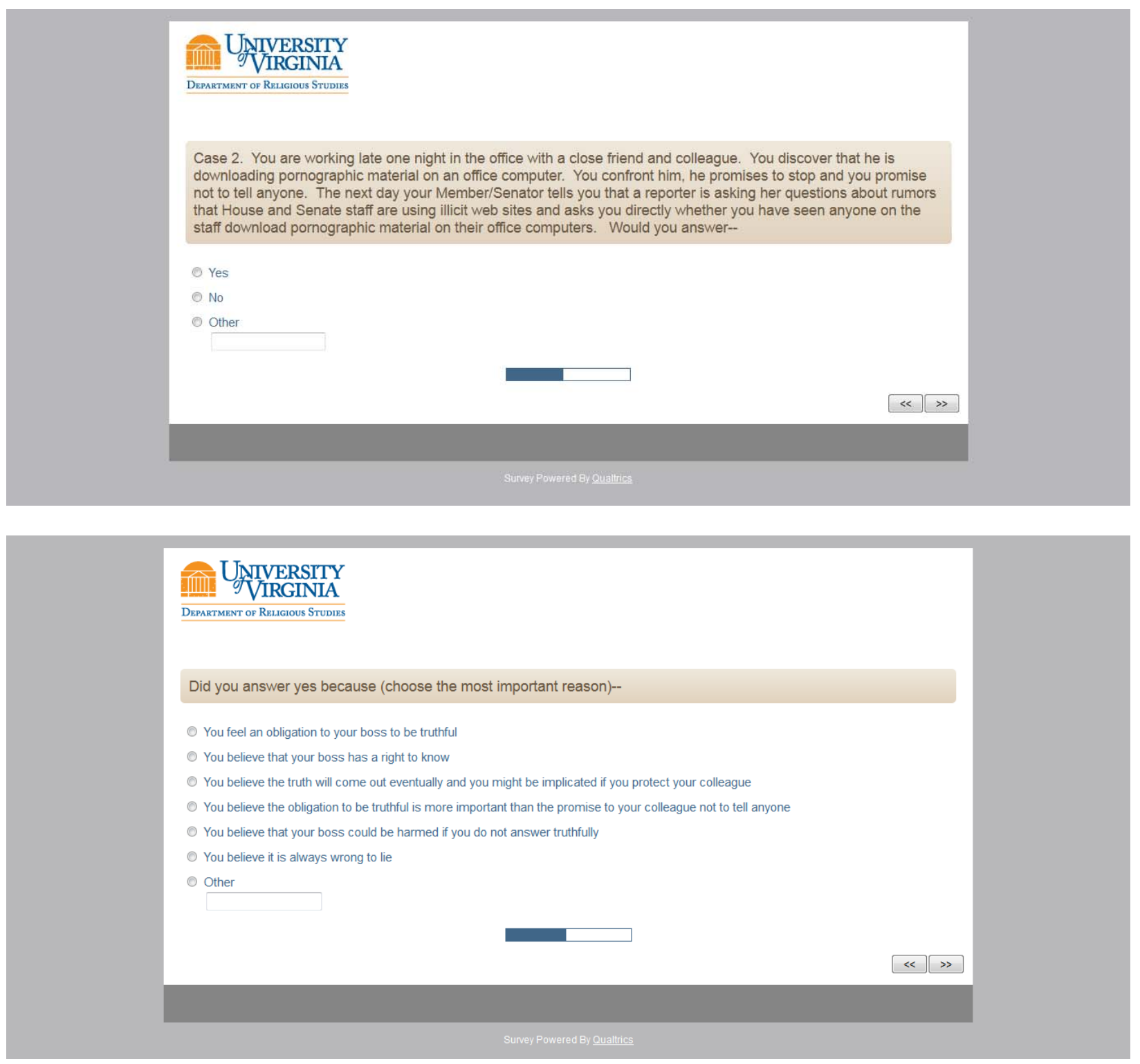

496 | P a g e 


\section{UNIVERSITY}

DEPARTMENT OF RRLGious STUDIE

Did you answer no because (choose the most important reason)-

The harm that would come to your friend is greater than the possible harm of the lie

You should not "sell out" your friends

This is not a lie. You didn't actually SEE the material being downloaded

The obligation to keep your promise outweighs the obligation to answer truthfully in this particular situation

Dother

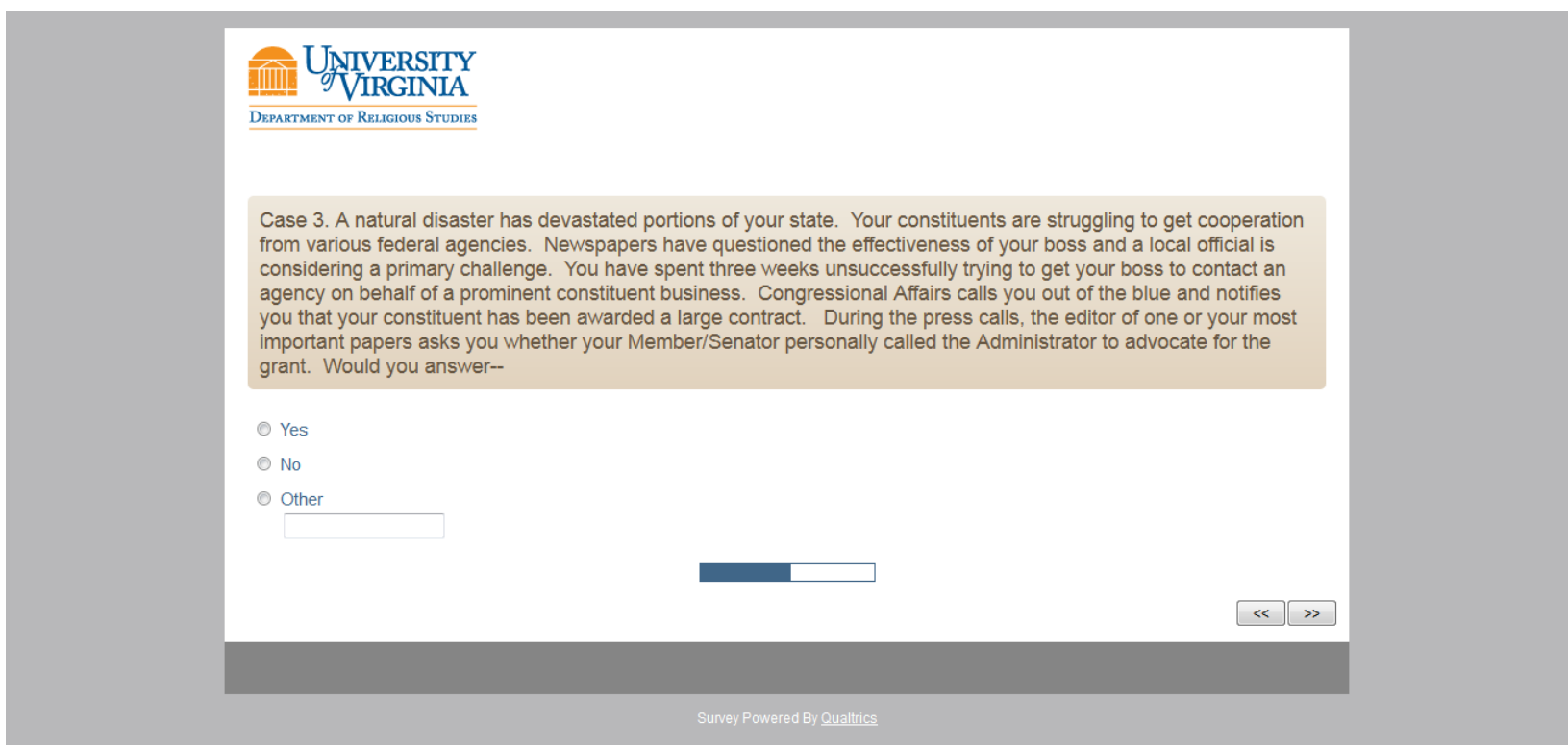




\section{UNIVERSITY}

DEPARTMENT OF RRLLGous StUdIE

Did you answer yes because (choose the most important reason)--

No one expects a completely truthful answer in this situation

The benefit to your boss is greater than any harm the lie might cause

A truthful answer will be used by the editor against your boss

- Your obligation to advocate for your boss is more important than your obligation to be truthful to the press in this instance

Other

\section{骨U UNIVERSTYY}

DEpartment of Remoious Studir

Did you answer no because (choose the most important reason)--

- You believe the editor has a right to the truth

The obligation to tell the truth is more important than your obligation to help your boss in this particular situation

The lie would cause more harm than good if it came out during the campaign

You believe it is always wrong to lie

Telling the truth will increase the level of trust and respect your constituent holds for you and your boss

Other

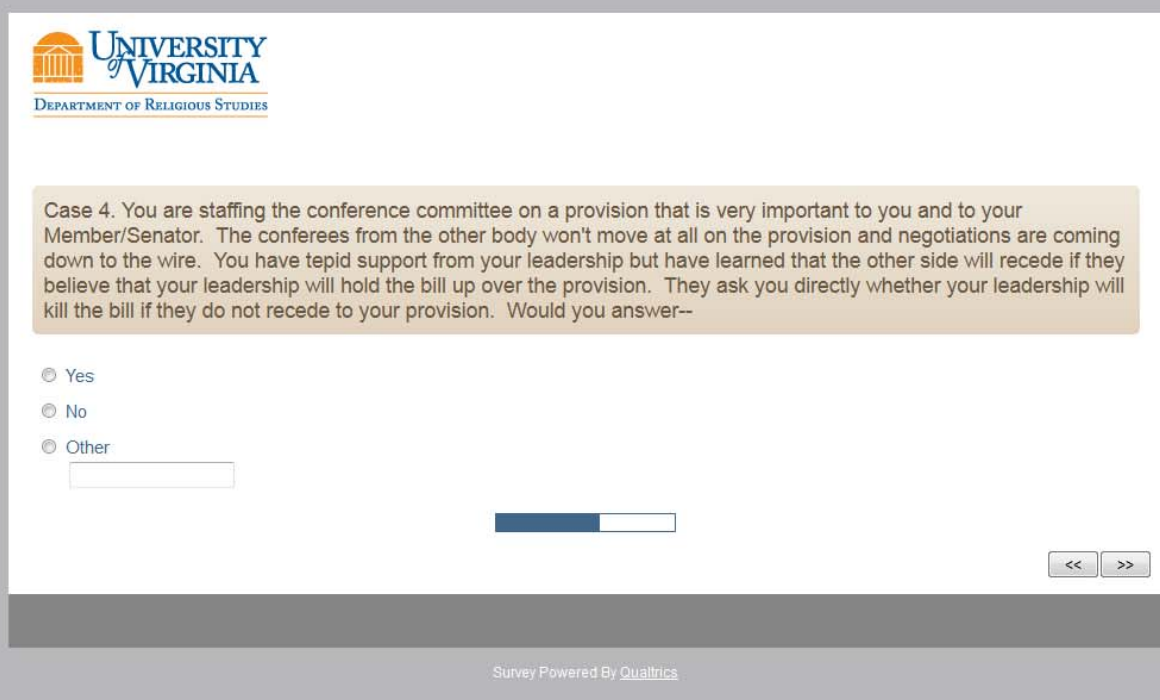



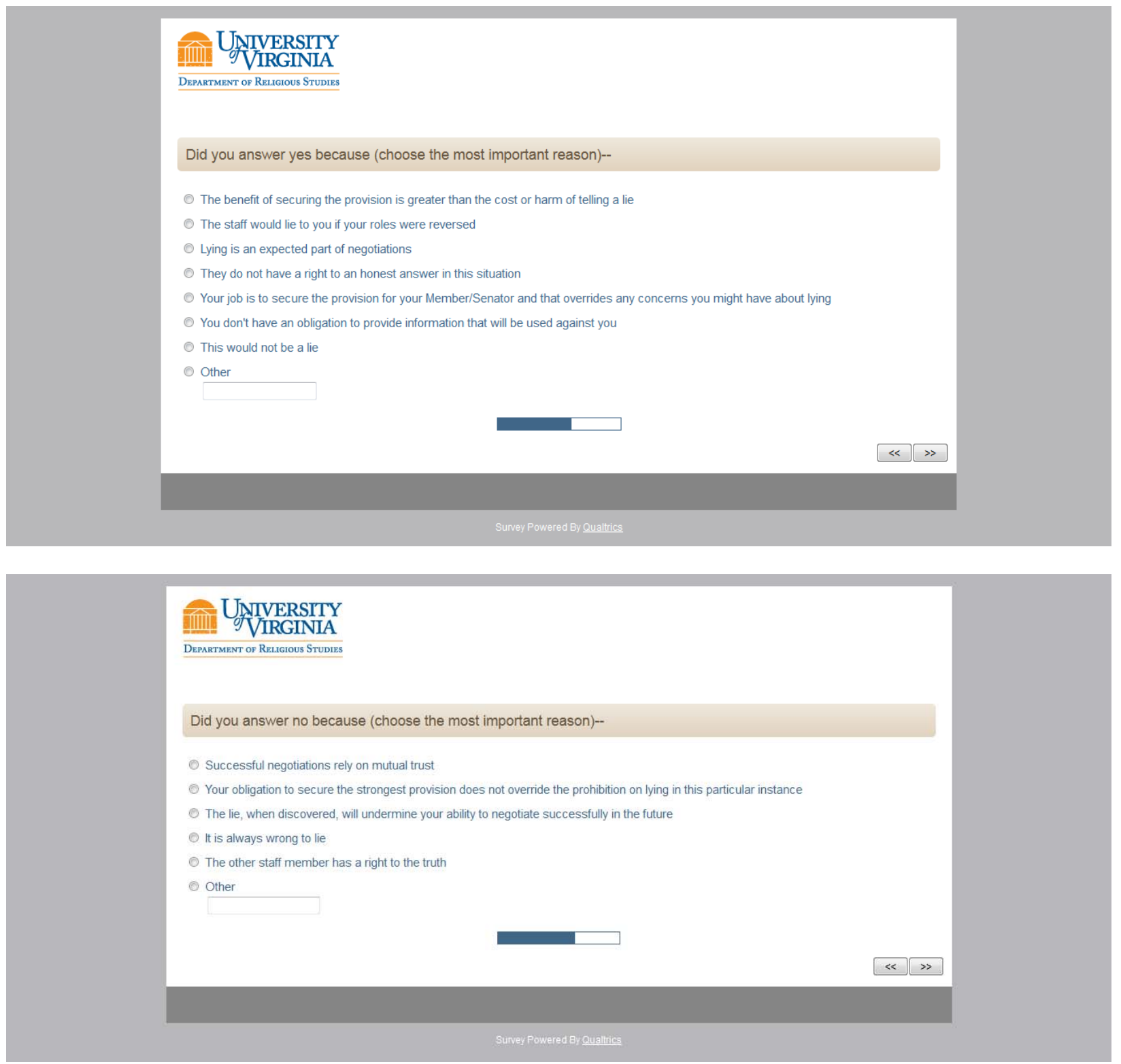

499 | P a g e 

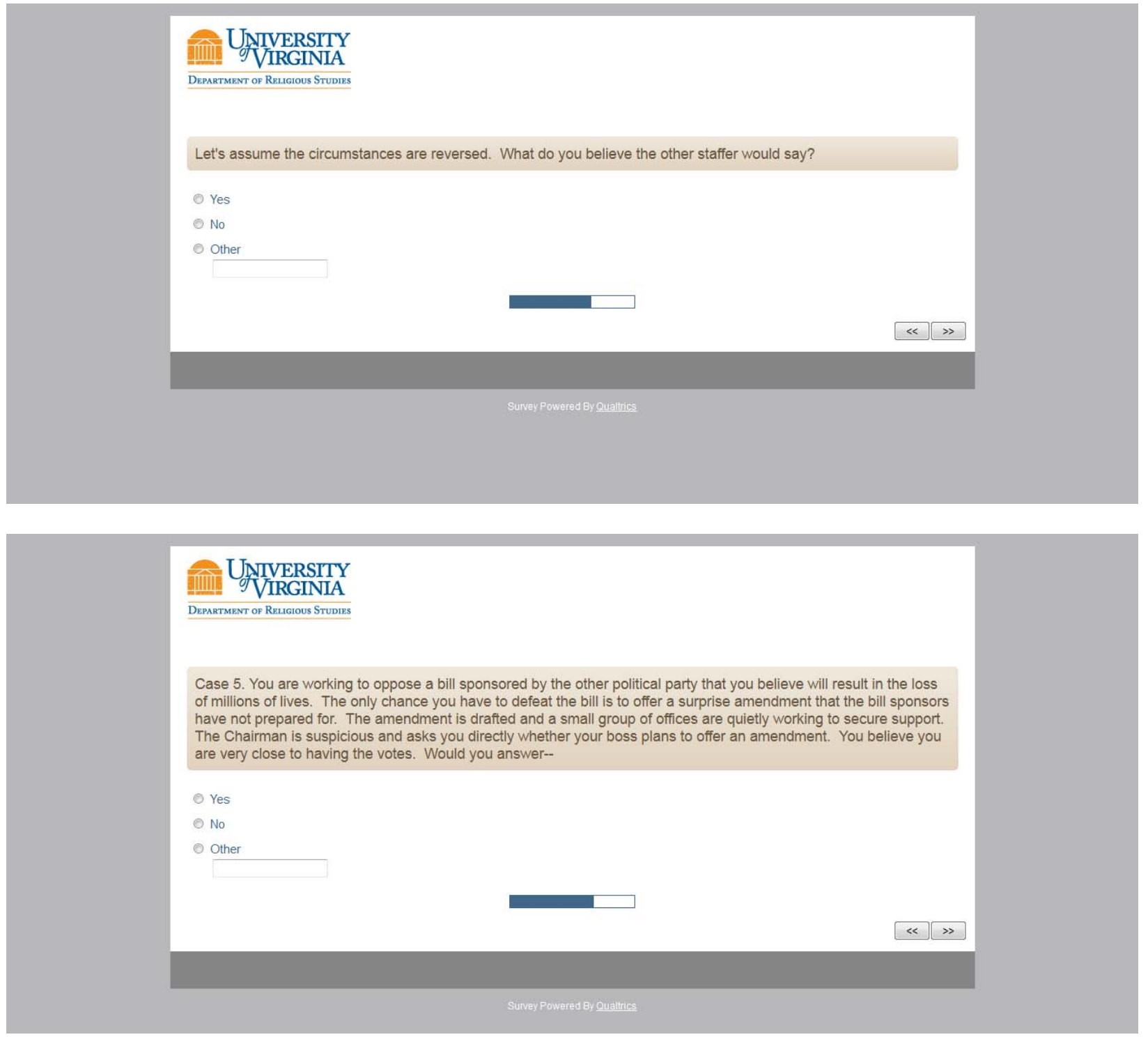

500 | P a g e 

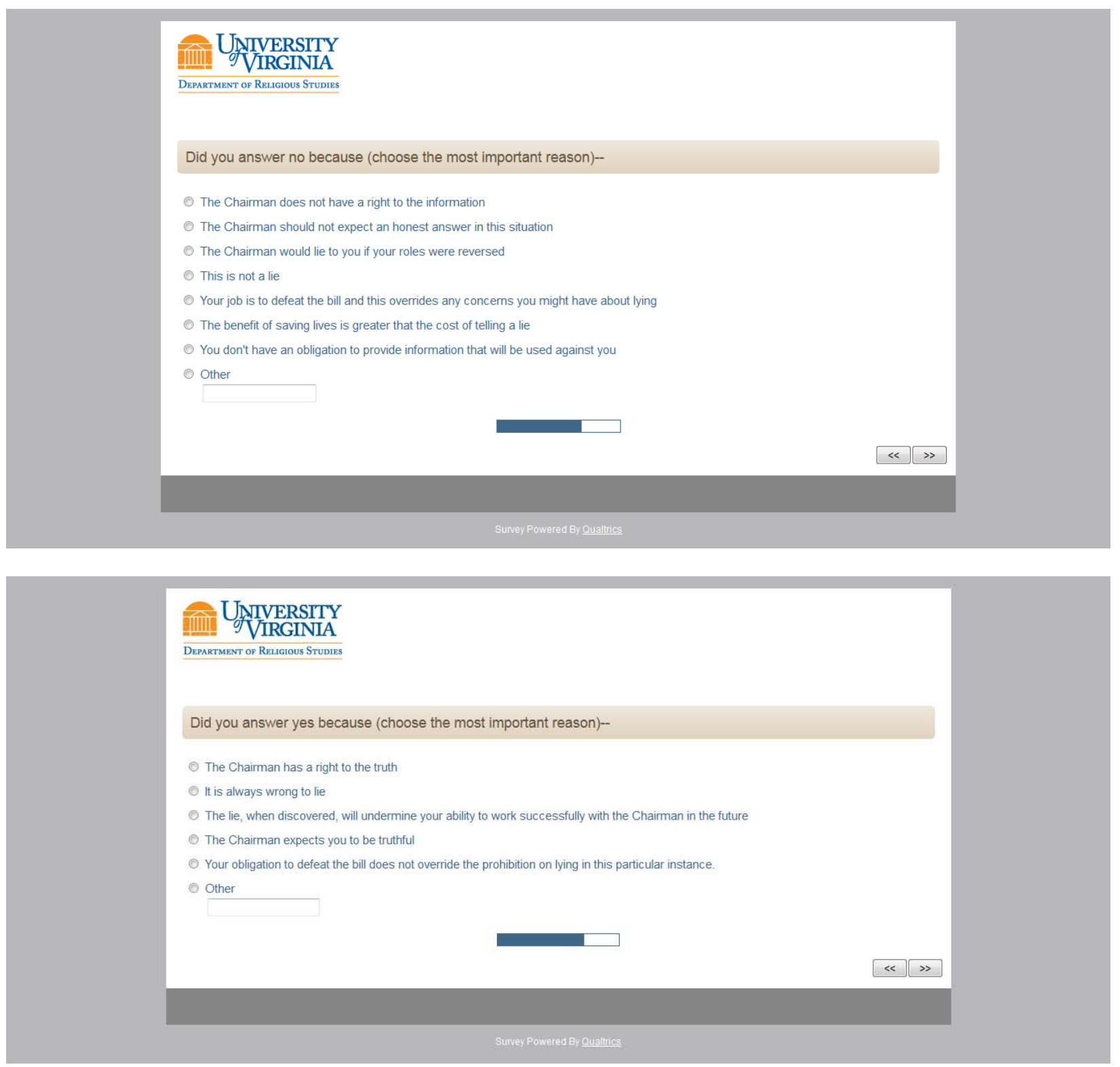

501 P a g e 

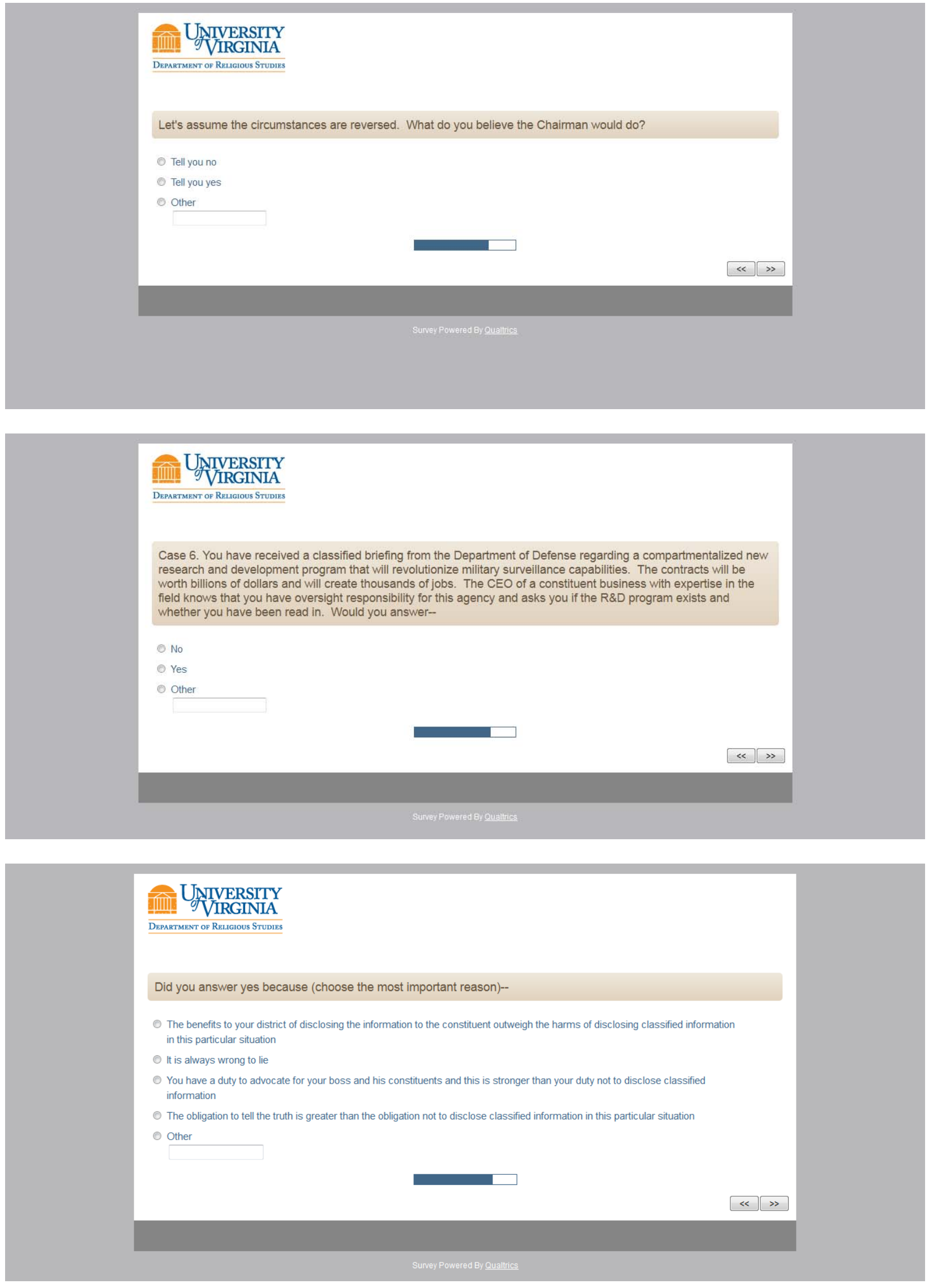

502 | P a g e 


\section{UNIVERSITY}

DEPARTMENT OF RELLGous StUDIE

Did you answer no because (choose the most important reason)--

No one should expect a truthful answer. Lying is an expected part of protecting classified information

The obligation not to disclose classified information is stronger than the obligation to tell the truth

(2) The harm of telling a lie is less than the harm caused by disclosing classified information

- The CEO does not have a right to this information

Other

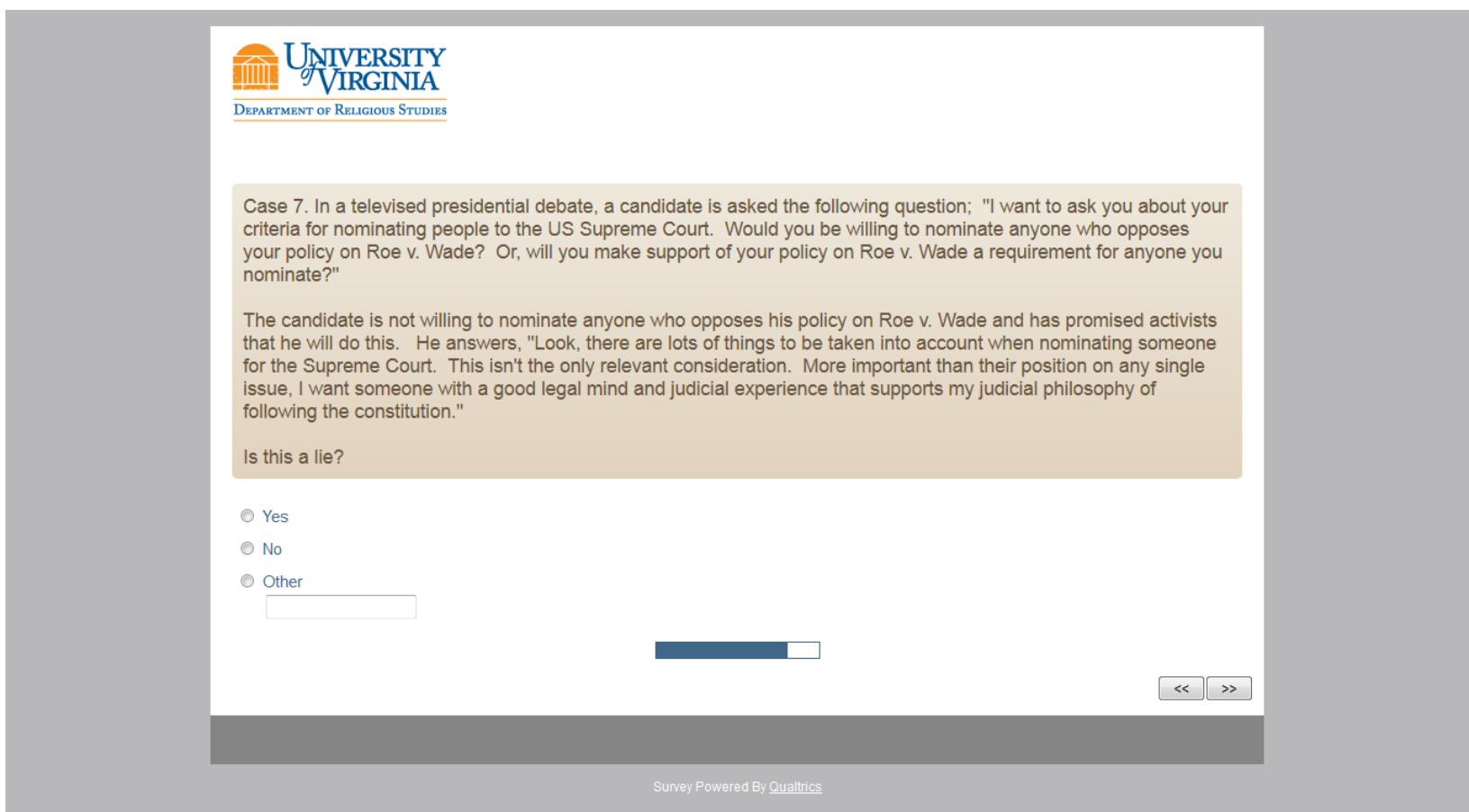



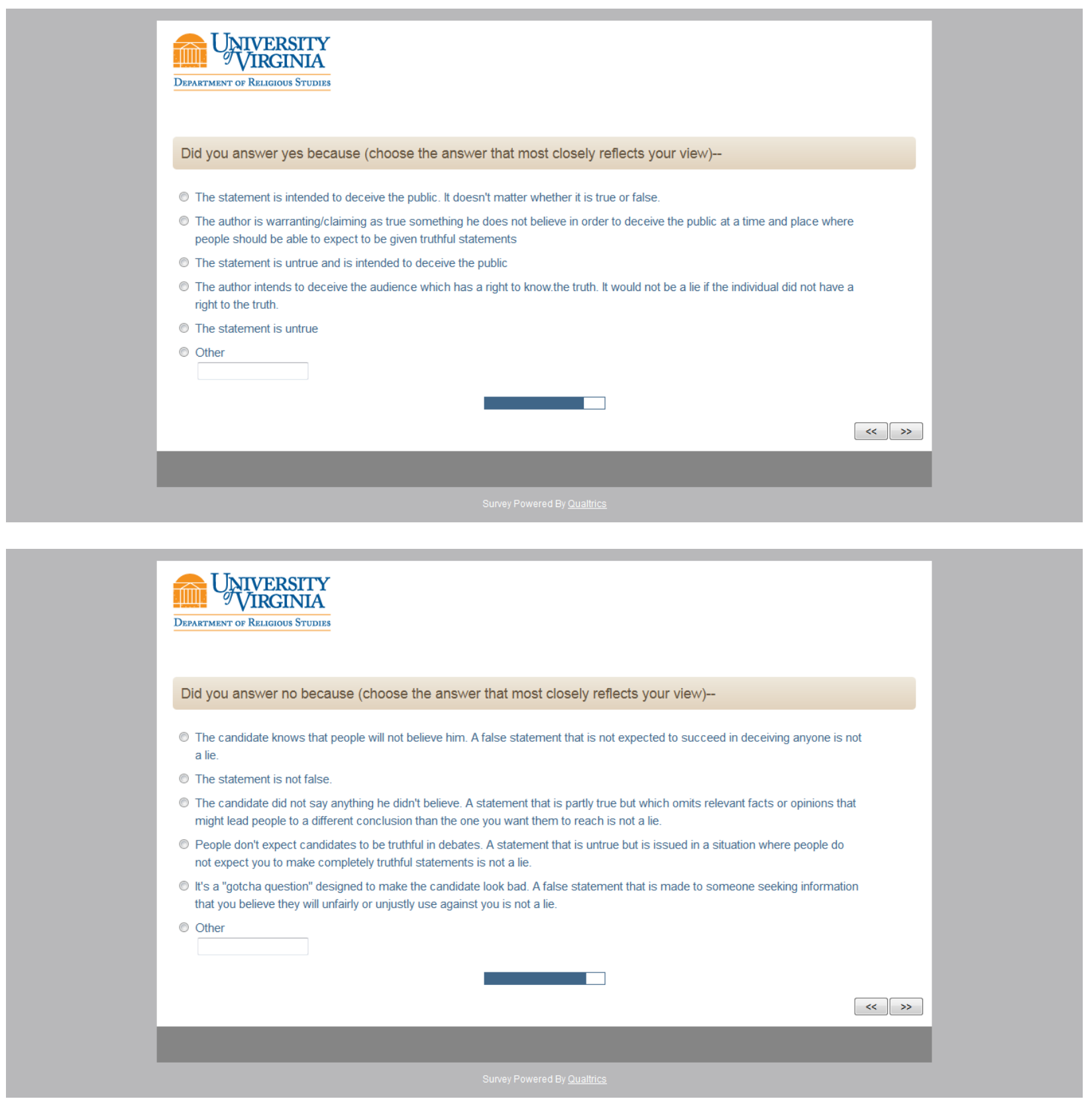

504 | P g g e 

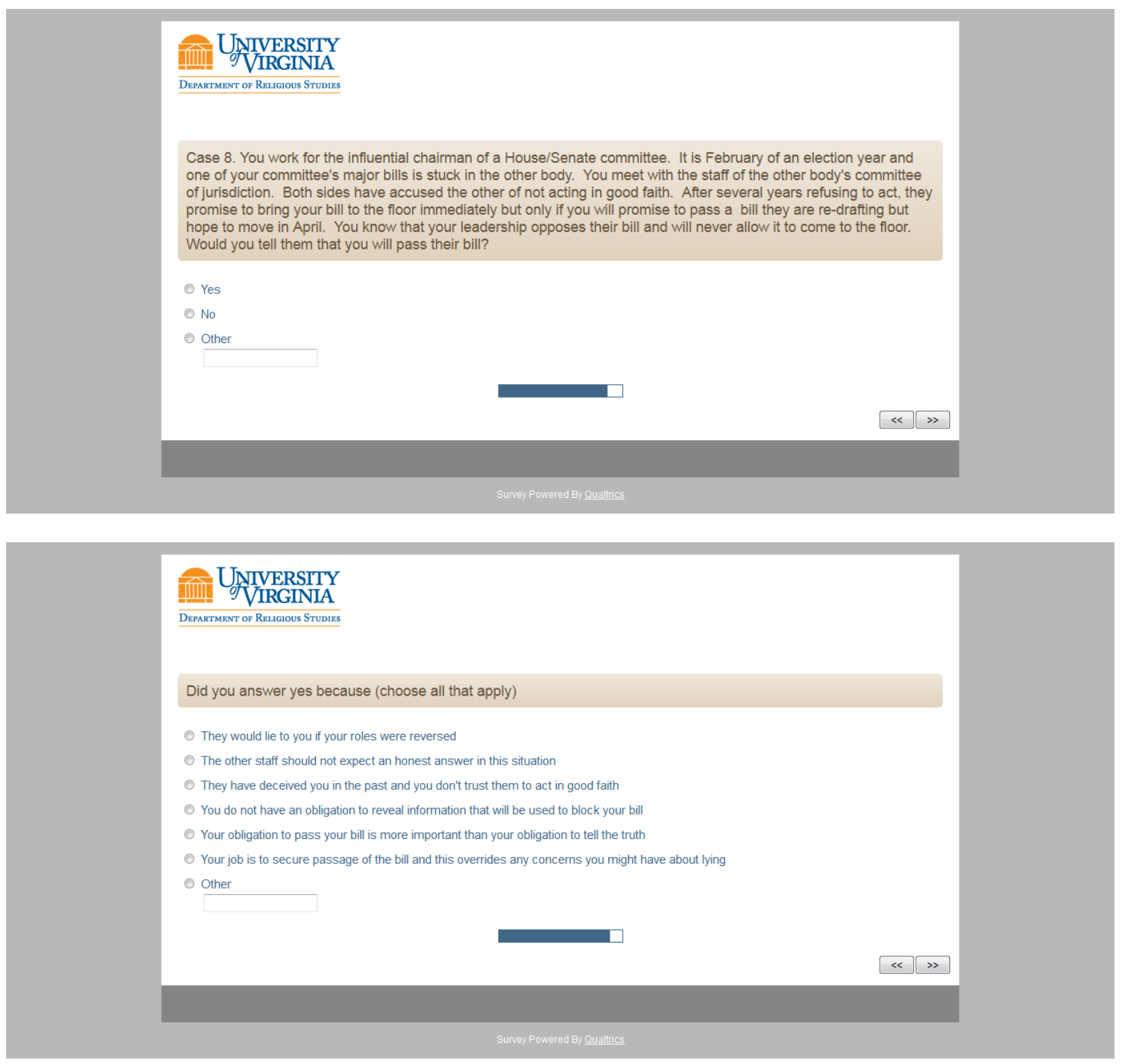

505 I P a g e 

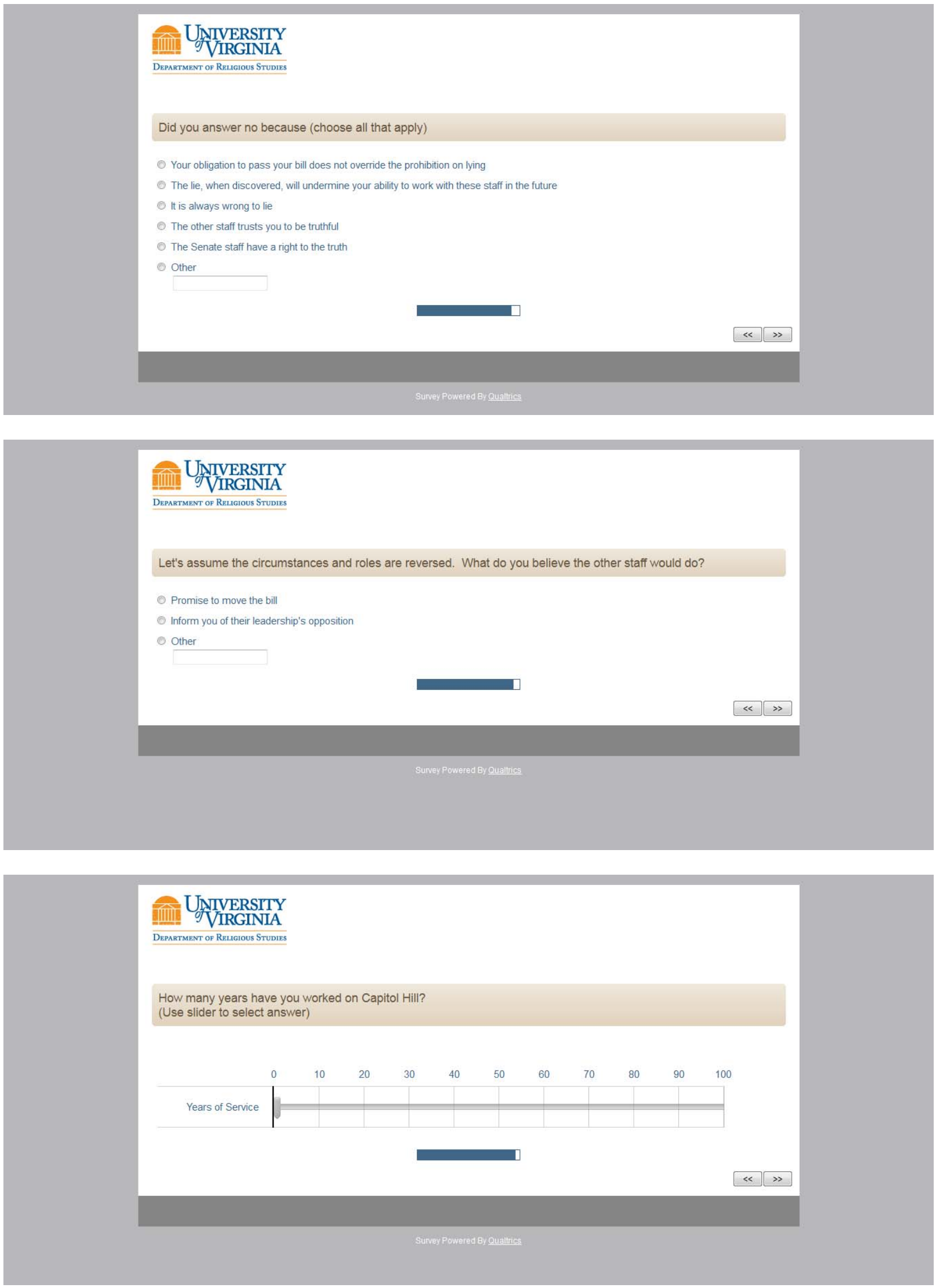

506 | P a g e 

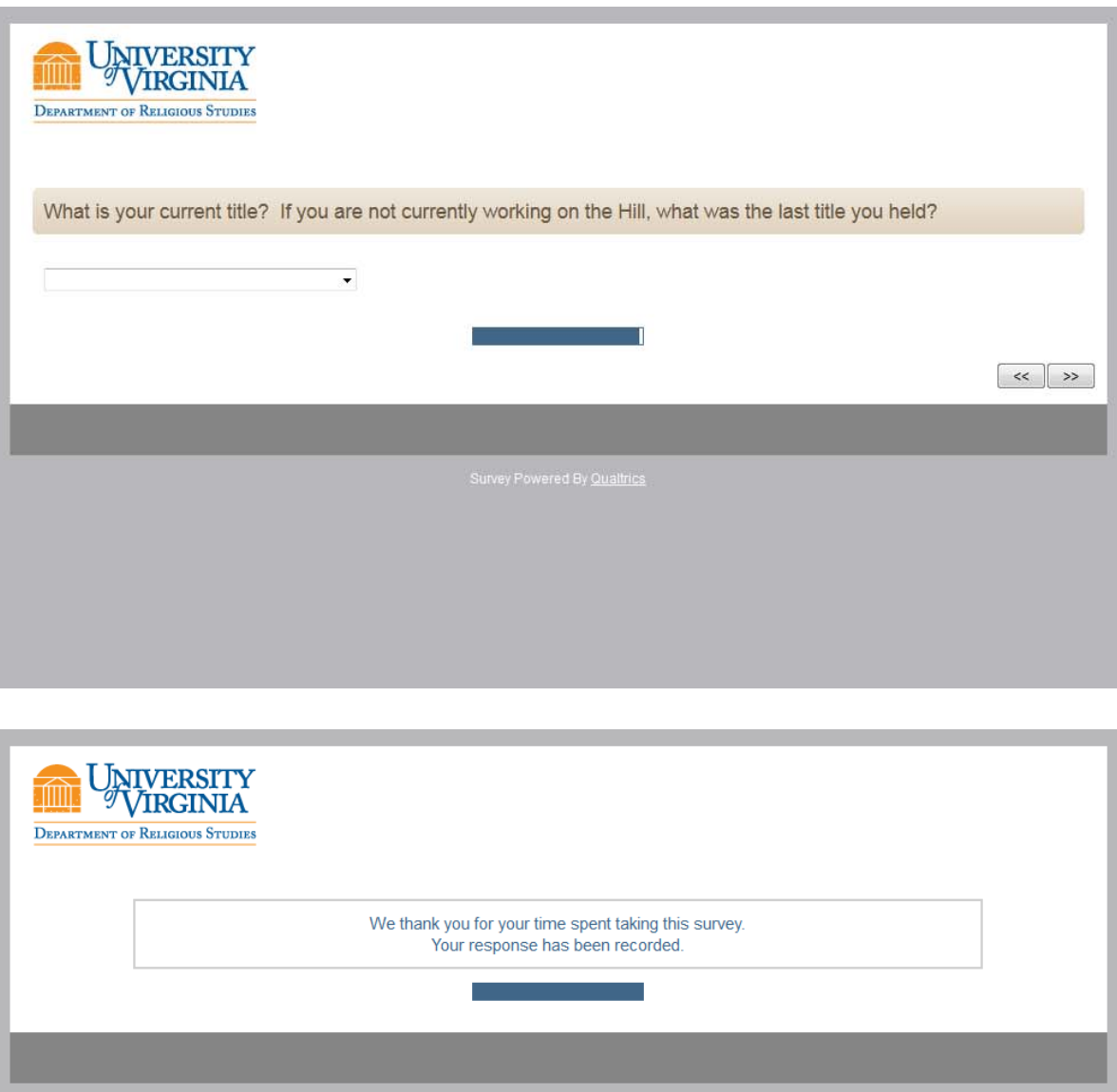


\section{Appendix B-Web Site}

Research on Religion and the Professional Practice of Congressional Staff

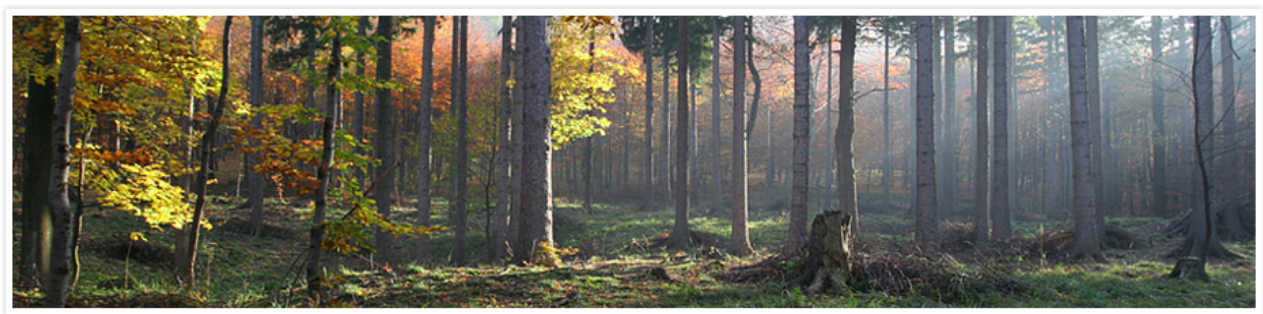

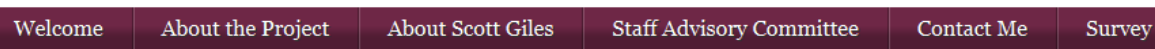

Welcome

This web site provides additional information about my research project on religious affiliation and the professional practice of Congressional staff. As a former Congressional staffer, I am very grateful for all of the support and advice that staff from both sides of the aisle have provided to make this project succeed. I would also like to thank the Stennis Center for Public Service Leadership for its interest in and participation in this project.

If you are here because you recently received an email inviting you to participate in the survey, let me take this opportunity to thank you for taking the time to learn more about the study. I hope you will join your colleagues by taking the time to fill out the survey that you received. I think you will find it both interesting and thought provoking.

Feel free to check back over the next couple of months for more information about the study and how it is progressing.

UNIVERSITY

Content copyright 2014. RELLGIONANDCONGRESS. ORG. All rights reserved.

FWEBSITE 
Research on Religion and the Professional Practice of Congressional Staff

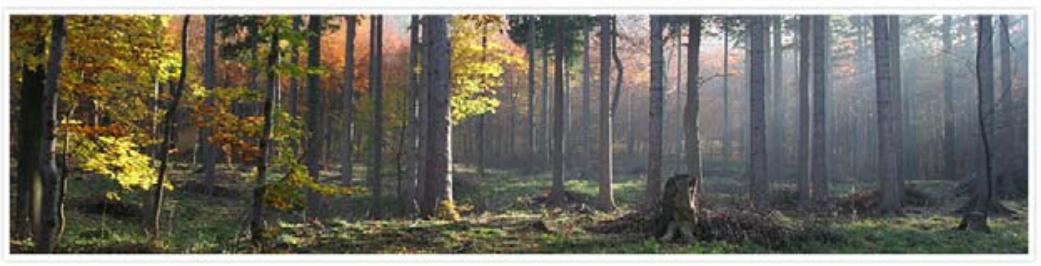

\section{\begin{tabular}{|l|l|l|l|l|l}
\hline Welcome & About the Project & About Scott Giles & Staff Advisory Committee & Contact Me & Survey
\end{tabular}}

About the Project

Inis research project represents the corrwergence of my experience as a House and Senate statter and my academic interest in the relationship Detween relligion and proftessional ife. One impontant note at the outset- I am not interestec in looking at political or party antiliaton. My goal is to understand the relationship between religious beilet and pradice am

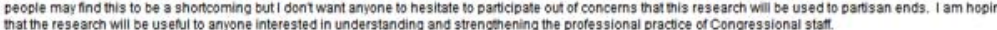

30. What exactly will I be doing? I am senaing an electronic suvvey to a random sample of House and Senate statt. The survey abks the respondents about their

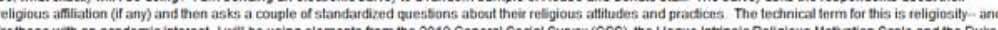

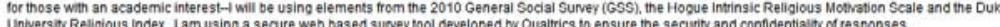

The remainder of the survey will explore the selected statters professional experience with and attudues towara ling. This may seem like an ods topic but

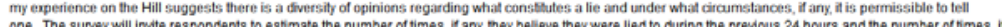
any, they told a lie. These que stions draw elements from diary research conoucted by Bellas Depaulo and recently published survey res earch conducted by kim Serota. Thave createc a series of cases (names have been changec but events were reali). trom my experience campaligning, negotiabng legisiabon, adwocating tor construents, and dealing with the press that allow respondents to apply their views.

A Couple Of Important Motes

This is academic research conducted for the purposes of completing my PnO at the University of Virginia and to adrance our knowtedge of the protessional iffe of Congressional statt. As such, it must meet requirements for born quality and for the protection of the indivouals who participate in the sunvey. Responses will

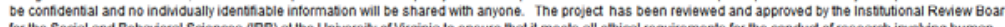

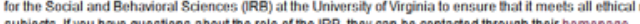

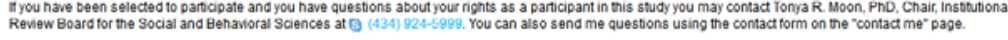

Finally, this project cannot succeed without your contribution to the suver. Thank you very much for taking the time to subport this project.

\section{UNIVERSITY}


Research on Religion and the Professional Practice of Congressional Staff

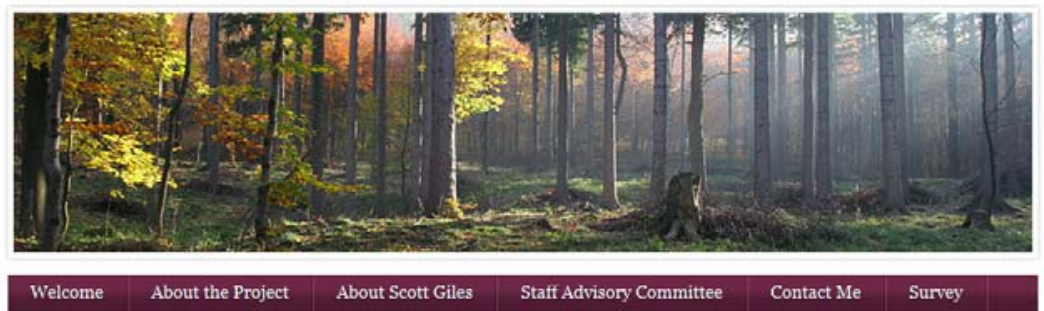

About Scott Giles

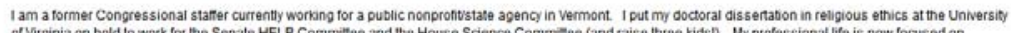

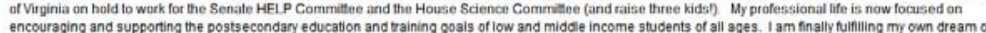

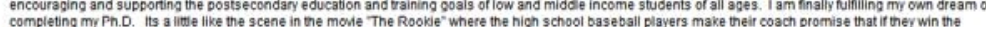
championship ne will pursue his long lost dream of tring out tor the majors.

I stanted working on the Hill for my hometown member of Congress in 1982. Like so many. I statted doing constituent senvices before working my way up to legislatave

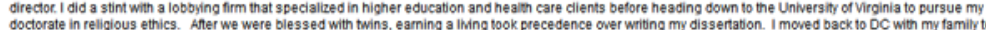
Work on the senior professional star of the Senate HELP Committee. Ifollowed this by joining the staft of the House Science Committee as Deputy Stat Directioc. During this time I was honored to be named a stennis Fellow

Illoved worving on the Hill but coming home to tuck my wds in at 9:00 at night and then heading back to the Hart and Rayburn bulldings to work on legisiation took a toll We aded noth to the greener pasture s/mountains of Vermont. Wy workis devoted to hel ping students of all ages obtain the

postsecondary educabon of training they need to achieve their social and economic goals. As my friends have heard me say many times, every statfer shoula have to

For those of you interested in more information about my background and interests, I am postng my curriculum vitae.

\section{IINTVERSITY \\ Dententa}

\section{QWEBSITE}

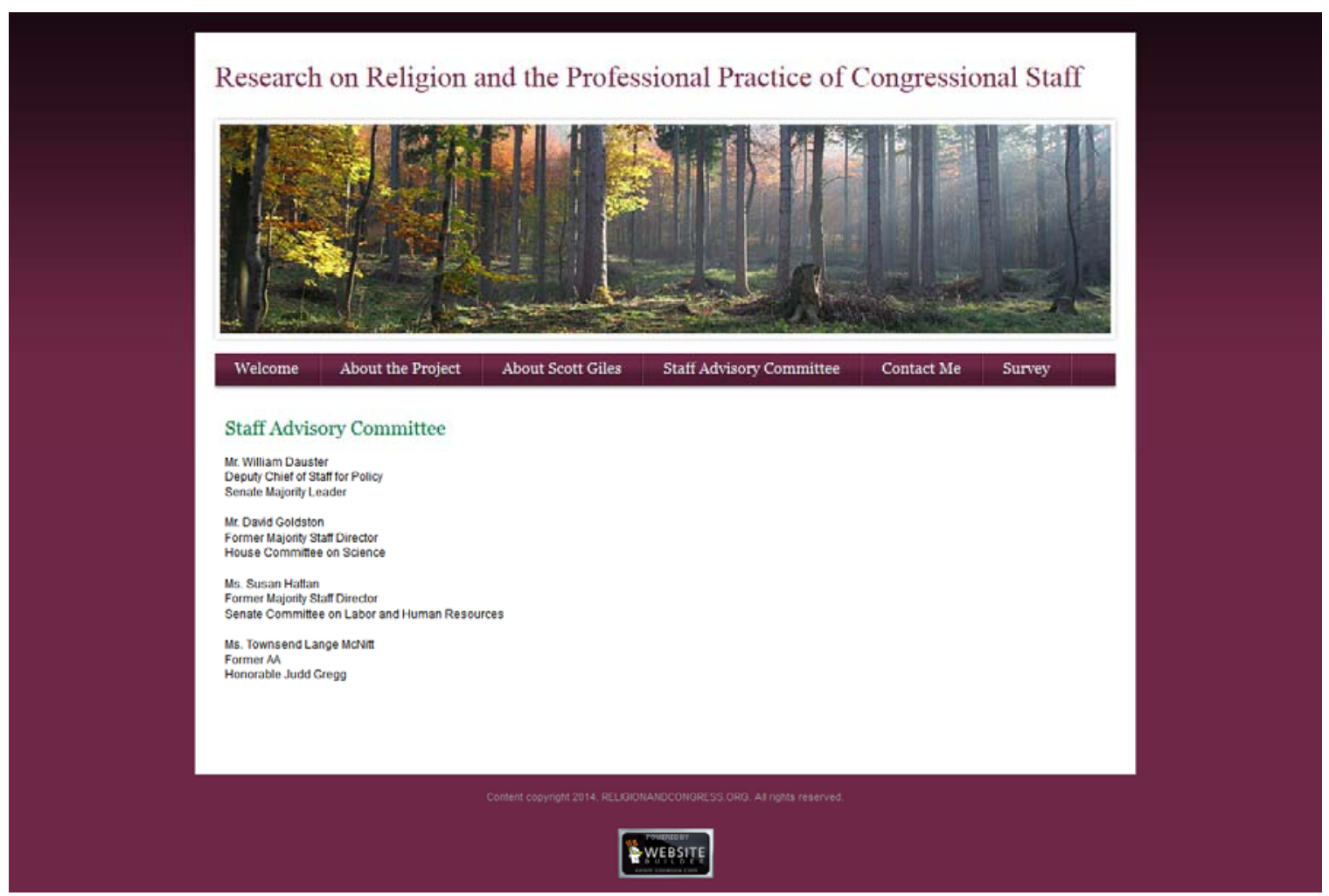

$510 \mid \mathrm{P}$ a g e 

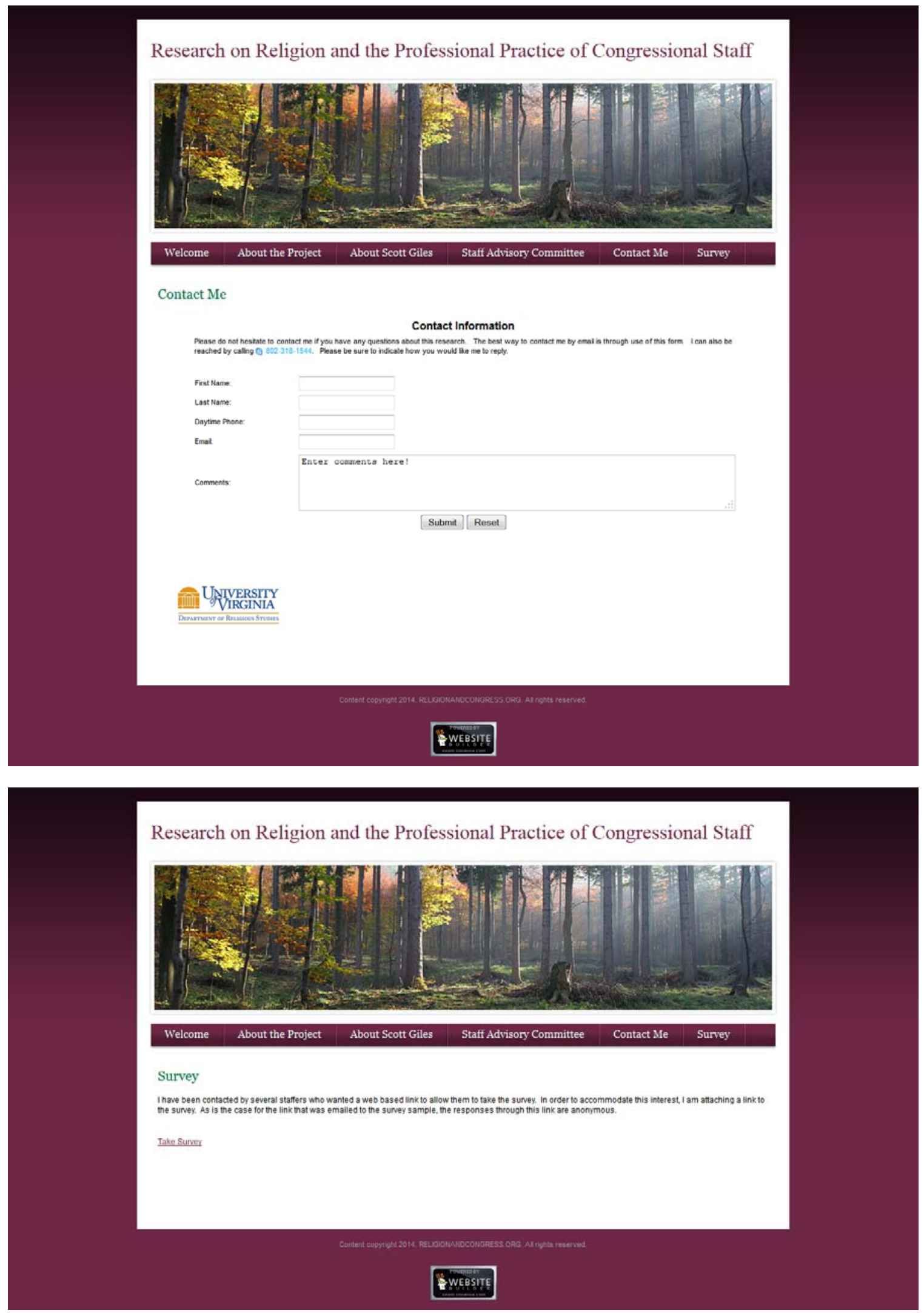